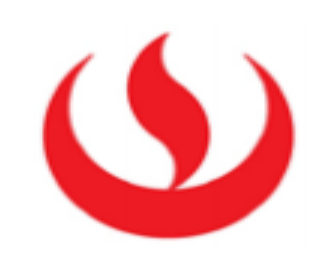

UNIVERSIDAD PERUANA DE CIENCIAS APLICADAS

FACULTAD DE INGENIERÍA

PROGRAMA DE INGENIERÍA INDUSTRIAL

\title{
PROPUESTA DE MEJORA EN LA PRODUCTIVIDAD DE LOS PROCESOS LOGÍSTICOS DE UNA EMPRESA DISTRIBUIDORA DE LIBROS
}

\author{
TESIS \\ Para optar por el título profesional de: Ingeniero Industrial \\ AUTOR \\ JAVIER MARTIN RAMIREZ CAVANI (0000-0001-5147-8977) \\ ASESOR DE TESIS \\ CYNTHIA CAROLA ELÍAS GIORDANO (0000-0002-2221-8946) \\ Lima, 19 de Julio de 2018
}


Dedicado a todos los que encontraron en la Ingeniería Industrial un nuevo mundo; ya explorado, pero aún fascinante 


\section{Agradecimientos}

El más cálido agradecimiento a mis dos Lizzeth, a mis padres y hermanos.

A mi tío "Bigman" quién forjo en mí gran interés universitario.

Al sr. Jaime Miranda, gran líder y visionario que creyó en mí (QEPD)

pág. 3 


\section{Resumen Ejecutivo}

Palabras Claves: Logística, Productividad, Lean thinking, Lean Logistics, VSM, KPI, Estandarización, Distribuidores, Mapeo de procesos, Logistica Esbelta, Almacén

El presente trabajo tiene como finalidad proponer mejoras en la productividad de los procesos logísticos de una distribuidora de libros, el cúal constó de tres puntos. Primero, se abarcó nociones teóricas para delimitar y entender el campo de desarrollo de la empresa en la industria mundial considerando que la organización estudiada no compite sola en el mercado, sino que pertenece a un sector industrial donde las empresas cumplen determinadas características y comportamientos del mercado en general. Se abarcaron temas como: Logística, Cadena de Abastecimiento, Pensamiento Lean, Productividad, entre otros. Segundo, se analizó la situación actual desde el sector industrial peruano de distribución de libros hasta las particularidades de la empresa; estas últimas evidencian los procesos actuales y la problemática encontrada. Utilizando sistemáticamente herramientas de calidad, se identificaron las principales causas del incremento de horas extras realizadas por los colaboradores de la empresa, estas causas fueron asociadas y analizadas en tres grupos: Proceso, Operación y Gestión ; destacando las adheridas al «proceso ». Tercero, se presentó como alternativa de solución la implementación de la metodología Lean Logistics para la optimización de la productividad y la reducción de las horas extras. Para ello, se utilizó y adaptó herramientas y principios Lean como el análisis VSM, KPI, 5S, Estandarización, Balance de línea. Finalmente, se obtuvo una reducción del tiempo de ciclo de los procesos logísticos en 39 h y la disminución de la variabilidad de los procesos de Recepción, Picking y Packing en más del $85 \%$ en base a su desviación estándar. 


\section{Summary}

Keywords: Logistics, Productivity, Lean Thinking, Lean Logistics, VSM, KPI, Standardization.

The purpose of this paper is to propose improvements in the productivity of the logistics processes of a book distributor, which consisted of three points. First, theoretical notions were included to delimit and understand the field of development of the company in the world industry considering that the organization studied does not compete alone in the market, but belongs to an industrial sector where companies meet certain characteristics and market behavior in general. Topics included: Logistics, Supply Chain, Lean Thinking, Productivity, among others. Second, the current situation was analyzed from the Peruvian industrial sector of book distribution to the particularities of the company; the latter show the current processes and the problems encountered. Using systematically quality tools, the main causes of the increase in overtime carried out by the company's collaborators were identified. These causes were associated and analyzed in three groups: Process, Operation and Management; highlighting those adhered to the «process». Third, the implementation of the Lean Logistics methodology for optimizing productivity and reducing overtime was presented as a solution alternative. To do this, Lean tools and principles were used and adapted, such as VSM, KPI, 5S analysis, Standardization, Line Balance. Finally, there was a reduction in the cycle time of the logistics processes in $39 \mathrm{~h}$ and the reduction in the variability of the reception, picking and packing processes by more than $85 \%$ based on their standard deviation 
Tabla de contenido

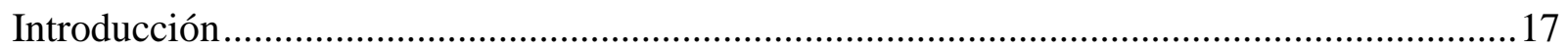

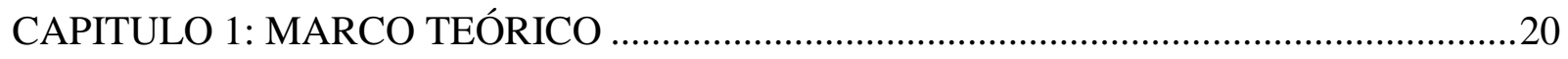

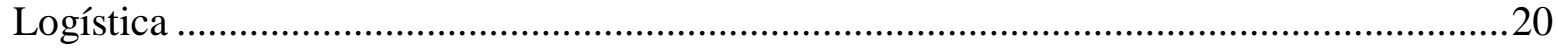

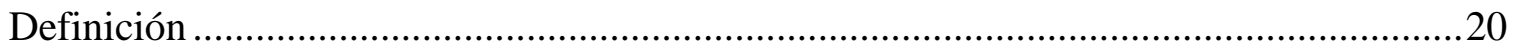

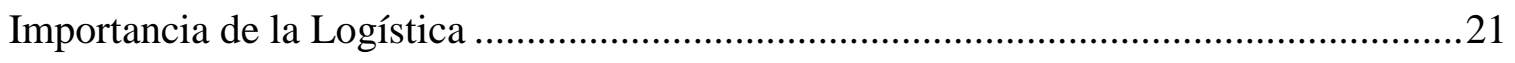

Operaciones básicas en un Centro Logístico ..........................................................22

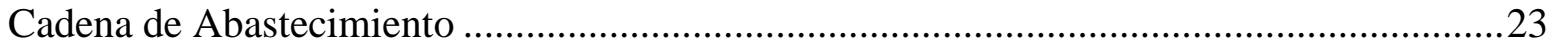

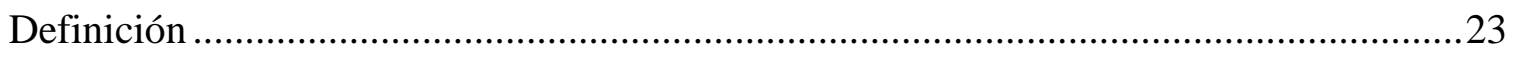

Alcances de la Gestión de la Cadena de Abastecimiento.................................................24

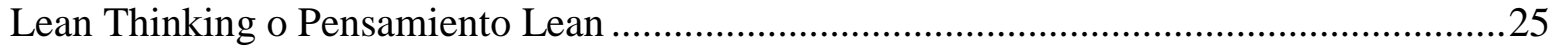

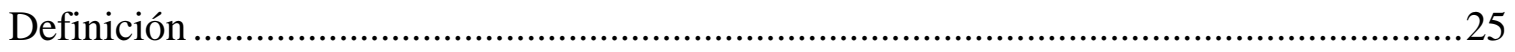

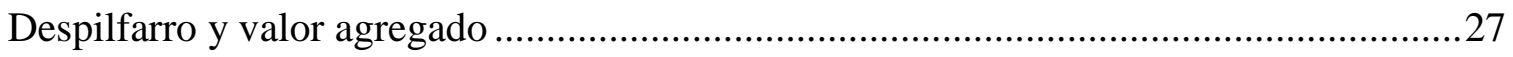

Beneficios de la implementación Lean .....................................................................29

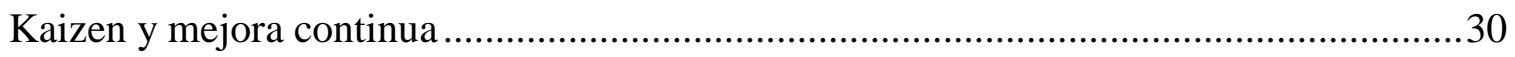

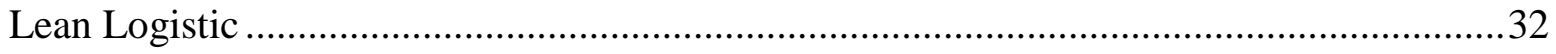

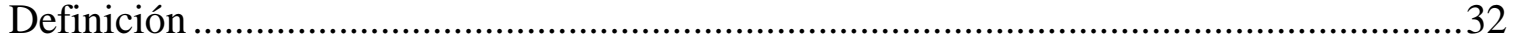

Herramientas de Lean Logistics ....................................................................... 34

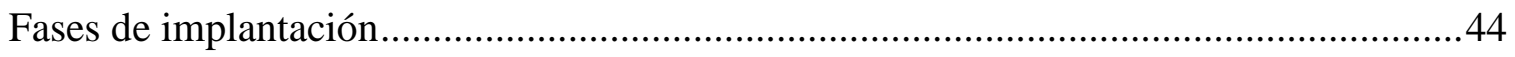

Enfoque basado en Procesos .............................................................................. 46

Definición de Procesos ...........................................................................................46

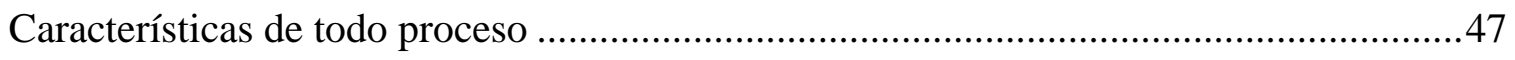

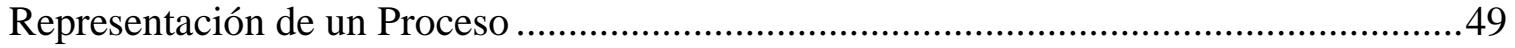

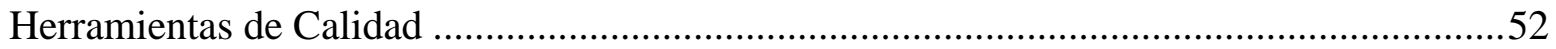

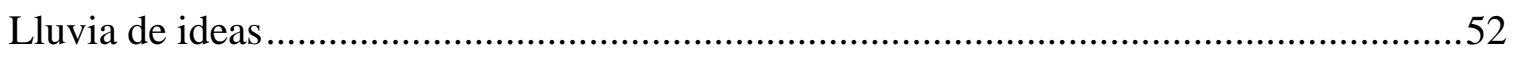

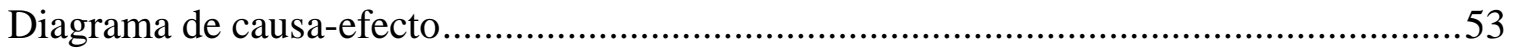

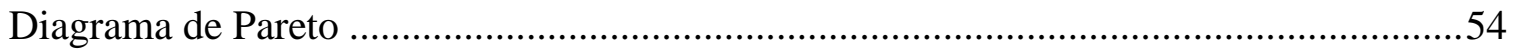

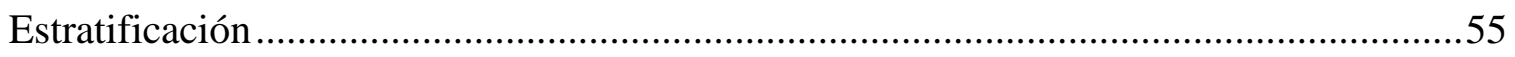

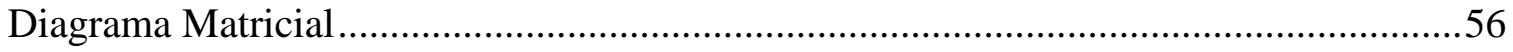

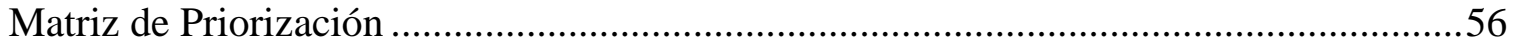




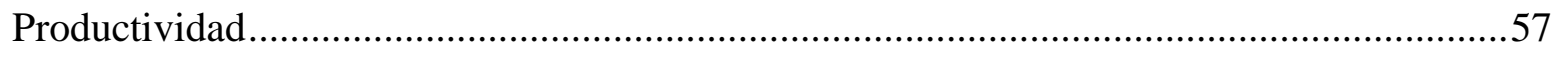

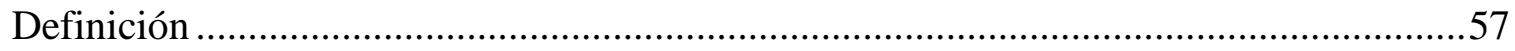

Factores que afectan la productividad ……………………........................................57

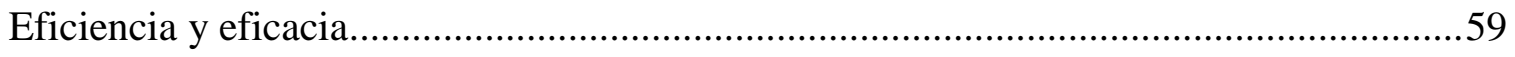

Medición de la productividad ........................................................................................59

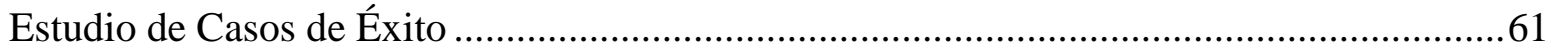

Aplicación de Value Stream Mapping en los procesos logísticos de una empresa embaladora de vidrio en Colombia..............................................................................61

Aplicación de balance de línea en una bodega de Almacenamiento ....................................62

Implementación de 5s en la logística de Rift Valley Railways ...........................................63

Implementación de la Estandarización en procesos Logísticos.............................................63

Aplicación de KPIs en diferentes organizaciones .............................................................64

Implementación de prácticas Lean en diferentes industrias ...............................................65

Herramientas de Ingeniería para el diagnóstico ..................................................................68

Estudio del trabajo ..................................................................................................68

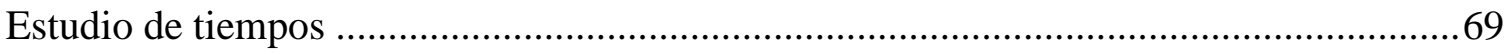

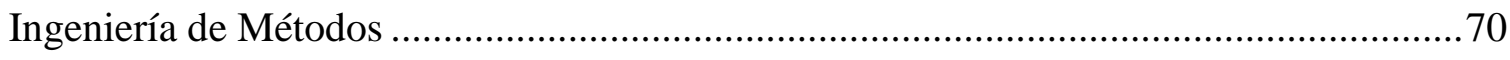

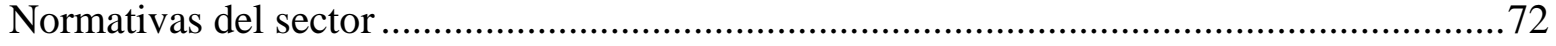

CAPITULO 2: ANÁLISIS DE LA SITUACIÓN ACTUAL_.....................................................74

Descripción del Negocio ....................................................................................................

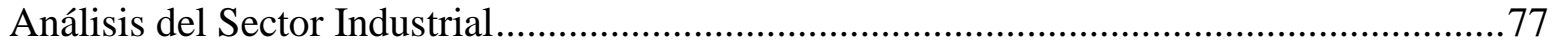

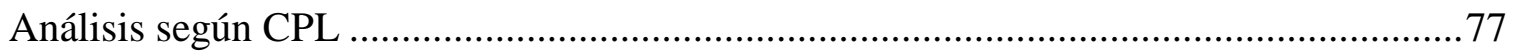

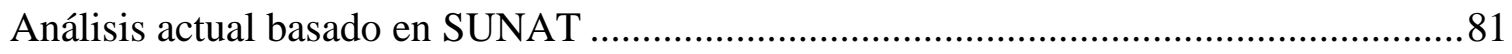

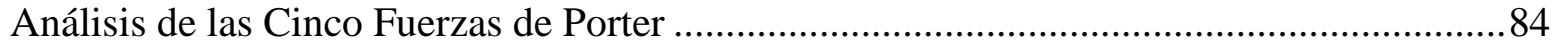

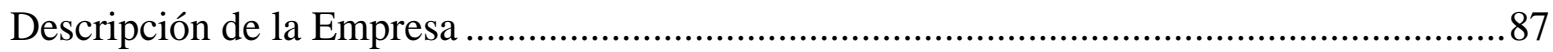

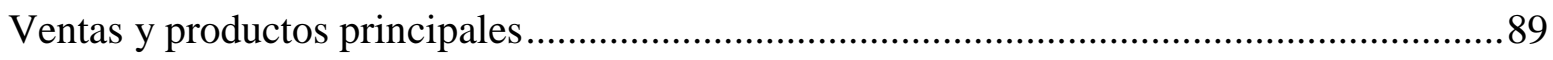

Cadena de Valor de la Empresa.............................................................................................93

Mapa de Procesos de la Empresa …………………………….............................................97

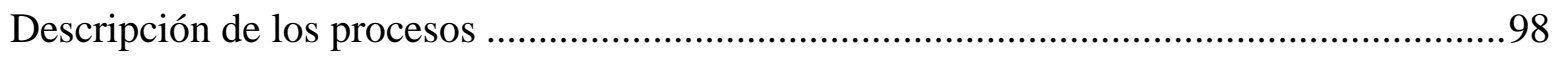

Proceso de Planificación (ver figura 19) ............................................................................99

Proceso de Aprovisionamiento (ver figura 20)...............................................................101 


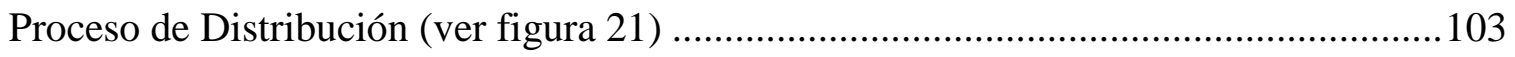

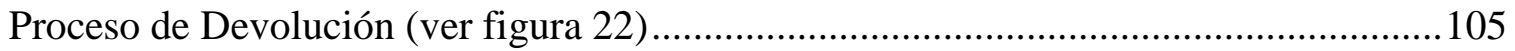

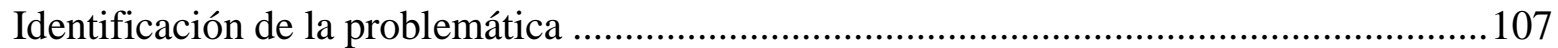

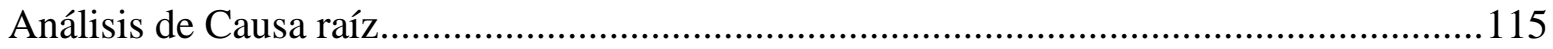

CAPITULO 3: DESARROLLO DE LA METODOLOGÍA PROPUESTA PARA LA MEJORA

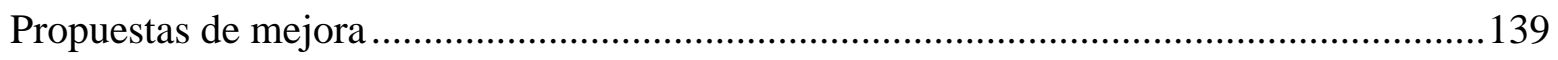

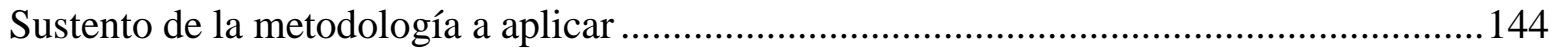

Hoja de ruta para la implantación de las técnicas Lean Logistics ........................................147

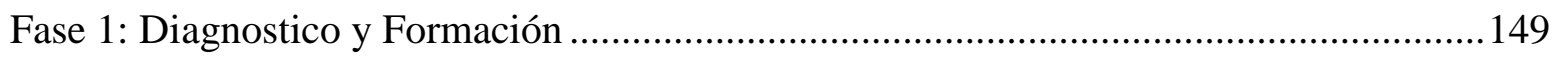

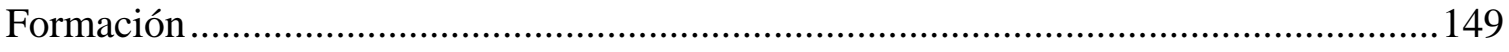

Recogida y análisis de datos .....................................................................................152

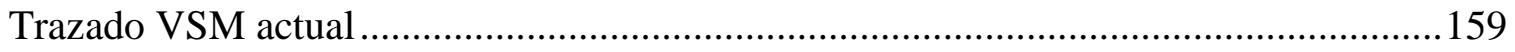

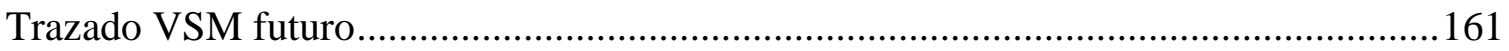

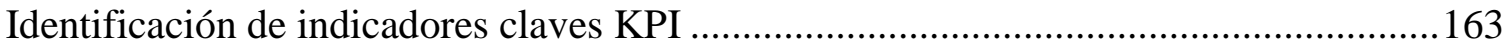

Fase 2: Planificación implantación Lean .............................................................................164

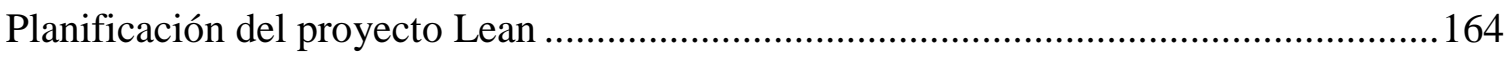

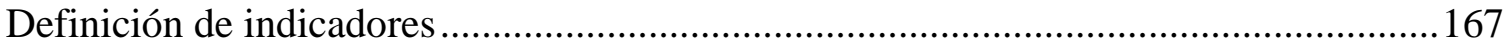

Organización y mentalización de equipos Lean ..............................................................169

Selección y definición de línea / área piloto ......................................................................170

Fase 3: Lanzamiento - Implementación de las 5S .............................................................172

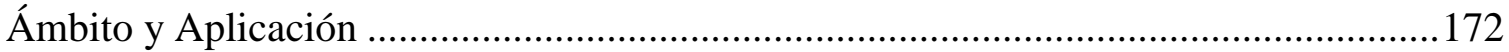

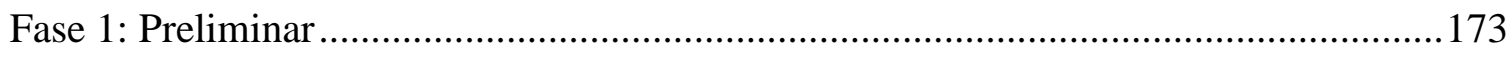

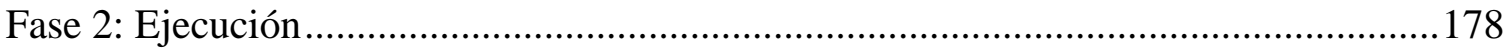

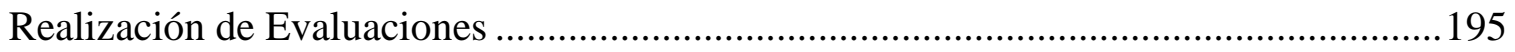

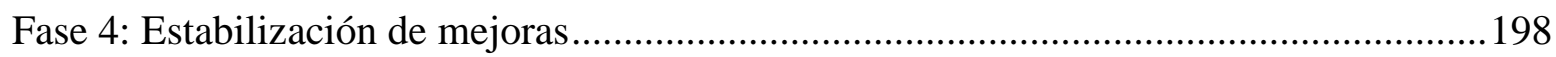

Mejora del proceso de Recepción y almacenamiento .......................................................198

Mejora del proceso de Picking ……………………………..................................208

Mejora del proceso de Packing ................................................................................2. 219

Fase 5: Estandarización ...................................................................................................225

Estándar para el proceso de Recepción e Inventario …………………………………...226 


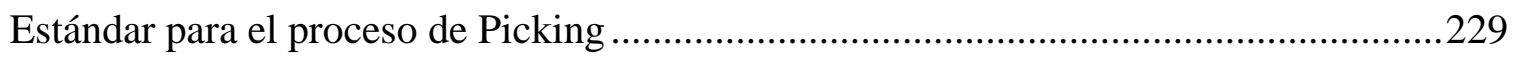

Estándar para el proceso de Packing ..........................................................................232

CAPITULO 4: VALIDACIÓN DE LA SOLUCIÓN DE INGENIERÍA Y EVALUACIÓN

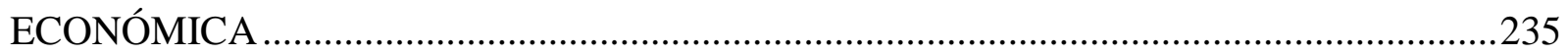

Fase 6: Resultados y evaluación del Plan piloto para la implementación de las propuestas de

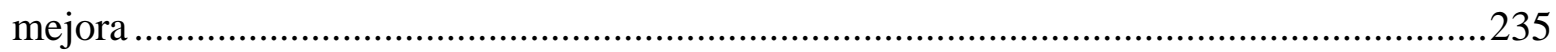

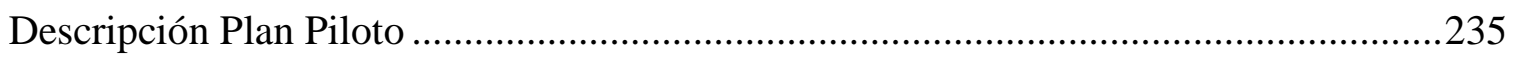

Descripción del desarrollo de las propuestas..................................................................240

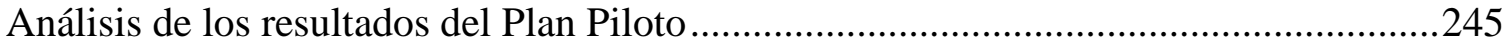

ANÁLISIS ECONÓMICO DE LAS PROPUESTAS.........................................................227

Presupuesto de Egresos relevantes ...............................................................................27

Valoración del ahorro obtenido ...................................................................................28

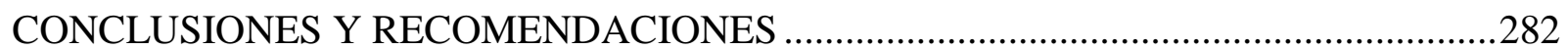

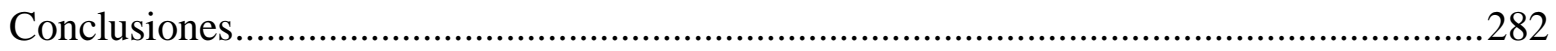

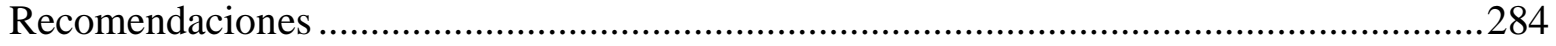

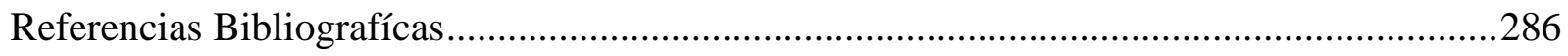

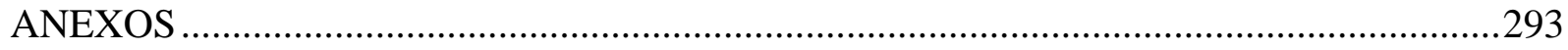


Indice de figuras

Figura 1: Papel de la logística Esbelta en la eliminación de desperdicios Logísticos .33

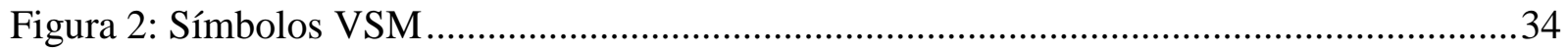

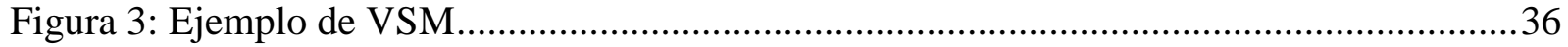

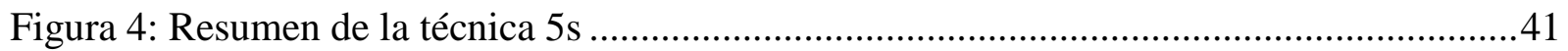

Figura 5: Hoja de ruta para implementación de Lean ......................................................45

Figura 6: Elementos de un proceso.............................................................................. 47

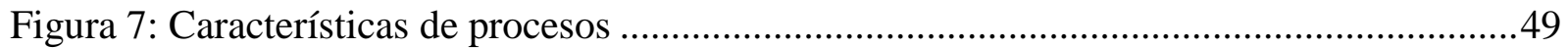

Figura 8: Símbolos más comunes para el diagrama de flujo ..............................................51

Figura 9: Ejemplo de diagrama de Ishikawa .....................................................................53

Figura 10: Factores de Productividad en las empresas .........................................................58

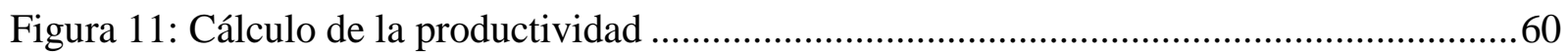

Figura 12: Resultados antes y después de implementar Lean Manufacturing ........................67

Figura 13: Esquema de comercialización de libros en el mercado peruano.............................75

Figura 14: Ventas y compras realizadas en el sector editorial ............................................78

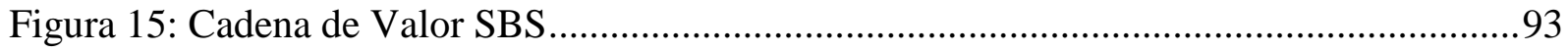

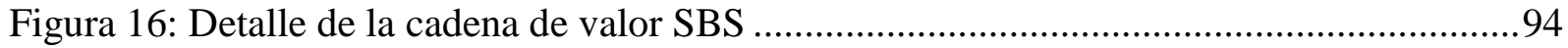

Figura 17: Mapa de procesos Special Book Services.........................................................97

Figura 18: Procesos principales de la Distribuidora SBS ..................................................99

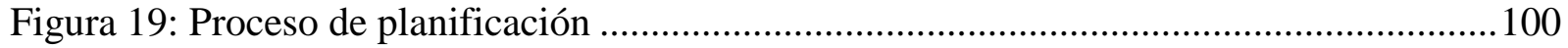

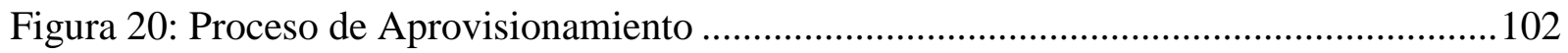

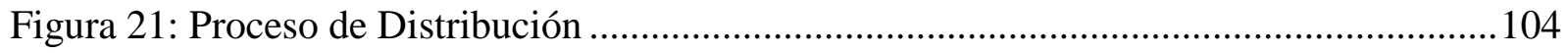

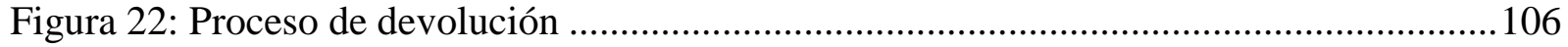

Figura 23: Aplicación sistemática de Herramientas de Calidad en el estudio de la productividad de SBS

Figura 24: Diagrama de Ishikawa para el análisis 6M de Calidad ......................................118

Figura 25: Propuesta de hoja de Ruta para la implantación en SBS ...................................148

Figura 26: Hoja de evaluación al colaborador para la conformación del equipo Lean ............151

Figura 27: DAP Proceso de Recepción de Mercadería .....................................................154

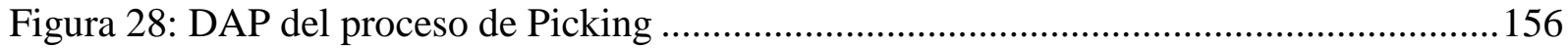




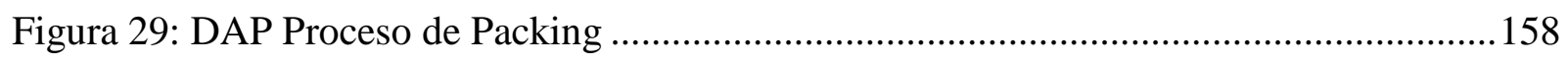

Figura 30: Análisis VSM de la Distribuidora SBS - Actual ......................................................160

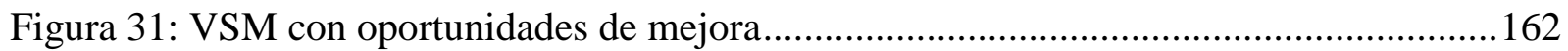

Figura 32: Cronograma de actividades para la implantación del Lean Logitics en la empresa

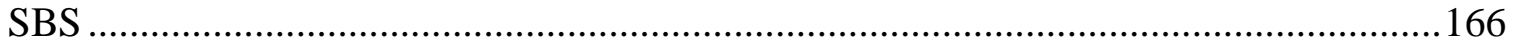

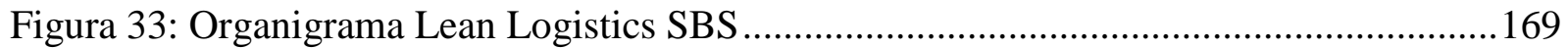

Figura 34: Aplicación de las prácticas Lean en los procesos Logísticos de SBS.....................171

Figura 35: Planificación de las actividades 5S para la implementación en SBS......................176

Figura 36: Modelo de tarjeta roja para la implementación de las 5s: Seiri ...............................180

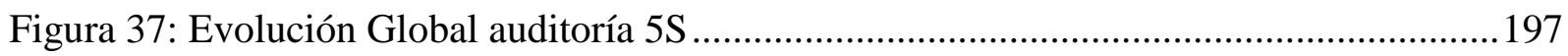

Figura 38: Procedimiento para el compromiso de disponibilidad del Montacargas ...............202

Figura 39: Parte final del proceso actual de recepción.............................................................206

Figura 40: Parte final del proceso propuesto de recepción.......................................................207

Figura 41: Sugerido para la Organización del almacén según análisis ABC ...........................215

Figura 42: Ejemplo de hoja de consolidado para programación de trabajo de montacargas ..219

Figura 43: Ficha del Proceso de Recepción e Inventario de Mercadería .................................227

Figura 44: DAP Propuesto para el proceso de Recepción e Inventario......................................228

Figura 45: Ficha del proceso de Picking ......................................................................230

Figura 46: DAP Propuesto para el proceso de Picking ………………………………...........231

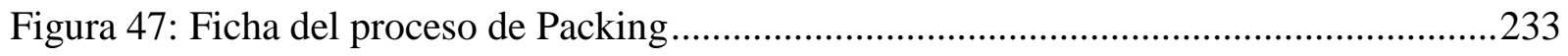

Figura 48: DAP Propuesto para el proceso de Packing ..........................................................2.234

Figura 49: Flujograma para el proceso de validación de resultados.........................................246

Figura 50: Desarrollo de la prueba de normalidad para el proceso de recepción......................248

Figura 51: Resultados de prueba no paramétrica para muestras relacionadas - Recepción ....249

Figura 52: Desarrollo de la prueba de normalidad para el proceso de Picking .......................256

Figura 53: Resultados de prueba no paramétrica para muestras relacionadas - Picking .........257

Figura 54: Desarrollo de la prueba de normalidad para el proceso de Packing ......................265

Figura 55: Resultados de prueba no paramétrica para muestras relacionadas - Packing ........266 
Indice de gráficos

Gráfico 1: Beneficios de la implementación Lean ……………………………………….....30

Gráfico 2: Ejemplo de Diagrama de Pareto .........................................................................55

Gráfico 3: Rubros a los que pertenecen las empresas asociadas a la CPL 2011 .........................76

Gráfico 4: Participación de las importaciones del rubro librero 2011 ........................................79

Gráfico 5: Participación de las principales importadoras 2011 ................................................... 81

Gráfico 6: Participación de las importadoras de libros 2015 en el Perú.......................................83

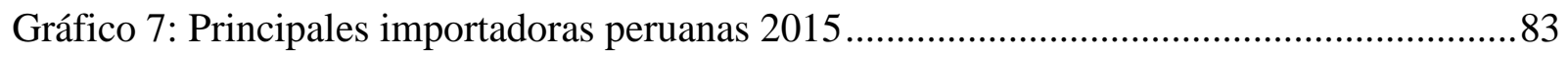

Gráfico 8: Ventas 2015 según grupo de producto ..................................................................92

Gráfico 9: Gráfico torta de las ventas 2015 según grupo de producto .......................................92

Gráfico 10: Costo de Mano de Obra - Almacén 2015 ................................................................107

Gráfico 11: Comparativo de Costo de MO base VS MO total ...................................................108

Gráfico 12: Gráfica apilada de Costo de MO Almacén 2015 ..................................................109

Gráfico 13: Costo MO Overtime - Almacén 2015 ...............................................................109

Gráfico 14: Costo S/. MO Almacén 2015 - Consolidado........................................................110

Gráfico 15: Productividad del proceso de Recepción e inventario 2015 .................................112

Gráfico 16: Productividad del proceso de Picking .................................................................113

Gráfico 17: Productividad del proceso de Packing ………………………….....................114

Gráfico 18: Análisis Pareto de improductividad asociada al proceso .......................................134

Gráfico 19: Análisis Pareto de Improductividad asociada a Operaciones................................136

Gráfico 20: Análisis Pareto de improductividad asociada a Gestión .........................................137

Gráfico 21: Productividad diaria Recep. e Invent. Set 2015 .................................................250

Gráfico 22: Productividad diaria de recepción e inventario Plan Piloto 2016 .........................252

Gráfico 23: Hora hombre Proceso de Recepción e Inventario "antes y después" ....................254

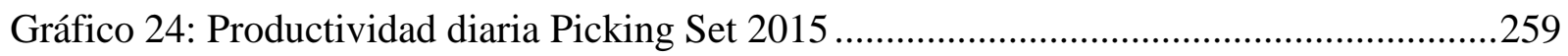

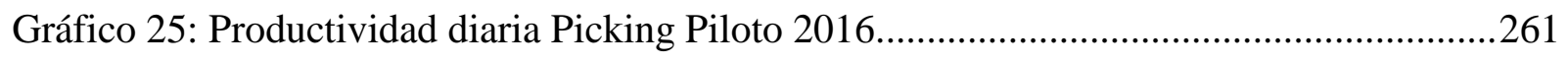

Gráfico 26: Hora hombre Proceso de Picking "antes y después"...............................................263

Gráfico 27: Productividad diaria Packing Set 2015 .............................................................267

Gráfico 28: Productividad diaria Packing Piloto 2016 ........................................................268 
Gráfico 29: Hora hombre Proceso de Packing "antes y después" .......................................270

Gráfico 30: Dead Time del proceso (minutos) ..................................................................22

Gráfico 31: Optimización del Dead Time ............................................................................22

Gráfico 32: Tiempo de ciclo del proceso..................................................................273

Gráfico 33: Ahorro del tiempo de ciclo del proceso .......................................................274

Gráfico 34: Tiempo de ciclo y dead time de los tres procesos .........................................2275

Gráfico 35: Optimización del tiempo en los tres procesos ...............................................276 
Indice de tablas

Tabla 1: Principales importadoras de libros en el Perú .82

Tabla 2: Criticidad - Impacto de la matriz de priorización ................................................. 132

Tabla 3: Indicadores de productividad del proceso Logístico de SBS ..................................164

Tabla 4: Análisis Hora Hombre de Inventario.....................................................................204

Tabla 5 Unidades procesadas por día - Inventario .........................................................204

Tabla 6: Balance de línea propuesto para Proceso de Recepción..........................................204

Tabla 7: Análisis Hora Hombre Proceso Picking ................................................................217

Tabla 8: Unidades procesadas por día - Picking............................................................217

Tabla 9: Balance de línea - Picking ....................................................................................217

Tabla 10: Análisis Hora Hombre Packing ..........................................................................223

Tabla 11: Unidades procesadas por día - Packing ...........................................................223

Tabla 12: Balance de Línea - Packing ...............................................................................224

Tabla 13: Balance de Línea - Inventario y Recepción .........................................................226

Tabla 14: Balance de Línea- Picking...............................................................................229

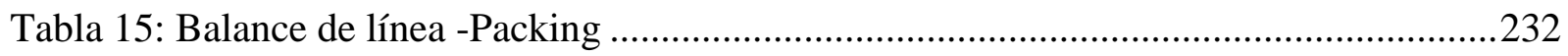

Tabla 16: Productividad media diaria del P. Recepción.......................................................247 
Indice de cuadros

Cuadro 1: Crecimiento y participación de las principales distribuidoras ................................80

Cuadro 2: Amenaza de nuevos competidores.................................................................. 84

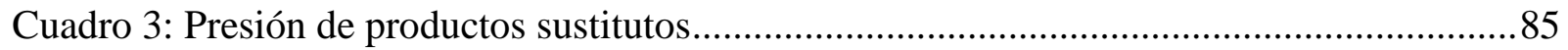

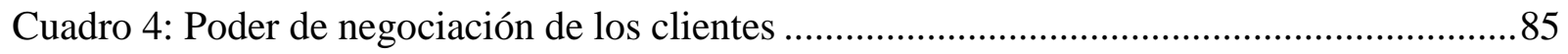

Cuadro 5: Poder de negociación de los proveedores ..........................................................86

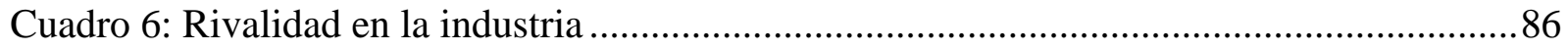

Cuadro 7: Principales productos ofrecidos por SBS ….......................................................90

Cuadro 8: Causas de improductividad relacionadas al "Método" ..........................................119

Cuadro 9: Causas de improductividad relacionadas a "Medición" ........................................ 120

Cuadro 10: Causas de improductividad relacionadas a "Medio Ambiente" ..........................120

Cuadro 11: Causas de improductividad relacionadas a "Material" .......................................121

Cuadro 12: Causas de improductividad relacionadas a "Mano de obra" ...............................121

Cuadro 13: Causas de improductividad relacionadas a "Máquina" ......................................121

Cuadro 14: Causas de Improductividad en Proceso ............................................................. 123

Cuadro 15: Causas de Improductividad en Operaciones ....................................................124

Cuadro 16: Causas de Improductividad en Gestión ...........................................................124

Cuadro 17: Resumen de Resultados de la Matriz Relacional...............................................126

Cuadro 18: Puntuación Matriz relacional asociado a la estratificación.................................128

Cuadro 19: Matriz de priorización para la solución de la improductividad en SBS ...............131

Cuadro 20: Principales causas de improductividad en procesos ......................................... 135

Cuadro 21: Principales causas de improductividad en operaciones ....................................137

Cuadro 22: Principales causas de improductividad en Gestión............................................138

Cuadro 23: Propuesta de solución para las principales causas de improductividad asociadas al

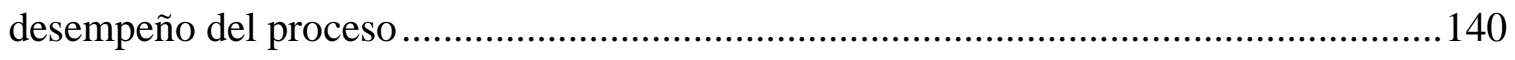

Cuadro 24 Comparación de Metodologías de Ingeniería ................................................... 145

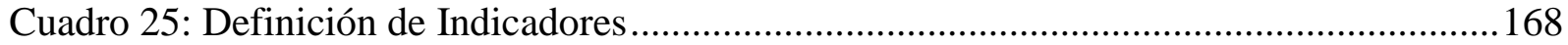

Cuadro 26: Resumen DAP Recepción de Mercadería..........................................................198

Cuadro 27: Identificación de actividades de valor no agregado y propuestas para su eliminación

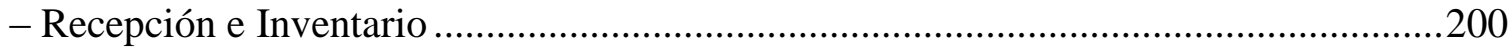


Cuadro 28: Resumen DAP Picking

Cuadro 29: Identificación de actividades de valor no agregado y propuestas para su eliminación

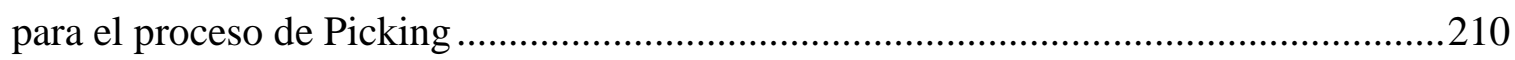

Cuadro 30: Clasificación ABC de almacén ........................................................................214

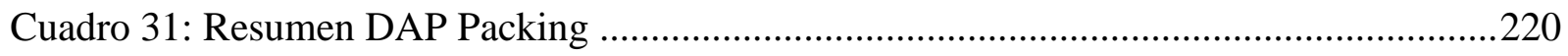

Cuadro 32: Identificación de actividades de valor no agregado y propuestas para su eliminación -Packing .221

Cuadro 33: Propuesta a desarrollar durante el plan piloto..................................................236

Cuadro 34: Cronograma para la implantación del plan piloto ............................................239

Cuadro 35: Estadísticos de Recepción e Inventario Setiembre 2015 ...................................250

Cuadro 36: Estadísticos de Recepción e Inventario Plan Piloto 2016...................................251

Cuadro 37: Productividad media diaria del P. Picking......................................................255

Cuadro 38: Estadísticos de Picking Setiembre 2015 .......................................................258

Cuadro 39: Estadísticos de Picking Piloto 2016.................................................................260

Cuadro 40: Productividad media diaria del P. Packing ........................................................264

Cuadro 41: Estadísticos de Packing Setiembre 2015 ........................................................267

Cuadro 42: Estadísticos de Packing Piloto 2016 ................................................................268

Cuadro 43: Inversión Formación Lean Logistics SBS …...................................................277

Cuadro 44: Inversión Implementación Lean ..............................................................2278

Cuadro 45: Inversión Compra de materiales ................................................................2278

Cuadro 46: Mano de obra preparación del plan piloto ......................................................279

Cuadro 47: Resumen de inversión Lean Logistics SBS ....................................................280

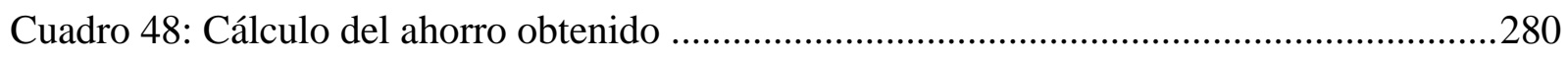

Cuadro 49: Flujo de caja mensual de la inversión Lean .....................................................281 


\section{Introducción}

La logística, en las industrias, vela por optimizar los flujos físicos de mercadería con la finalidad de que éstos se encuentren en la cantidad exacta y el momento preciso cuando sea requerida. En la actualidad, esta necesidad ha aumentado a tal punto, que el círculo proveedor, empresa y cliente requieren, no solo la mercadería, sino información del estado de sus pedidos basando sus decisiones tácticas y estratégicas en ellas.

En este sentido, son diversas las teorías de herramientas, técnicas y/o metodologías que han sido desarrolladas para optimizar las ganancias en las operaciones de las empresas sin descuidar a los clientes y fortalecer su relación. No todas las compañías logran comprender la importancia de estas técnicas que son mal ejecutadas, no aprovechadas al máximo e, incluso, llevan a grandes pérdidas en su implementación.

El presente proyecto busca destacar la trascendencia de la metodología LEAN, tan exitosa que ha llegado a ser considerada una filosofía organizacional y de mejora continua. La filosofía LEAN tuvo sus orígenes por los años 50 en la compañía de automóviles Toyota, su implementación se estableció en los procesos productivos de esta empresa, logrando en poco tiempo, posicionarla como líder del mercado.

Al ser implementada en el sector de producción fue conocida con el nombre Lean Manufacturing o producción esbelta. En la actualidad, son muchas las empresas que han adaptado esta metodología a diversos sectores, en cada uno toma el nombre de donde será aplicada: Lean Construction, Lean Service, Lean Managment, Lean Logistics, entre otros. 
Otros de concepto que soporta este estudio es la productividad, la cual permite asociar las nociones de eficiencia y eficacia a los procesos de las compañías y determinar el desempeño de las mismas. En grandes como en pequeñas organizaciones, la productividad es el principal interés de los gerentes y dueños quienes relacionan su control con la obtención de las ganancias. De este modo, el proyecto analiza a la empresa Special Book Services SA (SBS), dentro del rubro distribuidor de libros, que ha crecido exponencialmente desde sus inicios logrando posicionarse en el mercado como uno de los líderes tanto por sus ventas como por la preferencia del consumidor y que, con más de 20 años desde su fundación, enfrenta el gran reto de permanecer en esta posición, consolidarse, abarcar aún más el mercado y lograr objetivos financieros de rentabilidad.

Se reconoce que en el mercado de servicios uno de los factores más importantes en la preferencia de los clientes es el tiempo en que se atienden sus requerimientos; por lo cual SBS debe entregar sus pedidos en el menor tiempo posible garantizando obtener la máxima ganancia de sus operaciones. Con este propósito, SBS se ha visto en la necesidad de analizar y plantear mejoras dentro de sus procesos que optimicen los resultados de rentabilidad y el tiempo de atención a sus pedidos; sin embargo no cuenta con procesos estandarizados ni sistemas de medición de trabajo, siendo estos dos últimos de vital importancia antes de proponer una mejora; en definitiva, no existe la posibilidad de medir el impacto que generará la propuesta sino es en base a un estándar del proceso analizado. Otras de las carencias de SBS que el autor ha identificado, es la falta de un grupo especializado en observar, identificar, medir y analizar los problemas y sus incidencias dentro del proceso.

Ante la negativa de la empresa de no contar con procesos estandarizados, estudios de capacidad y desempeño de sus operaciones, y no mantener el registro de incidencias, frecuencias de fallas 
o variables que afecten la productividad de los procesos; el autor enfrenta el reto de demostrar que los resultados positivos en ventas se pueden seguir obteniendo utilizando menos recursos, es decir, si las cosas están marchando bien para la empresa, poder demostrar que se pueden hacer mejor.

Bajo este contexto, el proyecto se lleva a cabo en 4 importantes capítulos, en el primero se sustenta el marco teórico que servirá de soporte para el desarrollo de los siguientes capítulos, resultado de la búsqueda de información relevante de fuentes acreditas de diversas revistas científicas, libros y otros proyectos de investigación. En el segundo capítulo, se realiza el análisis de la situación actual, tanto del sector industrial al que pertenece la empresa como la estructura de la compañía con el fin de identificar y delimitar el desarrollo del estudio. Posteriormente, se realiza el tercer capítulo, en donde se detalla la propuesta para la mejora de los procesos logísticos analizados, el desarrollo de las herramientas del Lean Logistics más importantes, las mismas que han sido adaptadas a la empresa y al sector donde se desenvuelven. Por último, en el capítulo 4, se expone la validación de los resultados obtenidos a través de un plan piloto de aplicación y los beneficios económicos que estos reflejan. 


\section{CAPITULO 1: MARCO TEÓRICO}

\section{Logística}

\section{Definición}

Durante años se habló de la logística en el mundo de los negocios como la gestión encargada del almacenaje, transporte, servicio al cliente, administración de inventarios y compras, cuya misión era conseguir que los productos lleguen conformes en cantidad y tiempo donde los soliciten y al mínimo costo. ${ }^{1}$ Se seleccionó esta premisa del autor Frías para el inicio de la definición de la logística teniendo en cuenta la sencillez y exactitud de la idea considerando que es la definición habitual en los medios.

En la actualidad, la logística consiste en la administración del flujo de materiales y de la información durante los procesos que generan valor a los productos y/o servicios, en su mayoría de casos suelen ser procesos de aprovisionamiento, producción y distribución. ${ }^{2}$ Sólo en este último, estarían incluidas las actividades que menciona Frías en el párrafo anterior.

De manera similar, la logística es definida por la CSCMP (Council of Supply Chain Management Professional) como el proceso de planeamiento y ejecución de actividades y procedimientos que garantizan de manera eficaz y eficiente el transporte y almacenaje de los productos y/o servicio, simultáneamente, controla el flujo de información desde el punto de

\footnotetext{
${ }^{1}$ Cfr. Frías 2012: introducción ix

${ }^{2}$ Cfr. Contaduría y Administración 2015: 182
} 
origen hasta el consumo final del producto. ${ }^{3}$ Esta definición brindada por CSCMP es la más exacta sobre logística en la actualidad.

\section{Importancia de la Logística}

A través de la logística, las empresas pueden planificar las actividades que generan valor a los productos en escenarios internos y externos, impulsando, en efecto las inversiones a niveles empresariales como nacionales ${ }^{4} \mathrm{El}$ conocimiento y el buen control de las actividades logísticas referentes al flujo de mercadería pueden permitir una correcta planificación de actividades logrando, de este modo, atraer mayores inversionistas.

En la Revista de Economía Mundial se plasma la importancia de la Logística de manera similar con respecto a las inversiones. En un mundo totalmente globalizado como el actual, las economías con un mejor desempeño Logístico son capaces de crecer más rápido, volverse más competitivos e incrementar sus inversiones debido a que la Logística facilita el movimiento de los productos velando por su seguridad, rapidez y garantizando un menor costo, por ello, es que la logística se convierte en uno de los factores claves para el comercio internacional ${ }^{5}$

Para concluir, los autores Puertas, Martí y García (2014) expresan que la importancia de la Logística se establece en la suficiencia que tenga al resolver de manera eficaz y eficiente las dificultades de trasporte, almacenaje y embalaje de los productos y servicios ampliando, en consecuencia, la competitividad de las empresas, del sector y del país en general. ${ }^{6}$

\footnotetext{
${ }^{3}$ Cfr. Aguilar, Vásquez y Soto 2012: 222

${ }^{4}$ Cfr. Contaduría y Administración 2015: 185

${ }^{5}$ Cfr. Puertas, Martí y García 2014: 77-79

${ }^{6}$ Cfr. Puertas, Martí y García 2014: 79
} 


\section{Operaciones básicas en un Centro Logístico}

En este segmento, se explicarán las operaciones básicas que se realizan en un centro Logístico en base al estudio realizado por Becerra y Estela 2015 quienes abarcan análisis y diagnósticos para el desarrollo de un operador logístico, de tal modo se ha adaptado algunos conceptos al interés del presente estudio.

Recepción: operación donde se reciben los materiales físicamente y que va de párelo con la inspección de la misma mercadería; un ejemplo común es la llegada de un camión a un centro de distribución, realiza el desembarque mientras es inspeccionado por el personal a cargo, al finalizar y comprobada la conformidad se firman los documento correspondientes. ${ }^{7}$

Almacenaje: operación que comprende el traslado de la mercadería recepcionada hacia el lugar correspondiente del ítem en la bodega. Dentro de los más grandes $\mathrm{CD}$, los productos son llevados hacia los racks en pallets con la utilización de apiladores y/o stockas. ${ }^{8}$

Picking: operación que tiene por objetivo habilitar y garantizar la rapidez en el arme de los pedidos solicitados por los clientes. En esta operación se seleccionan los productos de sus ubicaciones de almacenaje y son llevados a la zona de preparación de pedidos (packing) ${ }^{9}$

Reposición: Con la finalidad de remover productos de sus ubicaciones de almacenamiento a una zona de fácil pickado o zona primaria de picking, se realiza esta operación. ${ }^{10}$

\footnotetext{
${ }^{7}$ Cfr. Becerra y Estela 2015: 58-63

${ }^{8}$ Cfr. Becerra y Estela 2015: 58-63

${ }^{9}$ Cfr. Becerra y Estela 2015: 58-63

${ }^{10} \mathrm{Cfr}$. Becerra y Estela 2015: 58-63
} 
Despacho: Este operación comprende las actividades realizadas después del picking hasta la entrega de los productos a un transportador. Estas actividades pueden ser Inspección de cantidad y calidad, carga de pedidos, entrega al transportador, etc. ${ }^{11}$

Distribución: Esta operación consiste en trasladar los pedidos hacia quien los solicito sean personas, instituciones, puntos de venta, etc. ${ }^{12}$

\section{Cadena de Abastecimiento}

\section{Definición}

El explicar conceptos de Cadena de Abastecimiento siempre se encontrará acompañado a definir en qué consiste la Gestión de la misma. Por ello, Simamora, Aiman y Subiyanto (2016) explican que la gestión de la cadena de suministro abarca todas las actividades vinculadas con el flujo y trasformación de los bienes desde materia prima hasta el consumidor final y toda la información que ésta pueda generar, incluyendo además, la coordinación que se puede originar con todos los participantes que intervienen a lo largo de la cadena. ${ }^{13}$ En base a lo sustentado anteriormente, se entiende que la cadena de suministro, a diferencia de la Logística, implica actividades logísticas de la empresa actual, de los proveedores y de los clientes basando todo tipo de actividad en el control de los flujos de bienes, de información y la interacción entre empresas. Por otro lado, con un enfoque a la cadena de abastecimiento del sector servicios, los autores Mejía, Agudelo y Soto indican que las funciones en las que se centra una cadena de suministro de servicios son la planificación y el gerenciamiento de compras, abastecimiento,

\footnotetext{
${ }^{11}$ Cfr. Becerra y Estela 2015: 58-63

${ }^{12}$ Cfr. Becerra y Estela 2015: 58-63

${ }^{13}$ Cfr. Simamora, Aiman y Subiyanto 2016: 34
} 
transformación y logística, además de gestionar en paralelo las relaciones con los proveedores, intermediarios, distribuidores y clientes; este enfoque ha tomado mayor relevancia en los últimos años debido a que el sector servicios está desplazando al de manufactura dando un mayor empoderamiento y diferenciación a las empresas que destaquen en las funciones de entrega de productos al usuario final. ${ }^{14}$ Con la perspectiva de estos autores, enfocados al sector servicios se demuestra, en adición al párrafo anterior, las diversas operaciones que se ejecutan a lo largo de la cadena, la interacción puede ser vertical de proveedor, productor, distribuidor y consumidor.

\section{Alcances de la Gestión de la Cadena de Abastecimiento}

Una correcta gestión de la cadena de abastecimiento comprende la organización estratégica y sistemática de las funciones primordiales del negocio, dentro de la empresa y ésta última con los integrantes de su cadena de abastecimiento. ${ }^{15}$ De esta manera las Cadenas de abastecimiento en todos sus niveles deberán centrar su estrategia en las funciones que aporten valor a su producto o servicio.

Una cadena de abastecimiento bien gestionada debe garantizar el cumplimiento de los siguientes aspectos: ${ }^{16}$

- Eficiencia del equilibrio entre la oferta y la demanda

- Reducción al máximo el tiempo de espera de los clientes

- Optimización del desempeño de los recursos

${ }^{14}$ Cfr. Mejía, Agudelo y Soto 2016: 98

${ }^{15}$ Cfr. Mejía, Agudelo y Soto 2016: 98

${ }^{16}$ Cfr. Mejía, Agudelo y Soto 2016: 99 
- Comprensión de las necesidades de los clientes actuales y potenciales dentro del mercado y el entorno

- Desarrollo de proveedores internos y externos

- Desarrollo de alianzas y relaciones en red para los clientes

- Creación del valor y desarrollo de ventajas competitivas enfocados al cliente

La importancia de una correcta gestión de la cadena de suministro ha sido reconocida por diferentes empresas que la han posicionado como una de las principales estrategias de negocios y de competitividad en el mercado. ${ }^{17}$ Es decir, hoy en día, las compañías reconocen que serán más exitosas en el mercado mientras mejor gestionada tengan su cadena de suministro frente al de la competencia.

\section{Lean Thinking o Pensamiento Lean}

\section{Definición}

En la actualidad, el pensamiento Lean o Lean Thinking es el enfoque más popular para la eficiencia y mejora en las organizaciones. EL pensamiento Lean es una filosofía organizacional basada en una gran variedad de principios que resaltan la relevancia del valor, el flujo y la mejora continua; su objetivo es brindar al cliente lo mejor del servicio o producto, en el lugar correcto, en el tiempo correcto y en las cantidades correctas al mínimo coste y/o desperdicio. ${ }^{18}$ Esta primera acepción de Lean resalta la optimización de los recursos, el conseguir más desde el punto de vista para el cliente con la utilización de menos o iguales recursos.

${ }^{17}$ Cfr. Simamora, Aiman y Subiyanto 2016: 33

${ }^{18}$ Cfr. Shaked y Stampf 2015: 4-5 
Como apoyo al texto anterior, Dolf Kahle (CEO VSM) añade que el enfoque de Lean es sistemático y está orientado a la identificación y eliminación del residuo y/o toda actividad que no genere valor, apoyándose para ello en la mejora continua y el flujo de los productos y servicios que brindan las empresas. El Lean es aplicado por todas las organizaciones en busca de la perfección, siendo estas de diferentes rubros industriales: producción, distribución, servicios, cuidados de la salud, etc. ${ }^{19}$ Debido a los diferentes campos donde el Lean puede implementarse, este concepto ha trascendido hacia los conceptos de Lean Manufacturing, Lean Office, Lean Logistics, Lean Constructions, entre otras.

Así mismo en una concepción que va más allá de un pensamiento, el Lean es una filosofía en la cual todo el personal en la organización aprende a identificar los desperdicios en los procesos, sabe cómo solucionarlos o, como mínimo, sabe a quién dirigirse para la solución del problema. El Lean Thinking utiliza una variedad de herramientas, técnicas y métodos para la mejora de los procesos y la reducción de la duplicación del esfuerzo, la eliminación del desperdicio y las actividades que no generan valor, la simplificación del proceso, la disminución de las fallas, etc. ${ }^{20}$

Por otro lado, en una tesis sobre el pensamiento Esbelto, Frank Córdova, plantea que el Lean Thinking comprende las relaciones humanas de todos los colaboradores que se desenvuelven dentro de la organización, en la cual las ideas de cada uno tienen y deben tener el mismo valor e importancia en la solución de problema encontrado con el fin de consolidar el trabajo en equipo y el empoderamiento del trabajador sin importar su jerarquía. ${ }^{21}$ Esta idea dinamiza el concepto de Lean interponiendo el recurso humano como fuente de implementación y desarrollo del Lean.

\footnotetext{
${ }^{19}$ Cfr. Kahle 2015:12

${ }^{20}$ Cfr. Grech 2011: 20-21

${ }^{21}$ Cfr. Córdova 2012: 8-9
} 
Argumentando lo anterior, la idea expuesta por Myerson propone que Lean no es una meta de ahorro o de reducción de gastos, la cual una vez alcanzada termina ahí; por lo contrario es la formación de todo un equipo basado en la mejora continua que sustente sus actividades en la identificación y la eliminación del desperdicio, es decir las actividades que no generan valor para la perspectiva del cliente, cumpliéndose esto se le otorga a las organizaciones la competitividad necesaria para afrontar el mercado cada vez más agresivo. ${ }^{22}$ Esto último ejemplifica que más allá de las nociones de pensamiento o filosofía, el Lean busca fomentar una "cultura" de mejora continua y reducción de costes dentro de la organización teniendo como principal soporte el recurso humano.

\section{Despilfarro y valor agregado}

La repuesta a lo que espera el cliente del proceso actual, sea un cliente interno del proceso siguiente o un cliente externo es lo que se define como valor agregado, de aquí se desprende que las actividades de un proceso pueden separarse en actividades que generen valor y en las

que no. ${ }^{23}$ Como se vio en la definición del pensamiento Lean, el equipo humano será el responsable de identificar y eliminar las actividades que no generen ningún valor.

En cambio y paralelamente, se define como despilfarro a las actividades que generan costos y que, a su vez, no agregan valor al producto o servicio. Del mismo autor, se presenta una breve explicación de tipo de despilfarro, desperdicio o muda que el Lean identifica: ${ }^{24}$

Sobreproducción: Consiste en producir más en cantidad y más pronto de lo que es requerido por el cliente. Trae como consecuencia el descontrol y el acumulamiento de lo que se produce. ${ }^{25}$

\footnotetext{
${ }^{22}$ Cfr. Myerson 2015: 32-34

${ }^{23}$ Cfr. Jiménez 2013: 31

${ }^{24}$ Cfr. Gutiérrez 2014: 96-97

${ }^{25}$ Cfr. Gutiérrez 2014: 96-97
} 
Esperas: Se manifiesta en el tiempo en que las máquinas y el personal están dedicados a realizar actividades que no agreguen valor al producto y/o servicio (tiempo desperdiciado). ${ }^{26}$

Transportación: Los despilfarros por transporte implican los movimientos innecesarios de los operarios, el material y los insumos siendo una de sus principales causas la distribución de planta en la cual se desarrollan gran manejo y movimientos de partes y largas distancias a recorrer de un proceso a otro. ${ }^{27}$

Sobre procesamiento: Son las actividades y esfuerzos que no son requeridos por los clientes, es decir, no generan valor en ellos. En su gran mayoría son representados por numerosas aprobaciones y autorizaciones redundantes. ${ }^{28}$

Inventarios: Los despilfarros del tipo inventario se ven expresados en la gran cantidad de partes, insumos o productos terminados que sobrepasan el mínimo requerido para la satisfacción del cliente. Gran parte de estos inventarios se vuelven obsoletos. ${ }^{29}$

Movimientos: Este tipo de despilfarro es resultado de la manipulación y de los movimientos innecesarios de herramientas, materiales y del personal dentro del proceso. Algunos ejemplos son la búsqueda de herramientas, excesivos desplazamientos del personal, doble manipulación de materiales, etc. ${ }^{30}$

Re trabajo: Es el despilfarro que se obtiene por la repetición o corrección de un proceso debido a la calidad del producto o servicio. Expresado en otras palabras, el despilfarro ocurre cuando se presenta defectos en la calidad del producto y/o servicio. ${ }^{31}$

\footnotetext{
${ }^{26}$ Cfr. Gutiérrez 2014: 96-97

${ }^{27}$ Cfr. Gutiérrez 2014: 96-97

${ }^{28}$ Cfr. Gutiérrez 2014: 96-97

${ }^{29}$ Cfr. Gutiérrez 2014: 96-97

${ }^{30}$ Cfr. Gutiérrez 2014: 96-97

${ }^{31}$ Cfr. Gutiérrez 2014: 96-97
} 
Algunos autores distinguen un octavo despilfarro que el Lean debe eliminar, es el caso de Kahle (2015) quien identifica que hay dos tipos de personalidades que no deben estar dentro del equipo Lean y solo logrando su reducción o eliminación se podrán conseguir los resultados. Al primero los hace llamar "Blockheads" colaboradores que tienen miedo al cambio, llegan a sus puestos de trabajo y demandan siempre lo mismo; el cambio no es parte de ellos y suelen bloquear a los demás sobre toda posibilidad de cambio. Kahle menciona que esta clase de colaboradores no puede ser convertida y debe eliminarse dentro del equipo Lean. Al segundo tipo de personalidad los hace llamar "But Heads" y son los colaboradores que siempre escuchan y está abiertas a nuevas ideas de cambios, sin embargo lo primero que suelen responder es "pero". Kahle expresa que este tipo de colaboradores les espanta el cambio pero, a diferencia del anterior, sí pueden ser convertidos. ${ }^{32}$ Con el análisis anterior, se muestra cómo se ha relacionado el octavo despilfarro del Lean con el factor humano, principal pilar dentro de la Cultura Lean.

\section{Beneficios de la implementación Lean}

Las organizaciones que logren implementar el pensamiento Lean obtendrán los siguientes beneficios en sus organizaciones: ${ }^{33}$

- Reducción y/o eliminación de las ocho tipos de despilfarro, anteriormente explicados

- Aumento en la calidad de los productos y/o servicios

- Disminución del tiempo de entrega al cliente

- Reducción de inventarios: en proceso, insumos y productos terminados

- Disminución en los costos de producción y/o operación.

- Optimización de la mano de obra y equipos utilizados

\footnotetext{
${ }^{32}$ Cfr. Kahle 2015:12

${ }^{33}$ Cfr. Córdova 2012:9
} 
Gráfico 1: Beneficios de la implementación Lean

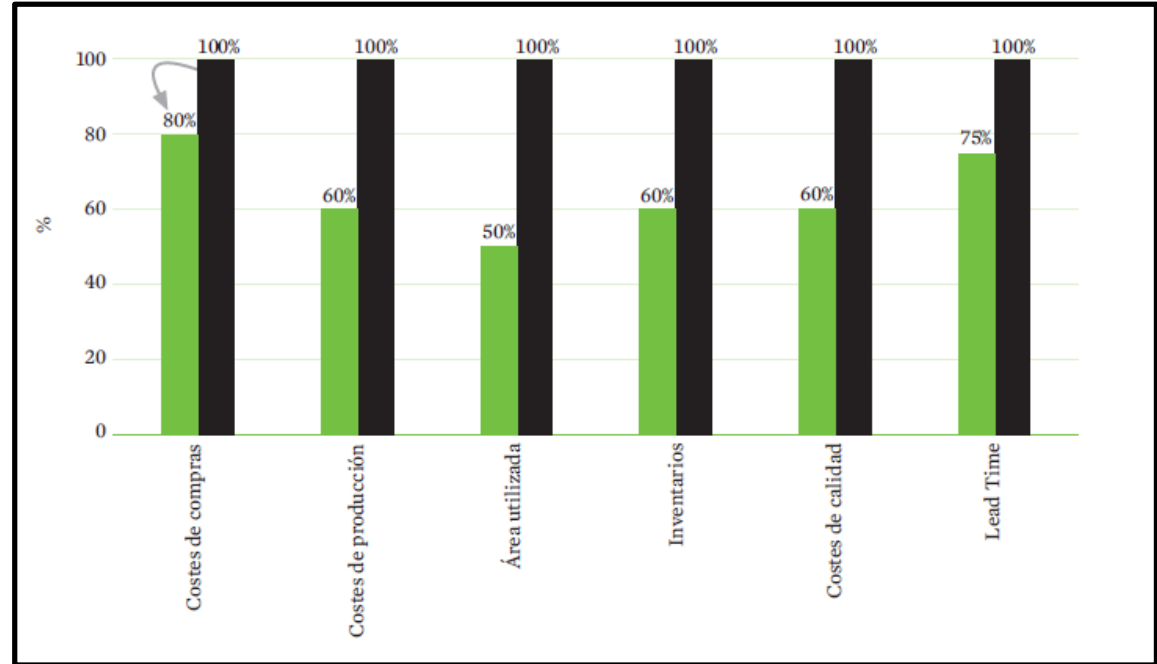

Fuente: Hernández y Vizán 2013:11. Basado en "Estudio 300 empresas Aberdeen Group, 2004"

El gráfico 1 muestra los beneficios que obtuvieron las empresas que implementaron el pensamiento Lean dentro de sus organizaciones como ejemplo y sustento de lo expresado en el párrafo anterior. Se observa que la reducción en los aspectos de costes de compras, producción, área utilizada, calidad y lead time oscila entre el 20 y el $50 \%$

\section{Kaizen y mejora continua}

Gutiérrez (2014) expone que la mejora continua está conformada por toda actividad que se realiza reiteradas veces con el fin de incrementar el desempeño de tres factores claves en la organización: calidad, productividad y competitividad; explica, además, que la mejora continua se da como resultado de una ordenada administración en la mejora de los procesos a través, por ejemplo, de la detección de causas raíz o restricciones, de la propuesta de nuevas ideas y proyectos de mejora, del estudio y aprendizaje de las consecuencias obtenidas y de la estandarización de los resultados positivos, ésta última, permitirá controlar el nuevo desempeño 
de los procesos. ${ }^{34}$ En este primer punto, se ha desarrollado la noción general de la mejora continua, su importancia y el origen a partir de buenas prácticas entre las que destaca la estandarización.

Por un lado, los autores Hernández y Vizán mencionan que la mejora continua representa un rol importante para el Lean, ya que consiste en la búsqueda permanente de la reducción del desperdicio y que a través de los años, la mejora continua pasó a denominarse espíritu Kaizen siendo uno de los factores determinantes en el éxito de la implementación Lean en las compañías japonesas. $^{35}$

Por otro lado, un estudio realizado por Professional Safety advierte una diferencia entre la mejora continua y los eventos kaizen. Los eventos kaizen se deben llevar a cabo entre 2 a 5 días, su compacta realización y autopreparación de contenido contrasta a la estructura de implementación de la mejora continua. Los grandes objetivos del Lean y de la mejora continua buscan siempre reducir las mudas, para ello se requiere de grandes y complejos esfuerzos en el día a día de los negocios, llevando a muchos de ellos a grandes pérdidas de dinero en el fallido intento de su implementación. En este contexto, los eventos kaizen ayudan a los colaboradores a replantear filosofías de trabajo y optimizar las operaciones al conseguir resultados en un corto tiempo. $^{36}$

\footnotetext{
${ }^{34}$ Cfr. Gutiérrez 2014:64

${ }^{35}$ Cfr. Hernández y Vizán 2013: 27-28

${ }^{36}$ Cfr. Professional Safety 2015: 20
} 


\section{Lean Logistic}

\section{Definición}

La logística Esbelta, por su traducción al español, deriva de la aplicación de las teorías y principios del Lean Thinking y/o Lean Manufacturing, que incluyen herramientas, métodos y técnicas que han logrado impactar favorablemente en las organizaciones, llevándolas a reflexionar en estructura y división del trabajo. De ello se desprende que la Logística Esbelta examina la eficiencia y el desempeño de todas las actividades logísticas orientándose en el principio de eliminar todo elemento, acción y operación que no agregue valora a la actividad. ${ }^{37}$ Dicho en otras palabras, la Logística Esbelta es la aplicación de pensamiento Lean a los campos de estudio y desarrollo de la logística y su principal objetivo es el de añadir valor basado en la eliminación del desperdicio.

Al mismo tiempo Myerson (2012) analiza el traslado del Lean a los intereses de la Cadena de Suministro y de la Logística, logrando destacar que la necesidad de implementar el Lean dentro de la organización no era viable sino se consideraban primero a los proveedores y los clientes; agrega además, que sin una estrecha relación con ellos, los resultados no son provechosos y que por el contrario, se cae en el error de culpar a los proveedores por todas las ineficiencias y a los clientes por su elasticidad en la demanda. ${ }^{38}$ La idea central de Myerson se basa en la valoración de la cadena de suministro y sus operaciones logísticas, lo cual incluye el reconocimiento de los proveedores y cliente como factor primordial en la productividad de la empresa; de esta manera

${ }^{37}$ Cfr. Zapata y Moreno 2011: 117-120

${ }^{38}$ Cfr. Myerson 2012a 
la aplicación del pensamiento Lean debe migrar hacia estos nuevos enfoques para asegurar sus objetivos.

Desde otra perspectiva, la logística esbelta se centra en garantizar las existencias mínimas requeridas para la producción sin descuidar el velar por el cumplimiento del plan de producción y suavizar la tasa de consumo de cada producto durante los plazos de entrega, además de responder eficientemente con contramedidas ante cualquier indicio de dificultades. ${ }^{39}$ En tal sentido, la logística esbelta asegurará el flujo de materiales de la manera más eficiente durante el desarrollo de las operaciones de la cadena de suministro.

La siguiente figura muestra los desperdicios logísticos de dos enfoques diferentes, uno son los propuestos por la Logística Esbelta (izquierda) y el otro son los siete desperdicios clásicos de Lean (derecha)

Figura 1: Papel de la logística Esbelta en la eliminación de desperdicios

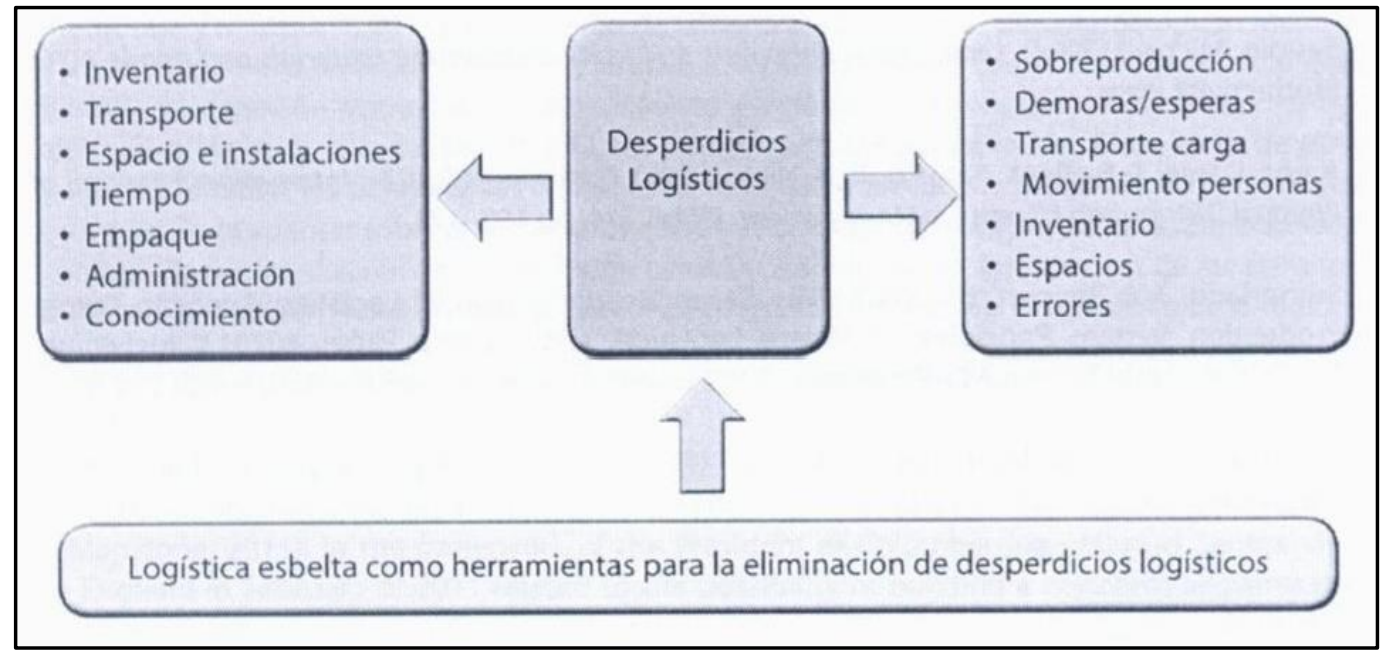

Fuente: Zapata y Moreno 2011:119

${ }^{39}$ Cfr. Bulej y otros 2011 
Con similitudes y diferencias, los desperdicios o despilfarros planteados en la figura anterior serán identificados y eliminados por el Lean Logistic reduciendo los costes y en consecuencia, elevando las utilidades en las compañías.

\section{Herramientas de Lean Logistics}

\section{Value Stream Mapping (VSM)}

Traducido al español como el mapa de la cadena de valor, es la representación gráfica de la cadena de valor en donde se representan el flujo de materiales y el flujo de información desde los proveedores hasta los clientes; su finalidad es expresar de forma simple y sencilla todas las actividades de la cadena de valor y permitir identificar, de igual modo, en qué actividades se desarrollan los mayores despilfarros del proceso. ${ }^{40}$ Como un tipo de mapa de proceso, el Lean ha orientado este concepto a la identificación de actividades que agreguen valor y las que no al proceso proponiendo a partir de aquí el concepto del mapa de cadena de valor (VSM).

Figura 2: Símbolos VSM

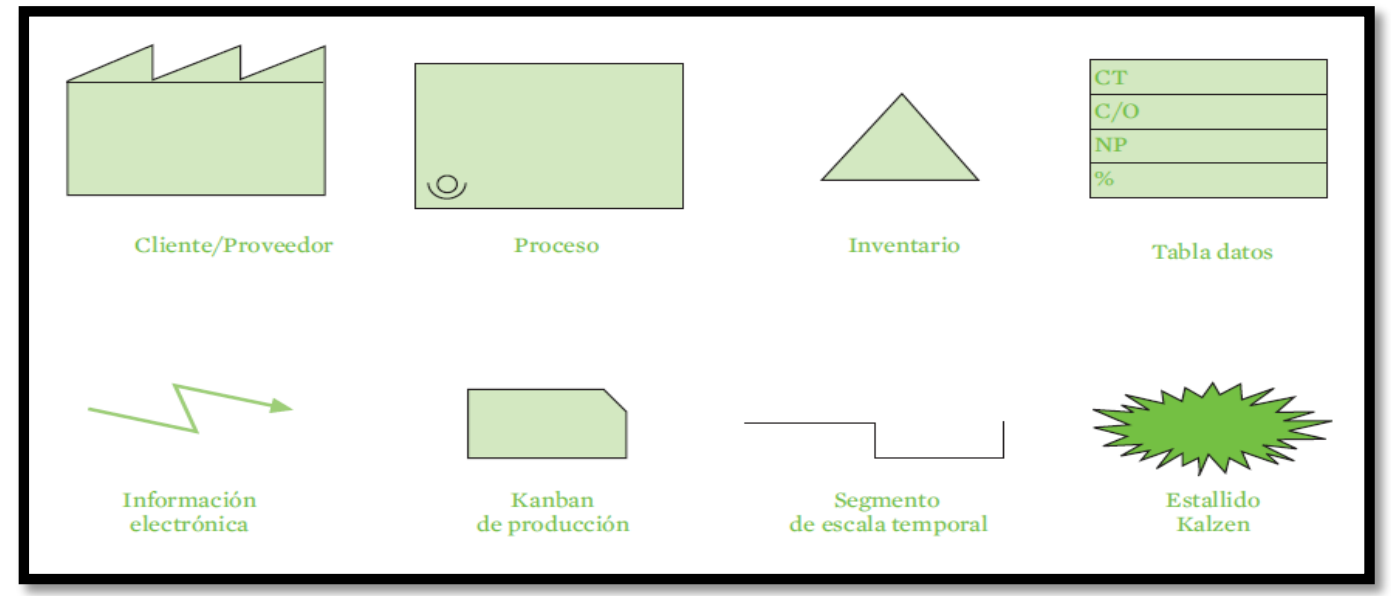

Fuente: Hernández y Vizán 2013: 90

${ }^{40}$ Cfr. Hernández y Vizán 2013:90 
La figura 2 muestra los símbolos más comunes en la elaboración de los mapas de la cadena de valor, con esto las organizaciones logran una mayor representatividad de sus actividades distinguiendo cuales agregan valor a los servicios prestados.

Para la aplicación del Lean en las operaciones logísticas, Paul Myerson manifiesta que el VSM es la manera más eficiente de encontrar los despilfarros, además, añade que hay dos áreas potenciales en las cuales el VSM puede detectar la gran cantidad de despilfarros: Transporte e inventarios. ${ }^{41}$ De esta manera Myerson relaciona el VSM con la identificación directa de los tipos de muda mencionados.

El VSM es catalogado como una de las principales herramientas del Lean, la cual enseña los elementos claves de los sistemas de producción y como estos elementos interactúan entre ellos; permite a sus usuarios la identificación de las actividades que los clientes están dispuestos a pagar y las que no. Se debe resaltar que el VSM muestra como el flujo de información va interactuando con el flujo del material añadiendo valor en conjunto, esto ayuda a los ingenieros industriales a visualizar como trabajan los sistemas de producción y prestación de servicios desde que el cliente inicia la orden hasta la atención de la misma ${ }^{42}$.

Para Duranik, Stopper y Ruzbarsky, el principal objetivo del VSM es la mejora de procesos, este objetivo se consigue con la distinción de qué áreas y actividades son las que generan el mayor desperdicio durante el proceso, mencionan también, que las organizaciones deben ser capaces de eliminar este tipo actividades. Por último, estos tres autores, expresa que el VSM permite la categorización de las actividades del proceso en dos: En primer lugar, "Actividades que agregan valor" al producto o servicio y que son las que el cliente reconoce. En segundo

\footnotetext{
${ }^{41}$ Cfr. Myerson 2012b
}

${ }^{42}$ Cfr. Shararah 2013: 46-50 
lugar, "Actividades que no agregan valor / Despilfarro" que consumen tiempo y/o recursos. ${ }^{43}$ Considerando lo anterior, el VSM realiza la función de herramienta para el diagnóstico siendo su utilización determinante al iniciar la implementación del Lean.

Según sea el rubro de la empresa, existen diversos VSM; se escogió el ejemplo de Forno y otros (2014) por ser el que cuenta con los tres factores principales como son el flujo de información, el flujo de mercadería y el tiempo de ciclo. (Ver figura 3)

Figura 3: Ejemplo de VSM

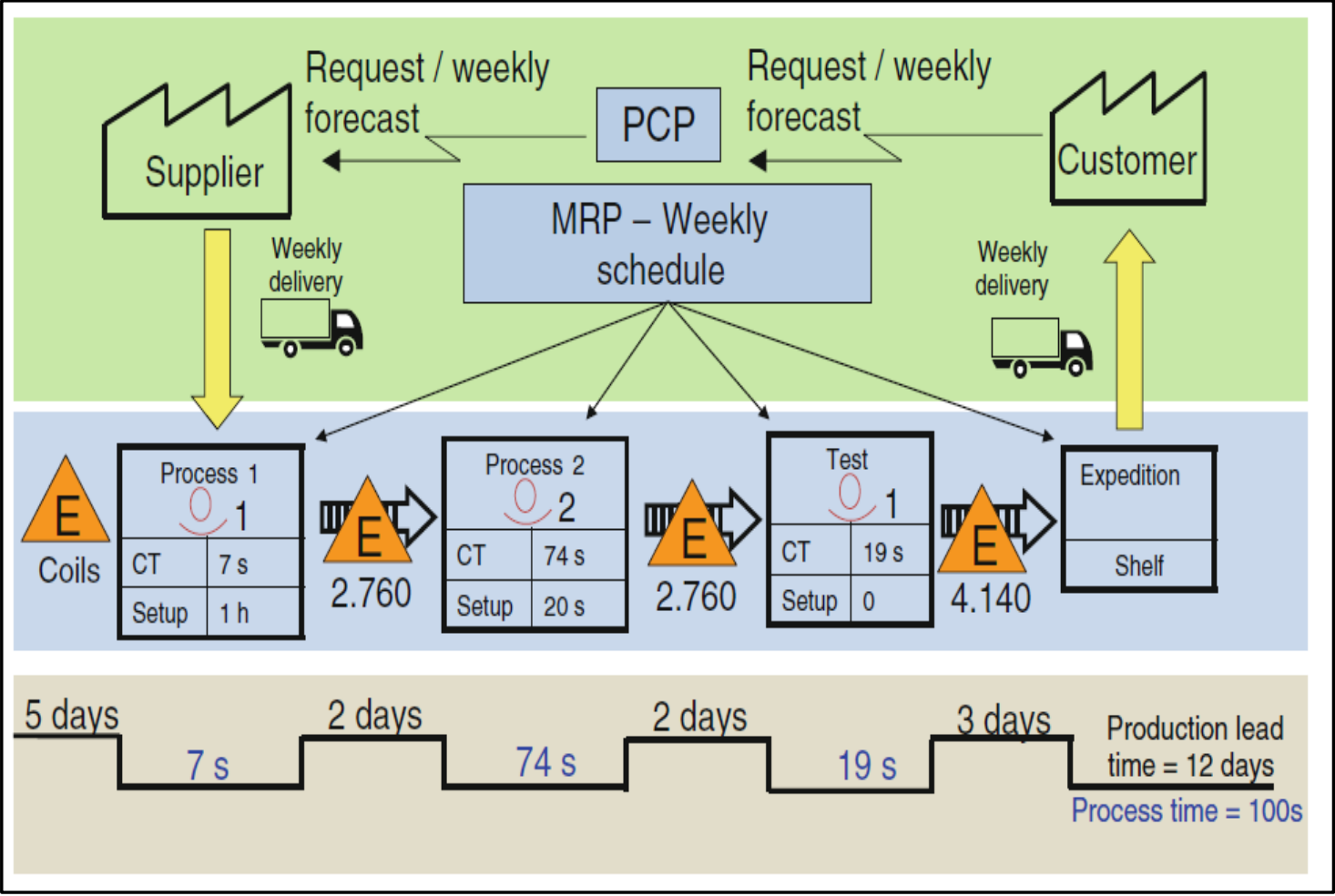

Fuente: Forno y otros 2014:780

En este ejemplo de VSM se puede identificar la interacción cliente, empresa y proveedor (flujo de información), seguidamente los procesos que se realizan (flujo de material) y por último, la

${ }^{43}$ Cfr. Duranik, Stopper y Ruzbarsky 2011: 969-970 
línea del tiempo. Estas tres secciones permitirán tener un mejor panorama de las actividades que se realizan en la compañía.

\section{Las 5S}

Las $5 \mathrm{~S}$ (cinco eses) es una metodología que compromete la colaboración de todos los trabajadores, permite a quienes la implementan la organización de los centros de trabajo: oficinas, plantas, almacenes, etc; enfocándose en los principios de orden, limpieza y disciplina. Su desarrollo se originó en repuesta al incremento de mudas (despilfarros) que se reflejaban en la disminución de la productividad y la lentitud de los procesos a consecuencia del desorden de los útiles, herramientas, equipos y documentos en el trabajo. ${ }^{44}$

En la revista internacional de la producción 2014 se explica que la metodología de las 5S es una de las mejores herramientas del Lean para gestar un cambio de actitud en los trabajadores orientándolos hacia una cultura de mejora continua en la realización de las diferentes actividades y operaciones realizadas en el centro de trabajo. También menciona que el nombre de las $5 \mathrm{~S}$ corresponde a la letra inicial de cinco principios japoneses: Seiri, Seiton, Seiso, Seiketsu, Shitsuke y traducidas al español corresponderían: Seleccionar, ordenar, limpiar, estandarizar y autodisciplinarse. Por último, indica que la utilización de esta metodología es el mejor medio para iniciar y conseguir procesos de mejora continua. ${ }^{45}$ Como mencionan los autores, la implementación de las $5 \mathrm{~S}$ es recomendable y necesaria para el inicio de todo plan de mejora continua, como por ejemplo las prácticas Lean.

\footnotetext{
${ }^{44}$ Cfr. Gutiérrez 2014: 110
}

${ }^{45}$ Cfr. Jaca y otros 2014 
El autor Paul Myerson expone en su obra que la metodología de las 5S logra transformar el centro de operaciones en un lugar limpio, ordenado, seguro y organizado, además, empodera a los trabajadores con una valores de éxito y mejora; de igual modo, Myerson afirma más beneficios de la implementación de las 5S: Disminución de los accidentes, mejora la eficiencia, disminuye el tiempo de búsqueda, reduce la contaminación, permite un mayor control visual y sirve como base para todas las actividades de mejora. Por último, Myerson, de igual modo que los autores anteriores, vuelve a enfatizar que las $5 \mathrm{~S}$ se implementan como primera práctica del Lean Logistics y que su uso es muy frecuente en los almacenes y centros de distribución en los cuales se realizan las principales funciones de la logística y la cadena de suministro. ${ }^{46}$

\section{$\underline{\text { Seleccionar (Seiri): }}$}

Que no solo consiste en clasificar los elementos del centro de trabajo, radica también en eliminar todos los elementos superfluos e innecesarios para las tareas y actividades que se desempeñan; para ello los colaboradores se realizan la interrogante: ¿Esto realmente es útil? Con la implementación de esta primera S se busca la eliminación de aquellos ítems que no sean útiles al proceso, el control del flujo de materiales que si son útiles y la prevención de despilfarros productos de manipulaciones y transportes innecesarios para el proceso. ${ }^{47}$

\footnotetext{
${ }^{46}$ Cfr. Myerson 2012c

${ }^{47}$ Cfr. Hernández y Vizán 2013: 38
} 


\section{Ordenar (Seiton):}

El propósito de esta segunda S es mantener lo que se identificó en la primera $\mathrm{S}$ como elemento útil en la operación, organizándolo de tal forma que tenga una ubicación obvia, habilitada y de fácil acceso para todos los colaboradores en el momento que sea necesario. Esta segunda $\mathrm{S}$ resalta la importancia de localizar algo y poder regresarlo a su ubicación corresponde, también enfatiza la máxima que todos los elementos deben tener un lugar donde guardarse y que deben estar ahí (un lugar para cada cosa y cada cosa en su lugar). ${ }^{48}$ En esta fase lo importante es disminuir y/o eliminar todo despilfarro producido por los movimientos innecesarios de trabajadores y materiales.

\section{Limpiar (Seiso):}

La tercera $\mathrm{S}$ dentro de esta metodología propone actividades de limpieza e inspección con el fin de anticipar que los defectos y despilfarros ocurran; esta aplicación incluye la integración de la limpieza como una rutina de trabajo diario, asume que la limpieza es una tarea de inspección necesaria y por último, se enfoca en la eliminación de los focos de suciedad y no en sus consecuencias. ${ }^{49}$

\section{Estandarizar (Seiketsu):}

En esta 4 fase se busca asegurar los resultados obtenidos en las tres fases anteriores. Estandarizar implica realizar un procedimiento y/o actividad con el mismo método, el cual debe ser el más sencillo, fácil y conocido por toda la organización. Este estándar puede estar establecido en un

\footnotetext{
${ }^{48}$ Cfr. Gutiérrez 2014: 111

${ }^{49}$ Cfr. Hernández y Vizán 2013: 39-40
} 
papel, una foto, un gráfico o un dibujo. En adición, la estandarización tiene como finalidad sostener los niveles en las tres $\mathrm{S}$ anteriores, el estándar debe estar al alcance de todos y en el momento indicado y, por último, debe permitir comprobar que las actividades se estén realizando correctamente. ${ }^{50}$

\section{Shitsuke (Disciplina):}

Gutiérrez (2014) expresa que la 5ta S denominada disciplina es el puente entre la metodología 5s y la mejora continua; permitiendo disfrutar los beneficios de esta metodología solo si llega a la disciplina. Con la disciplina se evita y/o elimina toda acción o elemento que perjudique los procesos y estándares constituidos en las anteriores fases a través del autocontrol de los colaboradores, el control periódico con visitas sorpresas, un mejor ambiente laboral y la fomentación de una cultura de respeto hacia los demás. ${ }^{51}$

De la obra de Hernández y Vizán se muestra un cuadro resumen de lo que implica cada etapa en las cinco S, qué actividades corresponden a cada una de ellas y la secuencia de las mismas. (Ver figura 4)

${ }^{50}$ Cfr. Hernández y Vizán 2013: 40

${ }^{51}$ Cfr. Gutiérrez 2014: 112 
Figura 4: Resumen de la técnica $5 \mathrm{~s}$

\begin{tabular}{|c|c|c|c|c|}
\hline $\begin{array}{c}\text { SEIRI } \\
\text { Separar y eli- } \\
\text { minar }\end{array}$ & $\begin{array}{l}\text { SEITON } \\
\text { Arreglar e } \\
\text { identificar }\end{array}$ & $\begin{array}{c}\text { SEIDO } \\
\text { Proceso diario } \\
\text { de limpieza }\end{array}$ & $\begin{array}{c}\text { SEIKETSU } \\
\text { Seguimiento de } \\
\text { los primeros } 3 \\
\text { pasos, asegurar un } \\
\text { ambiente seguro }\end{array}$ & $\begin{array}{l}\text { SHITSUKI } \\
\text { Construir el } \\
\text { hábito }\end{array}$ \\
\hline $\begin{array}{c}\text { Separar los } \\
\text { artículos nece- } \\
\text { sarios de los } \\
\text { no necesarios }\end{array}$ & $\begin{array}{l}\text { Identificar los } \\
\text { artículos nece- } \\
\text { sarios }\end{array}$ & $\begin{array}{l}\text { Limpiar cuan- } \\
\text { do se ensucia }\end{array}$ & $\begin{array}{c}\text { Definir métodos } \\
\text { de orden y lim- } \\
\text { pieza }\end{array}$ & $\begin{array}{c}\text { Hacer el orden y } \\
\text { la limpieza con } \\
\text { los trabajadores } \\
\text { de cada puesto }\end{array}$ \\
\hline $\begin{array}{l}\text { Dejar solo } \\
\text { los artículos } \\
\text { necesarios } \\
\text { en el lugar de } \\
\text { trabajo }\end{array}$ & $\begin{array}{c}\text { Marcar áreas } \\
\text { en el suelo para } \\
\text { elementos y } \\
\text { actividades }\end{array}$ & $\begin{array}{l}\text { Limpiar perió- } \\
\text { dicamente }\end{array}$ & $\begin{array}{l}\text { Aplicar el méto- } \\
\text { do general en } \\
\text { todos los puestos } \\
\text { de trabajo }\end{array}$ & $\begin{array}{c}\text { Formar a los } \\
\text { operarios de } \\
\text { cada puesto para } \\
\text { que hagan orden } \\
\text { y limpieza }\end{array}$ \\
\hline $\begin{array}{c}\text { Eliminar los } \\
\text { elementos no } \\
\text { necesarios }\end{array}$ & $\begin{array}{l}\text { Poner todos los } \\
\text { artículos en su } \\
\text { lugar definido }\end{array}$ & $\begin{array}{l}\text { Limpiar siste- } \\
\text { máticamente }\end{array}$ & $\begin{array}{l}\text { Desarrollar un } \\
\text { estándar especí- } \\
\text { fico por puesto } \\
\text { de trabajo }\end{array}$ & $\begin{array}{l}\text { Actualizar la } \\
\text { formación de los } \\
\text { operarios cuan- } \\
\text { do hay cambios }\end{array}$ \\
\hline $\begin{array}{l}\text { Verificar } \\
\text { periódicamen- } \\
\text { te que no haya } \\
\text { elementos no } \\
\text { necesarios }\end{array}$ & $\begin{array}{l}\text { Verificar que } \\
\text { haya "un lugar } \\
\text { para cada cosa } \\
\text { y cada cosa en } \\
\text { su lugar" }\end{array}$ & $\begin{array}{c}\text { Verificar siste- } \\
\text { máticamente } \\
\text { la limpieza de } \\
\text { los puestos de } \\
\text { trabajo }\end{array}$ & $\begin{array}{l}\text { Verificar que } \\
\text { exista un están- } \\
\text { dar actualizado } \\
\text { en cada puesto } \\
\text { de trabajo }\end{array}$ & $\begin{array}{c}\text { Crear un siste- } \\
\text { ma de auditoría } \\
\text { permanente de } \\
\text { planta visual } \\
\text { y } 5 \mathrm{~s}\end{array}$ \\
\hline
\end{tabular}

Fuente: Hernández y Vizán 2013:41 


\section{Control Visual}

Según Hernández y Vizán las técnicas de control visual que Lean propone son un grupo de estrategias pragmáticas de comunicación que tienen el fin de expresar de manera sencilla y evidente la condición actual de los procesos que se ejecutan en la organización, permitiendo de esta manera, identificar las anomalías y despilfarros ocurridos en las actividades que generan valor añadido. Los autores mencionan además, que estos mensajes deben ser entendidos por todos los colaboradores inmersos en el sistema a diferencia de los gráficos estadísticos y cifras de índole especializada y estática que solo son entendidos por expertos. Por último manifiestan que la implementación de técnicas de control visual incorpora diversos métodos de aplicación, cada uno ajustado según el objetivo que se quiere alcanzar. ${ }^{52}$

Por otro lado, Cuatrecasas (2010) manifiesta que en una correcta implementación Lean se puede obtener toda la información necesaria del sistema solo con un paseo por la planta gracias a la gestión y medidas de controles visuales; añade además que la gestión de controles visuales influyen positivamente en los diferentes aspectos de competitividad de la empresa como son eficiencia, productividad, calidad, respuesta rápida y flexibilidad. ${ }^{53}$

De modo similar la CGMA por sus siglas en ingles de Chartered Global Management Accountant explica que las técnicas de control visual son métodos documentados y procedimientos que incluyen señales fáciles de entender de acciones a tomar, con la utilización de estas herramientas visuales los gerentes y colaboradores tienen la capacidad de entender la situación actual del sistema de trabajo y diagnosticar la existencia de alguna anomalía. ${ }^{54}$

\footnotetext{
${ }^{52}$ Cfr. Hernández y Vizán 2013: 52-53

${ }^{53}$ Cfr. Cuatrecasas 2010: 326

${ }^{54}$ Cfr. CGMA® TOOLS 2016: 35
} 


\section{Estandarización}

Hernández y Vizán brindan un concepto de estándares que incluye y se aproxima a los principios de la filosofía Lean, ellos lo define a los estándares como la explicación escritas y gráficas que permiten interpretar y comprender las técnicas más eficaces y fiables en una organización, que a su vez, brindan información precisa de recursos como personas, máquinas, materiales, métodos, mediciones e información. ${ }^{55}$

Los autores De Diego, Sierra y García postulan que el trabajo estandarizado es la base de la mejora continua y le otorga al empleado la autonomía o autogestión de su labor; por otro lado, afirman que los estándares representan la práctica más óptima y conocida del trabajo los cuales facultan la reducción de la variabilidad de los resultados del proceso y finalmente, los autores refieren que los estándares deben ser realizados por mismos colaboradores de cada equipo que realiza el trabajo, que es donde está el conocimiento, puesto que de lo contrario, la empresa se llenará de MUDA o despilfarros al querer estandarizar toda la empresa con estándares realizados por departamentos ajenos al área. ${ }^{56}$

Finalmente, en el estudio de un caso práctico los autores Todorova y Dugger ponen énfasis en que las mejores prácticas deben estandarizarse y utilizarse como base para toda mejora y que estos estándares de los procesos suelen ir cambiando según la necesidad que requiere la organización de mejorar. ${ }^{57}$

\section{Heijunka - Nivelado de la carga de trabajo}

El principio Heijunka de la filosofía Lean propone la noción de un flujo ideal orientado a la optimización de dos tipos de despilfarro, el MURI que abarca la sobrecarga del personal y de

\footnotetext{
${ }^{55}$ Cfr. Hernández y Vizán

${ }^{56}$ Cfr. De Diego, Sierra y García 2009: 119

${ }^{57}$ Cfr. Todorova y Dugger 2015: 1-19
} 
las máquinas y el MURA orientado a las irregularidades en la carga del trabajo a través de la nivelación del mismo considerando los inventarios y las previsiones de la demanda. ${ }^{58}$ Por otro lado, autores como Matzka, Di Mascolo y Furmans señalan que el Heijunka es pieza fundamental del Sistema de Producción Toyota (TPS), donde se originó la noción de Lean Thinking, logrando nivelar el flujo de producción y manteniéndolo uniforme, en efecto, esto logra reducir el impacto que pueden generar las fluctuaciones de inventario y demanda. ${ }^{59}$

\section{Fases de implantación}

Hernández y Vizán (2013) consideran que la implantación Lean debe realizarse adaptando los conceptos y definiciones Lean a la realidad de la organización y la del sector, cada empresa debe tener su propia estructura de implantación, para lo cual ellos proponen una implantación general en seis fases, las cuales plasman en la hoja de ruta propuesta ${ }^{60}$ : (ver figura 5)

En la figura 5 se puede observar cada fase de implantación con sus respectivas herramientas, también se puede apreciar la participación paralela de elementos como equipos de mejora Lean, sistemas de sugerencias, trabajadores polivalentes, educación y entrenamiento, por otro lado se encuentran elementos como control visual, estandarización y mejora continua (kaizen).

\footnotetext{
${ }^{58}$ Cfr. De Diego, Sierra y García 2009: 118

${ }^{59}$ Cfr. Matzka, Di Mascolo y Furmans 2012: 49

${ }^{60}$ Cfr. Hernández y Vizán 2013: 80-82
} 
Figura 5: Hoja de ruta para implementación de Lean

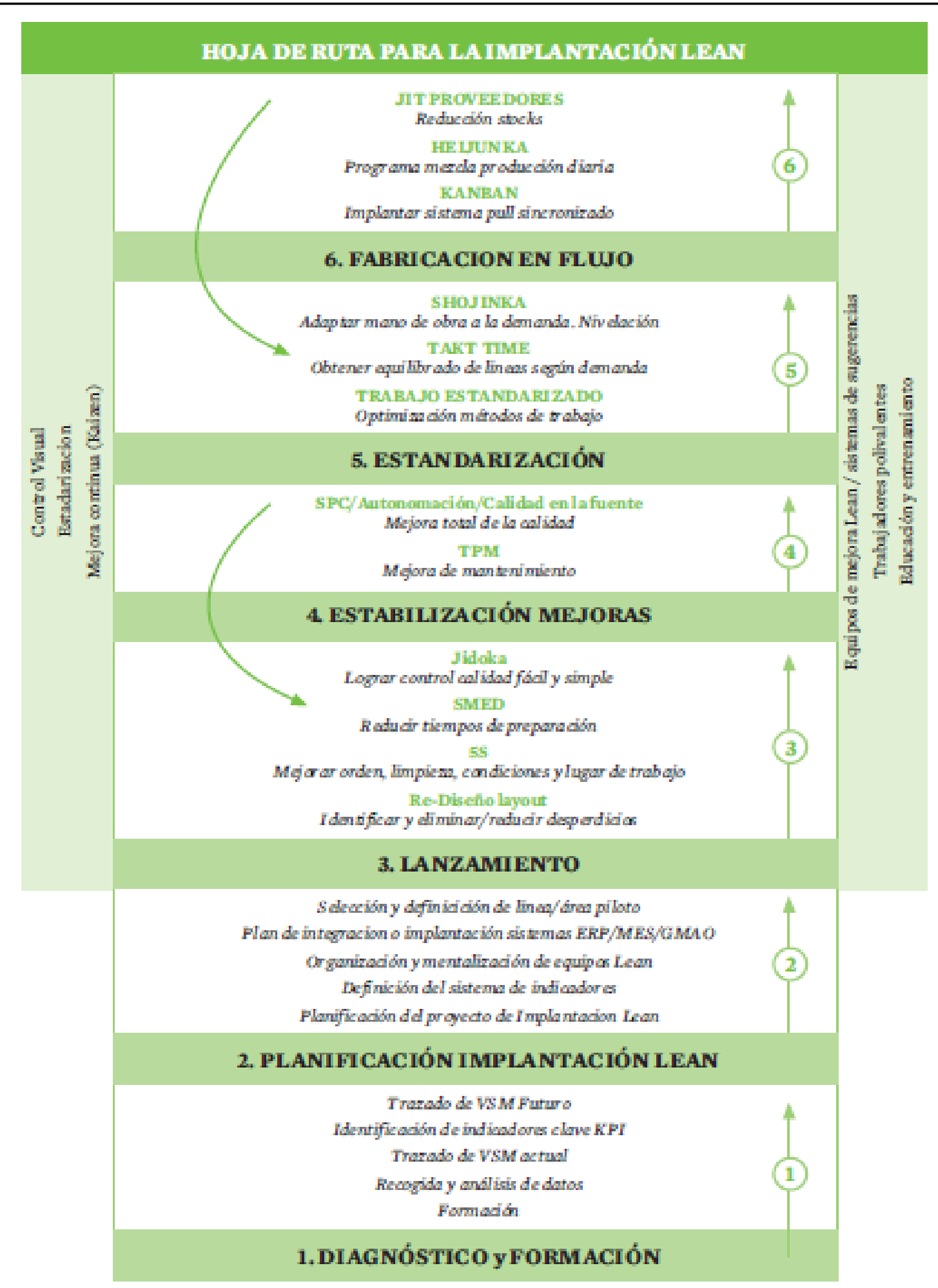

Fuente: Hernández y Vizán 2013:82 
Tal como se muestra en la figura 5, Hernández y Vizán manifiestan que se debe trazar la hoja de ruta para la implantación del Lean, la figura muestra una propuesta ya que como se mencionó anteriormente, la implantación dependerá de la adaptación de la situación actual del negocio y el sector en cual la empresa se desenvuelve.

\section{Enfoque basado en Procesos}

\section{Definición de Procesos}

Para la norma ISO 9001: 2008 la definición de proceso se da como:

"Un conjunto de actividades mutuamente relacionadas o que interactúan, las cuales transforman elementos de entrada en resultados”. (De Zan y Paipa 2012)

En base a esta definición, se argumenta que los procesos comprenden acciones y decisiones imprescindibles para la transformación de entradas en salidas que se adecuen correctamente a las necesidades planteadas de objetivos y tiempos. ${ }^{61}$ Con lo planteado anteriormente, se desprende que la transformación de entradas a salidas solo se da con la agregación del valor al producto.

Al mismo tiempo, De Zan y Paipa proponen que en un proceso bien definido se encuentran siete elementos claves como son: entradas salidas, procedimientos, recursos, cliente propietario o dueño del proceso e indicadores. ${ }^{62}$ La interacción de estos elementos se ven en la figura 6.

\footnotetext{
${ }^{61}$ Cfr. De Zan y Paipa 2012: 25

${ }^{62}$ Cfr. De Zan y Paipa 2012: 25-26
} 
Figura 6: Elementos de un proceso

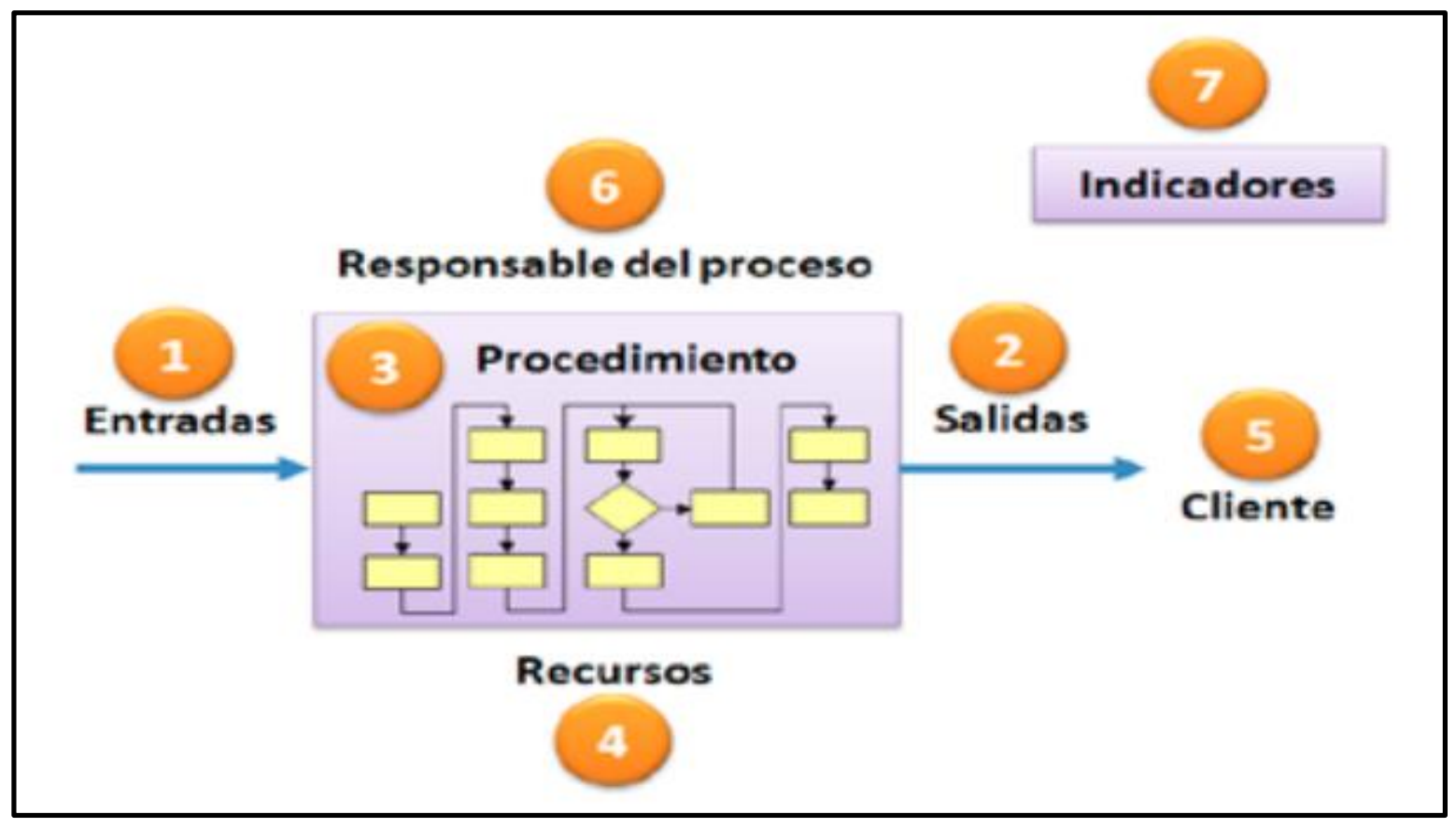

Fuente: De Zan y Paipa 2012: 26

En la figura 6 se observa que las entradas se convierten en salidas a través de los procedimientos, con la utilización de los recursos y la responsabilidad que recae en el dueño del proceso (otras veces llamado líder del proceso), toda esta interacción debe estar sujeta a la evaluación de indicadores.

\section{Características de todo proceso}

Para explicar las características de los procesos De Zan y Paipa plantean 5 características que toda actividad inmersa en el proceso debe cumplir ${ }^{63}$ :

${ }^{63}$ Cfr. De Zan y Paipa 2012: 26 
- El proceso y todas sus actividades inician con el requerimiento realizado por un cliente externo y finaliza con la satisfacción de los mismos.

- Todas las actividades de un proceso generan costos asignados en personal, materiales, equipos y otros recursos.

- Todas las actividades de un proceso se realizan en un intervalo de tiempo.

- Las actividades de un proceso influyen directamente en la calidad del producto y/o servicio.

- Todas las actividades de un proceso agregan o no valor frente a la expectativa del cliente. 
Figura 7: Características de procesos

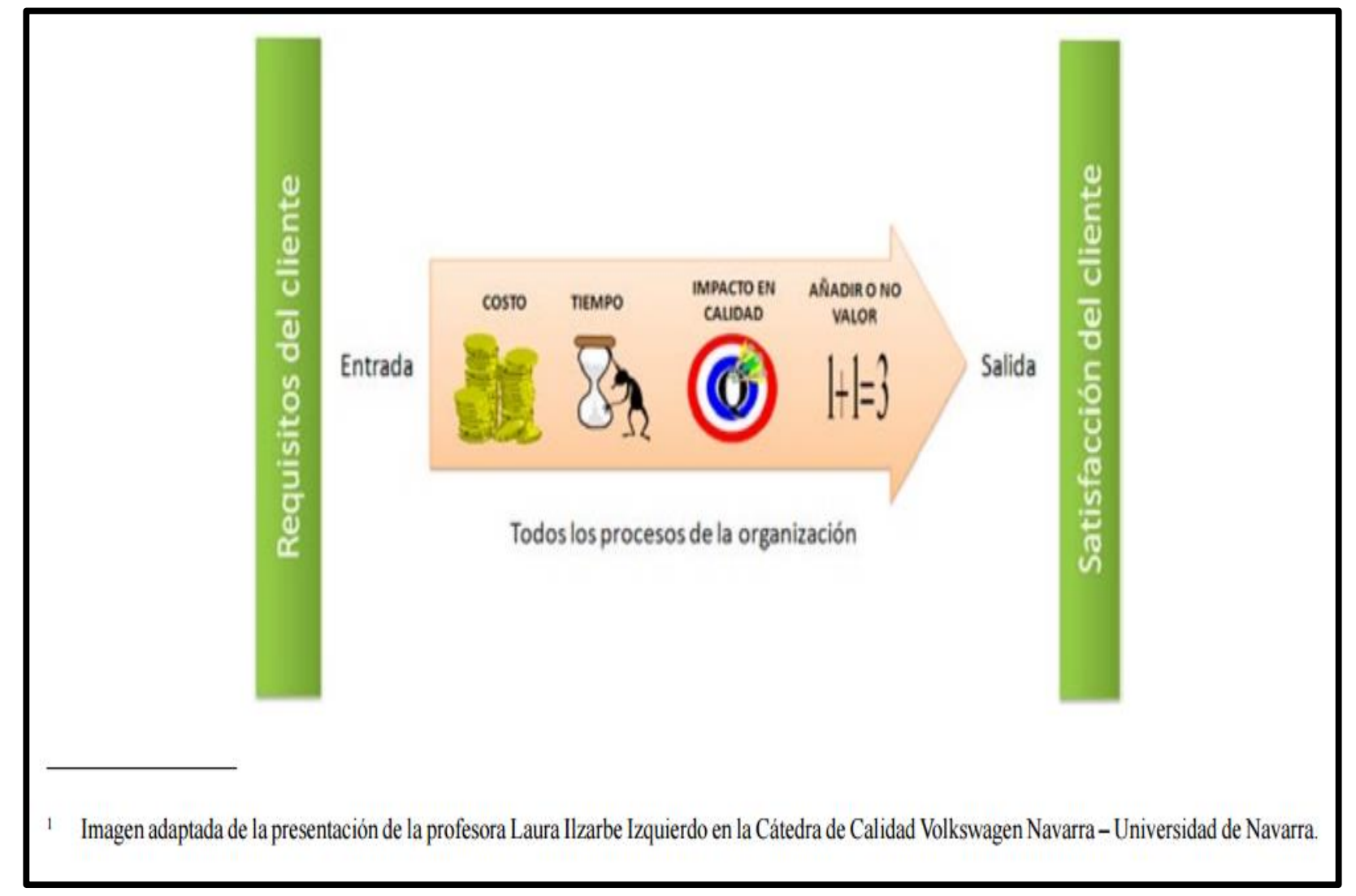

Fuente: De Zan y Paipa 2012: 26

En la figura 7 se explica de manera visual las 5 características mencionadas anteriormente, desde el inicio y fin del proceso, los costos y el tiempo en que incurren las actividades del proceso y por último la calidad y valor agregado de los resultados.

\section{Representación de un Proceso}

Los procesos se representan a través de gráficas como por ejemplo fotos, esquemas, diagramas y/o dibujos con el fin de difundir algo, explicar una instrucción, definir un procedimiento o demostrar el análisis de un problema, por ello se considera la utilización de gráficas como uno 
de los factores claves para la mejora del proceso ${ }^{64}$ En consecuencia, la representación gráfica de los procesos permite no solo la mejora del proceso sino estandarización del mismo.

\section{Diagrama de Flujo de procesos}

El diagrama de flujo de procesos se define como la manifestación gráfica y visual secuenciada de las actividades y pasos de un proceso, también se incluyen inspecciones y retrabajos; este diagrama es de gran importancia en el análisis y mejora de los procesos dado que permite identificar en qué consta el proceso y como están vinculadas las actividades. ${ }^{65}$

En la figura 8 se muestra un ejemplo del diagrama de procesos y los símbolos más utilizados en su realización.

${ }^{64}$ Cfr. Gutiérrez 2014: 213

${ }^{65}$ Cfr. Gutiérrez 2014: 213 
Figura 8: Símbolos más comunes para el diagrama de flujo

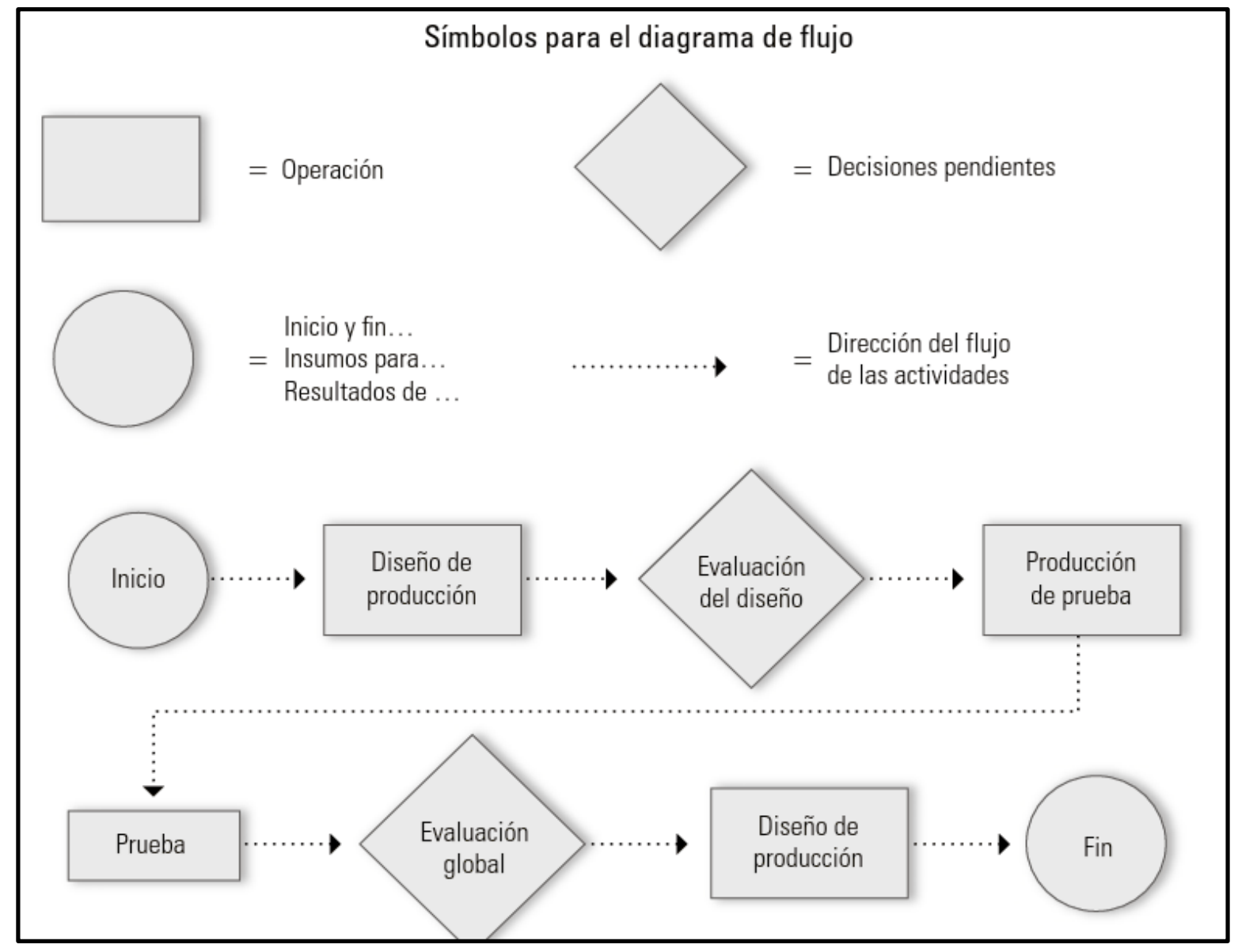

Fuente: Gutiérrez 2014: 214

En la figura 8 se muestra los símbolos más comunes del flujograma de proceso como son la operación, las decisiones pendientes y el inicio y fin del proceso, como estos elementos existen una gran variedad de elementos para representar los diferentes procesos, dependerá de cada autor su utilización. 


\section{Mapa de procesos}

Se considera al mapa de procesos como una ayuda visual para comprender la interacción de los distintos procesos en la organización. De esta manera el mapa de procesos permite la identificación, análisis, diseño y mantenimiento de los procesos, en consecuencia su uso es de gran utilidad en la reingeniería de los procesos permitiendo al individuo que lo emplea un mayor entendimiento de las tareas y problemas que se dan en la organización. ${ }^{66}$

Como característica adicional, el autor Gutiérrez (2014) añade que el mapa de proceso se utiliza en primera instancia para la delimitación del proceso y empezar el análisis del mismo. ${ }^{67}$ De esta manera Gutiérrez soporta lo sustentado en el párrafo anterior, resaltando la importancia del mapa de procesos.

\section{Herramientas de Calidad}

\section{Lluvia de ideas}

Esta herramienta de análisis grupal es utilizada frecuentemente por los equipos de mejora en diversas oportunidades durante el desarrollo de proyectos, se lleva a cabo cuando se necesitan generar ideas con el propósito de encontrar causas y/o soluciones a los problemas; su empleabilidad e importancia se basa en el fomento de trabajo en equipo, el pensamiento creativo, la reflexión y el diálogo de tema central con una base igualdad de sus participantes. ${ }^{68}$ Esta herramienta es conocida también por otros autores como tormenta de ideas.

\footnotetext{
${ }^{66}$ Cfr. Hernández, Medina y Nogueira 2009: 2

${ }^{67}$ Cfr. Gutiérrez 2014: 215

${ }^{68}$ Cfr. Gutiérrez 2014: 212
} 


\section{Diagrama de causa-efecto}

El diagrama de causa-efecto es también conocido como Espina de pescado y diagrama de Ishikawa, con esta herramienta se busca encontrar las posibles causas a través de un gráfico que permite representar y analizar la relación entre un efecto y sus posibles causas. El método de construcción más común de este diagrama se realiza dividiendo en seis ramas principales las posibles causas, cada rama o sección llevará el nombre de un M (método de las 6M): métodos de trabajo, mano de obra, materiales, maquinaria medición y medio ambiente. ${ }^{69}$ Se muestra un ejemplo del diagrama de causa-efecto:

Figura 9: Ejemplo de diagrama de Ishikawa

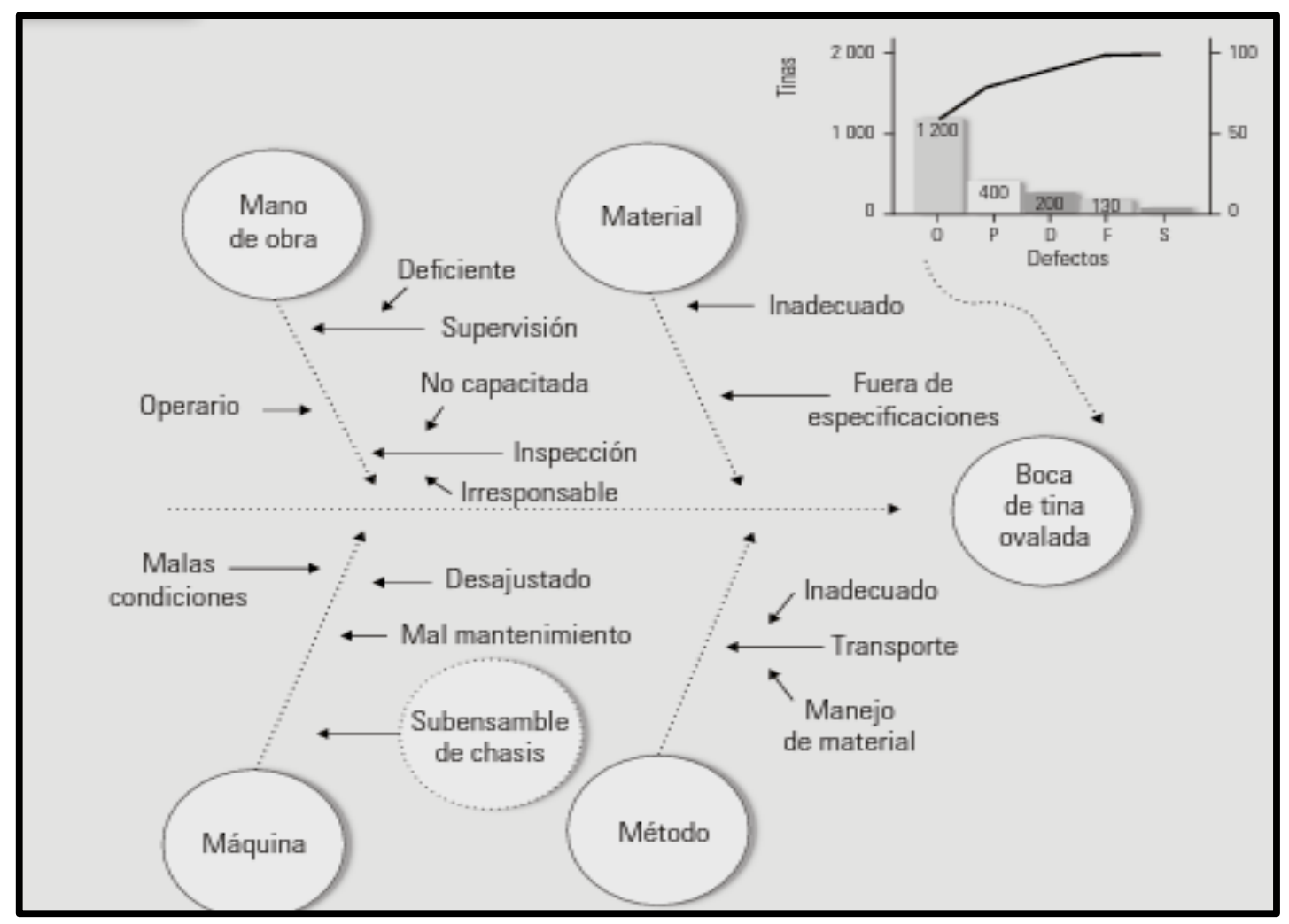

Fuente: Gutiérrez 2014: 207

${ }^{69}$ Cfr. Gutiérrez 2014: 206 


\section{Diagrama de Pareto}

El diagrama de Pareto (DP) es una herramienta que ayuda identificar el problema más vital basado en el principio de obtener grandes mejoras con el menor esfuerzo, conocido también como el principio de 80-20 del cual se desprende que de todos los problemas analizados en la compañía, solo un grupo reducido de ellos son los más importantes. Entre las bondades de esta herramienta destaca el fomento de la comunicación y motivación al personal, su aplicación se da a todo tipo de problemas: calidad, eficiencia, seguridad, etc. ${ }^{70}$

En adición, el diagrama de Pareto como herramienta estadística refuerza la toma de decisiones facilitando las prioridades de intervención y detectando las causas fundamentales del problema. $^{71}$

El gráfico 2 muestra el ejemplo del análisis de Pareto para las tinas defectuosas cuyas causas principales son las de tipo "O" y "P" porque representan el $80 \%$ de los defectos registrados.

\footnotetext{
${ }^{70}$ Cfr. Gutiérrez 2014: 193

${ }^{71}$ Cfr. López y López 2014: 77
} 
Gráfico 2: Ejemplo de Diagrama de Pareto

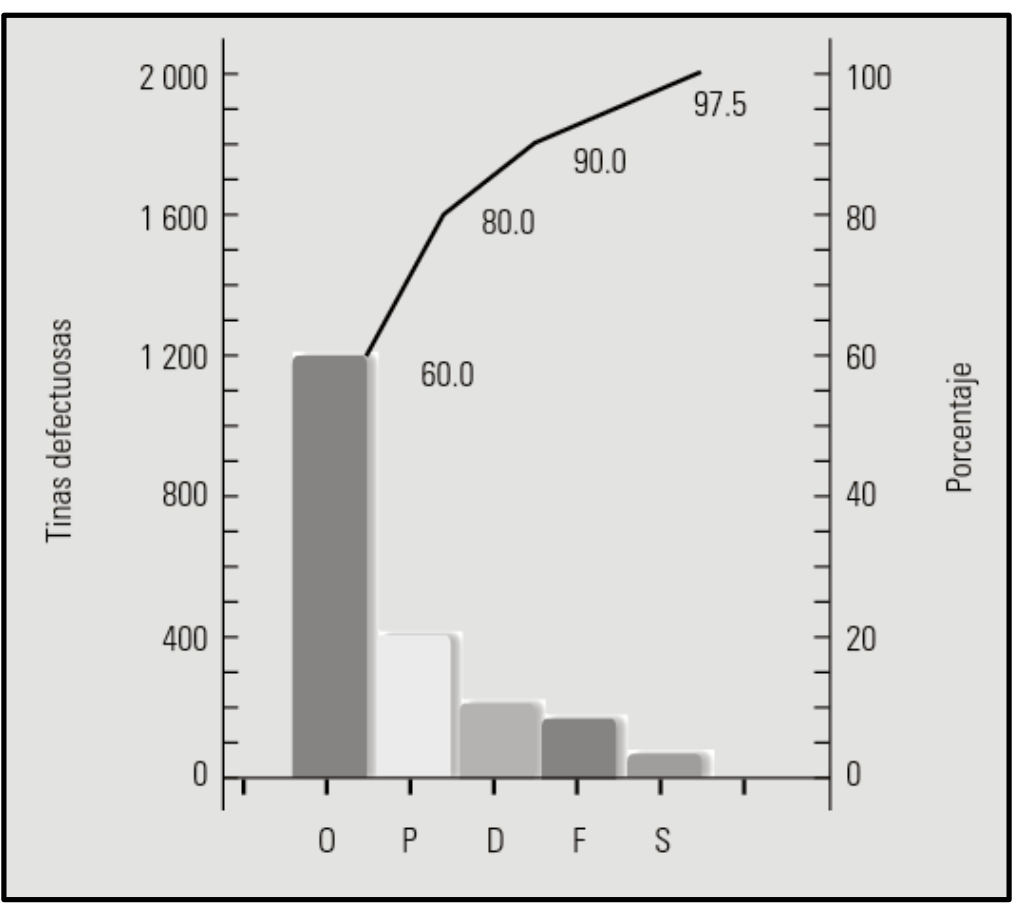

Fuente: Gutiérrez 2014: 194

\section{Estratificación}

Emplear la técnica de estratificación consiste en analizar problemas, quejas y/o datos asociándolos y organizándolos según presuntos factores que pueden, en primera instancia, contribuir en la importancia de los problemas observados proporcionando, de esta manera, escenarios a posibles soluciones; el funcionamiento de esta técnica posibilita el entendimiento de diversos factores que participan en la misma situación del problema, permitiendo, en consecuencia la delimitación de los agentes de variabilidad y las posibles causas al problema. Los factores más comunes en la estratificación son fallas, métodos de trabajo, maquinaria, turnos, obreros, materiales, etc. ${ }^{72}$

${ }^{72}$ Cfr. Gutiérrez 2014: 192 


\section{Diagrama Matricial}

Este diagrama brinda las facultades de analizar y calificar la relación que existe entre dos o más variables, los datos a analizar se muestran en tablas pudiendo ser estos objetivos o subjetivos, también se les puede asignar números o símbolos; el diagrama matricial puede presentarse en forma de L si analiza dos variables, en forma de T, Y o C si analiza a tres variables y en forma de X para el análisis de cuatro variables. ${ }^{73}$

\section{Matriz de Priorización}

La matriz de priorización fundamenta las prioridades a asuntos, tareas, entre otros, en base a una ponderación que resulta de la combinación de dos o más técnicas; su aplicación reduce, en forma razonable, las opciones o alternativas que tuviera el equipo antes de su implementación a través de la calificación y comparación cuatro criterios, comúnmente utilizados, como: rapidez de implementación, aceptación por los usuarios, tecnología disponible y bajo costo. ${ }^{74}$

\footnotetext{
${ }^{73}$ Cfr. Besterfield 2009: 500-502

${ }^{74}$ Cfr Besterfield 2009: 502-505
} 


\section{Productividad}

\section{Definición}

Al definir la productividad se refiere a comparar la eficiencia en que los recursos son utilizados en todo tipo de negocio, en consecuencia se puede definir que la productividad es la relación constituida entre la cantidad de productos producidos y la cantidad de recursos que se utilizaron para ello; similar a ello, otros autores han definido a la productividad como la eficiencia en que se realiza la producción o el aumento de la calidad los productos en relación a la disminución del re trabajo. ${ }^{75}$

En otras palabras, la productividad se basa en la producción por encima del promedio y la satisfacción de los consumidores a través de la utilización óptima de los recursos disponibles; por otro lado, se explica que la productividad no busca medir la producción ni los bienes fabricados, sino buscar medir lo bien que se han acoplado los recursos utilizados con el fin de alcanzar los objetivos específicos de los clientes. ${ }^{76}$

\section{Factores que afectan la productividad}

Para hablar de los diferentes factores que afectan la productividad, se empezará con la descripción realizada por D’Alessio 2015 donde plasma un modelo integrado de los factores de la productividad en una organización (Ver figura 10).

${ }^{75}$ Cfr. Hernández, Camargo y Martínez 2015:109

${ }^{76}$ Cfr. Córdoba 2015: 110 
Figura 10: Factores de Productividad en las empresas

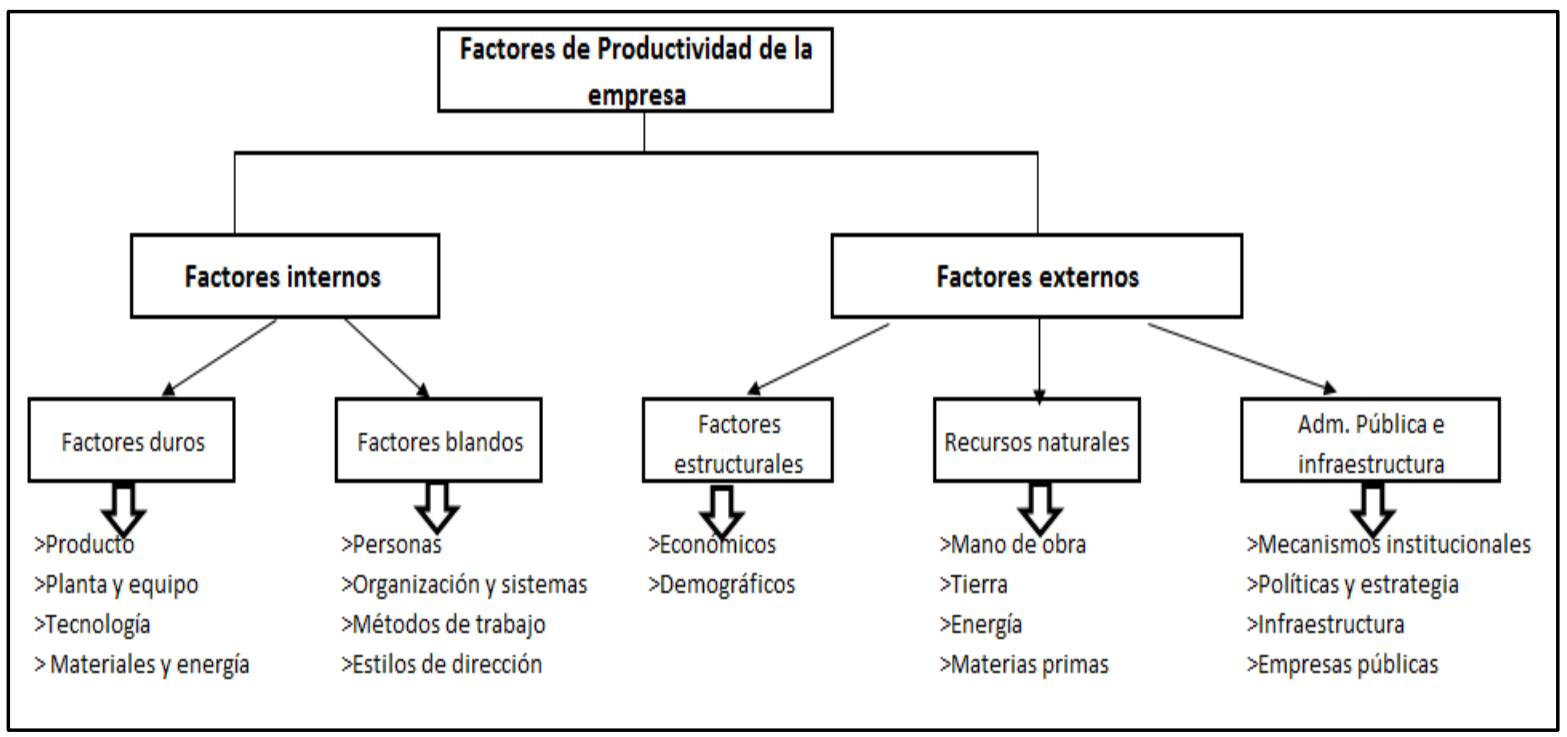

Fuente: Adaptado de D’Alessio 2015: 631

Este modelo indica que existen dos tipos de factores principales que afectan la productividad Externos e Internos, en el caso de este estudio se enfocará en los de tipo interno entre los que destacan:

- Factores duros, como producto, planta y equipo, tecnología, materiales y energía

- Factores blandos, como personas, organización, métodos de trabajo y estilos de dirección.

Por otro lado, Gutiérrez responde a la interrogante de cuáles son los agentes que causan la baja productividad proponiendo que más del $90 \%$ de las fallas no son responsabilidad directa del personal que labora, sino de los insumos y métodos que utiliza el proceso; añade que se debe revisar primero si los productos y servicios finales cumplen las exigencias de los clientes y si son entregados a tiempo; por último sugiere que la mejor manera de aumentar la productividad 
es capacitando y rediseñando los procesos y sistemas de la organización, mejorando los métodos utilizados. $^{77}$

\section{Eficiencia y eficacia}

Gutiérrez 2014 indica que comúnmente la productividad se encuentra asociada a dos conceptos: la eficiencia y la efectividad. La eficiencia se basa en la relación existente entre el resultado obtenido y los recursos que se utilizaron para conseguirlo, los análisis de eficiencia buscan optimizar los recursos y evitar que no existan desperdicios de los mismos. Por otro lado la eficacia se centra en el grado en que se desarrollan las actividades planificadas y la obtención de los resultados planificados, es decir, la eficacia se centra en la utilización de los recursos para conseguir los objetivos planeados. ${ }^{78}$

\section{Medición de la productividad}

Generalmente, las empresas suelen asociar la productividad con la consecución de los resultados conseguidos al final de un proceso un sistema relacionándolos con los recursos empleados; en base a esto, la productividad es medida con el cociente de los resultados obtenidos y los recursos

empleados. ${ }^{79}$ De este modo se explica la medición de la productividad según los puntos anteriores de eficiencia y eficacia, se relaciona a la primera con los recursos utilizados y a la segunda con los resultados alcanzados.

En la figura 11 se observa el planteamiento de Gutiérrez 2014 sobre la eficiencia y eficacia como componentes de la medición de la productividad.

\footnotetext{
${ }^{77}$ Cfr. Gutiérrez 2014:21-22

${ }^{78}$ Cfr. Gutiérrez 2014:21

${ }^{79}$ Cfr. Gutiérrez 2014:21
} 
Figura 11: Cálculo de la productividad

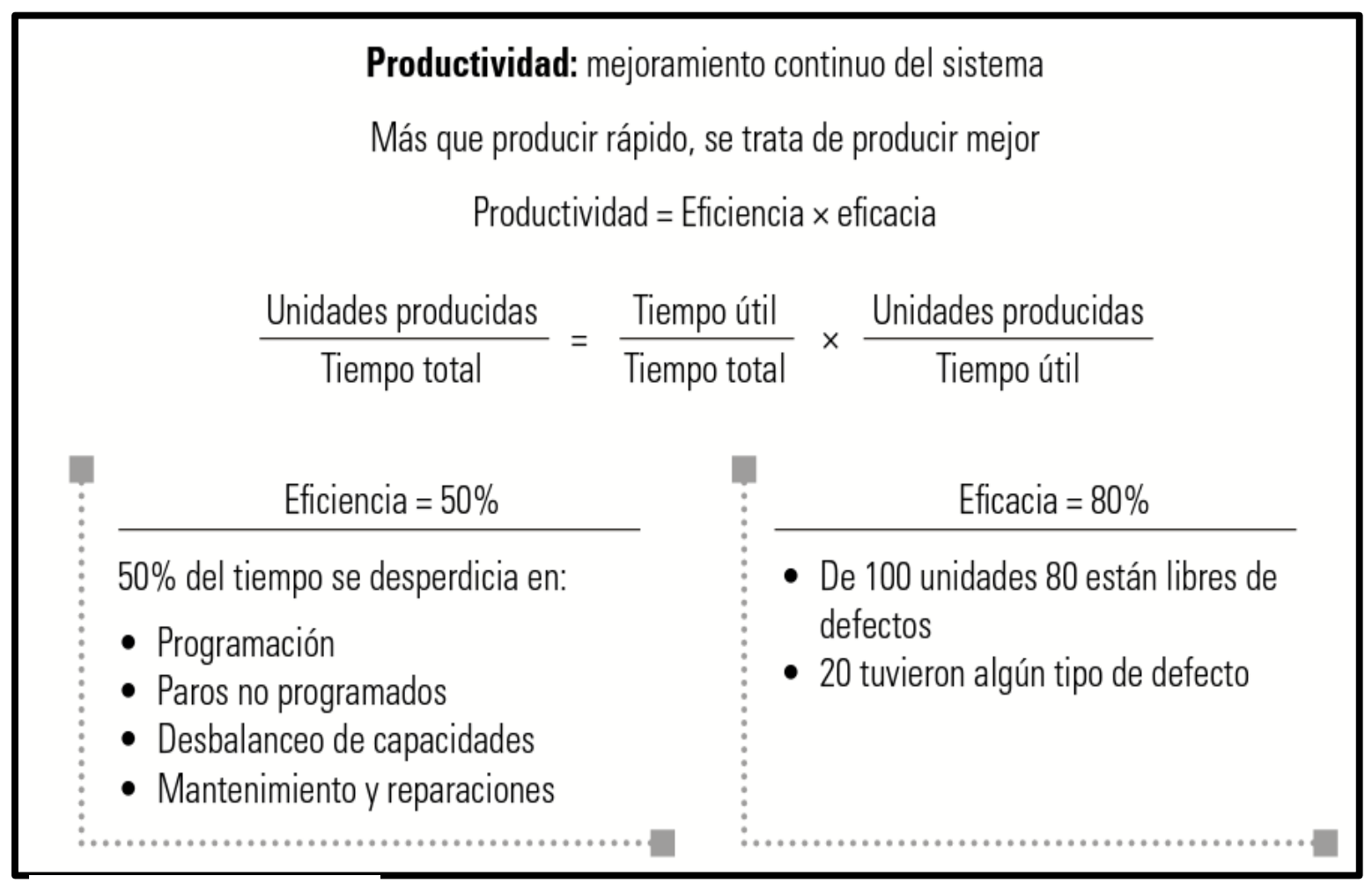

Gutiérrez 2014:21

La figura 11 muestra el cálculo de la productividad como el producto de la eficiencia por la eficacia. También, se observa que la principal unidad de medida de los recursos es el tiempo y, finalmente, se concluye que la productividad se expresará en unidades producidas sobre el tiempo total. 


\section{Estudio de Casos de Éxito}

Con el objetivos de sustentar la aplicabilidad de las herramientas y metodologías propuestas en el desarrollo de este proyecto se presentan diversos casos de estudio donde la implementación de herramientas y técnicas Lean han sido de gran utilidad y provechosas para las organizaciones y el sector.

\section{Aplicación de Value Stream Mapping en los procesos logísticos de una empresa embaladora de vidrio en Colombia}

El ingeniero Paredes presenta en su caso de estudio (PAREDES 2017) un importante análisis de aplicación de la herramienta Lean conocida como VSM, por sus siglas en inglés Value Stream Mapping, a una empresa encargada de embalar productos de vidrio en Colombia. Se realza la relación de este caso de éxito con la compañía analizada por el actual proyecto de investigación aplicada en que ambas se desempeñan en el sector servicios y se enfocan en los procesos logísticos en especial los de recepción y embalaje.

En este caso de éxito, el ing. Paredes destaca la premisa de que la herramienta VSM es aplicable en todo los diferentes escenarios, dando a entender, que puede ser implementada en compañías de diversos sectores. Por otro lado, indica que con la aplicación del VSM se busca llevar a cabo una serie de estrategias de mejora para el proceso logístico de la empresa. ${ }^{80}$

Paredes logra identificar las actividades que no generan valor a través del VSM y la toma de tiempos, luego aplica una serie de medidas correctivas para la reducción y/o eliminación de éstas. Posteriormente, plasma un proceso mejorado a través del VSM con visión futura. Para finalizar con el caso de éxito, Paredes afirma que en la empresa se concretizó la estrategia de

\footnotetext{
${ }^{80}$ Cfr. Paredes 2017: 263-264
} 
mejora, actualmente se encuentra implementándose y que ha conseguido beneficios económicos en el corto plazo. ${ }^{81}$

\section{Aplicación de balance de línea en una bodega de Almacenamiento}

El autor Peña explica en su análisis la ejecución de técnicas de Balance de Línea, herramienta comúnmente utilizada en TOC (teoría de restricciones) metodología utilizada como parte de la filosofía Lean Thinking. Expone que el balance de línea es clave para alcanzar la productividad de la compañía ya que tiene la misión de distribuir adecuadamente la capacidad del trabajo, garantizar un flujo continuo y estandarizado de los productos enfocándose en tres puntos importantes: cantidad, equilibrio y continuidad. ${ }^{82}$

En esta oportunidad, el autor presenta el análisis realizado a los almacenes de una ferretería y a las actividades que adentro se realizan; luego de haber analizado el tiempo medio en que se realizan las operaciones de recepción, picking y despacho, se logró equilibrar el tiempo de las operaciones y se pudo identificar al picking como el cuello de botella, es decir, es la que presenta mayor carga de trabajo; el balance se logró centrándose en las actividades inmersas al cuello de botella. ${ }^{83}$ De esta manera se quiere presentar como caso exitoso de aplicación en balance de línea el estudio realizado por Peña, si existen diferencias entre los productos analizados en el presente trabajo, se rescata su aplicabilidad en los procesos logísticos como recepción, picking y transporte.

${ }^{81}$ Cfr. Paredes 2017: 267-273

${ }^{82}$ Cfr. Peña 2016: 240

${ }^{83}$ Cfr. Peña 2016:239-246 


\section{Implementación de 5s en la logística de Rift Valley Railways}

La compañía Keniana RVR fue premiada en el 2015 por fomentar conciencia ambiental y cambio de conducta en sus trabajadores sustentado en la drástica reducción del $90 \%$ de accidentes y lesiones en sus centros de operaciones y almacenaje. Estos resultados se consiguieron gracias al proyecto de dos años en los que implementaron distintas metodologías, entre las que se realza la importancia de las $5 \mathrm{~S}$ cuyos principios se introdujeron en los trabajadores a través de sus cinco nociones básicas: Clasificación, Organización, Limpieza, Estandarización y Mantenimiento de la disciplina. Altos directivos de la empresa han reconocido que preocuparse por la salud y seguridad de sus trabajadores ha dado como resultado el incremento de la productividad al punto de mencionar que toda herramienta o material es encontrado con mayor facilidad; por otro lado mencionan que la empresa ha logrado un salto significativo en la estandarización de su producción y por último, destacan que simples cambios en la conducta del trabajador se puede conseguir importantes resultados en la organización. ${ }^{84}$

\section{Implementación de la Estandarización en procesos Logísticos}

Martina Džubáková y Michal Kopták presentan el caso de estudio de la implementación de un trabajo estandarizado para el desarrollo de los procesos logísticos de un almacén, el proceso que ellos analizan es el de recepción de mercadería y traslado que se realiza hasta guardarla en los estantes correspondientes. Apoyados en técnicas para la estandarización como son los métodos de medición del tiempo de actividades y de TWI por sus siglas en ingles de entrenamiento dentro de la industria logran justificar la presunción que los estándares obtenidos con estas técnicas influyen en el progreso del ciclo de mejora continua. ${ }^{85}$

\footnotetext{
${ }^{84}$ Cfr. The Safety \& Health Practitioner 2015: 17

${ }^{85}$ Cfr. Džubáková y Kopták 2017: 111
} 
Otra de las ideas que plantean Džubáková y Kopták con el análisis de la implementación de un trabajo estandarizado es que este es pieza clave para lograr los resultados de calidad necesarios en el mercado, además, logran identificar las principales complicaciones que se presentan en la implementación de los estándares y la reducción de la variabilidad, destacan: los trabajadores no logran un entendimiento profundo de las instrucciones y del estándar, difícilmente se puede utilizar como método de resolución de problemas, cuando se produce un cambio de mejora no actualiza con la rapidez necesaria, etc. ${ }^{86}$

\section{Aplicación de KPIs en diferentes organizaciones}

La autora Zakaria presenta el análisis del caso de éxito de cómo la implementación de los KPIs en las organizaciones se dan a través de un programa de cambio en la cultura de la empresa, es decir, que las mediciones y resultados identificados por los KPIs deben formar parte de las actividades que plantee la organización dentro su plan de cambio de cultura organizacional. ${ }^{87}$ Lo planteado por el autor en las líneas anteriores se puede comparar e incluir dentro de un concepto mayor como el de la Metodología Lean, explicado en puntos anteriores y que señala el éxito de la metodología se obtiene cuando es considerado por toda la organización.

La autora se basó en más de 60 entrevistas al personal, documentos y actas de reuniones en dos fases en distinto tiempo, comprobando que los mismos colaboradores entrevistados en la segunda fase reconocían que desde que empezó las mediciones con KPIs el interés sobre su productividad había aumentado. ${ }^{88}$

\footnotetext{
${ }^{86}$ Cfr. Džubáková y Kopták 2017: 112-116

${ }^{87}$ Cfr. Zakaria 2015: 932

${ }^{88}$ Cfr. Zakaria 2015: 935
} 


\section{Implementación de prácticas Lean en diferentes industrias}

\section{Proveedores del Sector Aeronáutico en España}

El estudio presentado por Sacristán, Garrido y García (2012) demuestra que las 15 empresas analizadas de una población de 123 del sector auxiliar de aeronáutica de Andalucía reconocen que haber cambiado sus operaciones a prácticas Lean fue un paso trascendental para la competitividad, la gestión y la cultura organizacional; estas empresas son proveedoras de primer y segundo grado del sector aeronáutico de España. ${ }^{89}$ Una de las ideas que sostiene el estudio es que el éxito de la implementación Lean depende en gran medida a la extensión de esta filosofía a través de su cadena de suministro, es decir proveedores a primer y segundo grado hasta los clientes. ${ }^{90}$ Por último, los autores destacan que las principales herramientas implementadas fueron VSM, 5S, TPM así como contar con programas kaizen y prácticas Poka - Yoke; además se destaca el compromiso de la alta dirección en las empresa que demostraron un mayor grado de implementación. ${ }^{91}$

\section{Planta Carrier Transicold E.E.U.U}

Dave Blanchard expone que esta planta de ensamblaje de camiones refrigerantes, ganadora del premio de las mejores plantas de la Semana de la Industria 2015, ha incrementado notablemente su productividad sosteniéndose en los principios de la cultura Lean y llegando a no registrar pérdidas por tiempos muerto por parte de sus trabajadores por varios años. ${ }^{92}$ En este punto se ejemplifica el principio Lean de la reducción de tiempos muertos.

\footnotetext{
${ }^{89}$ Cfr. Sacristán, Garrido y García 2012: 44-45

${ }^{90}$ Cfr. Sacristán, Garrido y García 2012: 34

${ }^{91}$ Cfr. Sacristán, Garrido y García 2012: 35-42

${ }^{92}$ Cfr. Blanchard 2016: 15
} 
Además, con la aplicación de herramientas Lean como el flujo de línea continuo, la mejora continua y kaizen se optimizaron los procesos en Carrier Transicold a tal punto que se cerró 60’000 pies cuadrados de instalaciones dentro de la planta en diciembre del 2013, lo cual se manifestó en el cambió de dos líneas de ensamblaje por la instalación de una nueva línea mixta. ${ }^{93}$

\section{Sunny Egypt Company for Electronics Industry - Egipto}

La planta de ensamblaje ubicada en Egipto llegó a implementar los principios de la filosofía Lean según lo expresa el estudio mostrado por El- Aty y otros (2015); en el cual se realizó el seguimiento y análisis a la línea de ensamblaje del televiso LCD 32" y cuyos resultados obtenido destacan la eliminación de desperdicios, el incremento de la productividad, ganancias, mejora de la calidad, disminución del tiempo de ciclo, costos, números de operarios, entre otros. ${ }^{94}$ En adición, este estudio muestra la comparación de los resultados obtenidos por la implantación Lean en la planta egipcia (ver figura 12)

\footnotetext{
${ }^{93}$ Cfr. Blanchard 2016: 14-15

${ }^{94}$ Cfr. El- Aty y otros 2015: 1431-1432
} 
Figura 12: Resultados antes y después de implementar Lean Manufacturing

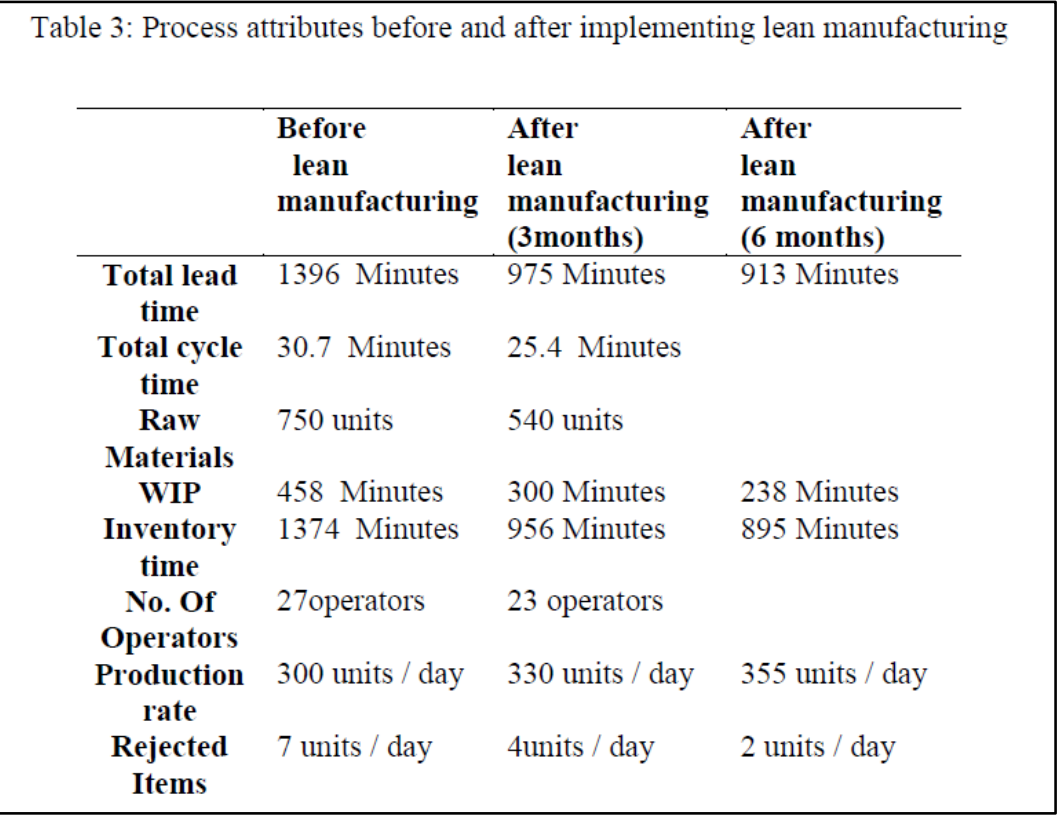

Fuente: El-Aty y otros 2015:1435

La figura 12 muestra los beneficios que se han obtenido en la planta de Sunny Egypt Company for Electronics Industry por la implantación del Lean Thinking en dos tiempos, el primero en tres meses de iniciar la implantación y el segundo luego de seis meses. Entre los principales beneficios destaca la evolución de la producción de la planta de 300 unid/día a 355 unid/día en seis meses y la disminución del tiempo de ciclo de 30.7 min a 25.4 min para un periodo de tres meses. 


\section{Herramientas de Ingeniería para el diagnóstico}

En este punto se abordan los conceptos utilizados para el diagnóstico del proyecto, los mismos que se adicionan a los explicados en puntos anteriores; de este modo el Estudio de tiempo y la Ingeniería de métodos soportan un concepto mayor: El Estudio del Trabajo; cuyo definición es aplicada dentro de los procesos logísticos de la empresa analizar en los siguientes capítulos.

\section{Estudio del trabajo}

El estudio del trabajo conocido por muchos años como ingeniería de movimientos y tiempos se define como aquellas técnicas que se emplean para estudiar los métodos con los que se están realizando el trabajo y para la medición del mismo, esto con el fin de realizar mejoras en eficiencia y efectividad de las operaciones analizadas y poder concretarse en términos económicos. ${ }^{95}$ De este modo se asocia que el Estudio del trabajo incluye dos conceptos importantes revisados anteriormente, ingeniería de métodos y el estudio de tiempos.

Al establecer procesos y/o operaciones y brindar información cuantificable, el estudio del trabajo soporta el desarrollo de otras disciplinas. ${ }^{96}$ Lo anterior es expuesto por los autores para asociar e introducir el Estudio del tiempo dentro de la cadena de suministro.

La OIT propone 8 pasos para realizar el estudio del trabajo ${ }^{97}$ :

1. Selección del proceso o del trabajo.

2. Registro de lo que sucede a través de percepción directa.

3. Análisis de los hechos registrados en el punto anterior

4. Concepción del nuevo método más óptimo

5. Medición y cálculo de la cantidad de trabajo y su tiempo de ejecución

6. Definición del nuevo método

\footnotetext{
${ }^{95}$ Cfr. Bojórquez y Bojórquez 2013: 13

${ }^{96}$ Cfr. Correa , Gómez y Botero 2012: 102

${ }^{97}$ Cfr. Bojórquez y Bojórquez 2013: 14
} 
7. Implantación del nuevo método

8. Elaboración de controles adecuados para mantener el nuevo método

\section{Estudio de tiempos}

Una de las definiciones más representativas del estudio de tiempo o medición del trabajo es la abordada por la OIT, donde sugiere que son las técnicas aplicadas para delimitar el tiempo en que se ejecuta una tarea específica y normada. ${ }^{98}$

El estudio de tiempos se desarrolló a través de la historia de la industria con la evolución del análisis del trabajo que comprendía una diversidad de técnicas y procesos precisos y no tan precisos; en este contexto, las primeras investigaciones fueron realizadas por Frederick Taylor y su “estudio de tiempos", en el cual, analizó desde un trabajó hasta su descomposición en varias tareas individuales logrando obtener un tiempo estándar para cada una de estas tareas, lo que permitió al trabajador desempeñarse más rápido y con mayor precisión. ${ }^{99}$

Por ello, a finales de la segunda guerra mundial, Taylor buscó la estandarización del trabajo y el desarrollo de sistemas técnicos para la mejora introduciendo el nuevo concepto de estudio de tiempos y presentándola como una de las técnicas claves de la administración científica, al mismo tiempo, Taylor asocia el estudio de tiempos y la administración científica como el cambio de pensamiento que necesita el trabajador y el administrador sobre sus deberes con respecto al trabajo. ${ }^{100}$

Con el estudio de tiempos dentro del trabajo, Taylor quiso demostrar que podía conseguir una aproximación del tiempo de las tareas y actividades jamás vistas anteriormente hasta esa fecha,

\footnotetext{
${ }^{98}$ Cfr. Bojórquez y Bojórquez 2013: 13

${ }^{99}$ Cfr. Koptak y otros 2017: 161

${ }^{100}$ Cfr. Olszewski y McHann 2010: 2
} 
así que este estudio se utilizó con fines analíticos y enfocó su utilización en tareas futuras más que en tareas pasadas. ${ }^{101}$

Gracias a que el estudio de tiempos ayuda a fijar estándares de tiempos de operación convenientes como asignar un tiempo específico para cada tarea es considerado como factor importante para la eficiencia en el trabajo; otros beneficios del estudio de tiempos es la obtención de tiempos estándares para la previsión de la producción, calcular plazos de entrega, realizar presupuestos, costear la mano de obra, fijar indicadores de productividad, etc. ${ }^{102}$ Algunos autores plantean que para desarrollar un estudio de tiempo se necesita como mínimo un cronómetro, un tablero o paleta y una calculadora, sin embargo con el avance de la tecnología, hoy en día se utilizan máquinas registradoras de tiempo, cámaras de video y cinematográficas en conjunto con las programas y equipos computacionales. ${ }^{103}$

\section{Ingeniería de Métodos}

La ingeniería de métodos data desde finales del siglo XVIII e inicios del siglo XIX, es considerada factor importante para lograr el incremento de la productividad, la mejora continua y la estandarización de las organizaciones que la implementan, de este modo se logra sustentar que la ingeniera de métodos logra resaltar la diferenciación entre las industrias de los países desarrollados y subdesarrollados. ${ }^{104}$

Se define a la ingeniería de métodos como las prácticas que registran y analizan de manera crítica el cómo se está realizando el trabajo actual con la finalidad de proponer e implementar nuevas formas de realizar el mismo trabajo. ${ }^{105}$

\footnotetext{
${ }^{101}$ Cfr. Olszewski y McHann 2010: 4

102 Cfr. Roncancio 2017: 19

${ }^{103}$ Cfr. Ruiz y otros 2017: 293

${ }^{104}$ Cfr. Correa, Gómez y Pérez 2012: 98-99

105 Cfr. Bojórquez y Bojórquez 2013: 13
} 
Hay que destacar que esta disciplina engloba procedimientos y análisis sistemáticamente de todas las operaciones de la organización con la finalidad de registrar, mejorar y estandarizar el trabajo realizado. ${ }^{106}$ En tal sentido se puede inferir que la ingeniería de métodos y el estudio de tiempos (explicado en el punto anterior) deben implementarse en forma simultanean para la consecución de los resultados en términos de productividad.

La ingeniería de métodos sigue siendo desarrollada en varios países y culturas llegando a ser analizada a nivel sociocultural y en términos de diversidad, sobre esto, los autores Misiego y Sols exponen el caso de Japón, en donde se desarrolla la ingeniería de Métodos de forma menos despersonalizada y sistemática, lo cual se sustenta en operar bajo normas no establecidas (o contractuales) generando una fuerte relación entre supervisores y subordinados que sostiene el gran sentido de autoridad y liderazgo en las organizaciones. ${ }^{107}$

\footnotetext{
${ }^{106}$ Cfr. Correa, Gómez y Botero 2012: 98
}

${ }^{107}$ Cfr. Misiego y Sols 2017:2 


\section{Normativas del sector}

En esta sección se abordarán dos leyes y su normatividad que ha influenciado notoriamente en el sector editorial Peruano, en la primera se sustenta el apoyo del estado y los beneficios que este otorga a las empresas editoras y en la otra, como estado regula la acción de estas empresas buscando neutralizar todo tipo de abuso en contra del consumidor.

Ley de democratización del libro y fomento de la lectura (Ley 28086): En el año 2004 se aprobó el reglamento de la ley 28086 que buscó impulsar el desarrollo de la industria editorial del libro y sus contenidos en diseño gráfico, impresión, edición, ilustración, etc. respetando para cada uno de ellos la propiedad intelectual. Dentro de los beneficios tributarios para el fomento de la actividad editorial, esta ley buscó beneficiar a todas a las empresas que participan en la circulación de libros y productos editoriales afines como son el caso de editoriales, distribuidoras, librerías, etc; así se tiene entre los principales beneficios: crédito tributario por reinversión, la exoneración del impuesto general a las ventas (IGV), el reintegro tributario, aranceles preferenciales a las importaciones, entre otras. ${ }^{108}$ Estos beneficios son los que sostienen los grandes esfuerzos del sector editorial en la inversión de la circulación de los productos editoriales.

En el año 2016 se logra firmar la modificación de reglamento de la ley 28086 donde se aumentó la vigencia de la exoneración del impuesto de renta (IGV) hasta tres años más de su caducidad. ${ }^{109}$ En esta modificación se tocaron varios puntos, de los cuales se ha hecho énfasis solo el de mayor importancia para el sector de análisis del presente proyecto.

${ }^{108}$ Cfr. CPL 2018

${ }^{109}$ Cfr. Diario El Peruano 2016 


\section{Ley 29839, Ley que protege a los consumidores de las prácticas abusivas en la selección}

o adquisición de textos escolares, para lograr su eficiencia: Esta ley busca, como su nombre lo dice, evitar las malas prácticas de las empresas que comercializan los textos escolares; de este modo la ley prohíbe a las instituciones educativas públicas y privadas exigir la utilización de textos nuevos o de primer uso, además sostiene que es el ministerio de educación debe ser el responsable de establecer los criterios de selección de textos para las instituciones privadas. ${ }^{110}$ Visto de este punto, el Estado busca regular el accionar de las empresas comercializadoras atribuyéndose un papel fiscalizador.

Por otro lado la ley 29839 decreta que las editoriales que comercializan los textos deben registrarse obligatoriamente en el Observatorio Nacional de Textos Escolares donde deberán declarar directamente el precio final de venta. ${ }^{111}$ Con esto, las empresas comercializadoras deben publicar sus precios y estos, a su vez, deben ser fijos para todo el territorio.

Finalmente, la ley contempla que para la selección de los textos escolares, esta debe estar ajena al beneficio económico de mismo centro educativo, el director, los promotores, directivos o algún personal administrativo. ${ }^{112}$ Esta norma se desarrolló durante la coyuntura del escándalo destapado por los noticieros de televisión, en donde una empresa comercializadora beneficiaba con incentivos económicos a los directores y/o profesores a cargo.

\footnotetext{
${ }^{110}$ Cfr. MINEDU 2018

${ }^{111}$ Cfr. MINEDU 2018

112 Cfr. MINEDU 2018
} 


\section{CAPITULO 2: ANÁLISIS DE LA SITUACIÓN ACTUAL}

\section{Descripción del Negocio}

Para describir el negocio de las distribuidoras, se revisará brevemente la definición de distribución que Chopra plantea. Él menciona que son las etapas que comprenden el movimiento y almacenaje de los productos desde un proveedor hasta los clientes finales, además, alude que los insumos y materias primas van dirigidos de proveedor a fabricante, en cambio los productos terminados van de fabricante al consumidor final. ${ }^{113}$ Es en el segundo traslado de fabricante a consumidor final, que las empresas distribuidoras basan sus actividades.

Un enfoque directo sobre el rubro de las distribuidoras de libros es presentado por la Cámara Peruana de Libro (CPL), indica que: son las editoriales, que actúan como proveedores, quienes fabrican y comercializan sus libros a través de organismos de comercio, que se encargan de brindar la oferta en el mercado, como ejemplo de estas editoriales se presentan los fondos editoriales de universidades, organismos públicos, autores - editores, editoriales de instituciones privadas, etc. ${ }^{114}$ Todas ellas recurren a las distribuidoras para que su producto llegue a más usuarios finales.

Sin embargo, la oferta en el mercado interno está compuesto por libros importados y los elaborados nacionalmente; de este modo, existen compañías distribuidoras y librerías que

\footnotetext{
${ }^{113}$ Cfr. Chopra y Meindl 2008: 75

${ }^{114}$ Cfr. CPL 2013: 75
} 
únicamente importan libros y los venden en el mercado local. ${ }^{115}$ Así se puede observar el desenvolvimiento de las operaciones de las distribuidoras de libros.

Figura 13: Esquema de comercialización de libros en el mercado peruano

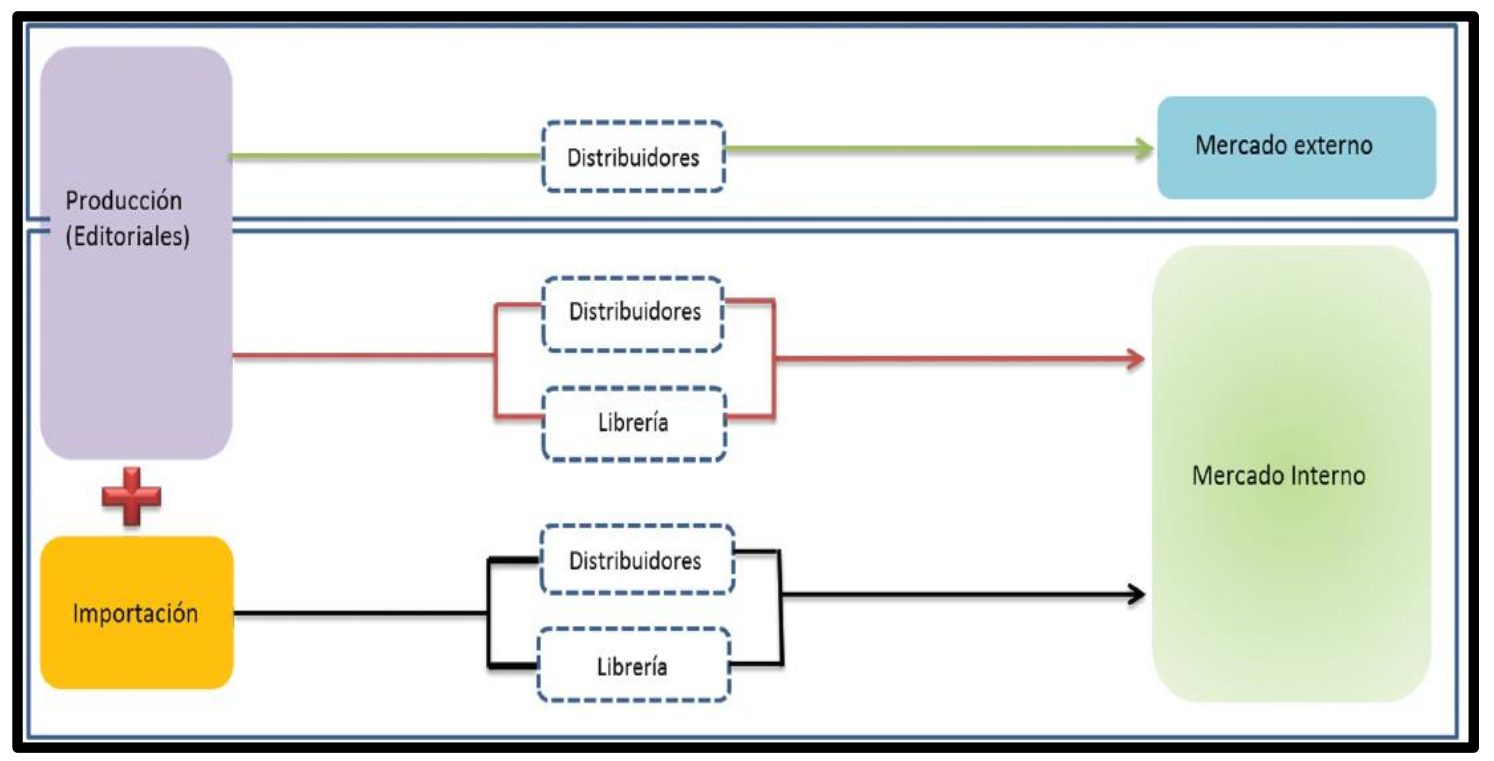

Fuente: CPL 2013:75

La figura 13 esquematiza la comercialización de los libros en el mercado, donde se aprecia la interacción de editoriales, distribuidores y librerías. Asimismo, se puede observar que los libros nacionales y los de importación utilizan los mismos canales para llegar al usuario final.

En el mercado peruano, las organizaciones dedicadas al rubro librero son representadas por la CPL, para ella sus asociadas se conforman de la siguiente manera: (Ver gráfico 3)

${ }^{115}$ Cfr. CPL 2013: 75 
Gráfico 3: Rubros a los que pertenecen las empresas asociadas a la CPL 2011

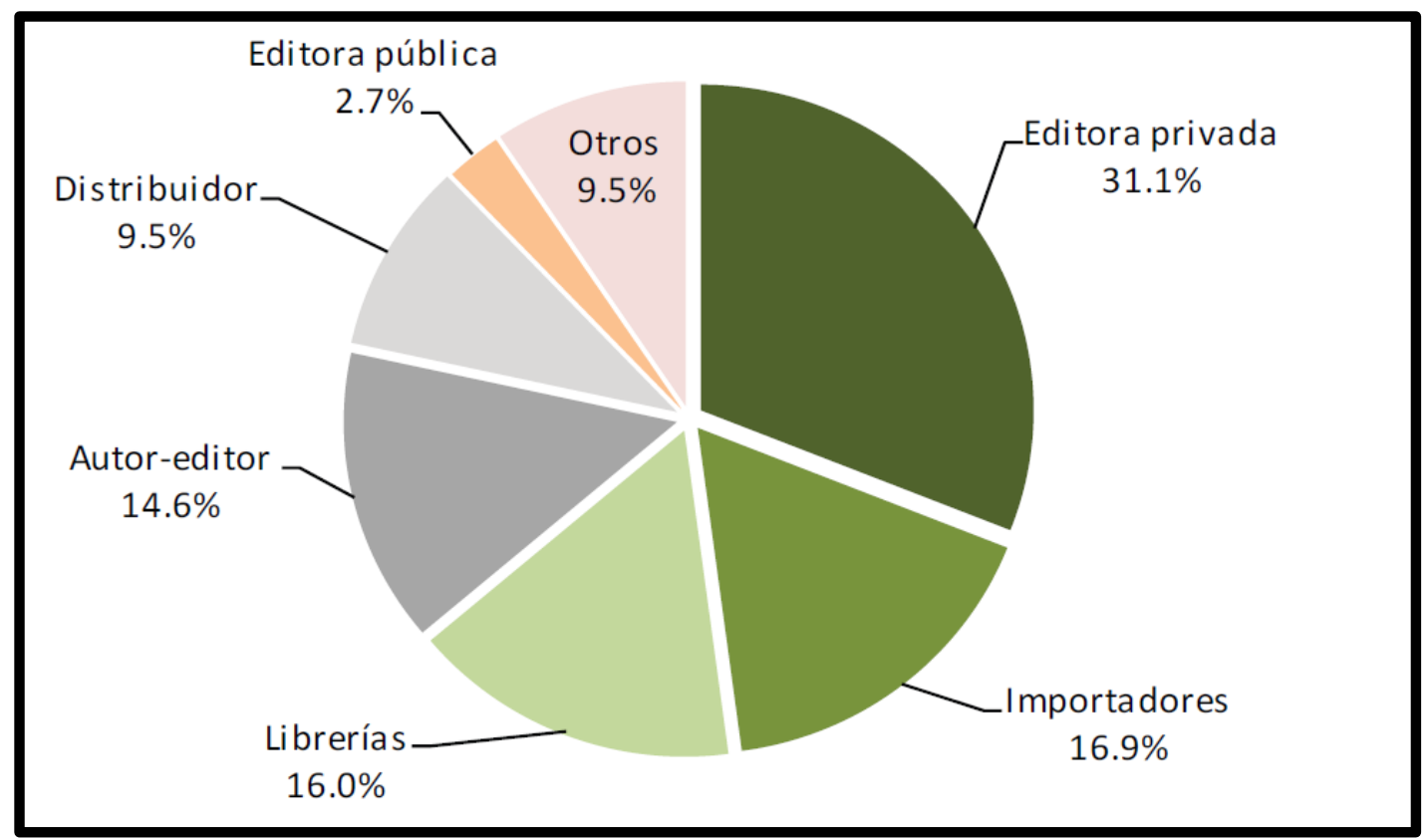

Fuente: CPL 2013: 81

Como se puede observar en el gráfico 3, las empresas de los rubros importador y distribuidor representan el $26.4 \%$, ellas con la Editorial privada son las más representativas de las compañías asociadas a la CPL. 


\section{Análisis del Sector Industrial}

El sector industrial donde se desempeña la empresa a analizar es el de: "Importación, distribución y comercialización de Textos Escolares". Para un breve análisis del sector se utilizará por un lado la información brindada por la Cámara Peruana de Libro (CPL) y posteriormente, se brindará cifras más actuales obtenidas de SUNAT.

\section{Análisis según CPL}

La Cámara Peruana del Libro es una sociedad de varias empresas editoriales, editoriales universitarias, distribuidores de libros, libreros, entre otros, quienes conforman un gremio cultural y sin fines de lucro cuyos objetivos se centran en promover la difusión del libro y los productos editoriales, ser fuente principal de búsqueda de información en las actividades editoras y libreras, y ser impulsadoras de mejoras en la legislación de la industria editorial. ${ }^{116}$

Se empezará comparando el nivel de compras y ventas del sector según los siguientes aspectos: Origen del producto (nacional o importado), Formalidad con el Estado Peruano y asociación a la CPL.

${ }^{116}$ Cfr. CPL 2016 
Figura 14: Ventas y compras realizadas en el sector editorial

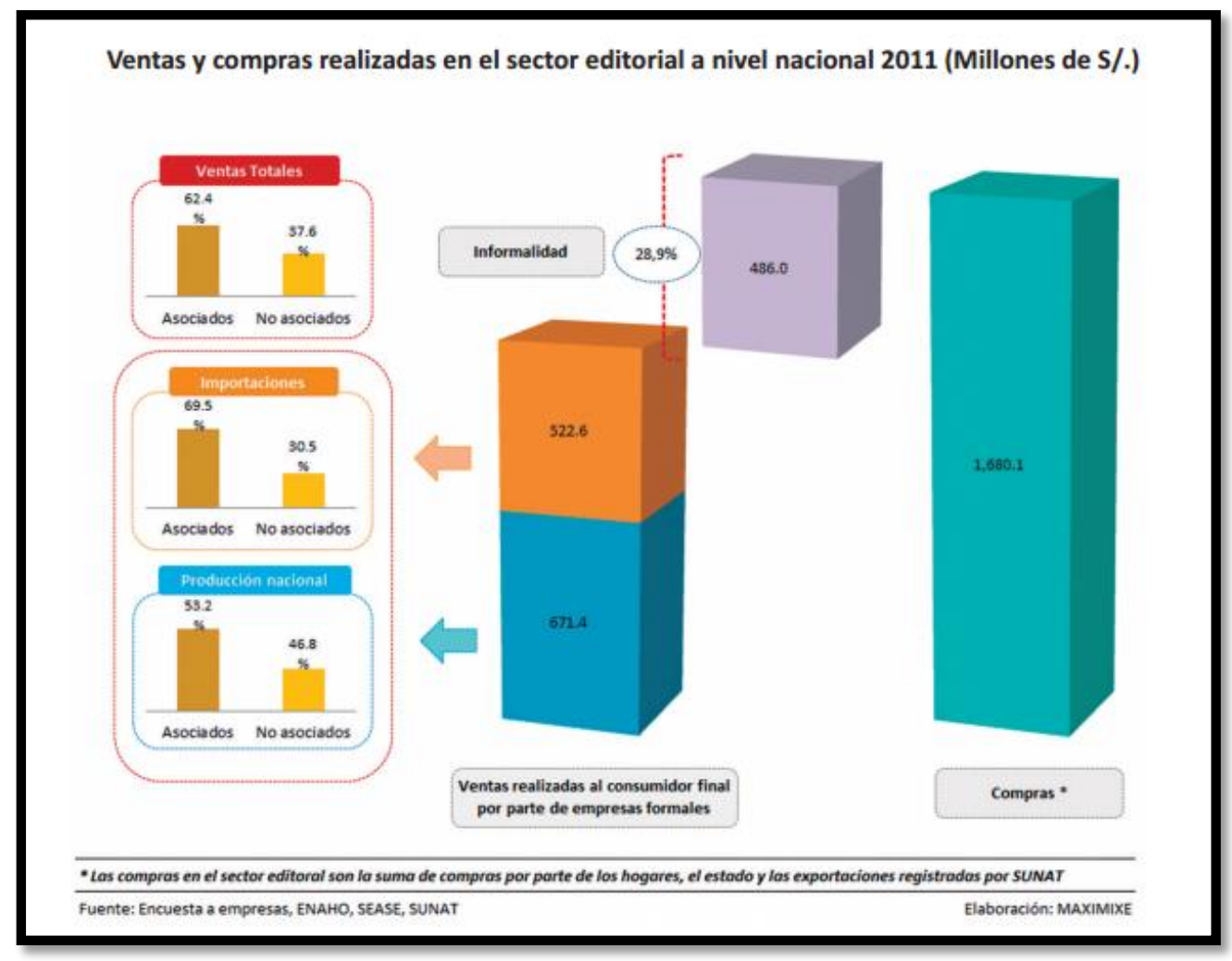

Fuente: CPL 2013:10

En la figura 14 se puede apreciar las ventas y compras realizadas en el sector editorial en el año 2011. Por un lado se observa el total de compras realizadas por los usuarios finales en base a las cifras brindadas por SUNAT, en contra parte se muestra que las ventas declaradas por las empresas solo abarcan el $71.1 \%$ de las compras realizadas; esto implica que la informalidad en ese año alcanzó un $28.9 \%$ del total de compras realizadas. A su vez, se evidencia que los libros producidos nacionalmente fueron los más comercializados abarcando casi el $40 \%$ de las compras totales y más del $56 \%$ de las compras formales. Por último, se identifica que del total de ventas efectuadas por producto importado, el $69.5 \%$ corresponden a las empresas asociadas a la Cámara Peruana de Libro, donde se destaca a Special Book Services (empresa de estudio) como un socio integrante. 
Para orientar el enfoque hacia las empresas importadoras de libros, se muestra el gráfico 4.

Gráfico 4: Participación de las importaciones del rubro librero 2011

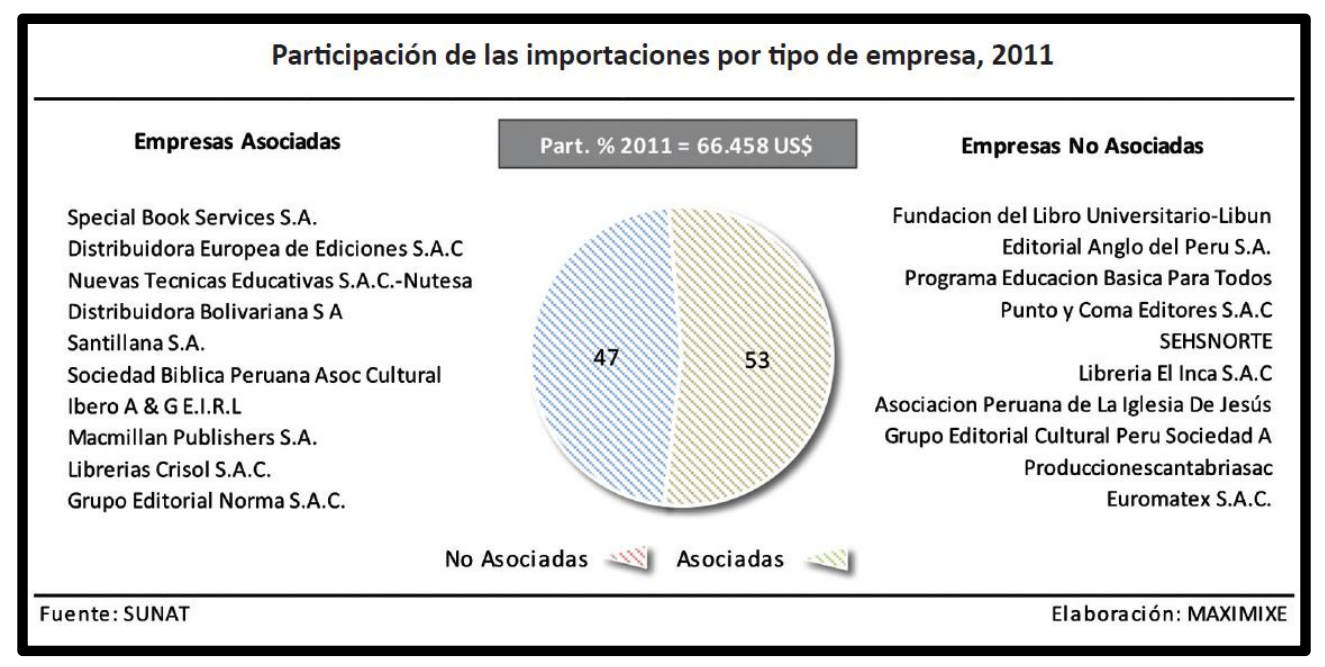

Fuente: CPL 2013:12

El gráfico 4 detalla que el 53\% de las importaciones realizadas para las ventas del 2011 (ver descripción del gráfico anterior) son ejecutadas por empresas asociadas a la Cámara Peruana del Libro, entre los principales importadores se puede observar el papel sobresaliente de SBS. No obstante, se identifica que las empresas no asociadas a la CPL están a una corta distancia detrás de las asociadas e influyen en un $47 \%$ del total de las importaciones.

Adicionalmente, con información reunida hasta el año 2011, la CPL muestra el crecimiento y la participación de las principales empresas importadoras. 
Cuadro 1: Crecimiento y participación de las principales distribuidoras

\begin{tabular}{|c|c|c|c|c|c|c|c|}
\hline Empresa importadora & 2008 & 2009 & 2010 & 2011 & $\begin{array}{c}\text { Crecimiento \% } \\
08-11\end{array}$ & Part.\% 2011 & Tendencia \\
\hline Special Book Services S.A. & 6.232 .932 & 5.432 .155 & 5.573 .678 & 8.049 .677 & $6,6 \%$ & $13,3 \%$ & \\
\hline Fundacion del Libro Universitario-Libun & 3.022 .947 & 3.732 .661 & 3.509 .213 & 3.669 .560 & $5,0 \%$ & $6,0 \%$ & \\
\hline Distribuidora Europea de Ediciones S.A.C. & 4.956 .655 & 2.182 .957 & 2.495 .899 & 2.703 .023 & $-14,1 \%$ & $4,5 \%$ & \\
\hline Nuevas Tecnicas Educativas S.A.C.-Nutesa & 2.294 .704 & 2.475 .759 & 3.334 .090 & 2.252 .932 & $-0,5 \%$ & $3,7 \%$ & \\
\hline Editorial Anglo del Peru S.A. & 914.709 & 2.019 .452 & 2.415 .151 & 2.023 .366 & $22,0 \%$ & $3,3 \%$ & \\
\hline Santillana S.A. & 2.157 .556 & 4.311 .538 & 3.000 .824 & 1.748 .600 & $-5,1 \%$ & $2,9 \%$ & \\
\hline Programa Educacion Basica Para Todos & 0 & 0 & 0 & 1.659 .452 & - & $2,7 \%$ & \\
\hline Sociedad Biblica Peruana Asoc Cultural & 1.232 .785 & 1.414 .389 & 1.752 .536 & 1.629 .411 & $7,2 \%$ & $2,7 \%$ & \\
\hline Distribuidora Bolivariana S.A. & 578.386 & 325.818 & 934.040 & 1.484 .331 & $26,6 \%$ & $2,4 \%$ & \\
\hline Ibero A \& G E.I.R.L & 790.829 & 722.172 & 898.986 & 1.457 .923 & $16,5 \%$ & $2,4 \%$ & \\
\hline Otros & 28.589 .897 & 31.805 .044 & 31.510 .164 & 34.061 .931 & $4,5 \%$ & $56,1 \%$ & \\
\hline Total General & 50.771 .400 & 54.421 .945 & 55.424 .581 & 60.740 .206 & & & \\
\hline \multicolumn{8}{|l|}{ *Otros contiene 1915 empresas } \\
\hline Fuente: SUNAT & & & & & & \multicolumn{2}{|c|}{ Elaboración: MAXIMIXE } \\
\hline
\end{tabular}

Fuente: CPL 2013:

El cuadro 1 muestra el comportamiento de las empresas importadoras en relación a la subpartida arancelaria 49.01.99.90.00 en la cual se encuentran la descripción de libros, folletos e impresos similares, incluso en hojas sueltas. Se observa que predomina, en la mayoría de las firmas, un crecimiento promedio aunque no se puede confirmar la existencia de una tendencia en el sector. Finalmente, se muestra el gráfico 5 donde se describe la participación de las principales distribuidoras en todas las importaciones realizadas en el mercado peruano: 
Gráfico 5: Participación de las principales importadoras 2011

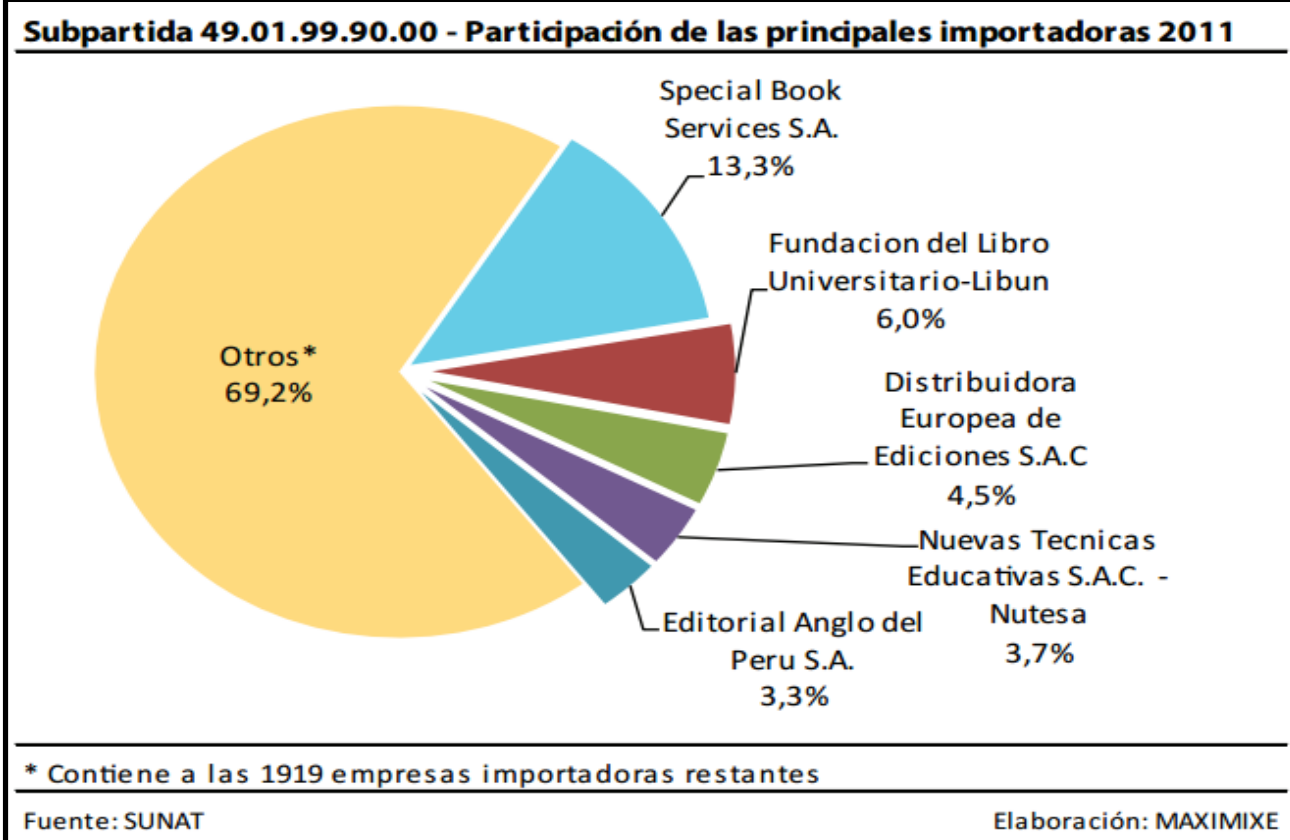

Fuente: CPL 2013:

Se puede observar en el gráfico 5, la presencia de SBS como número uno en la partición de los principales importadores del 2011 con una presencia mayor al 13\%, mientras que sus similares no alcanzaron el $10 \%$.

\section{Análisis actual basado en SUNAT}

En base a la información obtenida en SUNAT, se muestra la situación de las importaciones del año 2015 de la Partida Arancelaria 49.01.999.000 (ver anexo 1).

Luego de analizar la información en el anexo 1, se ha procedido a comparar las magnitudes en porcentajes obteniendo así el nivel de participación de las importaciones de libros. Los resultados se muestran en la tabla 1. 
Tabla 1: Principales importadoras de libros en el Perú

\begin{tabular}{|l|c|}
\hline \multicolumn{1}{|c|}{ IMPORTADOR } & Participación 2015 \\
\hline SPECIAL BOOK SERVICES S.A. & $16.31 \%$ \\
\hline UNIDAD EJECUTORA 12O PROGRAMA NACIONAL D & $7.52 \%$ \\
\hline DISTRIBUIDORA EUROPEA DE EDICIONES S.A.C & $6.09 \%$ \\
\hline LIBRERIAS CRISOL S.A.C. & $5.59 \%$ \\
\hline FUNDACION DEL LIBRO UNIVERSITARIO-LIBUN & $4.68 \%$ \\
\hline EDITORIAL ANGLO DEL PERU SA & $3.50 \%$ \\
\hline ASOCIACION SERVICIO EDUCACIONAL HOGAR Y & $3.34 \%$ \\
\hline PRODUCCIONES CANTABRIA S.A.C. & $3.16 \%$ \\
\hline DISTRIBUIDORA BOLIVARIANA S A & $2.87 \%$ \\
\hline NUEVAS TECNICAS EDUCATIVAS S.A.C.-NUTESA & $2.46 \%$ \\
\hline SOCIEDAD BIBLICA PERUANA ASOC CULTURAL & $2.45 \%$ \\
\hline IBERO A \& G S.A.C. & $2.36 \%$ \\
\hline MACMILLAN PUBLISHERS S.A. & $1.96 \%$ \\
\hline LENGUAJE Y COMERCIO SRLTDA. & $1.43 \%$ \\
\hline EDITORIAL OCEANO PERUANA S.A. & $1.41 \%$ \\
\hline SAN CRISTOBAL LIBROS S.A.C. & $1.35 \%$ \\
\hline PRESCRIPTION DATA DEL PERU S.A.C. & $1.17 \%$ \\
\hline COMMUNITAS S.A.C. & $1.17 \%$ \\
\hline LIBRERIA PERUANO BRITANICA S.R.LTDA. & $1.17 \%$ \\
\hline ASOCIACION PERUANA DE LA IGLESIA DE JESU & $1.12 \%$ \\
\hline EDITORIAL PANAMERICANA PERU S.A.C. & $1.09 \%$ \\
\hline EDITORIAL VICENS VIVES PERU SOCIEDAD ANO & $1.00 \%$ \\
\hline OtrOS (mENORS al 1\%) & $26.80 \%$ \\
\hline EII & \\
\hline
\end{tabular}

Elaboración propia basada en SUNAT

De la tabla anterior, se desprende que la firma Special Book Services sigue siendo la pionera en la participación de importaciones del rubro librero con más del $16 \%$. Sus similares no logran alcanzar una participación mayor al $10 \%$.

Con la presentación de las gráficas 6 y 7 se muestra visualmente la participación de las principales importadoras en el año 2015. Donde destaca la compañía Special Book Services, Unidad Ejecutora 120 Programa Nacional, Distribuidora Europea de Ediciones, Librerías Crisol y otras, las cuales forman parte del sector librero a nivel nacional. (ver gráficos) 
Gráfico 6: Participación de las importadoras de libros 2015 en el Perú

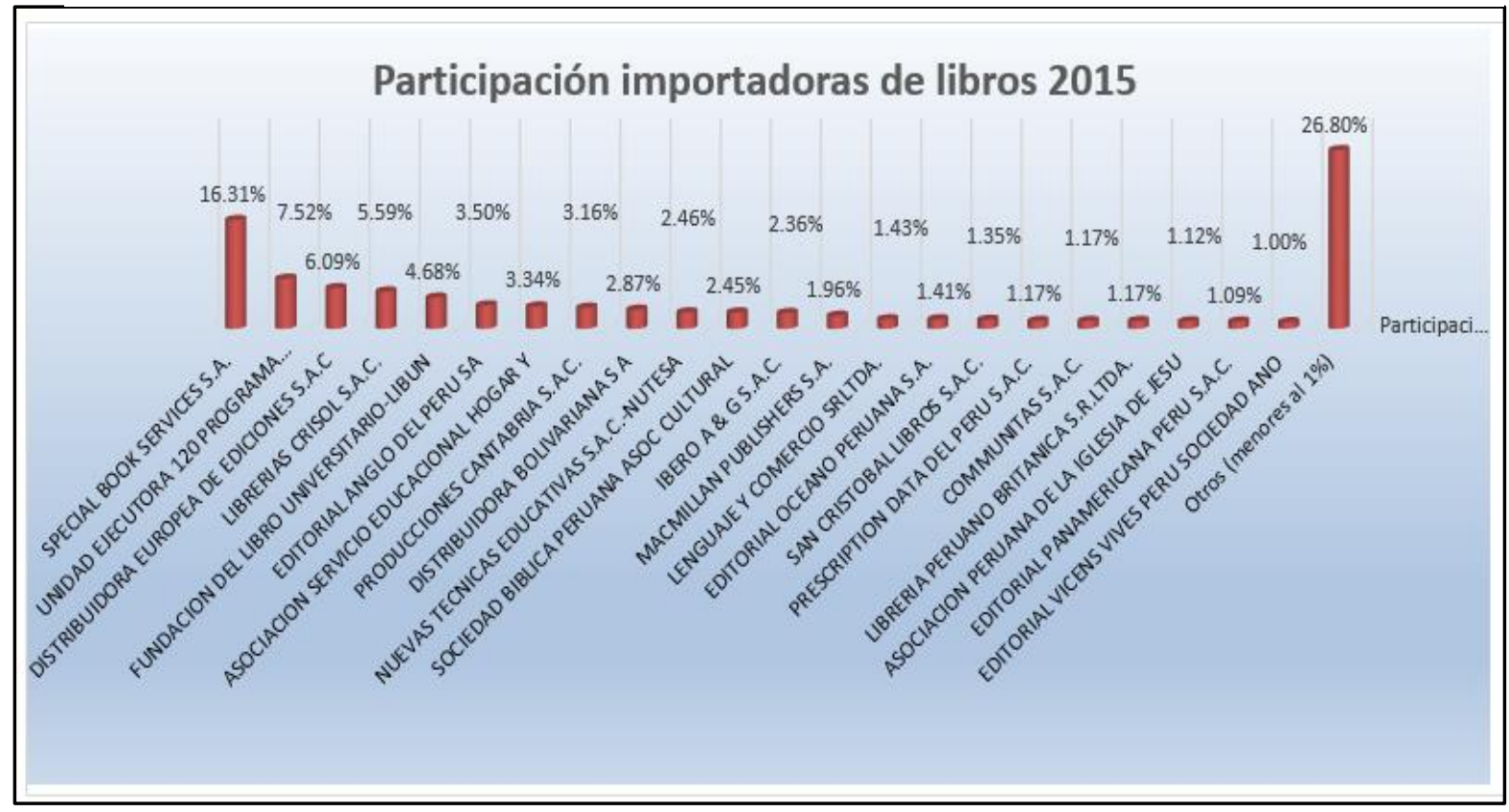

Fuente: Elaboración propia basada en SUNAT 2016

Gráfico 7: Principales importadoras peruanas 2015

\section{Participación: Importación 2015}

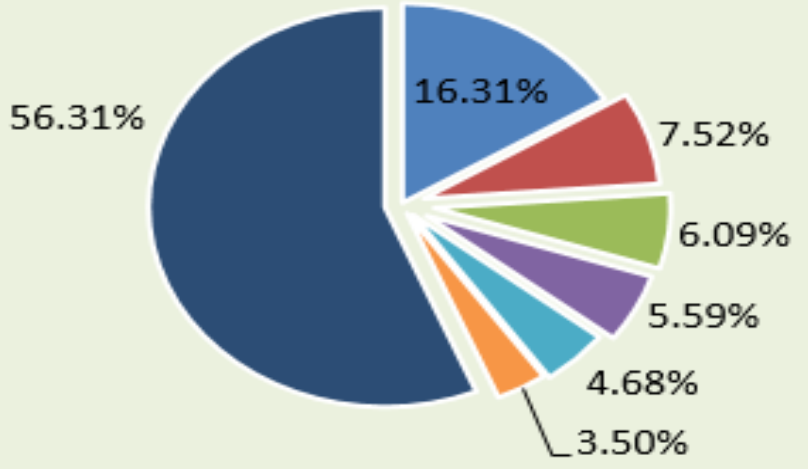

- SPECIAL BOOK SERVICES S.A.

- UNIDAD EJECUTORA 120 PROGRAMA NACIONAL D

- DISTRIBUIDORA EUROPEA DE EDICIONES S.A.C

- LIBRERIAS CRISOL S.A.C.

- FUNDACION DEL LIBRO UNIVERSITARIO-LIBUN

- EDITORIAL ANGLO DEL PERU SA

- OTROS

Fuente: Elaboración propia basada en SUNAT 2016 


\section{Análisis de las Cinco Fuerzas de Porter}

Terminado el análisis del sector industrial y la comparación estadística de las principales importadoras de libros, se procederá a realizar el análisis externo de las diferentes oportunidades y amenazas que se presentan en el sector, a través de la metodología planteada por Porter.

\section{Amenaza de nuevos competidores:}

La amenaza de nuevos competidores en el sector de las distribuidoras e importadoras de libros se presenta en el cuadro 2:

Cuadro 2: Amenaza de nuevos competidores

\begin{tabular}{|l|l|}
\hline \multicolumn{1}{|c|}{ OPORTUNIDADES } & \multicolumn{1}{c|}{ AMIENAZAS } \\
\hline $\begin{array}{l}\text { Las importaciones en cantidades } \\
\text { reducen los costos unitarios }\end{array}$ & $\begin{array}{l}\text { Gobierno impulsa la industria con } \\
\text { políticas de fomento de desarrollo } \\
\text { editorial y acceso a la lectura }\end{array}$ \\
\hline $\begin{array}{l}\text { Marcas identificadas de prestigioso } \\
\text { contenido editorial }\end{array}$ & $\begin{array}{l}\text { Los requisitos del gobierno son } \\
\text { cumplibles por nuevas industrias }\end{array}$ \\
\hline Se requieres Inversión Inicial muy alta & $\begin{array}{l}\text { Los canales de distribución no son } \\
\text { saturados }\end{array}$ \\
\hline Gran ventaja en los costos & $\begin{array}{l}\text { Las editoriales pueden decidir tener } \\
\text { bodegas en el país y/o atender } \\
\text { directamente }\end{array}$ \\
\hline La curva de experiencia es importante & $\begin{array}{l}\text { La competencia reacciona pasivamente } \\
\text { ante el ingreso de nuevos competidores }\end{array}$ \\
\hline
\end{tabular}

Fuente: Elaboración propia

El cuadro explica las oportunidades y amenazas que originan la aparición de nuevos competidores que surgen en el sector. 


\section{Presión de Productos Sustitutos:}

En el sector pueden aparecer nuevos productos sustitutos, se muestra el cuadro 3:

Cuadro 3: Presión de productos sustitutos

\begin{tabular}{|l|}
\hline \multicolumn{1}{|c|}{ OPORTUNIDADES } \\
\hline $\begin{array}{l}\text { La creación de valor de productos } \\
\text { sustitutos no afecta a la industria }\end{array}$ \\
\hline $\begin{array}{l}\text { Nivel de sustitución es mínimo, la fuerza } \\
\text { está en los contenidos }\end{array}$ \\
\hline $\begin{array}{l}\text { Los sustitutos no ofrecen ventajas } \\
\text { significativas sobre los contenidos }\end{array}$ \\
\hline
\end{tabular}

Fuente: Elaboración propia

En la actualidad, no existen productos sustitutos que generen preocupación al sector, siendo una opción el libro electrónico pero la tendencia del consumidor es aún recia al cambio, lo que desencadena oportunidades en el mercado.

\section{Poder de negociación de los clientes:}

El análisis de las oportunidades o amenazas que generan los clientes al según su poder de negociación se muestra en el siguiente cuadro.

Cuadro 4: Poder de negociación de los clientes

\begin{tabular}{|l|l|}
\hline \multicolumn{1}{|c|}{ OPORTUNIDADES } & \multicolumn{1}{c|}{ AMIENAZAS } \\
\hline $\begin{array}{l}\text { No hay integración ni interés de } \\
\text { agruparse entre ellos mismos }\end{array}$ & $\begin{array}{l}\text { Existen compradores importantes en } \\
\text { mediana concentración }\end{array}$ \\
$\begin{array}{l}\text { Clientes altamente diferenciados con } \\
\text { altos estándares de calidad Educativa }\end{array}$ & $\begin{array}{l}\text { Los clientes cambian de proveedor con } \\
\text { un costo de cambio manejable }\end{array}$ \\
\hline & Negociación de precios moderada \\
\hline
\end{tabular}

Fuente: Elaboración propia 
Los clientes cuentan con un poder de negociación moderada en el sector librero.

\section{Poder de negociación de los proveedores}

De igual manera se muestra el análisis de los proveedores en el sector librero.

Cuadro 5: Poder de negociación de los proveedores

\section{\begin{tabular}{l|l} 
OPORTUNIDADES & AMENAZAS
\end{tabular}}

Hay un alto costo por cambiar al Existen proveedores importantes

distribuidor. Pocos distribuidores en el rubro

No hay integración, ni interés de los Intensa negociación de precios

proveedores por integrarse

Alta diferenciación en calidad de

contenidos bibliográficos y educativos

Fuente: Elaboración propia

\section{Rivalidad de la Industria}

Por último, se muestra el análisis de la última y principal fuerza de Porter del sector distribuidor de libros:

Cuadro 6: Rivalidad en la industria

\begin{tabular}{|ll|}
\hline \multicolumn{1}{|c|}{ OPORTUNIDADES } & \multicolumn{1}{c|}{ AMENAZAS } \\
\hline Demanda en constante crecimiento & $\begin{array}{l}\text { La industria se enfoca a diferentes } \\
\text { objetivos }\end{array}$ \\
\hline Nuevas leyes de Calidad Educativa & Clara diferenciación de servicios \\
\hline Oportunidad de Negocios & Pequeños incrementos en capacidad \\
\hline Pocos competidores desarrollados & Costosas barreras de salida \\
\hline
\end{tabular}

Fuente: Elaboración propia 
En primer lugar, se puede inferir que el Sector Importación y Distribución de Libros en el Perú se encuentra en crecimiento constante dando lugar a oportunidades de desarrollo de nuevos negocios en la distribución de libros y textos educativos, donde la rivalidad del sector es reducida debido a los pocos actores con experiencia en la comercialización y distribución. Además, como toda industria que está en crecimiento, la estrategia está direccionada en abarcar mayor participación del mercado, por lo cual, resultaría viable las alianzas estratégicas con los proveedores editoriales para negociar stock y precios de los textos, que permitan a largo plazo el crecimiento sostenible del sector. Por último, se presenta como una amenaza peligrosa que las Editoriales (proveedores) decidan tener operaciones directas con los clientes, volviéndose competidores directos de los distribuidores actuales, por lo que, es necesario tener estrategias de valor agregado en el servicio al cliente, así como con los proveedores editoriales.

\section{Descripción de la Empresa}

Special Book Services Perú es parte del Grupo SBS Internacional que comprende SBS Brasil como casa Matriz con un Centro Logístico, 11 almacenes regionales y 37 Librerías, y SBS Argentina con un Centro Logístico en Buenos Aires, 03 almacenes regionales y 11 librerías, consolidando al Grupo SBS como una de las Distribuidoras de contenidos en cualquier formato más importantes de Sudamérica.

La empresa fue fundada 1996 y actualmente es el mayor distribuidor de libros en el Perú. La distribución a los clientes se realiza a través de su centro logístico en Lima para venta al por mayor y 12 librerías para venta al por menor ubicadas en: Lima (Angamos, Larco y Univ. Esan), Trujillo, Chiclayo, Piura, Pucallpa, Iquitos, Cusco, Arequipa, Tacna y Huancayo, por lo que es la mayor cadena nacional de librerías en el Perú. 
En SBS Perú son conscientes de la importancia que tiene actualmente la logística en el logro de competitividad y en la creación de valor, por lo cual se ha venido realizando año a año inversiones relevantes buscando un mejoramiento continuo en el nivel de servicio en cuanto a distribución de productos y la atención a clientes a nivel nacional (Colegios, Súper Mercados, Universidades, Institutos de Idiomas, Bibliotecas, etc.). Hoy en día, la compañía cuenta con un Centro de Distribución ubicado en la ciudad de Lima, diseñado con estándares logísticos y estructurales. Cuenta con un área bruta de más de 1,000 m2 de los cuales el 70\% están destinados como área útil de almacenamiento, además de contar con 715 ubicaciones de almacenaje en un sistema de rack estructural de 05 niveles. Los servicios de SBS se soportan en una adecuada metodología de trabajo, en la calificación y experiencia de sus profesionales, en una sólida estructura organizacional y con la infraestructura tecnológica necesaria para los procesos.

\section{Visión:}

“Ser la primera opción para el cliente ante cualquier necesidad de adquirir libros y contenidos en cualquiera de sus presentaciones en las diversas ramas del conocimiento."

\section{Misión:}

Actuar como productores y distribuidores, con el fin de facilitar el acceso de nuestros clientes a los contenidos disponibles a través de cualquier medio, cubriendo las más diversas áreas del conocimiento humano, expresado en cualquier idioma."

\section{Valores:}

- Ética

- Transparencia

- Eficiencia 
- Competencia

- Innovación

\section{Ventas y productos principales}

A manera de catálogo, se presenta una relación de productos y definiciones que ofrece la empresa Special Book Services en el mercado.

SBS cuenta con un diverso y amplio catálogo de productos a ofrecer, los cuales son agrupados según el tema de interés y el púbico a quien va dirigido. 
Cuadro 7: Principales productos ofrecidos por SBS

\begin{tabular}{|c|c|c|c|}
\hline GRUPO & COD & DESCRIPCIÓN & IMAGEN \\
\hline $\begin{array}{l}\text { EDUCACION } \\
\text { ESCOLAR \& } \\
\text { BACHILLERATO }\end{array}$ & EDU & $\begin{array}{l}\text { Libros de texto para cursos de } \\
\text { Educación Primaria y } \\
\text { Secundaria de Colegios } \\
\text { Particulares y/o del Bachillerato } \\
\text { Internacional IB }\end{array}$ & BIOLOGIA \\
\hline $\begin{array}{c}\text { ENSENANZA DE } \\
\text { DIONCAS }\end{array}$ & ELT & $\begin{array}{l}\text { Libros con metodologías para la } \\
\text { enseñanza del Idioma Inglés } \\
\text { para todos los niveles } \\
\text { Educativos, Inicial, Primaria, } \\
\text { Secundaria, Universitarioe } \\
\text { Institutos de Idiomas. }\end{array}$ & \\
\hline OTROSIDIOLAS & OID & $\begin{array}{l}\text { Libros metodológicos para la } \\
\text { enseñanza de idiomas } \\
\text { diferente al inglés como } \\
\text { Frances, Español, Ruso, } \\
\text { Italiano, etc. } \\
\text { Se incluye libros de referencia y } \\
\text { auto aprendizaje como } \\
\text { vocabulario, gramática, } \\
\text { lecturas niveladas etc. }\end{array}$ & $\begin{array}{l}\text { ESSENTIAL } \\
\text { TRALIAN } \\
\text { GRAMMAR } \\
\text { actmana }\end{array}$ \\
\hline PLANLECTOR & PLE & $\begin{array}{l}\text { Lecturas graduadas por edades } \\
\text { en idioma español para los } \\
\text { niveles de educación primaria y } \\
\text { secundaria regular. } \\
\text { De acuerdo a la estructura } \\
\text { curricular que define el DCN - } \\
\text { MINEDU }\end{array}$ & 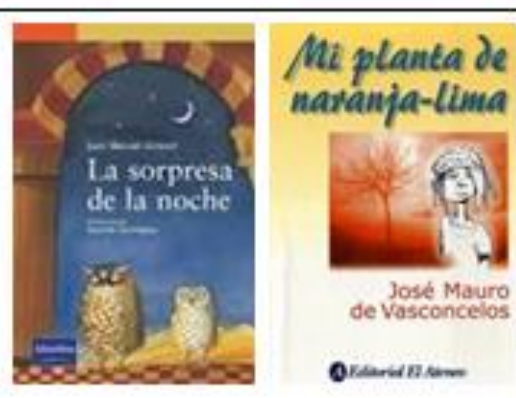 \\
\hline
\end{tabular}

Fuente: Elaboración propia 
Continuación del cuadro 7.Principales productos ofrecidos por SBS

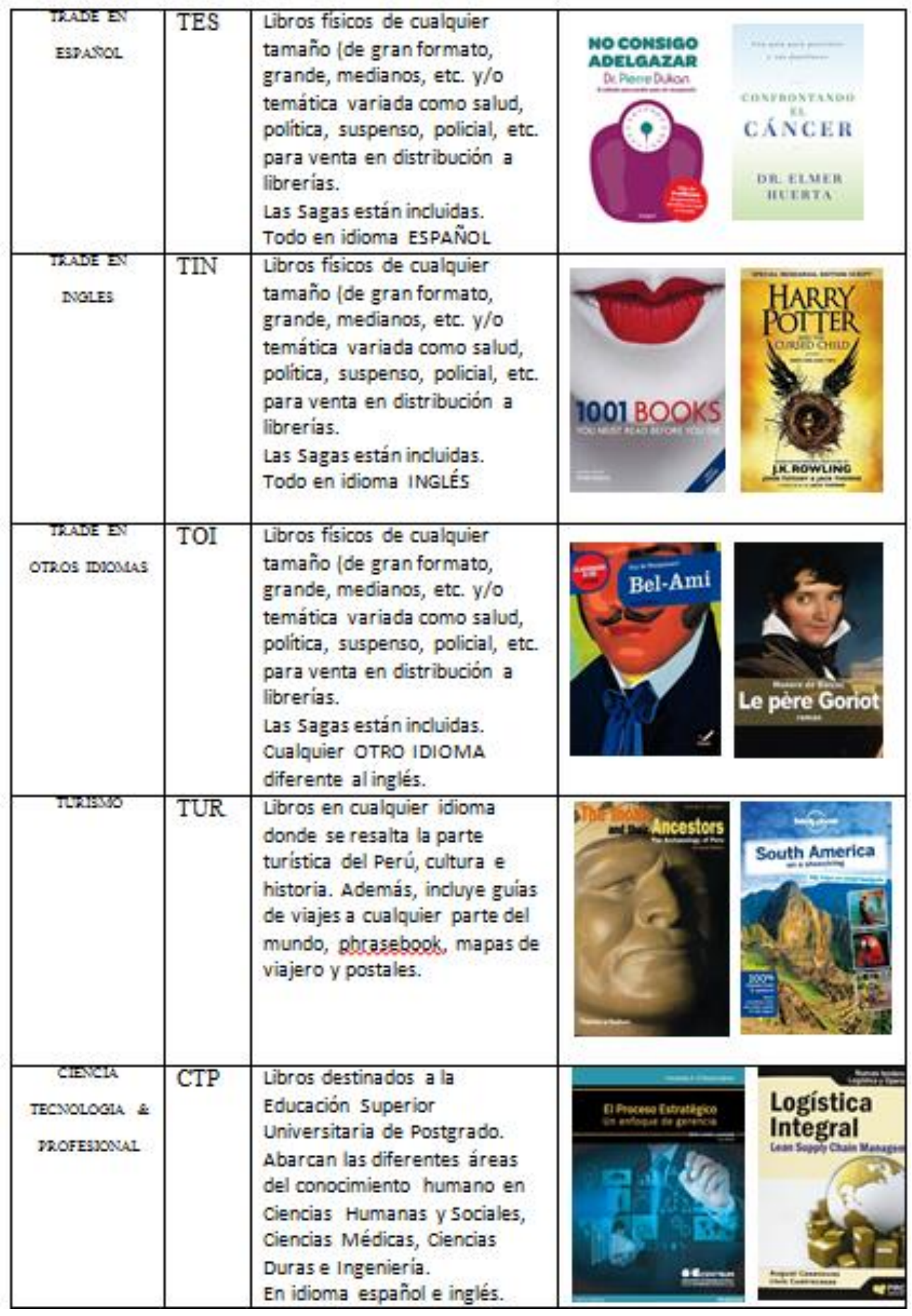

Fuente: Elaboración propia 
El nivel de participación en las ventas de cada grupo de productos es explicado en los siguientes gráficos:

Gráfico 8: Ventas 2015 según grupo de producto

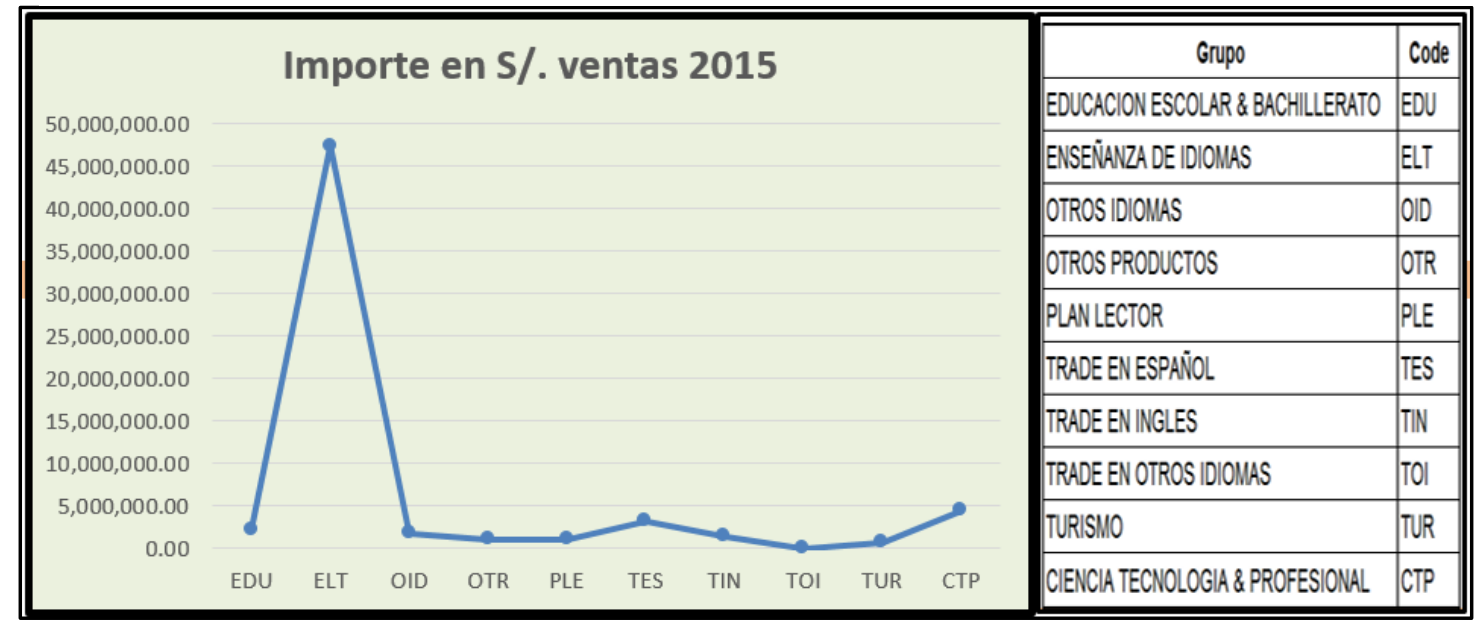

Fuente: Elaboración propia

Gráfico 9: Gráfico torta de las ventas 2015 según grupo de producto

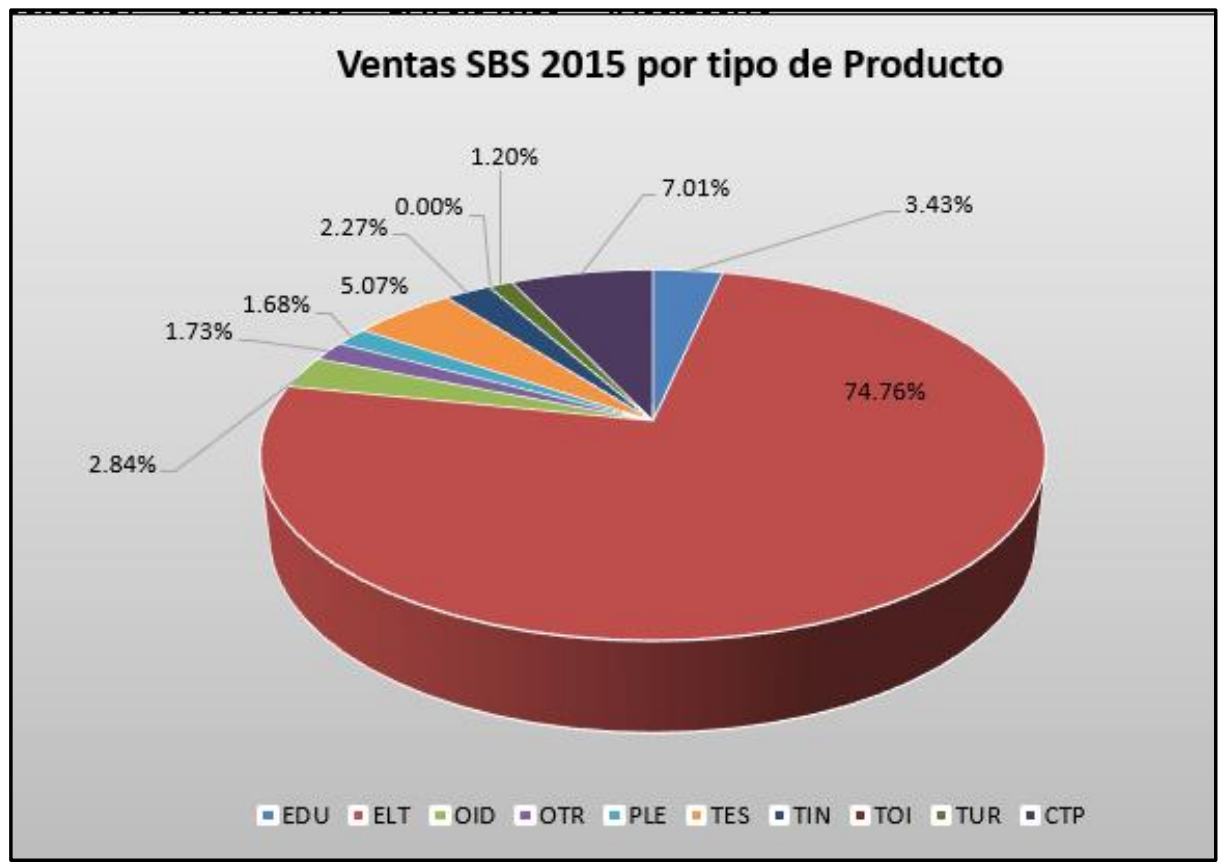

Fuente: Elaboración propia 
En las gráficas se observa que el producto con mayor impacto en las ventas del año 2015 fue ELT, cuyo importe facturado asciende por encima de los 45 millones de soles y representa cerca del 75\% del total de las ventas del año 2015. En segundo lugar se encuentra el producto CTP con una representatividad del 7\% y valor facturado cerca a los 5 millones de soles. Por último, se debe considerar al producto TES en un tercer lugar de impacto en las ventas con un porcentaje del $5 \%$ y ventas que sobrepasan los 3 millones. Se puede concluir que las ventas de estos tres tipos de productos representan más del $86 \%$ del total generado en el año 2015, de aquí se desprende la importancia de su análisis.

\section{Cadena de Valor de la Empresa}

Para obtener un mejor panorama de las actividades que generan valor en la empresa, se emplea el análisis de la cadena de valor. La cadena de valor de SBS detalla las actividades claves y las de apoyo según se muestran en las figuras 15 y 16.

Figura 15: Cadena de Valor SBS

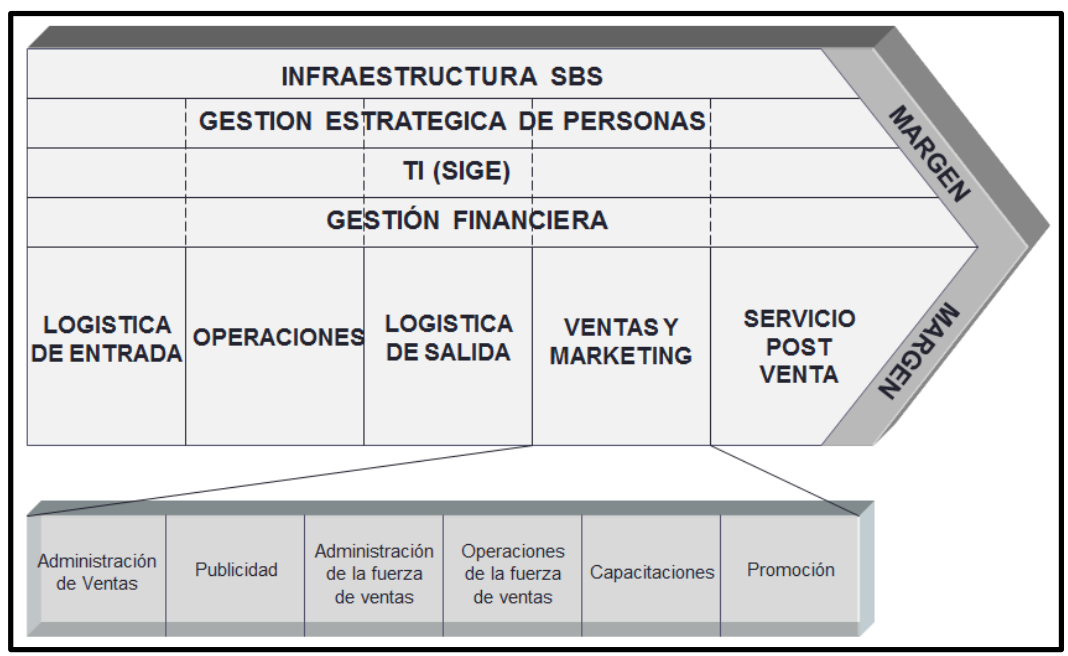

Fuente: Elaboración propia 
Figura 16: Detalle de la cadena de valor SBS

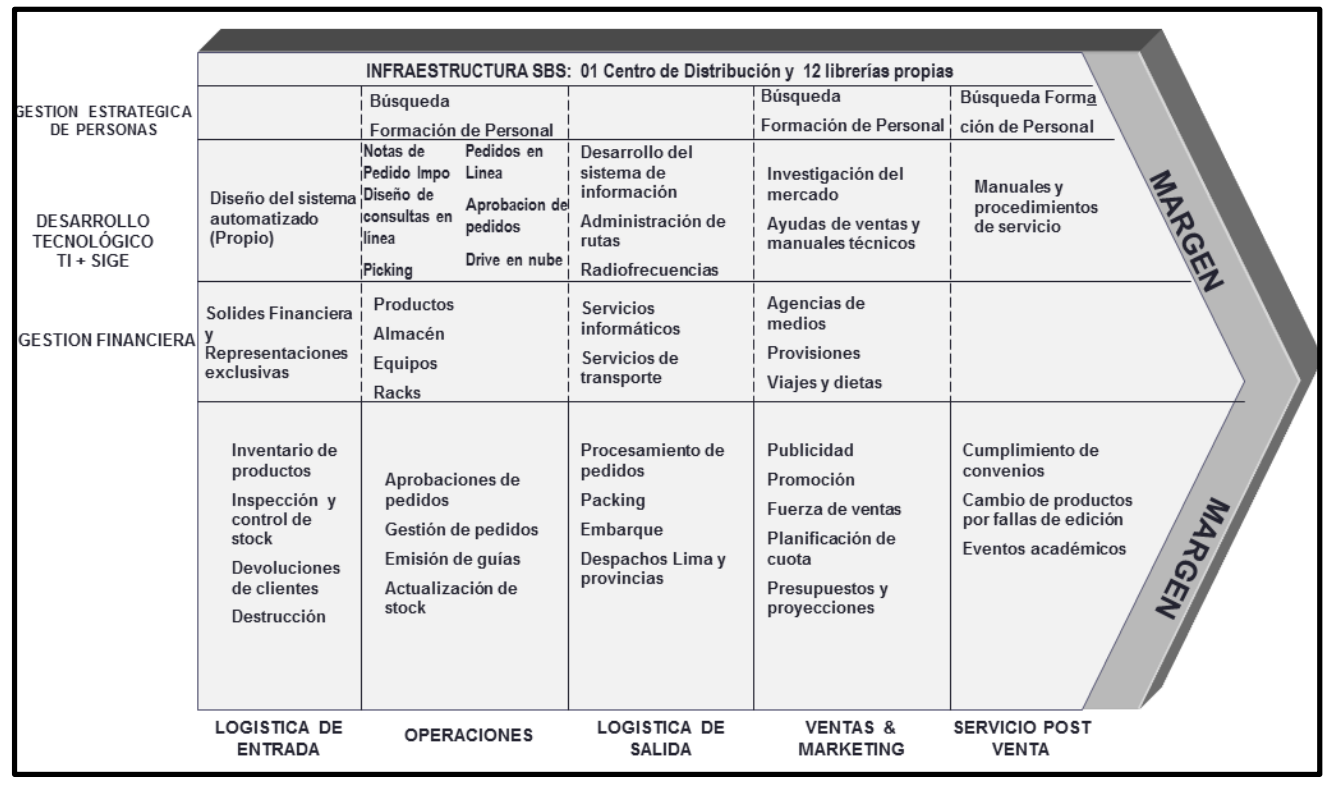

Fuente: Elaboración propia

En cuanto a infraestructura, SBS Perú forma parte del Grupo SBS Internacional conformado por SBS Brasil, Argentina y Perú, reconocidos por su sólido respaldo financiero. El Grupo SBS Internacional lleva a cabo una estrategia multidoméstica, que es un tipo de estrategia en donde las decisiones de la empresa están descentralizadas, de esta forma, se pueden hacer frente a las diferencias culturales y legales de cada país, teniendo autonomía de gestión cada Sede - país. Pasando por la investigación de mercados, desarrollo y diseño de campañas de productos: la empresa crea un servicio integral de apoyo académico a las Instituciones como un producto con características únicas, lo cual le ha permitido perdurar en el tiempo y diferenciarse de las demás empresas distribuidoras a lo largo de territorio peruano.

Con la etapa de Gestión Estratégica de Personas la empresa tiene un compromiso continuo hacia la formación y la creación de un lugar de trabajo confortable. De esta forma sus empleados pueden proporcionar la calidad de servicio deseado al cliente. La empresa proporciona el 
entrenamiento y herramientas necesarias para hacer frente a un mercado cambiante y para satisfacer las necesidades de los clientes. Además, la dirección de SBS Perú siempre busca ser líder y tener una visión amplia del mercado, tomando como mercado objetivo las instituciones educativas de nivel A y B para eso cuenta con un equipo humano profesional e idóneo, con un alto nivel de compromiso con la compañía; una adecuada infraestructura garantiza el mejoramiento continuo de todos los procesos, en busca siempre del valor agregado en el ejercicio de sus actividades para el beneficio de los clientes y su entorno.

En referencia al Desarrollo Tecnológico, SBS cuenta con un sistema informático propio WMS (Warehouse Management System) diseñado especialmente para cubrir las necesidades y actividades de apoyo: Finanzas, GEP y actividades primarias como la logística de entrada, operaciones, logística de salida, ventas y CRM, etc. Creando una ventaja en el manejo de información por la gestión integral, además el sistema trabaja en línea y está actualizado en tiempo real con los movimientos de stock de las sucursales a nivel nacional.

La Gestión Financiera permite un control de las operaciones de la empresa, buscando en los resultados e inversiones la mayor rentabilidad para los accionistas. La solidez financiera de SBS es el mejor respaldo frente a los proveedores y clientes, logrando así asociaciones estratégicas que permitan la operatividad, sostenibilidad y resultados de proyectos de expansión e inversión para la empresa.

En la logística de entrada como fase de la cadena de valor, SBS se aprovisiona y compra lotes grandes de productos en función de las proyecciones de la demanda y/o pedidos fijos. Una vez ingresado el producto al Centro de distribución, toda la cadena logística es manejada por SBS, teniendo como ventaja (logística de salida) el manejo de los tiempos y cumplimiento de los 
compromisos de entrega pues no dependen de terceros en la distribución de sub-distribuidores, puntos de ventas e instituciones generando un valor en el servicio al cliente.

El mercado cada vez más competitivo exige ser innovadores en la calidad de servicio, las Operaciones de gestión de pedidos optimizan recursos y simplifican los procesos que son percibidos y valorados por el cliente en beneficio de éstos. El buen resultado de las Operaciones se sostiene en el trabajo en equipo de las áreas involucradas en este proceso.

Las Ventas, SBS busca e intenta aprovechar al máximo las posibilidades de venta de sus productos y de crecimiento de mercado, mediante una fuerza de ventas a nivel nacional, asociaciones y convenios académicos con prestigiosas instituciones educativas y puntos de ventas propios. Como consecuencia de esto, el usuario final tiene la posibilidad de adquirir los contenidos bibliográficos de cualquier formato (físico y digital) en cualquier lugar del país. El Marketing diseña las campañas comerciales buscando el fortalecimiento de la marca SBS dentro del mercado de textos educativos, para mantenerla invierte en campañas y programas de fidelización de clientes, teniendo un trabajo de soporte y colaboración del CRM y de Servicio al cliente.

La asociación estratégica de SBS con sus proveedores ha contribuido a la fidelización de los clientes con el servicio post venta que ha permitido agregar valor al servicio de distribución de libros, no quedando únicamente como proveedores de libros, sino como un socio estratégico que aumenta el nivel académico de la instituciones mediante la consultoría académica y eventos pedagógicos con expositores de prestigio internacional.

Se puede concluir que los servicios de SBS se soportan en una adecuada metodología de trabajo, en la calificación y experiencia de sus profesionales, en una sólida estructura organizacional y con la infraestructura tecnológica necesaria para los procesos. 


\section{Mapa de Procesos de la Empresa}

El mapa de procesos, según se planteó en el capítulo 1, tiene como finalidad brindar una visión general de todos los procesos en la organización. Para ello se muestra, en la figura 17, el mapa de procesos de la empresa Special Book Services.

Figura 17: Mapa de procesos Special Book Services

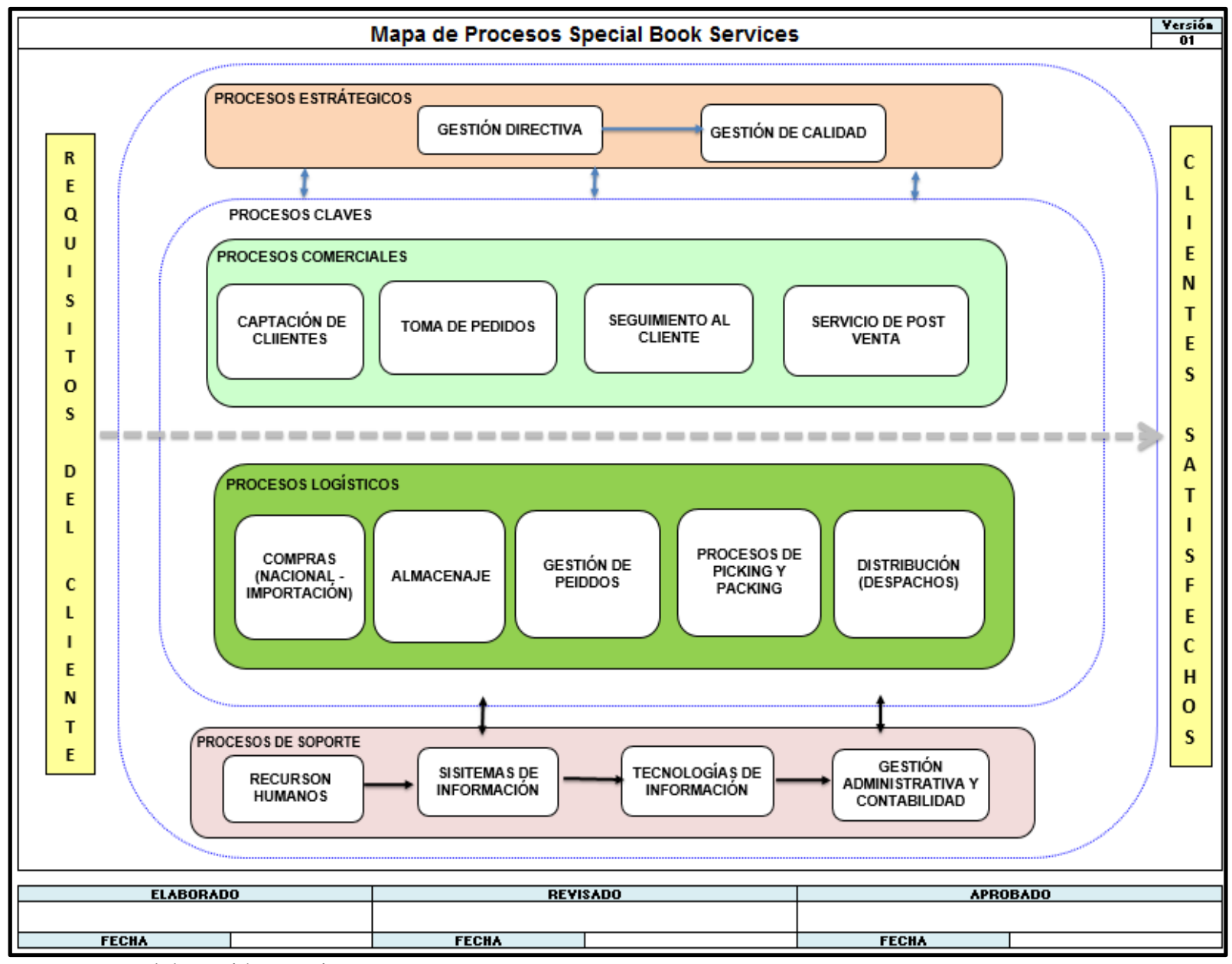

Fuente: Elaboración propia 
Del mapa de procesos de SBS se puede apreciar que los procesos claves son de dos tipos: comerciales y logísticos; estos procesos son los que brindan el valor agregado que percibe el cliente. También se encuentran los procesos estratégicos, como son los procesos de gestión que velan por la planificación, ejecución y control de los procesos claves; en esta clasificación SBS cuenta con procesos estratégicos de gestión directiva y gestión comercial. Por último, en los procesos de soporte y apoyo de los procesos claves se han identificado los procesos de recursos humanos, sistemas de información, tecnologías de información, gestión administrativa y. La interacción de todos estos procesos con la finalidad de satisfacer al cliente son reflejados en el mapa de procesos.

El aporte del análisis del mapa de procesos de Special Book Services es la identificación de los procesos claves tanto comerciales como de índole Logístico, éste último cimenta la importancia de la logística en la empresa debido al rubro que ocupa en el mercado, el de la distribución. En consecuencia, los procesos logísticos serán foco de análisis del presente proyecto.

\section{Descripción de los procesos}

Para describir los procesos de la Distribuidora SBS se han asociado y organizado según como los plantea el Consejo de Cadena de Suministros (SCC), la cual clasifica en 5 los tipos de procesos que se llevan a cabo en toda cadena de suministro: Planificación, Aprovisionamiento, Fabricación, Distribución y Devolución. Adaptando esta noción a la distribuidora SBS, se han clasificado en 4, obviando en este caso al proceso de Fabricación debido a que SBS compra y distribuye productos terminados: Libros empastados.

Según lo explicado líneas arriba, se muestra la figura 18: 
Figura 18: Procesos principales de la Distribuidora SBS

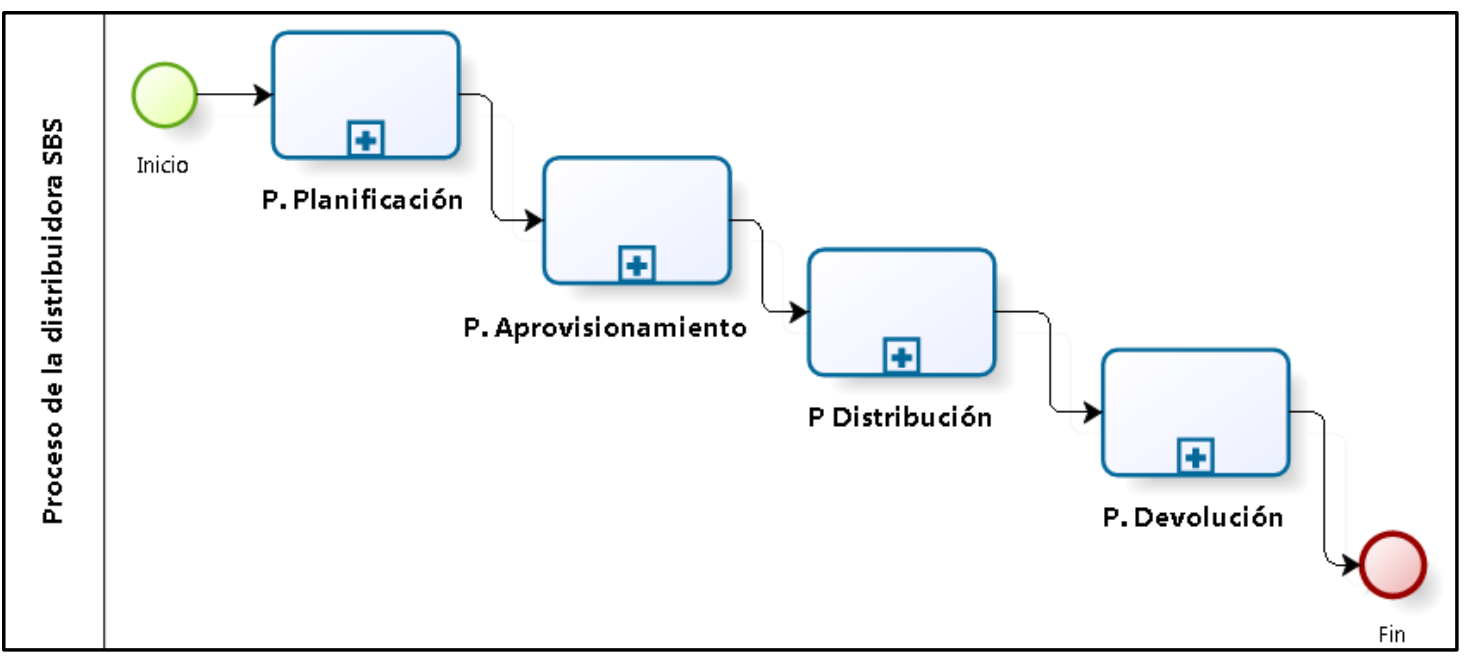

Fuente: Elaboración propia

En esta figura se pude apreciar la secuencia en la que se ejecutan los procesos en la distribuidora SBS; primero se lleva a cabo el proceso de planificación, seguido del proceso de aprovisionamiento, luego el de distribución y por último el proceso de devolución.

\section{Proceso de Planificación (ver figura 19)}

El proceso de planificación en la cadena de suministro de la distribuidora SBS comienza con la manifestación del cliente por la adquisición de libros, esto ocurre después del proceso clave de tipo comercial “captación de clientes" visto en el mapa de procesos anterior, luego de ocurren las actividades relacionadas a la emisión y aprobación de la cotización. Seguidamente, el cliente formaliza la aceptación de la cotización con una orden de compra, un contrato o un pedido formal. Esta información es recibida por los representantes de ventas (área comercial) quienes ingresan al sistema la información de títulos y cantidades. A partir de este ingreso toma codificación y número correlativo para el respectivo seguimiento. Ejemplo: NP - 00001. De 
este primer registro en el sistema se puede definir que la NP (pedido de importación) es la célula o base del proceso actual de distribución en SBS.

Figura 19: Proceso de planificación

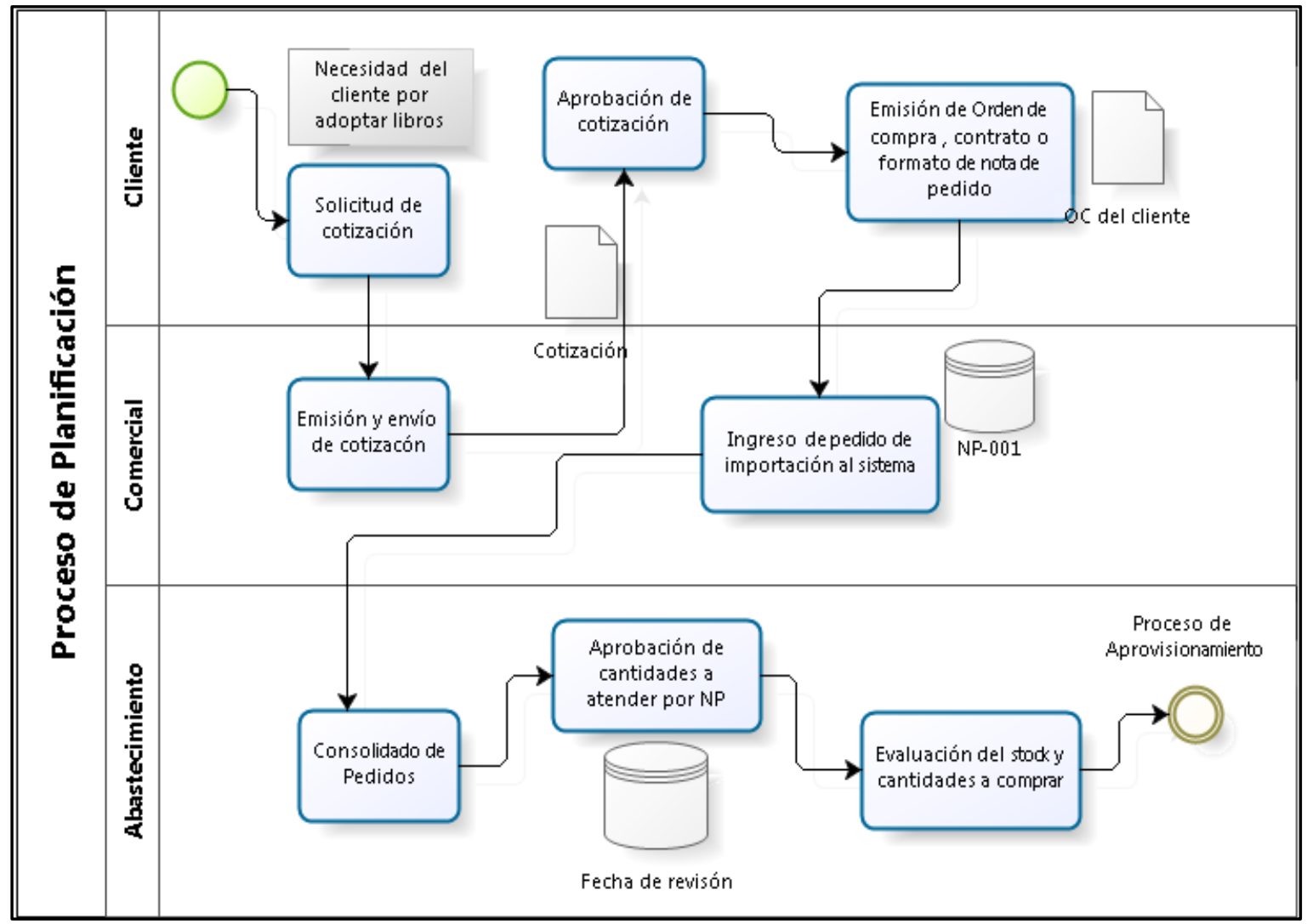

Fuente: Elaboración propia

La encargada de evaluar los pedidos ingresados al sistema, procesarlos y emitir las órdenes de compra a los distintos proveedores; para esta evaluación se dispone de fechas establecidas, que reciben el nombre de fecha de revisión, en la cual se realiza un corte y son evaluados todos los pedidos ingresados hasta la fecha (consolidado de pedidos). Seguidamente se aprueban las cantidades a atender para cada NP (planificación de la demanda). La evaluación de las cantidades a comprar se realiza considerando el stock que existe en el almacén principal de Lima y en las demás sucursales, de este stock se descuentan los pedidos que están próximos a atender 
y se manda a importar la diferencia. Por ejemplo: si la suma total de los pedidos a nivel nacional del título "A" es 200 unidades, en el stock tenemos 100; pero de estos cien, 30 ya han sido considerados en la anterior evaluación, solo se requiere a importar 130 unidades y se completa el pedido con los 70 libros disponibles del stock. Del ejemplo anterior, se observa que el stock disponible, en la mayoría de los casos, se encuentra distribuido en todas las filiales al interior del país y no se evidencia que área es la responsable de gestionar los traslados al CD (centro de distribución) principal.

\section{Proceso de Aprovisionamiento (ver figura 20)}

El proceso de aprovisionamiento es el que se da inmediatamente después del proceso de planificación. Una vez identificadas las cantidades de los productos a comprar se realizan actividades coordinadas con los proveedores de las distintas editoriales.

Las órdenes de compra con destino a los proveedores se generan asociando la información de la fecha de revisión, esta fecha es única por día y de ésta pueden generarse varias OC, cada una para distintos proveedores; además, antes de ser enviadas a los proveedores, las OC son remitidas a la gerencia de Supply Chain para su revisión y autorización; en esta fase, las cantidades a solicitar en la OC pueden ser reducidas por diferentes factores: presupuesto, nuevo análisis de demanda, etc. Con esta reducción de las cantidades solicitadas se observa que no se registra ni se identifica a qué cliente (número de NP) afecta la reducción, se debe recordar que las compras se realizan por volumen, sumando todas las cantidades solicitadas del mismo título por diferentes clientes. 
Figura 20: Proceso de Aprovisionamiento

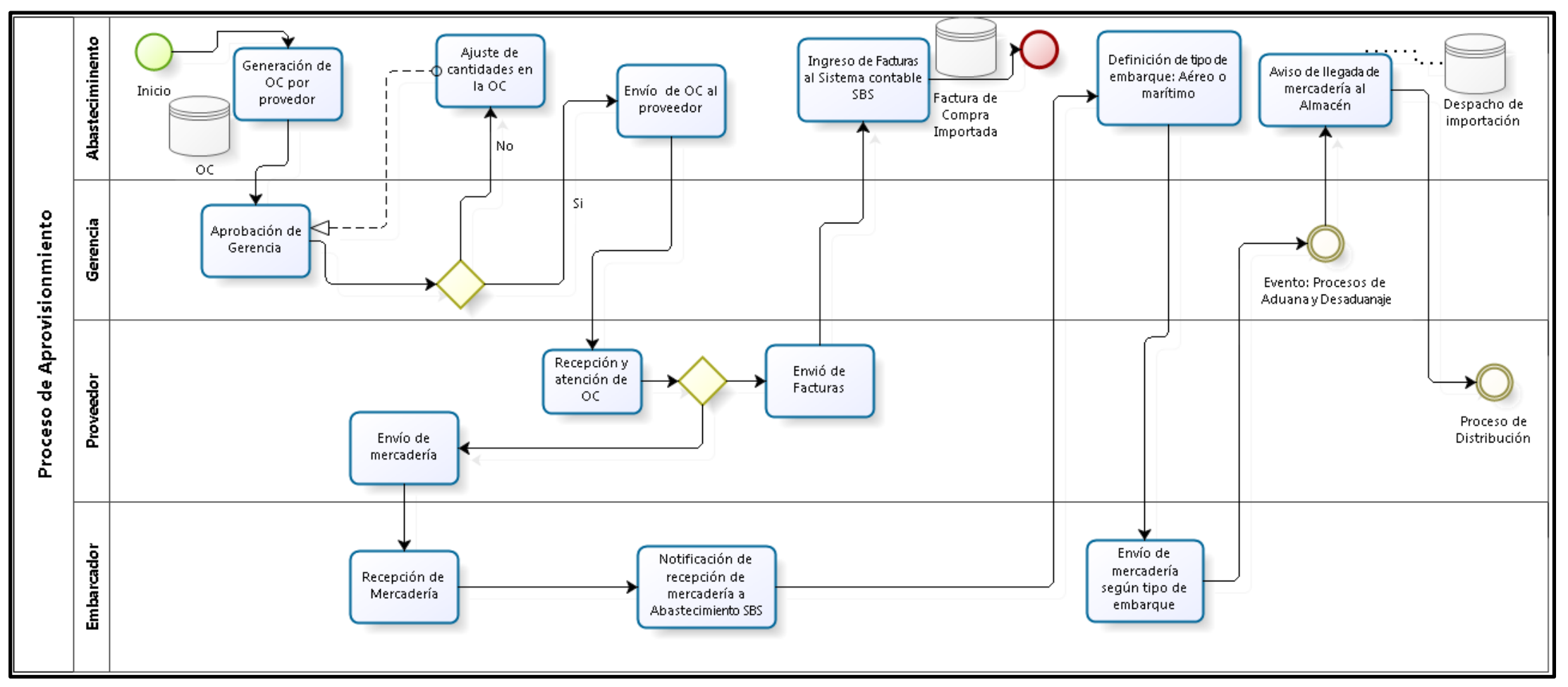

Fuente: Elaboración propia 
Después de recepcionar las órdenes de compra de la distribuidora SBS, los proveedores responden las diferentes solicitudes y envían las facturas respectivas a cada OC al personal de abastecimiento de SBS. Paralelamente, el proveedor envía la mercadería al embarcador, SBS cuenta con cuatro distintos embarcadores en diferentes países ubicados estratégicamente en diferentes países para el consolidado de mercadería. Los embarcadores reciben las instrucciones de SBS para enviar la mercadería vía marítima o aérea. Para finalizar el proceso de aprovisionamiento, el área de abastecimiento informa al centro de distribución (almacén) la programación de la llegada de mercadería que es enumerada y codificada a través de una denominación interna llamada orden de despacho.

\section{Proceso de Distribución (ver figura 21)}

Este proceso se inicia con la recepción de la mercadería, la realización del inventario, el almacenamiento y la actualización de los kardex respectivamente. Este proceso se desarrolla a partir de que los libros llegan al CD embalados en cajas y organizados en paletas, todos estos identificados con el código de llegada del embarque al que se le "denomina número de despacho"; esta compra por volumen tiene que ser procesada por el área de Facturación y Distribución que se encarga de identificar los pedidos y clientes a quienes corresponde la mercadería. Para la identificación de los pedidos, Distribución analiza ítem por ítem el número de OC al proveedor, detallado en el reporte del despacho de importación, luego evidencia la fecha de revisión y comprueba qué números de NP pertenecen a esta fecha; seguido, se emiten los pedidos para lo cual se asocian las NP del cliente respectivo; por último, las cantidades a despachar se deben controlar para evitar los quiebres de stock. Se observa que este procedimiento se realiza manualmente ítem por ítem; actividad compleja si se revisan más de 80 ítems aproximadamente por despacho. 
Figura 21: Proceso de Distribución

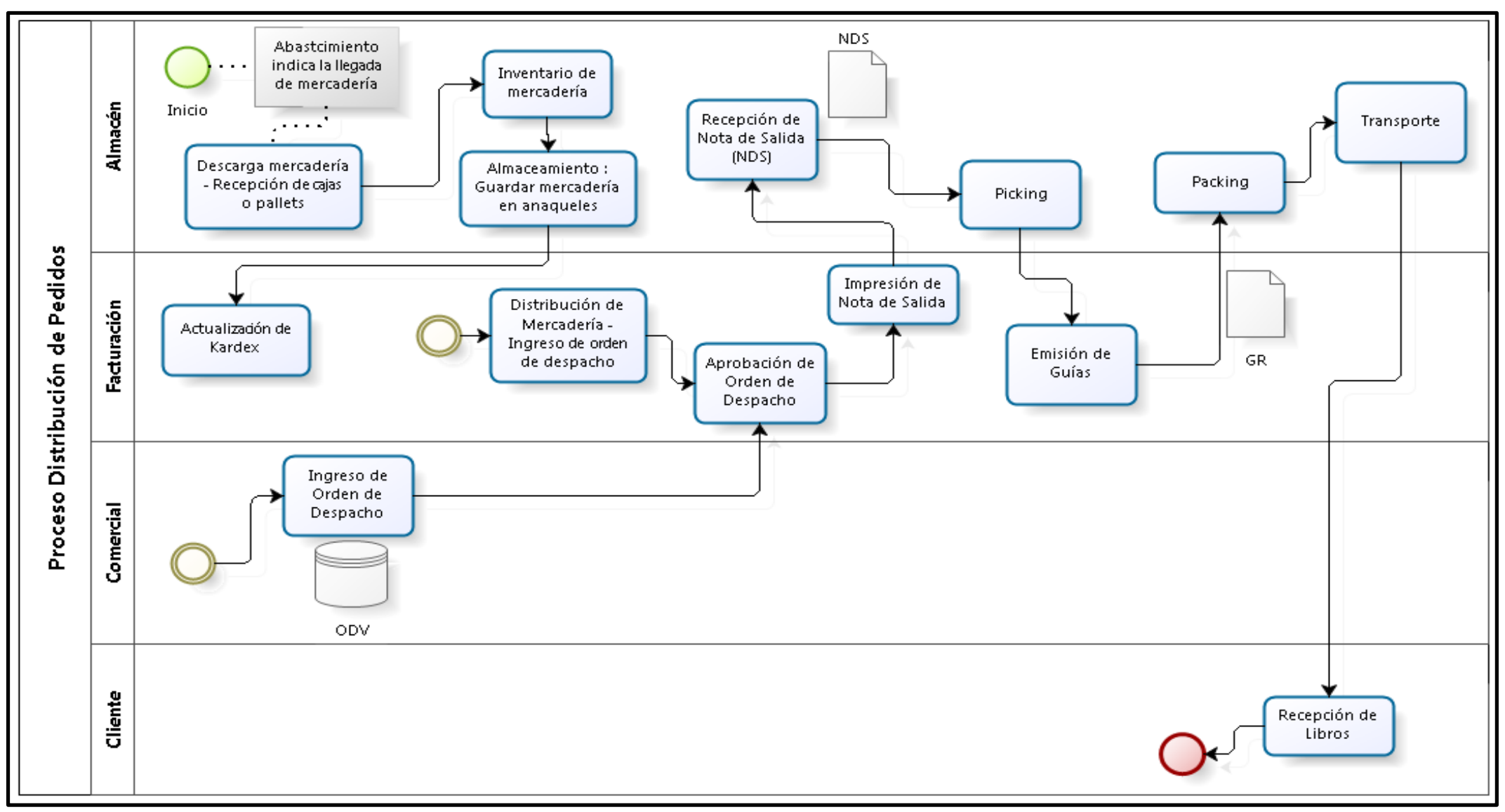

Fuente: Elaboración propia 
Después de identificar los clientes a los cuales corresponden los libros arribados y emitir los pedidos en el sistema de SBS (generación de la ODV), se procede con la aprobación de las órdenes de despacho, se genera la nota de salida (NDS) que es un documento impreso en hoja simple con el objetivo de la realización del picking por parte del personal de almacén, la NDS indica, además, en qué ubicación encontrar el libro solicitado, por último, se realiza la guía de remisión una vez dada la conformidad en la NDS, la guía de remisión es el documento final que da soporte a la realización del packing, el transporte y la entrega al cliente.

\section{Proceso de Devolución (ver figura 22)}

El último proceso a considerar en la cadena de Suministro de SBS y el más informal para la empresa es el proceso de Devolución de mercadería por parte del cliente. Este proceso inicia cuando cliente manifiesta la necesidad de devolver mercadería, en algunos casos por motivo de las presiones de cobranzas, en otros por iniciativa propia. El cliente tiene diferentes canales de comunicar la devolución, la cual es recibida sin ninguna restricción. El proceso finaliza con la actualización de los kardex y los estados de cuenta del cliente. (Ver figura 22) 
Figura 22: Proceso de devolución

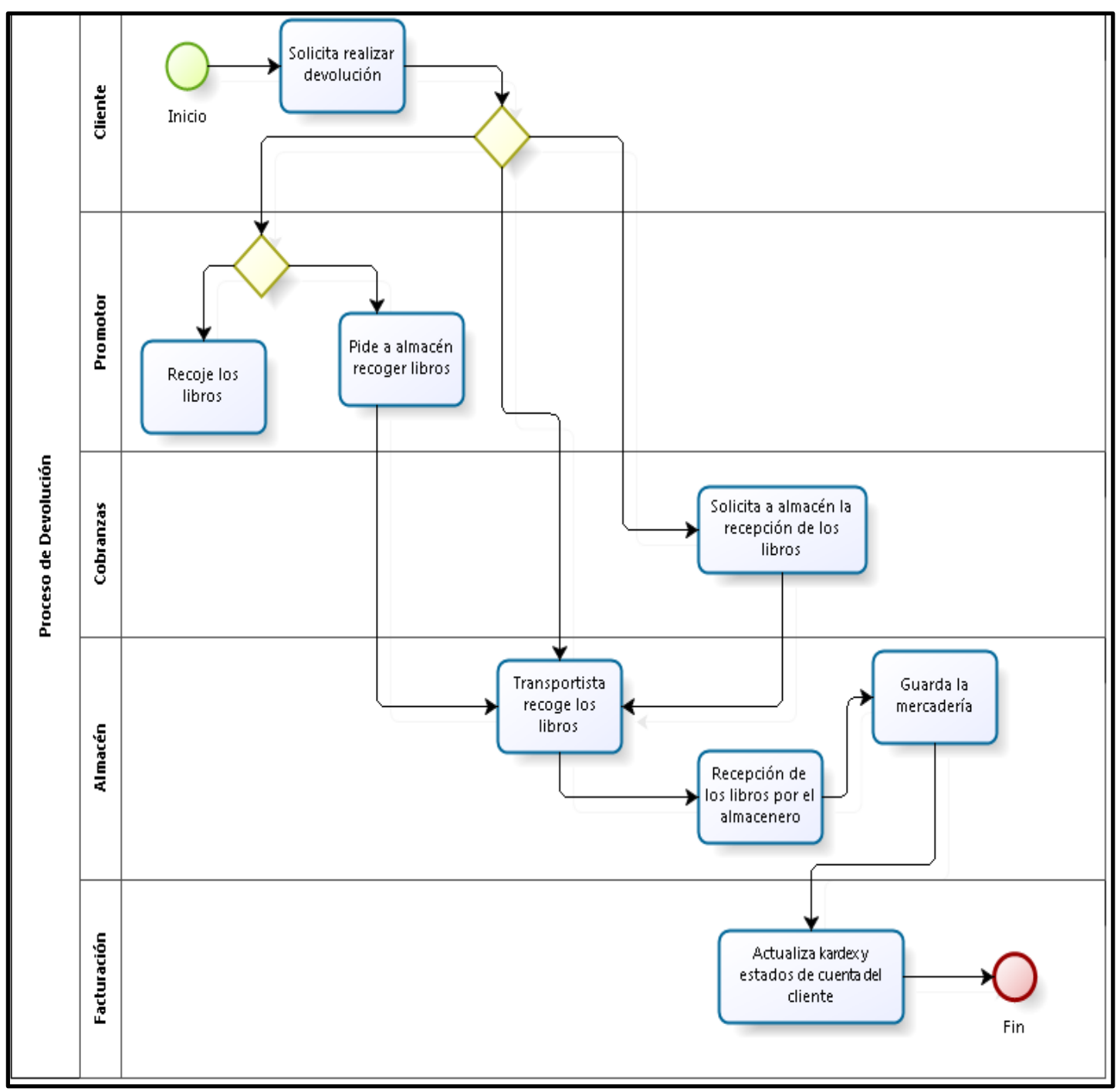

Fuente: Elaboración propia 


\section{Identificación de la problemática}

En la elaboración del presupuesto para el año 2016, las gerencias observaron que los desembolsos para el pago del personal de almacén durante el 2015 fueron mayor a lo presupuestado para ese año, observaron además que no se contrató personal adicional a lo presupuestado, de esto se desprende que el personal de almacén está realizando horas extras (overtime) ya que la empresa cuenta con políticas abiertas al pago de estas. El comportamiento de estos desembolsos se muestra en los siguientes gráficos:

Gráfico 10: Costo de Mano de Obra - Almacén 2015

\section{Costo S/. Mano de Obra Total - Almacén 2015}

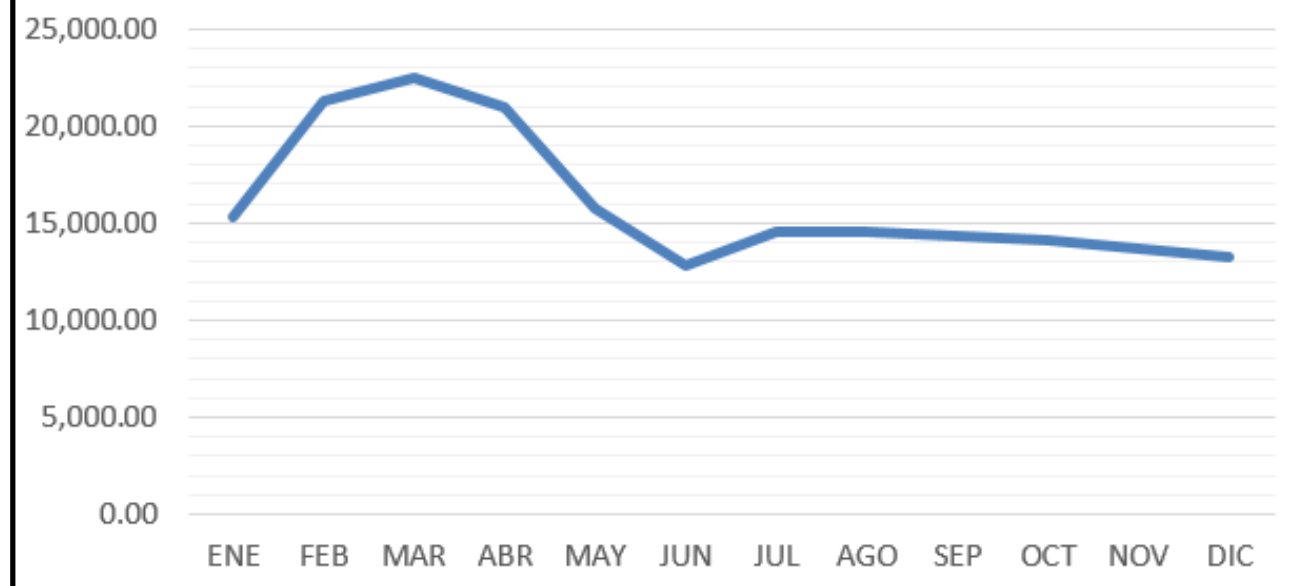

Fuente: Datos de la empresa (Elaboración propia)

En el gráfico 10 se observa el comportamiento oscilatorio mes a mes del costo de la mano de obra para el almacén durante el año 2015, el mismo que muestra picos elevados superiores a 20 mil soles en los primeros meses del año, en época de campaña escolar, luego el costo disminuye 
por debajo de los 15 mil soles en los últimos meses del año. Los valores mostrados incluyen los costos del tiempo base de mano de obra y el tiempo extra (overtime) realizado en cada mes.

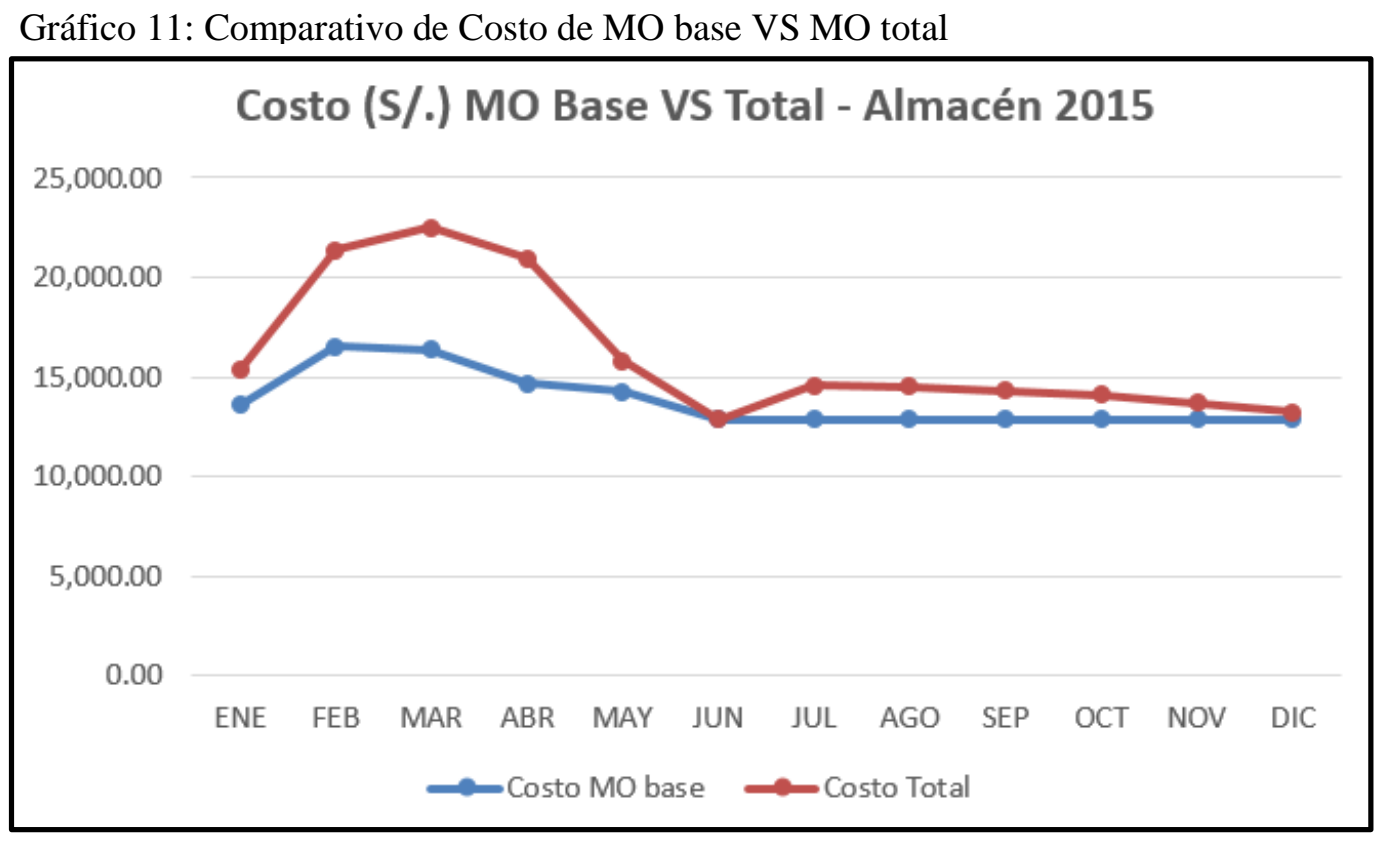

Fuente: Datos de la empresa (Elaboración propia)

El gráfico 11 muestra la comparación mes a mes del costo por MO del personal de almacén que debió realizarse según lo planificado y contemplado por la empresa; es decir el costo base (línea de color azul) es lo calculado con 8 horas diarias trabajando seis días a la semana y el costo total de la MO (línea color rojo) que es lo que realmente registraron los trabajadores de almacén. La distancia que separa cada punto de ellos es el trabajo extra que se reconoció en el periodo.

En la siguiente gráfica (ver gráfico 12) se muestra los costos de mano de obra de almacén desglosando lo costos planificados (color azul) y el overtime (color rojo), además se observa que en el mes de junio y diciembre son lo que menos overtime presentaron; sucede lo contrario con los meses febrero, marzo y abril que son meses donde el overtime se manifestó con mayor incidencia. 
Gráfico 12 · Gráfica anilada de Costo de MO Almacén 2015

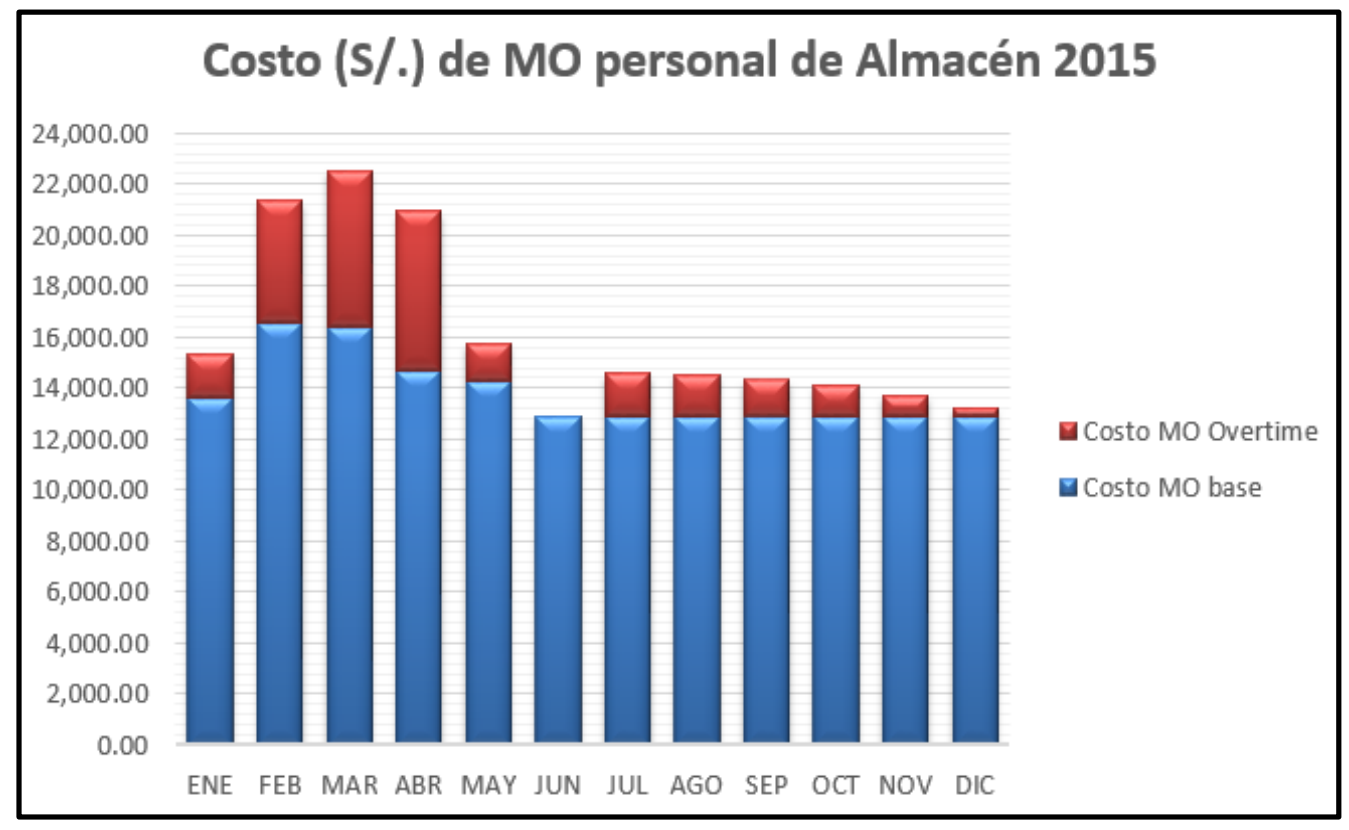

Fuente: Datos de la empresa (Elaboración propia)

Seguidamente, se muestra el gráfico 13 para brindar mayor detalle de los costos generados por el overtime.

Gráfico 13: Costo MO Overtime - Almacén 2015

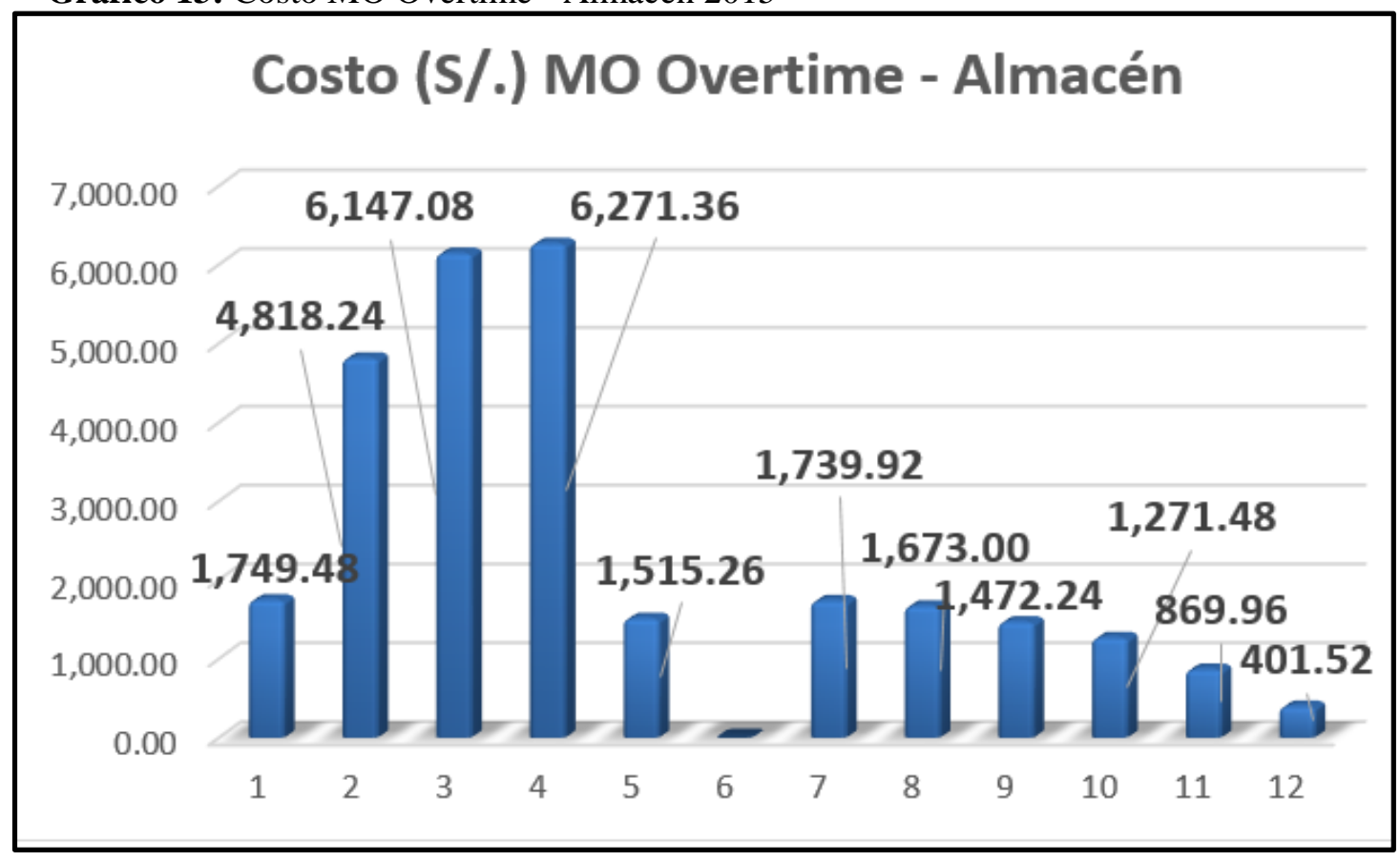

Fuente: Datos de la empresa (Elaboración propia) 
En el gráfico 13 se muestra a detalle el monto del costo del overtime de MO, siendo los mayores valores registrados en los meses de febrero a abril con valores superiores a los 4 mil soles. También se observa que el mínimo desembolso por overtime, sin incluir el mes de junio, es de 400 soles aproximados, valor que no es significativo pero si importante.

Por último, se proyecta la información del comparativo de los valores totales de los costos de mano de obra en el almacén con el fin observar y cuantificar el impacto anual del sobretiempo realizado por el área. (Ver gráfico 14)

Gráfico 14: Costo S/. MO Almacén 2015 - Consolidado

\section{Costo (S/) de Mano de obra Almacén 2015}

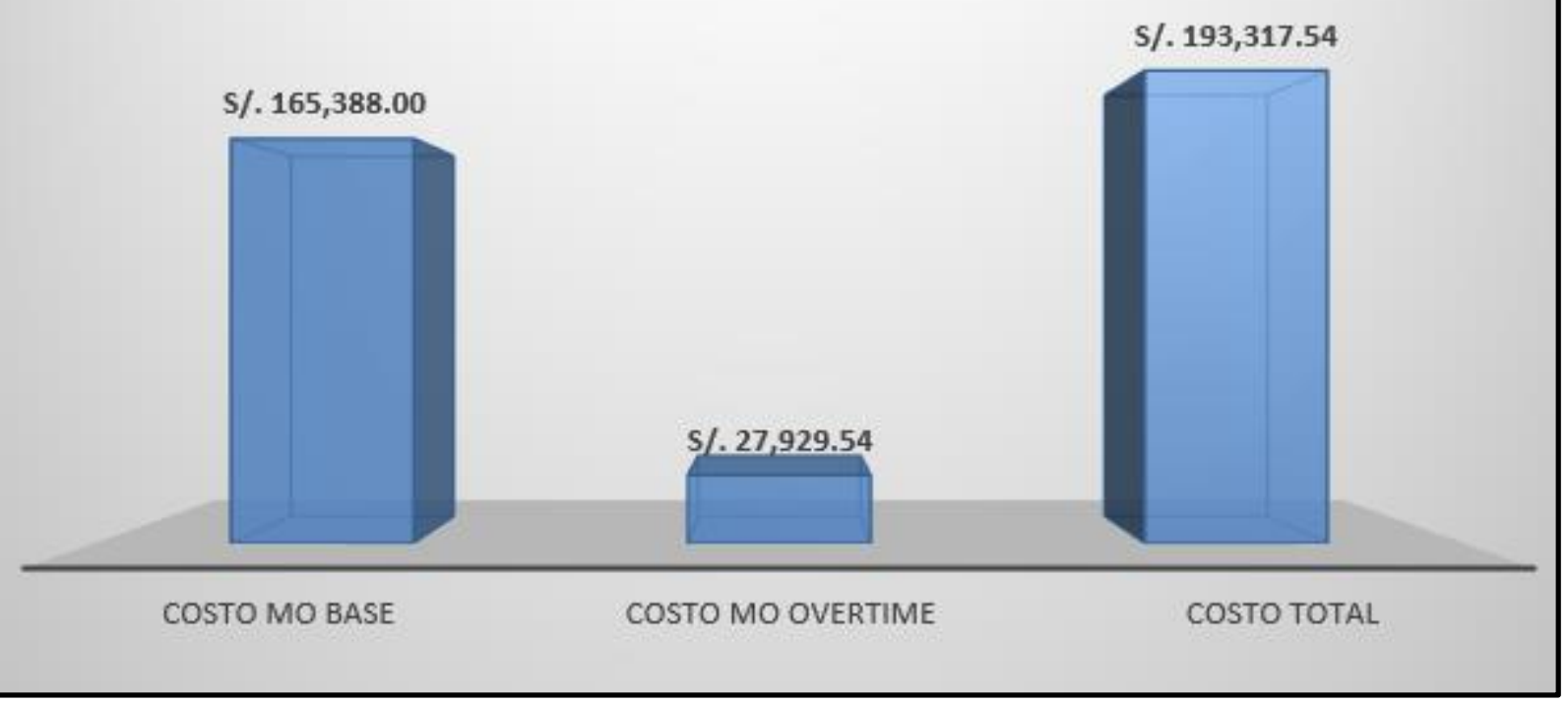

Fuente: Datos de la empresa (Elaboración propia) 
Con un valor anual de S/ 27'929.54 el gráfico 14 revela que el overtime del año 2015 representa casi el 15\% del costo total de mano de obra por parte del área de almacén y que es de vital importancia lograr su optimización. En base a ello, se ha solicitado mayor información al área de almacén y otras ligadas a la información con el fin de discernir los motivos del por qué el personal se queda laborando por encima de lo establecido.

La respuesta de la empresa, tanto de almacén, operaciones y TI fue que no se tienen información de fallas del proceso, incidencias y frecuencias de variables y/o factores que afecten la productividad de los procesos y generen el overtime; es decir la empresa viene trabajando sin una cultura de registro y medición del desempeño de sus actividades, lo que dificulta la toma de decisión sobre qué acciones tomar para la mejora de la situación.

Según se ha mencionado en los párrafos anteriores, al no contar con información de todos los procesos a lo largo de la cadena, se ha consolidado información de la productividad y su variabilidad de los tres principales procesos de Distribución de la cadena de suministro: Recepción e Inventario, Picking y Packing para la ilustración de la problemática; la observación de estos tres procesos resultan de la trascendencia de los procesos que interactúan con el flujo físico de mercadería. De modo que se recopiló de manera extraordinaria las cantidades procesadas durante el año 2015 para luego cruzar esta información con la cantidad de trabajadores que se dedicaron a cada proceso durante el periodo de tiempo respectivo.

Los resultados fueron: 
Gráfico 15: Productividad del nroceso de Recención e inventario

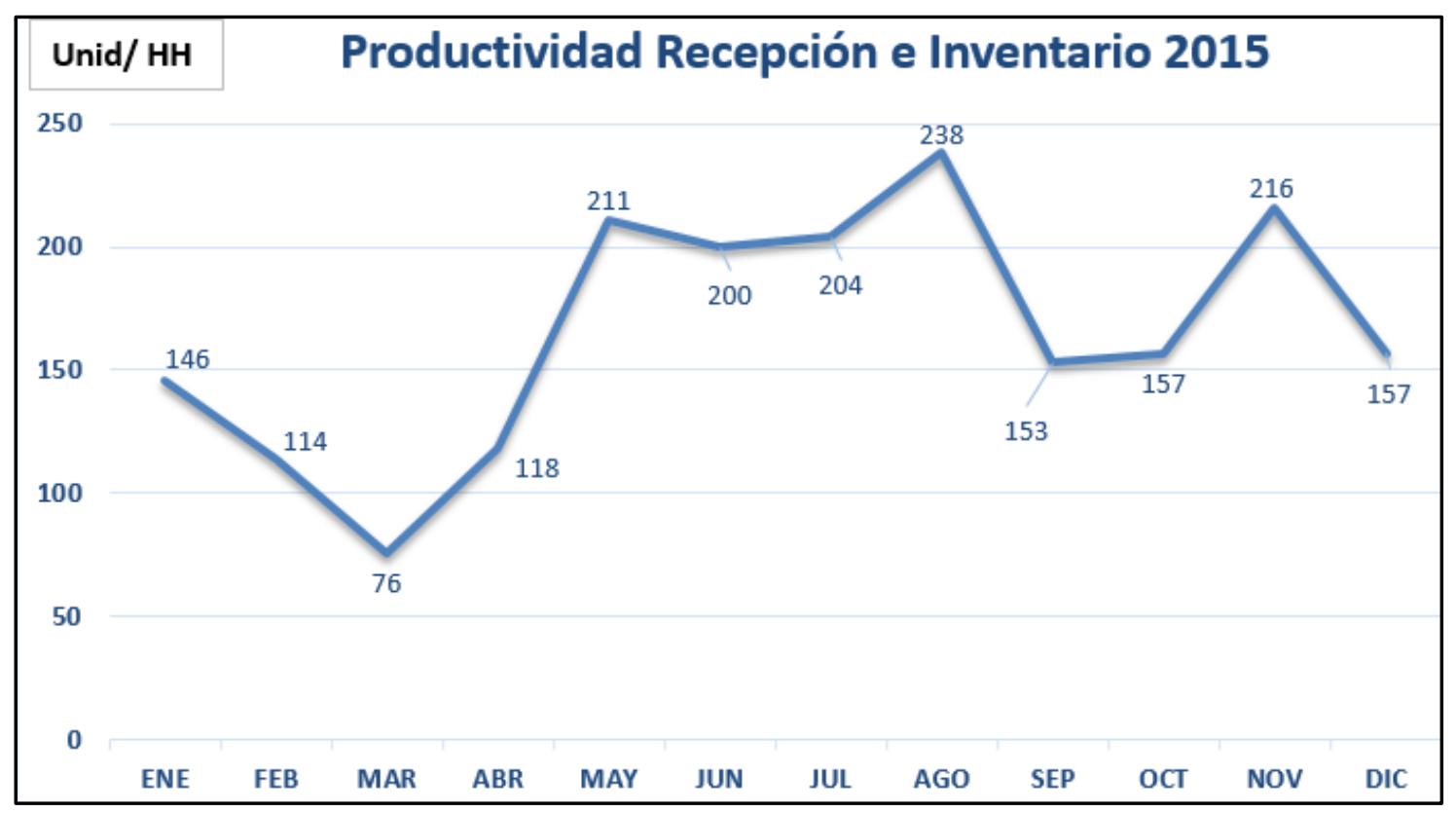

Fuente: Elaboración propia

En la observación del primer proceso de Recepción e Inventario se identificaron bajas de productividad en los cuatro primeros meses del año; en otras palabras la productividad del recurso humano fue mayor a 150 unidades/hora hombre $(\mathrm{HH})$ a partir de mayo hasta diciembre del 2015, mientras que en los meses de enero, febrero, marzo y abril la productividad fue menor de 150 unid/HH identificándose un disminución máxima en el mes de marzo con solo 76 unid/HH. Por otro lado, se observa que en el mes de agosto el promedio de unidades inventariadas alcanzó la máxima productividad de 238 unidades por cada hora hombre asignada: esto evidencia que el proceso de recepción e inventarió varió en 162 unid/HH al comparar la productividad de sus meses extremos. 
Gráfico 16: Productividad del proceso de Picking

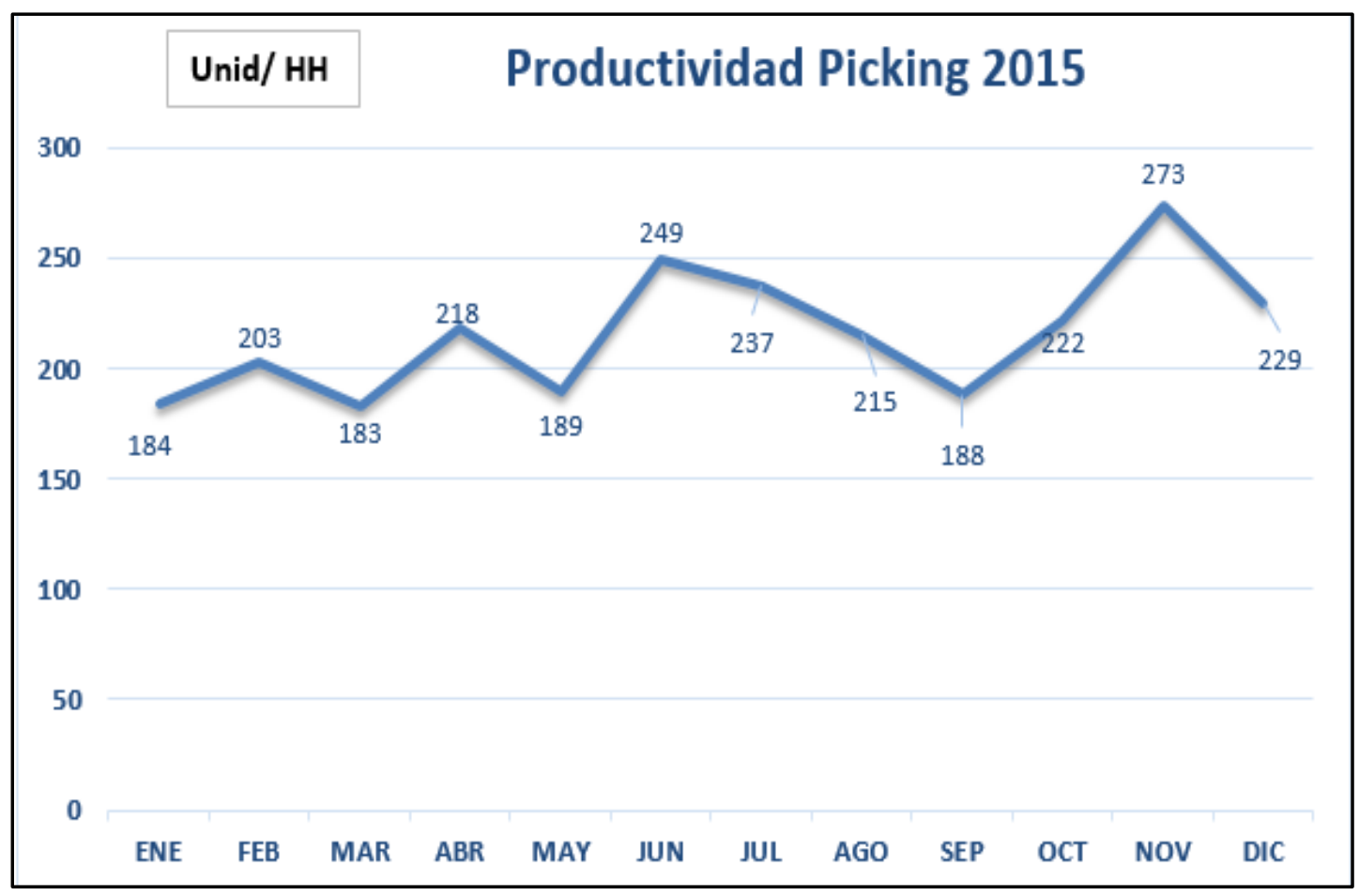

Fuente: Elaboración propia

El gráfico 16 muestra los resultados de la observación del proceso de Picking, el cual evidencia una productividad mínima en el mes de marzo con 183 unid/HH, luego ésta haciende durante los siguientes meses obteniendo el pico de productividad más alto en el mes de noviembre con un alcance de 273 unid/HH para después descender al siguiente mes. Este proceso obtiene una de diferencia de 90 unid/HH entre los meses extremos de su productividad.

Por último se muestra el gráfico del proceso de Packing: 
Gráfico 17: Productividad del proceso de Packing

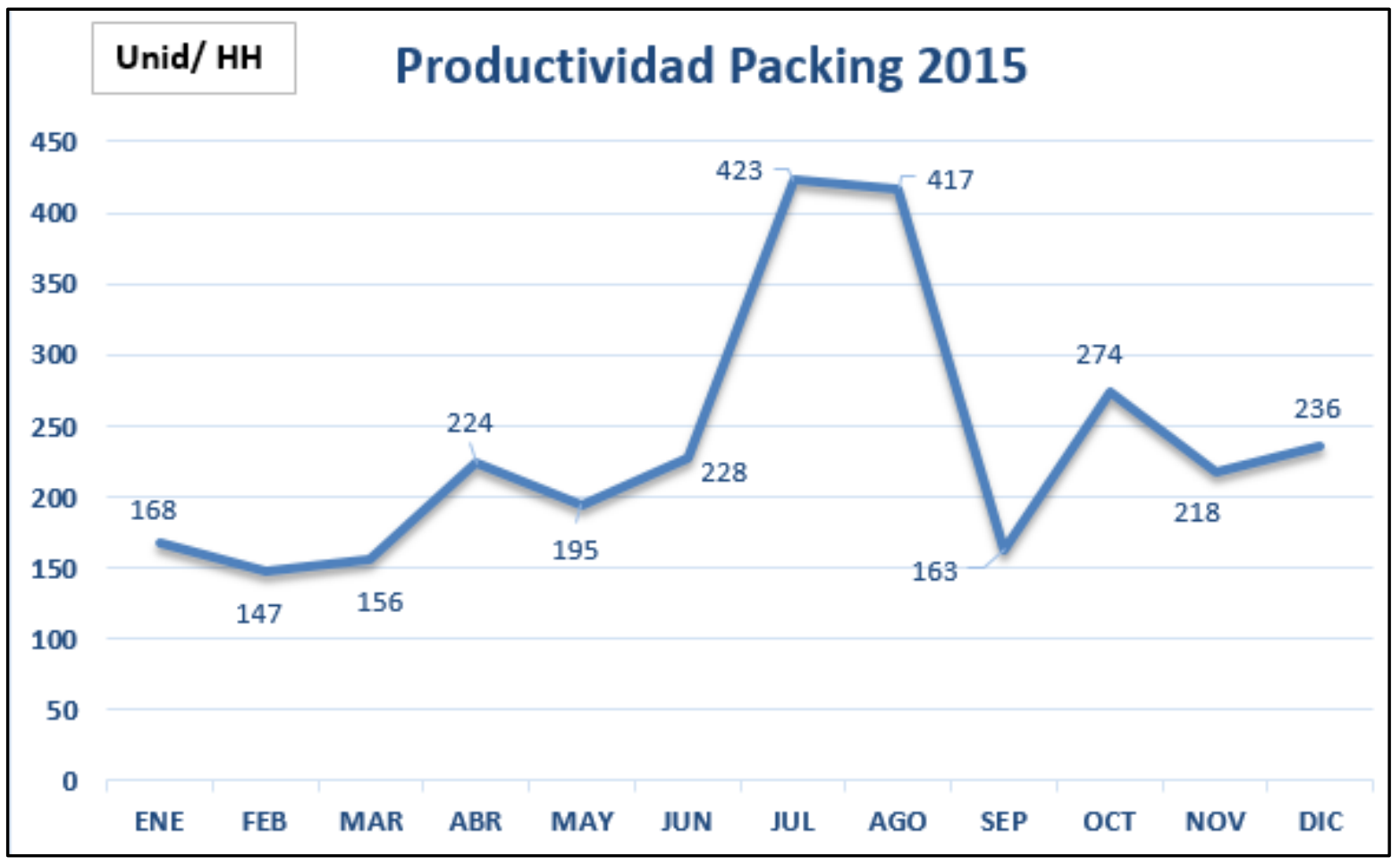

Fuente: Elaboración propia

En el gráfico 17 se evidencia que el proceso de packing obtuvo mayor productividad en los meses de julio y agosto alcanzando hasta 423 unid/HH en su pico más alto. También se identifica que en el mes de febrero la productividad por hora hombre fue la más baja con solo 147 unidades. La diferencia de los valores extremos de productividad ascendió en este proceso a 276 unid/HH.

¿Por qué si el proceso de recepción puede procesar hasta 238 unidades por cada hora hombre no logra su ideal desempeño en los otros meses?, ¿Qué está pasando en el desarrollo del proceso de picking durante los meses de enero hasta mayo que solo se procesan unidades por debajo de 218 por cada hora hombre? ¿Por qué si en el mes de Agosto, el proceso de packing logró una capacidad de 423 unid/HH no se obtuvo el mismo resultado en los meses de febrero y marzo? 
Identificar qué variables, factores o elementos influyen en el desempeño de los procesos logísticos de SBS será el objetivo de los siguientes capítulos.

\section{Análisis de Causa raíz}

Es preciso indicar que la empresa carece de información relevante al desempeño de sus procesos, no hay estándares definidos, no hay registros de problemas, fallas o reprocesos los cuales se relacionen con la baja productividad. Con el fin de realizar un estudio el cual muestre resultados de procesos estandarizados y que esté a su vez, sirva de base para propuestas de mejora a los procesos de la empresa, se ha procedido al levantamiento de información. En una primera etapa el levantamiento de información se realizó con el mapeo de los procesos presentados en los puntos anteriores: Mapa de procesos y Descripción de los procesos. Seguidamente, la segunda etapa del levantamiento de información se desarrolló presentando la información del costo de overtime y de la productividad de los procesos. En lo que resta del capítulo se direccionará la investigación hacia la identificación de causas raíces relacionadas a la baja productividad en la empresa, esto en base a un análisis cualitativo.

Con el conocimiento de las herramientas de calidad estudiadas en el capítulo 1, se ha seleccionado un de grupo de ellas que se aplicarán de forma sistemática para el análisis de los principales problemas de improductividad y sus causas. Según lo anterior, se muestra en la figura 23: 
Figura 23: Aplicación sistemática de Herramientas de Calidad en el estudio de la productividad de SBS

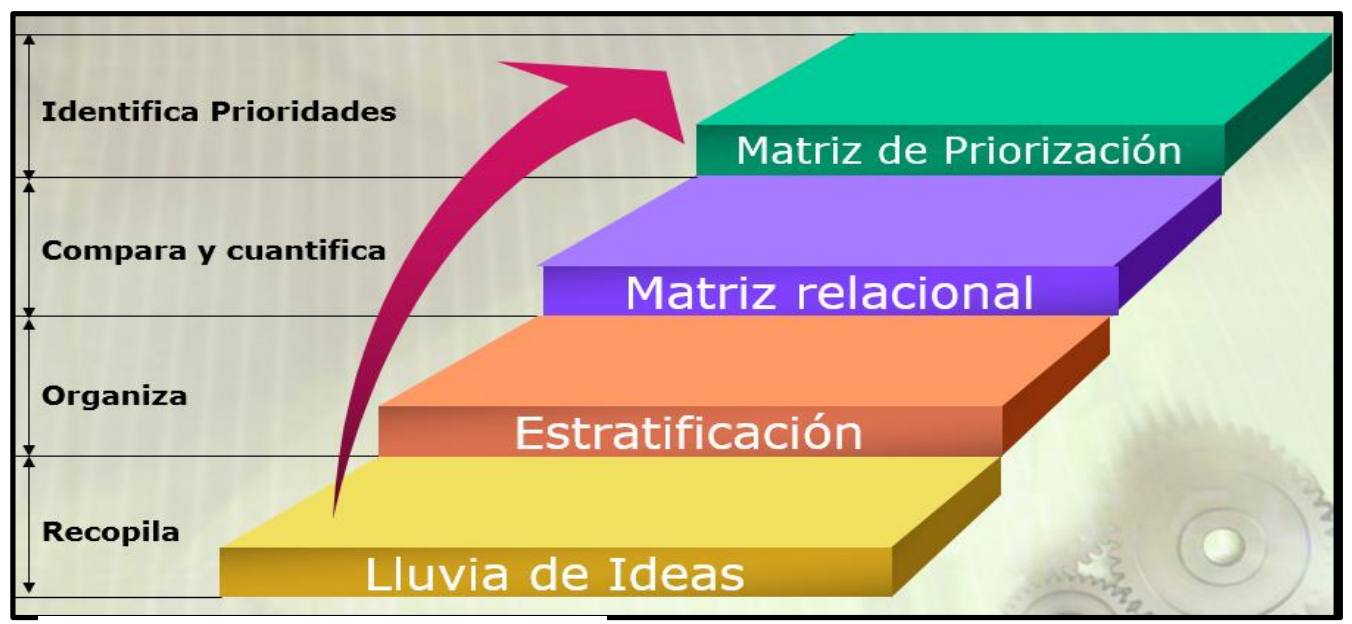

Fuente: Elaboración propia

En tal sentido y con el fin de identificar las principales manifestaciones de improductividad que se presentan durante todo el proceso logístico de la empresa, se ha realizado el seguimiento a toda área involucrada solicitando a cada operario que exprese en forma individual y/o grupal los principales problemas relacionados con la productividad que perciben en el desarrollo de sus labores.

Previamente, se ha explicado a cada aportador del estudio los conceptos y definiciones planteados en el capítulo 1 del presente proyecto como son productividad, valor añadido y los tipos de despilfarros que plantea el Lean por ejemplo: sobreproducción, esperas, transporte, sobreproceso, inventarios, movimientos y retrabajo por defectos en la calidad; todas estas definiciones se han adaptado al entorno logístico. Se ha recolectado toda la información sin importar la jerarquía del colaborador en quién cae la responsabilidad y/o la importancia de la idea. (Ver anexo 2) 
La información en el anexo 2 muestra las posibles causas de improductividad en las actividades logísticas dentro de la empresa. Son un total de 85 potenciales causas de improductividad, las cuales han sido codificados según el orden de registro para el presente estudio. Esta codificación permitirá la utilización y organización más dinámica de la información.

Luego de recopilar la información en el anexo 2, se procedió a organizar la información para un mejor análisis empleando dos métodos de estratificación: El primero se basa en el modelo convencional de las $6 \mathrm{M}$ de la calidad y el segundo considera la estratificación por el tipo u origen del problema, que para este caso han sido propuestos tres objetos de estudios los cuales son parte del análisis de todo proceso: Gestión, Proceso y Operación.

En la realización del modelo de las $6 \mathrm{M}$ se han identificado a qué categoría está asociada cada una de las ideas brindadas por los colaboradores. Así se obtiene su representación a través del diagrama de espina de pescado mostrada en la figura 24 que organiza y clasifica las ideas en medición, material, mano de obra, medio ambiente y/o máquina.

La figura 24 muestra el detalle del diagrama de Causa - Efecto, el cual tiene como efecto principal la baja productividad de las actividades logísticas de SBS y clasifica en seis categorías los problemas planteados, al mismo tiempo este diagrama permite, de manera visual, una mejor interpretación de la situación actual. Como resultado se observa que la categoría principal es "Método" debido a que está constituido por 29 ideas, siendo ésta la que registra el número mayor de registros. Seguido, se encuentra la categoría "Medición" con 18 y, "Medio ambiente" y "Mano de obra" como categorías medias con 17 y 15 incidencias. Las categorías que están constituidas por menos problemas son "Material" y "Máquina" con apenas 5 y 1 respectivamente. Seguidamente, se muestra el detalle de cada segmento. 
Figura 24: Diagrama de Ishikawa para el análisis 6M de Calidad

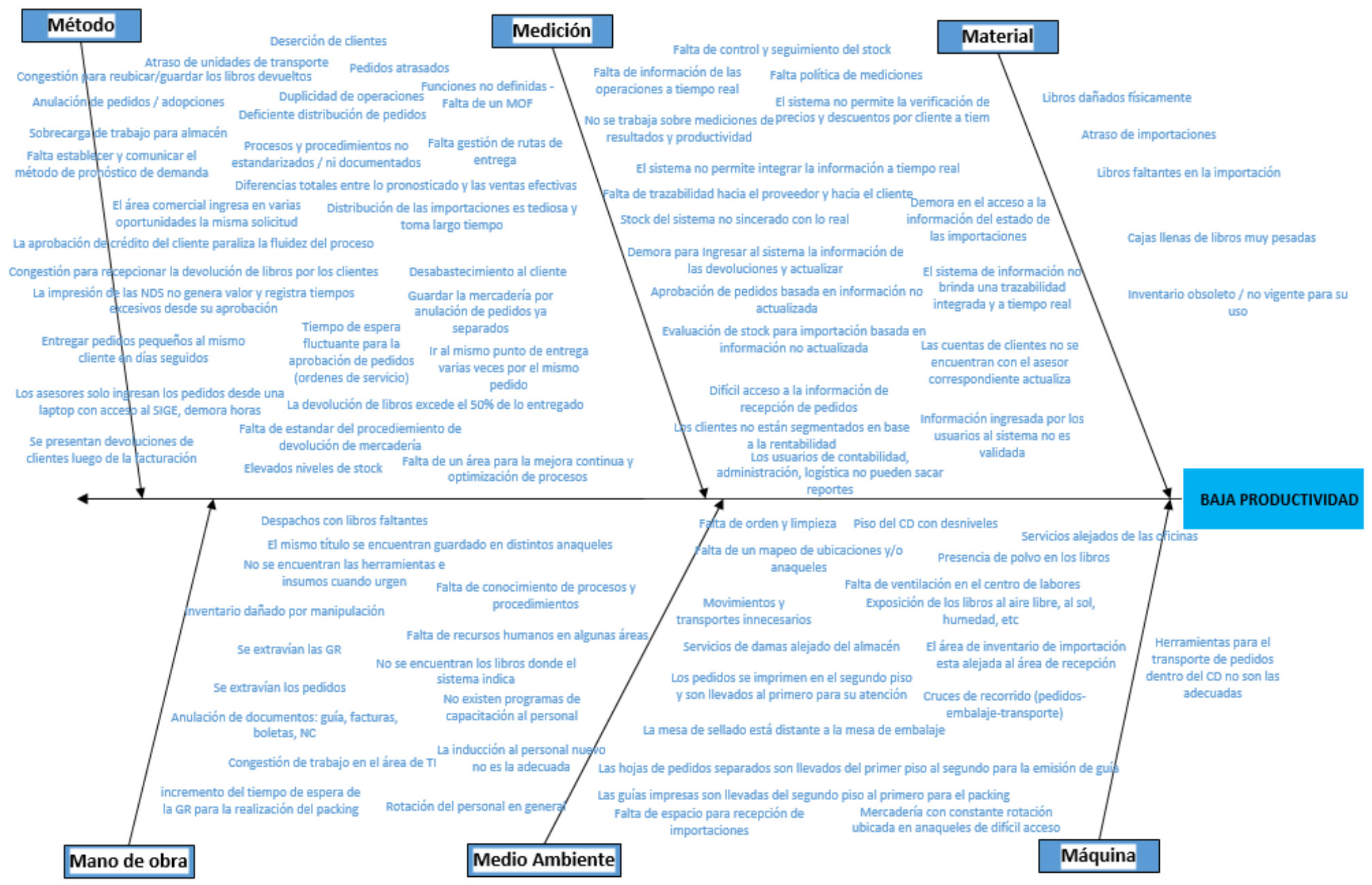

Fuente: Elaboración propia 
Cuadro 8: Causas de improductividad relacionadas al "Método"

\begin{tabular}{||l|l||}
\hline Cod & \multicolumn{1}{|c|}{ Causas que afectan la productividad - "Método" } \\
\hline P02 & Pedidos atrasados \\
\hline P03 & Atraso de unidades de transporte \\
\hline P07 & Anulación de pedidos / adopciones \\
\hline P08 & Deserción de clientes \\
\hline P09 & Sobrecarga de trabajo para almacén \\
\hline P22 & Procesos y procedimientos no estandarizados / ni documentados \\
\hline P24 & Duplicidad de operaciones \\
\hline P29 & Deficiente distribución de pedidos \\
\hline P31 & Falta establecer y comunicar el método de pronóstico de demanda \\
\hline P32 & Diferencias totales entre lo pronosticado y las ventas efectivas \\
\hline P35 & Distribución de las importaciones es tediosa y toma largo tiempo \\
\hline P38 & La impresión de las NDS no genera valor y registra tiempos excesivos desde su aprobación \\
\hline P39 & E1 área comercial ingresa en varias oportunidades la misma solicitud \\
\hline P40 & La aprobación de crédito del cliente paraliza la fluidez del proceso \\
\hline P47 & Congestión para recepcionar la devolución de libros por los clientes \\
\hline P48 & Congestión para reubicar/guardar los libros devueltos \\
\hline P52 & Guardar la mercaderia por anulación de pedidos ya separados \\
\hline P54 & Falta gestión de rutas de entrega \\
\hline P55 & Ir al mismo punto de entrega varias veces por el mismo pedido \\
\hline P56 & Entregar pedidos pequeños al mismo cliente en dias seguidos \\
\hline P58 & Tiempo de espera fluctuante para la aprobación de pedidos (ordenes de servicio) \\
\hline P59 & Los asesores solo ingresan los pedidos desde una laptop con acceso al SIGE, demora horas \\
\hline P67 & Desabastecimiento al cliente \\
\hline P70 & Se presentan devoluciones de clientes luego de la facturación \\
\hline P71 & La devolución de libros excede el 50\% de lo entregado \\
\hline P72 & Falta de estandar del procediemiento de devolución de mercaderia \\
\hline P74 & Falta de un área para la mejora continua y optimización de procesos \\
\hline P50 & Funciones no definidas - Falta de un MOF \\
\hline P55 & Elevados niveles de stock \\
\hline
\end{tabular}

Fuente: Elaboración propia 


\section{Cuadro 9: Causas de improductividad relacionadas a "Medición"}

\begin{tabular}{||l|l||}
\hline Cod & \multicolumn{1}{|c|}{ Causas que afectan la productividad - "Medición" } \\
\hline P10 & Falta de información de las operaciones a tiempo real \\
\hline P25 & No se trabaja sobre mediciones de resultados y productividad \\
\hline P33 & Falta de control y seguimiento del stock \\
\hline P34 & Stock del sistema no sincerado con lo real \\
\hline P36 & Falta de trazabilidad hacia el proveedor y hacia el cliente \\
\hline P37 & E1 sistema no permite integrar la información a tiempo real \\
\hline P41 & E1 sistema no permite la verificación de precios y descuentos por cliente a tiempo real \\
\hline P49 & Demora para Ingresar al sistema la información de las devoluciones y actualizar el kardex \\
\hline P50 & Aprobación de pedidos basada en información no actualizada \\
\hline P51 & Evaluación de stock para importación basada en información no actualizada \\
\hline P53 & Falta política de mediciones \\
\hline P60 & Demora en el acceso a la información del estado de las importaciones \\
\hline P61 & Dificil acceso a la información de recepción de pedidos \\
\hline P65 & E1 sistema de información no brinda una trazabilidad integrada y a tiempo real \\
\hline P66 & Los clientes no están segmentados en base a la rentabilidad \\
\hline P68 & Las cuentas de clientes no se encuentran con el asesor correspondiente actualizado en el sistema \\
\hline P77 & Los usuarios de contabilidad, administración, logística no pueden sacar reportes \\
\hline P81 & Información ingresada por los usuarios al sistema no es validada \\
\hline
\end{tabular}

Fuente: Elaboración propia

\section{Cuadro 10: Causas de improductividad relacionadas a "Medio Ambiente"}

\begin{tabular}{|l|l||}
\hline Cod & \multicolumn{1}{|c|}{ Causas que afectan la productividad - "Medio Ambiente" } \\
\hline P11 & Falta de orden y limpieza \\
\hline P12 & Falta de un mapeo de ubicaciones y/o anaqueles \\
\hline P14 & Falta de ventilación en el centro de labores \\
\hline P15 & Movimientos y transportes innecesarios \\
\hline P16 & Servicios de damas alejado del almacén \\
\hline P17 & Servicios alejados de las oficinas \\
\hline P21 & Piso del CD con desniveles \\
\hline P26 & Presencia de polvo en los libros \\
\hline P27 & Exposición de los libros al aire libre, al sol, humedad, etc \\
\hline P42 & Los pedidos se imprimen en el segundo piso y son llevados al primero para su atención \\
\hline P43 & La mesa de sellado está distante a la mesa de embalaje \\
\hline P44 & Cruces de recorrido (pedidos-embalaje-transporte) \\
\hline P45 & Las hojas de pedidos separados son llevados del primer piso al segundo para la emisión de guía \\
\hline P46 & Las guías impresas son llevadas del segundo piso al primero para el packing \\
\hline P82 & Falta de espacio para recepción de importaciones \\
\hline P83 & E1 área de inventario de importación esta alejada al área de recepción \\
\hline P84 & Mercadería con constante rotación ubicada en anaqueles de dificil acceso \\
\hline
\end{tabular}

Fuente: Elaboración propia 
Cuadro 12: Causas de improductividad relacionadas a "Mano de obra"

\begin{tabular}{|l|l||}
\hline Cod & \multicolumn{1}{|c|}{ Causas que afectan la productividad -"Mano de obra" } \\
\hline P06 & Despachos con libros faltantes \\
\hline P13 & El mismo título se encuentran guardado en distintos anaqueles \\
\hline P18 & No se encuentran las herramientas e insumos cuando urgen \\
\hline P23 & Falta de conocimiento de procesos y procedimientos \\
\hline P30 & Inventario dañado por manipulación \\
\hline P57 & incremento del tiempo de espera de la GR para la realización del packing \\
\hline P62 & Se extravían los pedidos \\
\hline P63 & Se extravían las GR \\
\hline P64 & No se encuentran los libros donde el sistema indica \\
\hline P69 & Anulación de documentos: guía, facturas, boletas, NC \\
\hline P73 & Falta de recursos humanos en algunas áreas \\
\hline P75 & No existen programas de capacitación al personal \\
\hline P76 & La inducción al personal nuevo no es la adecuada \\
\hline P78 & Congestión de trabajo en el área de TI \\
\hline P79 & Rotación del personal en general \\
\hline \hline
\end{tabular}

Fuente: Elaboración propia

Cuadro 11: Causas de improductividad relacionadas a "Material"

\begin{tabular}{||l|l||}
\hline Cod & Causas que afectan la productividad - "Material" \\
\hline P01 & Libros dañados físicamente \\
\hline P04 & Atraso de importaciones \\
\hline P05 & Libros faltantes en la importación \\
\hline P19 & Cajas llenas de libros muy pesadas \\
\hline P28 & Inventario obsoleto / no vigentepara su uso \\
\hline \hline
\end{tabular}

Fuente: Elaboración propia

Cuadro 13: Causas de improductividad relacionadas a "Máquina"

\begin{tabular}{||c|c|}
\hline Cod & Causas que afectan la productividad - "Máquina" \\
\hline P20 & Herramientas para el transporte de pedidos dentro del CD no son las adecuadas \\
\hline
\end{tabular}

Fuente: Elaboración propia 
Para el análisis con el segundo método de estratificación se han considerado las categorías Gestión, Proceso y Operaciones, las mismas han sido seleccionadas según el origen y tipología del problema. Los problemas asignados a la categoría "Gestión" se refieren a una falla en la gestión del proceso Logístico, es decir, en brindar los recursos necesarios para el desarrollo del proceso y controlarlo. Los problemas asignados a la categoría "Proceso" aluden que el proceso se está ejecutando correctamente según lo planificado pero que los resultados no se están consiguiendo. Por último, los problemas asignados a la etiqueta "Operaciones" exponen que el proceso no se está desarrollando según lo planificado, en otras palabras, las fallas se presentan en las operaciones del proceso.

Como resultado de éste análisis se concluyó que la categoría "Proceso" predomina dentro de las tres categorías con una incidencia de 45 registros, seguidamente están las categorías “Operaciones” y "Gestión” con 21y 19 registros respectivamente. De ello se desprende que la principal causa de improductividad en los procesos logísticos de la empresa SBS es por falla del proceso en sí. Así se obtiene que la improductividad en la empresa es percibida por gran parte de los trabajadores en causas relacionadas al desempeño del proceso entre las cuales se pueden mencionar la falta de trazabilidad e información, cruces de recorrido, sobrecarga del trabajo en almacén, los traslados de las guías de un piso a otro, entre otros.

Los siguientes cuadros muestran al detalle las tres categorías y sus problemas asociados: 


\section{Cuadro 14: Causas de Improductividad en Proceso}

\begin{tabular}{|c|c|c|}
\hline Cod & Causas de improductividad & Estrato \\
\hline P04 & Atraso de importaciones & Proceso \\
\hline P09 & Sobrecarga de trabajo para almacén & Proceso \\
\hline P10 & Falta de información de las operaciones a tiempo real & Proceso \\
\hline P12 & Falta de un mapeo de ubicaciones y/o anaqueles & Proceso \\
\hline P15 & Movimientos y transportes innecesarios & Proceso \\
\hline P22 & Procesos y procedimientos no estandarizados / ni documentados & Proceso \\
\hline P23 & Falta de conocimiento de procesos y procedimientos & Proceso \\
\hline P24 & Duplicidad de operaciones & Proceso \\
\hline P28 & Inventario obsoleto / no vigentepara su uso & Proceso \\
\hline P29 & Deficiente distribución de pedidos & Proceso \\
\hline P31 & Falta establecer y comunicar el método de pronóstico de demanda & Proceso \\
\hline P32 & Diferencias totales entre lo pronosticado y las ventas efectivas & Proceso \\
\hline P34 & Stock del sistema no sincerado con lo real & Proceso \\
\hline P35 & Distribución de las importaciones es tediosa y toma largo tiempo & Proceso \\
\hline P36 & Falta de trazabilidad hacia el proveedor y hacia el cliente & Proceso \\
\hline P37 & El sistema no permite integrarla información a tiempo real & Proceso \\
\hline P38 & La impresión de las NDS no genera valor y registra tiempos excesivos des de su aprobación & Proceso \\
\hline P40 & La aprobación de crédito del cliente paraliza la fluidez del proceso & Proceso \\
\hline P41 & El sistema no permite la verificación de precios y descuentos por cliente a tiempo real & Proceso \\
\hline P42 & Los pedidos se imprimen en el segundo piso y son llevados al primero para su atención & Proceso \\
\hline P44 & Cruces de recorrido (pedidos-embalaje-transporte) & Proceso \\
\hline P45 & Las hojas de pedidos separados son llevados del primer piso al segundo para la emisión de guía & Proceso \\
\hline P46 & Las guías impresas son llevadas del segundo piso al primero para el packing & Proceso \\
\hline P47 & Congestión para recepcionar la devolución de libros por los clientes & Proceso \\
\hline P48 & Congestión para reubicar/guardarlos libros devueltos & Proceso \\
\hline P50 & Aprobación de pedidos basada en información no actualizada & Proceso \\
\hline P51 & Evaluación de stock para importación basada en información no actualizada & Proceso \\
\hline P52 & Guardar la mercadería por anulación de pedidos ya separados & Proceso \\
\hline P55 & Ir al mismo punto de entrega varias veces por el mismo pedido & Proceso \\
\hline P56 & Entregar pedidos pequeños al mismo cliente en días seguidos & Proceso \\
\hline P57 & incremento del tiempo de espera de la GR para la realización del packing & Proceso \\
\hline P58 & Tiempo de espera fluctuante para la aprobación de pedidos (ordenes de servicio) & Proceso \\
\hline P59 & Los asesores solo ingresan los pedidos desde una laptop con acceso al SIGE, demora horas & Proceso \\
\hline P60 & Demora en el acceso a la información del estado de las importaciones & Proceso \\
\hline P61 & Difícil acceso a la información de recepción de pedidos & Proceso \\
\hline P65 & El sistema de información no brinda una trazabilidad integrada y a tiempo real & Proceso \\
\hline P67 & Desabastecimiento al cliente & Proceso \\
\hline P70 & Se presentan devoluciones de clientes luego de la facturación & Proceso \\
\hline P71 & La devolución de libros excede el $50 \%$ de lo entregado & Proceso \\
\hline P72 & Falta de estandar del procediemiento de devolución de mercadería & Proceso \\
\hline P74 & Falta de un área para la mejora continua yoptimización de procesos & Proceso \\
\hline P78 & Congestión de trabajo en el área de $\mathrm{TI}$ & Proceso \\
\hline P80 & Funciones no definidas - Falta de un MOF & Proceso \\
\hline P81 & Información ingresada por los usuarios al sistema no es validada & Proceso \\
\hline P84 & Mercadería con constante rotación ubicada en anaqueles de dificil acceso & Proceso \\
\hline
\end{tabular}

Fuente: Elaboración propia 


\section{Cuadro 15: Causas de Improductividad en Operaciones}

\begin{tabular}{|c|c|c|}
\hline Cod & Causas de improductividad & Estrato \\
\hline P01 & Libros dañados físicamente & Operación \\
\hline P02 & Pedidos atrasados & Operación \\
\hline P03 & Atraso de unidades de transporte & Operación \\
\hline P05 & Libros faltantes en la importación & Operación \\
\hline P06 & Despachos con libros faltantes & Operación \\
\hline P11 & Falta de orden y limpieza & Operación \\
\hline P13 & El mismo título se encuentran guardado en distintos anaqueles & Operación \\
\hline P18 & No se encuentran las herramientas e insumos cuando urgen & Operación \\
\hline P19 & Cajas llenas de libros muy pesadas & Operación \\
\hline P26 & Presencia de polvo en los libros & Operación \\
\hline P27 & Exposición de los libros al aire libre, al sol, humedad, etc & Operación \\
\hline P30 & Inventario dañado por manipulación & Operación \\
\hline P39 & El área comercial ingresa en varias oportunidades la misma solicitud & Operación \\
\hline P43 & La mesa de sellado está distante a la mesa de embalaje & Operación \\
\hline P49 & Demora para Ingresar al sistema la información de las devoluciones y actualizar el kardex & Operación \\
\hline P62 & Se extravían los pedidos & Operación \\
\hline P63 & Se extravían las GR & Operación \\
\hline P64 & No se encuentran los libros donde el sistema indica & Operación \\
\hline P68 & Las cuentas de clientes no se encuentran con el asesor correspondiente actualizado en el sistema & Operación \\
\hline P69 & Anulación de documentos: guía, facturas, boletas, NC & Operación \\
\hline P77 & Los usuarios de contabilidad, administración, logística no pueden sacar reportes & Operación \\
\hline
\end{tabular}

Fuente: Elaboración propia

\section{Cuadro 16: Causas de Improductividad en Gestión}

\begin{tabular}{|l|l|c|}
\hline Cod & \multicolumn{1}{|c|}{ Causas de improductividad } & Estrato \\
\hline P07 & Anulación de pedidos / adopciones & Gestión \\
P08 & Deserción de clientes & Gestión \\
P14 & Falta de ventilación en el centro de labores & Gestión \\
P16 & Servicios de damas alejado del almacén & Gestión \\
P17 & Servicios alejados de las oficinas & Gestión \\
P20 & Herramientas para el transporte de pedidos dentro del CD no son las adecuadas & Gestión \\
P21 & Piso del CD con desniveles & Gestión \\
P25 & No se trabaja sobre mediciones de resultados y productividad & Gestión \\
P33 & Falta de control yseguimiento del stock & Gestión \\
P53 & Falta política de mediciones & Gestión \\
P54 & Falta gestión de rutas de entrega & Gestión \\
P66 & Los clientes no están segmentados en base a la rentabilidad & Gestión \\
P73 & Falta de recursos humanos en algunas áreas & Gestión \\
P75 & No existen programas de capacitación al personal & Gestión \\
P76 & La inducción al personal nuevo no es la adecuada & Gestión \\
P79 & Rotación del personal en general & Gestión \\
P82 & Falta de espacio para recepción de importaciones & Gestión \\
P83 & Elárea de inventario de importación esta alejada al área de recepción & Gestión \\
P85 & Elevados niveles de stock & Gestión \\
\hline
\end{tabular}

Fuente: Elaboración propia 
Después de haber organizado la información con las distintas técnicas de estratificación, se ha realizado el análisis de la matriz relacional con el cual se reconocen qué problemas están relacionadas con otros (la relación planteada para este análisis es causa - consecuencia) y cuáles son los que originan la mayor cantidad de fuentes de improductividad en la empresa. La matriz relacional compara cada una de las causas con su similar, de modo que se podrá identificar la que mayor impacto genera al proceso en base a la cantidad de problemas que genera.

Con tal propósito se muestra el anexo 3, en el cual se ha realizado la comparación de cada problema de improductividad con su similar, colocando una calificación de "1" si la relación es positiva y "0" si no existe relación alguna, como se mencionó en el párrafo anterior, la relación consiste en causa - consecuencia, es decir, si una origina a la otra. El análisis considera como “causas" las premisas en la columna y como "efecto" las que están en fila. Es preciso mencionar que esta evaluación la realizó el autor en constante coordinación con las jefaturas responsables de cada área.

Los resultados de la puntuación de cada problema de improductividad a través de la matriz relacional son expuestos en el cuadro17. Este análisis revela que el problema "El sistema no permite integrar la información a tiempo real" influye en la generación de otros 46 problemas de improductividad, siendo el de mayor puntuación; seguido se encuentran "Procesos y procedimientos no estandarizados / ni documentados" y "falta de políticas". 
Cuadro 17: Resumen de Resultados de la Matriz Relacional

\begin{tabular}{|c|c|c|}
\hline Cod & Causas de improductividad en la empresa SBS & $\begin{array}{c}\text { Puntuación } \\
\text { Matriz } \\
\text { Relacional }\end{array}$ \\
\hline P37 & El sistema no permite integrar la información a tiempo real & 46 \\
\hline $\mathrm{P} 22$ & Procesos y procedimientos no estandarizados / ni documentados & 42 \\
\hline P53 & Falta política de mediciones & 39 \\
\hline $\mathrm{P} 23$ & Falta de conocimiento de procesos y procedimientos & 38 \\
\hline P74 & Falta de un área para la mejora continua y optimización de procesos & 34 \\
\hline P79 & Rotación del personal en general & 33 \\
\hline $\mathrm{P} 10$ & Falta de información de las operaciones a tiempo real & 31 \\
\hline P33 & Falta de control y seguimiento del stock & 29 \\
\hline $\mathrm{P} 48$ & Congestión para reubicar/guardar los libros devueltos & 28 \\
\hline P76 & La inducción al personal nuevo no es la adecuada & 28 \\
\hline P36 & Falta de trazabilidad hacia el proveedor y hacia el cliente & 27 \\
\hline $\mathrm{P} 65$ & El sistema de información no brinda una trazabilidad integrada y a tiempo real & 27 \\
\hline P44 & Cruces de recorrido (pedidos-embalaje-transporte) & 26 \\
\hline P81 & Información ingresada por los usuarios al sistema no es validada & 26 \\
\hline P80 & Funciones no definidas - Falta de un MOF & 25 \\
\hline $\mathrm{P} 29$ & Deficiente distribución de pedidos & 24 \\
\hline $\mathrm{P} 35$ & Distribución de las importaciones es tediosa y toma largo tiempo & 24 \\
\hline P49 & Demora para Ingresar al sistema la información de las devoluciones y actualizar el kardex & 24 \\
\hline P50 & Aprobación de pedidos basada en información no actualizada & 24 \\
\hline $\mathrm{P} 73$ & Falta de recursos humanos en algunas áreas & 24 \\
\hline P75 & No existen programas de capacitación al personal & 24 \\
\hline $\mathrm{P} 34$ & Stock del sistema no sincerado con lo real & 22 \\
\hline $\mathrm{P} 60$ & Demora en el acceso a la información del estado de las importaciones & 22 \\
\hline P32 & Diferencias totales entre lo pronosticado y las ventas efectivas & 21 \\
\hline P59 & Los asesores solo ingresan los pedidos desde una laptop con acceso al SIGE, demora horas & 21 \\
\hline $\mathrm{P} 11$ & Falta de orden y limpieza & 20 \\
\hline $\mathrm{P} 13$ & El mismo título se encuentran guardado en distintos anaqueles & 20 \\
\hline $\mathrm{P} 25$ & No se trabaja sobre mediciones de resultados y productividad & 19 \\
\hline $\mathrm{P} 30$ & Inventario dañado por manipulación & 19 \\
\hline P31 & Falta establecer y comunicar el método de pronóstico de demanda & 19 \\
\hline $\mathrm{P} 04$ & Atraso de importaciones & 18 \\
\hline $\mathrm{P} 09$ & Sobrecarga de trabajo para almacén & 18 \\
\hline P47 & Congestión para recepcionar la devolución de libros por los clientes & 18 \\
\hline P84 & Mercadería con constante rotación ubicada en anaqueles de difícil acceso & 18 \\
\hline
\end{tabular}




\begin{tabular}{|c|c|c|}
\hline P26 & Presencia de polvo en los libros & 17 \\
\hline P51 & Evaluación de stock para importación basada en información no actualizada & 17 \\
\hline P39 & El área comercial ingresa en varias oportunidades la misma solicitud & 16 \\
\hline P64 & No se encuentran los libros donde el sistema indica & 16 \\
\hline $\mathrm{P} 12$ & Falta de un mapeo de ubicaciones y/o anaqueles & 15 \\
\hline $\mathrm{P} 24$ & Duplicidad de operaciones & 15 \\
\hline P06 & Despachos con libros faltantes & 14 \\
\hline $\mathrm{P} 28$ & Inventario obsoleto / no vigente para su uso & 14 \\
\hline $\mathrm{P} 43$ & La mesa de sellado está distante a la mesa de embalaje & 14 \\
\hline P58 & Tiempo de espera fluctuante para la aprobación de pedidos (ordenes de servicio) & 14 \\
\hline P66 & Los clientes no están segmentados en base a la rentabilidad & 14 \\
\hline $\mathrm{P} 05$ & Libros faltantes en la importación & 13 \\
\hline $\mathrm{P} 15$ & Movimientos y transportes innecesarios & 13 \\
\hline $\mathrm{P} 27$ & Exposición de los libros al aire libre, al sol, humedad, etc. & 13 \\
\hline $\mathrm{P} 42$ & Los pedidos se imprimen en el segundo piso y son llevados al primero para su atención & 13 \\
\hline P82 & Falta de espacio para recepción de importaciones & 13 \\
\hline $\mathrm{P} 01$ & Libros dañados físicamente & 12 \\
\hline P54 & Falta gestión de rutas de entrega & 12 \\
\hline P71 & La devolución de libros excede el $50 \%$ de lo entregado & 12 \\
\hline P72 & Falta de estándar del procedimiento de devolución de mercadería & 12 \\
\hline $\mathrm{P} 40$ & La aprobación de crédito del cliente paraliza la fluidez del proceso & 11 \\
\hline $\mathrm{P} 41$ & El sistema no permite la verificación de precios y descuentos por cliente a tiempo real & 11 \\
\hline P70 & Se presentan devoluciones de clientes luego de la facturación & 11 \\
\hline $\mathrm{P} 02$ & Pedidos atrasados & 10 \\
\hline P07 & Anulación de pedidos / adopciones & 10 \\
\hline $\mathrm{P} 18$ & No se encuentran las herramientas e insumos cuando urgen & 10 \\
\hline $\mathrm{P} 20$ & Herramientas para el transporte de pedidos dentro del CD no son las adecuadas & 10 \\
\hline $\mathrm{P} 38$ & La impresión de las NDS no genera valor y registra tiempos excesivos desde su aprobación & 10 \\
\hline P63 & Se extravían las GR & 10 \\
\hline P45 & Las hojas de pedidos separados son llevados del primer piso al segundo para la emisión de guía & 9 \\
\hline P55 & Ir al mismo punto de entrega varias veces por el mismo pedido & 9 \\
\hline P56 & Entregar pedidos pequeños al mismo cliente en días seguidos & 9 \\
\hline P57 & incremento del tiempo de espera de la GR para la realización del packing & 9 \\
\hline P83 & El área de inventario de importación está alejada al área de recepción & 9 \\
\hline $\mathrm{P} 03$ & Atraso de unidades de transporte & 8 \\
\hline P52 & Guardar la mercadería por anulación de pedidos ya separados & 8 \\
\hline P69 & Anulación de documentos: guía, facturas, boletas, NC & 8 \\
\hline $\mathrm{P} 14$ & Falta de ventilación en el centro de labores & 7 \\
\hline $\mathrm{P} 21$ & Piso del CD con desniveles & 7 \\
\hline $\mathrm{P} 46$ & Las guías impresas son llevadas del segundo piso al primero para el packing & 7 \\
\hline P61 & Difícil acceso a la información de recepción de pedidos & 7 \\
\hline
\end{tabular}




***Continuación del cuadro 17.
\begin{tabular}{|l|l|l|} 
P62 & Se extravían los pedidos & 7 \\
\hline P68 & Las cuentas de clientes no se encuentran con el asesor correspondiente actualizado en el sistema & 7 \\
\hline P19 & Cajas llenas de libros muy pesadas & 6 \\
\hline P78 & Congestión de tra Fuente: Elaboración propia & 5 \\
\hline P17 & Servicios alejados ue ras onicinas & 4 \\
\hline P85 & Elevados niveles de stock & 4 \\
\hline P67 & Desabastecimiento al cliente & 3 \\
\hline P16 & Servicios de damas alejado del almacén & 2 \\
\hline P77 & Los usuarios de contabilidad, administración, logística no pueden sacar reportes & 1 \\
\hline P08 & Deserción de clientes & 0 \\
\hline
\end{tabular}

Fuente: Elaboración propia

Por la cantidad de información a analizar y la variedad de temas relacionados a cada problema es poco recomendable basar las acciones de mejora solo en los tres problemas más representativos, una evidencia de ello es que cada uno de los tres mencionados, anteriormente, refieren a temas de estudios diferentes cuyas metodologías de mejora son independientemente entre sí. Por esta razón, se recomienda utilizar el análisis matricial asociado a los resultados de estratificación con el fin de proponer herramientas y técnicas afines a cada estrato que puedan resolver gran parte de los problemas analizados. (Cuadro 18)

Cuadro 18: Puntuación Matriz relacional asociado a la estratificación

\begin{tabular}{|l|l|c|c|}
\hline Cod & \multicolumn{1}{|c|}{ Causas de improductividad en la empresa SBS } & Estrato & $\begin{array}{c}\text { Puntuación } \\
\text { Matriz } \\
\text { relacional }\end{array}$ \\
\hline P01 & Libros dañados físicamente & 12 \\
P02 & Pedidos atrasados & Operación & 10 \\
P03 & Atraso de unidades de transporte & Operación & 8 \\
P04 & Atraso de importaciones & Operación & 18 \\
P05 & Libros faltantes en la importación & Operación & 13 \\
P06 & Despachos con libros faltantes & Operación & 14 \\
P07 & Anulación de pedidos / adopciones & Gestión & 10 \\
P08 & Deserción de clientes & Gestión & 0 \\
P09 & Sobrecarga de trabajo para almacén & Proceso & 18 \\
P10 & Falta de información de las operaciones a tiempo real & Proceso & 31 \\
P11 & Falta de orden y limpieza & Operación & 20 \\
P12 & Falta de un mapeo de ubicaciones y/o anaqueles & Proceso & 15
\end{tabular}




\begin{tabular}{|c|c|c|c|}
\hline P13 & El mismo título se encuentran guardado en distintos anaqueles & Operación & 20 \\
\hline P14 & Falta de ventilación en el centro de labores & Gestión & 7 \\
\hline P15 & Movimientos y transportes innecesarios & Proceso & 13 \\
\hline P16 & Servicios de damas alejado del almacén & Gestión & 2 \\
\hline P17 & Servicios alejados de las oficinas & Gestión & 4 \\
\hline P18 & No se encuentran las herramientas e insumos cuando urgen & Operación & 10 \\
\hline P19 & Cajas llenas de libros muy pesadas & Operación & 6 \\
\hline P20 & Herramientas para el transporte de pedidos dentro del CD no son las adecuadas & Gestión & 10 \\
\hline P21 & Piso del CD con desniveles & Gestión & 7 \\
\hline P22 & Procesos y procedimientos no estandarizados / ni documentados & Proceso & 42 \\
\hline P23 & Falta de conocimiento de procesos y procedimientos & Proceso & 38 \\
\hline P24 & Duplicidad de operaciones & Proceso & 15 \\
\hline P25 & No se trabaja sobre mediciones de resultados y productividad & Gestión & 19 \\
\hline P26 & Presencia de polvo en los libros & Operación & 17 \\
\hline P27 & Exposición de los libros al aire libre, al sol, humedad, etc. & Operación & 13 \\
\hline P28 & Inventario obsoleto / no vigente para su uso & Proceso & 14 \\
\hline P29 & Deficiente distribución de pedidos & Proceso & 24 \\
\hline P30 & Inventario dañado por manipulación & Operación & 19 \\
\hline P31 & Falta establecer y comunicar el método de pronóstico de demanda & Proceso & 19 \\
\hline P32 & Diferencias totales entre lo pronosticado y las ventas efectivas & Proceso & 21 \\
\hline P33 & Falta de control y seguimiento del stock & Gestión & 29 \\
\hline P34 & Stock del sistema no sincerado con lo real & Proceso & 22 \\
\hline P35 & Distribución de las importaciones es tediosa y toma largo tiempo & Proceso & 24 \\
\hline P36 & Falta de trazabilidad hacia el proveedor y hacia el cliente & Proceso & 27 \\
\hline P37 & El sistema no permite integrar la información a tiempo real & Proceso & 46 \\
\hline P38 & La impresión de las NDS no genera valor y registra tiempos excesivos desde su aprobación & Proceso & 10 \\
\hline P39 & El área comercial ingresa en varias oportunidades la misma solicitud & Operación & 16 \\
\hline P40 & La aprobación de crédito del cliente paraliza la fluidez del proceso & Proceso & 11 \\
\hline P41 & El sistema no permite la verificación de precios y descuentos por cliente a tiempo real & Proceso & 11 \\
\hline P42 & Los pedidos se imprimen en el segundo piso y son llevados al primero para su atención & Proceso & 13 \\
\hline P43 & La mesa de sellado está distante a la mesa de embalaje & Operación & 14 \\
\hline P44 & Cruces de recorrido (pedidos-embalaje-transporte) & Proceso & 26 \\
\hline P45 & $\begin{array}{l}\text { Las hojas de pedidos separados son llevados del primer piso al segundo para la emisión } \\
\text { de guía }\end{array}$ & Proceso & 9 \\
\hline P46 & Las guías impresas son llevadas del segundo piso al primero para el packing & Proceso & 7 \\
\hline P47 & Congestión para recepcionar la devolución de libros por los clientes & Proceso & 18 \\
\hline P48 & Congestión para reubicar/guardar los libros devueltos & Proceso & 28 \\
\hline P49 & Demora para Ingresar al sistema la información de las devoluciones y actualizar el kardex & Operación & 24 \\
\hline P50 & Aprobación de pedidos basada en información no actualizada & Proceso & 24 \\
\hline P51 & Evaluación de stock para importación basada en información no actualizada & Proceso & 17 \\
\hline P52 & Guardar la mercadería por anulación de pedidos ya separados & Proceso & 8 \\
\hline P53 & Falta política de mediciones & Gestión & 39 \\
\hline
\end{tabular}

Fuente: Elaboración propia 


\begin{tabular}{|c|c|c|c|}
\hline P54 & Falta gestión de rutas de entrega & Gestión & 12 \\
\hline P55 & Ir al mismo punto de entrega varias veces por el mismo pedido & Proceso & 9 \\
\hline P56 & Entregar pedidos pequeños al mismo cliente en días seguidos & Proceso & 9 \\
\hline P57 & incremento del tiempo de espera de la GR para la realización del packing & Proceso & 9 \\
\hline P58 & Tiempo de espera fluctuante para la aprobación de pedidos (ordenes de servicio) & Proceso & 14 \\
\hline P59 & Los asesores solo ingresan los pedidos desde una laptop con acceso al SIGE, demora horas & Proceso & 21 \\
\hline P60 & Demora en el acceso a la información del estado de las importaciones & Proceso & 22 \\
\hline P61 & Difícil acceso a la información de recepción de pedidos & Proceso & 7 \\
\hline P62 & Se extravían los pedidos & Operación & 7 \\
\hline P63 & Se extravían las GR & Operación & 10 \\
\hline P64 & No se encuentran los libros donde el sistema indica & Operación & 16 \\
\hline P65 & El sistema de información no brinda una trazabilidad integrada y a tiempo real & Proceso & 27 \\
\hline P66 & Los clientes no están segmentados en base a la rentabilidad & Gestión & 14 \\
\hline P67 & Desabastecimiento al cliente & Proceso & 3 \\
\hline P68 & $\begin{array}{l}\text { Las cuentas de clientes no se encuentran con el asesor correspondiente actualizado en el } \\
\text { sistema }\end{array}$ & Operación & 7 \\
\hline P69 & Anulación de documentos: guía, facturas, boletas, NC & Operación & 8 \\
\hline P70 & Se presentan devoluciones de clientes luego de la facturación & Proceso & 11 \\
\hline P71 & La devolución de libros excede el $50 \%$ de lo entregado & Proceso & 12 \\
\hline P72 & Falta de estándar del procedimiento de devolución de mercadería & Proceso & 12 \\
\hline P73 & Falta de recursos humanos en algunas áreas & Gestión & 24 \\
\hline P74 & Falta de un área para la mejora continua y optimización de procesos & Proceso & 34 \\
\hline P75 & No existen programas de capacitación al personal & Gestión & 24 \\
\hline P76 & La inducción al personal nuevo no es la adecuada & Gestión & 28 \\
\hline P77 & Los usuarios de contabilidad, administración, logística no pueden sacar reportes & Operación & 1 \\
\hline P78 & Congestión de trabajo en el área de TI & Proceso & 5 \\
\hline P79 & Rotación del personal en general & Gestión & 33 \\
\hline P80 & Funciones no definidas - Falta de un MOF & Proceso & 25 \\
\hline P81 & Información ingresada por los usuarios al sistema no es validada & Proceso & 26 \\
\hline P82 & Falta de espacio para recepción de importaciones & Gestión & 13 \\
\hline P83 & El área de inventario de importación está alejada al área de recepción & Gestión & 9 \\
\hline P84 & Mercadería con constante rotación ubicada en anaqueles de difícil acceso & Proceso & 18 \\
\hline P85 & Elevados niveles de stock & Gestión & 4 \\
\hline
\end{tabular}

Fuente: Elaboración propia

Como última herramienta, se presenta la matriz de priorización que se obtiene de comparar los análisis de la estratificación y la matriz relacional: 
Cuadro 19: Matriz de priorización para la solución de la improductividad en SBS

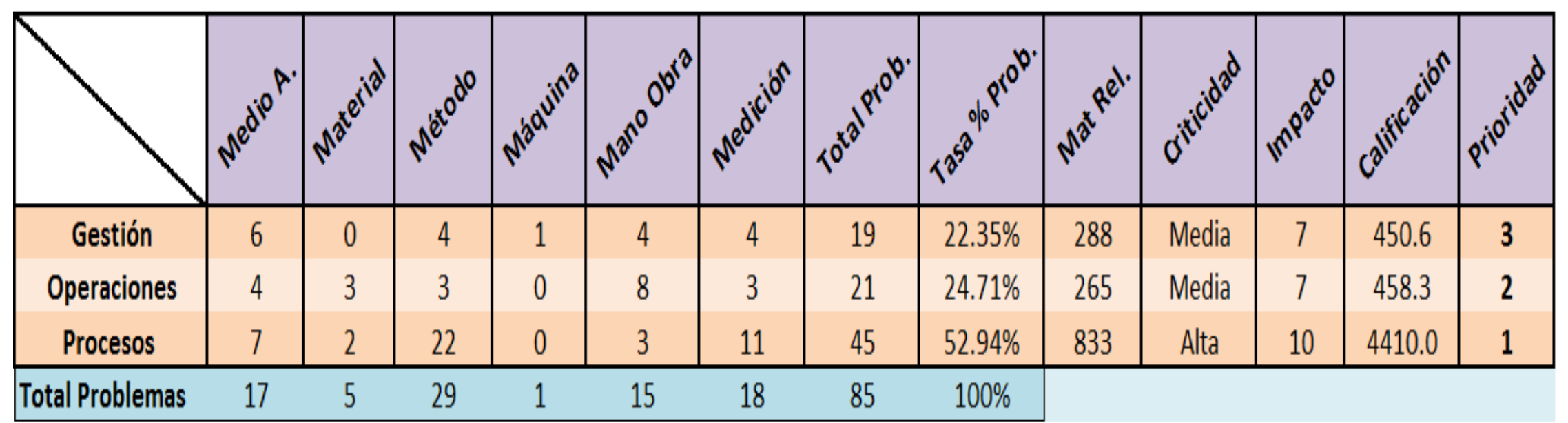

Fuente: Elaboración propia 
Como se puede apreciar en el cuadro19, la matriz de priorización expone en su primera parte la cantidad de problemas que están relacionados al estrato por tipo de problema y estos, al mismo tiempo, se encuentran organizados según la categoría identificada en las $6 \mathrm{M}$ de la calidad.

En la columna "criticidad", la matriz de priorización indica el nivel de importancia con la que debe tratarse el problema, este nivel ha sido definido por el autor y los gerentes de la empresa. La columna "impacto" es la expresión numérica de la "criticidad" y su relación está definida según se muestra en la tabla 2:

Tabla 2: Criticidad - Impacto de la matriz de priorización

\begin{tabular}{|c|c|}
\hline Criticidad & Impacto \\
\hline Baja & 5 \\
\hline Media & 7 \\
\hline Alta & 10 \\
\hline
\end{tabular}

Fuente: Elaboración propia

La columna "Calificación" es el producto del porcentaje de problemas identificados, la suma del resultado de la matriz relacional por estrato y su impacto. De este modo se obtiene el orden de prioridad según la calificación obtenida. Se puede concluir que los problemas relacionados a los Procesos deberán resolverse con prontitud, mientras que los de Operaciones y Gestión deberán ser solucionados con mayor anticipación.

Se debe considerar que el cuadro de priorización añade otro tipo de análisis, el cual implica la estructura de las 6M de la calidad utilizadas en uno de los modelos de estratificación. Desde esta perspectiva, se obtiene que de las 85 posibles causas encontradas la gran parte son por 
método y medición, alcanzando un total de 47 registros que representan más del $50 \%$ de los problemas encontrados. En síntesis, el cuadro de priorización muestra que se han analizado 85 causas relacionadas a la improductividad, los cuales son originados por deficiencias en el método, medición, medio ambiente y mano de obra con los que la empresa viene desarrollando sus actividades (el factor máquina no se ha considerado debido a que solo registra una incidencia); pero estos a la vez están organizados según el tipo de problema en los análisis de la ingeniería como Procesos, Operaciones y Gestión.

Finalmente, en el orden de prioridad definido anteriormente, se analizarán las causas más relevantes por estrato según la puntuación obtenida en el análisis de la matriz relacional y de ello se desprenderá las propuestas de solución.

\section{Identificación de los principales problemas de improductividad a través del} Análisis de Pareto

Luego de identificar la prioridad de los elementos a analizar: Procesos, operaciones y gestión, se observa que las causas asociados a estas tres temáticas son numerosas: 45, 25 y19 respectivamente y proponer acciones correctivas a cada una de ellas comprendería un trabajo muy denso y de largo alcance. Es por tal razón que se seleccionarán las causas más representativas de cada estrato evaluando el nivel de criticidad de cada una sustentado en la matriz relacional que representa a la vez, la asociatividad entre las causas.

En efecto, se procederá a calcular la frecuencia acumulada en base a la puntuación obtenida en la matriz relacional para cada estrato y, de esta manera, obtener los análisis de Pareto. (Ver anexo 4) 
En primer lugar se muestra el gráfico de Pareto de los problemas asociados a los procesos, de los cuales se han identificado que 20 de ellos representan el $65.43 \%$ de criticidad de todos las causas asociadas a los procesos.

Gráfico 18: Análisis Pareto de improductividad asociada al proceso

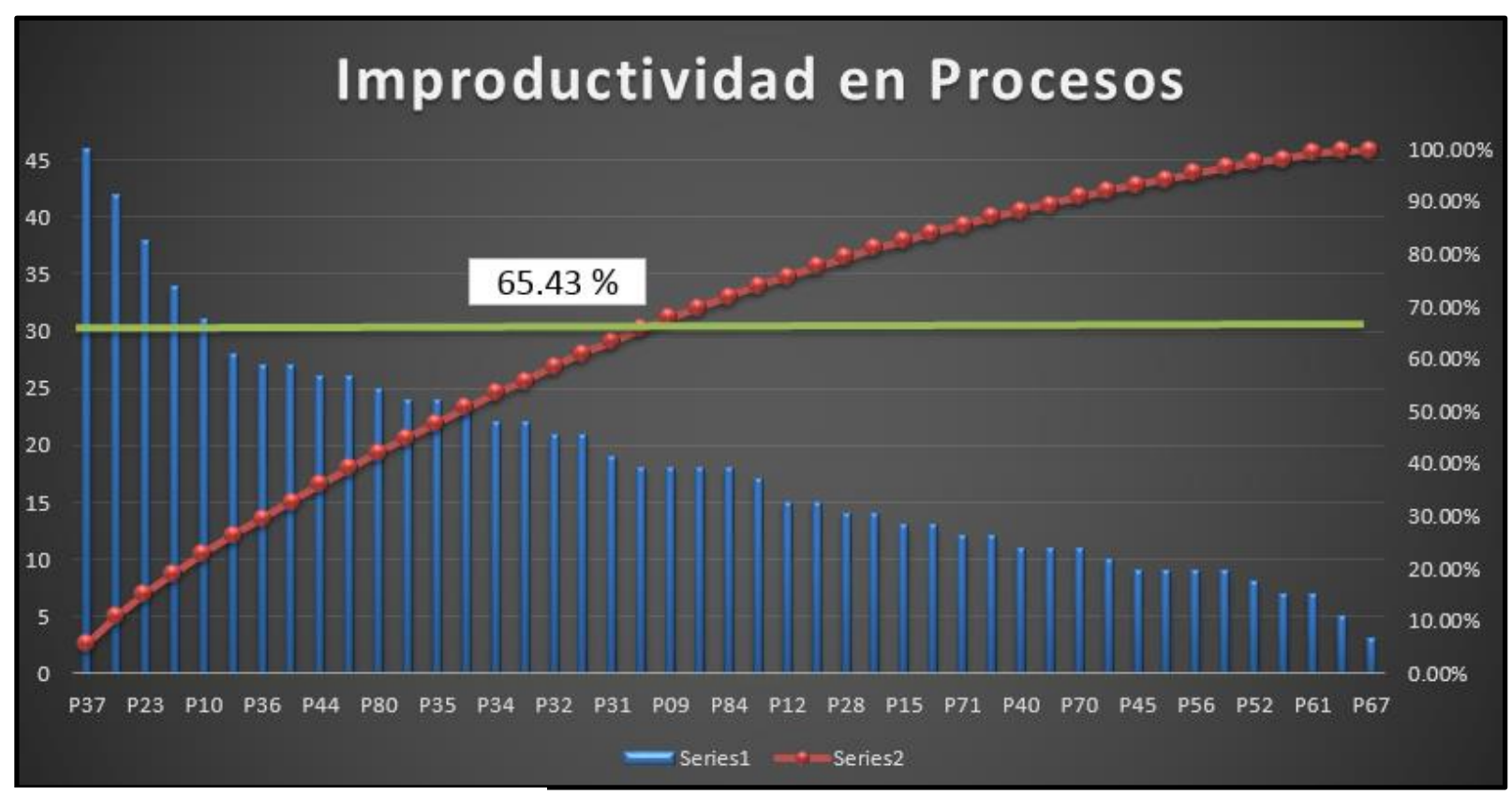

Fuente: Elaboración propia

Es de esta forma que de un total de 45 causas asociadas a la improductividad en los procesos se han desprendido solo 20 de ellas para las cuales se propondrán acciones de mejora. Entre las tres principales se encuentran que el sistema no permite integrar la información a tiempo real, procesos y procedimientos no estandarizados $\mathrm{y}$, la falta de conocimiento de procesos $\mathrm{y}$ procedimientos.

Los problemas encontrados dentro de este grupo que representa más del $65 \%$ de criticidad del estrato "proceso" son: 
Cuadro 20: Principales causas de improductividad en procesos

\begin{tabular}{|l|l|}
\hline \multicolumn{2}{|c|}{ Principales causas de improductividad en Procesos } \\
\hline P37 & El sistema no permite integrar la información a tiempo real \\
\hline P22 & Procesos y procedimientos no estandarizados / ni documentados \\
\hline P23 & Falta de conocimiento de procesos y procedimientos \\
\hline P74 & Falta de un área para la mejora continua y optimización de procesos \\
\hline P10 & Falta de información de las operaciones a tiempo real \\
\hline P48 & Congestión para reubicar/guardar los libros devueltos \\
\hline P36 & Falta de trazabilidad hacia el proveedor y hacia el cliente \\
\hline P65 & El sistema de información no brinda una trazabilidad integrada y a tiempo real \\
\hline P44 & Cruces de recorrido (pedidos-embalaje-transporte) \\
\hline P81 & Información ingresada por los usuarios al sistema no es validada \\
\hline P80 & Funciones no definidas - Falta de un MOF \\
\hline P29 & Deficiente distribución de pedidos \\
\hline P35 & Distribución de las importaciones es tediosa y toma largo tiempo \\
\hline P50 & Aprobación de pedidos basada en información no actualizada \\
\hline P34 & Stock del sistema no sincerado con lo real \\
\hline P60 & Demora en el acceso a la información del estado de las importaciones \\
\hline P32 & Diferencias totales entre lo pronosticado y las ventas efectivas \\
\hline P59 & Los asesores solo ingresan los pedidos desde una laptop con acceso al SIGE, demora horas \\
\hline P31 & Falta establecer y comunicar el método de pronóstico de demanda \\
\hline P04 & Atraso de importaciones \\
\hline
\end{tabular}

Fuente: Elaboración propia

En segundo lugar, se muestra el análisis de Pareto de los problemas de improductividad asociados a las operaciones con una representatividad del 70.19\%. El detalle se presenta en el gráfico 19: 
Gráfico 19: Análisis Pareto de Improductividad asociada a Operaciones

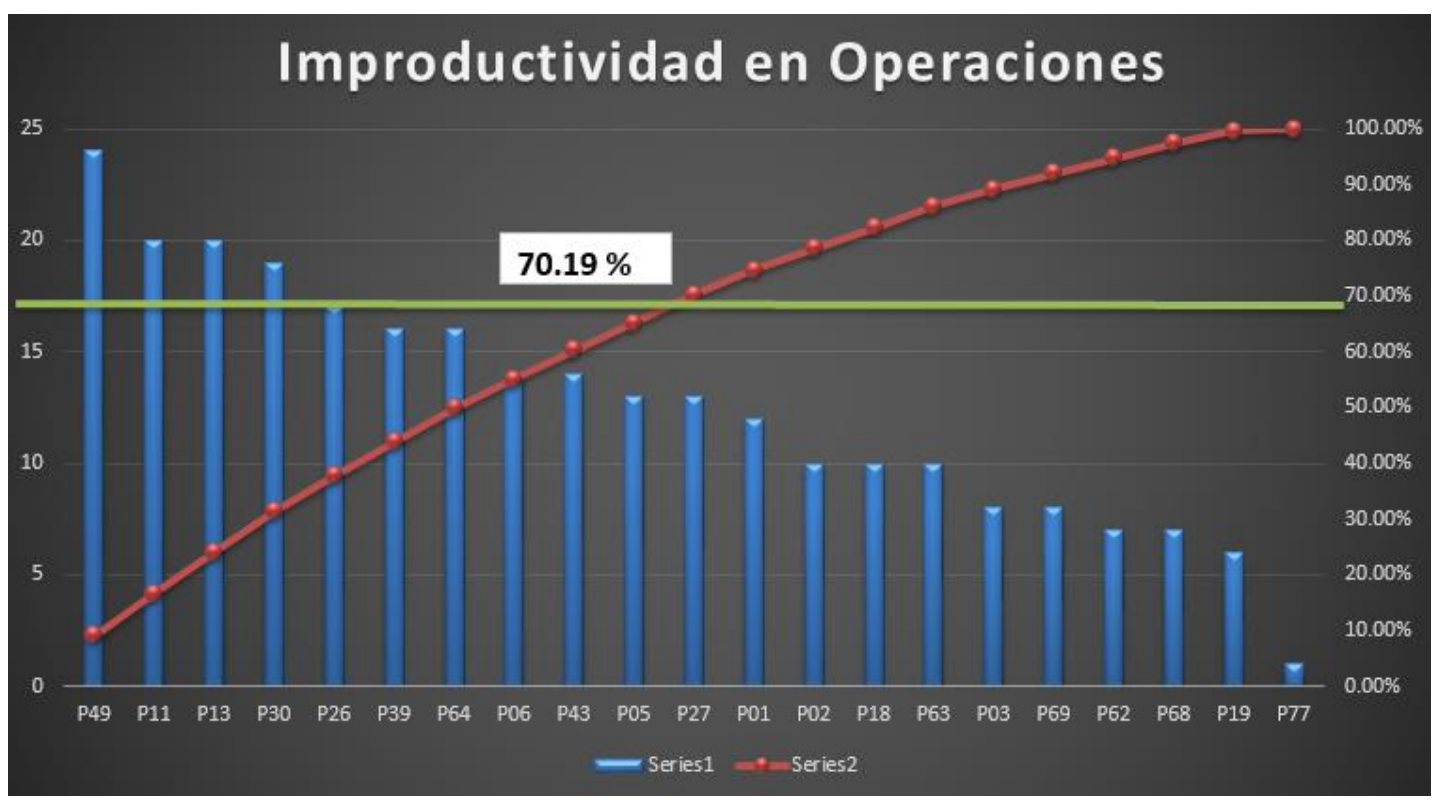

Fuente: Elaboración propia

De similar manera al análisis anterior, se expone el gráfico 19 donde se identifica que 9 de las 21 causas asociadas a las operaciones representan el $70 \%$ del total de importancia e impacto que generan en la improductividad.

En el siguiente cuadro se detallan cada una de ellas: 
Cuadro 21: Principales causas de improductividad en operaciones

\begin{tabular}{|l|l||}
\hline \multicolumn{2}{|c|}{ Principales causas de improductividad en Operaciones } \\
\hline P49 & Demora para Ingresar al sistema la información de las devoluciones y actualizar el kardex \\
\hline P11 & Falta de orden y limpieza \\
\hline P13 & El mismo título se encuentran guardado en distintos anaqueles \\
\hline P30 & Inventario dañado por manipulación \\
\hline P26 & Presencia de polvo en los libros \\
\hline P39 & El área comercial ingresa en varias oportunidades la misma solicitud \\
\hline P64 & No se encuentran los libros donde el sistema indica \\
\hline P06 & Despachos con libros faltantes \\
\hline P43 & La mesa de sellado está distante a la mesa de embalaje \\
\hline P05 & Libros faltantes en la importación \\
\hline P27 & Exposición de los libros al aire libre, al sol, humedad, etc \\
\hline
\end{tabular}

Fuente: Elaboración propia

Por último, se presenta el análisis Pareto de los problemas de improductividad asociados a la gestión del proceso. En el cual se han identificado que 8 de los 19 problemas de este estrato representan cerca del $73 \%$ del impacto total de la categoría.

Gráfico 20: Análisis Pareto de improductividad asociada a Gestión

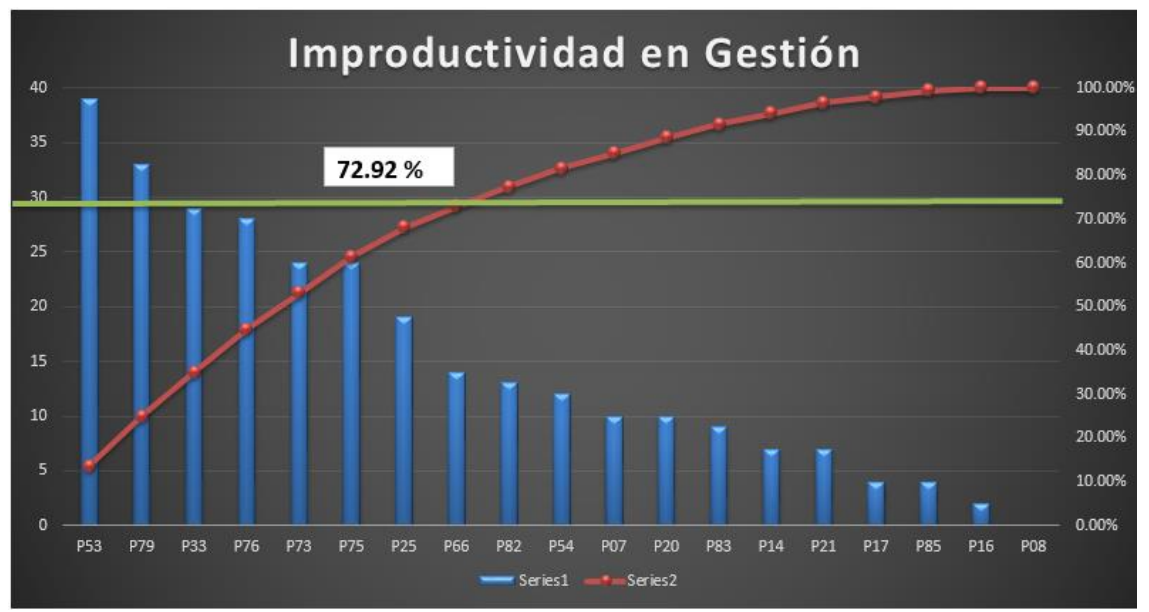

Fuente: Elaboración propia 
Con un corte al $72.92 \%$ del nivel total de criticidad que genera esta categoría, el detalle de las principales causas se muestran en el siguiente cuadro:

Cuadro 22: Principales causas de improductividad en Gestión

\begin{tabular}{||c|l||}
\hline \multicolumn{2}{||}{ Principales causas de improductividad en Gestión } \\
\hline P53 & Falta política de mediciones \\
\hline P79 & Rotación del personal en general \\
\hline P33 & Falta de control y seguimiento del stock \\
\hline P76 & La inducción al personal nuevo no es la adecuada \\
\hline P73 & Falta de recursos humanos en algunas áreas \\
\hline P75 & No existen programas de capacitación al personal \\
\hline P25 & No se trabaja sobre mediciones de resultados y productividad \\
\hline P66 & Los clientes no están segmentados en base a la rentabilidad \\
\hline
\end{tabular}

Fuente: Elaboración propia

De esta forma el análisis cualitativo de las principales causas de improductividad en la empresa ha direccionado el estudio a enfocar mayor interés en el desarrollo de los procesos logísticos de la compañía (como resultado de la matriz de priorización). Del cual se han identificado que 20 causas son las más importantes de un total de 45 .

El desarrollo del proyecto se basará a partir de ahora, en el análisis de las causas asociadas a la ejecución del proceso por ser la principal prioridad (resultado de la matriz de priorización) en la organización. 


\section{CAPITULO 3: DESARROLLO DE LA METODOLOGÍA PROPUESTA PARA LA MEJORA}

\section{Propuestas de mejora}

Según el análisis del capítulo anterior, se han identificado 20 causas relacionadas al desarrollo del proceso, las cuales influyen en la productividad de la empresa. Si bien, no hay registros de incidencia ni frecuencias de sucesos que demuestren su influencia en la productividad, utilizando un análisis cualitativo se procedió a levantar información de los protagonistas del proceso, los dueños del proceso y sus colaboradores. A partir de ahí se muestran las siguientes acciones correctivas para cada una de ellas, organizadas esquematizadamente en un cuadro de análisis. (Ver cuadro 23)

El cuadro 23 ha sido organizado de la adaptación del interrogatorio sistemático de las $5 \mathrm{~W}$, en este caso, en la primera columna “¿Qué?” se detalla la causa de improductividad identificada del análisis anterior, le sigue la columna “¿Cuándo? Que explica cuando se lleva a cabo la falla indicada, luego corresponde la columna “¿Dónde?” que indica el lugar físico de donde ocurre la falla, seguidamente la columna “¿Por qué?” En donde se expresa una pequeña explicación del por qué ocurre la falla y finalmente, la columna “¿Cómo? que detalla la herramienta a aplicar o la acción a realizar para contrarrestar la falla. 
Cuadro 23: Propuesta de solución para las principales causas de improductividad asociadas al desempeño del proceso

\begin{tabular}{|c|c|c|c|c|}
\hline ¿Qué? & ¿Cuándo? & ¿Dónde? & ¿Por qué? & ¿Cómo? \\
\hline $\begin{array}{l}\text { El sistema no permite integrar } \\
\text { la información a tiempo real }\end{array}$ & $\begin{array}{l}\text { Se desarrollan los proceso } \\
\text { que implican el flujo de } \\
\text { mercadería }\end{array}$ & $\begin{array}{l}\text { En el centro de } \\
\text { distribución }(C D)\end{array}$ & $\begin{array}{l}\text { Las activdades se } \\
\text { desarrollan sin cultura de } \\
\text { registro }\end{array}$ & $\begin{array}{l}\text { Estandarización } \\
\text { - KPI }\end{array}$ \\
\hline $\begin{array}{l}\text { Procesos y procedimientos no } \\
\text { estandarizados / ni } \\
\text { documentados }\end{array}$ & $\begin{array}{l}\text { En la actualidad, en el } \\
\text { desarrollo de todos los } \\
\text { procesos }\end{array}$ & En toda la empresa & Falta de estándares & Estandarización \\
\hline $\begin{array}{l}\text { Falta de conocimiento de } \\
\text { procesos y procedimientos }\end{array}$ & $\begin{array}{l}\text { En la actualidad, en el } \\
\text { desarrollo de todos los } \\
\text { procesos }\end{array}$ & $\begin{array}{l}\text { En toda la empresa, } \\
\text { principalmente en el } \\
\text { CD }\end{array}$ & $\begin{array}{lcr}\text { Hay ausencia } & \text { de } \\
\text { estándares } & \text { explicados } & \text { en } \\
\text { manuales } & \text { y } & \text { la } \\
\text { capacitación } & \text { de } & \text { los } \\
\text { mismos } & & \end{array}$ & Estandarización \\
\hline $\begin{array}{l}\text { Falta de un área para la mejora } \\
\text { continua y optimización de } \\
\text { procesos }\end{array}$ & $\begin{array}{l}\text { Se requiere alcanzar } \\
\text { objetivos concretos }\end{array}$ & En toda la empresa & $\begin{array}{l}\text { No hay concientización de } \\
\text { las oportunidades de } \\
\text { mejora }\end{array}$ & Estandarización \\
\hline $\begin{array}{l}\text { Falta de información de las } \\
\text { operaciones a tiempo real }\end{array}$ & $\begin{array}{l}\text { Se desarrollan los proceso } \\
\text { que implican el flujo de } \\
\text { mercadería }\end{array}$ & $\begin{array}{l}\text { En el centro de } \\
\text { distribución }(\mathrm{CD})\end{array}$ & $\begin{array}{l}\text { Las actividades se } \\
\text { desarrollan sin cultura de } \\
\text { registro }\end{array}$ & $\begin{array}{l}\text { Estandarización } \\
\text { - KPI }\end{array}$ \\
\hline
\end{tabular}




\begin{tabular}{|c|c|c|c|c|}
\hline $\begin{array}{lrr}\text { Congestión } & & \text { para } \\
\text { reubicar/guardar los } & \text { libros } \\
\text { devueltos } & & \end{array}$ & $\begin{array}{l}\text { Se realizan las } \\
\text { devoluciones del cliente }\end{array}$ & En el CD - almacén & $\begin{array}{l}\text { No se programa la } \\
\text { recepción de las } \\
\text { devoluciones, no se } \\
\text { cuenta con personal, hay } \\
\text { pasadizos obstruidos de } \\
\text { otros elementos }\end{array}$ & $\begin{array}{l}\text { Mejora del } \\
\text { proceso - 5S }\end{array}$ \\
\hline $\begin{array}{l}\text { Falta de trazabilidad hacia el } \\
\text { proveedor y hacia el cliente }\end{array}$ & $\begin{array}{l}\text { En la actualidad, en el } \\
\text { desarrollo de todos los } \\
\text { procesos }\end{array}$ & En toda la empresa & $\begin{array}{l}\text { Las activdades se } \\
\text { desarrollan sin cultura de } \\
\text { registro }\end{array}$ & $\begin{array}{l}\text { Estandarización } \\
\text { - KPI }\end{array}$ \\
\hline $\begin{array}{l}\text { El sistema de información no } \\
\text { brinda una trazabilidad } \\
\text { integrada y a tiempo real }\end{array}$ & $\begin{array}{l}\text { La información es } \\
\text { requerida en el desarrollo } \\
\text { de todo el proceso }\end{array}$ & $\begin{array}{l}\text { En toda la empresa, } \\
\text { especialmente para los } \\
\text { procesos desarrollados } \\
\text { en el CD }\end{array}$ & $\begin{array}{l}\text { Las activdades se } \\
\text { desarrollan sin cultura de } \\
\text { registro }\end{array}$ & $\begin{array}{l}\text { Estandarización } \\
\text { - KPI }\end{array}$ \\
\hline $\begin{array}{l}\text { Cruces de recorrido } \\
\text { (separación-embalaje- } \\
\text { transporte) }\end{array}$ & $\begin{array}{l}\text { Se desarrollan los proceso } \\
\text { que implican el flujo de } \\
\text { mercadería }\end{array}$ & En el CD - almacén & $\begin{array}{l}\text { La mercadería, } \\
\text { herramienta e insumos son } \\
\text { transportados de un lugar } \\
\text { a otro en el mismo día }\end{array}$ & $\begin{array}{l}\text { Mejora del } \\
\text { proceso - 5S }\end{array}$ \\
\hline $\begin{array}{l}\text { Información ingresada por los } \\
\text { usuarios al sistema no es } \\
\text { validada }\end{array}$ & $\begin{array}{l}\text { Al ingresar pedidos de } \\
\text { importación u órdenes de } \\
\text { despacho }\end{array}$ & $\begin{array}{l}\text { En toda la empresa - } \\
\text { área comercial }\end{array}$ & $\begin{array}{l}\text { No hay quien fiscalice o } \\
\text { normalice la información } \\
\text { que brindan párala } \\
\text { atención de pedidos }\end{array}$ & Estandarización \\
\hline
\end{tabular}




\begin{tabular}{|c|c|c|c|c|}
\hline $\begin{array}{l}\text { Funciones no definidas - Falta } \\
\text { de un MOF }\end{array}$ & $\begin{array}{l}\text { Se desarrollan los proceso } \\
\text { que implican el flujo de } \\
\text { mercadería }\end{array}$ & En el CD - almacén & $\begin{array}{l}\text { Existen duplicidad de } \\
\text { funciones y actividades }\end{array}$ & Estandarización \\
\hline $\begin{array}{l}\text { Deficiente distribución de } \\
\text { pedidos }\end{array}$ & $\begin{array}{l}\text { Se realiza aprobación a } \\
\text { pedidos }\end{array}$ & $\begin{array}{l}\text { En el área de Logística } \\
\text { Administrativa }\end{array}$ & $\begin{array}{l}\text { La información pertinente } \\
\text { no es oportuna para la } \\
\text { toma de decisiones }\end{array}$ & $\begin{array}{l}\text { Mejora del } \\
\text { proceso } \\
\text { Estandarización }\end{array}$ \\
\hline $\begin{array}{l}\text { Distribución de las } \\
\text { importaciones es tediosa } y \\
\text { toma largo tiempo }\end{array}$ & Llegan las importaciones & $\begin{array}{l}\text { En el área de Logística } \\
\text { Administrativa }\end{array}$ & $\begin{array}{l}\text { La información se defesa } \\
\text { al momento de consolidar } \\
\text { las importaciones }\end{array}$ & $\begin{array}{l}\text { Mejora del } \\
\text { proceso } \\
\text { Estandarización }\end{array}$ \\
\hline $\begin{array}{l}\text { Aprobación de pedidos basada } \\
\text { en información no actualizada }\end{array}$ & $\begin{array}{l}\text { Se realiza aprobación a } \\
\text { pedidos }\end{array}$ & $\begin{array}{l}\text { En el área de Logística } \\
\text { Administrativa }\end{array}$ & $\begin{array}{l}\text { La información pertinente } \\
\text { no es oportuna para la } \\
\text { toma de decisiones }\end{array}$ & $\begin{array}{l}\text { Mejora del } \\
\text { proceso } \\
\text { Estandarización }\end{array}$ \\
\hline $\begin{array}{l}\text { Stock del sistema no } \\
\text { sincerado con lo real }\end{array}$ & $\begin{array}{l}\text { Se requiere información } \\
\text { delos niveles de stock }\end{array}$ & En el CD - almacén & $\begin{array}{l}\text { Hay diferencias entre lo } \\
\text { físico y que indica el stock }\end{array}$ & Estandarización \\
\hline $\begin{array}{l}\text { Demora en el acceso a la } \\
\text { información del estado de las } \\
\text { importaciones }\end{array}$ & $\begin{array}{l}\text { Es necesario la } \\
\text { información de las llegadas } \\
\text { de importación }\end{array}$ & $\begin{array}{l}\text { En el área de Logística } \\
\text { Administrativa }\end{array}$ & $\begin{array}{l}\text { Hay retraso al ingresar la } \\
\text { información al sistema del } \\
\text { estado de las } \\
\text { importaciones }\end{array}$ & $\begin{array}{l}\text { Mejora } \\
\text { proceso }\end{array}$ \\
\hline $\begin{array}{l}\text { Diferencias totales entre lo } \\
\text { pronosticado y las ventas } \\
\text { efectivas }\end{array}$ & $\begin{array}{l}\text { Cuando se produce la } \\
\text { atención al cliente }\end{array}$ & $\begin{array}{l}\text { En el área de Logística } \\
\text { Administrativa y CD - } \\
\text { almacén }\end{array}$ & $\begin{array}{l}\text { Los libros no llegan a } \\
\text { tiempo o llegan en } \\
\text { cantidades superiores }\end{array}$ & $\begin{array}{l}\text { Mejora } \\
\text { proceso }\end{array}$ \\
\hline
\end{tabular}




\begin{tabular}{|c|c|c|c|c|}
\hline $\begin{array}{l}\text { Los asesores solo ingresan los } \\
\text { pedidos desde una laptop con } \\
\text { acceso al SIGE, demora horas }\end{array}$ & $\begin{array}{l}\text { Los clientes hacen sus } \\
\text { requerimientos y los } \\
\text { asesores están fuera de las } \\
\text { oficinas }\end{array}$ & En el área comercial & $\begin{array}{l}\text { No hay acceso remoto o } \\
\text { vía Web al ERP de la } \\
\text { empresa }\end{array}$ & $\begin{array}{l}\text { Mejora } \\
\text { Proceso }\end{array}$ \\
\hline $\begin{array}{l}\text { Falta establecer y comunicar } \\
\text { el método de pronóstico de } \\
\text { demanda }\end{array}$ & $\begin{array}{l}\text { Se requiere tomar } \\
\text { decisiones sobre las } \\
\text { cantidades a atender }\end{array}$ & $\begin{array}{l}\text { En las principales áreas } \\
\text { de Gestión }\end{array}$ & $\begin{array}{l}\text { No hay procesos definidos } \\
\mathrm{y}\end{array}$ & Estandarización \\
\hline Atraso de importaciones & $\begin{array}{l}\text { Se requieren libros con } \\
\text { suma urgencia }\end{array}$ & $\begin{array}{l}\text { En el área de } \\
\text { Abastecimiento } \\
\text {-y } \\
\text { CD } \\
\text { almacén }\end{array}$ & $\begin{array}{l}\text { Ocurren diferentes } \\
\text { factores internos y } \\
\text { externos. }\end{array}$ & $\begin{array}{l}\text { Mejora } \\
\text { proceso }\end{array}$ \\
\hline
\end{tabular}

Fuente: Elaboración propia 


\section{Sustento de la metodología a aplicar}

Las propuestas de herramientas y prácticas de mejora a realizar son Estandarización, aplicación de KPI, implementación de las 5S y mejoras en los procesos. Comúnmente estas herramientas se aplican por separado e independientemente a la otra, sin embargo, sus orígenes forman parte del Lean Thinking según se ha explicado en el capítulo 1. Dicho de otro modo, la aplicación de estas herramientas de manera sistemática son propuestas por la filosofía Lean Thinking que a su vez, si es llevado a la práctica en una empresa que considera sus procesos Logísticos como claves y que generan valor para el cliente, se le denominará Lean Logistics (explicado también en el capítulo 1 del proyecto).

Si las principales causas de improductividad en la empresa son las asociadas a los procesos Logísticos, el principal objetivo será convertir estos procesos lo más esbeltos posibles, lo que implica la eliminación u optimización de muda (despilfarros). Es por esta razón que se sustenta la aplicación de las herramientas Lean en los procesos Logísticos de la empresa.

Otro punto que soporta la decisión de elección de la metodología Lean toma como base el estudio de comparación realizado por el ingeniero de origen brasileño Diego Augusto de Jesús Pacheco en su obra traducida al español "TOC, Lean y Six Sigma: El eslabón perdido para aumentar la productividad." De la misma, se ha adaptado el cuadro comparativo de las tres metodologías con el fin de explicar y sustentar la selección de la metodología Lean como la idónea para mejorar la productividad en la distribuidora de Libros. 
Cuadro 24 Comparación de Metodologías de Ingeniería

\begin{tabular}{|c|c|c|c|}
\hline Criterio & TOC -Teoría de Restricciones & Lean Manufacturing & Six Sigma \\
\hline Fuente & Goldratt (1980) & Toyota (Toyoda, Ohno and Shingo 1950's) & Motorola e General Electrics (1980's) \\
\hline Teoría & $\begin{array}{l}\text { Genera ganancias con la gestión de } \\
\text { la restricción }\end{array}$ & $\begin{array}{l}\text { Aumenta las ganancias con la eliminación } \\
\text { de desperdicios }\end{array}$ & Reduce la Variabilidad \\
\hline $\begin{array}{l}\text { Estructura de } \\
\text { aplicación }\end{array}$ & $\begin{array}{l}\text { 1- Identificar la restricción } \\
\text { 2- Explorar la restricción } \\
\text { 3- Subordinar todo a la restricción } \\
\text { anterior } \\
\text { 4- Elevar la restricción } \\
\text { 5- Volver al paso } 1 \\
\end{array}$ & $\begin{array}{l}\text { 1- Especificar valor } \\
\text { 2- Identificar el flujo del valor } \\
\text { 3- Fluir } \\
\text { 4- Pull - Halar } \\
\text { 5- Buscando la perfección }\end{array}$ & $\begin{array}{l}\text { 1- Definir } \\
\text { 2- Medir } \\
\text { 3- Analizar } \\
\text { 4- Mejorar } \\
\text { 5- Controlar }\end{array}$ \\
\hline Enfoque & En la restricción & En el flujo & En el problema \\
\hline Meta & Mejora continua en las ganacias & Maximizar la productividad & Maximizar los resultados \\
\hline $\begin{array}{c}\text { Objetivo } \\
\text { Estratégico }\end{array}$ & Sincronizar & Simplificar & Estabilizar \\
\hline Supuestos & $\begin{array}{l}\text { Énfasis en volumen y velocidad } \\
\text { Analiza sistemas existentes } \\
\text { Existe interdependencia entre } \\
\text { procesos }\end{array}$ & $\begin{array}{l}\text { La reducción de desperdicios aumenta el } \\
\text { rendimiento de la empresa } \\
\text { Varias pequeñas mejoras son mejor que el } \\
\text { análisis global del sistema }\end{array}$ & $\begin{array}{l}\text { Existe un problema } \\
\text { Utiliza herramientas estadísticas } \\
\text { La reducción de la variabilidad del } \\
\text { proceso mejora la tasa efectiva de } \\
\text { productos terminados }\end{array}$ \\
\hline Efectos primarios & $\begin{array}{l}\text { Aumenta las ganancias } \\
\text { rápidamente }\end{array}$ & Reduce el tiempo de flujo & $\begin{array}{l}\text { Uniformiza el tasa de producción del } \\
\text { proceso }\end{array}$ \\
\hline Deficiencias & $\begin{array}{l}\text { Se ignora partes de la organización } \\
\text { para concentrarse en la producción } \\
\text { y la restricción }\end{array}$ & $\begin{array}{l}\text { No utiliza herramientas estadísticas para el } \\
\text { análisis del sistema }\end{array}$ & $\begin{array}{l}\text { Crea una elite de empleados - Realiza } \\
\text { mejoras en el proceso de forma } \\
\text { independiente }\end{array}$ \\
\hline $\begin{array}{c}\text { Nivel de } \\
\text { implementación }\end{array}$ & Mayor dificultad & Menor dificultad & Mediana dificultad \\
\hline $\begin{array}{c}\text { Nivel de gestión y } \\
\text { aplicación }\end{array}$ & Dirección superior & Primeros niveles & Gerencia intermedia - Nivel técnico \\
\hline $\begin{array}{l}\text { Efecto en la } \\
\text { Variabilidad } \\
\end{array}$ & Absorve & Reduce & Reduce \\
\hline $\begin{array}{l}\text { Distribución del } \\
\text { conocimiento }\end{array}$ & Centrado en las restricciones & $\begin{array}{l}\text { Se comparte el conocimento para la } \\
\text { reducción de desperdicios y la } \\
\text { responsabilidad en todos }\end{array}$ & $\begin{array}{l}\text { El conocimiento se centra en los } \\
\text { Cinturones y su entrenamiento } \\
\end{array}$ \\
\hline Perfil de Lider & Conductor & Facilitador & Conductor \\
\hline $\begin{array}{l}\text { Información } \\
\text { requerida }\end{array}$ & $\begin{array}{l}\text { La cantidad y exactitud de la } \\
\text { información es de menor } \\
\text { importancia }\end{array}$ & $\begin{array}{l}\text { La cantidady exactitud de la información } \\
\text { es parte importante }\end{array}$ & $\begin{array}{l}\text { Requiere gran cantidad y exactitud de } \\
\text { información para la toma de } \\
\text { desiciones }\end{array}$ \\
\hline Planificación & Simulación computarizada & Kanban & No hay referencia \\
\hline $\begin{array}{l}\text { Tecnología de la } \\
\text { información }\end{array}$ & Fuentes computarizadas & Baja necesidad & Fuentes computarizadas \\
\hline
\end{tabular}

Fuente: Adaptado de Pacheco 2015: 513-520 
Entre los principales puntos a favor de la metodología Lean sobre el TOC y el Six Sigma con respecto a la implementación en la compañía Special Book Services para la mejora de su productividad se han identificado:

El origen o la fuente: El Lean se remonta a las décadas de los 50's, es más antigua y por lo tanto mayor obtiene mayor trascendencia.

La teoría, el enfoque y la meta: La metodología Lean basa su teoría en la eliminación de las pérdidas o desperdicios, se concentra en el flujo o proceso siendo su principal meta la maximización de la productividad. A diferencia de las otras dos que se centran en la restricción y el problema propiamente demostrado.

El objetivo estratégico del Lean es "simplificar" y su efecto primario es la reducción del tiempo de flujo. A esto, se puede adicionar que consigue reducir la variabilidad del proceso.

Posee el menor grado de dificultad de implementación de las tres metodologías analizadas, su aplicación se lleva a cabo desde los primeros niveles. El líder a cargo posee un perfil de facilitador del conocimiento, a diferencia del TOC y Six Sigma que sus líderes cuentan con un perfil de conductor y sus niveles de conocimientos son centralizados en pocos.

Por último, el Lean se diferencia en que la cantidad de información requerida no es muy compleja a diferencia del Six Sigma. El nivel de planificación y la tecnología de información no son muy relevante, por lo que las fuentes computarizadas no logran a hacer la diferencia. 


\section{Hoja de ruta para la implantación de las técnicas Lean Logistics}

Para la implantación de las técnicas Lean Logistics en la empresa SBS se ha desarrollado una hoja de ruta que indica la secuencia de herramientas y técnicas a ejecutar. Esta hoja de ruta ha sido adaptada de Hernández y Vizán 2013 en su obra para la Escuela de Organización Industrial (EOI) en España, la cual ha sido revisada en el capítulo 1 del presente estudio.

En la elaboración de la hoja de ruta se han considerado solo las herramientas y técnicas que pueden adaptarse a la realidad y situación actual de la empresa SBS resaltando la importancia de las técnicas que mayor impacto tengan en la logística de la compañía. Como se ha descrito en el anterior capítulo, la empresa Special Book Services (SBS) pertenece al rubro de distribuidor de libros catalogándose como una empresa del sector logístico, en consecuencia, no han sido consideradas las herramientas que se aplican al sector manufacturero del modelo de Hernández y Vizán.

En la figura 25 se muestra la propuesta de hoja de ruta para la implantación Lean, la cual cuenta con seis fases detallando, en cada una de ellas, las herramientas y metodologías a desarrollar. 
Figura 25: Propuesta de hoja de Ruta para la implantación en SBS

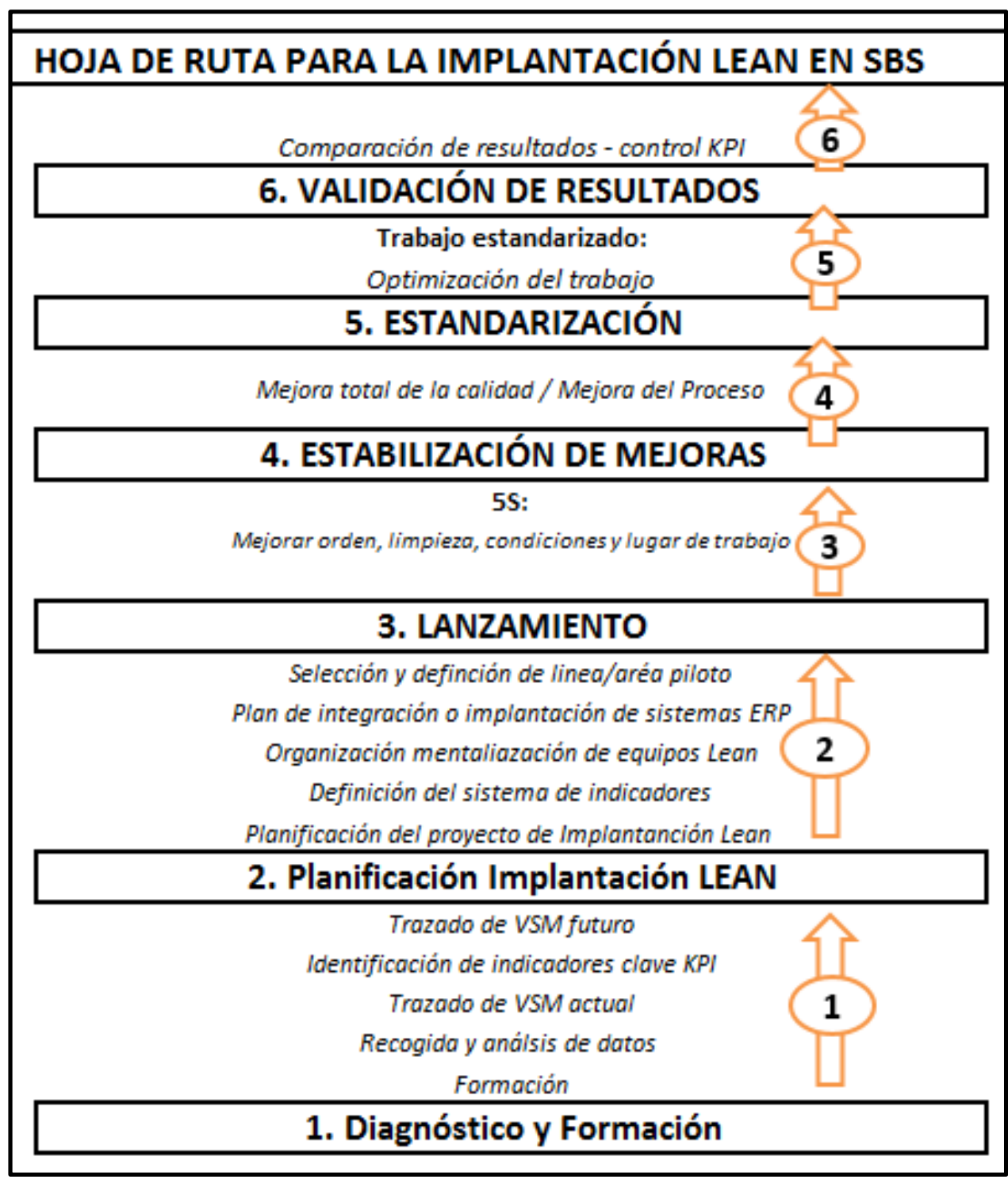

Fuente: Elaboración propia basado en Hernández y Vizán 2013 


\section{Fase 1: Diagnostico y Formación}

Esta primera fase de implantación Lean, en especial el diagnóstico, se otorga una importante valoración debido a que los análisis sugeridos por Lean sobre las actividades que no generan valor y el recurso que estas utilizan aportarán un análisis cuantitativo de la situación actual de la organización. De esta manera, si en el capítulo anterior se propuso evaluar la productividad de los procesos logísticos de la empresa e identificar sus causas a través de un análisis cualitativo, ahora se podrá comparar información cuantitativa de los procesos que servirán como base ante nuevas propuestas.

\section{Formación}

La primera parte de esta fase de implementación Lean consiste en la formación de los recursos humanos en los conceptos más comunes y especializados del Lean, como se vio en el capítulo 1, el Lean Thinking no sólo es considerado más que un grupo de herramientas y técnicas para la mejora, sino que es considerado una cultura organizacional. Para fomentar el Lean como cultura en la empresa es de vital importancia valorar los recursos humanos de la organización, puesto que son los colaboradores quiénes realicen la implantación Lean.

El comité Lean será el encargado de evaluar y calificar al personal más apto y capacitado para recibir la formación Lean y posteriormente se encargue de llevar las diferentes técnicas a la práctica. Este comité está conformado por:

- Gerente General de la empresa

- Gerente de recursos humanos

- Gerente de operaciones

- Gerente de Administración y Finanzas 
Este comité deberá seleccionar a un grupo de colaboradores que conformen el equipo Lean, quienes recibirán capacitación en las diferentes herramientas y metodologías que Lean abarca. Para la selección del personal, el comité debe considerar los siguientes aspectos de cada colaborador multiplicando la puntuación con el peso respectivo:

- Años dentro de la empresa. Que tendrá un peso de $20 \%$ y se evaluará con la puntuación 3 para los colaboradores que tengan hasta 2 años dentro de la empresa, 5 para colaboradores de 2 a 4 años y 7 para los que superen los 4 años en la organización.

- Nivel de formación: Con un peso de 30\% considera el nivel de estudios de cada trabajador. La puntuación se basa en 2 para los que no tengan ningún estudio superior, 5 para quienes estén cursando estudios universitarios superando el sexto ciclo, 7 para quienes tengan estudios técnicos terminados y 10 para los que hayan culminado una carrera universitaria.

- Experiencia laboral en puestos afines: Con un peso de 15\%, se da una puntuación de 1 para los que no tengan ninguna experiencia laboral, 5 para los que hayan estado hasta en dos empresas distintas a SBS y 7 para los colaboradores que hayan laborado en más de dos empresas.

- Habilidades y rendimiento: Con un peso de 35\% se procederá a entrevistar al jefe directo del colaborador a analizar el rendimiento de este último recibiendo una puntuación de 0 si no cumple, 3 para los de rendimiento regular, 5 para bueno y 7 para los muy bueno.

Después de multiplicar la puntuación con el peso (expresado en porcentaje) en cada aspecto evaluado, se suman estos cuatro resultados por cada colaborador. Será decisión del comité Lean la cantidad de colaboradores a seleccionar y puede oscilar entre 8 a 12 personas, lo seleccionados serán los que alcancen mayores puntuaciones.

Se muestra como ejemplo la figura 26 donde se detalla la evaluación de un colaborador: 
Figura 26: Hoja de evaluación al colaborador para la conformación del equipo Lean

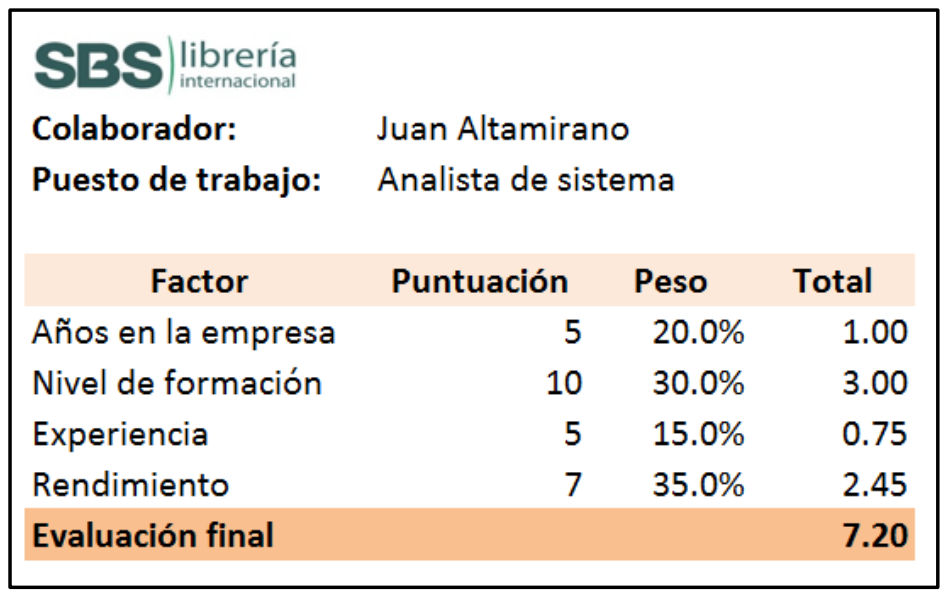

Fuente: Elaboración propia

Este ejemplo muestra la evaluación al colaborador Juan Altamirano quien presenta una calificación total de 7.20. Juan presta sus servicios de analista como sistemas por más de tres año en la empresa, es recientemente egresado de la carrera de Ingeniería de Sistemas, ha estado en dos empresas anteriores a SBS y su jefe inmediato ha dado muy buenas referencias sobre su rendimiento.

Seguidamente, el comité Lean debe realizar la programación temporal de la capacitación. Esta programación debe incluir las herramientas propuestas en la hoja de ruta dentro de los contenidos a tratar. Para la formación en conceptos teóricos se debe contratar los servicios a un grupo de consultores Lean quienes tienen experiencia en implementación Lean en diversas empresas y facilitan, además de información, material audiovisual, visitas a empresas que hayan implantado el Lean.

Entre los temas de formación se debe destacar que todos los involucrados deben ser capaces, al terminar las capacitaciones, de identificar los siete tipos de despilfarros en la empresa y en sus actividades según lo explicado en el capítulo 1 de este estudio. 


\section{Recogida y análisis de datos}

En esta etapa se emplean las diferentes herramientas de recopilación de información y diagnostico estudiadas en el marco teórico.

\section{Análisis Del Diagrama de Actividades del Proceso (DAP)}

Para el análisis con la herramienta DAP se han seleccionado los procesos que se llevan a cabo en el centro de distribución y que implican flujos físicos de mercadería como son Recepción e inventario de importaciones, Picking y Packing. Se ha realizado el seguimiento a una serie de pedidos e ingresos de importaciones de los productos de tipo ELT durante los principales meses de campaña, puesto que la comercialización de este producto representa más del 70\% de todas las ventas en la empresa, para ello se ha recopilado toda información comprometida con el proceso a criterio del autor.

Para el caso de la recepción de la mercadería de importación se realizó el seguimiento y estudio a 169 llegadas de importación de un total de 219 registros en lo que va del año, este análisis permitió identificar la media de los tiempos en que se ejecutan las principales actividades del proceso de recepción. Esta muestra empleada supera lo calculado para una confianza del 95\% y una significación hasta un 0.05 con valores p y q de 0.5 .

Para el caso de los procesos de Picking y Packing se procedió a hacer seguimiento y analizar las actividades de 385 pedidos, magnitud resultante al utilizar la fórmula de tamaño muestral para la obtención de media de variables cuantitativas en las que la población es infinita, el método de muestreo fue por conveniencia y se basó en una confiabilidad del 95\% y un error admisible hasta del 5\%. La cantidad de unidades promedio de estos 385 pedidos fue de 300 unidades por pedido. 


\section{DAP Recepción de Mercadería}

En la figura 27 se observa las medias muestrales de los tiempos en las que son ejecutadas las actividades del proceso de recepción de mercadería de importación. Con un total de 22 actividades identificadas, el proceso es llevado a cabo con 10 operaciones, 5 transportes, 3 demoras, 2 inspecciones, 1 operación combinada y 1 registro de inventario.

El proceso es realizado en 7,944 minutos, equivalentes a 132.4 horas o 5.5 días, registrando el mayor tiempo de ejecución las actividad de mercadería almacenada y la de espera de inicio de inventario con un registro de 5,760 y 1,440 minutos respectivamente.

Paralelamente, se desprende que el recorrido realizado en el proceso de recepción es de 495 metros, siendo las actividades de trasladar la mercadería de la zona de inventario a la zona de almacenaje y la actividad de llevar pallets a la zona de inventario las que presentan mayor distancia de recorrido.

Otra información que se puede obtener del DAP del proceso de recepción es que las actividades que no genera valor (por el contrario son consideradas despilfarros) como esperas, transportes e inventario acumulan un total de 7,286 min o 121.4 horas que representan más del $91.7 \%$ del tiempo en que se ejecuta todo el proceso. 
Figura 27: DAP Proceso de Recepción de Mercadería

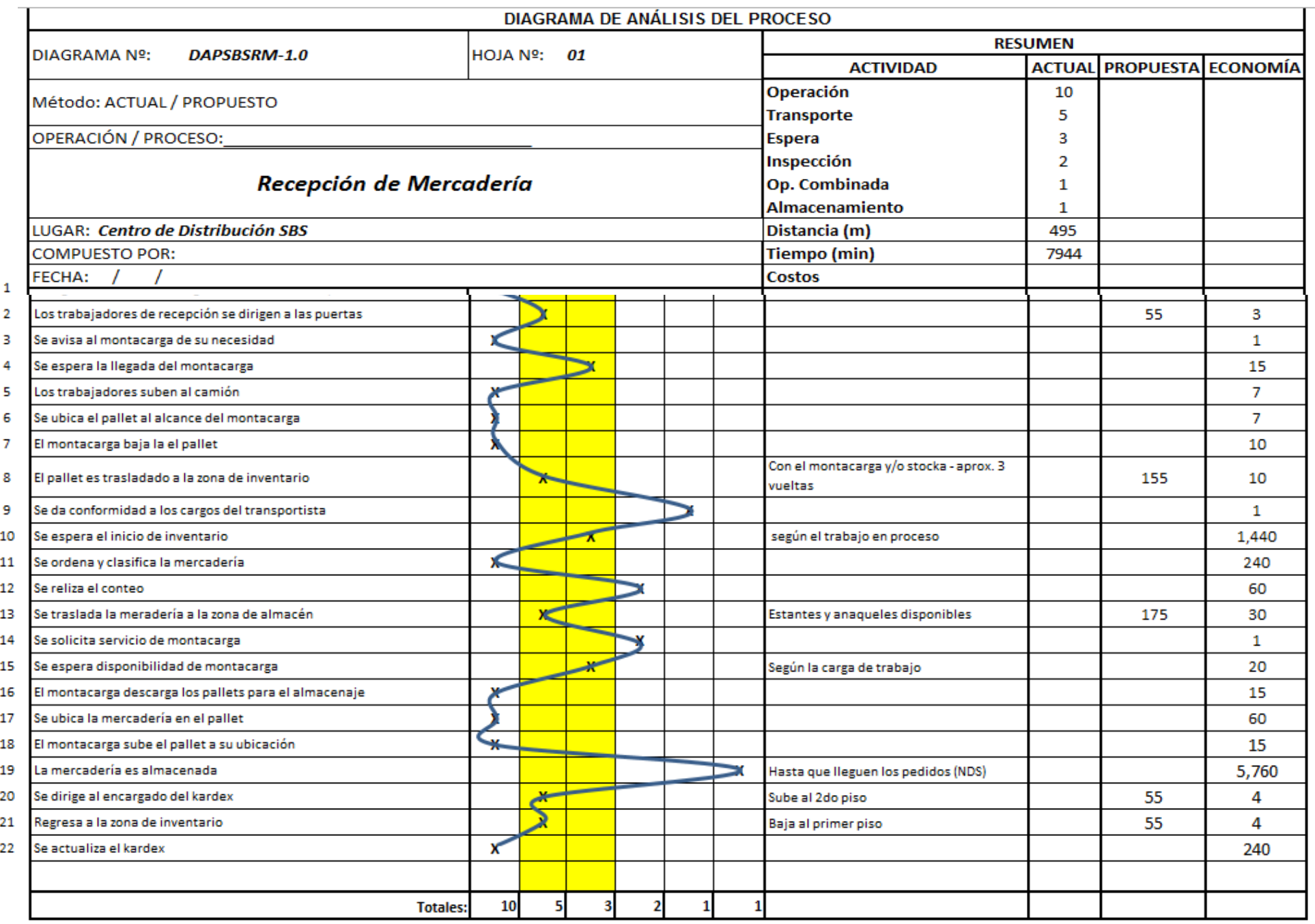

Fuente: Elaboración propia 


\section{DAP Picking}

De manera similar al anterior proceso, se presenta la figura 28 con el DAP del proceso de Picking, el cual manifiesta que en este proceso se desempeñan un total de 23 actividades principales: 7 actividades de operación, 7 de transporte, 3 esperas, 3 de inspección, 2 operaciones combinadas y se produce una de almacenamiento.

Este proceso es realizado en un tiempo medio de 1,552 minutos, equivalentes a 25.87 horas o un día aprox. La actividad que mayor tiempo medio registra en su ejecución es la "espera antes de comenzar a separar los libros" con un registro de 1,440 min; como toda actividad de espera es considerada tiempo improductivo, se desprende que más del 90\% del tiempo de realización de este proceso no añade valor al mismo.

Dentro del análisis de las actividades de transporte, se observa que las de mayor recorrido se realizan sin transportar libros sino, por el contrario, se origina en trasladar pedidos impresos (NDS) tanto para el inicio del picking como para la finalización del mismo, estos registros de recorrido medio son 110 metros al inicio del picking y otros 110 metros a concluir el proceso, esto debido a que los digitadores se encuentran en el segundo piso. Se debe considerar que en todo el proceso se recorre un total de 265 metros por pedido.

Por último, se desprende del DAP que los tiempos medios de ejecución de las actividades que no generan valor al proceso como esperas, transportes innecesario e inventarios suman un total de 1519 minutos y representan el $97.8 \%$ del tiempo total en el que se ejecuta este proceso. 
Figura 28: DAP del proceso de Picking

\begin{tabular}{|c|c|c|c|c|c|c|c|c|c|c|}
\hline \multirow{2}{*}{ DIAGRAMA NO: DAPSBSPI-1.o } & \multirow{2}{*}{\multicolumn{6}{|c|}{ HOJA No: $\quad 02$}} & \multicolumn{4}{|c|}{ RESUMEN } \\
\hline & & & & & & & ACTIVIDAD & ACTUAL & PROPUESTA & ECONOMÍA \\
\hline \multicolumn{7}{|l|}{ Método: ACTUAL/ PROPUESTO } & $\begin{array}{l}\text { Operación } \\
\text { Transporte }\end{array}$ & $\begin{array}{l}7 \\
7\end{array}$ & & \\
\hline \multirow{2}{*}{\multicolumn{7}{|c|}{ OPERACIÓN / PROCESO: }} & Espera & 3 & & \\
\hline & & & & & & & $\begin{array}{l}\text { Inspección } \\
\text { Op. Combinada } \\
\text { Almacenamiento }\end{array}$ & $\begin{array}{l}3 \\
2 \\
1\end{array}$ & & \\
\hline \multirow{2}{*}{\multicolumn{7}{|c|}{$\begin{array}{l}\text { LUGAR: Centro de Distribución SBS } \\
\text { COMPUESTO POR: }\end{array}$}} & Distancia (m) & 265 & & \\
\hline & & & & & & & Tiempo (min) & 1552 & & \\
\hline \multicolumn{7}{|l|}{ FECHA: $/ /$} & Costos & & & \\
\hline \multirow{2}{*}{ DESCRIPCION } & \multicolumn{6}{|c|}{ SIMBOLO } & \multirow{2}{*}{ OBSERVACIONES } & \multirow[t]{2}{*}{ C } & \multirow[t]{2}{*}{$\mathrm{D}(\mathrm{m})$} & \multirow[t]{2}{*}{$\mathbf{T}(\mathrm{min})$} \\
\hline & $\infty$ & $\Longrightarrow$ & D & & $\mathrm{O}$ & $\nabla$ & & & & \\
\hline Personal transporta los pedidos y regresa & & & & & & & $\begin{array}{l}\text { Del segundo al primer piso } \\
\text { y viceversa }\end{array}$ & & 110 & 6 \\
\hline Se recepcionan pedidos impresos (NDS) & $x$ & & & & & & Por personal de almacén & & & 1 \\
\hline Se espera antes de comenzar a separar os libros & & & x & & & & & & & 1440 \\
\hline Se selecionan pedidos a separar & & & & & & & & & & 5 \\
\hline Se identifican las ubicaciones accesibles & & & & $\boldsymbol{x}$ & & & & & & 3 \\
\hline Se dirige a las ubicaciones accesibles & & - & & & & & & & 9 & 3 \\
\hline Se cogen los libros & S & & & & & & & & & 5 \\
\hline Se realiza check en la NDS & & & & & $\mathrm{D}_{\mathrm{x}}$ & & & & & 1 \\
\hline Se dirige a la zona de pedidos en proceso & & 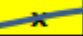 & & & & & & & 18 & 3 \\
\hline Se dejan los libros en la zona de pedidos en proceso & So & & & & & & & & & 2 \\
\hline Los libros se almacenan temporalmente & & & & & & $m$ & Hasta completar el pedido & & & 30 \\
\hline Se identifican ubicaciones no accesibles & & & & $\pi$ & & & De segundo nivel a más & & & 3 \\
\hline Se solicita servicio de montacargas & $x<$ & & & & & & & & & 1 \\
\hline Se espera la disponibilidad del montecargas & & & $\$$ & & & & & & & 15 \\
\hline Se dirige a la zona de descarga & & $x$ & & & & & & & 9 & 2 \\
\hline Se espera que el montacarga baje los libros & & & $x_{x}$ & & & & & & & 10 \\
\hline Se cogen los libros & $\approx$ & & & & & & & & & 5 \\
\hline Se realiza check en la NDS & & & & & 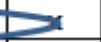 & & & & & 1 \\
\hline Se dirige hacia la zona de pedidos en proceso & & 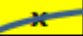 & & & & & & & 9 & 3 \\
\hline Se dejan los libros en la zona pedidos en proceso & $x \leq$ & & & & & & & & & 5 \\
\hline Se dirige al digitador de guias & & 2. & & & & & Al segundo piso & & 55 & 4 \\
\hline Se Deja el pedido con las confirmaciones realizadas & $x<$ & & & & & & & & & 1 \\
\hline Regresa para separar más pedidos & & $x$ & & & & & Al primer piso & & 55 & 3 \\
\hline Totales: & 7 & 7 & 3 & 3 & 2 & 1 & & & & \\
\hline
\end{tabular}

Fuente: Elaboración propia 


\section{DAP Packing}

Se presenta el DAP del proceso de packing en la figura 29, en el cual se han identificado 14 actividades principales constituidas por 5 operaciones, 4 transportes, 2 esperas, 1 inspección, 1 operación combinada y un almacenamiento. Se debe recordar que este proceso inicia con la emisión de las guías de remisión y termina con la colocación del pedido embalado en la zona de productos embalados para el siguiente proceso (transporte).

El tiempo medio del proceso de packing es de 349 minutos, equivalentes a 5.8 horas (aprox. medio día de horas laborales). La actividad que mayor tiempo medio registra es la espera para iniciar a embalar el pedido con 240 minutos (cuatro horas), el cual equivale al $68.8 \%$ de tiempo del proceso.

Para el análisis de las actividades de transporte se identifica que el recorrido medio del proceso es 133 metros. Similar al anterior proceso, la actividad con mayor recorrido se origina por llevar las guías impresas del segundo piso al primero y regresar, el recorrido medio de esta actividad fue es de 110 metros.

La suma de las actividades de espera, transportes y almacenamiento representan un $90.8 \%$ del total del tiempo en el que se realiza este proceso con 317 minutos o 5.28 horas. 
Figura 29: DAP Proceso de Packing

\begin{tabular}{|c|c|c|c|c|c|c|c|c|c|c|}
\hline \multicolumn{11}{|c|}{ DIAGRAMA DE ANÁLISIS DEL PROCESO } \\
\hline \multirow{2}{*}{ DIAGRAMA №: $\quad$ DAPSBSPA-1.0 } & \multirow{2}{*}{\multicolumn{2}{|c|}{ HOJA №: }} & \multirow{2}{*}{\multicolumn{4}{|c|}{03}} & \multicolumn{4}{|c|}{ RESUMEN } \\
\hline & & & & & & & ACTIVIDAD & ACTUAL & PROPUESTA & ECONOMÍA \\
\hline \multicolumn{7}{|l|}{ Método: ACTUAL / PROPUESTO } & $\begin{array}{l}\text { Operación } \\
\text { Transporte }\end{array}$ & $\begin{array}{l}5 \\
4\end{array}$ & & \\
\hline \multicolumn{7}{|l|}{ OPERACIÓN / PROCESO: } & Espera & 2 & & \\
\hline \multirow{3}{*}{\multicolumn{7}{|c|}{ Packing }} & Inspección & 1 & & \\
\hline & & & & & & & Op. Combinada & 1 & & \\
\hline & & & & & & & Almacenamiento & 1 & & \\
\hline \multicolumn{7}{|l|}{$\begin{array}{l}\text { LUGAR: Centro de Distribución SBS } \\
\text { COMPUESTO POR: }\end{array}$} & Distancia (m) & 133 & & \\
\hline COMPUESTO POR: & & & & & & & Tiempo (min) & 349 & & \\
\hline \multicolumn{7}{|l|}{ FECHA: $/ /$} & Costos & & & \\
\hline \multirow{2}{*}{ DESCRIPCION } & \multicolumn{6}{|c|}{ SIMBOLO } & \multirow{2}{*}{ OBSERVACIONES } & \multirow[t]{2}{*}{ c } & \multirow[t]{2}{*}{$\mathrm{D}(\mathrm{m})$} & \multirow[t]{2}{*}{$T(\min )$} \\
\hline & 0 & $\Longrightarrow$ & $\bar{D}$ & & 0 & $\nabla$ & & & & \\
\hline Se espera la emisión de las $G R$ & & & $-x$ & & & & Empieza según el trabajo pendiente & & & 60 \\
\hline Se emite la GR & 5 & & & & & & $\begin{array}{l}\text { La guía se emite cuando el dgitador } \\
\text { termina lo pendiente }\end{array}$ & & & 5 \\
\hline Se bajan las GR al almacén y regresa & & $x$ & & & & & Al primer piso & & 110 & 8 \\
\hline Se espera turno para empezar a embalar & & & $x$ & & & & Según la carga detrabajo & & & 240 \\
\hline Se selecciona GR a embalar & & & & $\lambda$ & & & & & & 3 \\
\hline Se dirige a la zona de pedidos en proceso & & 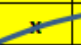 & & & & & & & 9 & 1 \\
\hline Coge los libros del pedido correspondiente & 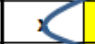 & & & & & & & & & 2 \\
\hline Se dirige a la mesa de embalaje & & $\sum$ & & & & & & & 9 & 4 \\
\hline Se ordenan y apilan los libros & $=1$ & & & & & & & & & 10 \\
\hline Se cuentan los libros / Check con la GR & & & & & $>$ & & & & & 4 \\
\hline Se embalan los libros en cajas $y / 0$ bolsas & $\infty$ & & & & & & & & & 5 \\
\hline Se transportan los bultos a los pallets para despacho & & $\sum$ & & & & & & & 5 & 4 \\
\hline Se deja el pedido embalado en los pallets para despacho & 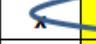 & & & & & & & & & 3 \\
\hline Los pedidos son almacenados hasta su programación de despacho & & & & & 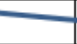 & $-x$ & La mercadería sale al turno siguiente & & & \\
\hline 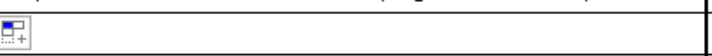 & & & & & & & & & & \\
\hline & & & & & & & & & & \\
\hline Totales: & 5 & 4 & 2 & 1 & 1 & 1 & & & & \\
\hline
\end{tabular}

Fuente: Elaboración propia 


\section{Trazado VSM actual}

Como se presentó en el capítulo 1 (marco teórico) el diagnóstico VSM o mapa de la cadena de valor es una de las herramientas que propone Lean para el diagnóstico de la situación actual y plasma de manera gráfica y visual las actividades de la cadena valor identificando el flujo de información y el flujo de productos.

En base a la información presentada en los DAP de cada proceso, en los cuales se analiza los pedidos de libros ELT durante los principales meses de campaña escolar, se ha realizado el VSM actual de la distribuidora SBS (ver figura 30).

Para el análisis del flujo de información, se han centrado las actividades en el centro Logístico de SBS debido a que en él se recepcionan los pedidos de los clientes a través de diferentes formatos, luego, se envían diferentes órdenes de compra a cada proveedor. Del centro logístico, también parte la información necesaria para cada proceso como: Aviso de llegada de importación, Notas de salida (pedidos) y guías de remisión.

Dentro del flujo de mercadería, las operaciones inician desde el proveedor hacia el proceso de recepción e inventario; luego, el flujo sigue hacia los procesos de picking, packing, y transporte hasta el cliente.

La información del tiempo de ciclo y las actividades de valor agregado también se muestran en el VSM actual, dando como resultado un total de 64 días con 6 horas, mientras el tiempo de valor agregado es de 74.26 horas para pedidos con un promedio de 300 unidades diarias. 
Figura 30: Análisis VSM de la Distribuidora SBS - Actual

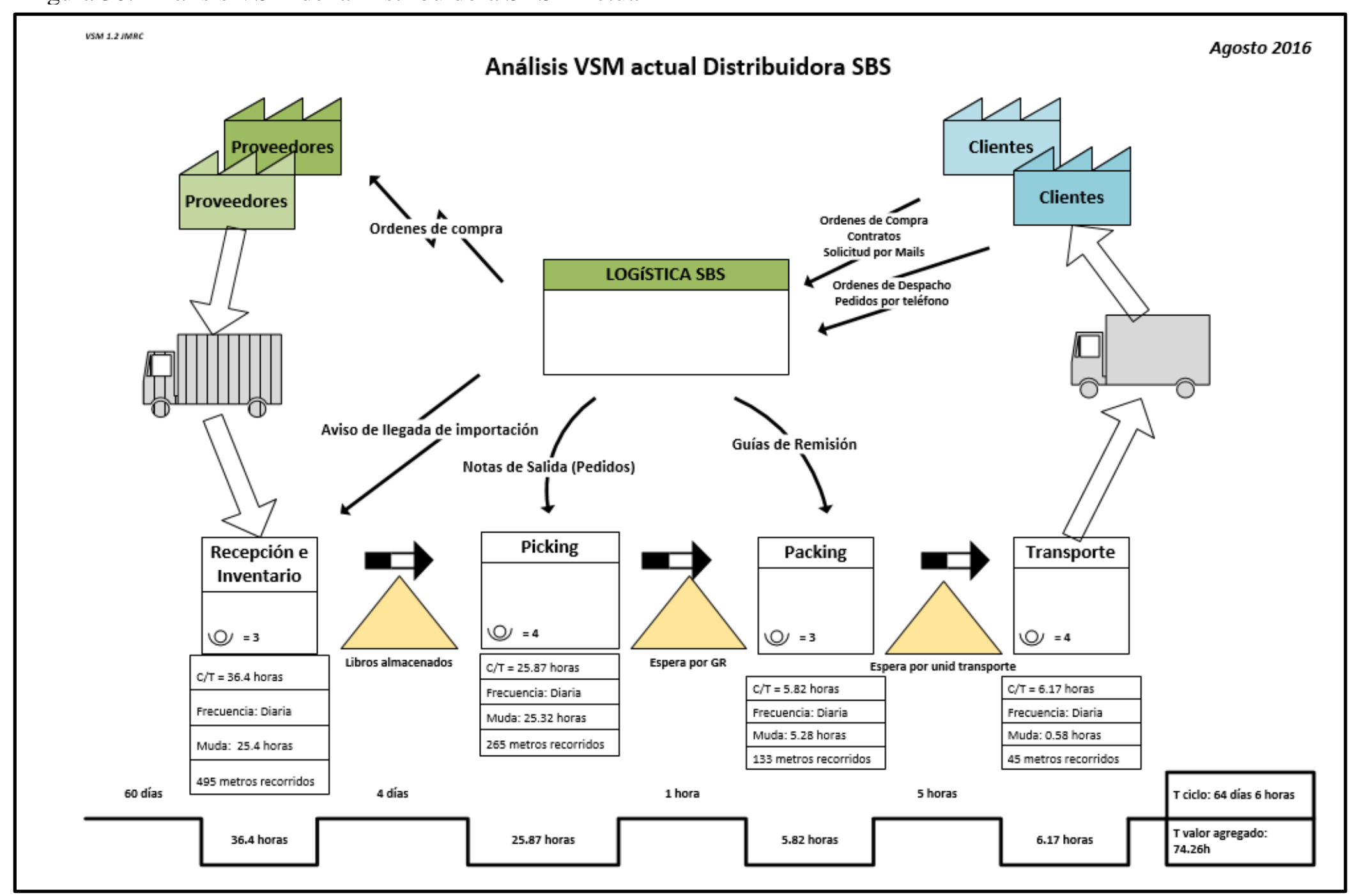

Fuente: Elaboración propia 


\section{Trazado VSM futuro}

Luego de identificar los procesos que agregan valor al cliente en la figura anterior, se observa que estos procesos son en su mayoría los que interactúan con el flujo físico de mercadería y se desarrollan en el centro de distribución. Los procesos presentan una medición en base al recurso que utilizan en su desarrollo: el tiempo. En adición, en cada uno de ellos se evidencia la cantidad de minutos en los que se realizan las actividades que no generan valor (muda). A partir del mapeo del VSM se logran identificar las oportunidades de mejora. En los procesos de recepción e inventario, picking y packing se puede implementar las 5S con el fin de preparar la planta en su organización manteniendo el orden y la limpieza para la implantación de mejoras en el proceso como cambios y ajustes en el método de desarrollar las operaciones. Otra herramienta que se puede aplicar es la Estandarización; una vez implantada la mejora en el proceso y/o método se realizará la aplicación de estándares para que de este modo se puedan realizar mediciones y comparaciones de los resultados anteriores y los nuevos obtenidos. Por último, al indicar que se realizarán mediciones y comparaciones de los resultados, se alude a la implantación de KPI donde se establecerá la forma de medir el desempeño de los procesos.

En la siguiente página se muestra el VSM con las oportunidades de mejora (ver figura 31). 
Figura 31: VSM con oportunidades de mejora

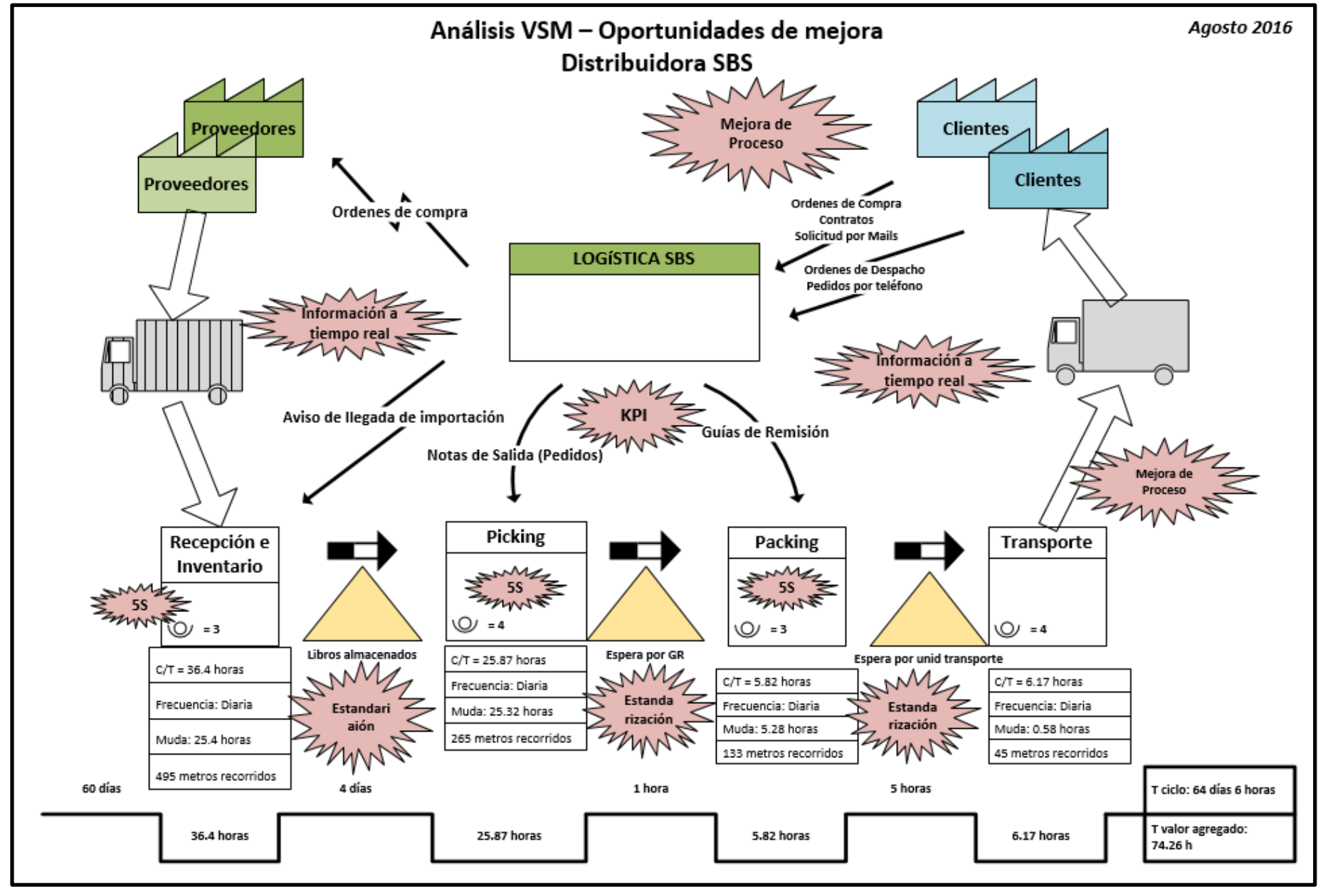

Fuente: Elaboración propia 


\section{Identificación de indicadores claves KPI}

Como siguiente paso, se deben identificar los indicadores clave de desempeño en la distribuidora SBS. Teniendo en cuenta los análisis de los procesos en donde interviene el flujo físico de mercadería - como son los procesos de recepción e inventario, picking y el packing mostrados a través del análisis del diagrama de proceso (DAP) y la representación gráfica del VSM actual - se ha expuesto como se van desenvolviendo las actividades inmersas en cada proceso. Con el fin de fijar una base del desempeño actual se ha estudiado algunos indicadores de productividad para cada proceso.

En consecuencia, se ha extraído información de 90 días correspondientes a los tres meses del período de campaña: febrero, marzo y abril del 2016 con el propósito de identificar cuantas unidades son procesadas por cada hora hombre de trabajo.

- En el proceso de recepción e inventario, se obtuvo que la media de cantidades recibidas por día es de 12,409 que divididas entre las doce horas que se trabajan durante los meses analizados dan un valor total de 1034 unidades/hora hombre. Por otro lado, las unidades procesadas al final de esta estación de recepción e inventario indican un una media 7,018 unidades, este valor se divide entre las 12 horas trabajadas por los 3 colaboradores que participan en el proceso teniendo un desempeño de 195 unid/hora hombre.

- La media de unidades separadas como resultado del proceso picking es de 8,811 que relacionadas con las 48 horas hombre que intervienen en este proceso indican que la productividad del proceso es de 184 unidades/horas hombre. En este proceso, cabe mencionar, que el flujo de unidades solicitadas tanto de material recién importado con material de stock es de 972 unidades/hora. 
- Las unidades embaladas como resultado del proceso de packing cuentan con una productividad de 224 unidades/hora hombre, este resultado se obtuvo de relacionar la media de 8,056 unidades embaladas entre las 36 horas hombre producto de las doce horas trabajadas a día por los tres trabajadores del proceso.

De manera resumen se muestra la tabla 3.

Tabla 3: Indicadores de productividad del proceso Logístico de SBS

\begin{tabular}{||l|c|c|c|c||}
\hline \multicolumn{1}{|c|}{ Variable // proceso } & Throughput & $\begin{array}{c}\# \\
\text { trabajad } \\
\text { ores }\end{array}$ & $\begin{array}{c}\text { Horas } \\
\text { trab. }\end{array}$ & $\begin{array}{c}\text { Unid. } \\
\text { Procesada por } \\
\text { día }\end{array}$ \\
\hline Unidades recepcionadas & $1034 \mathrm{unid} / \mathrm{H}$ & & 12 & 12,409 \\
\hline Unidades inventariadas & $195 \mathrm{unid} / \mathrm{HH}$ & 3 & 12 & 7,018 \\
\hline Unidades solicitadas & $972 \mathrm{unid} / \mathrm{H}$ & & 12 & 11,665 \\
\hline Unidades separadas // Picking & $184 \mathrm{unid} / \mathrm{HH}$ & 4 & 12 & 8,811 \\
\hline Unidades embaladas// Packing & $224 \mathrm{unid} / \mathrm{HH}$ & 3 & 12 & 8,056 \\
\hline
\end{tabular}

Fuente: Elaboración propia

\section{Fase 2: Planificación implantación Lean}

\section{Planificación del proyecto Lean}

Según la hoja de ruta propuesta, terminada la implementación de la fase 1, el primer paso en la fase 2, es la planificación del proyecto donde se detalla la programación y la secuencia de las actividades y cronogramas a desarrollar para el cumplir con los objetivos Lean. Esto se ejecutará y plasmará a través del diagrama de Gantt.

La planificación del proyecto inicia con la organización del equipo Lean, tal como se manifestó en la primera fase, esta organización deberá ser realizada por el comité Lean conformado por las gerencias de la organización durante las primeras dos semanas. Las siguientes tres semanas, 
el equipo Lean deberá recibir la formación y capacitación en las herramientas Lean, esto se explicó a mayor detalle en la fase 1.

Culminada la formación del equipo Lean o durante la última semana del 1er mes, se desarrollaran las primeras mediciones de los indicadores KPI y se realizará el primer trazado actual del VSM. Para inicios del tercer mes, se debe llevar a cabo la implantación de las 5s como pre requisito para la aplicación de la mejora de proceso que debe culminar en su primer ciclo hasta la mitad del cuarto mes. La propuestas de mejora al proceso y/o al método de desarrollarlo se deben estar ejecutando desde finales de 3er mes. Mientras que la estandarización de la mejora del proceso deberá hacerse efectiva a mediados del 5 to mes.

Durante el sexto mes se llevará a cabo la mejora continua, empezando con la nueva medición de los indicadores KPI y el trazado del nuevo VSM pudiendo identificar nuevas oportunidades de mejora y continuar el ciclo.

Para una mayor ilustración se muestra la figura 32 con la planificación de las actividades Lean. 
Figura 32: Cronograma de actividades para la implantación del Lean Logitics en la empresa SBS

\begin{tabular}{|c|c|c|c|c|c|c|c|c|c|c|c|c|c|c|c|c|c|c|c|c|c|c|c|c|c|}
\hline \multirow{2}{*}{$\begin{array}{c}\text { Fase de } \\
\text { implantación }\end{array}$} & \multirow{2}{*}{ Actividad Lean } & \multicolumn{4}{|c|}{ Mes 1} & \multicolumn{4}{|c|}{ Mes 2} & \multicolumn{4}{|c|}{ Mes 3} & \multicolumn{4}{|c|}{ Mes 4} & \multicolumn{4}{|c|}{ Mes 5} & \multicolumn{4}{|c|}{ Mes 6} \\
\hline & & s1 & S2 & s3 & S4 & S5 & S6 & s7 & S8 & s9 & S10 & S11 & S12 & S13 & S14 & S15 & S16 & S17 & S18 & S19 & S20 & S21 & 522 & S23 & S24 \\
\hline Fase 1 & Selección y formación del equipo Lean & & & & & & & & & & & & & & & & & & & & & & & & \\
\hline Fase 1 & Formación del equipo Lean - Capacitación & & & & & & & & & & & & & & & & & & & & & & & & \\
\hline Fase 1 & Trazado del VSM actual - identificación de mejoras & & & & & & & & & & & & & & & & & & & & & & & & \\
\hline Fase 2 & Primeras mediciones de indicadores claves & & & & & & & & & & & & & & & & & & & & & & & & \\
\hline Fase 3 & Implantación de las $5 \mathrm{~s}$ & & & & & & & & & & & & & & & & & & & & & & & & \\
\hline & **Clasificar & & & & & & & & & & & & & & & & & & & & & & & & \\
\hline & **ordenar & & & & & & & & & & & & & & & & & & & & & & & & \\
\hline & **timpiar & & & & & & & & & & & & & & & & & & & & & & & & \\
\hline & ***standarizar & & & & & & & & & & & & & & & & & & & & & & & & \\
\hline & ***Disciplinar & & & & & & & & & & & & & & & & & & & & & & & & \\
\hline Fase 4 & Mejora de Procesos & & & & & & & & & & & & & & & & & & & & & & & & \\
\hline & **Identificación de Oportunidades & & & & & & & & & & & & & & & & & & & & & & & & \\
\hline & **Sustento de propuesta & & & & & & & & & & & & & & & & & & & & & & & & \\
\hline & ***Desarrollo de prouestas & & & & & & & & & & & & & & & & & & & & & & & & \\
\hline Fase 5 & Estandarización de las mejoras & & & & & & & & & & & & & & & & & & & & & & & & \\
\hline Fase 6 & Plan Piloto & & & & & & & & & & & & & & & & & & & & & & & & \\
\hline & Estandarización de los procesos & & & & & & & & & & & & & & & & & & & & & & & & \\
\hline & Nueva medición de indicadores claves KPI & & & & & & & & & & & & & & & & & & & & & & & & \\
\hline & Trazado del VSM actual - identificación de mejoras... & & & & & & & & & & & & & & & & & & & & & & & & \\
\hline
\end{tabular}

Fuente: Elaboración propia 


\section{Definición de indicadores}

Actualmente la empresa no cuenta con indicadores de gestión y de control de los procesos, tampoco desarrolla sus operaciones bajo una cultura de medición de tiempos. Se debe considerar que estos problemas fueron los que mayor representatividad presentaron en el análisis y diagnóstico de la situación actual. Ante esta circunstancia, el autor, realizó la medición a un grupo representativo de pedidos cuyo promedio era 300 unidades solicitadas por pedido, los resultados se mostraron en el análisis del diagrama del proceso (DAP) en la fase 1 de diagnóstico y recopilación de información. Adicional a ello, durante la primera fase, también se analizó la productividad (throughput) por día y por hora hombre $(\mathrm{HH})$ de cada proceso analizado en el punto de identificación de indicadores claves.

Para la presentación y medición del actual proyecto de aplicación de herramientas Lean, se utilizarán los indicadores clave de productividad de los principales procesos que implican el flujo físico de la mercadería: Recepción y almacenamiento, Picking y Packing. No se considera el proceso de transporte (despachos de pedidos) por implicar actividades de transporte que se realizan fuera del centro de distribución.

En tal sentido se muestra el cuadro 24 con el nombre de los indicadores, los procesos a que corresponden, una breve definición de ellos, la base de donde se parte y la meta propuesta. 
Cuadro 25: Definición de Indicadores

\begin{tabular}{|c|c|c|c|c|c|c|c|}
\hline $\begin{array}{l}\text { Indicador de } \\
\text { Productividad }\end{array}$ & Proceso & Definición & Cálculo & Registro & $\begin{array}{c}\text { Ciclo de } \\
\text { Evaluación }\end{array}$ & Base & Meta \\
\hline $\begin{array}{l}\text { Capacidad promedio } \\
\text { de inventario diario }\end{array}$ & $\begin{array}{c}\text { Recepción y } \\
\text { almacenamiento }\end{array}$ & $\begin{array}{l}\text { Se registran los tiempos por hora hombre y unidades de las } \\
\text { operaciones de inventario y almacenaje, es decir, el indicador } \\
\text { registra el tiempo desde la recepción de la mercadería hasta su } \\
\text { almacenamiento. Compara la relación entre la cantidad de } \\
\text { unidades procesadas al fnal del día y el recurso utilizado para ello } \\
\text { (HH: horas hombre) }\end{array}$ & $\frac{\text { unid.Inventariadas } x \text { día }}{\text { HH (hora hombre utilizado })}$ & Diario & Mensual & 195 unid/HH & 224 unid/HH \\
\hline $\begin{array}{l}\text { Capacidad pomedio de } \\
\text { separación diaria }\end{array}$ & $\begin{array}{c}\text { Picking // Separación } \\
\text { de pedidos }\end{array}$ & $\begin{array}{l}\text { Registra la relación entre la cantidad de libros separados al día y el } \\
\text { recurso que se empleó para ello expresado en horas hombre (HH). } \\
\text { Los registros van desde la recepción de los pedidos hasta dejar los } \\
\text { libros en la zona de embalado. }\end{array}$ & $\frac{\text { unid. separadas } x \text { día }}{\text { HH (hora hombre utilizado })}$ & Diario & Mensual & 184 unid/HH & 211 unid/HH \\
\hline $\begin{array}{l}\text { Capacidad promedio } \\
\text { de Embalaje diario }\end{array}$ & $\begin{array}{c}\text { Packing // Embalaje } \\
\text { de pedidos }\end{array}$ & \begin{tabular}{|l} 
Registra la relación entre la cantidad de libros embalados al día y el \\
recurso que se empleó para realizar las operaciones de embalaje \\
expresado en horas hombre. Los registros inician con la recepción \\
de la GR y la puesta del pedido en la zona de despacho.
\end{tabular} & $\frac{\text { unid.embaladas } x \text { día }}{\text { HH (hora hombre utilizado })}$ & Diario & Mensual & 224 unid/HH & 257 unid/HH \\
\hline
\end{tabular}

Fuente: Elaboración propia 


\section{Organización y mentalización de equipos Lean}

El equipo Lean será el encargado de llevar a cabo el desarrollo, implementación y control de la metodología y herramientas Lean. Los integrantes de este equipo serán escogidos en consenso por el comité Lean, conformado por las cuatro gerentes según se explicó en la primera fase, en base a la evaluación y ponderación de factores como año en la empresa, nivel de formación, experiencia y rendimiento del colaborador. (Según lo explicado en el punto 3.3.1)

En tal sentido, el equipo Lean será multidisciplinario y estará conformado por la siguiente estructura:

Figura 33: Organigrama Lean Logistics SBS

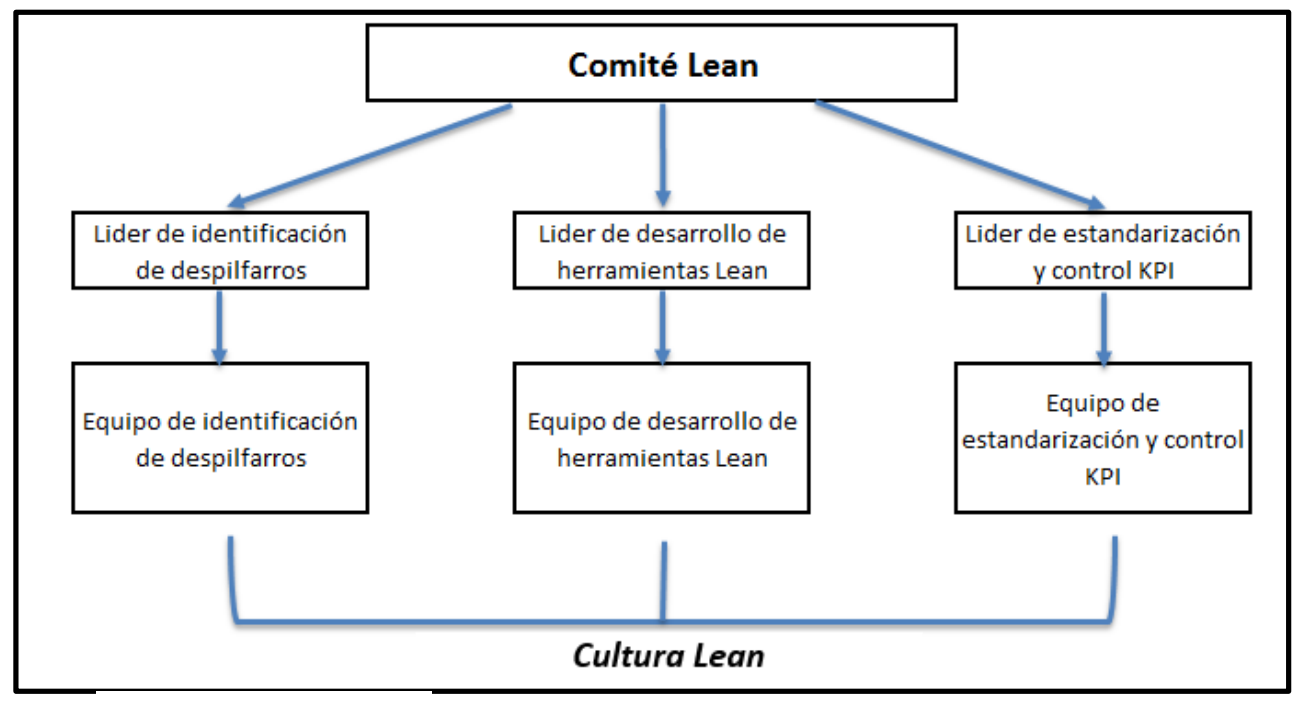

Fuente: Elaboración propia

Como se observa en la figura 33 para la implantación se formarán tres equipos. El primero se denomina "Equipo de identificación de despilfarros" y estará encargado del análisis de estadístico, mapeos de diagrama de valor e identificación de oportunidades de mejora. El segundo equipo, será el encargado de la planificación e implantación de las herramientas y metodologías Lean. Por último, el tercer equipo estará a cargo de elaborar los procedimientos y 
manuales que soporten la estandarización del proceso, así como velar que los procesos estén controlados correctamente por indicadores KPI.

\section{Selección y definición de línea / área piloto}

Para el presente estudio de propuesta de herramientas Lean Logistics se ha tomado en cuenta como parte de diagnóstico la línea de producto ELT (por sus siglas en ingles English Language teaching) debido a que este representa más del $74 \%$ de la facturación de la empresa. Como este tipo de libros es utilizado para la enseñanza del curso de inglés en los colegios, el periodo a analizar, implementar y medir la propuesta será durante la campaña escolar en los meses Febrero, Marzo y Abril.

Del mapeo de procesos realizados en el análisis de la situación actual, se identificó los 4 procesos claves de la cadena de suministro de la empresa Special Book Services: Planificación, Aprovisionamiento, Distribución y Devolución. De estos cuatro procesos, la implantación Lean se ejecutará en el proceso de Distribución, el cual desarrolla sus actividades en el centro de distribución de la compañía, los mismo que implican la interacción del flujo físico de mercadería. 
Figura 34: Aplicación de las prácticas Lean en los procesos Logísticos de SBS

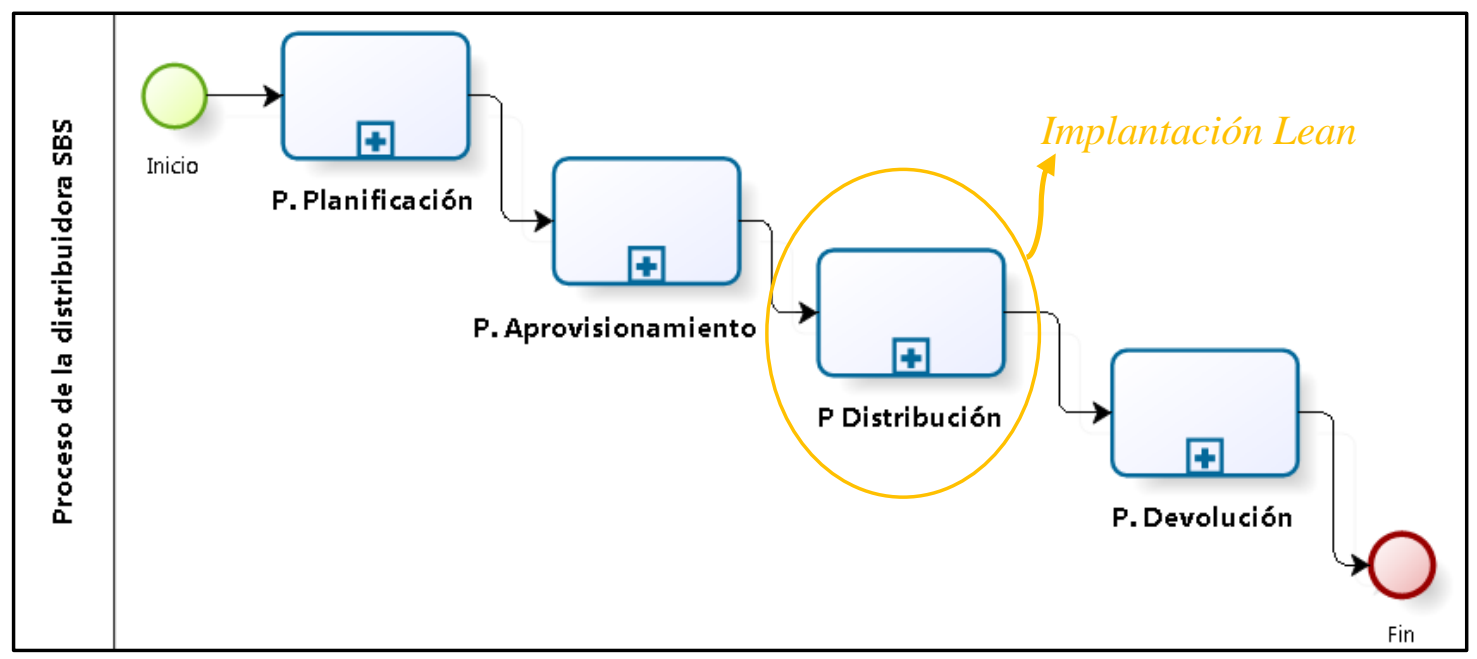

Fuente: Elaboración propia

Gracias al mapeo de la cadena de valor VSM se identificó que existen cuatro sub procesos que agregan valor al proceso de distribución: Recepción y almacenamiento, Picking, Packing y transporte; de los cuales los tres primeros serán foco de la implementación de mejoras debido a que todas sus actividades se desarrollan dentro del centro de distribución a diferencia del sub proceso de transporte. 


\section{Fase 3: Lanzamiento - Implementación de las 5S}

\section{Ámbito y Aplicación}

Se ha definido como ámbito de aplicación de la Estrategia 5’S el Almacén Central de SBS por ser una de las áreas importantes dentro de la cadena de valor de la empresa, el cual forma parte del Centro de Distribución de la empresa y es en dónde se desarrollan los diversos procesos que interactúan con el flujo físico de mercadería. Igualmente, se ha constatado que durante todo el proceso, el flujo de mercadería (entrada - salida) es constante y permanente; en ese sentido, hacer más productivo y eficiente estos procesos aportará a rentabilizar los resultados de la empresa en beneficio de todos sus miembros.

El Almacén Central tiene áreas definidas de trabajo, el criterio de clasificación se ha basado en estas áreas propias del proceso de acondicionamiento de la mercadería, es decir Recepción y almacenamiento, Picking y Packing.

Áreas del Almacén:

- Recepción y almacenamiento

- Picking

- Packing 


\section{Fase 1: Preliminar}

\section{Compromiso de la dirección}

Las mejoras para brindar un servicio de calidad e implementar iniciativas como la Metodología 5’S pueden surgir desde cualquier área de la empresa o nivel jerárquico. En este caso, la iniciativa surgió a solicitud del autor, quien en coordinaciones con su jefe directo (gerente de operaciones), expuso al Gerente General, de manera sencilla, los beneficios que podía aportar la implantación de las 5s en la empresa, a su vez, también se explicó que ésta implantación es parte de una serie de herramientas y propuestas por la metodología Lean Logístics. El gerente general de la empresa respaldó la iniciativa, autorizó y dispuso directamente los recursos necesarios para el proceso de implementación

\section{Organización del Comité 5'S}

La Gerencia General, Gerente de RR HH, Gerente de Operaciones y la Gerencia de Finanzas consensaron que el Gerente de Operaciones con apoyo del autor sea el encargado de seleccionar el Equipo de Trabajo que estará a cargo de liderar el proceso de implementación de la Metodología 5'S en la empresa. Al equipo se le denominará “Comité 5S” y se les brindó una inmersión y sensibilización con respecto a los objetivos a alcanzar de la Metodología 5’S.

Para SPECIAL BOOK SERVICES SA, la organización del Comité 5’S estará encabezado por el Gerente de Operaciones, el Jefe de Almacén, 01 Colaborador del proceso de Picking, 01 colaborador del proceso de Packing y 01 colaborador del proceso Recepción de mercadería.

Los miembros han sido seleccionados por su liderazgo, compromiso, colaboración, comunicación, actitud y ejemplo para sus compañeros. El Comité tiene la responsabilidad de trabajar en base a las etapas del ciclo Deming: Planear, Hacer, Verificar y Actuar. 


\section{Lanzamiento Oficial de la Metodología 5'S}

Para Special Book Services realizar el lanzamiento oficial de la estrategia de las 5'S fue el punto de partida e inicio al proceso de implementación. La participación de la Gerencia General en el Lanzamiento de la Metodología dará a conocer las decisiones tomadas con respecto a este tema y lo que se espera lograr a través de ella. En el Lanzamiento Oficial se realizó la presentación de los miembros del Comité 5’S con el fin de generar compromiso e impacto positivo entre los trabajadores de la empresa.

El lanzamiento se efectuó el 17 de junio del 2016

Lanzamiento 5S -SBS

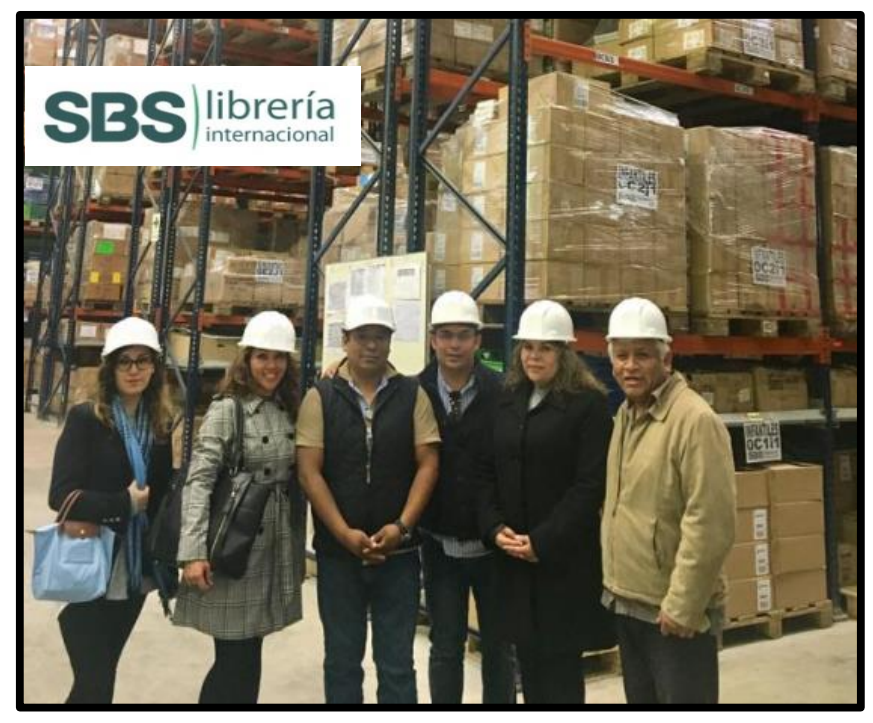

Fuente: La empresa
Lanzamiento 5S - SBS

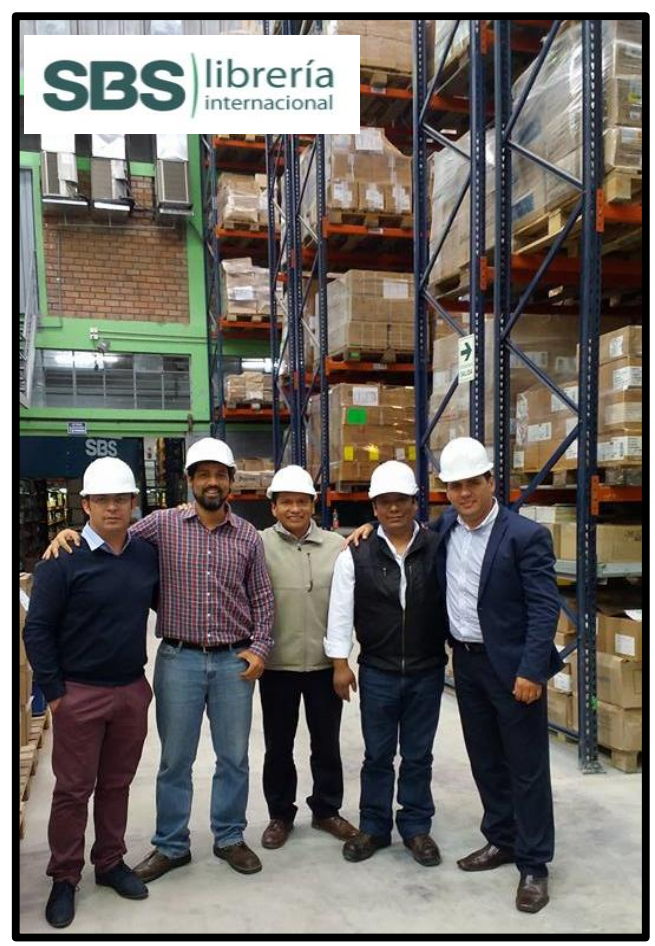

Fuente: La empresa 


\section{Planificación de actividades}

Con el propósito de empezar con el proceso de implementación de la herramienta 5S en Special Book Services, se ha establecido un cronograma y/o plan de trabajo donde se detallan las actividades a realizar, período y el lugar donde se ejecutarán y responsables de cada una de ellas garantizando su ejecución totalmente efectiva. Con ello se delimitan las actividades en sus primeras etapas y se advierten posibles errores de ejecución. Efectuar las actividades respetando la secuencia lógica propuesta reducirá las pérdidas de los recursos invertidos, entre ellos el tiempo; por otro lado, acelerará su desarrollo con una constante validación y control de las actividades programadas.

La idea central de la planificación de las $5 \mathrm{~S}$ para esta implementación consiste en que su buena ejecución se cimienta en adaptar flexiblemente la metodología de implementación a las características particulares de la empresa, en efecto, la organización desarrollara su propio estilo de implementación.

En consecuencia se muestra a modo de ejemplo, el cronograma de actividades que se utilizó para la planificación de las actividades 5S en Special Book Services. Si bien su consecución no fue exacta, fue oportuna al momento de planificar las actividades pendientes y comprobar su avance. 
Figura 35: Planificación de las actividades 5S para la implementación en SBS

\begin{tabular}{|c|c|c|c|c|c|c|c|c|c|c|c|c|c|c|c|}
\hline \multirow{3}{*}{ ACTIVIDAD } & \multirow{3}{*}{ RESPONSABLE } & \multirow{3}{*}{ ACTIVIDADES } & \multicolumn{13}{|c|}{2016} \\
\hline & & & \multirow{2}{*}{\begin{tabular}{|c|} 
MES \\
SEMANA
\end{tabular}} & \multicolumn{4}{|c|}{ JUN } & \multicolumn{4}{|c|}{ JULIO } & \multicolumn{4}{|c|}{ AGO } \\
\hline & & & & 1 & 2 & 3 & 4 & 3 & 4 & 5 & 6 & 7 & 8 & 9 & \# \\
\hline \multirow{3}{*}{$\begin{array}{l}\text { Organización } \\
\text { del comité }\end{array}$} & Gerente General & \multicolumn{2}{|l|}{ Conformación del Comité 5'S } & & & & & & & & & & & & \\
\hline & Jefe de Proyecto & \multicolumn{2}{|l|}{ Determinar las directices y Objetivos } & & & & & & & & & & & & \\
\hline & Jefe de Proceso & \multicolumn{2}{|l|}{ Velar por el cumplimiento del Proyecto } & & & & & & & & & & & & \\
\hline \multirow{3}{*}{$\begin{array}{l}\text { Lanzamiento } \\
\text { Oficial }\end{array}$} & Jefe de Proyecto & \multicolumn{2}{|l|}{ Organizar con GEP las campañas de intriga de las 5'S } & & & & & & & & & & & & \\
\hline & Gerente General & \multicolumn{2}{|l|}{ Lanzamiento Oficial } & & & & & & & & & & & & \\
\hline & & & & & & & & & & & & & & & \\
\hline \multirow{3}{*}{$\begin{array}{l}\text { Capacitación } \\
\text { Interna }\end{array}$} & Jefe de Proyecto & \multicolumn{2}{|l|}{ Capacitación al grupo guía } & & & & & & & & & & & & \\
\hline & Jefe de Proyecto & \multicolumn{2}{|l|}{ Elaboración del Material para la capacitación } & & & & & & & & & & & & \\
\hline & Jefe de Proceso & \multicolumn{2}{|l|}{ Capacitación del Personal } & & & & & & & & & & & & \\
\hline \multirow{3}{*}{$\begin{array}{l}\text { Inicio de } \\
\text { Clasificar }\end{array}$} & Jefe de Proyecto & \multicolumn{2}{|l|}{ Separar lo necesario de lo innecesario } & & & & & & & & & & & & \\
\hline & \begin{tabular}{|l|} 
Jefe de Proceso \\
\end{tabular} & \multicolumn{2}{|l|}{ Buscar destino a lo no necesario } & & & & & & & & & & & & \\
\hline & & & & & & & & & & & & & & & \\
\hline \multirow{3}{*}{$\begin{array}{l}\text { Inicio de } \\
\text { Ordenar }\end{array}$} & & \multicolumn{2}{|l|}{ Organizar espacios } & & & & & & & & & & & & \\
\hline & Jefe de Proyecto & \multicolumn{2}{|l|}{ Ubicar e identificar las herramientas según su uso } & & & & & & & & & & & & \\
\hline & Jefe de Proceso & \multicolumn{2}{|l|}{ Delimitar, áreas, estantes } & & & & & & & & & & & & \\
\hline \multirow{3}{*}{$\begin{array}{l}\text { Inicio de } \\
\text { Limpiar }\end{array}$} & & \multicolumn{2}{|l|}{ Asgnación de limpieza por áreas } & & & & & & & & & & & & \\
\hline & Jefe de Proyecto & Establecer roles de limpieza y frecuencia & & & & & & & & & & & & & \\
\hline & Jefe de Proceso & Concientizar para manener todo limpio & & & & & & & & & & & & & \\
\hline & & Preservar orden y limpieza & & & & & & & & & & & & & \\
\hline InIClo de & Jefe de Proyecto & Definir estándares & & & & & & & & & & & & & \\
\hline estandarizar & Jefe de Proceso & Informar avances y retroalimentación al persona & & & & & & & & & & & & & \\
\hline & & & & & & & & & & & & & & & \\
\hline Diccinlina & Jefe de Proyecto & Implementación de procedimientos y formatos & & & & & & & & & & & & & \\
\hline Disciplina & Jefe de Proceso & Curso de trabajo en equipo & & & & & & & & & & & & & \\
\hline
\end{tabular}

Fuente: Elaboración propia 


\section{Capacitación del personal en 5S}

Las capacitaciones internas en 5S para el personal de SBS tienen como objetivo principal el transmitir y facilitar a los colaboradores los conocimientos, criterios, conceptos y metodología afines para la implementación eficaz de las actividades de la estrategia de las 5'S. Además, en SBS se busca sensibilizar y desarrollar una nueva cultura de trabajo, de este modo se va preparando a los trabajadores al cambio que implica el pensamiento Lean, donde la limpieza y el orden sean propios de los procesos logísticos asociados al compromiso y responsabilidad de cada colaborador. Asimismo, SBS orienta las capacitaciones de las 5S en el fomento del trabajo en equipo, liderazgo, cooperación y un cambio de actitud frente a las actividades que se han identificado que no generan valor a la empresa.

Capacitación 5S - Almuerzo de Confraternidad

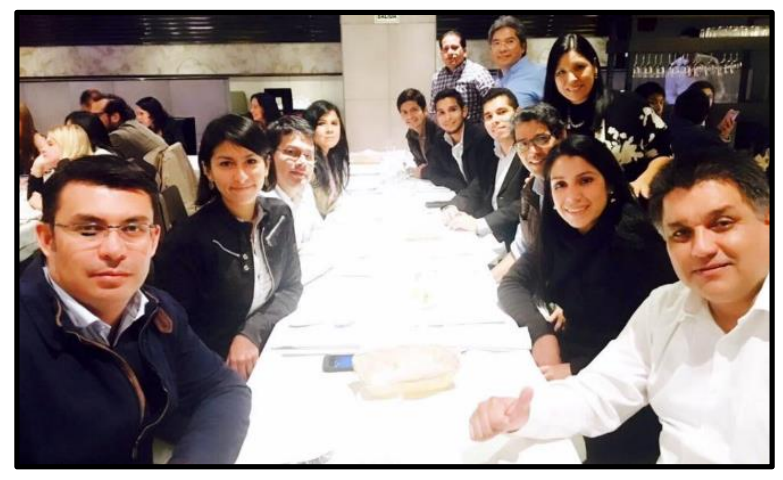

Fuente: La empresa

Capacitación 5S - Día de cierre

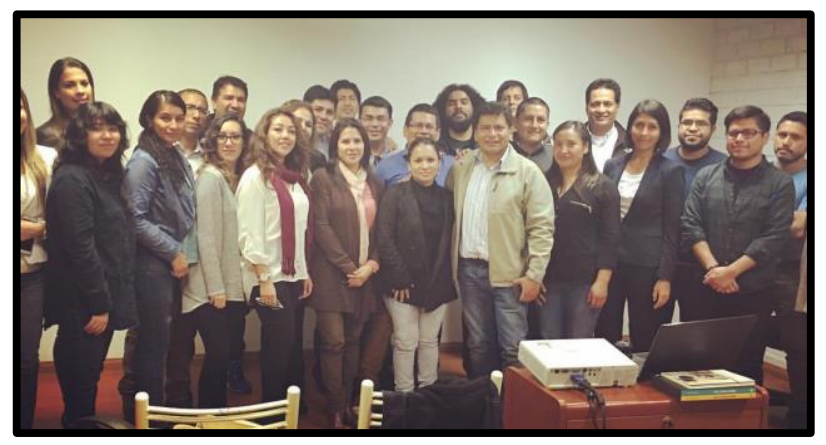

Fuente: La empresa 


\section{Fase 2: Ejecución}

\section{Implementación de la primera S: SEIRI}

La adaptación de la primera S: Seiri en la empresa SBS se realizó empoderando la siguiente idea "Mantener solo lo necesario"

Se determinó que se deben eliminar del área de trabajo todos los elementos innecesarios en la realización de las labores diarias.

Los pasos realizados en esta etapa fueron:

- Se ha efectuado un registro fotográfico inicial donde se puede observar las diversas áreas que componen el almacén central

\section{Seiri SBS}

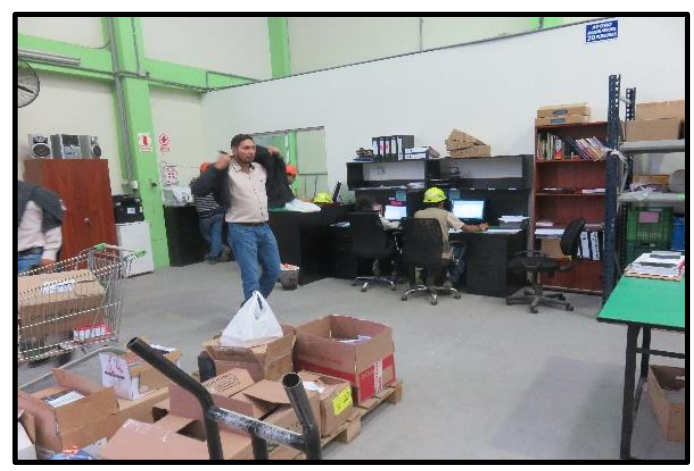

Pasillos con paletas de cajas y carretillas

Fuente: La empresa 


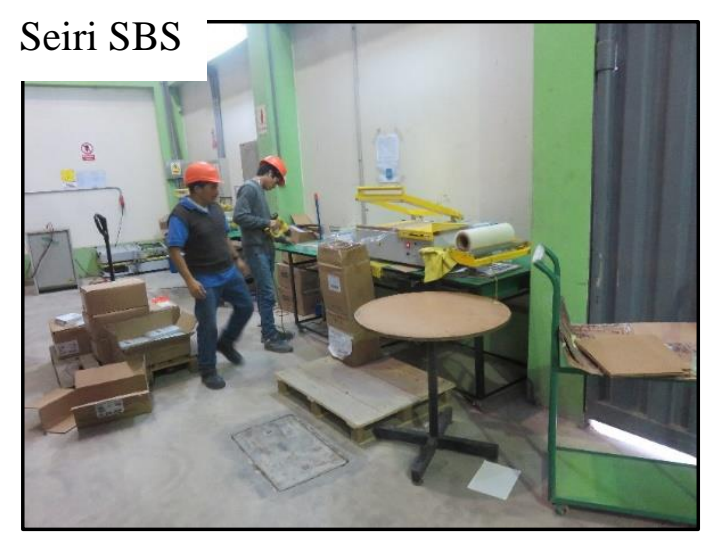

Área de retractilado con cajas, mesas y carretillas

Fuente: La empresa

\section{Seiri SBS}

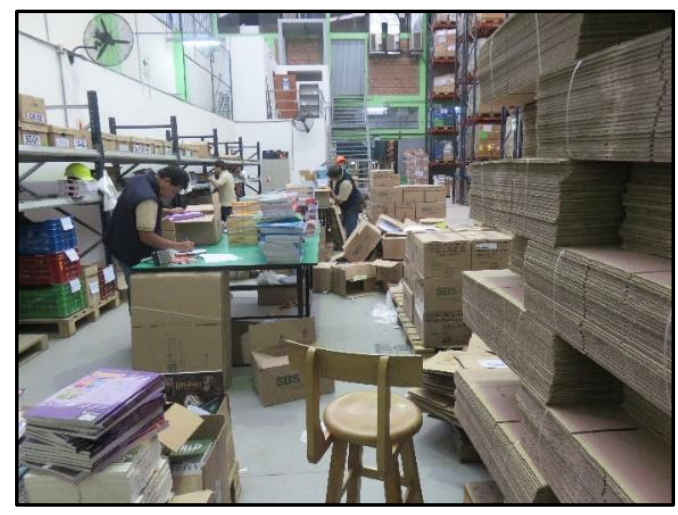

Área de embalaje con cajas y sillas que obstruyen pasillos

Fuente: La empresa

- En los registros fotográficos se observa que los pasillos y/o rutas de acceso están ocupadas por diversos elementos ajenos a la labor establecida en cada área respectiva del trabajo.

- Se observa, además, que el personal de almacén no toma la iniciativa de ordenar y limpiar sus propias áreas de trabajo. 
- Las líneas amarillas de seguridad son obstaculizadas por diversos materiales y herramientas que son utilizadas por los colaboradores y abandonados en cualquier lugar.

- Para el Centro de Distribución, lugar donde se desarrollan los procesos seleccionados de recepción y almacenamiento, picking y packing, se ha elaborado las correspondientes tarjetas rojas que cumplen el rol de notificar los elementos seleccionados para su eliminación.

Figura 36: Modelo de tarjeta roja para la implementación de las 5s: Seiri

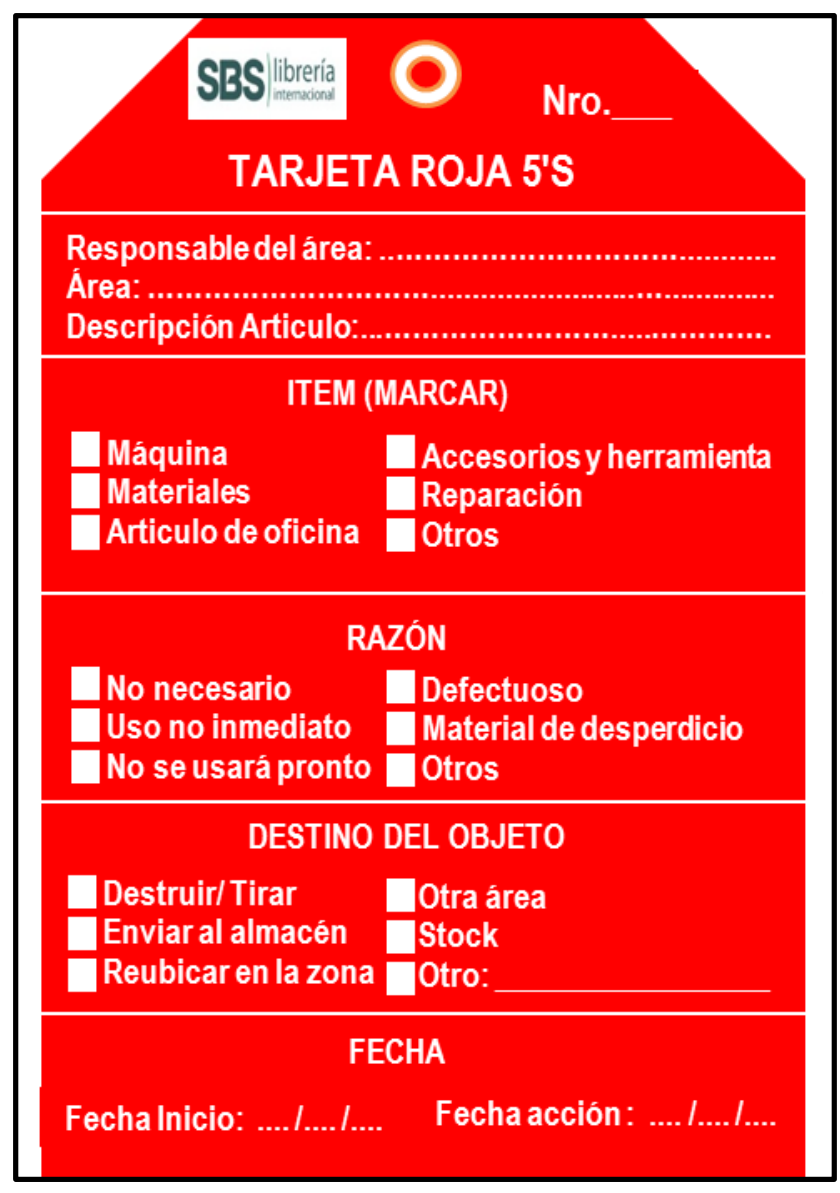

Fuente: Elaboración propia 
- Se procedió con el control visual mediante el uso y aplicación de las tarjetas rojas con el supuesto que si el elemento no es utilizado en 24 horas pasará a denominarse como elemento innecesario, de esta manera se identificó y elaboró un listado de estos elementos.

Se presentan registros fotográficos de algunos de los objetos seleccionados con la tarjeta roja:

Seiri SBS - Tarjeta roja

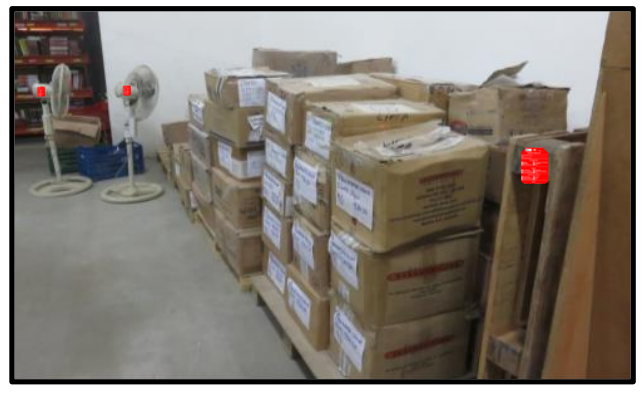

Fuente: La empresa

Seiri SBS -tarjeta roja

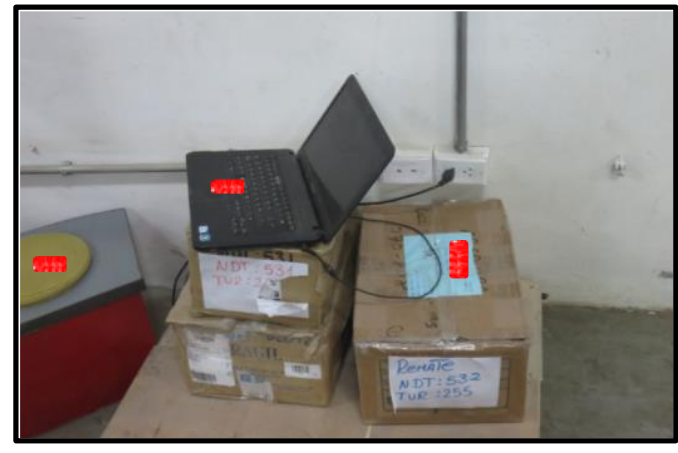

Fuente: La empresa
Seiri SBS - tarjeta roja

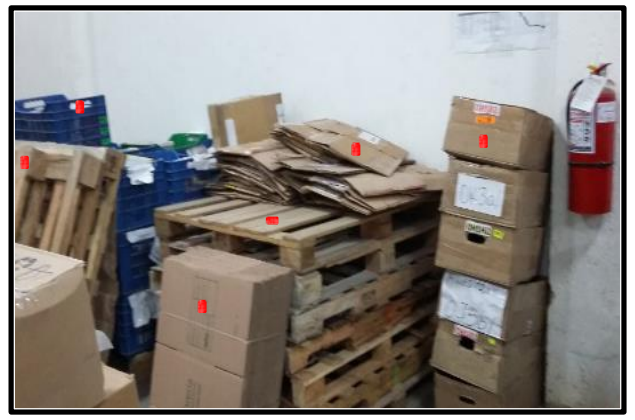

Fuente: La empresa

Seiri SBS - tarjeta roja

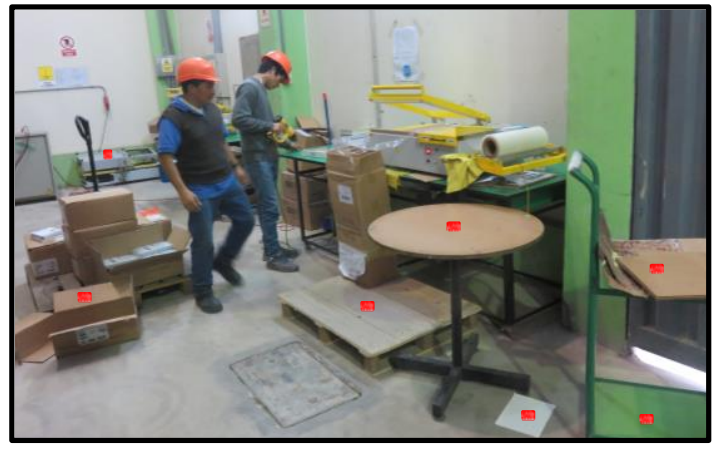

Fuente: La empresa 
Seiri SBS - etiqueta roja

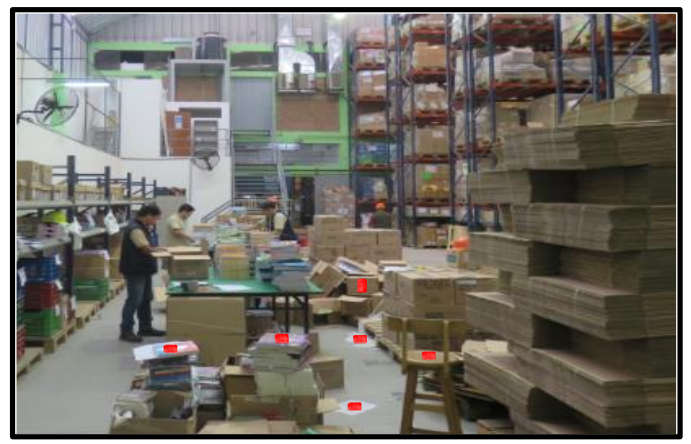

Fuente: La empresa

Seiri SBS - tarjeta roja

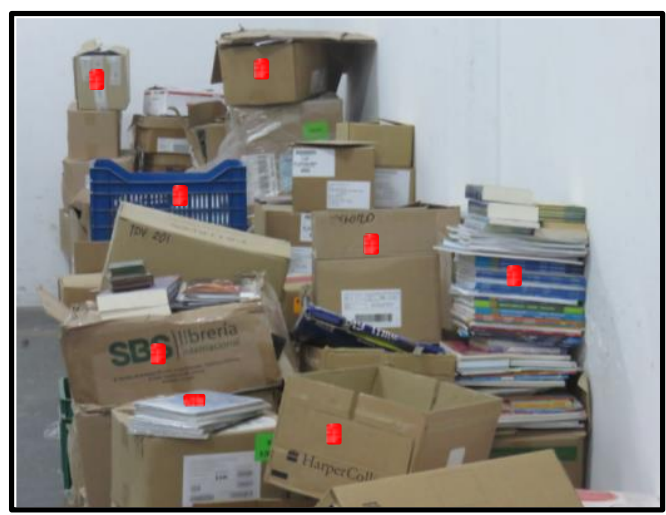

Fuente: La empresa

Seiri SBS - etiqueta roja

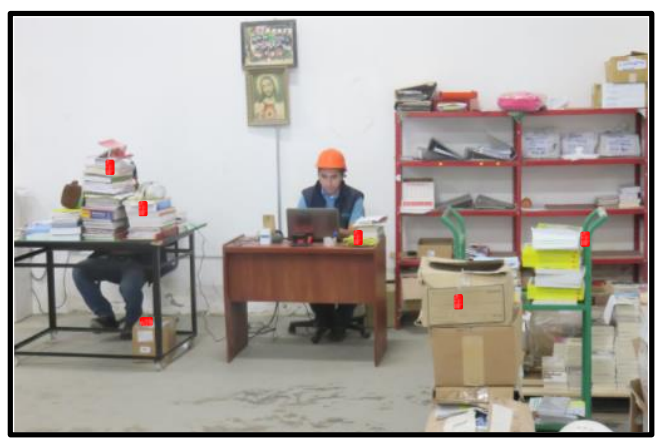

Fuente: La empresa
Seiri SBS - etiqueta roja

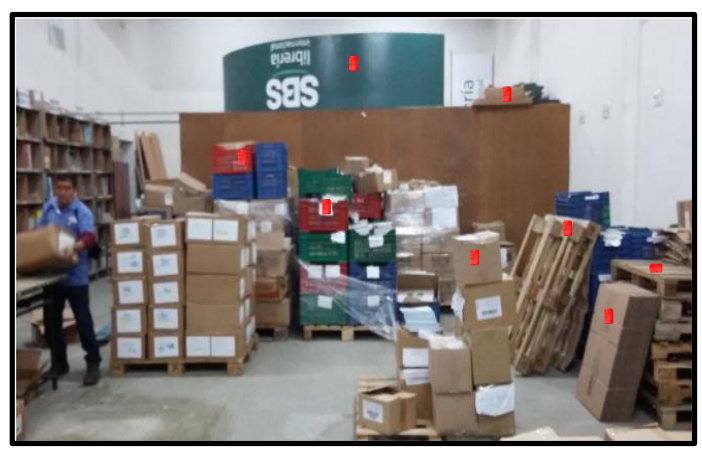

Fuente: La empresa

Seiri SBS - tarjeta roja

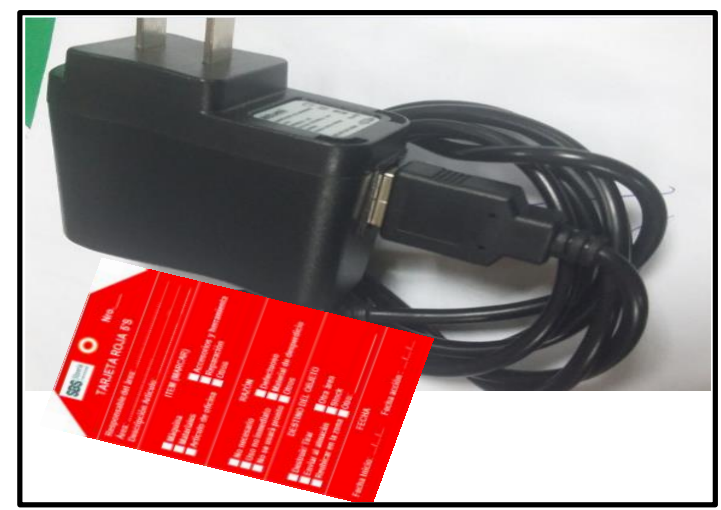

Fuente: La empresa

Seiri SBS - etiqueta roja

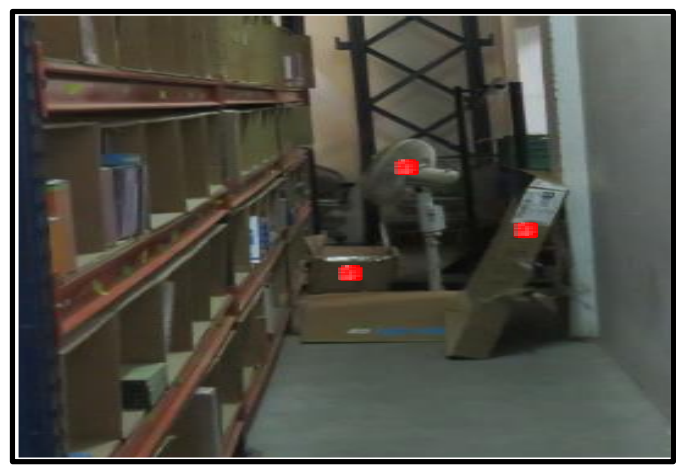

Fuente: La empresa 
Seiri SBS - Tarjeta roja

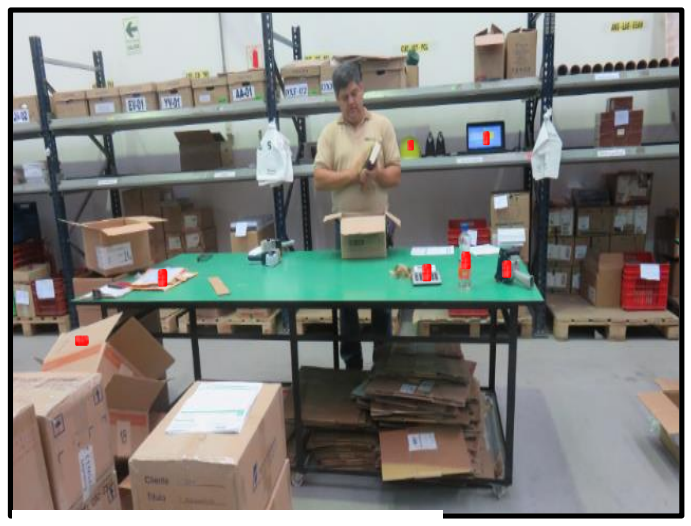

Fuente: La empresa
Seiri SBS - Tarjeta roja

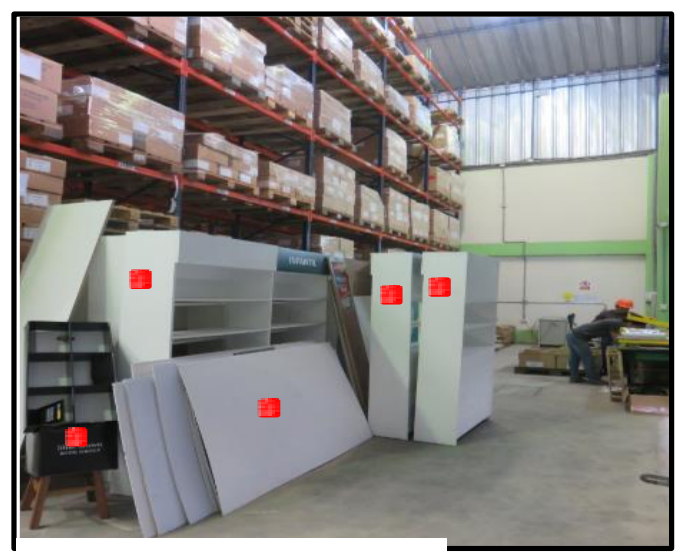

Fuente: La empresa

- Se procedió con el traslado de los elementos innecesarios a un sitio temporal para luego, ser eliminados. Finalmente se elaboraron los informes de avance de las acciones planificadas.

En las siguientes imágenes se muestran las plantillas con la relación de los objetos identificados y puestos a observación para su posible eliminación: 
Lista de Objetos Innecesarios 1

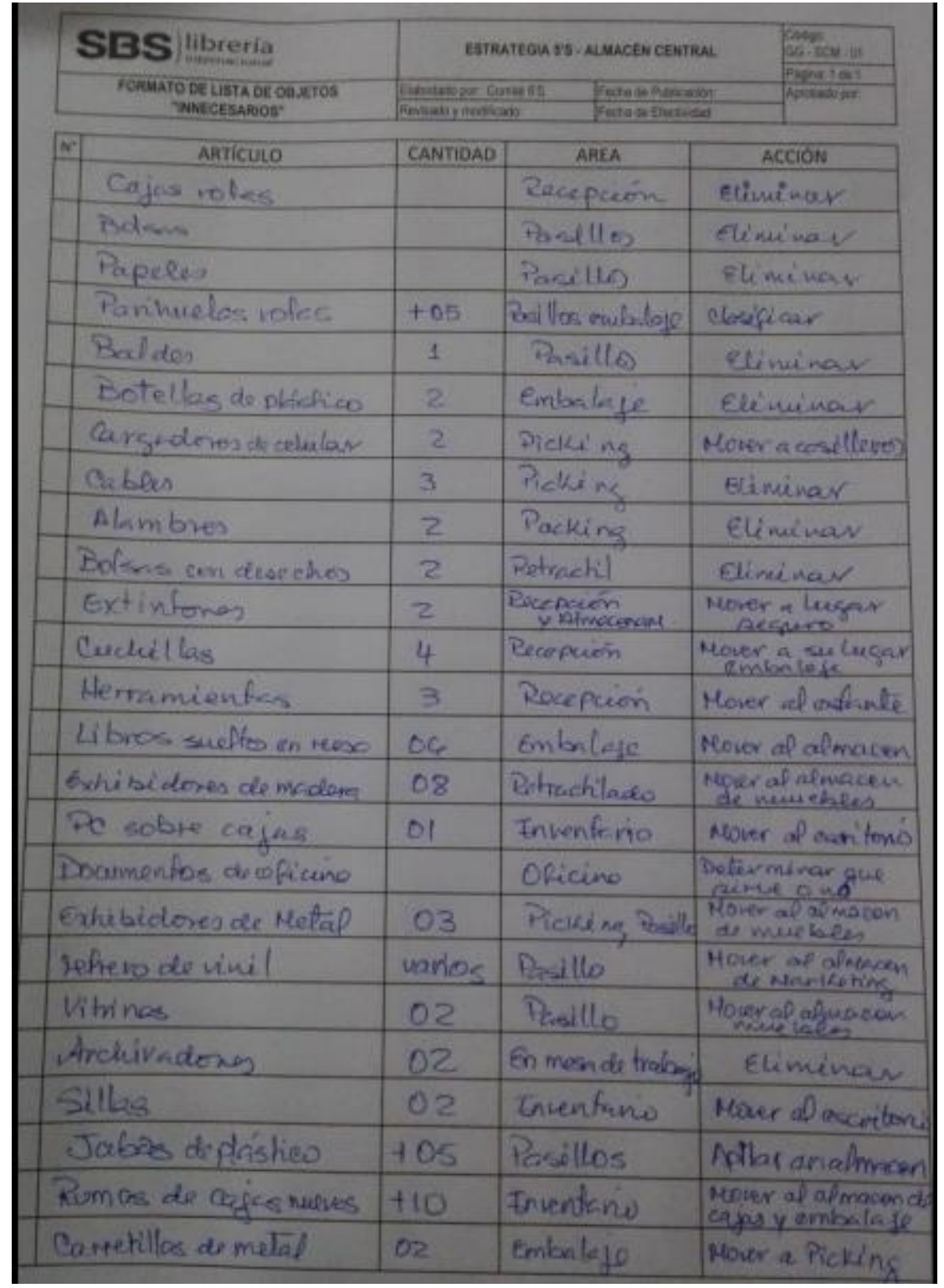

Fuente: La empresa 
Lista de Objetos Innecesarios 2

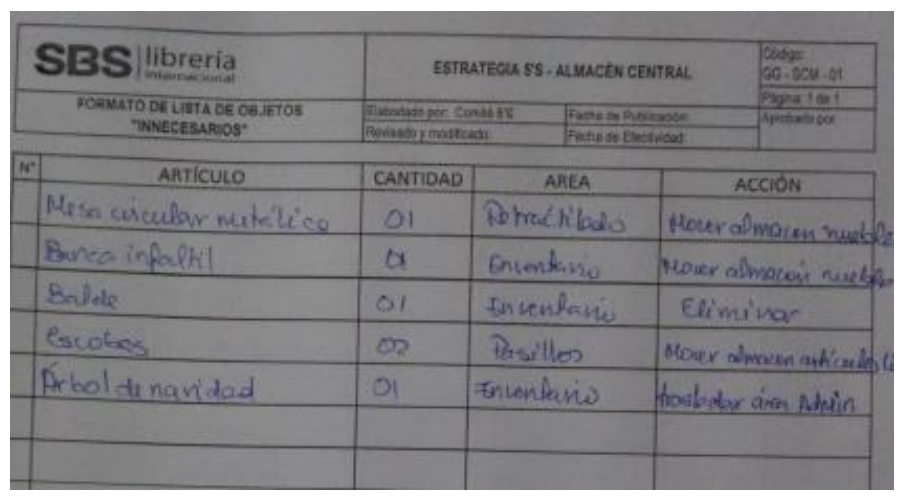

Fuente: La empresa

\section{Lista de Objetos necesarios}

\begin{tabular}{|c|c|c|c|c|}
\hline \multirow{2}{*}{\multicolumn{2}{|c|}{ 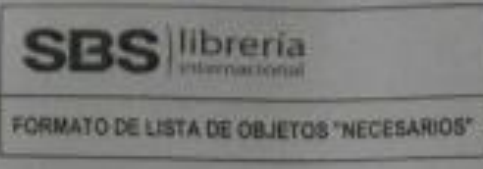 }} & \multicolumn{2}{|c|}{ ESTRATESUA SB - ALUACEV CENIRAL } & 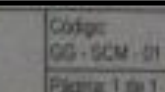 \\
\hline & & \multicolumn{3}{|c|}{ 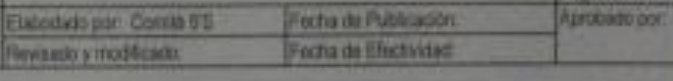 } \\
\hline * & ARTICULO & CANTIDAD & AREA & ACOON \\
\hline 1 & Cinta embataje & 03 & Packirgs & \\
\hline 2 & Cajas & OZ & Psoking: & \\
\hline 4 & ETiquetridor & & Pocking & \\
\hline & Rollo ietractel & & Rotractiledo & \\
\hline & Benzine & & Evinatage & \\
\hline & Thowine sellidera & & Denep rerced & \\
\hline & Bobino plastiea & & $\infty>$ & \\
\hline & Dispermuter de cints: & & Packing & \\
\hline & Plasties bur bujes & & Embakje & \\
\hline & Filme trumpaisnte & & embrlye & \\
\hline & Bolensplastican & & Embalefe & \\
\hline & Etiquetras. & & amblate & \\
\hline & Lapiceros & & todas los alas & \\
\hline & Archivadones & & Reropuon & \\
\hline & & & & \\
\hline
\end{tabular}

Fuente: La empresa 


\section{Implementación de la segunda S: SEITON}

En la implementación de la segunda S en SBS se realizó la organización del almacén y se trabajó bajo la acepción de mantener el orden y ganar espacio. SBS con la implementación de SETION busca conseguir el objetivo de realizar un trabajo más eficiente y productivo al recuperar la disponibilidad del espacio físico para el desarrollo de sus operaciones.

Entre los principales criterios que el comité 5S de SBS planteó para implementar el orden y organización de equipos, herramientas, objetos y materiales necesarios para el trabajo, destaca la importancia de la frecuencia y la secuencia del uso.

Los pasos realizados en esta etapa fueron:

- Se organizó los elementos a ser usados según criterios PEPS, es decir, primeros en entrar son los primeros en salir.

- Se analizaron y definieron el lugar de colocación

- Se asignó la forma de colocación

- Se rotuló el sitio de localización

A continuación se presenta registros fotográficos de la implementación: 


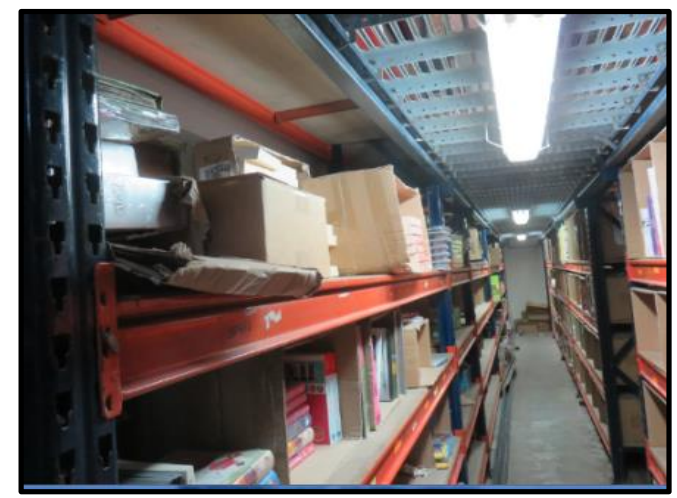

Fuente: La empresa

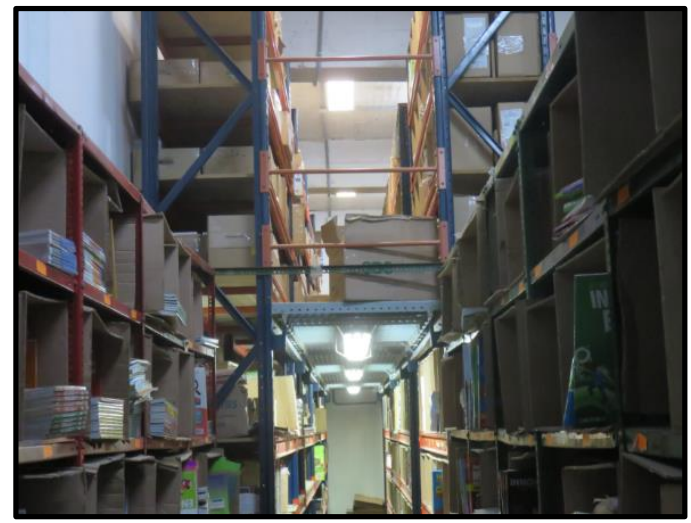

Fuente: La empresa

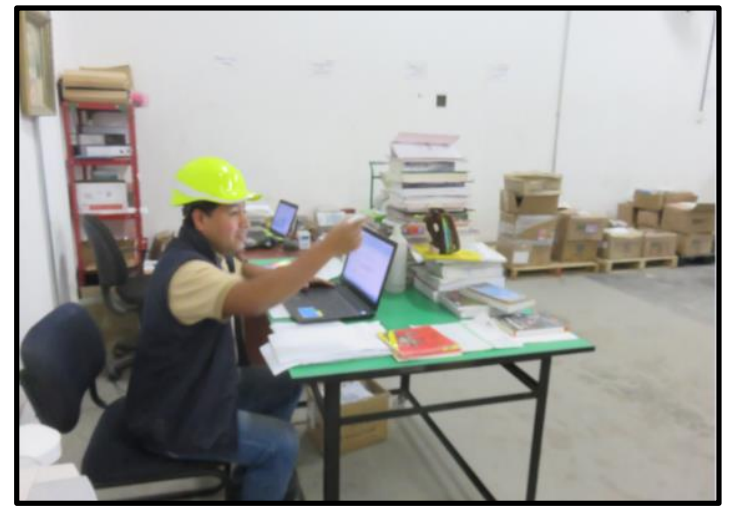

Fuente: La empresa
Se identifican lugares de colocación donde optimizar el espacio
En la imagen se observa una caja fuera de lugar, en pleno pasadizo
Los elementos encontrados fuera de lugar $\mathrm{y}$ que su uso es necesario fueron scienadoc a nuavos lucraras 


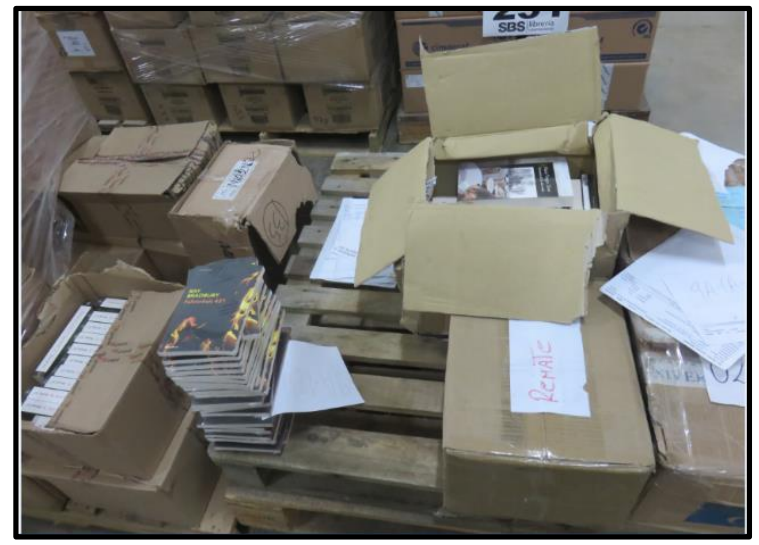

Fuente: La empresa

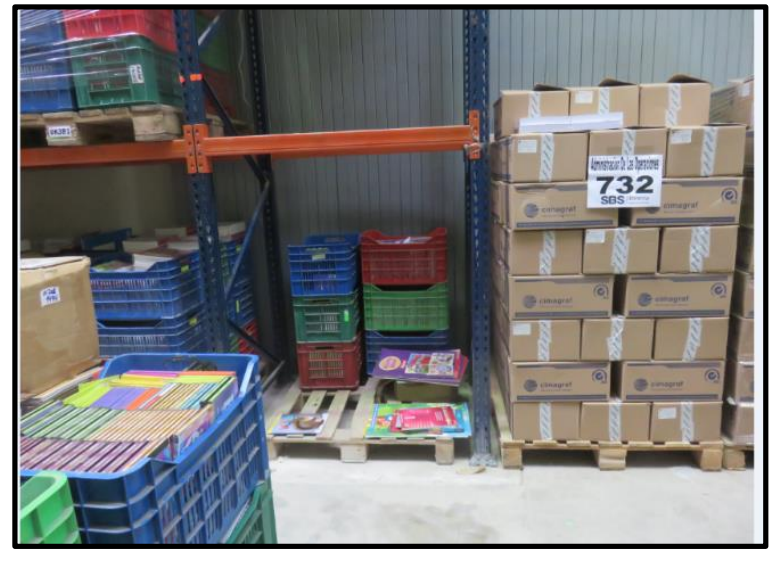

Fuente: La empresa

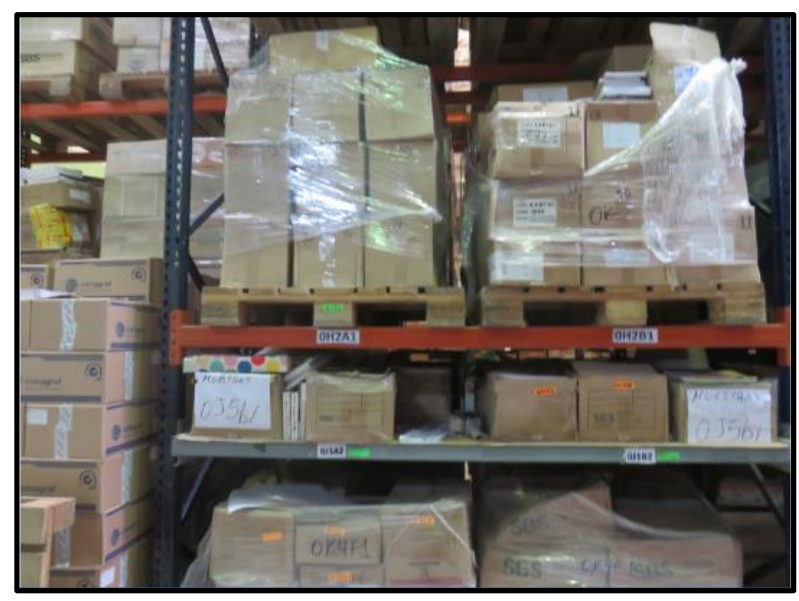

Fuente: La empresa
Elementos encontrados fuera de lugar, como resultado de la primera S.

Los espacios de ubicación fueron optimizados para adicionar más olamantore

Luego cada espacio fue ocupado, se asignó cada cosa en su lugar 


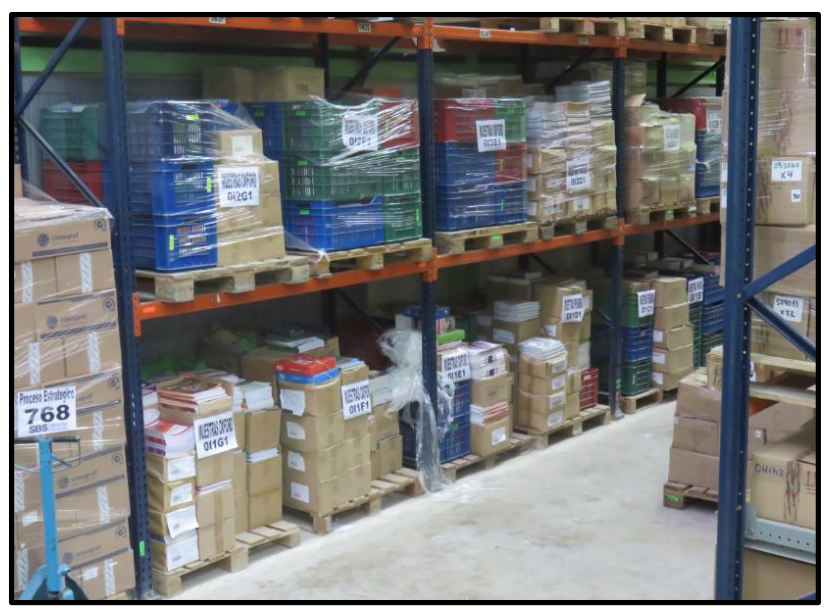

Al final de la segunda $S$, el almacén se encontraba con pasadizos despejados, lugares organizados y señalizados

Fuente: La empresa

\section{Implementación de la tercera S: SEISO}

En la implementación del SEISO, SBS se enfocó en mantener todo limpio por lo que se identificaron las fuentes que generan suciedad para reducirlas o eliminarlas. Se siguieron estos tres pasos:

- Identificar el ámbito de aplicación

- Planificar las actividades de limpieza

- Realizar la limpieza

Se presenta registros fotográficos de la implementación de la tercera S. 


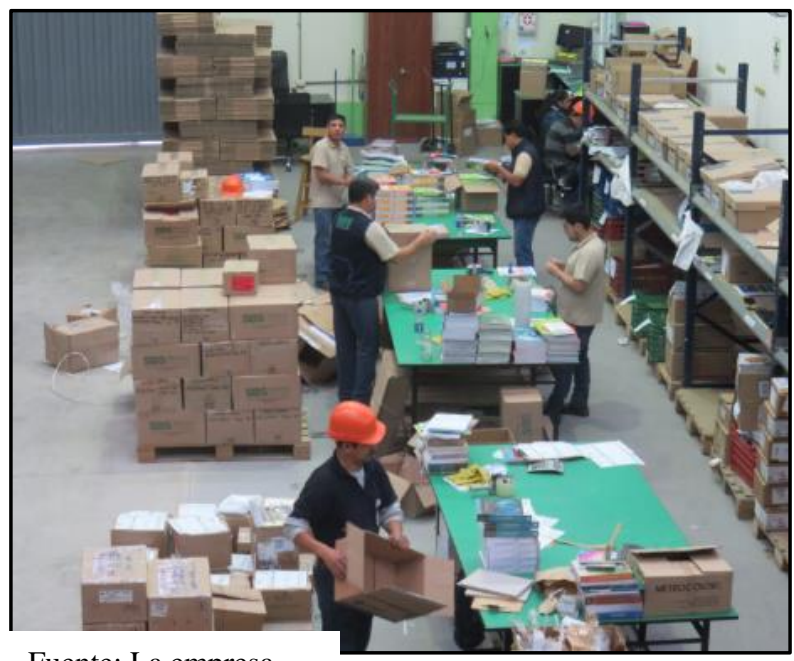

Fuente: La empresa

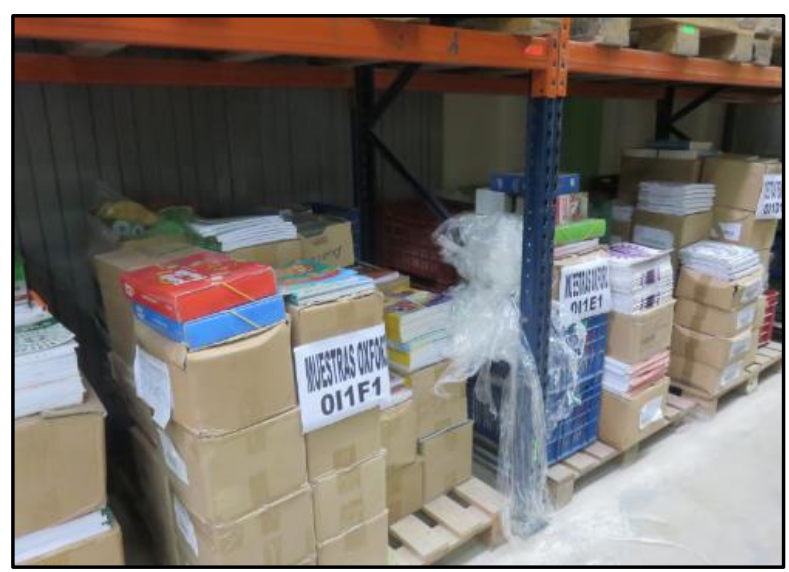

Fuente: La empresa

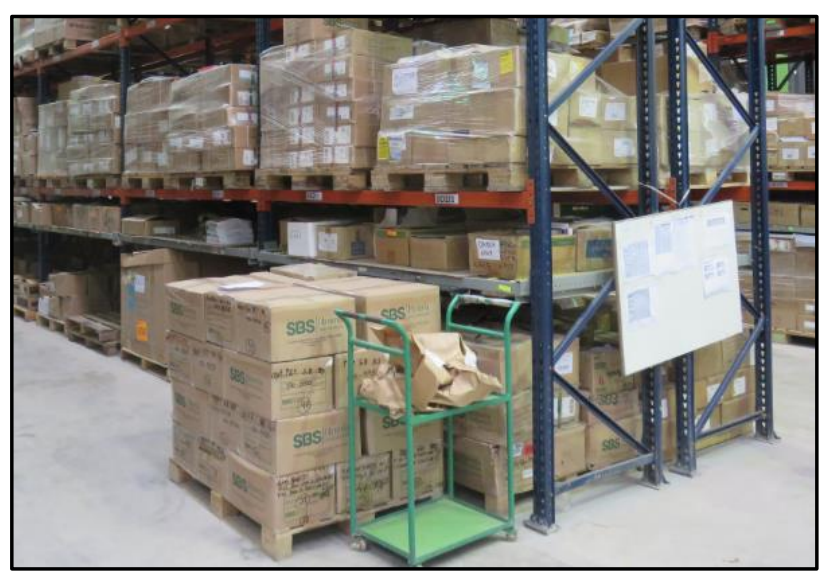

Fuente: La empresa
Se identifica que el principal foco de generación de desperdicios es el método de trabajo

Identificación de generación de desperdicios, plástico retraible colocado encima de la
Identificación de generación de desperdicios, el papel que cubre a los libros es dejado en cualquier lugar 


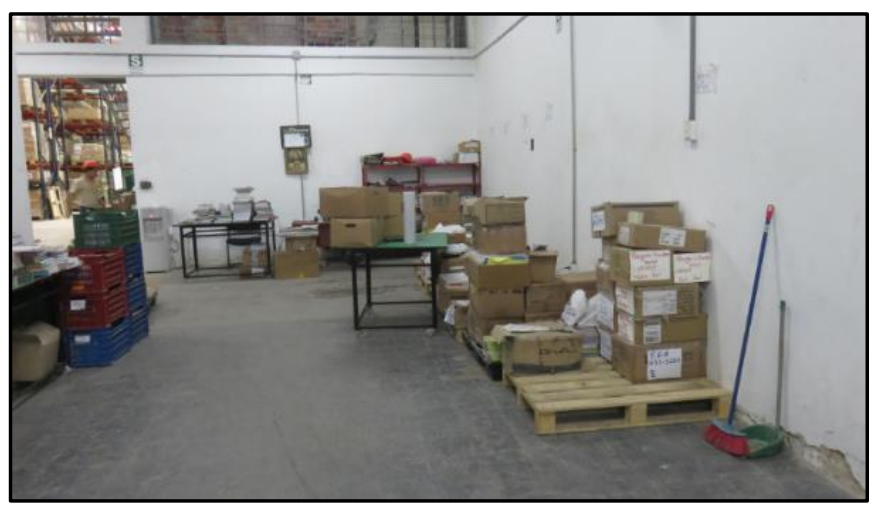

Se programan días de limpieza

Fuente: La empresa

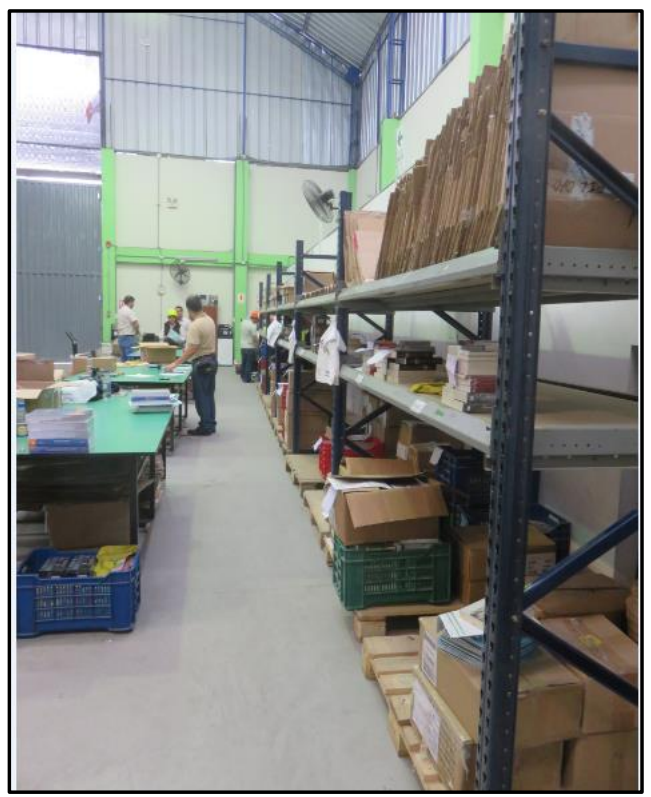

Fuente: La empresa
Resultados después del día de limpieza, pasadizos limpios y área de trabajo más organizada

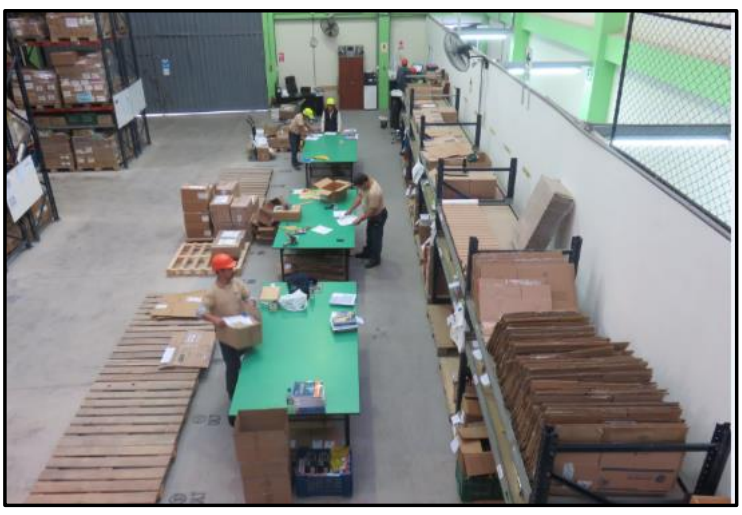

Fuente: La empresa 


\section{Implementación de la cuarta S: SEIKETSU}

La finalidad que tuvo SBS en la implementación de la cuarta S fue conservar adecuadamente un estado de clasificación, orden y limpieza en un nivel óptimo. Es buscar mecanismos que no sólo detecten el origen de la suciedad para tomar acciones necesarias con el fin de evitar estar limpiando a cada momento sino señalizar anomalías y determinar la fuente para tomar acciones rápidas. La aplicación de SEIKETSU es continuar con el desarrollo el SEIRI, SEITON Y SEISO en forma permanente, a fin de crear un ambiente saludable al entorno del empleado y establecer puntos de control claves para mantener el orden.

Para el SEIKETSU fue necesario seguir los siguientes pasos:

- Delegar responsabilidades para identificar fuentes

- Realizar asiduamente las actividades de implementación de las 3S

- Monitorear el mantenimiento y constancia de las 3S

- Disponer medidas preventivas y de señalización

- Exponer proyectos de mejora

\section{Implementación de la quinta S: SHITSUKE}

SBS en esta quinta $\mathrm{S}$ busca orientar a sus colaboradores y sus actividades a la disciplina para seguir mejorando. Para garantizar el funcionamiento de la implementación de las 4'S anteriores, es necesario cumplir con los procedimientos y reglas establecidos por la empresa, el compromiso de las gerencias y del personal de todas las áreas; así concretar el eficiente desarrollo de las acciones de mejoras. En tal sentido, esta etapa consiste en estandarizar y mantener lo establecido. La disciplina y el hábito en los procedimientos garantizan el funcionamiento de la Metodología. Se establecerán como base del proceso las Auditorías periódicas que permitan detectar falencias para establecer mejoras. Se reforzarán capacitaciones 
para los colaboradores, de manera que el personal adquiera una actitud activa y de identificación con el cumplimiento de la Metodología 5'S de manera consciente y voluntaria.

El comité 5 S de SBS estableció seguir los siguientes pasos para esta quinta S:

- Identificar y estandarizar procesos

- Definir y desarrollar actividades que fomenten la participación del personal

- Establecer el escenario para implantar la disciplina

- Reforzar conocimientos en el tema de autodisciplina

Se muestran los resultados del almacén luego de implementadas las tres primeras S y durante el desarrollo de las dos últimas. 


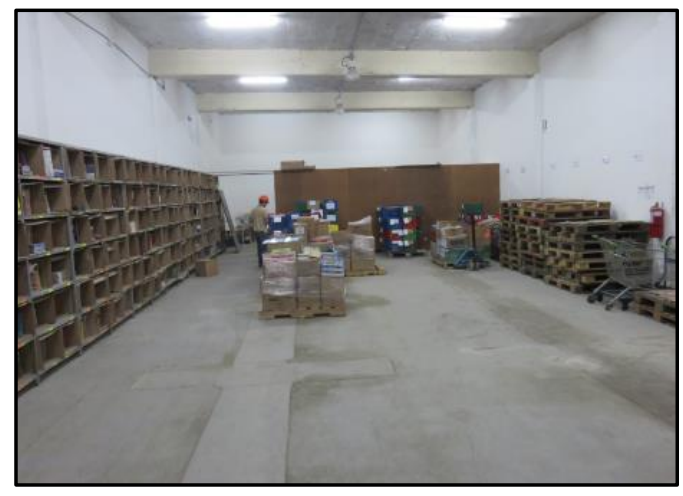

Fuente: La empresa

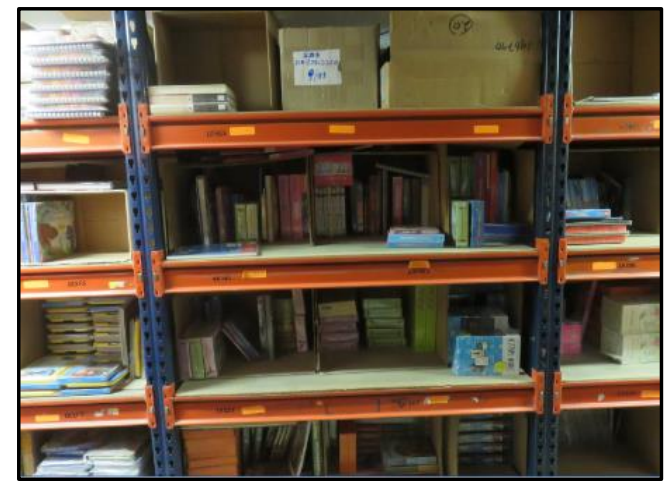

Fuente: La empresa

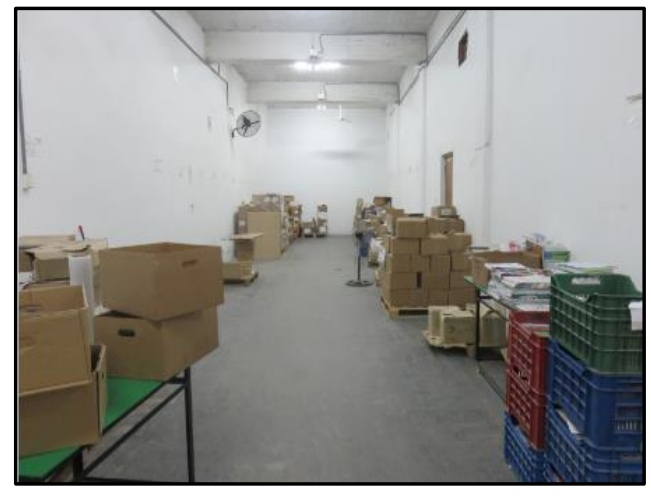

Fuente: La empresa

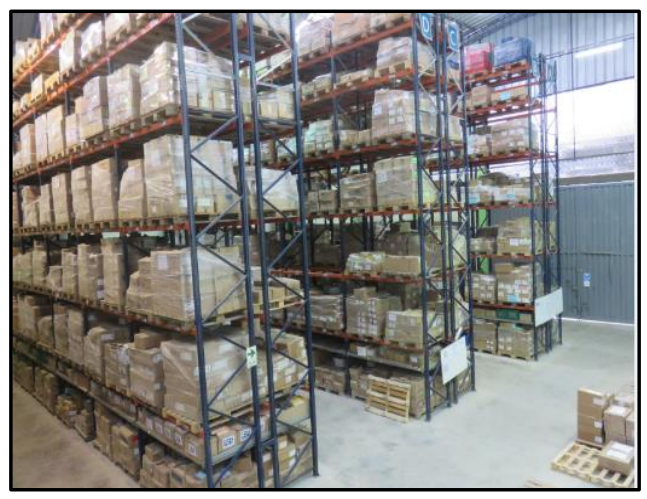

Fuente: La empresa

Las imágenes muestran pasadizos libres, espacios mejores organizados y la constancia del orden en el almacén. 


\section{Realización de Evaluaciones}

Para la realización de las evaluaciones de las $5 \mathrm{~S}$, se destaca la importancia que la Gerencia General de SBS participe y se involucre en toda evaluación parcial o total del cumplimiento de las $5 \mathrm{~S}$ con el fin de conocer el grado de cumplimiento de las 5'S o las diferencias que puedan existir con su aplicación entre las áreas de trabajo.

En un primer momento las evaluaciones se realizan mediante:

- Inspecciones 5'S: Consiste en recorridos periódicos en las áreas del almacén de SBS para determinar el estado de los procesos y evaluar la situación actual.

- Auditorías internas 5'S: Esta auditoría se realizará con la utilización de un formulario en donde se detallaran los puntos a evaluar indicando dónde cuándo, quién y la periodicidad. Será utilizada para medir el grado de aplicación de cada una de las "S". De este modo, las auditorias garantizan la mejora continua y son objetivas al proceso. Es determinante que el auditor y/o evaluador NO audite su propia área.

\section{Revisión de evaluaciones y difusión de resultados}

En toda implementación $5 \mathrm{~S}$ se necesita medir el grado de aplicación en las que se ejecutan cada una de ellas. Los resultados de esta evaluación demostrarán la efectividad del proceso de aplicación y determinarán si la estrategia 5'S forma parte del que hacer habitual de los colaboradores. 


\section{Establecimiento del plan de mejora}

Según los resultados que se obtengan de las evaluaciones y auditorias, debe elaborarse el plan de mejora que consolide y dinamice las actividades específicas de las 5'S con el fin de establecer que las 5'S sean parte inherente de las labores habitualmente realizadas y equilibrar el nivel de desarrollo de las mismas.

Por último, en el proceso de implementación de las 5'S en SBS se busca el perfeccionamiento de las actividades del proceso, mantener una mejora continua y constante cambio del nivel de aplicación de las operaciones a nivel de todo el proceso.

\section{Resultados de las Mediciones 5S}

Según lo explicado anteriormente, se muestran los resultados obtenidos de las mediciones de aplicación de las 5S, la primera de ellas fue realizada de manera inopinada antes de la implementación de esta metodología (Junio 2016) y la segunda medición se llevó a cabo durante el mes de finalizada la implementación de la última S: Shitsuke (Julio 2016)

Se detallan los resultados en la figura 37, en la cual se observa una pendiente positiva que representa la evolución de la forma de pensar y de actuar de los trabajadores en lo que respecta a la realización de sus tareas. Se muestra además la evolución de cada $\mathrm{S}$ contrastando el cumplimiento de los parámetros y criterios analizados en las auditorías. 
Figura 37: Evolución Global auditoría 5S

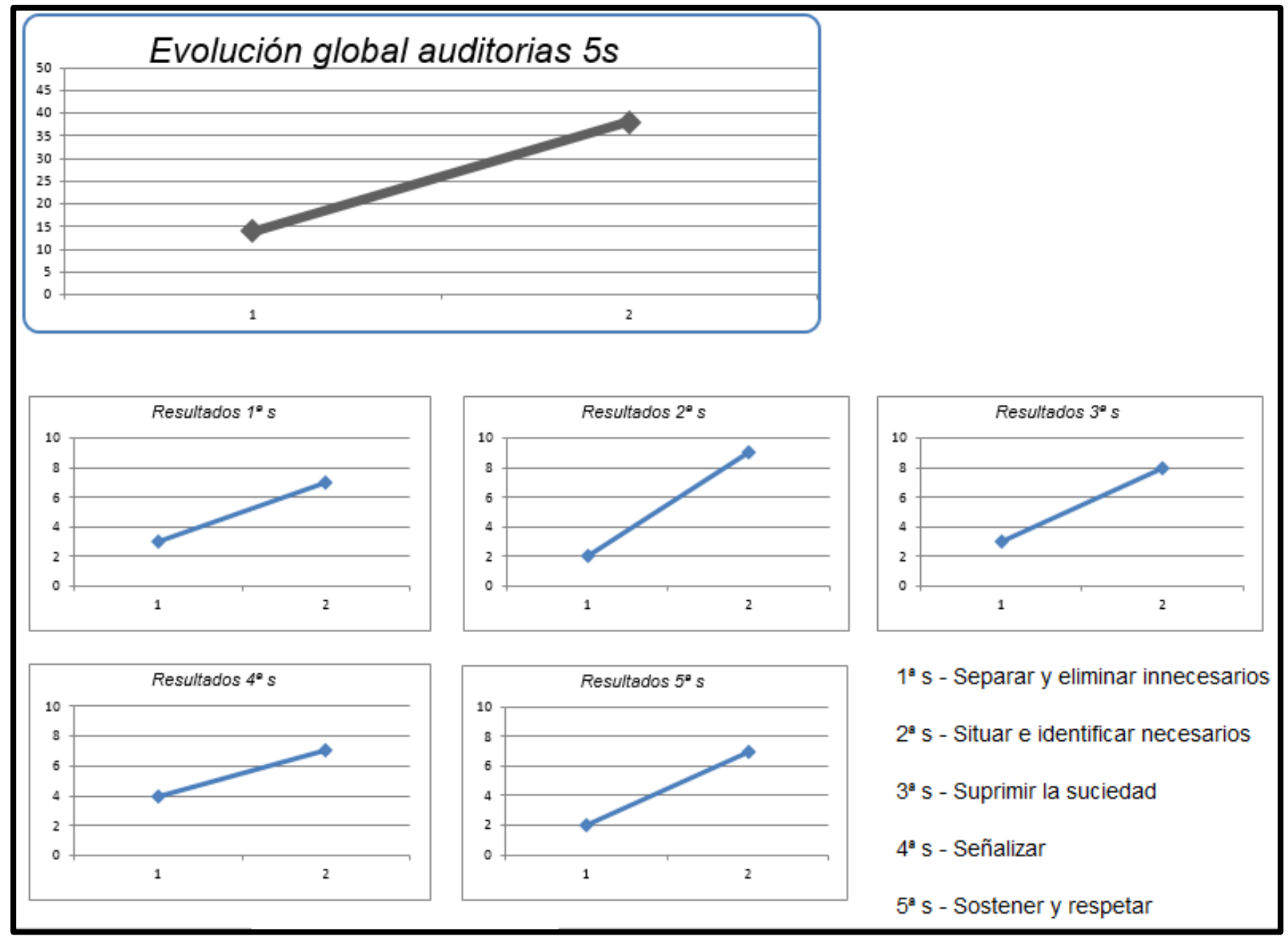

Fuente: Elaboración propia 


\section{Fase 4: Estabilización de mejoras}

En base a lo planteado por Hernández y Vizán, en este punto se explicarán las propuestas de mejoras para cada proceso seleccionado del centro de distribución en base a la información recopilada en la fase 1 .

\section{Mejora del proceso de Recepción y almacenamiento}

El proceso de recepción y almacenamiento abarca la tarea principal de inventario de productos, desde su recepción hasta su disponibilidad en los anaqueles del almacén y el registro respectivo en los kardex del sistema. Es de esta manera que se identifica al inventario como la función principal del proceso de recepción y almacenamiento.

Del análisis DAP de este proceso se obtuvo el siguiente resumen:

Cuadro 26: Resumen DAP Recepción de Mercadería

\begin{tabular}{|l|c|}
\hline \multicolumn{1}{|c|}{ Actividad } & Resultado \\
\hline Operación & 10 \\
\hline Transporte & 5 \\
\hline Espera & 3 \\
\hline Inspección & 2 \\
\hline Op Combinada & 1 \\
\hline Almacenamiento & 1 \\
\hline Distancia (m) & 495 \\
\hline Tiempo (min) & 7,944 \\
\hline
\end{tabular}

Fuente: Elaboración propia

Según lo revisado en los capítulos anteriores, las actividades que no generan valor son las de almacenamiento, espera y transporte. Los tiempos de las actividades de espera y transporte 
suman un total de 1526 min y la de almacenamiento, ocurrido al final del proceso, es de 5760 min. Para este análisis se excluirá el tiempo de inventario por que se presenta terminado el proceso de conteo, actualizado el kardex y guardada la mercadería; este tiempo de inventario no depende directamente de las áreas del centro de distribución sino de una planeación y gestión de pedidos que debe realizarse por las áreas administrativas de Logística. En consecuencia se obtiene que:

$7944 \min \longrightarrow$ Tiempo detallado en el DAP

$\underline{5760 \mathrm{~min}} \longrightarrow$ Tiempo de Almacenamiento

$2184 \mathrm{~min} \longrightarrow$ Tiempo disponible para el proceso o tiempo total del proceso

$\underline{1526 \mathrm{~min}} \square$ Tiempo de valor no agregado (esperas y transporte)

$658 \mathrm{~min} \longrightarrow$ Tiempo de valor agregado

De esto se desprende el índice de Tiempo de valor no agregado como:

$\frac{\sum \text { Tiempo valor no agregado (TVNA) }}{\sum \text { Tiempo total del proceso (TTP) }} \longrightarrow \frac{1526}{2184} \longrightarrow 0.70$

Con un valor 0.70 el índice demuestra que del tiempo total del proceso, el $70 \%$ es desperdiciado en actividades que no generan valor al proceso.

En el siguiente cuadro se presentan las acciones propuestas para la optimización de los tiempos de las actividades de transporte y esperas: 
Cuadro 27: Identificación de actividades de valor no agregado y propuestas para su eliminación - Recepción e Inventario

\begin{tabular}{|c|c|c|c|c|c|}
\hline \multicolumn{6}{|c|}{ Proceso de Recepción de meradería } \\
\hline $\begin{array}{l}\text { Tipo y número de } \\
\text { Actividad }\end{array}$ & Actividad & $\begin{array}{c}\text { Tiempo } \\
(\mathrm{min})\end{array}$ & $\begin{array}{l}\text { Código de } \\
\text { Propuesta }\end{array}$ & Propuesta de mejora & $\begin{array}{c}\begin{array}{c}\text { Tiempo estimado } \\
(\mathrm{min})\end{array} \\
\end{array}$ \\
\hline Espera / 04 & Se espera la llegada del montacargas & 15 & PMR1 & $\begin{array}{l}\text { Normalización de disposición del Montacargas y su operario ante la llegada de } \\
\text { mercadería importada }\end{array}$ & 3 \\
\hline Espera / 10 & Se espera el inicio del inventario & 1440 & PMR2 & $\begin{array}{l}\text { Balance de linea ajustado a } 600 \text { minutos. A través de asignación del personal según la } \\
\text { cantidad de libros a procesar }\end{array}$ & $\begin{array}{r}600 \\
(\max )\end{array}$ \\
\hline Espera / 15 & Se espera la disponibilidad del montacarga & 20 & PMR3 & Habilitación de pasadizos del almacén para facilitar el tránsito.Como resultado de las $5 \mathrm{~S}$ & 15 \\
\hline Transporte / 02 & $\begin{array}{l}\text { Los trabajadores de recepción se dirigen a } \\
\text { las puertas }\end{array}$ & 3 & & Se mantiene & 3 \\
\hline Transporte / 08 & $\begin{array}{l}\text { El pallet es trasladado a la zona de } \\
\text { inventario }\end{array}$ & 10 & & Se mantiene & 10 \\
\hline Transporte / 13 & $\begin{array}{l}\text { Se traslada la meraderia a la zona de } \\
\text { almacén }\end{array}$ & 30 & PMR3 & Habilitación de pasadizos del almacén para facilitar el tránsito.Como resultado de las $5 \mathrm{~S}$ & 20 \\
\hline Transporte / 20 & $\begin{array}{l}\text { Se dirige al encargado del kardex - al } \\
\text { segundo piso }\end{array}$ & 4 & PMR4 & Digitalización de los documentos de sustento de inventario & 0 \\
\hline Transporte / 21 & $\begin{array}{l}\text { Regresa a la zona de inventario - baja al } \\
\text { primer piso }\end{array}$ & 4 & PMR4 & Digitalización de los documentos de sustentode inventario & 0 \\
\hline
\end{tabular}


PMR1. Normalización de disposición del Montacargas y su operario ante la llegada de mercadería importada:

La primera propuesta de mejora en el proceso de recepción es en respuesta a la espera que realizan los colaboradores por la disponibilidad del montacargas para que se descargue la mercadería del camión en el que llega al almacén. El montacargas es de tipo apilador y es manejado por diferentes colaboradores quienes recibieron la capacitación por parte del proveedor de servicio de alquiler. Luego de la aplicación de prácticas $5 \mathrm{~s}$, los pasadizos para el tránsito del montacargas quedarán despejados; en este contexto, la propuesta de mejora consiste en normalizar el siguiente procedimiento:

- El agente aduanero debe notificar apenas salga la carga de aduanas al personal administrativo a cargo de las importaciones en las oficinas de SBS.

- Las oficinas logísticas de SBS deben informar al encargado de almacén SBS la cantidad de bultos, el tipo de empaque en el que está llegando la mercadería y el tiempo aproximado de llegada al CD que oscila entre 1 hora a dos horas.

- El encargado de almacén debe garantizar la disponibilidad de la máquina y del personal que lo conducirá, siempre y cuando la mercadería que esté llegando sea mayor o igual a un pallet. Caso contrario, será el personal encargado de recepción de descargar la mercadería sin el uso del montacargas.

- El conductor de la unidad móvil que transporta la mercadería debe informar cuando éste se encuentre a unos quince minutos de llegar a las instalaciones de SBS aproximadamente en los cruces de las av. Separadora Industrial - av. Las torres. 
- Esta garantía debe ser firmada por las autoridades de la empresa (comité Lean) y elaborada bajo formato de memorándum de compromiso para todos los involucrados: Agente Aduanero, Oficinas Logísticas SBS, encargado de almacén.

Figura 38: Procedimiento para el compromiso de disponibilidad del Montacargas

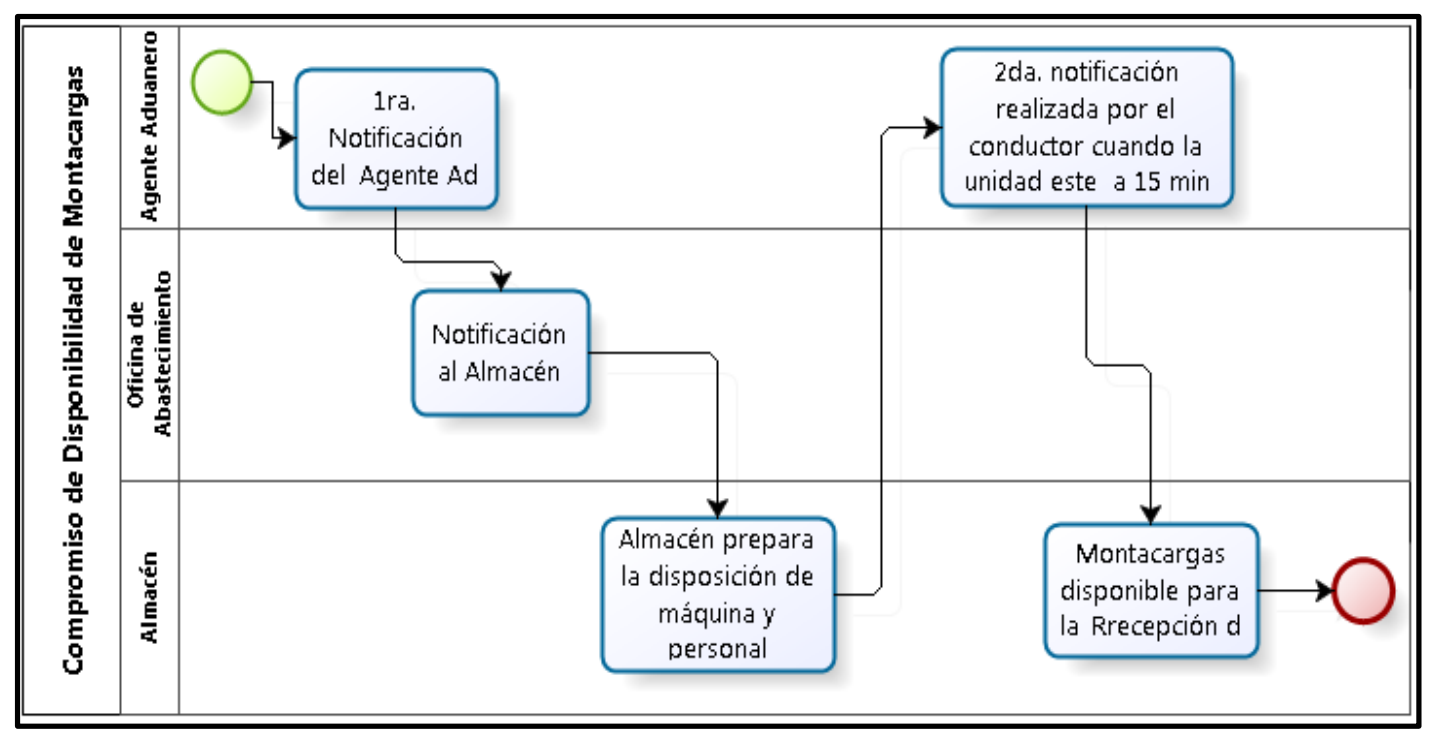

Fuente: Elaboración propia

Al normalizar y estandarizar el procedimiento de disponibilidad del montacargas, se busca que el tiempo de espera de los colaboradores por el montacargas se reduzca significativamente de 15 minutos a 03 minutos como máximo en el proceso de recepción de mercadería. Solo las nuevas mediciones de esta actividad permitirán saber cuál es el nuevo tiempo estándar y comprobar si se pudo eliminar la espera innecesaria. 
PMR2. Balance de línea ajustado a 600 minutos. A través de asignación del personal según la cantidad de libros a procesar.

La segunda propuesta para el proceso de recepción se origina partir de esperar a la mercadería recién llegada por ser inventariada debido a la carga de trabajo, es decir, hay mercadería que está en proceso de inventario.

Es necesario mencionar, que actualmente se viene trabajando bajo la modalidad PEPS: primeras entradas primeras salidas, es decir, las importaciones son procesadas en el orden en que van ingresado, de uno en uno. Por lo que se propone cambiar esta modalidad de trabajo (método) partiendo desde el análisis actual de las unidades que pueden ser procesadas bajos las actuales condiciones, esperando realizar ajustes según progresen los análisis de desempeño.

Según se ha mostrado durante el desarrollo del proyecto, en el proceso de recepción e inventario intervienen 3 colaboradores, quienes trabajan en un turno de 12 horas por día, logrando procesar 195 unid. Por cada hora hombre (195 unid/HH). Por otro lado, en base a la información del VSM y del DAP del proceso de recepción, una importación promedio demora en ser inventariada y puesta a disposición en un tiempo de 36.4 horas, que divididas en turnos de 12 horas equivalen a tres días/turnos laborables.

Mayor información se desprende de las tablas: 
Tabla 4: Análisis Hora Hombre de Inventario

\begin{tabular}{|l|c|}
\hline & $\begin{array}{c}\text { RECEPCION E } \\
\text { INVENTARIO }\end{array}$ \\
\hline Unidades por día & 7018.00 \\
\hline No Operarios & 3.00 \\
\hline Turno trab. X día & 12.00 \\
\hline Horas Hombre & 36.00 \\
\hline Unid/HH & $\mathbf{1 9 5 . 0 0}$ \\
\hline
\end{tabular}

Tabla 5 Unidades procesadas por día - Inventario

\begin{tabular}{|c|c|c|c|}
\hline $\begin{array}{c}\text { Unid } \\
\text { Recepciona } \\
\text { das }\end{array}$ & $\begin{array}{c}\text { Unid. } \\
\text { Inventariad } \\
\text { as }\end{array}$ & $\begin{array}{c}\text { Unid En } \\
\text { proceso } \\
\text { Invent }\end{array}$ & $\begin{array}{c}\text { Eficacia de } \\
\text { Inventario }\end{array}$ \\
\hline 12409 & 7018 & 5391 & $56.56 \%$ \\
\hline
\end{tabular}

Fuente: Elaboración propia

Fuente: Elaboración propia

Tanto en la tabla 4 y 5 se muestran los resultados del método de trabajo actual, sin un balance del recurso asignado al proceso. Estos resultados expresan que el 56.56\% de la mercadería se logra poner a disposición para el próximo proceso en un turno de 12 horas, como se detalló anteriormente, el resto es procesado durante el tiempo de ciclo de 36.4 horas.

En el contexto de trabajar en un turno de 10 horas al día, se propone establecer un tiempo estándar para realización del inventario de 10 horas o su equivalente en minutos: 600. Es decir, la espera máxima de un despacho de importación sin que esté siendo procesada (inventario) será a lo máximo de 600 minutos. Para ello, se establece la cantidad de colaboradores a destinar al proceso de recepción e inventario según la cantidad de unidades recibidas en el día:

Tabla 6: Balance de línea propuesto para Proceso de Recepción PROCESO DE INVENTARIO Y RECEPCIÓN: Balance a 10 horas Incremento: $\quad 15 \%$

\begin{tabular}{|c|c|c|c|c|c|}
\hline \# Colaboradores & $\begin{array}{c}\text { Hora } \mathrm{x} \\
\text { turno }\end{array}$ & $\begin{array}{c}\text { Horas Hombre } \\
\text { disponible } \\
\text { (HH) }\end{array}$ & Base unid/HH & $\begin{array}{c}\text { Meta } \\
\text { unid/HH }\end{array}$ & $\begin{array}{c}\text { Max. Unid a } \\
\text { procesar }\end{array}$ \\
\hline 1 & 10 & 10 & & & 2,243 \\
2 & 10 & 20 & & & 4,485 \\
3 & 10 & 30 & 195 & 224 & 6,728 \\
4 & 10 & 40 & & & 8,970 \\
5 & 10 & 50 & & & 11,213 \\
6 & 10 & 60 & & & \\
\hline
\end{tabular}

Fuente: Elaboración propia 
Según lo planteado en la tabla 6 , el proceso se está balanceado para realizar el inventario en un plazo máximo de 10 horas, logrando procesar todo el consolidado de mercadería que ingresó en

el turno anterior. A inicio del turno se determinará qué cantidad de trabajadores participarán del proceso; cuando la mercadería sobrepase las 2,240 unidades se asignará dos personas, cuando pase las 4,485 serán tres colaboradores; si el volumen de mercadería sobrepasa las 6,728 unidades, al proceso se le asignarán 04 colaboradores y así sucesivamente.

PMR3. Habilitación de pasadizos del almacén para facilitar el tránsito. Como resultado de las $5 S$

Como resultado de la implantación de las 5S propuesto en la fase tres de la implantación Lean se espera un ligero impacto en el tiempo de espera del montacargas y el tiempo de transporte de la mercería inventariada hacia los anaqueles. Este punto y sus resultados son detallados en la fase anterior de Lanzamiento Lean.

\section{PMR4. Digitalización de los documentos de sustento de inventario}

La cuarta propuesta de mejora para el proceso de recepción se enfoca en la eliminación de los transportes realizados por trasladar los documentos que sustentan la conformidad del inventario, estos documentos han sido considerados del tipo burocrático sin aporte de valor ya que consiste en entregar la información impresa al personal administrativo en el segundo nivel del centro de distribución para la actualización de los kardex en el sistema. 
El nuevo procedimiento para la realización de las actividades analizadas será implementado con recursos y propios de la empresa, esta habilitación del sistema será coordinada con el analista de sistema.

Antes:

Figura 39: Parte final del proceso actual de recepción

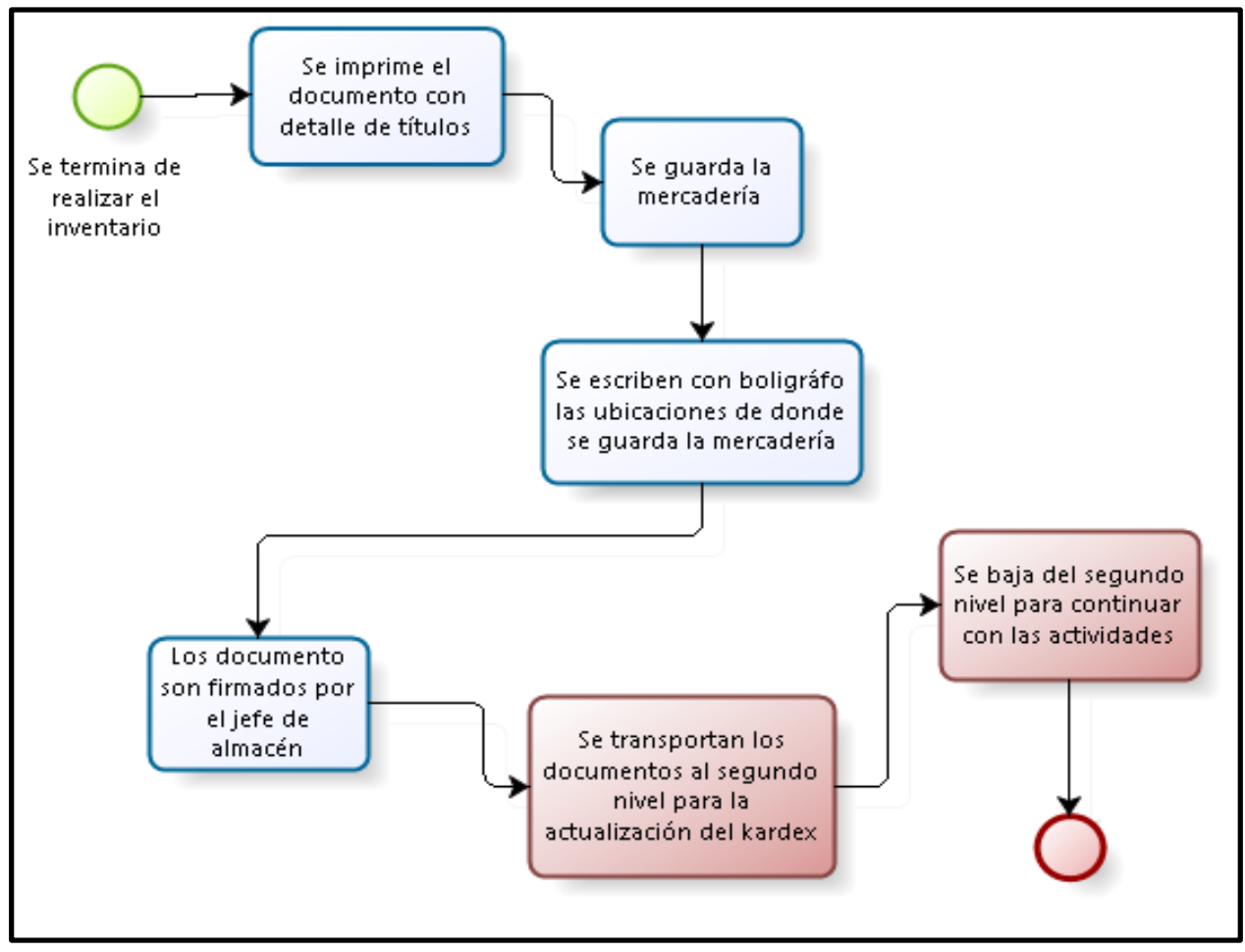

Fuente: Elaboración propia 
Ahora:

Figura 40: Parte final del proceso propuesto de recepción

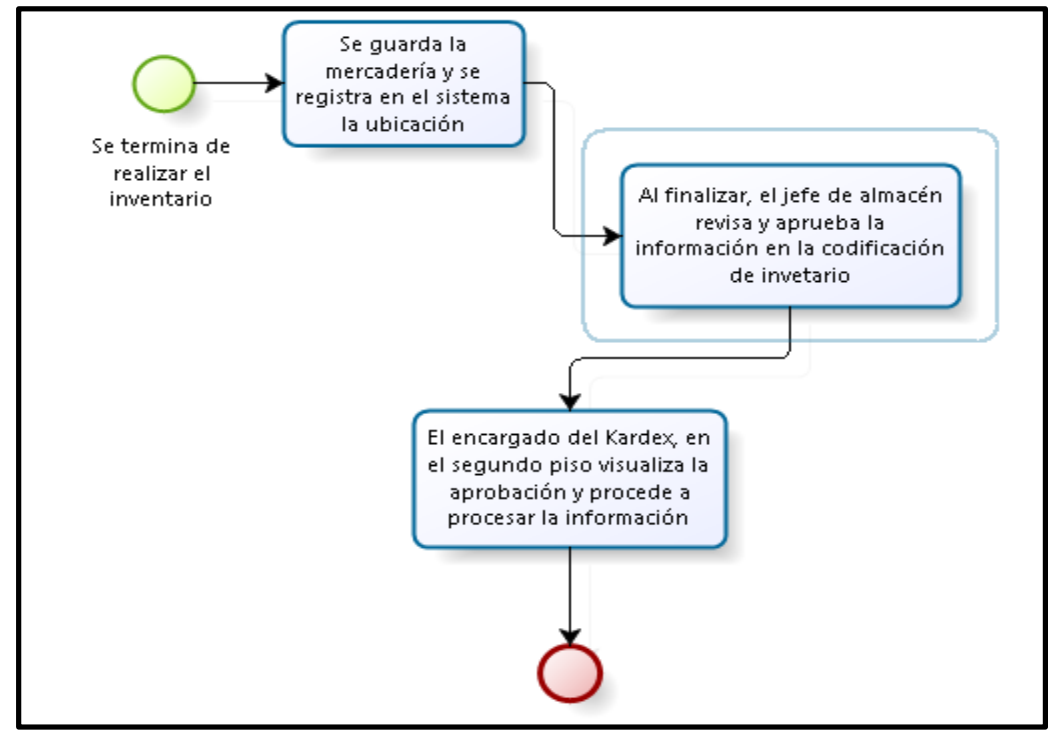

Fuente: Elaboración propia

De esta manera se eliminan los transportes innecesarios solo por subir documentación al segundo nivel y regresar al centro de distribución, ahorrando así 8 minutos de proceso de recepción e inventario. 


\section{Mejora del proceso de Picking}

El proceso de Picking enfoca sus actividades en separar los libros de los estantes o anaqueles y colocarlos organizadamente en la zona de pedidos en proceso para que estos pasen al siguiente proceso denominado Packing o embalaje. Este proceso inicia con la emisión de las órdenes de servicio que en la empresa SBS son denominadas Notas de salida NDS, las cuales detallan la cantidad de libros a separar y sus ubicaciones disponibles para que el colaborador realice el Picking.

Según lo manifestado en el análisis del diagrama del proceso DAP, se obtuvo la siguiente información:

\section{Cuadro 28: Resumen DAP Picking}

\begin{tabular}{|l|c|}
\hline \multicolumn{1}{|c|}{ Actividad } & Resultado \\
\hline Operación & 7 \\
\hline Transporte & 7 \\
\hline Espera & 3 \\
\hline Inspección & 3 \\
\hline Op Combinada & 2 \\
\hline Almacenamiento & 1 \\
\hline Distancia (m) & 265 \\
\hline Tiempo (min) & 1,552 \\
\hline
\end{tabular}

Fuente: Elaboración propia

Para el caso del proceso de Picking se han identificado un total de 11 actividades que no agregan valor como es el caso de almacenamiento, esperas y transportes con 1, 3 y 7 actividades registradas respectivamente; el análisis de los tiempos de valor no agregado y la relación con el tiempo total del proceso se presenta con la siguiente estructura: 
$1552 \mathrm{~min} \longrightarrow$ Tiempo detallado en el DAP = TTP

1519 min $\Longrightarrow$ Tiempo de valor no agregado (esperas, transporte y almacenamiento)

$33 \mathrm{~min} \longrightarrow$ Tiempo de valor agregado

De modo similar al anterior proceso, se desprende el índice del tiempo de valor no agregado:

$\frac{\sum \text { Tiempo valor no agregado (TVNA) }}{\sum \text { Tiempo total del proceso (TTP) }} \gg \frac{1519}{1552} \square 0.98$

Con un índice de 0.98 se infiere que solo el $2 \%$ del tiempo total en que se realiza el Picking añade valor al proceso.

Las actividades que generan tiempo de valor no agregado son identificadas en el cuadro 29.

Seguidamente, se ha procedido a indicar la acción de mejora para cada actividad. 
Cuadro 29: Identificación de actividades de valor no agregado y propuestas para su eliminación para el proceso de Picking

\begin{tabular}{|c|c|c|c|c|c|}
\hline \multicolumn{6}{|c|}{ Proceso de Picking } \\
\hline $\begin{array}{l}\text { Tipo y número de } \\
\text { Actividad }\end{array}$ & Actividad & $\begin{array}{c}\text { Tiempo } \\
(\min )\end{array}$ & $\begin{array}{l}\text { Código de } \\
\text { Propuesta }\end{array}$ & Propuesta de mejora & Tiempo estimado \\
\hline Transporte / 01 & $\begin{array}{l}\text { Personal transporta los pedidos impresos y } \\
\text { regresa - Del segundo al primer piso y } \\
\text { viceversa }\end{array}$ & 6 & PMPI1 & Habilitación de un nuevo canal de impresión de pedidos. Del segundo al primer piso & 0 \\
\hline Transporte / 06 & Se dirige a las ubicaciones accesibles & 3 & & Se mantiene & 3 \\
\hline Transporte / 09 & Se dirige a la zona de pedidos en proceso & 3 & PMPI2 & Habilitación de pasadizos del almacén para facilitar el tránsito.Como resultado de las $5 \mathrm{~S}$ & 2 \\
\hline Transporte / 15 & Se dirige a la zona de descarga & 2 & & Se mantiene & 2 \\
\hline Transporte / 19 & $\begin{array}{l}\text { Se dirige hacia la zona de pedidos en } \\
\text { proceso }\end{array}$ & 3 & PMPI2 & Habilitación de pasadizos del almacén para facilitar el tránsito.Como resultado de las $5 \mathrm{~S}$ & 2 \\
\hline Transporte / 21 & $\begin{array}{l}\text { Se dirige al digitador de guias - Al segundo } \\
\text { piso }\end{array}$ & 4 & PMPI3 & Reubicación del lugar de trabajo (escritorio) del digitador de guias & 0 \\
\hline Transporte / 23 & Regresa para separar más pedidos & 3 & PMPI3 & Reubicación del lugar de trabajo (escritorio) del digitador de guias & 0 \\
\hline Espera / 03 & $\begin{array}{l}\text { Se espera antes de comenzar a separar los } \\
\text { libros }\end{array}$ & 1440 & PMPI4 & $\begin{array}{l}\text { Organización del almacén según la clasificación } \mathrm{ABC} \text { de los productos y balance de } \\
\text { linea ajustado a1 } 80 \text { minutos (según la cantidad de libros a procesar) }\end{array}$ & 180 \\
\hline Espera / 14 & $\begin{array}{l}\text { Se espera la disponibilidad del } \\
\text { montecargas }\end{array}$ & 15 & PMPI5 & $\begin{array}{l}\text { Planificación del trabajo del montacarga a través de un consolidado: Realizará un solo } \\
\text { recorrido para la separación de varios pedidos }\end{array}$ & 0 \\
\hline Almacenamiento / 11 & $\begin{array}{l}\text { Los libros se almacenan temporalmente - } \\
\text { Hasta completar el pedido }\end{array}$ & 30 & PMPI5 & $\begin{array}{l}\text { Planificación del trabajo del montacarga a través de un consolidado: Realizará un solo } \\
\text { recorrido para la separación de varios pedidos }\end{array}$ & 12 \\
\hline \multicolumn{5}{|c|}{ Total } & 201 \\
\hline
\end{tabular}

Fuente: Elaboración propia 
PMPI1. Habilitación de un nuevo canal de impresión de pedidos. Del segundo al primer piso

La primera propuesta de mejora para el proceso de Picking se fundamenta en la eliminación de la primera actividad de este proceso (según DAP del proceso de picking), siendo del tipo transporte y que consiste en trasladar los pedidos impresos (NDS) del segundo piso al primero. Para suprimir esta acción se propone instalar una impresora de tipo laser solo para la impresión de pedidos (NDS) en el primer piso del centro de distribución y contará con una bandeja del tamaño ideal para que las hojas impresas no se traspapelen. Es preciso resaltar que ésta impresora es de uso exclusivo para la impresión de los pedidos. A razón de esto se establece:

- El personal administrativo, ubicado en el segundo piso, encargado de la impresión de pedidos realizará esta acción seleccionando la impresora instalada en el primer piso, de haber alguna urgencia podrá ser comunicada por los canales de teléfono, chat corporativo y/o correo electrónico.

- El personal cercano a la nueva impresora, instalada en la zona de oficinas del jefe de almacén y sus principales asistentes, deberá recoger los pedidos impresos de la bandeja principal y los organizará en distintos tableros según el tipo de pedido y su urgencia hasta que sean procesados por el personal a cargo del Picking. 
PMPI2. Habilitación de pasadizos del almacén para facilitar el tránsito como resultado de las 5S

Las actividades número 09 y 19 de tipo transporte del proceso de Picking se verá influenciada positivamente con la implantación de las 5s como se explicó en la fase tres del presente proyecto. De similar modo que el proceso anterior, con la implantación de las $5 \mathrm{~s}$ se podrá mantener los pasadizos despejados de cuerpos que obstaculicen el libre tránsito; con ello se estima que el ahorro del tiempo será de dos minutos por cada pedido que se procese con un promedio de 300 unidades (según análisis en la fase diagnostico)

\section{PMPI3 Reubicación del lugar de trabajo (escritorio) del digitador de guías}

Los transportes originados por las actividades 21 y 23 del proceso de Picking suceden por la necesidad de trasladar las hojas de los pedidos impresos que ya están separados hacia el segundo piso donde se encuentra el personal que emitirá la guía de remisión y así empezar el siguiente proceso: Packing. Por ello se propone eliminar estos traslados con la reubicación del personal a cargo de emitir las GR hacia el primer piso dentro del CD. De esta manera, se dispone que la instalación del personal sea inmediata puesto que se cuenta con espacio disponible en las zonas de escritorios cercanas al jefe de almacén.

Esto permitirá la eliminación o reducción de siete minutos del total del tiempo de valor no agregado del tiempo de Picking. 


\section{PMPI4.1 Organización del almacén según la clasificación ABC de los productos}

La actividad que genera el mayor tiempo de valor no agregado en la separación de un pedido es la espera por empezar con el Picking puesto que ya se están procesando anteriores pedidos. Actualmente el tiempo que espera una NDS en iniciar su proceso de atención es de 1,440 min equivalentes a 24 horas que divididos en turnos de 12 horas dan una espera de dos turnos.

Como primera medida para la reducción del tiempo de espera se propone organizar la distribución de los productos en base a la frecuencia en que son solicitados, a esto se denomina clasificación $\mathrm{ABC}$ de almacén. En todo centro de distribución se pretende disminuir los recorridos realizados desde el depósito y la zona de embalaje y viceversa. Con este fin, se propone, en el análisis ABC de Almacén, identificar qué artículos de los más de 10 mil que se tienen almacenados son los que más son solicitados por los clientes.

Este análisis se enfoca en la frecuencia de un título requerido en la Nota de Salida NDS es decir no es lo mismo atender una vez al año 2 mil unidades del artículo "A" que atender 200 veces al año 5 unidades del artículo “B”. En tal sentido, los artículos que sean frecuentemente solicitados deberán estar a una distancia más corta de la zona de embalaje.

Luego de identificar la frecuencia de pedidos por cada título, se establece que los que obtengan un valor mayor a 50 serán catalogados con la clasificación "A", los títulos que tengan la frecuencia de pedidos entre 20 y 49 serán encasillados en la clasificación "B” y los que obtengan una frecuencia de pedido menor a 19 pertenecerán a la sección "C".

Luego de realizar los cálculos correspondientes con la ayuda del ERP de la empresa en base a información de un año, se presentan los resultados en el anexo 5. Seguidamente, se detallan la cantidad de títulos que se identificaron para cada clasificación. 
Cuadro 30: Clasificación ABC de almacén

\begin{tabular}{|c|c|c|}
\hline Clasificación & Frecuencia de pedidos & Cantidad de títulos \\
\hline A & $\mathrm{f} \geq 50$ & 217 \\
\hline B & $20 \leq \mathrm{f} \leq 49$ & 632 \\
\hline C & $\mathrm{f} \leq 19$ & 11,770 \\
\hline
\end{tabular}

Fuente: Elaboración propia

Del cuadro 30 se debe resaltar que solo 217 títulos conforman la clasificación A, por consiguiente, estos títulos son los que deberán estar más próximos entre los anaqueles y la zona de embalaje para su rápida separación y preparación.

Se presenta como referencia el layout del centro de distribución, donde se indican qué pabellones y niveles son los más recomendados para ubicar la mercadería según su clasificación. (Ver figura 41) 
Figura 41: Sugerido para la Organización del almacén según análisis ABC

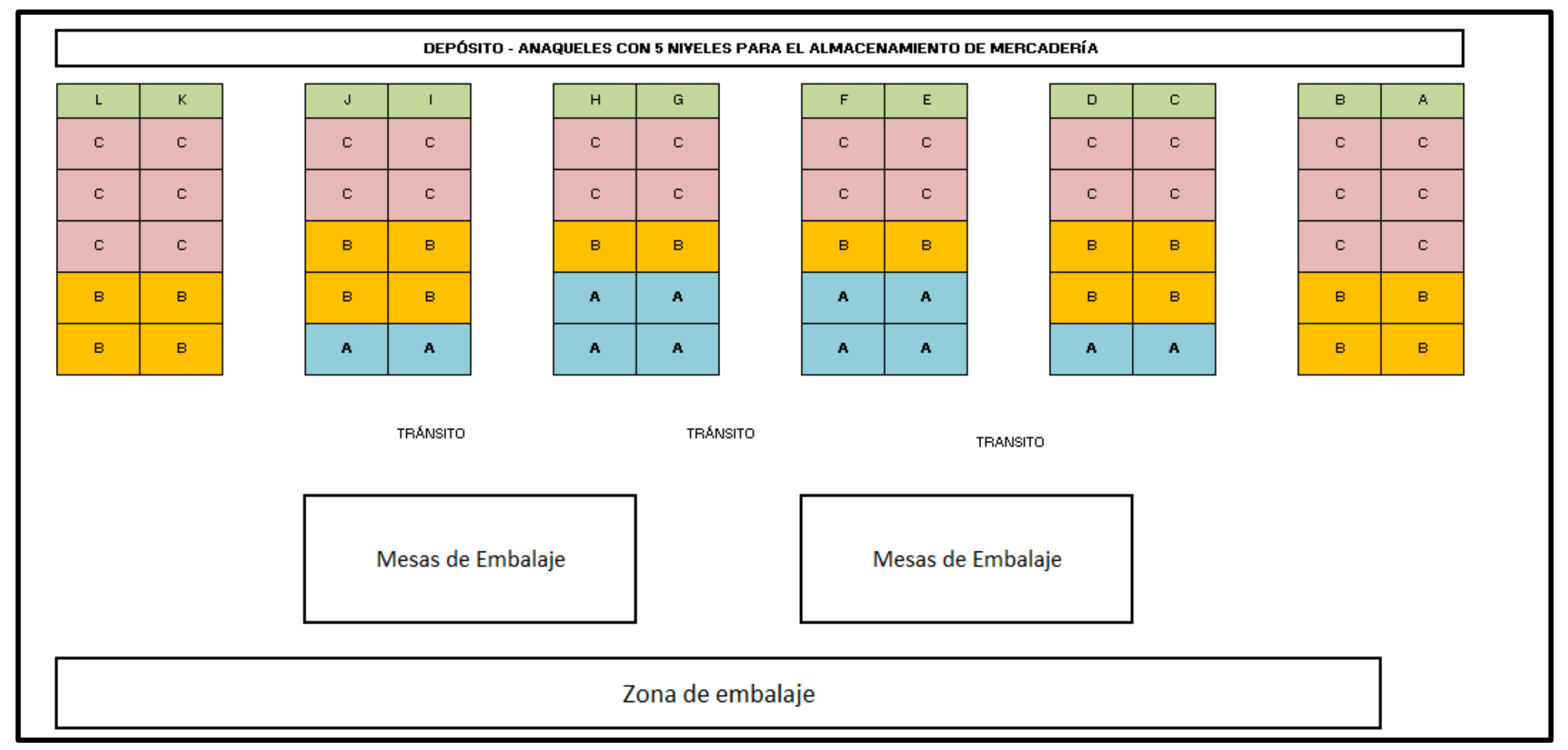

Fuente: Elaboración propia 
La figura 41 muestra el método de distribución más sencillo y recomendado para la ubicación del inventario según la clasificación $\mathrm{ABC}$, la vista que se expone es desde la zona de embalaje, en esa relación se puede observar qué filas de estantes serán las destinadas para almacenar la mercadería. Implementar, estandarizar y mantener este método permitirá llevar a cabo mediciones orientadas al control de tiempos y distancias recorridas para luego ser objeto de análisis con herramientas de distribución de planta, las cuales abarcan mucho más que distribuir ubicaciones de almacenaje, sino, por lo contrario modificar y evaluar todas las estructuras del centro de distribución.

PMPI4.2 balance de línea ajustado a180 minutos (según la cantidad de libros a procesar)

De similar manera al proceso anterior, en el presente estudio se ha identificado que el proceso de Picking cuenta con 4 colaboradores y que en este proceso se logra atender 184 unidades por cada hora hombre.

Actualmente se viene trabajando bajo la modalidad PEPS: primeras entradas primeras salidas, es decir, los primeros pedidos impresos en NDS son procesados en el orden en que van ingresado, de uno en uno. Por lo que se propone cambiar esta modalidad de trabajo (método) partiendo desde el análisis actual de las unidades que pueden ser procesadas bajos las actuales condiciones, esperando realizar ajustes según progresen los análisis de desempeño.

Las cifras actuales del proceso se muestran en las siguientes tablas: 
Tabla 7: Análisis Hora Hombre Proceso Picking

\begin{tabular}{|l|c|}
\hline & PICKING \\
\hline Unidades por día & 8811.00 \\
\hline No Operarios & 4.00 \\
\hline Turno trab. X día & 12.00 \\
\hline Horas Hombre & 48.00 \\
\hline Unid/HH & $\mathbf{1 8 4 . 0 0}$ \\
\hline
\end{tabular}

Tabla 8: Unidades procesadas por día - Picking

Fuente: $\quad$ Elabora

\begin{tabular}{|c|c|c|c|}
\hline $\begin{array}{c}\text { Total } \\
\text { Solicitado }\end{array}$ & $\begin{array}{c}\text { Total } \\
\text { Picking }\end{array}$ & $\begin{array}{c}\text { Unid En } \\
\text { proceso } \\
\text { picking }\end{array}$ & $\begin{array}{c}\text { Eficacia de } \\
\text { Picking }\end{array}$ \\
\hline 11664.6 & 8810.9 & 2854 & $75.54 \%$ \\
\hline
\end{tabular}

Tanto en la tabla 7 y 8 se muestran los resultados del método de trabajo actual, sin un balance del recurso asignado al proceso. Estos resultados expresan que el $75.54 \%$ de la mercadería se logra poner a disposición para el próximo proceso en un turno de 12 horas y como se detalló anteriormente, el resto es procesado durante el tiempo de ciclo de 25.87 horas.

Como propuesta se organizará el trabajo del proceso de Picking tres veces al día en las siguientes horas: $11 \mathrm{am} ; 3$ pm y $6 \mathrm{pm}$, separados equivalentemente cada tres horas, considerando una hora adicional en el refrigerio realizado en el turno de 11 a $3 \mathrm{pm}$. En las horas detalladas se debe realizar un corte con todos los pedidos recibidos hasta esa hora y calcular la cantidad de libros a separar para asignar el número de colaboradores que intervendrán en el proceso. Con la meta de atenderlos en tres horas, la cantidad de colaboradores se define de la siguiente manera:

Tabla 9: Balance de línea - Picking

PROCESO DE PICKING: Balance a 03 horas Incremento: $\quad 15 \%$

\begin{tabular}{|c|c|c|c|c|c|}
\hline \# Colaboradores & $\begin{array}{c}\text { Hora x } \\
\text { turno }\end{array}$ & $\begin{array}{c}\text { Horas Hombre } \\
\text { disponible } \\
\text { (HH) }\end{array}$ & Base unid/HH & $\begin{array}{c}\text { Meta } \\
\text { unid/HH }\end{array}$ & $\begin{array}{c}\text { Max. Unid a } \\
\text { procesar }\end{array}$ \\
\hline 1 & 3 & 3 & & & 635 \\
2 & 3 & 6 & & & 1,270 \\
3 & 3 & 9 & 184 & 212 & 1,904 \\
4 & 3 & 12 & & & 2,539 \\
6 & 3 & 15 & & & 3,174 \\
& 3 & 18 & & & 3,809 \\
\hline
\end{tabular}


En tal sentido, se estima reducir el tiempo de espera de los pedidos antes de ser procesados con un máximo de tres horas; lo que implica que si un pedido ingresa pasado las $11 \mathrm{am}$, este deberá ser procesado en el turno de las 3 pm obteniendo un tiempo de valor no agregado de 180 minutos.

PMPI5. Planificación del trabajo del montacargas a través de un consolidado: Realizará un solo recorrido para la separación de varios pedidos

El proceso de Picking obtiene 55 minutos de valor no agregado solo por la espera del montacargas como se puede observar en el cuadro resumen de las actividades que no generan valor del proceso de Picking. Con la finalidad de reducir los tiempos de valor no agregado que originan las actividades de espera 14, 16 y la actividad de almacenamiento 11 se propone que el trabajo de montacargas sea planificado por un consolidado de pedidos realizado en cada turno de la propuesta anterior.

Por consiguiente, los pedidos se consolidarán en las horas 11am, 3 pm y 6 pm. Esta consolidación permitirá resumir las ubicaciones, títulos y cantidades que el montacargas deberá poner a disposición de los colaboradores de Picking. Es preciso mencionar que actualmente el montacargas atiende la solicitud de cada trabajador pedido por pedido, pudiendo bajar tantas veces el mismo pallet según se repita en cada pedido.

Para ello, se le solicitará al área de sistemas TI la implementación de un reporte en el ERP, el cual consolide las NDS que el usuario asigne y dé como resultado todas las ubicaciones (pallets) que se deben bajar a partir del segundo nivel para atender los pedidos. 
Figura 42: Ejemplo de hoja de consolidado para programación de trabajo de montacargas

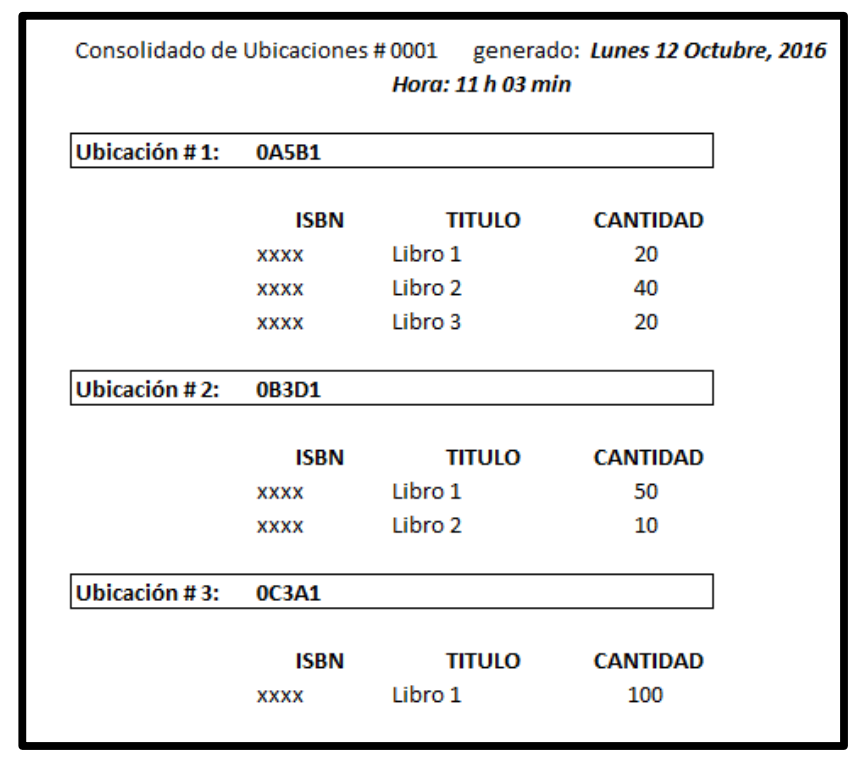

Fuente: Elaboración propia

En la figura 42 se muestra un ejemplo del reporte a solicitar a los programadores del sistema. La primera letra indica el panel donde su ubica el pallet según se mostró en la organización ABC de almacén. El número central indica el nivel donde se encuentra guardado el libro; a partir del segundo nivel, el montacargas deberá bajar según los requerimientos.

\section{Mejora del proceso de Packing}

El proceso de Packing o embalaje en la empresa SBS toma como entrada los pedidos separados en el proceso de Picking y devuelve pedidos embalados: empaquetados o embolsados y organizados disponibles para el proceso siguiente de transporte y entrega del producto.

Según el DAP mostrado en la primera fase de diagnóstico se obtiene la siguiente información: 


\section{Cuadro 31: Resumen DAP Packing}

\begin{tabular}{|l|c|}
\hline \multicolumn{1}{|c|}{ Actividad } & Resultado \\
\hline Operación & 5 \\
\hline Transporte & 4 \\
\hline Espera & 2 \\
\hline Inspección & 1 \\
\hline Op Combinada & 1 \\
\hline Almacenamiento & 1 \\
\hline Distancia (m) & 133 \\
\hline Tiempo (min) & 349 \\
\hline \hline
\end{tabular}

Fuente: Elaboración propia

El tiempo total registrado del proceso de Packing es de 349 minutos el cual se constituye de la siguiente manera:

349 min $\square$ Tiempo total del proceso (TTP)

$\underline{317 \mathrm{~min}} \square$ Tiempo de valor no agregad (TVNA)

$32 \min \square$ Tiempo de valor agregado

$\frac{\sum \text { Tiempo valor no agregado }(T V N A)}{\sum \text { Tiempo total del proceso }(T T P)} \square \frac{317}{349} \square 0.91$

El índice del tiempo de valor no agregado indica que más del 90\% del tiempo total del proceso está enfocado a actividades que no generan valor. 
Cuadro 32: Identificación de actividades de valor no agregado y propuestas para su eliminación -Packing

\begin{tabular}{|c|c|c|c|c|c|}
\hline \multicolumn{6}{|c|}{ Proceso de Packing } \\
\hline $\begin{array}{l}\text { Tipo y número de } \\
\text { Actividad }\end{array}$ & Actividad & $\begin{array}{c}\text { Tiempo } \\
(\min )\end{array}$ & $\begin{array}{l}\text { Código de } \\
\text { Propuesta } \\
\end{array}$ & Propuesta de mejora & $\begin{array}{c}\begin{array}{c}\text { Tiempo estimado } \\
(\mathrm{min})\end{array} \\
\end{array}$ \\
\hline Espera / 01 & $\begin{array}{l}\text { Se espera la emisión de las GR - Empieza } \\
\text { según el trabajo pendiente }\end{array}$ & 60 & PMPA1 & $\begin{array}{l}\text { Cambio del input necesario para el inicio del proceso. Se establece que el input para el } \\
\text { proceso es la confirmación de picking }\end{array}$ & 0 \\
\hline Espera / 04 & $\begin{array}{l}\text { Se espera turno para empezar a embalar - } \\
\text { Según la carga detrabajo }\end{array}$ & 240 & PMPA2 & $\begin{array}{l}\text { Balance de linea ajustado a } 180 \text { minutos. A través de asignación del personal según la } \\
\text { cantidad de libros a procesar // Se aligera el trabajo por influencia de las } 5 \mathrm{~S}\end{array}$ & 180 \\
\hline Transporte / 03 & $\begin{array}{l}\text { Se bajan las } \mathrm{GR} \text { al almacén y regresa }-\mathrm{Al} \\
\text { primer piso }\end{array}$ & 8 & PMPA4 & Se elimina el transporte hacia el segundo piso, las GR serán emitidas en el primer piso & 0 \\
\hline Transporte / 06 & Se dirige a la zona de pedidos en proceso & 1 & & se mantiene & 1 \\
\hline Transporte / 08 & Se dirige a la mesa de embalaje & 4 & & se mantiene & 4 \\
\hline Transporte / 12 & $\begin{array}{l}\text { Se transportan los bultos a los pallets para } \\
\text { despacho }\end{array}$ & 4 & PMPA3 & Habilitación de pasadizos del almacén para facilitar el tránsito.Como resultado de las $5 \mathrm{~S}$ & 3 \\
\hline
\end{tabular}

Fuente: Elaboración propia 
En el cuadro 32 se muestra las diferentes actividades que no generan valor al proceso de Packing, seguidamente se observa la acción a ejecutar para la eliminación u optimización de las mismas.

PMPA1. Cambio del input necesario para el inicio del proceso. Se establece que el input para el proceso es la confirmación de picking

Como primera propuesta de mejora para el proceso de Packing se busca eliminar el tiempo de espera que se presenta antes de dar inicio al proceso, esto ocurre porque se inicia el Packing con la guía de remisión emitida e impresa y su realización depende del área administrativa. En tal sentido, se establece que el inicio del proceso de Packing ya no necesite la guía de remisión; si no, se iniciará con la confirmación de la finalización del Picking en el sistema (definido como la última actividad del proceso de Picking).

El proceso de Packing, de similar modo que su proceso antecesor, consolidará los pedidos a procesar tres veces al día en las mismas horas que el proceso de Picking: $11 \mathrm{am}-3 \mathrm{pm}-6 \mathrm{pm}$. En cada hora establecida se iniciará el embalaje de los pedidos que han culminado su separación en el turno anterior. Para ello, el sistema habilitará la impresión de los pedidos que hayan sido confirmados al final del Picking, ésta impresión será realizada por los responsables del Packing y realizarse simple.

\section{PMPA2. Balance de línea ajustado a 180 minutos. A través de asignación del personal según la cantidad de libros a procesar}

La segunda propuesta del proceso del Packing también asignará el número de trabajadores según los índices de productividad por hora hombre. Según lo mostrado durante el desarrollo del 
proyecto, el proceso de Packing procesa 224 unidades por cada hora hombre. La explicación se muestra en la siguiente tabla:

Tabla 10: Análisis Hora Hombre Packing

\begin{tabular}{|l|c|}
\hline & PACKING \\
\hline Unidades por día & 8056.00 \\
\hline No Operarios & 3.00 \\
\hline Turno trab. X día & 12.00 \\
\hline Horas Hombre & 36.00 \\
\hline Unid/HH & $\mathbf{2 2 4 . 0 0}$ \\
\hline
\end{tabular}

Fuente: Elaboración propia
Tabla 11: Unidades procesadas por día - Packing

\begin{tabular}{|c|c|c|c|}
\hline $\begin{array}{c}\text { Total } \\
\text { Solicitado a } \\
\text { embalar }\end{array}$ & $\begin{array}{c}\text { Total } \\
\text { Packing }\end{array}$ & $\begin{array}{c}\text { Unid En } \\
\text { proceso } \\
\text { packing }\end{array}$ & $\begin{array}{c}\text { Eficacia de } \\
\text { Packing }\end{array}$ \\
\hline 8810 & 8056 & 754 & $91.44 \%$ \\
\hline
\end{tabular}

Fuente: Elaboración propia

Tanto en la tabla 10 y 11 se muestran los resultados del método de trabajo actual, sin un balance del recurso asignado al proceso. Estos resultados expresan que el $91.44 \%$ de la mercadería se logra poner a disposición para el próximo proceso en un turno de 12 horas y como se detalló anteriormente, el resto es procesado durante el tiempo de ciclo de 5.82 horas.

En el contexto de seguir trabajando en un turno de 10 horas al día, se propone establecer un tiempo estándar para realización del packing cada 3 horas o su equivalente en minutos: 180. Es decir, la espera máxima de un pedido que ya se encuentre separado será a lo máximo de 180 minutos. Para ello, se establece la cantidad de colaboradores a destinar al proceso de packing según sea la cantidad de unidades a procesar cada tres horas: 
Tabla 12: Balance de Línea - Packing PROCESO DE PACKING: Balance a 03 horas

\begin{tabular}{|c|c|c|c|c|c|}
\hline \multicolumn{4}{|c|}{ PROCESO DE PACKING: Balance a 03 horas } & \multirow{2}{*}{$\begin{array}{c}\text { Incremento: } \\
\text { Meta } \\
\text { unid/HH }\end{array}$} & $15 \%$ \\
\hline \# Colaboradores & $\begin{array}{c}\text { Hora } x \\
\text { turno }\end{array}$ & $\begin{array}{c}\text { Horas Hombre } \\
\text { disponible } \\
\text { (HН) }\end{array}$ & Base unid/HH & & $\begin{array}{c}\text { Max. Unid a } \\
\text { procesar }\end{array}$ \\
\hline 1 & 3 & 3 & & & 773 \\
\hline 2 & 3 & 6 & & & 1,546 \\
\hline 3 & 3 & 9 & & & 2,318 \\
\hline 4 & 3 & 12 & $2 \angle 4$ & 250 & 3,091 \\
\hline 5 & 3 & 15 & & & 3,864 \\
\hline 6 & 3 & 18 & & & 4,637 \\
\hline
\end{tabular}

Fuente: Elaboración propia

Con la asignación del número de colaboradores según la tabla 12 se pretende disminuir el tiempo de espera que un pedido puede presentar para ser embalado de 240 minutos a 180 minutos que es el tiempo transcurrido de un consolidado a otro.

La cantidad de unidades a embalar se obtendrá de la suma de unidades en los pedidos que fueron finalizados de Picking durante el turno anterior. Por ejemplo, cuando el total de mercadería a embalar sea menor a 773 unidades se asignará a un solo colaborador, cuando sea superior a 773 pero menor a 1546 unidades se asignará a dos colaboradores y así sucesivamente.

PMPA3. Habilitación de pasadizos del almacén para facilitar el tránsito como resultado de las 5S

Como se ha visto en los anteriores dos procesos, la implantación de las 5s, según se explica en la fase 3 , influye positivamente en el fluir de las actividades. Para este caso, se estima que la reducción del tiempo de valor no agregado obtenida directamente de las $5 \mathrm{~S}$ será de un minuto 
sobre las actividades de transporte que se desarrollan dentro del centro de distribución, en este caso durante el proceso de Packing.

\section{PMPA4. Eliminación de transporte hacia el segundo piso}

En el DAP del proceso actual de packing, este transporte es presentado como la actividad número tres del proceso en el cual las guías de remisión impresas se llevaban al primer piso para que inicie el proceso de packing. Hay dos acciones de mejora que suprimen esta actividad: la primera es la reubicación del lugar de trabajo (escritorio) del digitador de guías que se presentó en el proceso anterior y la segunda, es el establecimiento del nuevo input para el inicio del proceso, es decir, los colaboradores ya no esperan la GR para empezar a embalar los libros.

\section{Fase 5: Estandarización}

En esta fase, según Hernández y Vizán (2013), se debe estandarizar las propuestas de mejora y todos los cambios realizados a los procesos para lograr una adecuada medición e impacto de los cambios. Por consiguiente, se presentarán los nuevos DAP (análisis del diagrama del proceso) de los procesos de Recepción, Picking y Packing detallando la nueva secuencia de actividades que han surgido a partir de los cambios propuestos, los tiempos que se muestran por cada actividad son también resultados de los tiempos obtenidos en la prueba piloto que se presentará en el siguiente capítulo.

Se desprende que a partir de estos estándares, los procesos se deben llevar a cabo en base a lo propuesto, siendo la obligación de todo colaborador respetarlo según se indica. 


\section{Estándar para el proceso de Recepción e Inventario}

Consideraciones:

- Este proceso se llevará a cabo en turnos de 10 horas diarias

- Las importaciones que lleguen durante el día se procesarán (inventario) a primeras horas del día siguiente.

- Al inicio de cada turno, 8 am, se medirá la cantidad de libros que hay por inventariar (procesar) y en base a la magnitud resultante se asignará el número de colaboradores a intervenir en el proceso.

- El cálculo del número de trabajadores se realizará en base a la propuesta presentada en el balance de línea del proceso de Recepción:

Tabla 13: Balance de Línea - Inventario y Recepción

PROCESO DE INVENTARIO Y RECEPCIÓN: Balance a 10 horas
\begin{tabular}{|c|c|c|c|c|c|}
\hline \# Colaboradores & $\begin{array}{c}\text { Hora x } \\
\text { turno }\end{array}$ & $\begin{array}{c}\text { Horas Hombre } \\
\text { disponible } \\
\text { (HH) }\end{array}$ & Base unid/HH & $\begin{array}{c}\text { Meta } \\
\text { unid/HH }\end{array}$ & $\begin{array}{c}\text { Max. Unid a } \\
\text { procesar }\end{array}$ \\
\hline 1 & 10 & 10 & & & 2,243 \\
2 & 10 & 20 & & & 4,485 \\
3 & 10 & 30 & 195 & 224 & 6,728 \\
4 & 10 & 40 & & & 8,970 \\
5 & 10 & 50 & & & 11,213 \\
6 & 10 & 60 & & & 13,455 \\
\hline
\end{tabular}

Fuente: Elaboración propia

- Luego de identificado el número de colaboradores, el jefe de almacén decidirá qué personal se dedicará al desarrollo de proceso, manteniendo siempre al líder del proceso como primera opción.

Se presenta la ficha del proceso y el DAP con el detalle y secuencias de actividades a seguir. 
Figura 43: Ficha del Proceso de Recepción e Inventario de Mercadería

\begin{tabular}{|c|c|}
\hline CóDIGO & PROCESO DE RECEPCIÓN E INVENTARIO DE MERCADERÍA \\
\hline SBSRMO01 & 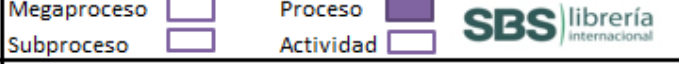 \\
\hline ELABORACIÓN & Martín Ramirez C. \\
\hline RESPONSABLES & Jefe de Almacén - Coordinador de recepción e inventario \\
\hline INICIA & Llegada de mercadería en las puertas del Centro de Distribución \\
\hline TERMINA & Mercadería inventariada puesta en los anaqueles del almacén \\
\hline PROCEDIMIENTO ACTUAL & $\begin{array}{l}\text { El proceso de recepción se lleva a cabo con un método PEPS } \\
\text { (primeras entradas primeras salidas) es decir las } \\
\text { importaciones eran inventariadas y puestas a disposición } \\
\text { según el turno de llegada uno por uno. Son tres los trabajadores } \\
\text { que intervienen en este proceso sin importar la cantidad de } \\
\text { libros a procesar, es decir el trabajo se realiza de una forma } \\
\text { desbalanceada y no guarda relación a la productividad del } \\
\text { recurso humano }\end{array}$ \\
\hline $\begin{array}{l}\text { PROCEDIMIENTO } \\
\text { PROPUESTO }\end{array}$ & $\begin{array}{l}\text { El proceso se realizará con la consiladación de importaciónes } \\
\text { cada } 12 \text { horas, las que han llegado en el turno anterior; la } \\
\text { estación de trabajo para este proceso realiza sus operaciones } \\
\text { en un turno de } 12 \text { horas al día; de este modo todas las mañana } \\
\text { se realizará un corte y se pedirá la información de cuántas } \\
\text { unidades están por inventariar. Según esta cantidad se } \\
\text { balanceará la línea a que todo el trabajo se finalice en } 12 \text { horas } \\
\text { (un turno); es decir, la cantidad de trabajdores se asignará de } \\
\text { aruerdna la rantidad de lihrne aue havowe nrarecarv loe }\end{array}$ \\
\hline $\begin{array}{l}\text { OBJETIVO / META DE LA } \\
\text { PROPUESTA }\end{array}$ & $\begin{array}{l}\text { La finalidad del proceso es poner a disposición la mercadería } \\
\text { ingresante en información y accesibilidad para los nuevos } \\
\text { pedidos. La meta del cambio de metodo propuesto es reducir en } \\
10 \% \text { el tiempo de ciclo en el que se lleva a cabo el proceso. }\end{array}$ \\
\hline $\begin{array}{l}\text { INDICADORES DEL } \\
\text { PROCESO }\end{array}$ & $\begin{array}{l}\text { Cantidad promedio de inventario diario } \\
\text { Tiempo de ciclo del proceso recepción e inventario }\end{array}$ \\
\hline $\begin{array}{l}\text { INFORMACIÓN DE } \\
\text { ENTRADA }\end{array}$ & $\begin{array}{l}\text { Aviso de llegada de importación - Correo eletronico } \\
\text { Despacho de importación - Documento Interno } \\
\text { Guías y Cargos del Agente Aduanero }\end{array}$ \\
\hline INPUTS & Mercadería de importación // Camión o contenedor de Aduana \\
\hline PROVEEDORES & Agente Aduanero - Area de Compras \\
\hline $\begin{array}{l}\text { INFORMACIÓN DE } \\
\text { SALIDA }\end{array}$ & $\begin{array}{l}\text { Cantidades de libros disponibles para la venta // guía interna } \\
\text { de invetario asociada al despacho de despacho de importación }\end{array}$ \\
\hline OUTPUTS & $\begin{array}{l}\text { Libros disponibles para la venta guardados en los anaqueles } \\
\text { del almacén }\end{array}$ \\
\hline CLIENTES & $\begin{array}{l}\text { Área Comercial - Gestión de Pedidos (logística) - Proceso de } \\
\text { Picking }\end{array}$ \\
\hline RECURSO HUMANO & Asitentes de almacén \\
\hline
\end{tabular}

Fuente: Elaboración propia 
Figura 44: DAP Propuesto para el proceso de Recepción e Inventario

\begin{tabular}{|c|c|c|c|c|c|c|c|c|c|c|}
\hline \multicolumn{11}{|c|}{ DIAGRAMA DE ANÁLISIS DEL PROCESO } \\
\hline \multirow{2}{*}{ DIAGRAMA №: $\quad$ DAPSBSRM-1.5 } & \multirow{2}{*}{\multicolumn{6}{|c|}{ HOJA No: 01}} & \multicolumn{4}{|c|}{ RESUMEN } \\
\hline & & & & & & & ACTIVIDAD & ACTUAL & PROPUESTA & ECONOMÍA \\
\hline \multicolumn{7}{|l|}{ Método: ACTUAL/ PROPUESTO } & Operación & & \begin{tabular}{c|c}
11 \\
3
\end{tabular} & \\
\hline \multicolumn{7}{|l|}{ OPERACIÓN / PROCESO: } & Espera & & 3 & \\
\hline \multicolumn{7}{|c|}{ Recepción de Mercadería } & $\begin{array}{l}\text { Inspección } \\
\text { Op. Combinada } \\
\text { Almacenamiento }\end{array}$ & & $\begin{array}{l}2 \\
1 \\
1\end{array}$ & \\
\hline \multicolumn{7}{|l|}{ LUGAR: Centro de Distribución SBS } & Distancia (m) & & 385 & \\
\hline \multicolumn{7}{|l|}{ COMPUESTO POR: } & Tiempo (min) & & 6,876 & \\
\hline \multicolumn{7}{|l|}{ FECHA: $/ /$} & Costos & & & \\
\hline \multirow{2}{*}{ DESCRIPCION } & \multicolumn{6}{|c|}{ SIMBOLO } & \multirow{2}{*}{ OBSERVACIONES } & \multirow[t]{2}{*}{$\mathrm{C}$} & \multirow[t]{2}{*}{$\mathrm{D}(\mathrm{m})$} & \multirow[t]{2}{*}{$\mathrm{T}(\mathrm{min})$} \\
\hline & $Q$ & $\Longrightarrow$ & $\bar{D}$ & & $\mathrm{O}$ & $\nabla$ & & & & \\
\hline El seguridad avisa de la llegada de mercadería a puertas del CD & $x$ & & & & & & & & & 1 \\
\hline Los trabajadores de recepción se dirigen a las puertas & & k & & & & & & & 55 & 3 \\
\hline Se avisa al montacarga de su necesidad & $x-$ & $\sim$ & & & & & & & & 1 \\
\hline Se espera la llegada del montacarga & & & $\lambda$ & & & & & & & 5 \\
\hline Los trabajadores suben al camión & $h^{\prime}$ & & & & & & & & & 7 \\
\hline Se ubica el pallet al alcance del montacarga & - & & & & & & & & & 7 \\
\hline El montacarga baja la el pallet & $\lambda$ & & & & & & & & & 10 \\
\hline El pallet es trasladado a la zona de inventario & & x & & & & & $\begin{array}{l}\text { Con el montacarga y/o stocka - aprox. } 3 \\
\text { vueltas }\end{array}$ & & 155 & 8 \\
\hline Se da conformidad a los cargos del transportista & & & & & $\mathbf{y}$ & & & & & 1 \\
\hline Se espera el inicio de inventario & & & * & & & & según el trabajo en proceso & & & 613 \\
\hline Se ordena y clasifica la mercadería & $x<$ & & & & & & & & & 240 \\
\hline Se reliza el conteo & & & - & $-x$ & & & & & & 60 \\
\hline Se traslada la meradería a la zona de almacén & & $x$ & & & & & Estantes $\mathrm{y}$ anaqueles disponibles & & 175 & 24 \\
\hline Se solicita servicio de montacarga & & & 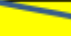 & & & & & & & 1 \\
\hline Se espera disponibilidad de montacarga & & & $x$ & & & & Según la carga de trabajo & & & 13 \\
\hline El montacarga descarga los pallets para el almacenaje & $x$ & - & & & & & & & & 15 \\
\hline Se ubica la mercaderia en el pallet & $x$ & & & & & & & & & 60 \\
\hline El montacarga sube el pallet a su ubicación & $x$ & & & & & & & & & 15 \\
\hline La mercadería es almacenada & & & & & & $x$ & Hasta que lleguen los pedidos (NDS) & & & 5,760 \\
\hline Se realiza la validación del Jefe de almacén via Sistema (ERP) & & & & & & & & & & 2 \\
\hline Se actualiza el kardex & $x$ & & & & & & & & & 30 \\
\hline Totales: & 11 & 3 & 3 & 2 & 1 & 1 & & & & \\
\hline
\end{tabular}

Fuente: Elaboración propia 


\section{Estándar para el proceso de Picking}

Consideraciones:

- Este proceso se llevará a cabo en 3 turnos de 3 horas al día. Se trabaja de 8 am a 6 pm.

- Los pedidos serán atendidos en consolidados cada tres horas al día.

- Las horas asignadas para la realización de los cortes y consolidados son 8.00 am - 11.00 am y 3.00 pm (considerando una hora de refrigerio en el segundo turno)

- Al inicio de cada turno, se medirá la cantidad de libros que hay por separar (picking) y en base a la magnitud resultante se asignará el número de colaboradores a intervenir en el proceso.

- El cálculo del número de trabajadores se realizará en base a la propuesta presentada en el balance de línea del proceso de Picking.

Tabla 14: Balance de Línea- Picking

\begin{tabular}{|c|c|c|c|c|c|}
\multicolumn{4}{|c}{ PROCESO DE PICKING: Balance a 03 horas } & \multicolumn{1}{|c|}{ Incremento: } & 15\% \\
\hline \# Colaboradores & $\begin{array}{c}\text { Hora x } \\
\text { turno }\end{array}$ & $\begin{array}{c}\text { Horas Hombre } \\
\text { disponible } \\
\text { (HH) }\end{array}$ & Base unid/HH & $\begin{array}{c}\text { Max. Unid a } \\
\text { unid/HH } \\
\text { procesar }\end{array}$ \\
\hline 1 & 3 & 3 & & & 635 \\
2 & 3 & 6 & & & 1,270 \\
3 & 3 & 9 & 184 & 212 & 1,904 \\
4 & 3 & 12 & & & 2,539 \\
5 & 3 & 15 & & & 3,174 \\
6 & 3 & 18 & & & 3,809 \\
\hline
\end{tabular}

Fuente: Elaboración propia 
- Luego de identificado el número de colaboradores, el jefe de almacén decidirá qué personal se dedicará al desarrollo de proceso, manteniendo siempre al líder del proceso como primera opción.

Se presenta la ficha del proceso y el DAP con el detalle y secuencias de actividades a seguir

Figura 45: Ficha del proceso de Picking

\begin{tabular}{|c|c|}
\hline $\begin{array}{l}\text { CÓDIGO } \\
\text { SBSPIOOO1 }\end{array}$ & 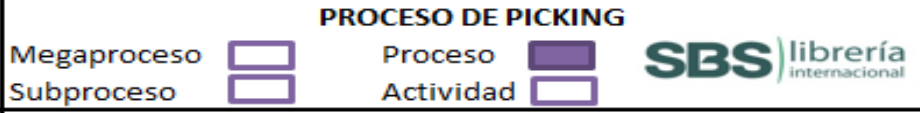 \\
\hline ELABORACIÓN & Martín Ramirez C. \\
\hline RESPONSABLES & Jefe de Almacén - Coorinador de recepción \\
\hline INICIA & Impresión de Notas de salida (NDS): Pedidos \\
\hline TERMINA & $\begin{array}{l}\text { Libros separados puestos en la zona de pedidos en proceso / } \\
\text { entrega de NDS al digitador de guías }\end{array}$ \\
\hline $\begin{array}{l}\text { PROCEDIMIENTO } \\
\text { ACTUAL }\end{array}$ & $\begin{array}{l}\text { El proceso de PICKING se lleva a cabo con un método PEPS } \\
\text { (primeras entradas primeras salidas) es decir los pedidos son } \\
\text { separados según orden de llegada uno a uno. Los trabajadores } \\
\text { que intervienen en este proceso son } 4 \text { sin importar el volumen } \\
\text { de trabajo a procesar, es decir el trabajo se realiza de una forma } \\
\text { desbalanceada y no guarda relación a la productividad del } \\
\text { recurso humano }\end{array}$ \\
\hline $\begin{array}{l}\text { PROCEDIMIENTO } \\
\text { PROPUESTO }\end{array}$ & $\begin{array}{l}\text { El proceso se realizará con la consolidacón de los pedidos en las } \\
\text { horas } 8 \text { am - } 11 \text { am - } 3 \text { pm, es decir tres veces al día. El personal } \\
\text { se asignará según la cantidad de libros a procesar y el estudio } \\
\text { realizado de productiviad de cada hora hombre. El proceso se }\end{array}$ \\
\hline INDICADORES & $\begin{array}{l}\text { Capacidad promedido de separación diaria } \\
\text { Tiempo de ciclo del proceso }\end{array}$ \\
\hline $\begin{array}{l}\text { INFORMACIÓN DE } \\
\text { ENTRADA }\end{array}$ & $\begin{array}{l}\text { Cantidad de libros solicitados por turno } \\
\text { Nombre del cliente que realiza la solicitud }\end{array}$ \\
\hline INPUTS & Notas de Salida (NDS) impresas \\
\hline PROVEEDORES & Área y Proceso de Gestión de Pedidos \\
\hline $\begin{array}{l}\text { INFORMACIÓN DE } \\
\text { SALIDA }\end{array}$ & $\begin{array}{l}\text { Cantidades solicitadas confirmadas } \\
\text { Listado de pedidos separados }\end{array}$ \\
\hline OUTPUTS & $\begin{array}{l}\text { Libros separados y organizados por clientes a disposición de } \\
\text { embalaje } \\
\text { Nota de Salida con confirmación de separación de picking }\end{array}$ \\
\hline CLIENTES & $\begin{array}{l}\text { Digitador de Guía } \\
\text { Proceso de Packing }\end{array}$ \\
\hline RECURSO HUMANO & Asistentes de Almacén \\
\hline
\end{tabular}

Fuente: Elaboración propia 
Figura 46: DAP Propuesto para el proceso de Picking

\begin{tabular}{|c|c|c|c|c|c|c|c|c|c|c|}
\hline \multirow{2}{*}{ DIAGRAMA NN: $\quad$ DAPSBSPI-1.5 } & \multirow{2}{*}{\multicolumn{6}{|c|}{ HOJA No: $\quad 01$}} & \multicolumn{4}{|c|}{ RESUMEN } \\
\hline & & & & & & & ACTIVIDAD & ACTUAL & PROPUESTA & ECONOMIA \\
\hline \multicolumn{7}{|l|}{ Método: ACTUAL / PROPUESTO } & \multirow{3}{*}{$\begin{array}{l}\text { Operación } \\
\text { Transporte } \\
\text { Espera } \\
\text { Inspección } \\
\text { Op. Combinada } \\
\text { Almacenamiento } \\
\end{array}$} & \multirow{3}{*}{\multicolumn{2}{|c|}{$\begin{array}{l}7 \\
5 \\
1 \\
2 \\
2 \\
1\end{array}$}} & \\
\hline OPERACIÓN / PROCESO: & & & & & & & & & & \\
\hline \multicolumn{7}{|l|}{ Picking } & & & & \\
\hline \multicolumn{7}{|l|}{ LUGAR: Centro de Distribución SBS } & Distancia (m) & & 50 & \\
\hline \multicolumn{7}{|l|}{ COMPUESTO POR: } & Tiempo (min) & & 237 & \\
\hline \multicolumn{7}{|l|}{ FECHA: $/ /$} & Costos & & & \\
\hline \multirow{2}{*}{ DESCRIPCION } & \multicolumn{6}{|c|}{ SIMBOLO } & \multirow{2}{*}{ OBSERVACIONES } & \multirow[t]{2}{*}{ C } & \multirow[t]{2}{*}{$\mathrm{D}(\mathrm{m})$} & \multirow[t]{2}{*}{$T(\min )$} \\
\hline & O & $\Rightarrow$ & D & L & 0 & $\nabla$ & & & & \\
\hline Se recepcionan pedidos impresos (NDS) & $x$ & & . & & & & En la bandeja del primer piso & & & 1 \\
\hline Se espera antes de comenzar a separar los libros & & & D & & & & & & & 180 \\
\hline Se imprime consolidado de ubicaciones para el montacargas & $\therefore$ & & & & & & Planificación del montacargas & & & 2 \\
\hline Se selecionan pedidos a separar & & & & $x$ & & & & & & 5 \\
\hline \begin{tabular}{|l|l|} 
Se identifican las ubicaciones accesibles \\
\end{tabular} & & & & ד & & & & & & 3 \\
\hline Se dirige a las ubicaciones accesibles & & $\pi$ & & & & & & & 9 & 3 \\
\hline Se cogen los libros & k & & & & & & & & & 5 \\
\hline Se realiza check en la NDS & & & & & $>$ & & & & & 1 \\
\hline Se dirige a la zona de pedidos en proceso & & $\pi$ & & & & & & & 18 & 2 \\
\hline Se dejan los libros en la zona de pedidos en proceso & $\%$ & & & & & & & & & 2 \\
\hline Los libros se almacenan temporalmente & & & & & & X & Hasta completar el pedido & & & 16 \\
\hline Se dirige a la zona de descarga del montacarga & & & & & & & $\begin{array}{l}\text { El montaarga va trabajando simultaneamente la } \\
\text { programación de su ruta a separar }\end{array}$ & & 9 & 2 \\
\hline Se cogen los libros según según planificación del montacargas & & & & & & & & & & 5 \\
\hline Se realiza check en la NDS & & & & & 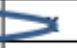 & & & & & 1 \\
\hline Se dirige hacia la zona de pedidos en proceso & & $\pi$ & & & & & & & 9 & 2 \\
\hline Se dejan los libros en la zona pedidos en proceso & $x$ & & & & & & & & & 5 \\
\hline Se dirige a digitador de guia & & 2 & & & & & & & 5 & 1 \\
\hline Se deja la NDS y se realiza la "confirmación de finalización de Picking" & $x$ & & & & & & Actualización de información de cantidades & & & 1 \\
\hline Totales: & 7 & 5 & 1 & 2 & 2 & 1 & & & & \\
\hline
\end{tabular}

Fuente: Elaboración propia 


\section{Estándar para el proceso de Packing}

Consideraciones:

- Este proceso se llevará a cabo en 3 turnos de 3 horas al día. Se trabaja de 8 am a 6 pm.

- Los pedidos a embalar serán procesados en consolidados cada tres horas al día.

- Las horas asignadas para la realización de los cortes y consolidados son 8.00 am - 11.00 am y 3.00 pm (considerando una hora de refrigerio en el segundo turno)

- Al inicio de cada turno, se medirá la cantidad de libros que hay por embalar (packing) y en base a la magnitud resultante se asignará el número de colaboradores a intervenir en el proceso.

- El cálculo del número de trabajadores se realizará en base a la propuesta presentada en el balance de línea del proceso de Packing.

Tabla 15: Balance de línea -Packing

\begin{tabular}{|c|c|c|c|c|c|}
\multicolumn{4}{|c|}{ PROCESO DE PACKING: Balance a 03 horas } & \multicolumn{1}{|c|}{ Incremento: } & $\mathbf{1 5 \%}$ \\
\hline \# Colaboradores & $\begin{array}{c}\text { Hora x } \\
\text { turno }\end{array}$ & $\begin{array}{c}\text { Horas Hombre } \\
\text { disponible } \\
\text { (HH) }\end{array}$ & Base unid/HH & Max. Unid a \\
unid/HH & procesar \\
\hline 1 & 3 & 3 & & & 773 \\
2 & 3 & 6 & & & 1,546 \\
3 & 3 & 9 & 224 & 258 & 2,318 \\
4 & 3 & 12 & & & 3,091 \\
5 & 3 & 15 & & & 3,864 \\
6 & 3 & 18 & & & 4,637 \\
\hline
\end{tabular}

Fuente: Elaboración propia

- Luego de identificado el número de colaboradores, el jefe de almacén decidirá qué personal se dedicará al desarrollo de proceso, manteniendo siempre al líder del proceso como primera opción. 
- Se presenta la ficha del proceso y el DAP con el detalle y secuencias de actividades a seguir.

Figura 47: Ficha del proceso de Packing

\begin{tabular}{|c|c|}
\hline $\begin{array}{l}\text { CÓDIGO } \\
\text { SBSPA001 }\end{array}$ & 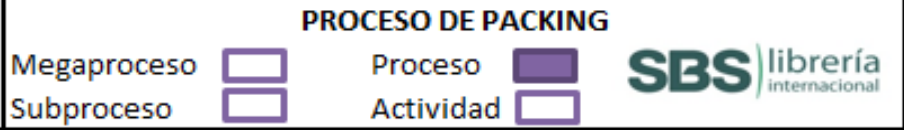 \\
\hline ELABORACIÓN & Martín Ramirez C. \\
\hline RESPONSABLES & Jefe de Almacén - Coordinador de Packing \\
\hline INICIA & Consolidado de pedidos confirmados de picking \\
\hline TERMINA & Pedidos embalados puestos a disposición para el transporte \\
\hline $\begin{array}{l}\text { PROCEDIMIENTO } \\
\text { ACTUAL }\end{array}$ & $\begin{array}{l}\text { El proceso de PACKING se lleva a cabo con un método PEPS } \\
\text { (primeras entradas primeras salidas) es decir los pedidos son } \\
\text { embalados según orden de llegada uno a uno. Los trabajadores } \\
\text { que intervienen en este proceso son } 3 \text { sin importar el volumen } \\
\text { de trabajo a procesar, es decir el trabajo se realiza de una forma } \\
\text { desbalanceada y no guarda relación a la productividad del } \\
\text { recurso humano }\end{array}$ \\
\hline $\begin{array}{l}\text { PROCEDIMIENTO } \\
\text { PROPUESTO }\end{array}$ & $\begin{array}{l}\text { El proceso se realizará con la consolidacón de los pedidos a } \\
\text { embalar en las horas } 8 \mathrm{am} \text { - } 11 \mathrm{am} \text { - } 3 \mathrm{pm} \text {, es decir tres veces al } \\
\text { día. El personal se asignará según la cantidad de libros a } \\
\text { procesar y el estudio realizado de productiviad de cada hora } \\
\text { hombre. El proceso se balancerá para terminar en tres horas. }\end{array}$ \\
\hline $\begin{array}{l}\text { OBJETIVO / META DE LA } \\
\text { PROPUESTA }\end{array}$ & $\begin{array}{l}\text { La finalidad del proceso es realizar el embalaje de los libros } \\
\text { según solicitud de cliente para que estos paen de manera } \\
\text { ordenda al proceso de transporte. La meta del cambio de } \\
\text { método propuesto es reducir en } 10 \% \text { el tiempo de ciclo en el } \\
\text { que se lleva a cabo el proceso. }\end{array}$ \\
\hline INDICADORES & $\begin{array}{l}\text { Capacidad promedio de embalaje diario } \\
\text { Tiempo de ciclo del proceso }\end{array}$ \\
\hline $\begin{array}{l}\text { INFORMACIÓN DE } \\
\text { ENTRADA }\end{array}$ & $\begin{array}{l}\text { Relación de pedidos a embalar } \\
\text { Cantidad de libros a embalar }\end{array}$ \\
\hline INPUTS & $\begin{array}{l}\text { NDS con confirmación de picking } \\
\text { Guías de remisión (GR) }\end{array}$ \\
\hline PROVEEDORES & $\begin{array}{l}\text { Proceso de Picking } \\
\text { Digitador de Guías }\end{array}$ \\
\hline $\begin{array}{l}\text { INFORMACIÓN DE } \\
\text { SALIDA }\end{array}$ & $\begin{array}{l}\text { Lista de clientes y pedidos embalados para el traslado de los } \\
\text { productos al cliente }\end{array}$ \\
\hline OUTPUTS & $\begin{array}{l}\text { Pedido embalados en cajas y/o bolsas con guía de remisión } \\
\text { programados para el transporte }\end{array}$ \\
\hline CLIENTES & Proceso de transporte \\
\hline RECURSO HUMANO & Asistentes de almacén \\
\hline
\end{tabular}

Fuente: Elaboración propia 
Figura 48: DAP Propuesto para el proceso de Packing

\begin{tabular}{|c|c|c|c|c|c|c|c|c|c|c|}
\hline \multicolumn{11}{|c|}{$\begin{array}{ll}\text { DIAGRAMA DE ANÁLISIS DEL PROCESO } \\
\end{array}$} \\
\hline \multirow{2}{*}{ DIAGRAMA No: $\quad$ DAPSBSPA-1.5 } & \multirow{2}{*}{\multicolumn{2}{|c|}{ HOJA №: }} & \multirow{2}{*}{\multicolumn{4}{|c|}{ 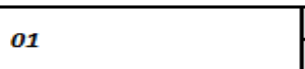 }} & \multicolumn{4}{|c|}{ RESUMEN } \\
\hline & & & & & & & ACTIVIDAD & ACTUAL & PROPUESTA & ECONOMÍA \\
\hline \multicolumn{7}{|l|}{ Método: ACTUAL / PROPUESTO } & $\begin{array}{l}\text { Operación } \\
\text { Transporte }\end{array}$ & & $\begin{array}{l}8 \\
4\end{array}$ & \\
\hline \multicolumn{7}{|l|}{ OPERACIÓN / PROCESO: } & Espera & & 1 & \\
\hline \multicolumn{7}{|l|}{ Packing } & $\begin{array}{l}\text { Inspección } \\
\text { Op. Combinada } \\
\text { Almacenamiento }\end{array}$ & & $\begin{array}{l}\mathbf{1} \\
\mathbf{1} \\
\mathbf{1}\end{array}$ & \\
\hline \multirow{2}{*}{\multicolumn{7}{|c|}{\begin{tabular}{|l} 
LUGAR: Centro de Distribución SBS \\
COMPUESTO POR:
\end{tabular}}} & Distancia (m) & & 28 & \\
\hline & & & & & & & Tiempo (min) & & 225 & \\
\hline \multicolumn{7}{|l|}{ FECHA: $/ /$} & Costos & & & \\
\hline & $\Longrightarrow$ & $\square$ & L & $\square$ & $\square \cup$ & 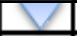 & & & & \\
\hline Se espera turno para empezar a embalar & & & $x$ & & & & & & & 180 \\
\hline Se realiza el consolidado de los pedidos confirmados en el picking & & & & & & & $\begin{array}{l}\text { Se imprimen los pedidos en hoja simple y se } \\
\text { obtienen el total de libros a empacar }\end{array}$ & & & 3 \\
\hline Se dispone la cantidad de colaboradores a procesar & & & & & & & & & & 2 \\
\hline Se selecciona pedidos a embalar & & & & 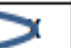 & & & & & & 2 \\
\hline Se dirige a la zona de pedidos en proceso & & $\pi$ & & & & & & & 9 & 1 \\
\hline Coge los libros del pedido correspondiente & & & & & & & & & & 2 \\
\hline Se dirige a la mesa de embalaje & & $x$ & & & & & & & 9 & 4 \\
\hline Se ordenan y apilan los libros & R. & & & & & & & & & 10 \\
\hline Se cuentan los libros / Check con la GR & & & & & & & & & & 4 \\
\hline Se embalan los libros en cajas $\mathrm{y} / \mathrm{o}$ bolsas & & & & & & & & & & 5 \\
\hline Se transportan los bultos a los pallets para despacho & & $x$ & & & & & & & 5 & 2 \\
\hline Se deja el pedido embalado en los pallets para despacho & 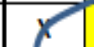 & & & & & & & & & 3 \\
\hline Se emiten la GR (guia de remisión) & & & & & & & & & & 3 \\
\hline Se trasladan guías impresas & & X & & & & & & & 5 & 1 \\
\hline Se asocian las GR a los pedidos & 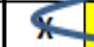 & & & & & & & & & 3 \\
\hline Los pedidos son almacenados hasta su programación de despacho & & & & & & $x$ & La mercadería sale al turno siguiente & & & \\
\hline Totales: & 8 & 4 & 1 & 1 & 1 & 1 & & & & \\
\hline
\end{tabular}

Fuente: Elaboración propia 


\section{CAPITULO 4: VALIDACIÓN DE LA SOLUCIÓN DE INGENIERÍA Y EVALUACIÓN ECONÓMICA}

\section{Fase 6: Resultados y evaluación del Plan piloto para la implementación de las propuestas de mejora}

Para el análisis de los posibles resultados de las propuestas desarrolladas anteriormente correspondientes a la fase 4 manifestada a través de la hoja de ruta de implantación Lean utilizada como base en este proyecto, se procedió con la ejecución de un piloto. El análisis se constituye de lo siguiente:

En primer lugar se describirá el proyecto piloto que se realizó en la empresa en un periodo de 15 días hábiles con los cambios y acciones propuestas para la mejora del proceso; esta descripción incluirá detallar el Alcance, Objetivo, Responsables y Cronogramas del proyecto piloto. Seguidamente, se describirán las acciones implementadas, en qué consistió emplearlas durante este período y dar a conocer puntos importantes durante el desarrollo del plan piloto. Por último, se explicará el análisis de los resultados obtenidos en comparación a la situación anterior de la empresa.

\section{Descripción Plan Piloto}

Alcance: La implantación del plan piloto tiene como propósito cuantificar, medir y evaluar los resultados obtenidos de la aplicación de las propuestas de mejora desarrolladas durante el punto "Fase 4.Estabilización de mejoras" del presente proyecto, las cuales se llevaran a cabo en los procesos de Recepción, Picking y Packing que conforman gran parte del proceso 
clave de "Distribución" en la cadena de suministro de la empresa Special Book Services. Estas propuestas serán aplicadas en 15 días útiles de trabajo y en simultáneo.

Objetivo: Obtener resultados cuantitativos de los tiempos promedio en que se ejecutan las actividades durante y luego de la aplicación de las propuestas de mejora y así permitir el estudio del impacto generado en base a la situación actual de los procesos de la empresa, como la viabilidad del proyecto.

Límites: El plan piloto consta de la aplicación de las siguientes propuestas de mejora (ver cuadro 33)

Cuadro 33: Propuesta a desarrollar durante el plan piloto

\begin{tabular}{|c|c|c|}
\hline Propuesta & Código & Proceso \\
\hline $\begin{array}{l}\text { Normalización de disposición del Montacargas y su operario ante la } \\
\qquad \text { llegada de mercadería importada }\end{array}$ & PMRl & Recepción \\
\hline $\begin{array}{c}\text { Balance de linea ajustado a } 600 \text { minutos. A través de asignación del } \\
\text { personal según la cantidad de libros a procesar }\end{array}$ & PMR2 & Recepción \\
\hline Digitalización de los documentos de sustento de inventario & PMR4 & Recepción \\
\hline $\begin{array}{l}\text { Habilitación de un nuevo canal de impresión de pedidos. Del segundo al } \\
\text { primer piso }\end{array}$ & PMPII & Picking \\
\hline Reubicación del lugar de trabajo (escritorio) del digitador de guías & PMPI3 & Picking \\
\hline Organización del almacén según la clasificación $A B C$ de los productos & PMPI4.1 & Picking \\
\hline $\begin{array}{c}\text { Balance de línea ajustado al } 80 \text { minutos (según la cantidad de libros a } \\
\text { procesar) }\end{array}$ & PMPI4.2 & Picking \\
\hline Planificación del trabajo del montacarga a través de un consolidado & PMPI5 & Picking \\
\hline $\begin{array}{c}\text { Cambio del input necesario para el inicio del proceso. Se establece que } \\
\text { el input para el proceso es la confirmación de picking }\end{array}$ & $P M P A 1$ & Packing \\
\hline $\begin{array}{c}\text { Balance de linea ajustado a } 180 \text { minutos. A través de asignación del } \\
\text { personal según la cantidad de libros a procesar }\end{array}$ & $P M P A 2$ & Packing \\
\hline
\end{tabular}

Fuente: Elaboración propia 
Las propuestas detalladas en el cuadro 33 serán aplicadas en simultáneo durante 15 días útiles. En estos días se registrarán el tiempo de las actividades correspondiente a cada proceso y así obtener el nuevo tiempo promedio de los procesos.

Durante los 15 días de implantación los procesos de recepción, picking y packing se desarrollarán en un horario de 10 horas por día.

\section{Responsables:}

El desarrollo del plan piloto cuenta con el respaldo de la gerencia general quien es la parte con mayor interés sobre los resultados que se obtendrán, por ello ha brindado el respaldo necesario para llevar a cabo las actividades programadas y ha otorgado las facultades necesarias para su correcto desarrollo a los colaboradores:

Sr. Martín Ramirez: Autor del proyecto principal de propuesta de aplicación de herramientas Lean, quien se encargará de reunir todos los registros de tiempo de las actividades para cada proceso, además, asesorar el desarrollo de cada propuesta orientando a los demás responsables a cumplir con el objetivo.

Sr. Harold Taipe: Tiene a cargo el almacén y garantizará la colaboración del personal para el desarrollo de las propuestas de mejora.

Sr. Pedro La Rosa: Analista y programador de sistemas. Es la persona asignada del área TI para brindar el soporte necesario en cuanto a los requerimientos en el sistema de gestión (SIGE) o ERP de la empresa.

Sr. José Chuecas: A cargo de la parte administrativa de la logística. Se encargará de las coordinaciones con el agente aduanero, también, participara en la planificación ABC de almacén y coordinará la reubicación del personal involucrado que tiene a cargo. 


\section{Cronograma:}

Los días seleccionados para la aplicación de las propuestas de mejoras son durante la semana del 12 al 16 de setiembre, la semana del 19 al 23 de setiembre y la semana del 26 al 30 de setiembre del presente año. En este tiempo se trabajará 10 horas al día en los tres procesos. Los días previos: jueves 8 , viernes 9 y sábado 10 de setiembre serán los días para atender los requerimientos y capacitar a los colaboradores involucrados en el proceso por parte de los responsables asignados.

Se representa gráficamente en el cuadro 34. 
Cuadro 34: Cronograma para la implantación del plan piloto

\begin{tabular}{|c|c|c|c|c|c|c|c|c|}
\hline \multirow{2}{*}{ Propuesta } & \multirow{2}{*}{ Proceso } & \multicolumn{3}{|c|}{ Preparación } & \multicolumn{3}{|c|}{$\begin{array}{l}\text { Desarrollo del Piloto } \\
\end{array}$} & \multirow{2}{*}{$\begin{array}{c}\text { Analisis de Piloto } \\
\text { oct-16 }\end{array}$} \\
\hline & & \begin{tabular}{|l} 
semana $1-2$ de setiembre \\
\end{tabular} & 08 de set & 9 de set 10 de set & Semana 12-16 & Semana 19-23 & Semana 26-30 & \\
\hline $\begin{array}{l}\text { Normalización de disposición del Montacargas y su operario ante la } \\
\text { llegada de mercadería importada }\end{array}$ & Recepción & & & & & & & \\
\hline $\begin{array}{l}\text { Balance de linea ajustado a } 720 \text { minutos. A través de asignación del } \\
\text { personal según la cantidad de libros a procesar }\end{array}$ & Recepción & & & & & & & \\
\hline Digitalización de los documentos de sustento de inventario & Recepción & & & & & & & \\
\hline $\begin{array}{l}\text { Habilitación de un nuevo canal de impresión de pedidos. Del } \\
\text { segundo al primer piso }\end{array}$ & Picking & & & & & & & \\
\hline Reubicación del lugar de trabajo (escritorio) del digitador de guías & Picking & & & & & & & \\
\hline Organización del almacén según la clasificación ABC de los & Picking & & & & & & & \\
\hline $\begin{array}{l}\text { Balance de línea ajustado a180 minutos (según la cantidad de libros } \\
\text { a procesar) }\end{array}$ & Picking & & & & & & & \\
\hline Planificación del trabajo del montacarga a través de un consolidado & Picking & & & & & & & \\
\hline $\begin{array}{l}\text { Cambio del input necesario para el inicio del proceso. Se establece } \\
\text { que el input para el proceso es la confirmación de picking }\end{array}$ & Packing & & & & & & & \\
\hline $\begin{array}{l}\text { Balance de linea ajustado a } 180 \text { minutos. A través de asignación del } \\
\text { personal según la cantidad de libros a procesar }\end{array}$ & Packing & & & & & & & \\
\hline
\end{tabular}

Fuente: Elaboración propia 


\section{Descripción del desarrollo de las propuestas}

PMR1 Normalización de disposición del Montacargas y su operario ante la llegada de mercadería importada

En coordinaciones con el agente de aduanas, durante los días previos a la implementación del plan piloto, se estableció los dos avisos que tenía que reportar el conductor del camión antes de llegar al CD de SBS para dejar cualquier tipo de mercadería; la respuesta fue inmediata y positiva.

Sobre el primer aviso, el agente de aduana no tiene dificultad alguna para informar la salida de la mercadería de Aduanas puesto que es una práctica que ser realiza constante. Sobre el segundo aviso que debe hacer el conductor del transporte cuando esté en el cruce de las Av. Canadá y Circunvalación, será una nueva práctica que incluirán dentro del servicio ofrecido a la empresa SBS.

De forma paralela, se ha reunido a los asistentes del área de compras y al jefe de almacén, explicándoles la importancia y objetivos de la propuesta. Los asistentes de compras deben compartir de forma inmediata la información que obtengan del conductor del camión de carga con el encargado de almacén, este último deberá asumir la responsabilidad de tener preparado el montacargas y su conductor con anticipación.

Todos los participantes aceptaron el compromiso y se desarrollaron las actividades según lo expuesto durante los días 08 y 09 de setiembre.

PMR2 Balance de línea ajustado a 600 minutos. A través de asignación del personal según la cantidad de libros a procesar 
El cálculo de la cantidad de colaboradores que participaran en el proceso de inventario será realizado al inicio de cada día durante el periodo que se desarrolla el plan piloto. Este cálculo se basará en la cantidad de mercadería por inventariar que se ha acumulado durante el día anterior, información que será brindada por los asistentes de compra al jefe de almacén, quien tiene a su cargo la responsabilidad del proceso.

El día viernes 9 de setiembre se capacitó al jefe de almacén, en una reunión formal, sobre el método del cálculo del personal para el inventario en base a la tabla expuesta en el sustento de las propuestas. Otros puntos que se tocaron fueron la prioridad del personal para este proceso, puesto que una vez que se cubría el número de operarios en el proceso de recepción e inventario, los colaboradores no asignados pasarán a disposición de los demás procesos y actividades.

De esta manera, se procedió durante los diez días de implantación del plan piloto, contando con una supervisión del responsable del plan piloto una vez al día. Los resultados fueron registrados satisfactoriamente.

\section{PMR4 Digitalización de los documentos de sustento de inventario}

El desarrollo de esta propuesta tuvo como primera fase la habilitación en el sistema, por parte del analista, de un paso adicional en la interfaz de usuario que permitía al jefe de almacén dar visto de conformidad a las guías internas de inventario realizadas por los asistentes de almacén. Seguidamente, estas guías internas con el visto del jefe de almacén podrían ser ingresadas al kardex por el asistente administrativo de logística. Esta habilitación fue elaborada del 08 al 09 de setiembre.

Como segunda fase, se capacitó en los días viernes 09 y sábado 10 de setiembre al jefe de almacén y a sus colaboradores sobre el nuevo proceder y la no utilización del papel impreso en este fin, tal como se demostró en el sustento de la propuesta. 
Finalmente, durante los días de implantación del plan piloto las actividades se desarrollaron acorde a lo establecido, se resolvieron las consultas de los colaboradores que participaron durante el proceso.

PMPI1 Habilitación de un nuevo canal de impresión de pedidos. Del segundo al primer piso

Para la implantación del plan piloto se determinó la configuración de la impresora que se disponía en el primer piso del centro de distribución cerca a los escritorios del jefe de almacén y sus asistentes. La configuración fue realizada el día sábado 10 de setiembre por el personal de TI actualizando las computadoras a los usuarios que imprimen los pedidos.

Desde el jueves 08 de setiembre, este cambio fue anunciado en la pizarra de anuncios del

almacén y enviado vía correo a los colaboradores del área de facturación quiénes imprimen los pedidos.

\section{PMPI3. Reubicación del lugar de trabajo (escritorio) del digitador de guías}

Durante los 15 días de implementación del plan piloto se reubicó al asistente de facturación quien se encarga de emitir las guías de remisión para los despachos. No se registraron inconvenientes, reclamos y/o contratiempos por parte del personal.

Para la instalación se utilizó uno de los escritorios disponibles en el almacén, así que solo se tuvo que trasladar equipos de cómputo, formatos de guías y accesorios de escritorio. En este traslado, realizado en las últimas horas del día viernes 09 (día de preparación), se contó con el apoyo del personal TI a cargo de las instalaciones y redes.

\section{PMPI4.1 Organización del almacén según la clasificación ABC de los productos}

Para la preparación de la propuesta, se procedió a identificar los productos de clasificación "A" es decir, los que cuentan con una frecuencia igual o mayor a 50 veces en el último año. 
Los 217 títulos identificados en este grupo fueron puestos en las ubicaciones propuestas. La reubicación de la mercadería empezó con una semana de anticipación y fue desarrollada por el equipo de almacén encargado del almacenaje y el alquiler de un montacargas tipo apilador.

\section{PMPI4.2 - PMPA2 Balance de línea ajustado a180 minutos (según la cantidad de libros} a procesar) para los procesos de Picking y Packing

Se ha definido que el proceso de Picking y Packing se realice consolidando todo el material a procesar cada tres hora, es decir 180 minutos, por lo tanto, todas las solicitudes entrantes en este tiempo deben ser procesadas completamente. Para este propósito, se asignará el número de trabajadores a cada proceso según las tablas de productividad mostradas en cada propuesta.

El responsable de estos procesos es el jefe de almacén, quien a su vez es apoyado por el líder de Picking y el líder de despacho. A estos tres colaboradores se les capacitó en los días jueves 8 y viernes 9 de setiembre, en esta reunión se trataron de temas de cómo proceder a calcular el número de libros a procesar en las horas 8 am - 11 am y 3 pm. Además, se les concientizó de la importancia de la prueba piloto y las demás propuestas.

La supervisión durante los días del plan piloto fue realizada dos veces al día para asegurar que todo se esté desarrollando según lo planificado.

\section{PMPI5 Planificación del trabajo del montacargas a través de un consolidado}

Junto con la consolidación de pedidos se realizará la planificación de la ruta del montacargas, el cual consiste en la preparación de un reporte que consolide los títulos y cantidades a separar de las ubicaciones a partir del segundo nivel y arroje en orden las ubicaciones donde se 
bajarán los pallets. Este reporte fue preparado por el analista de sistema en los días jueves 8 y viernes 9 de setiembre.

Durante el desarrollo del plan piloto las actividades fueron registradas correctamente.

PMPA1 Cambio del input necesario para el inicio del proceso. Se establece que el input para el proceso es la confirmación de picking

En la reunión de capacitación de los días 8 y 9 de setiembre, se explicó este cambio para el inicio del packing. Todos los pedidos que fueron finalizados de picking en el turno anterior podrán ser impresos en título y cantidades en hoja simple, sea este papel reciclado o papel continuo.

De esta manera se inicia el proceso de Packing, luego anexada al pedido las guías de remisión correspondientes. 


\section{Análisis de los resultados del Plan Piloto}

Los resultados obtenidos de la productividad de los procesos de recepción e inventario, picking y packing durante el desarrollo de las prácticas propuestas en el plan piloto serán presentados y comparados con los datos obtenidos en el mes de setiembre 2015. Para realizar esta comparación se procederá según el flujograma mostrado en la figura 49 (pág. Siguiente) De la figura 49 se precisa que:

Seleccionar el Proceso: El flujo de validación incluye los tres procesos analizados Recepción e inventario, Picking y Packing

Seleccionar una muestra de 15 valores de la productividad media diaria de setiembre 2015: Se considera 15 valores para igualar el tamaño de muestra con la información obtenida en del plan piloto (15 días) y el mes de setiembre del 2015 para mantener los diversos factores que se dan en ese periodo de trabajo por ejemplo: demanda, promociones, campañas, ferias, etc

$\square$ Presentar los 15 valores obtenidos de la productividad media diaria del plan piloto: Esta información será comparada con la información anterior

Realizar pruebas de Normalidad a los datos: Para reconocer si los datos muestran una distribución normal o no y poder discernir qué pruebas de comparación de medias se utilizará, si las paramétricas o en caso contrario las no paramétricas.

Prueba de Shapiro Wilk: Esta prueba de Normalidad se utilizará para muestras pequeñas menores a 30 registros 
Fioura 49. Flıiograma nara el nroceso de validación de resultados

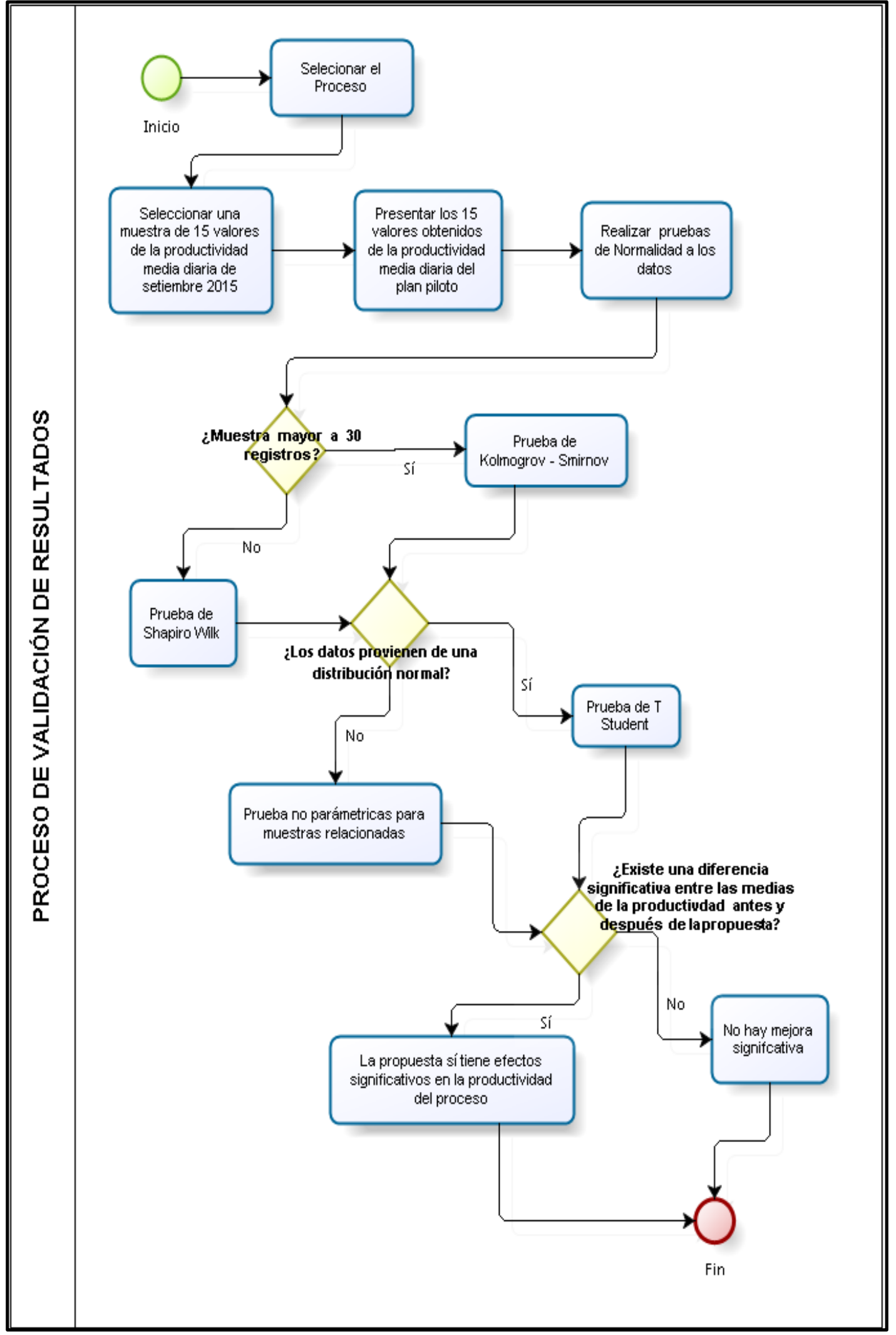

Fuente: Elaboración propia

pág. 246 
Prueba de Kolmogrov - Smirnov: Prueba de normalidad para muestras con registros mayores o iguales a 30

Prueba de T Student: Se utilizará si los datos provienen de una distribución normal para comparar las medias muestrales de ambos grupos: antes (set 2015) y después (Piloto realizado en el 2016)

Prueba no paramétricas para muestras relacionadas: En caso los datos no muestren un comportamiento normal, se utilizará esta prueba para la comparación de medias y comprobar si existe diferencias significativas en ambos grupos.

\section{Proceso de Recepción e inventario}

Para la validación de los resultados, en primer lugar se seleccionará el proceso de Recepción e inventario para lo cual se muestran los quince valores obtenidos del período setiembre 2015 y los valores obtenidos durante el desarrollo del plan piloto 2016.

Tabla 16: Productividad media diaria del P. Recepción

\begin{tabular}{|c|c|}
\hline \multicolumn{2}{|c|}{$\begin{array}{c}\text { Productividad media diaria unid/HH } \\
\text { Proceso de Recepción e Inventario }\end{array}$} \\
\hline Set 2015 & Piloto 2016 \\
\hline 56 & 200 \\
\hline 112 & 217 \\
\hline 52 & 188 \\
\hline 156 & 200 \\
\hline 215 & 205 \\
\hline 54 & 219 \\
\hline 209 & 219 \\
\hline 215 & 215 \\
\hline 170 & 195 \\
\hline 777 & 213 \\
\hline 253 & 220 \\
\hline 296 & 210 \\
\hline 111 & 221 \\
\hline 205 & 220 \\
\hline 36 & 223 \\
\hline
\end{tabular}

Fuente: La empresa (Elaboración propia) 
Seguidamente se procede a realizar las pruebas de normalidad a los dos grupos. Para los cálculos respectivos de cada prueba se ha utilizado el programa estadístico informático SPSS. La prueba se realizó con la siguiente secuencia:

Figura 50: Desarrollo de la prueba de normalidad para el proceso de recepción

\begin{tabular}{|c|c|c|c|c|c|c|}
\hline \multicolumn{7}{|c|}{ Planteamiento de Hipotesis } \\
\hline \multicolumn{7}{|c|}{$\mathrm{H} 0=$ Los datos provienen de una distriución normal } \\
\hline \multicolumn{7}{|c|}{$\mathrm{Hl}=$ Los datos no provienen de una distriución normal } \\
\hline \multicolumn{7}{|c|}{ Nivel de Confianza $=0.8$} \\
\hline \multicolumn{7}{|c|}{$\alpha=0.20$} \\
\hline \multicolumn{7}{|c|}{ Prueba de Normalidad } \\
\hline \multicolumn{7}{|c|}{ KOLMOGROV - SMIRNOV para muestras $>30$} \\
\hline \multicolumn{7}{|c|}{ SHAPIRO WILK para muestras $<30$} \\
\hline \multicolumn{7}{|c|}{ Pruebas de normalidad } \\
\hline & \multicolumn{3}{|c|}{ Kolmogorov-Smirnov ${ }^{a}$} & \multicolumn{3}{|c|}{ Shapiro-Wilk } \\
\hline & Estadístico & gl & Sig. & Estadistico & gl & Sig. \\
\hline RECEPSTE15 & .255 & 15 & .010 & .706 & 15 & .000 \\
\hline RECEPPILOT016 & .177 & 15 &, 200 & .884 & 15 & .054 \\
\hline \multicolumn{5}{|c|}{ NORMALIDAD } & & \\
\hline \multirow{2}{*}{\multicolumn{2}{|c|}{$\begin{array}{l}\text { P - Valor (productividad antes) } \\
\text { P - Valor (productividad despues) }\end{array}$}} & 0.000 & $<$ & $a=0.20$ & & \\
\hline & & 0.054 & $<$ & $a=0.20$ & & \\
\hline
\end{tabular}

Fuente: Elaboración propia basada en SPSS software estadístico 
Con un nivel de confianza de 0.8 y una significación de 0.20 , los correspondientes a tamaños de muestra aproximados a 10 registros ideal en la ejecución de un plan piloto, se observa el valor $\mathrm{p}$ menor al valor $\alpha$ establecido por lo que se rechaza que los datos muestren un comportamiento normal (se rechaza la hipótesis nula), en consecuencia se puede afirmar la H1 = Los datos no provienen de una distribución normal.

Como los datos no cumplen una distribución normal, se realizará la comparación de medias de ambos grupos con la opción: pruebas no paramétricas para muestras relacionadas del programa SPSS.

Los resultados se muestran en 1 figura 51

Figura 51: Resultados de prueba no paramétrica para muestras relacionadas - Recepción

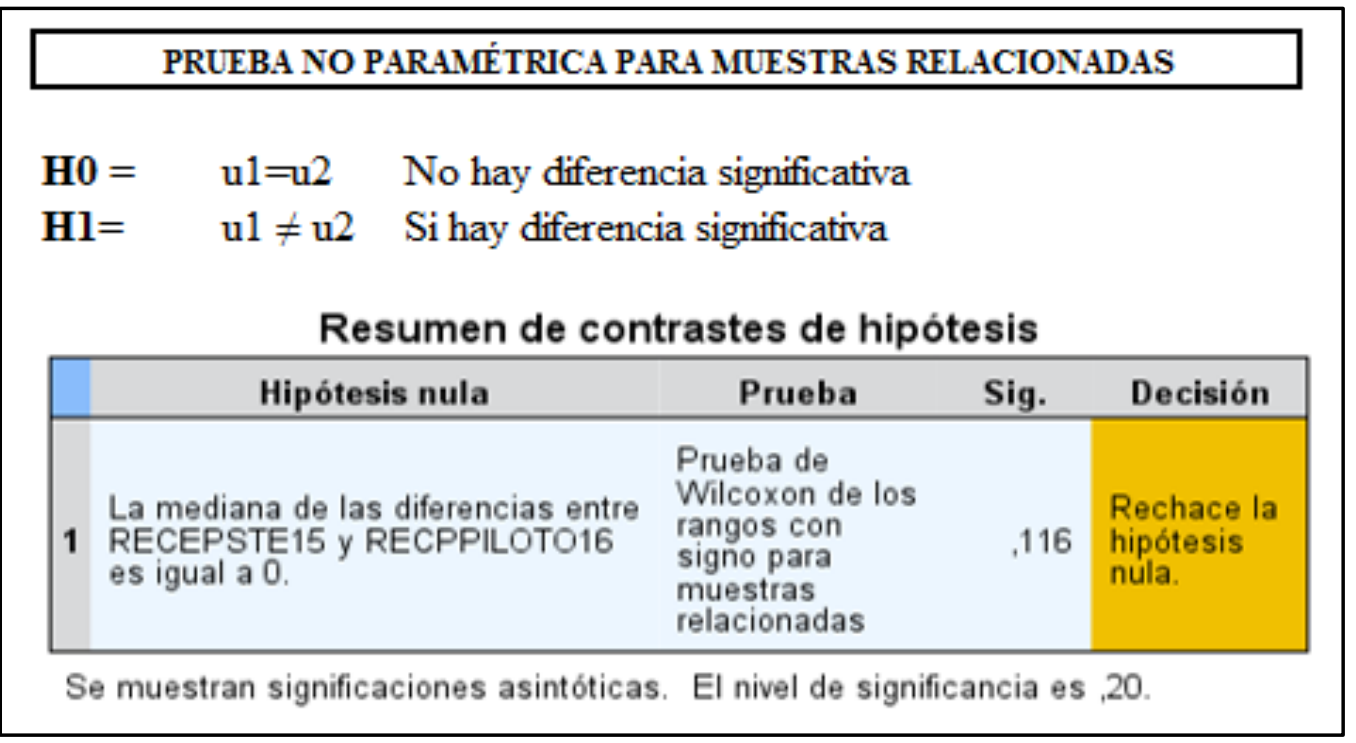

Fuente: Elaboración propia basada en SPSS software estadístico

Con un valor P de 0.116 menor a 0.20 se rechaza la hipótesis nula "no hay una diferencia significativa".

De la muestra analizada se desprende que hay una diferencia significativa entre las medias de la productividad del proceso de recepción e inventario antes y después de implementar las propuestas de mejora. Por tanto, se concluye que el desarrollo de las propuestas planteadas 
durante el plan piloto tiene efectos significativos en la productividad del proceso de recepción e inventario.

\section{Análisis estadístico de la productividad del proceso de Recepción e inventario "Antes"}

Se analiza la situación de los datos obtenidos de manera aleatoria de la productividad diaria de setiembre 2015, obteniéndose los siguientes datos estadísticos:

Cuadro 35: Estadísticos de Recepción e Inventario Setiembre 2015

\begin{tabular}{|l|r|}
\hline \multicolumn{2}{|l|}{ Proceso de Recepción e Inventario Set } \\
\hline Media & 194 \\
\hline Desviación estándar & 180.16 \\
\hline Varianza de la muestra & 32457.41 \\
\hline Límite superior de Control (LSC) & 374 \\
\hline Límite inferior de Control (LIC) & 14 \\
\hline Mínimo & 36 \\
\hline Máximo & 777 \\
\hline Cuenta & 15 \\
\hline
\end{tabular}

Fuente: Elaboración propia

Gráfico 21: Productividad diaria Recen. e Invent. Set 2015

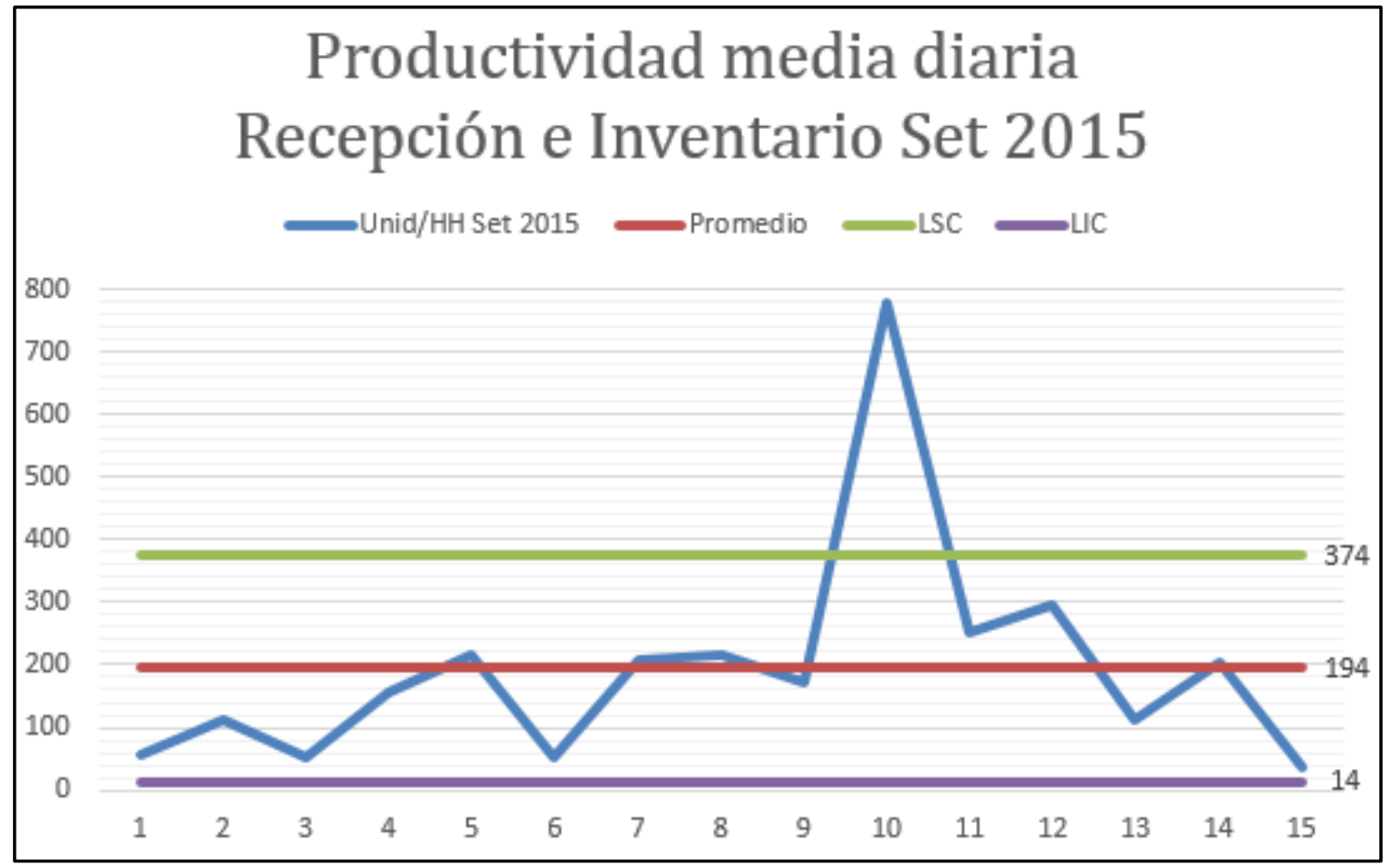

Fuente: La empresa (elaboración propia) 
La gráfica de control de la productividad del periodo setiembre 2015 expone que el proceso de recepción e inventario obtuvo una media de 194 unid/HH con una desviación estándar de 180.16. Aunque en el gráfico se observa un proceso controlado al registrar solo un valor fuera de sus límites de control, la desviación estándar que presenta es muy grande lo que implica que los valores oscilen entre 14 y 374 .

Análisis estadístico de la productividad del proceso de Recepción e inventario "Después"

Paralelamente, se muestran los análisis estadísticos de los resultados obtenidos durante la implantación del plan piloto para el proceso de recepción e inventario:

Cuadro 36. Fctadíctimac do Ramanción a Invantarin Plan
\begin{tabular}{|l|r|}
\hline Proceso de Recepción e Inventario Piloto 2016 \\
\hline Media & 211 \\
\hline Desviación estándar & 10.87 \\
\hline Varianza de la muestra & 118.14 \\
\hline Límite superior de Control (LSC) & 222 \\
\hline Límite inferior de Control (LIC) & 200 \\
\hline Mínimo & 188 \\
\hline Máximo & 223 \\
\hline Cuenta & 15 \\
\hline
\end{tabular}

Fuente: Elaboración Propia 
Gráfico 22: Productividad diaria de recepción e inventario

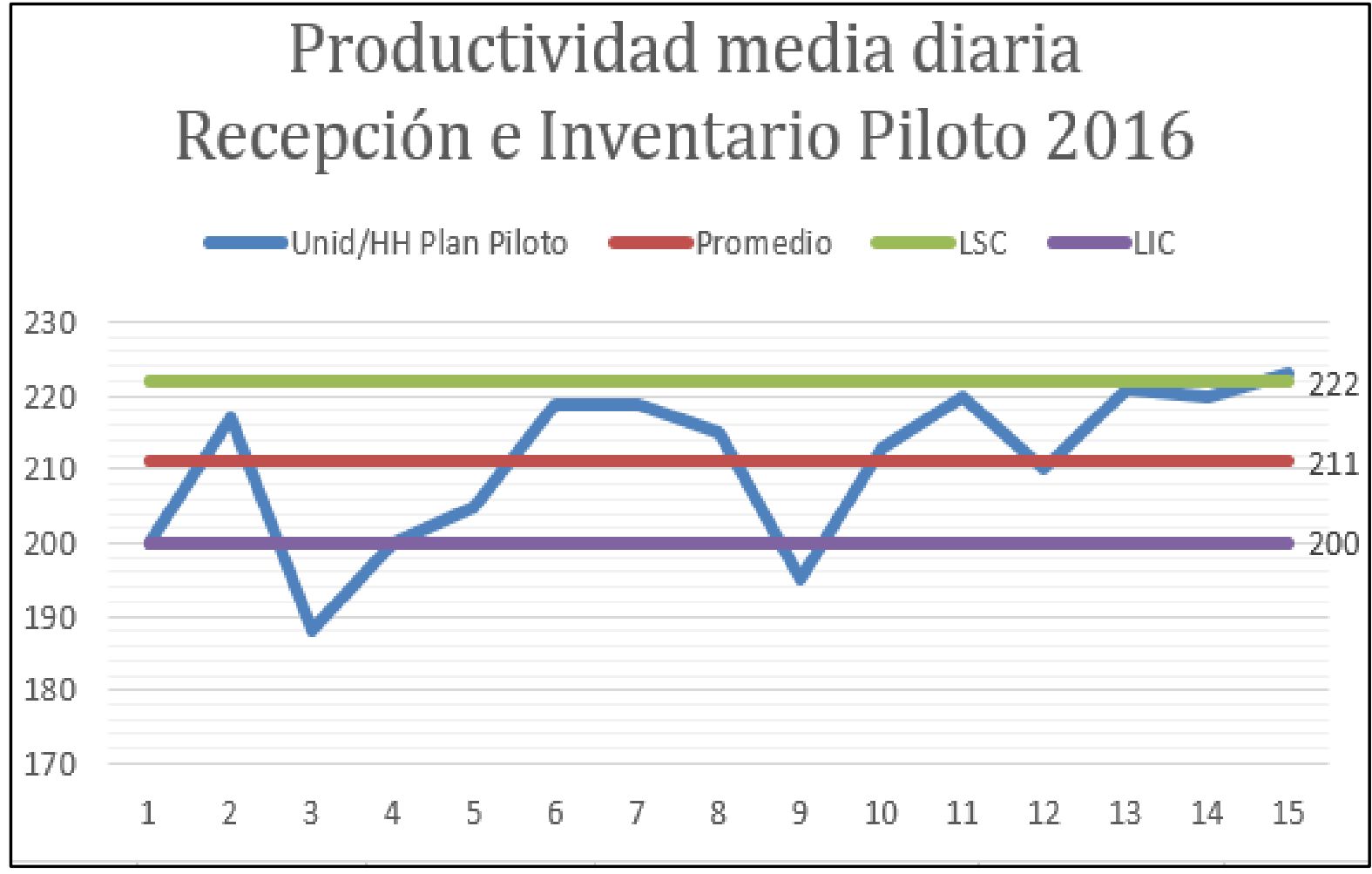

Fuente: La empresa (elaboración propia)

Los resultados del plan piloto para el proceso de recepción e inventario detallan una media de 211 unid/HH y una desviación estándar de 10.87.

La optimización del proceso de recepción de inventario cumple con dos aspectos primordiales en la mejora de procesos:

- La media se desplazó de 194 unid/HH a 211 unid/HH. Es decir el personal procesa en promedio $8.76 \%$ más unidades por hora que en el año anterior.

- La variabilidad del proceso se optimizó, basado en la desviación estándar de 180.16 a 10.87; lo que implica que el proceso ajustó su variabilidad en $93.97 \%$. Como resultado, se puede expresar que los límites de control se redujeron en relación a la media, si antes 
la productividad media diaria oscilaba entre 14 unid/HH y 374 unid/HH, ahora la productividad media diaria brinda valores entre $200 \mathrm{unid} / \mathrm{HH}$ y $220 \mathrm{unid} / \mathrm{HH}$.

\section{Ahorro expresado en Hora Hombre:}

El proceso de recepción e inventario durante el periodo 2015, laborando bajo el anterior método, disponía de cuatro colaboradores que realizaban sus operaciones durante 10 horas diarias sin importar el volumen de unidades a procesar. Por esta razón el promedio de hora hombre que se utilizaba diariamente era de $40 \mathrm{HH}$.

Con la implantación de las propuestas de mejora para el proceso de recepción e inventario desarrolladas durante el plan piloto y el nuevo método de balance de línea según la cantidad a procesar se obtiene que la media de Hora Hombre diaria es de 28, obteniéndose un ahorro diario de $12 \mathrm{HH}$ para este proceso. 
Gráfico 23: Hora hombre Proceso de Recepción e Inventario "antes y después"

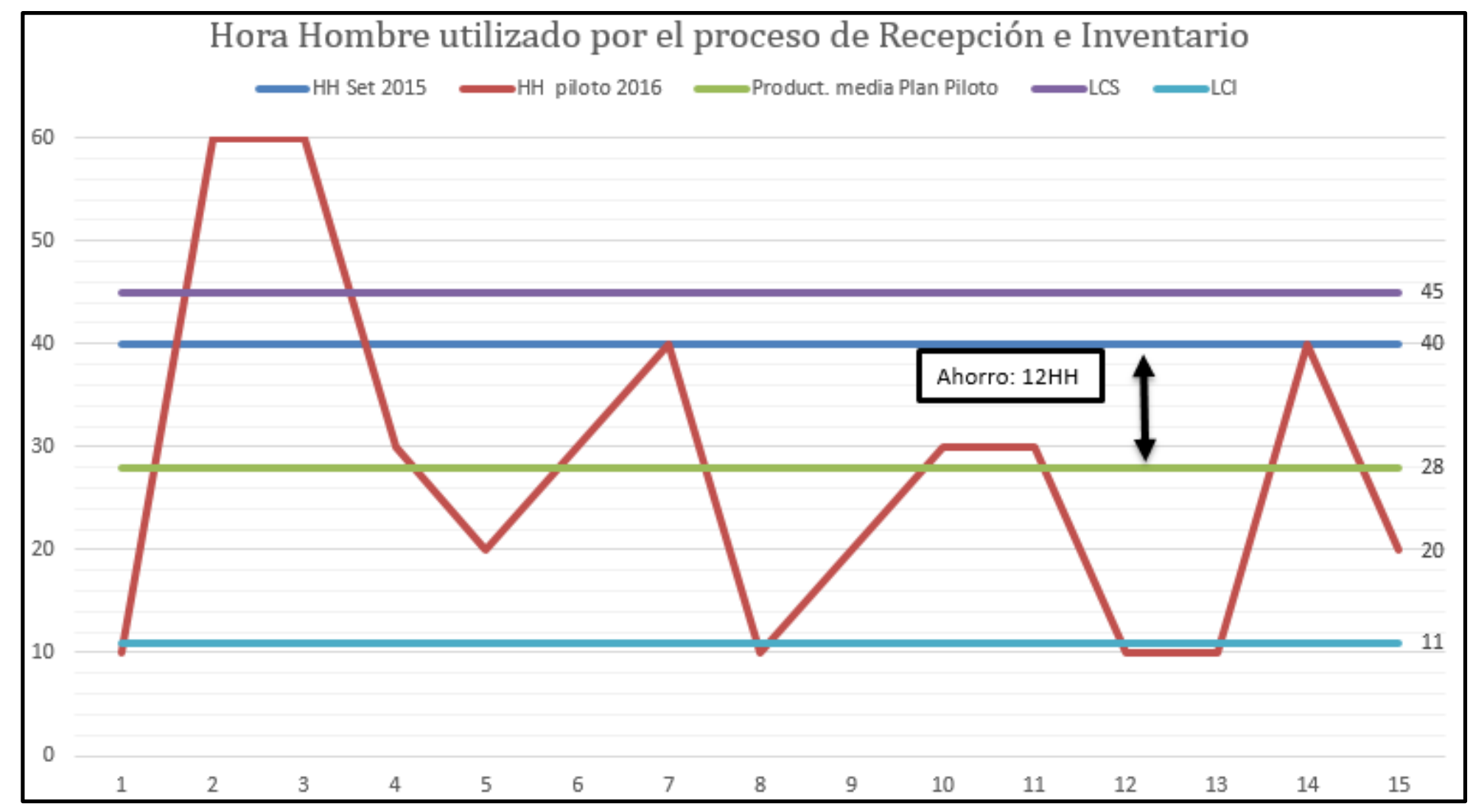

Fuente: La empresa (elaboración propia) 
En el gráfico se muestra la cantidad de hora hombre medio utilizado diariamente en el proceso de recepción e inventario. La línea de color azul indica la hora hombre utilizado en setiembre del 2015 con un promedio de $40 \mathrm{HH}$, de color verde se expresa la media diaria de las horas hombres utilizados en el plan piloto con un valor de $28 \mathrm{HH}$ e incidencias que oscilan entre $11 \mathrm{HH}$ y $45 \mathrm{HH}$.

\section{Proceso de Picking}

En segundo lugar, se realiza las pruebas estadísticas al proceso de Picking. Se muestra la selección de datos correspondientes al periodo setiembre 2015 y los obtenidos en la implantación del plan piloto.

Cuadro 37: Productividad media diaria del P. Picking

\begin{tabular}{|c|c|}
\hline \multicolumn{2}{|c|}{$\begin{array}{c}\text { Productividad media diaria } \\
\text { unid/HH Proceso de Picking }\end{array}$} \\
\hline Set 2015 & Piloto 2016 \\
\hline 72 & 188 \\
\hline 198 & 190 \\
\hline 97 & 185 \\
\hline 43 & 186 \\
\hline 45 & 185 \\
\hline 75 & 178 \\
\hline 217 & 187 \\
\hline 153 & 194 \\
\hline 391 & 186 \\
\hline 442 & 187 \\
\hline 127 & 205 \\
\hline 237 & 203 \\
\hline 166 & 209 \\
\hline 102 & 203 \\
\hline 106 & 209 \\
\hline Fuente: La empresa (Elaboración propia) \\
\hline
\end{tabular}


Con esta información se procede a realizar las pruebas de normalidad de los dos grupos de medición de la productividad del proceso de picking. Para los cálculos respectivos de cada prueba se ha utilizado el programa estadístico informático SPSS. La prueba se realizó con la siguiente secuencia:

Figura 52: Desarrollo de la prueba de normalidad para el proceso de Picking

\begin{tabular}{|c|c|c|c|c|c|c|}
\hline \multicolumn{7}{|c|}{ Planteamiento de Hipotesis } \\
\hline \multicolumn{7}{|c|}{ H0 = Los datos provienen de una distriución normal } \\
\hline \multicolumn{7}{|c|}{$\mathrm{Hl}=\mathrm{Los}$ datos no provienen de una distriución normal } \\
\hline \multicolumn{7}{|c|}{ Nivel de Confianza $=0.8$} \\
\hline \multicolumn{7}{|c|}{$a=0.20$} \\
\hline \multicolumn{7}{|c|}{ Prueba de Normalidad } \\
\hline \multicolumn{7}{|c|}{ KOLMOGROV - SMIRNOV para muestras $>30$} \\
\hline \multicolumn{7}{|c|}{ SHAPIRO WILK para muestras $<30$} \\
\hline \multicolumn{7}{|c|}{ Pruebas de normalidad } \\
\hline & \multicolumn{3}{|c|}{ Kolmogorov-Smirnov ${ }^{2}$} & \multicolumn{3}{|c|}{ Shapiro-Wilk } \\
\hline & Estadistico & \begin{tabular}{l|l}
1 & \\
1 & -1
\end{tabular} & Sig. & Estadistico & gl & Sig. \\
\hline PICKINGSET15 & .162 & 15 & $200^{*}$ & .852 & 15 & .018 \\
\hline PICKINGPILOT16 & .224 & 15 & .042 & .873 & 15 & .037 \\
\hline \multicolumn{7}{|c|}{$\begin{array}{l}\text { *. Esto es un limite inferior de la significación verdadera. } \\
\text { a. Corrección de significación de Lilliefors }\end{array}$} \\
\hline \multicolumn{5}{|c|}{ NORMALIDAD } & & \\
\hline P - Valor (productivi & d antes) & 0.018 & $<$ & $\alpha=0.20$ & & \\
\hline P - Valor (productivi & A despues) & 0.037 & $<$ & $\alpha=0.20$ & & \\
\hline
\end{tabular}

Fuente: Elaboración propia basada en SPSS software estadístico

Con un nivel de confianza de 0.8 y una significación de 0.20 , los correspondientes a tamaños de muestra aproximados a 10 registros ideal en la ejecución de un plan piloto, se observa el valor $\mathrm{p}$ menor al valor $\alpha$ establecido por lo que se rechaza que los datos muestren un comportamiento normal (se rechaza la hipótesis nula), en consecuencia se puede afirmar la H1 = Los datos no provienen de una distribución normal. 
Como los datos no cumplen una distribución normal, se realizará la comparación de medias de ambos grupos con la opción: pruebas no paramétricas para muestras relacionadas del programa SPSS.

Los resultados se muestran en la figura 53.

Figura 53: Resultados de prueba no paramétrica para muestras relacionadas - Picking

PRUEBA NO PARAMETRÍCA PARA MUESTRAS RELACIONADAS

$$
\begin{array}{lll}
\mathbf{H 0}= & \mathrm{u} 1=\mathrm{u} 2 & \text { No hay diferencia significativa } \\
\mathbf{H 1}= & \mathrm{u} 1 \neq \mathrm{u} 2 & \text { Si hay diferencia significativa }
\end{array}
$$

\section{Resumen de contrastes de hipótesis}

\begin{tabular}{|llll|}
\hline \multicolumn{1}{|c}{ Hipótesis nula } & \multicolumn{1}{c|}{ Prueba } & Sig. & Decisión \\
\hline $\mathbf{1}$ & $\begin{array}{l}\text { Prueba de } \\
\text { Wilcoxon de los }\end{array}$ & 156 $\begin{array}{l}\text { Rechace la } \\
\text { hipótesis } \\
\text { nula. } \\
\text { es igual a 0. }\end{array}$ & $\begin{array}{l}\text { Wangos con } \\
\text { signo para } \\
\text { muestras } \\
\text { relacionadas }\end{array}$ \\
\hline
\end{tabular}

Se muestran significaciones asintóticas. El nivel de significancia es ,20.

Fuente: Elaboración propia basada en SPSS software estadístico

Con un valor $\mathrm{P}$ de 0.156 menor a 0.20 se rechaza la hipótesis nula "no hay una diferencia significativa".

De la muestra analizada se desprende que hay una diferencia significativa entre las medias de la productividad del proceso de picking antes y después de implementar las propuestas de mejora. Por tanto, se concluye que el desarrollo de las propuestas planteadas durante el plan piloto tiene efectos significativos en la productividad del proceso de picking.

\section{Análisis estadístico de la productividad del proceso de Picking "Antes"}


Se analiza la situación de los datos obtenidos de manera aleatoria de la productividad diaria de setiembre 2015, obteniéndose los siguientes datos estadísticos:

Cuadro 38: Fstadísticos de Pickino Setiemhre 2015

\begin{tabular}{|l|r|}
\hline \multicolumn{2}{|c|}{ Proceso de Picking Set 2015} \\
\hline Media & 165 \\
\hline Desviación estándar & 118.47 \\
\hline Varianza de la muestra & 14034.07 \\
\hline Límite superior de Control (LSC) & 283 \\
\hline Límite inferior de Control (LIC) & 46 \\
\hline Mínimo & 43 \\
\hline Máximo & 442 \\
\hline Cuenta & 15 \\
\hline
\end{tabular}

Fuente: Elaboración Propia

Con una media de 165 unid/HH por día, el proceso de picking desarrolló sus actividades durante el periodo setiembre 2015. La desviación estándar con respecto a la media fue de 118.47. Lo que se expresa en el siguiente gráfico: 
Gráfico 24: Productividad diaria Picking Set 2015

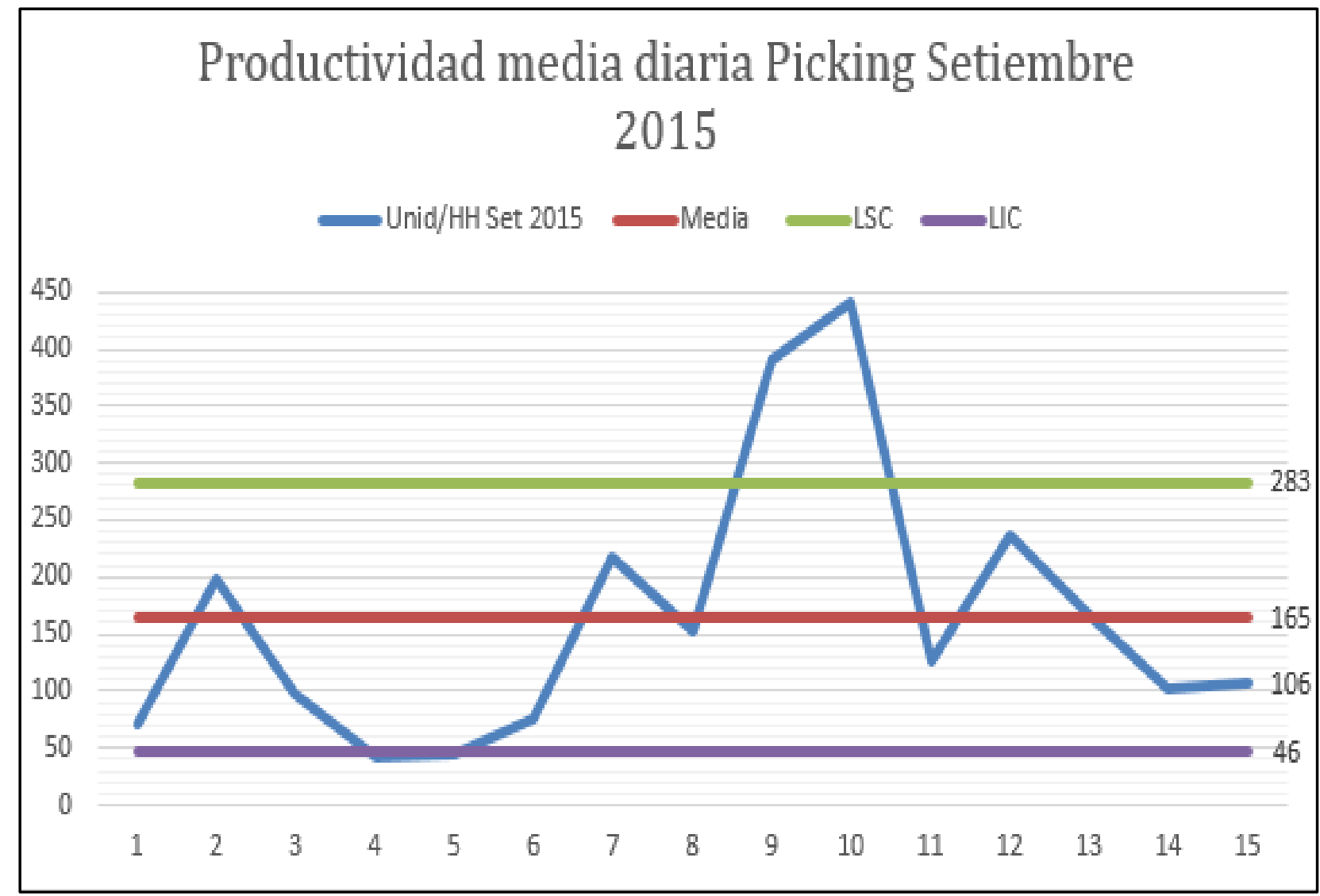

Fuente: Elaboración Propia 
El gráfico muestra valores de la productividad diaria del proceso de Picking que oscilan entre los límites de control de 46 unid/HH y 283 unid/HH.

\section{Análisis estadístico de la productividad del proceso de Picking "Después"}

Se muestran los análisis estadísticos de los resultados obtenidos durante la implantación del plan piloto para el proceso de Picking.

Cuadro 39: Estadísticos de Picking Piloto 2016

Proceso de Picking Piloto 2016

\begin{tabular}{|l|c|}
\hline Media & 193 \\
\hline Desviación estándar & 10.05 \\
\hline Varianza de la muestra & 101 \\
\hline Límite superior de Control (LSC) & 203 \\
\hline Límite inferior de Control (LIC) & 183 \\
\hline Mínimo & 178 \\
\hline Máximo & 209 \\
\hline Cuenta & 15 \\
\hline
\end{tabular}

Fuente: Elaboración Propia

Con una media de 193 unid/HH por día, el proceso de picking desarrolló sus actividades durante la prueba piloto 2016. La desviación estándar con respecto a la media fue de 10.05. Lo que se expresa en el siguiente gráfico. 
Gráfico 25: Productividad diaria Picking Piloto 2016

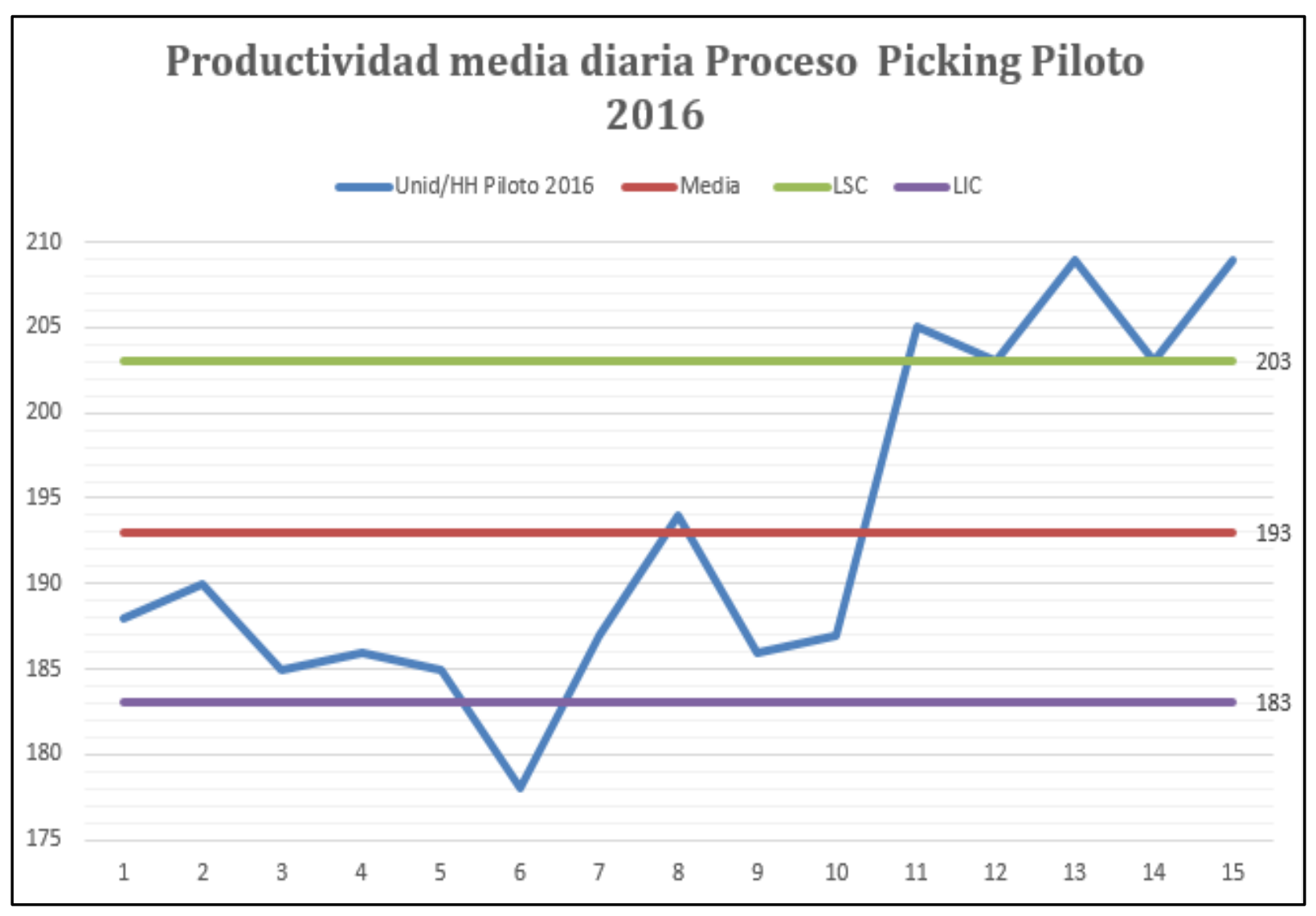

Fuente: Elaboración Propia 
Los resultados del plan piloto para el proceso picking detallan una media de 193 unid/HH y una desviación estándar de 10.05 .

La optimización del proceso de picking cumple con dos aspectos primordiales en la mejora de procesos:

- La media se desplazó de 165 unid/HH a 193 unid/HH. Es decir el personal procesa en promedio $16.97 \%$ más unidades por hora que en el año anterior.

- La variabilidad del proceso se optimizó; basado en la desviación estándar de 118.47 a 10.05; lo que implica que el proceso ajustó su variabilidad en $91.52 \%$. Como resultado, se puede expresar que los límites de control se redujeron en relación a la media, si antes la productividad media diaria oscilaba entre 46 unid/HH y 283 unid/HH, ahora la productividad media diaria brinda valores entre 183 unid/HH y 203 unid/HH.

\section{Ahorro expresado en Hora Hombre:}

El proceso de Picking durante el periodo 2015, laborando bajo el anterior método, disponía de cuatro colaboradores que realizaban sus operaciones durante 10 horas diarias sin importar el volumen de unidades a procesar. Por esta razón el promedio de hora hombre que se utilizaba diariamente era de $40 \mathrm{HH}$.

Con la implantación de las propuestas de mejora del proceso de Picking desarrolladas durante el plan piloto y el nuevo método de balance de línea según la cantidad procesar, se obtiene que la media de Hora Hombre diaria es 26, obteniéndose un ahorro medio diario de $14 \mathrm{HH}$ para este proceso 
Gráfico 26: Hora hombre Proceso de Picking "antes y después"

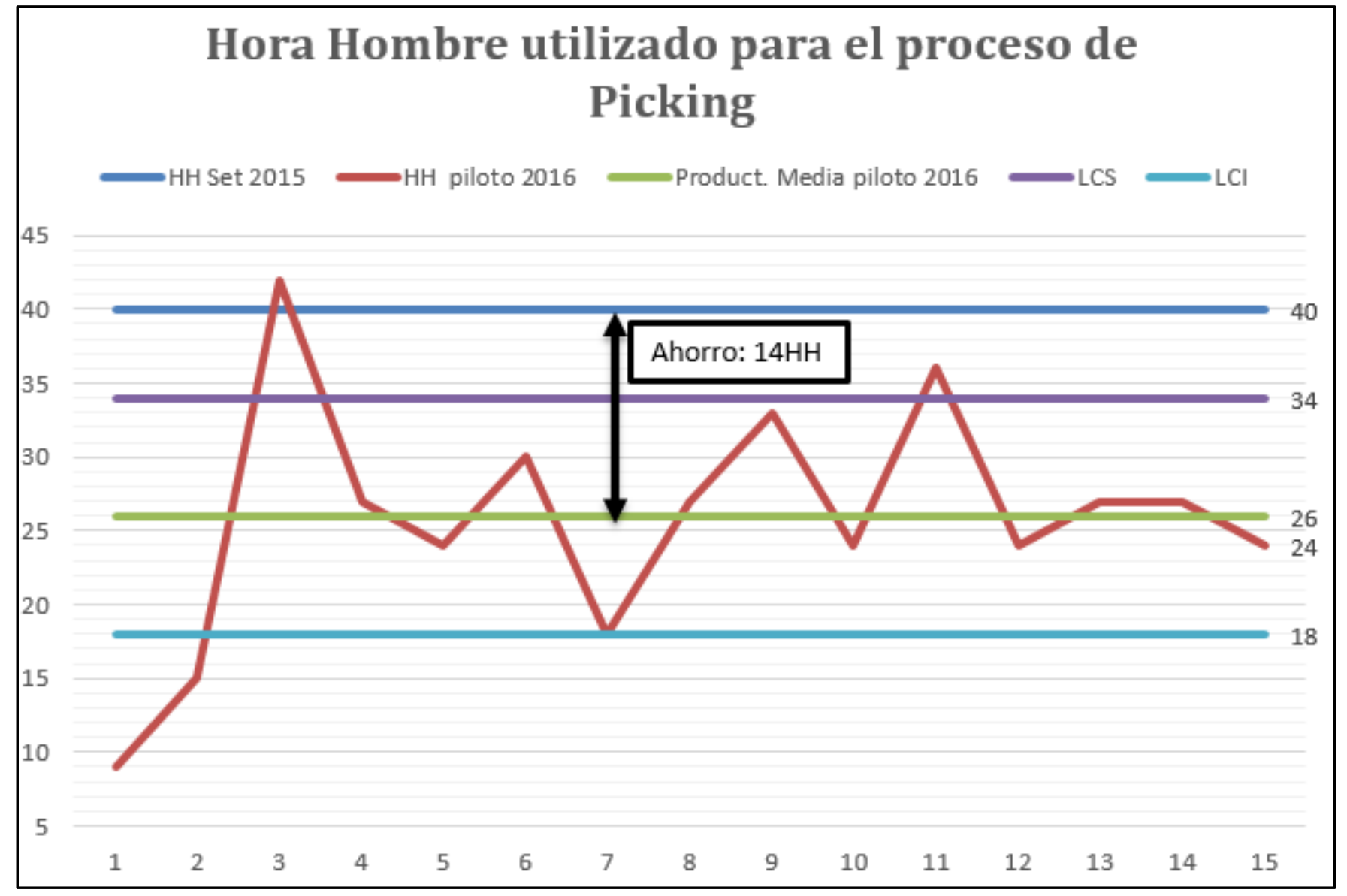

Fuente: Elaboración Propia 
Del gráfico se obtiene que las horas hombre utilizadas en el proceso de picking oscilan entre $18 \mathrm{HH}$ y $34 \mathrm{HH}$, teniendo una media de $26 \mathrm{HH}$ por día. Estas $26 \mathrm{HH}$ promedio al día sustentan que el ahorro medio el mes de setiembre es de $14 \mathrm{HH}$ contra las $40 \mathrm{HH}$ que se detallaron al inicio de la medición, representado una optimización media del recurso de $35 \%$.

\section{Proceso de Packing}

Por último, se realizan las pruebas estadísticas al proceso de Packing. Se muestra la selección de datos correspondientes al periodo setiembre 2015 y los obtenidos en la implantación del plan piloto.

Cuadro 40: Productividad media diaria del P. Packing

\begin{tabular}{|c|c|}
\hline \multicolumn{2}{|c|}{$\begin{array}{c}\text { Productividad media diaria } \\
\text { unid/HH Proceso de Packing }\end{array}$} \\
\hline Set 2015 & Piloto 2016 \\
\hline 70 & 209 \\
\hline 175 & 187 \\
\hline 129 & 223 \\
\hline 371 & 203 \\
\hline 415 & 211 \\
\hline 85 & 225 \\
\hline 193 & 181 \\
\hline 152 & 188 \\
\hline 77 & 227 \\
\hline 100 & 216 \\
\hline 8 & 202 \\
\hline 47 & 223 \\
\hline 255 & 205 \\
\hline 125 & 224 \\
\hline 96 & 208 \\
\hline
\end{tabular}

Fuente: La empresa (Elaboración propia)

Con esta información se procede a realizar las pruebas de normalidad de los dos grupos de medición de la productividad del proceso de packing. Para los cálculos respectivos de cada prueba se ha utilizado el programa estadístico informático SPSS. La prueba se realizó con la siguiente secuencia: 
Figura 54: Desarrollo de la prueba de normalidad para el proceso de Packing

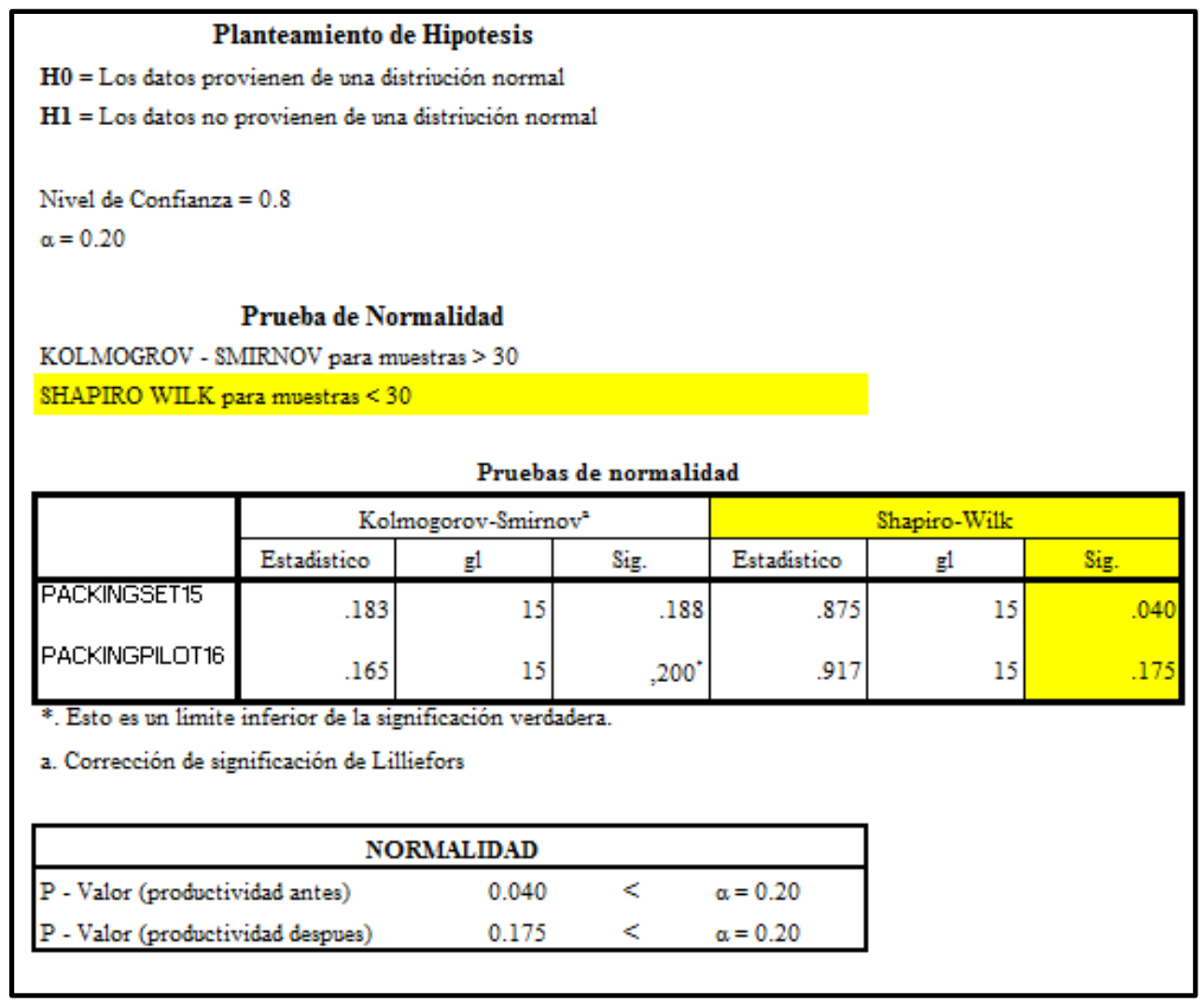

Fuente: Elaboración propia basada en SPSS software estadístico

Con un nivel de confianza de 0.8 y una significación de 0.20 , los correspondientes a tamaños de muestra aproximados a 10 registros ideal en la ejecución de un plan piloto, se observa el valor $\mathrm{p}$ menor al valor $\alpha$ establecido por lo que se rechaza que los datos muestren un comportamiento normal (se rechaza la hipótesis nula), en consecuencia se puede afirmar la H1 = Los datos no provienen de una distribución normal.

Como los datos no cumplen una distribución normal, se realizará la comparación de medias de ambos grupos con la opción: pruebas no paramétricas para muestras relacionadas del programa SPSS.

Los resultados se muestran en la figura: 
Figura 55: Resultados de prueba no paramétrica para muestras relacionadas - Packing

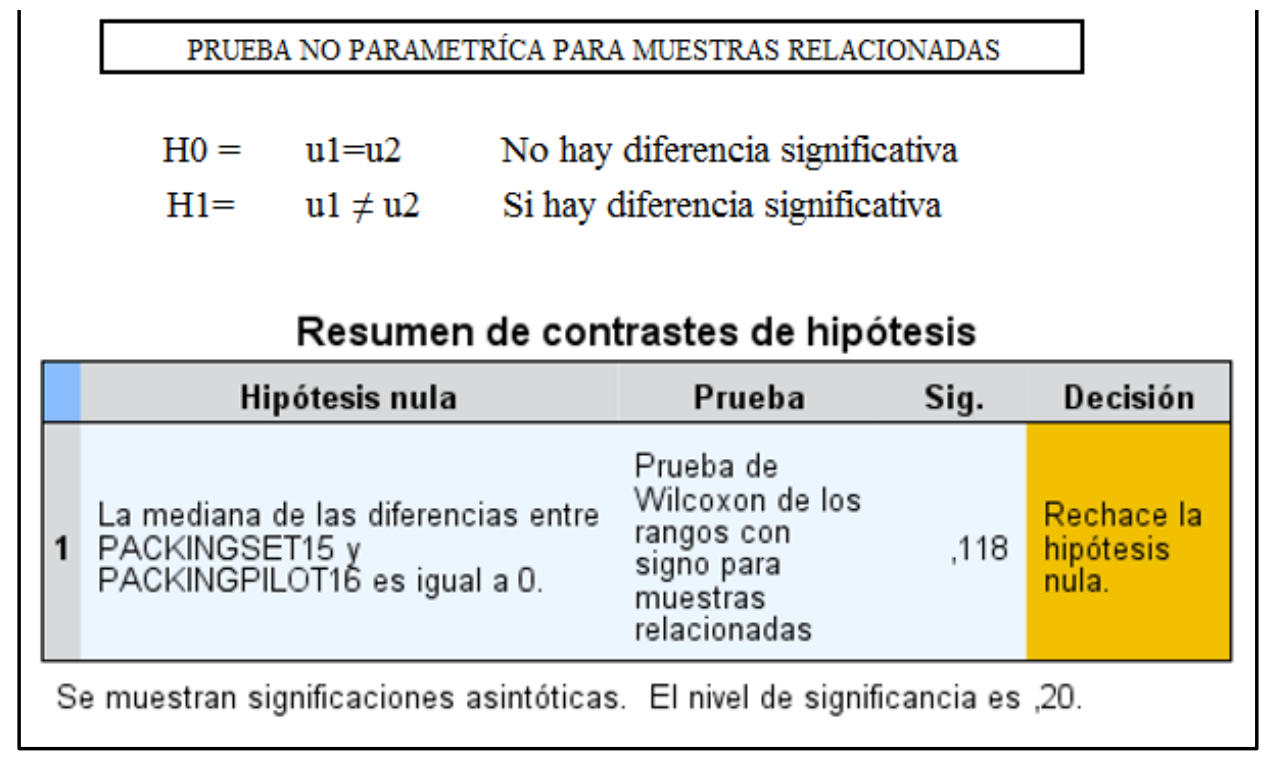

Fuente: Elaboración propia basada en SPSS software estadístico

Con un valor $\mathrm{P}$ de 0.118 menor a 0.20 se rechaza la hipótesis nula "no hay una diferencia significativa".

De la muestra analizada se desprende que hay una diferencia significativa entre las medias de la productividad del proceso de packing antes y después de implementar las propuestas de mejora. Por tanto, se concluye que el desarrollo de las propuestas planteadas durante el plan piloto tiene efectos significativos en la productividad del proceso de packing.

\section{Análisis estadístico de la productividad del proceso de Packing "Antes"}

Se detallan los valores estadísticos para la muestra aleatoria obtenida de la productividad diaria del packing durante el periodo de setiembre 2015: 
Cuadro 41: Estadísticos de Packing Setiembre 2015

\begin{tabular}{|l|r|}
\hline \multicolumn{2}{|c|}{ Proceso de Packing Set 2015} \\
\hline Media & 153 \\
\hline Desviación estándar & 115.15 \\
\hline Varianza de la muestra & 13258.89 \\
\hline Límite superior de Control (LSC) & 268 \\
\hline Límite inferior de Control (LIC) & 38 \\
\hline Mínimo & 8 \\
Máximo & 415 \\
\hline Cuenta & 15 \\
\hline
\end{tabular}

Fuente: Elaboración Propia

Gráfico 27: Productividad diaria Packing Set 2015

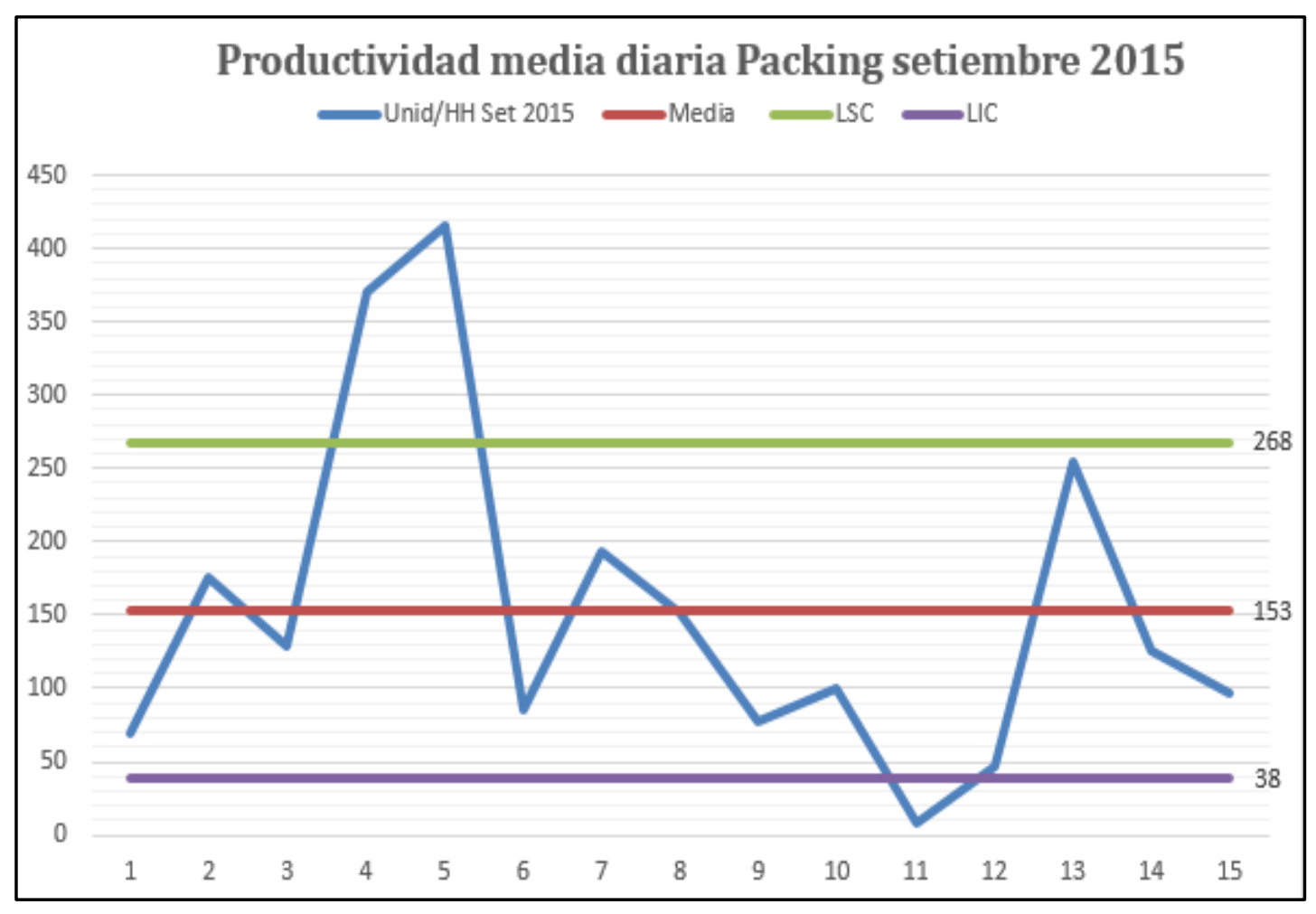

Fuente: Elaboración Propia 
Del gráfico se puede observar que para el período de Setiembre 2015 la productividad del proceso de packing oscilaba entre los valores de 38 unid/HH y 268 unid/HH con una media diaria de $153 \mathrm{unid} / \mathrm{HH}$.

\section{Análisis estadístico de la productividad del proceso de Packing "Después"}

En otra posición, se muestran los resultados estadísticos y el gráfico de control de los resultados obtenidos en la implantación del pan piloto del proceso de packing.

Cuadro 42: Estadísticos de Packing Piloto 2016

\begin{tabular}{|l|r|}
\hline \multicolumn{2}{|c|}{ Proceso de Packing piloto 2016} \\
\hline Media & 209 \\
\hline Desviación estándar & 14.79 \\
\hline Varianza de la muestra & 218.60 \\
\hline Límite superior de Control (LSC) & 224 \\
\hline Límite inferior de Control (LIC) & 194 \\
\hline Mínimo & 181 \\
\hline Máximo & 227 \\
\hline Cuenta & 15 \\
\hline
\end{tabular}

Fuente: Elaboración Propia

Gráfico 28: Productividad diaria Packing Piloto 2016

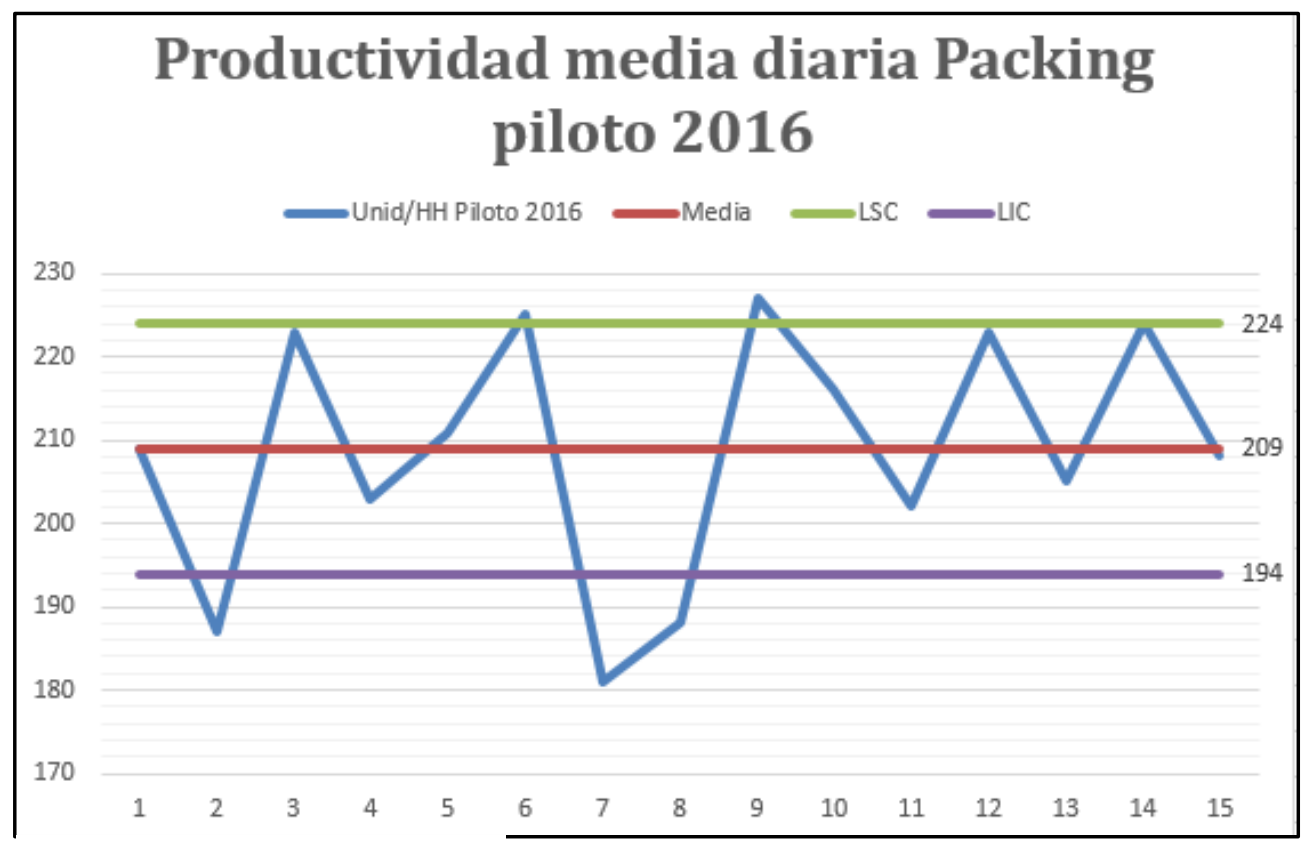

Fuente: Elaboración Propia 
Los resultados del plan piloto para el proceso packing detallan una media de 209 unid/HH y una desviación estándar de 14.79.

La optimización del proceso de packing cumple con dos aspectos primordiales en la mejora de procesos:

- La media se desplazó de 153 unid/HH a 209 unid/HH. Es decir el personal procesa en promedio $36.60 \%$ más unidades por hora que en el año anterior.

- La variabilidad del proceso se optimizó; basado en la desviación estándar de 115.15 a 14.79; lo que implica que el proceso ajustó su variabilidad en $87.16 \%$. Como resultado, se puede expresar que los límites de control se redujeron en relación a la media; si antes la productividad media diaria oscilaba entre 38 unid/HH y 263 unid/HH, ahora la productividad media diaria brinda valores entre 194 unid/HH y 224 unid/HH.

\section{Ahorro expresado en Hora Hombre:}

El proceso de Packing durante el periodo 2015, laborando bajo el anterior método, disponía de cuatro colaboradores que realizaban sus operaciones durante 10 horas diarias sin importar el volumen de unidades a procesar. Por esta razón el promedio de hora hombre que se utilizaba diariamente era de $40 \mathrm{HH}$.

Con la implantación de las propuestas de mejora del proceso de Packing desarrolladas durante el plan piloto y el nuevo método de balance de línea según la cantidad procesar, se obtiene que la media de Hora Hombre diaria es 24, obteniéndose un ahorro medio diario de $16 \mathrm{HH}$ para este proceso. 
Gráfico 29- Hora homhre Procesn de Packino "antes v desnués"

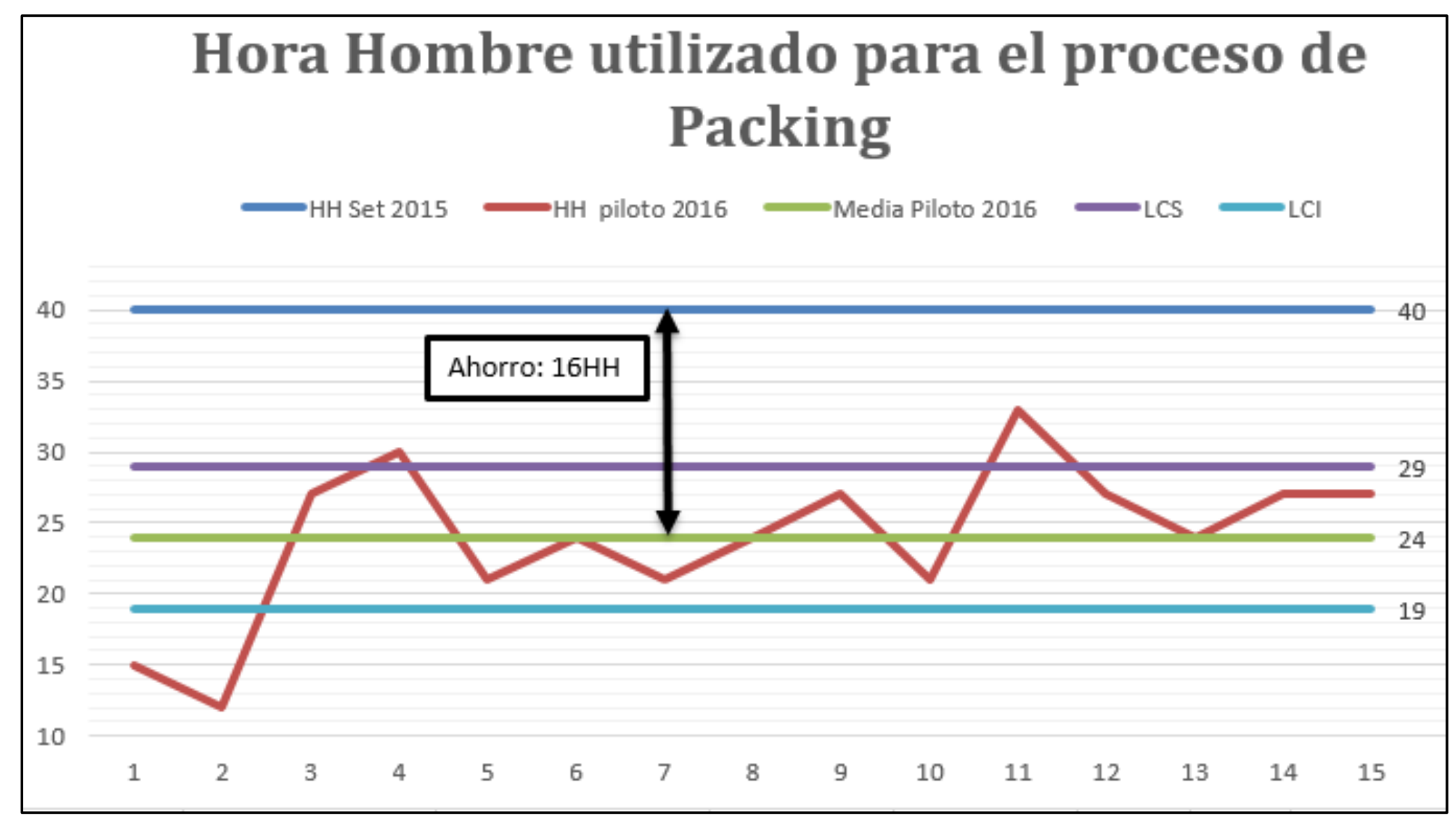

Fuente: Elaboración Propia 
Según el gráfico mostrado, la diferencia entre la media de las horas hombre utilizadas en el proceso de packing en el periodo setiembre 2015 y lo correspondiente a la implantación del plan piloto es de $16 \mathrm{HH}$. Es decir, con la implantación de las mejoras el proceso de packing empleó $16 \mathrm{HH}$ menos que su similar en el año anterior implicando una reducción del $40 \%$.

Por otro lado, en referencia al estudio Lean Thinking y la eliminación u optimización de actividades que no generan valor, se ha realizado el estudio comparativo del tiempo de ciclo de los procesos analizados y los dead time (tiempos muertos donde las actividades no se generan valor) correspondientes a cada uno de ellos. Como se ha expresado durante el desarrollo del presente estudio, no se cuenta con información de la medición de tiempos de cada actividad y sus procesos del año 2015; en consecuencia se empezó a realizar el registro y medición de estas actividades durante los meses Enero, Febrero y Marzo del año 2016 y con esta información se desarrolló los análisis del diagrama de Proceso para determinar qué actividades no aportan valor. A partir de este estudio se han realizado las comparaciones con la información recopilada durante la implantación del plan piloto.

Es preciso mencionar que para análisis de los resultados se tomaron las siguientes medidas:

- Se igualaron las muestras a quince registros cada uno

- Los resultados catalogados como "antes" corresponden a los datos escogidos aleatoriamente pertenecientes a los meses Enero, Febrero y Marzo 2016.

- Los resultados catalogados como "actual" corresponden a los datos obtenidos durante la implantación del plan piloto.

- Para los procesos de picking y packing se realizaron seguimiento a los pedidos cuya solicitudes comprendía entre 300 a 400 libros para estabilizar e igual las condiciones del tiempo demandado. 
Sobre el Dead Time del Proceso:

Gráfico 30: Dead Time del proceso (minutos)

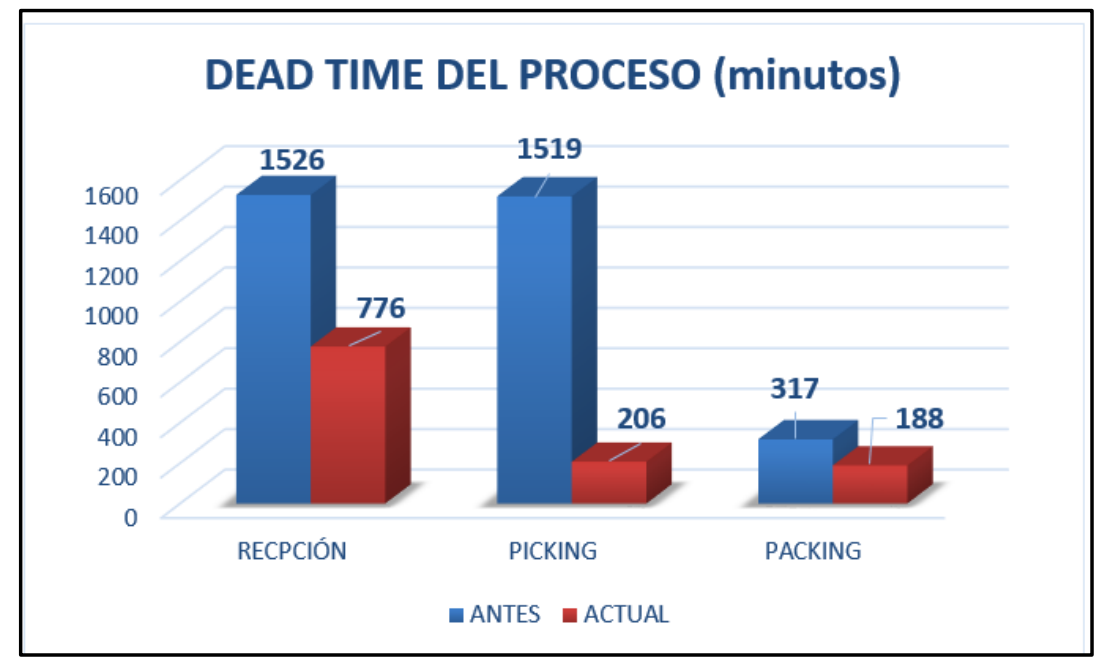

Fuente: Elaboración Propia

Gráfico 31: Optimización del Dead Time

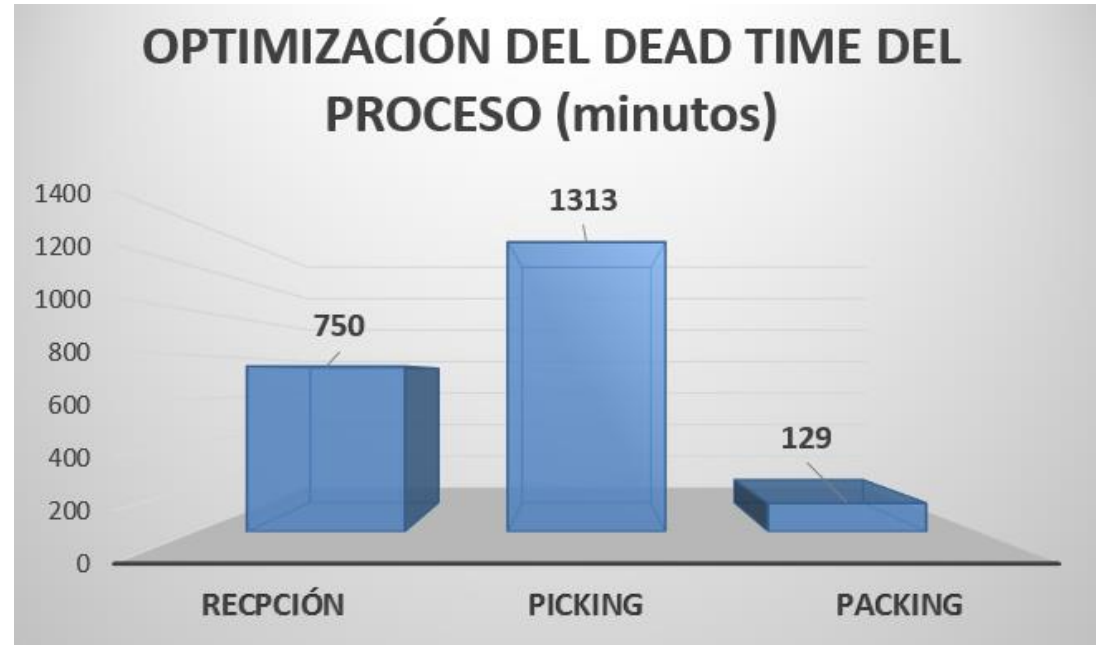

Fuente: Elaboración Propia 
El Dead time del proceso, que refiere al tiempo de las actividades que no agregan valor, se ha reducido notablemente. En el caso del proceso de recepción e inventario la disminución es de 750 minutos, para el proceso de picking es de 1,313 minutos y para el packing es 129 minutos. Esto implica que dentro de cada proceso se han eliminado o reducido actividades que no generaban valor al proceso. Desde otro punto de vista, los resultados evidencian que en estos tres procesos se está dedicando más recurso (tiempo) a las actividades que si generan valor.

Sobre el tiempo de ciclo de proceso:

Gráfico 32: Tiempo de ciclo del proceso

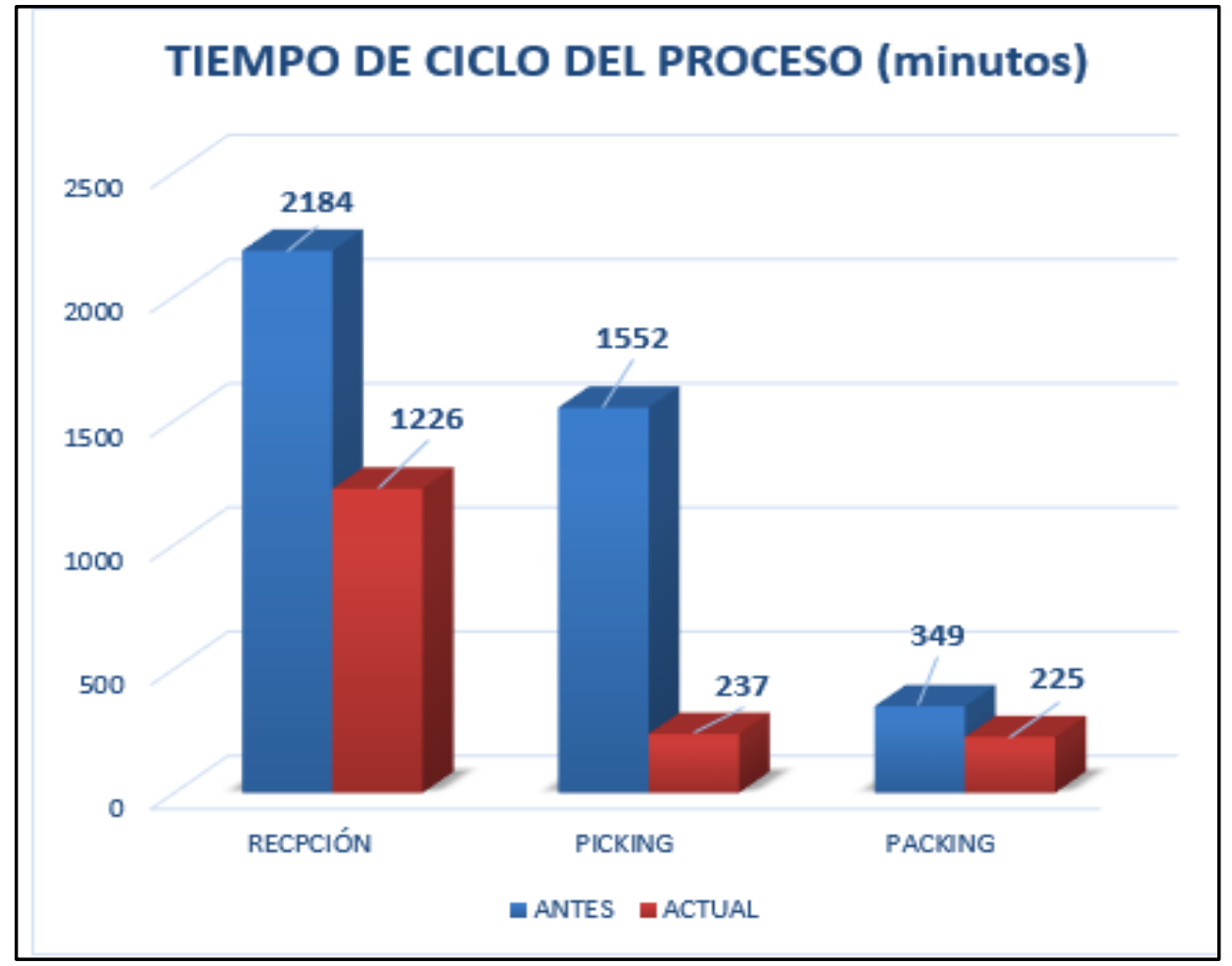

Fuente: Elaboración Propia 
Gráfico 33: Ahorro del tiempo de ciclo del proceso

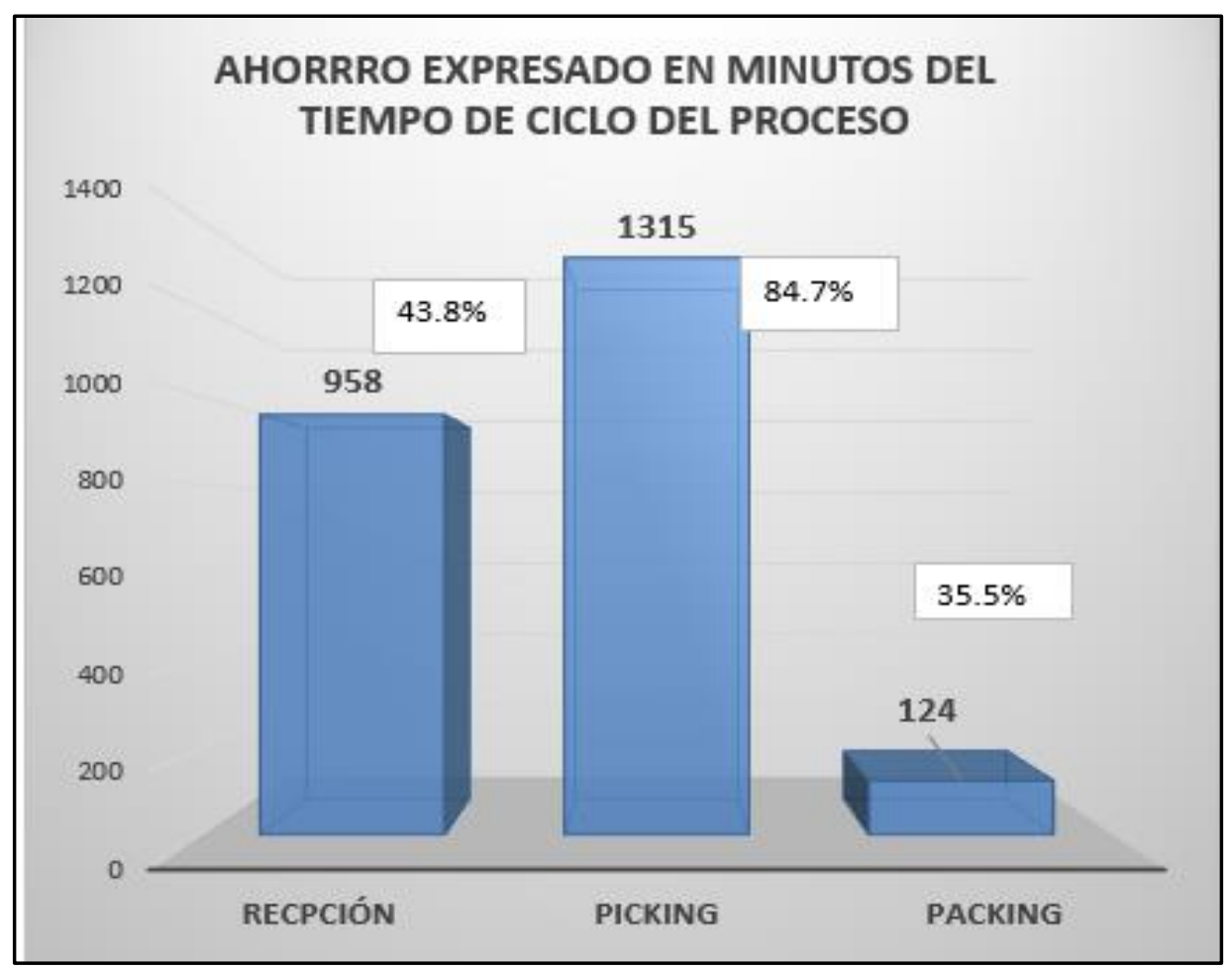

Fuente: Elaboración Propia

El tiempo de ciclo de los procesos de recepción e inventario, picking y packing se redujeron en $43.8 \%, 84.7 \%$ y $35.5 \%$ respectivamente. De ello se desprende que el tiempo en que se está llevando el proceso se redujo significativamente. En comparación al dead time, no sólo se ha reducido el tiempo de las actividades que no agregan valor sino, además, este cambio ha impactado positivamente en el tiempo total de proceso.

En el proceso de recepción e inventario, la optimización del tiempo de ciclo fue de 2,184 a 1,226 minutos contabilizando una diferencia de 958 minutos o 16 horas aprox. (15.96 h).

En el proceso de picking, la optimización del tiempo de ciclo del proceso fue de 1,552 a 237 minutos, significando una reducción del $84.7 \%$. De los tres procesos, el picking es el que 
presenta la mayor reducción e impacto del tiempo de ciclo en el que se desarrolla el proceso, optimizándose un total de 1315 minutos equivalentes a 22 horas aprox. (21.92 h).

Por último, el proceso de packing presentó una disminución de 124 minutos; antes el tiempo de ciclo del proceso era de 349 minutos, ahora se realiza en 225 minutos. Esta optimización equivale a 2 horas aprox. $(2.07 \mathrm{~h})$.

Sobre el tiempo de ciclo y el dead time en total consolidando los tres procesos:

Gráfico 34: Tiempo de ciclo y dead time de los tres procesos

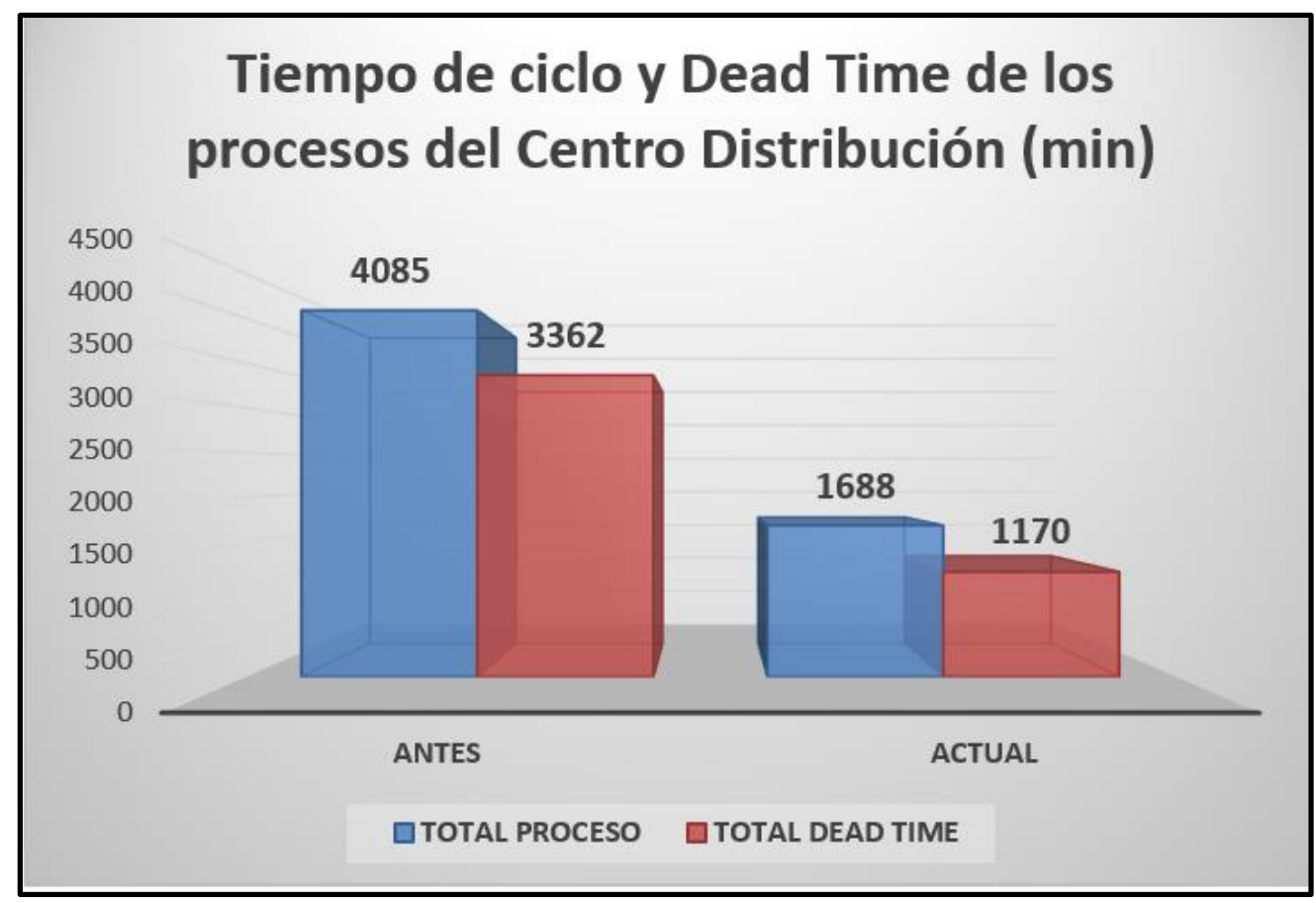

Fuente: Elaboración Propia 
Gráfico 35: Optimización del tiempo en los tres procesos

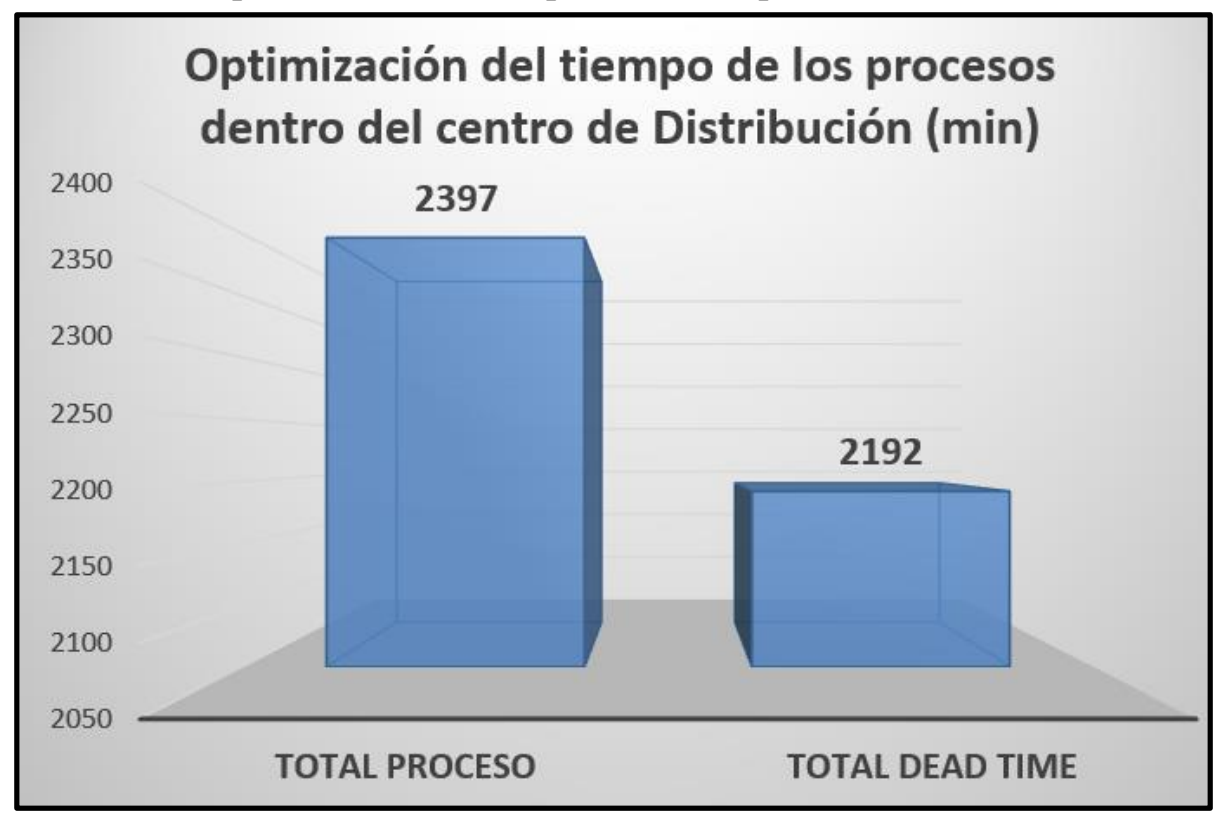

Fuente: Elaboración Propia

Comparando los resultados en total de los tres procesos, el proyecto optimizó un total de 2,397 minutos (39.95 h) del tiempo de ciclo de los procesos, esto implica que los pedidos fueron atendidos casi 40 horas antes de lo que se venía trabajando. Por otro lado, el dead time del proceso obtuvo una disminución total de 2,192 minutos $(36.53 \mathrm{~h})$, esto quiere decir que el tiempo y los recursos fueron destinados más a actividades que agregan valor al proceso y es percibido por el cliente; por lo que se puede decir que los procesos son ahora más productivos. 


\section{ANÁLISIS ECONÓMICO DE LAS PROPUESTAS}

\section{Presupuesto de Egresos relevantes}

En esta sección se enumerarán los gastos e inversiones relacionados a las distintas fases de la implantación de la metodología Lean Logistics en la empresa SBS, desde la formación del equipo Lean hasta el desarrollo de las primeras prácticas de mejora del proceso sustentadas en el plan piloto.

En primer lugar, se detallan los gastos representados por la primera etapa de la implantación Lean, la cual busca formar y capacitar a los integrantes del equipo Lean SBS.

Cuadro 43: Inversión Formación Lean Logistics SBS

\begin{tabular}{|c|c|c|c|c|}
\hline \multicolumn{5}{|c|}{ PRMERA FORMACIÓN LEAN LOGISTICS SBS } \\
\hline DESCRIPCION & Valor & Cant. & Total & OBS \\
\hline CAPACITACIÓN LEAN - In House & 12,000 & 1 & $12,000.00$ & $1 \mathrm{mes}$ \\
\hline CAPACITACIÓN OPERARIOS & 40 & 5 & 200.00 & $1 \mathrm{mes}$ \\
\hline ANALISTA DE SISTEMAS & 2,000 & 1 & $2,000.00$ & 1 mes \\
\hline PROMOCIÓN DE LA METODOLOGIA & 300 & 1 & 300.00 & $1.5 \mathrm{mes}$ \\
\hline \multicolumn{2}{|c|}{$\begin{array}{l}\text { TOTAL PRIMERA FORMACIÓN LEAN LOGITICS SBS } \\
\end{array}$} & SI. & 14,500 & \\
\hline
\end{tabular}

Como se detalla en el cuadro anterior, la capacitación para el Equipo Lean (05 personas) será realizada por una empresa externa en la modalidad In house, la misma que se ajustará a los requerimientos de la Gerencia General y Equipo Lean, a excepción de la capacitación de Operarios y Colaboradores de almacén que deberá ser realizada por el equipo Lean, los costos detallados como gastos administrativos cubren manuales, papelería, folders y coffe break durante la capacitación a los colaboradores.

La promoción de la Metodología hace referencia a la inversión de la campaña de difusión y envío de emailing al personal interno generando intriga sobre la metodología a implementar, impresión de afiches y polos. 
Seguidamente, se muestra la inversión realizada en implantación de la metodología propuesta en sus diversas fases:

Cuadro 44: Inversión Implementación Lean

\begin{tabular}{|c|c|c|c|c|c|}
\hline \multicolumn{6}{|c|}{ IMPLEMENTACIÓN LEAN SBS } \\
\hline DESCRIPCIÓN & $\begin{array}{c}\text { Tiempo } \\
\text { (sem) }\end{array}$ & Dias & Personas & $\begin{array}{l}\text { Costo } \\
\text { diario }\end{array}$ & Costo Total \\
\hline Selección y definición de línea / aréa piloto & 1 & 3 & 1 & 35.00 & 105.00 \\
\hline Toma de tiempos, recorridos y procesos & 9 & 5 & 1 & 30.00 & $1,350.00$ \\
\hline Definición de las acciones a tomar & 2 & 3 & 2 & 25.00 & 300.00 \\
\hline Elaboración del Manual 5's ( Encuestas, desarrollo, responsables) & 1 & 2 & 6 & 25.00 & 300.00 \\
\hline Capacitación al personal en las herramientas & 1 & 3 & 6 & 15.00 & 270.00 \\
\hline Implementación de las 5s en la empresa & 12 & 1 & 6 & 10.00 & 720.00 \\
\hline Desarrollo para la organización ABC del almacén & 2 & 4 & 2 & 50.00 & 800.00 \\
\hline Elaboración de Manuales & 1 & 2 & 4 & 15.00 & 120.00 \\
\hline Auditorias a la implementación (Desarrollo de material, auditoria) & 4 & 4 & 2 & 20.00 & 640.00 \\
\hline \multicolumn{4}{|c|}{ TOTAL IMPLEMENTACIÓN LEAN SBS } & Sl. & S/. $\quad 4,605.00$ \\
\hline
\end{tabular}

Fuente: Elaboración Propia

La inversión para implementación Lean asciende a S/ 4,605.00

La inversión en compra de materiales a utilizar en la implementación Lean es expuesta en el cuadro 45.

Cuadro 45: Inversión Compra de materiales

\begin{tabular}{|c|c|c|c|}
\hline \multicolumn{4}{|c|}{ COMPRA DE MATERIALES } \\
\hline DESCRIPCIÓN & Unid & Costo & Total \\
\hline Estante para almacen Seiri & 1 & 350.00 & 350.00 \\
\hline Compra y/o elaboración de Materiales de señalización & 1 & 200.00 & 200.00 \\
\hline Elementos de protección Personal EPPs & 12 & 200.00 & $2,400.00$ \\
\hline Materiales de oficina & 1 & 150.00 & 150.00 \\
\hline \multicolumn{2}{|c|}{ TOTAL COMPRA DE MATERIALES } & Sl. & 3,100 \\
\hline
\end{tabular}

Fuente: Elaboración Propia

Los materiales que se estiman comprar ascienden a 3,100.00 
Para la preparación del desarrollo del plan piloto, se muestran los costos de mano de obra de todo el personal que intervino en la preparación del almacén para la aplicación de las acciones de mejora consideradas por el plan piloto.

Cuadro 46: Mano de obra preparación del plan piloto

\begin{tabular}{|l|c|c|c|c|}
\hline \multicolumn{3}{|c|}{ MANO DE OBRA PREPARACIÓN DEL PLAN PILOTO } \\
\hline \multicolumn{1}{|c|}{ DESCRIPCIÓN } & AREA & Horas & Costo & Total \\
\hline Gerente de Operaciones y Logística & Global & 2 & 25.27 & $\mathbf{5 0 . 5 4}$ \\
\hline Jefe de Almacén & Centro Distribución & 12 & 12.77 & $\mathbf{1 5 3 . 2 4}$ \\
\hline Coord. de Inventarios recepción y almacenamiento & Inventarios & 8 & 5.63 & $\mathbf{4 5 . 0 4}$ \\
\hline Personal de recepción y almacenamiento 2 & Inventarios & 4 & 4.55 & $\mathbf{1 8 . 2 0}$ \\
\hline Personal de recepción y almacenamiento 3 & Inventarios & 4 & 4.55 & $\mathbf{1 8 . 2 0}$ \\
\hline Personal de recepción y almacenamiento 4 & Inventarios & 4 & 4.55 & $\mathbf{1 8 . 2 0}$ \\
\hline Coordinador de Embalaje & Embalaje & 8 & 5.63 & $\mathbf{4 5 . 0 4}$ \\
\hline Personal de embalaje 2 & Embalaje & 4 & 4.55 & $\mathbf{1 8 . 2 0}$ \\
\hline Personal de embalaje 3 & Embalaje & 4 & 4.55 & $\mathbf{1 8 . 2 0}$ \\
\hline Personal de embalaje 4 & Embalaje & 4 & 4.55 & $\mathbf{1 8 . 2 0}$ \\
\hline Coordinador de Picking & Picking - Operador & 8 & 5.63 & $\mathbf{4 5 . 0 4}$ \\
\hline Personal de Picking 2 & Picking - Operador & 4 & 4.55 & $\mathbf{1 8 . 2 0}$ \\
\hline Personal de Picking 3 & Picking - Operador & 4 & 4.55 & $\mathbf{1 8 . 2 0}$ \\
\hline Personal de Picking 4 & Picking - Operador & 4 & 4.55 & $\mathbf{1 8 . 2 0}$ \\
\hline Asistente de TI & TI & 6 & 5.63 & $\mathbf{3 3 . 7 8}$ \\
\hline \multicolumn{1}{|c|}{ TOTAL MANO DE OBRA PREPARACIÓN PLAN PILOTO } & & SI. & $\mathbf{5 3 6 . 4 8}$ \\
\hline
\end{tabular}

Fuente: Elaboración Propia

Luego de haber detallado los costos de inversión de los diferentes aspectos que involucra la aplicción de herramientas Lean a travé de la metodología propuesta y adaptada a la compañía, se muestran el cuadro resumen: 
Cuadro 47: Resumen de inversión Lean Logistics SBS

\begin{tabular}{|c|c|c|}
\hline RESUMEN INVERSION INICIAL & & TOTAL \\
\hline FORMACIÓN LEAN LOGISTICS SBS & & $14,500.00$ \\
\hline IMPLEMENTACIÓN LEAN SBS & & $4,605.00$ \\
\hline COMPRA DE MATERIALES & & $3,100.00$ \\
\hline MANO DE OBRA PREPARACIÓN PLAN PILOTO & & 536.48 \\
\hline TOTAL INVERSION INICIAL & Sl. & $22,741.48$ \\
\hline
\end{tabular}

Fuente: Elaboración Propia

Como se muestra en el cuadro 47, la inversión total al inicio de la implantación Lean en SBS se estima que es de $22,741.48$

\section{Valoración del ahorro obtenido}

En el capítulo anterior se identificó el valor medio ahorrado en horas hombre para cada proceso analizado, la valoración anual se explica en el siguiente cuadro:

Cuadro 48: Cálculo del ahorro obtenido

\begin{tabular}{|c|cccccc||}
\hline Proceso & $\begin{array}{c}\text { Ahorro } \\
\text { diario HH }\end{array}$ & $\begin{array}{c}\text { Días hábiles } \\
\text { al mes }\end{array}$ & $\begin{array}{c}\text { Ahorro } \\
\text { Mensual HH }\end{array}$ & $\begin{array}{c}\text { Valor en S/ } \\
\text { de HH }\end{array}$ & $\begin{array}{c}\text { Ahorro Mensual } \\
\text { Expresado en S/ }\end{array}$ & $\begin{array}{c}\text { Ahorro } \\
\text { anual S/ }\end{array}$ \\
\hline $\begin{array}{c}\text { Recepción } \mathbf{~} \\
\text { Inventario } \\
\text { Picking }\end{array}$ & 12 & 20 & 240 & 4.78 & 1147.2 & 13766.4 \\
Packing & 14 & 20 & 280 & 4.78 & 1338.4 & 16060.8 \\
& 16 & 20 & 320 & 4.78 & 1529.6 & 18355.2 \\
\hline
\end{tabular}

Fuente: Elaboración Propia

En base a un ahorro diario de 42 horas en los tres procesos de recepción, picking y packing se estima que el ahorro medio mensual es de S/. 4,015.20 y que su equivalente en un año es de S/. $48,182.40$. 
Cuadro 49: Flujo de caja mensual de la inversión Lean

\begin{tabular}{|c|c|c|c|c|c|c|c|c|c|c|c|c|c|c|}
\hline \multicolumn{15}{|c|}{ FLUJO DE CAJA OPERATIVO PARA ANÁLISIS COSTO BENEFICIO IMPLANTACIÓN LEAN SBS } \\
\hline CONCEPTO & MES 0 & MES 1 & MES 2 & MES 3 & MES 4 & MES 5 & MES 6 & MES 7 & MES 8 & MES 9 & MES 10 & MES 11 & MES 12 & TOTAL \\
\hline SALDO INICIAL DE CAJA & & $.22,741.48$ & $-18,726.28$ & $-14,711.08$ & $-10,695.88$ & $-6,680.68$ & $-2,665.48$ & $1,349.72$ & $5,364.92$ & $9,380.12$ & $13,395.32$ & $17,410.52$ & $21,425.72$ & \\
\hline INGRESOS OPERATIVOS & 0.00 & $4,015.20$ & $4,015.20$ & $4,015.20$ & $4,015.20$ & $4,015.20$ & $4,015.20$ & $4,015.20$ & $4,015.20$ & $4,015.20$ & $4,015.20$ & $4,015.20$ & $4,015.20$ & $48,182.40$ \\
\hline Ahorro Proceso Repción e Inv. & & $1,147.20$ & $1,147.20$ & $1,147.20$ & $1,147.20$ & $1,147.20$ & $1,147.20$ & $1,147.20$ & $1,147.20$ & $1,147.20$ & $1,147.20$ & $1,147.20$ & $1,147.20$ & $13,766.40$ \\
\hline Ahorro Proceso de Picking & & $1,338.40$ & $1,338.40$ & $1,338.40$ & $1,338.40$ & $1,338.40$ & $1,338.40$ & $1,338.40$ & $1,338.40$ & $1,338.40$ & $1,338.40$ & $1,338.40$ & $1,338.40$ & $16,060.80$ \\
\hline Ahorro Proceso de Packing & & $1,529.60$ & $1,529.60$ & $1,529.60$ & $1,529.60$ & $1,529.60$ & $1,529.60$ & $1,529.60$ & $1,529.60$ & $1,529.60$ & $1,529.60$ & $1,529.60$ & $1,529.60$ & $18,355.20$ \\
\hline & & & & & & & & & & & & & & \\
\hline FLUJO DE CAJA OPERATIVO & 0.00 & $4,015.20$ & $4,015.20$ & $4,015.20$ & $4,015.20$ & $4,015.20$ & $4,015.20$ & $4,015.20$ & $4,015.20$ & $4,015.20$ & $4,015.20$ & $4,015.20$ & $4,015.20$ & $48,182.40$ \\
\hline INVERSIONES & $-22,741.48$ & 0.00 & 0.00 & 0.00 & 0.00 & 0.00 & 0.00 & 0.00 & 0.00 & 0.00 & 0.00 & 0.00 & 0.00 & 0.00 \\
\hline FORMACIÓN LEAN LOGISTICS SBS & $14,500.00$ & & & & & & & & & & & & & \\
\hline IMPLEMENTACIÓN LEAN SBS & $4,605.00$ & & & & & & & & & & & & & \\
\hline COMPRA DE MATERIALES & $3,100.00$ & & & & & & & & & & & & & \\
\hline MANO DE OBRA PREPARACIÓN PLAN PILOTO & 536.48 & & & & & & & & & & & & & \\
\hline & & & & & & & & & & & & & & \\
\hline FLUJO DE CAJA DEL PERÍODO & $-22,741.48$ & $4,015.20$ & $4,015.20$ & $4,015.20$ & $4,015.20$ & $4,015.20$ & $4,015.20$ & $4,015.20$ & $4,015.20$ & $4,015.20$ & $4,015.20$ & $4,015.20$ & $4,015.20$ & \\
\hline SALDO FINAL DE CAJA & $-22,741.48$ & $-18,726.28$ & $-14,711.08$ & $-10,695.88$ & $-6,680.68$ & $-2,665.48$ & $1,349.72$ & $5,364.92$ & $9,380.12$ & $13,395.32$ & $17,410.52$ & $21,425.72$ & $25,440.92$ & \\
\hline & & $\begin{array}{c}\text { COK (anual) } \\
\text { COK (mensual) } \\
\text { TIR (mensual) } \\
\text { TIR (anual) } \\
\text { VAN } \\
\text { B/C } \\
\end{array}$ & \begin{tabular}{r|}
$10.00 \%$ \\
$0.80 \%$ \\
$2.43 \%$ \\
$33.39 \%$ \\
$11,201.82$ \\
2.01 \\
\end{tabular} & & & & & & & & & & & \\
\hline
\end{tabular}

Fuente: Elaboración Propia

Las conclusiones de los resultados obtenidos del análisis costo beneficio se realizarán en el siguiente capítulo. 


\section{CONCLUSIONES Y RECOMENDACIONES}

\section{Conclusiones}

- El proyecto es rentable según el análisis costo beneficio que manifestó en primer lugar un valor neto actual (VAN) positivo de S/11,201.82. En segundo lugar la tasa interna de retorno (TIR) es del 33.39\% muy superior al costo de oportunidad capital por lo que se sostiene que el proyecto puede ser aceptado. Finalmente, el ratio de Beneficio-Costo $(\mathbf{B} / \mathbf{C})$ muestra un valor 2.01, al ser superior a uno se concluye que el proyecto es rentable y que por cada sol invertido se obtendría S/2.01 de ganancia neta.

- Para mejorar la productividad de los procesos logísticos de Special Book Services se ha utilizado nociones de ingeniería industrial como es el estudio de tiempos mostrados en el análisis DAP y el estudio de métodos manifestado en la eliminación de actividades que no generaban valor hacia otras actividades que si lo hacen, estas dos nociones se incluyen en el estudio del trabajo; además se ha propuesto partir de la estandarización hacia la mejora de los procesos. Paralelamente, adquiere relevancia en el desarrollo del proyecto, los principios de Lean Thinking que promueven la generación del valor a partir de la eliminación del desperdicio o muda concretizadas a través de las actividades que no agregan valor a los procesos.

- Para el inicio del proyecto, la empresa Special Book Services no contaba con información del desempeño de sus procesos logísticos, no contaba con registros, incidencias o frecuencias de fallas o defectos en el desarrollo de las operaciones. Por esta razón, se recurrió a una serie de herramientas de calidad que fueron empleadas sistemáticamente con el propósito de identificar el origen de la baja productividad en algunos periodos del año y direccionar la investigación a fuentes de información cuantitativa.

- Las ideas expresadas en la herramienta lluvia de ideas son de origen cualitativo, lo que no significa que estas ideas no existan; por el contrario se manifiestan y son percibidas en el malestar de cada trabajador que colaboró con la investigación. 
- El análisis de la matriz de priorización fue realizada en base a dos herramientas predecesoras: La estratificación y la matriz relacional. Como resultado de este análisis, se concluyó que las causas asociadas al desarrollo de los procesos logísticos eran de prioridad; en consecuencia, se identificó las causas más importantes de este segmento y se propuso acciones de mejora para contrarrestar el impacto generado por ellas.

- La metodología propuesta para el desarrollo de las acciones de mejora es Lean Logistics porque su concepción abarca cada una de las herramientas propuestas para las mejoras de los procesos, las desarrolla de manera organizada y sistemática y orienta la cultura organizacional hacia la mejora continua.

- El levantamiento de información cuantitativa es explicado en la fase 1 de la implantación Lean: Diagnostico y formación, el cual consistió en desglosar las actividades de los proceso estudiados y empezar a registrar los tiempos de ejecución de cada tarea; con esto se obtuvo información relevante como el tiempo de ciclo del proceso, el dead time del proceso y la identificación de las actividades que no generan valor al proceso.

- Luego de la implantación del plan piloto donde se desarrollaron las propuestas para la optimización y/o eliminación de las actividades que no generan valor, se demuestra que el ahorro medio obtenido en los procesos de recepción e inventario, picking y packing es de un total de $42 \mathrm{HH}$ al día y que valorizado en un año otorga un valor de S/ 48,182.40. Además, el tiempo de ciclo de proceso para la atención de los pedidos obtuvo una disminución de 40 horas aproximadamente.

- Se concluye que se mejoró la productividad en los procesos debido a dos enfoques. El desplazamiento de la media a niveles superiores y la reducción de la desviación estándar:

- Proceso de Recepción e inventario: La productividad media incrementó en $8.76 \%$ y su desviación estándar disminuyó en 93.97\%

- Proceso de Picking: La productividad media incrementó en $16.97 \%$ y su desviación estándar disminuyó en $91.52 \%$

- Proceso de Packing: La productividad media incrementó en $36.60 \%$ y su desviación estándar en $87.16 \%$ 
- Según lo expuesto en el punto anterior, la disminución significativa de la desviación estándar demuestra una reducción de la variabilidad del proceso por lo que podemos concluir que los procesos son ahora más estables y controlados

\section{Recomendaciones}

- Los indicadores financieros demuestran la viabilidad del proyecto, por lo tanto se recomienda a la empresa seguir con la implantación del Lean Logistics formando y capacitando al equipo Lean de tal manera que se realicen nuevas mediciones e identifiquen nuevas actividades que no estén agregando valor; también el equipo debe mantener las prácticas $5 \mathrm{~S}$ que ya fueron implementadas en una primera instancia con resultados exitosos; por último, se deben promover nuevas acciones de mejora al proceso y así contribuir con la mejora continua.

- Dados los resultados del positivos de la implantación Lean, se recomienda a la empresa trasladar las prácticas y estudios Lean a los demás procesos y áreas con el fin de garantizar el desarrollo de una cultura Lean a nivel de toda la organización.

- Se recomienda a la empresa considerar este proyecto como estudio base para futuras mediciones, análisis y propuestas que permitan mejorar el desempeño de los procesos.

- Se recomienda, la elaboración de un manual de funciones MOF que contribuya con la estandarización de los procesos propuestos y desarrollados desde la implantación del plan piloto.

- Las propuestas de mejora y herramientas a implementar fueron en base a las causas asociadas al proceso en sí como resultado del análisis de la matriz de priorización; se recomienda evaluar las causas asociadas a las operaciones y la gestión de los procesos e identificar cuáles persisten y qué herramienta Lean puede optimizarlas.

- Se recomienda evaluar periódicamente el mapa de flujo de valor VSM de la compañía orientando los procesos a los nuevos objetivos organizacionales que se plantee la empresa.

- Se recomienda a la empresa seguir con las prácticas $5 \mathrm{~S}$ garantizando su cumplimiento y evaluación a través de las auditorías. 
- Se recomienda reunir información de la nueva productividad hasta finalizado en el mes de abril 2017 y así comparar los resultados con el periodo base de observación realizado a inicios del año 2016. 


\section{Referencias Bibliografícas}

AGUILAR, Oscar; VÁSQUEZ, Rafael y SOTO, Martha (2012) El otro lado de la Logística, una visión estratégica: tendencias de aprovisionamiento en las cadenas de valor para el desarrollo sostenible, pp. 221-232. En: Revista de Centro de Investigación - Universidad La Salle, vol. 38. Julio - Diciembre 2012 (consulta: 22 de Junio del 2016) (http://web.b.ebscohost.com/ehost/pdfviewer/pdfviewer?sid=51da3128-41b9-4754-bfce743bb3116d8c\%40sessionmgr107\&vid=9\&hid=115)

BLANCHARD, Dave (2016) Lean Culture Helps Carrier Transicold Keep Its Cool, pp. 17-16. En: Material Handling \& Logistics, vol. 71. Abril del 2016 (consulta: 28 de octubre del 2016) (http://web.b.ebscohost.com/ehost/pdfviewer/pdfviewer?sid=4843a0e0-8efc-4e31-866b5216a6051a5e\%40sessionmgr105\&vid=43\&hid=102)

BECERRA, Claudia y ESTELA, David (2015) Propuesta de mejora de los procesos de recepción, gestión de inventarios y distribución de un operador logístico (tesis para optar el grado de ingeniero industrial). Lima: Universidad Peruana de Ciencias Aplicadas

BESTERFIELD, Dale (2009) Control de calidad 8va edición. México D.F: Pearson Educación

BOJÓRQUEZ, Alberto y BOJÓRQUEZ, Fernando (2013) Origen de la productividad, ¿capital humano? o ¿administración y estudio del trabajo? pp. 5-29. En: Mercados y Negocios, vol. 14 (consulta: $\quad 19 \quad$ de $\quad$ abril $\quad$ del (http://web.a.ebscohost.com/ehost/pdfviewer/pdfviewer?vid=10\&sid=60ccf66a-91f3-430a8b5f-d2036f032027\%40sessionmgr4009)

BULEJ, Vladimir y otros (2011) Material flow improvement in automated assembly lines using lean logistics, pp. 253-254. En: Annals of DAAAM \& Proceedings, vol. 22. (consulta: 21 de abril 2016) (http://web.a.ebscohost.com/ehost/pdfviewer/pdfviewer?sid=fcf0e02c-c087-417593d7-fb6973d5d43e\%40sessionmgr4003\&vid=9\&hid=4104)

CÁMARA PERUANA DE LIBRO (CPL) (2013) El mercado editorial en el Perú, 2008-2011. Lima: $\quad$ FM Servicios $\quad$ Gráficos

CÁMARA PERUAN DE LIBRO (CPL) (2016) (http://www.cpl.org.pe/quienes-somos/) Sitio web oficial de la CPL, contiene información sobre la asociación y enlaces de interés (consulta: 26

CÁMARA PERUANA DE LIBRO (CPL) (2018) (http://www.cpl.org.pe/ley-del-libro-ypirateria/) Sitio web oficial de la CPL, contiene información sobre la asociación y enlaces de interés (consulta:

de abril) 
CGMA® TOOLS (2016) Lean Management Techniques, pp. 33-41. En: Journal of Accountancy (consulta: $30 \quad$ de $\quad$ agosto 2016 ) (http://web.b.ebscohost.com/ehost/pdfviewer/pdfviewer?sid=fd7d3533-b460-4f48-829e7402826efb9b\%40sessionmgr101\&vid=13\&hid=124)

CHOPRA, Sunil y MEINDL, Peter (2008) Administración de la cadena de suministro. Estrategia, planeación y operación $3^{\mathrm{a}}$ ed. México D. F: Pearson Educación

CONTADURÍA Y ADMINISTRACIÓN (2015) Modelo de gestión logística para pequeñas y medianas empresas en México, pp. 181-203. En: Revista Contaduría y Administración, vol. 60. Enero - Marzo 2015 (consulta: 12 de julio del 2016) (http://www.sciencedirect.com.ezproxy.upc.edu.pe:2048/science/article/pii/S01861042157215 10)

CÓRDOVA, Frank (2012) Mejoras en el proceso de fabricación de spools en una empresa metalmecánica usando la manufactura esbelta (tesis para optar el título ingeniero industrial) Lima: Pontificia Universidad Católica del Perú

CÓRDOBA, Mónica (2015) Implementación de tecnologías como estrategia para fortalecer la productividad y competitividad de las pymes de la confección en Medellín, pp. 105-119. En: Revista Trilogía, vol. 7. (Consulta: 03 de setiembre del 2016) (http://web.b.ebscohost.com/ehost/pdfviewer/pdfviewer?vid=15\&sid=fa3e5c86-6505-49628837-312224b9b163\%40sessionmgr104\&hid=115)

CORREA, Alexander; GÓMEZ, Rodrigo y BOTERO, Cindy (2012) La ingeniería de métodos y tiempos como herramienta en la cadena de suministro, pp. 89 - 109. En: Revista Soluciones De Postgrado EIA, vol. 8 (consulta: 04 de abril del 2018) (https://search.proquest.com/docview/1399140907/fulltextPDF/7602491FA6E74485PQ/1?acc ountid=43860)

CUATRECASAS, Lluís (2010) Lean management: la gestión competitiva por excelencia. Implantación progresiva en siete etapas. Barcelona: Profit editorial

D’ALESSIO, Fernando (2015) El proceso estratégico. Un enfoque de gerencia, 3ra ed. Lima: Pearson

DE DIEGO, Asier; SIERRA, Nagore y GARCÍA, Sergio (2009) «Las claves del éxito de Toyota». LEAN, más que un conjunto de herramientas y técnicas, pp. 113-122. En: Cuadernos de Gestión, vol. 9. (Consulta: 14 de setiembre del 2016) (http://web.b.ebscohost.com/ehost/pdfviewer/pdfviewer?sid=e2a2c7e8-75a3-40e9-b1900a58122dffc9\%40sessionmgr104\&vid=4\&hid=102)

DE ZAN, Arturo y PAIPA, Luis (2012) Elementos de diseño de un currículo basado en el enfoque de procesos, pp. 22-34. En: Revista Educación en Ingeniería, vol. 7. (consulta: 30 de agosto del 2016) (http://web.b.ebscohost.com/ehost/pdfviewer/pdfviewer?sid=872f0554-517d- 
DIARIO EL PERUANO (2016) Modificación del Reglamento de la Ley de Democratización del Libro y Fomento de la Lectura, aprobado mediante Decreto Supremo ${ }^{\circ} 008-2004-E D$. En: Diario El Peruano, 13 de Julio del 2016 (consulta: 29 de abril del 2018) (http://www.cpl.org.pe/wp-content/uploads/2017/03/modificacion-del-reglamento-de-la-leyde-democratizacion-del-decreto-supremo-n-002-2016-mc-1403788-3.pdf)

DURANIK, Tomas; STOPPER, Markus y RUZBARSKY, Juraj (2011) Applying value stream mapping to identify hidden reserves and avoid bottlenecks, pp. 969-970. En: Annals of DAAAM $\&$ Proceedings, vol. 22. (consulta: 13 de junio 2016) (http://web.b.ebscohost.com/ehost/pdfviewer/pdfviewer?sid=53738c70-9b33-4311-9ed13295068 ca402\%40sessionmgr106\&vid=22\&hid=102)

DŽUBÁKOVÁ, Martina y KOPTÁK, Michal (2017) Work Standardisation in Logistics Processes, pp. 109-123. En: Quality Innovation Prosperity / Kvalita Inovácia Prosperita. (consulta: 28 de marzo del (http://web.b.ebscohost.com/ehost/pdfviewer/pdfviewer?vid=74\&sid=4f8d2fc5-85d8-40a899d5-c70877c5f0ac\%40sessionmgr103)

FORNO, Ana y otros (2014) Value Stream Mapping: a study about the problems and challenges found in the literature from the past 15 years about application of Lean tools, pp. 779-790. En: International Journal of Advanced Manufacturing Technology, vol. 72. Mayo 2014. (consulta: 13 de junio 2016) (http://web.b.ebscohost.com/ehost/pdfviewer/pdfviewer?sid=53738c709b33-4311-9ed1-3295068ca402\%40sessionmgr106\&vid=17\&hid=102)

FRIAS, Arturo (2012) 10 estrategias logísticas. El valor de la logística en los negocios. México D.F: Cengage Learning

GRECH, Stephen (2011) Cut to the chase with lean thinking, pp. 20-21. En: Government News, vol. 31. Abril - Mayo 2011 (consulta: 18 de abril 2016) (http://web.a.ebscohost.com/bsi/pdfviewer/pdfviewer?vid=9\&sid=c8915b4a-d227-473f-b0df46426a472460\%40sessionmgr4005\&hid=4104)

GUTIÉRREZ, Humberto (2014) Calidad y productividad 4ta edición. México D.F: Mc Graw Hill Education

HERNÁNDEZ, Eileen; CAMARGO, Zulieth y MARTÍNEZ, Paloma (2015) Impact of 5S on productivity, quality, organizational climate and industrial safety in Caucho Metal Ltda, pp. 107-117. En: INGENIARE - Revista Chilena De Ingeniería, vol. 23 (consulta: 18 de Julio) (http://web.a.ebscohost.com/ehost/pdfviewer/pdfviewer?sid=b3ed9a42-caca-4189-8223594b94de5a46\%40sessionmgr4002\&vid=68\&hid=4206)

HERNÁNDEZ, Arialys; MEDINA, Alberto y NOGUEIRA, Dianelys (2009) Criterios para la elaboración de mapas de procesos particularidades para los servicios hospitalarios, pp. 1-7. En: revista Ingeniería Industrial, vol. 30. (consulta: 30 de mayo del 2016) 
(http://web.a.ebscohost.com/ehost/pdfviewer/pdfviewer?sid=df29a464-6c43-4edd-93aa$38 \mathrm{~b} 5 \mathrm{e} 7 \mathrm{~b} 6444 \mathrm{~b} \% 40$ sessionmgr4006\&vid=6\&hid=4112)

HERNÁNDEZ, Juan y VIZÁN, Antonio (2013) Lean Manufacturing. Conceptos, técnicas e implantación. Madrid: Fundación Escuela de Organización Industrial (EOI)

JACA, Carmen y otros (2014) Learning 5S principles from Japanese best practitioners: case studies of five manufacturing companies, pp. 4574- 4586. En: International Journal Of Production Research, vol. 52. (consulta: 13 de junio del 2016) (http://web.b.ebscohost.com/ehost/pdfviewer/pdfviewer?sid=53738c70-9b33-4311-9ed13295068 ca402\%40sessionmgr106\&vid=41\&hid=102)

JIMÉNEZ, José (2013) Análisis de la reducción de pérdidas por falta de surtimiento mediante métodos heurísticos y de optimización en una planta manufacturera caso GKN (tesis para optar el grado académico de doctor en ciencia y tecnología en la especialidad de ingeniería industrial y de manufactura) León (Guanajuato): Centro de Innovación Aplicada en Tecnologías Competitivas.

KAHLE, Dolf (2015) Lean thinking and culture: A proven model of productivity improvements for organizations, pp. 12. En: Smart Business Akron/Canton, vol. 25. Junio 2015 (consulta: 20 de abril del 2016) (http://web.b.ebscohost.com/bsi/pdfviewer/pdfviewer?vid=15\&sid=4a2e4959-dd6f-48a2b477-a520aff05e03\%40sessionmgr120\&hid=102)

KOPTAK y OTROS (2017) Work Standards in Selected Third Party Logistics Operations: MTM-LOGISTICS Case Study, pp. 160 - 166. En: Procedia Engineering vol. 187 (consulta: 27 de marzo del

(http://web.b.ebscohost.com/ehost/pdfviewer/pdfviewer?vid=2\&sid=784a2eb1-1448-4d95b49c-658f965fd3ec\%40sessionmgr104)

LÓPEZ, María y LÓPEZ, Patricia (2014) Uso secuencial de herramientas de control de calidad en procesos productivos: una aplicación en el sector agroalimentario, pp. 73-95. En: Pecvnia no. 18. Enero - junio 2014 (consulta: 29 de Agosto del 2016) (http://web.b.ebscohost.com/ehost/pdfviewer/pdfviewer?sid=a4c20bb4-540c-407f-a735c86ab683f0c4\%40sessionmgr106\&vid=8\&hid=124)

MATZKA, Judith; DI MASCOLO, María y FURMANS, Kai (2012) Buffer sizing of a Heijunka Kanban system, pp. 49-60. En: Journal Of Intelligent Manufacturing, vol. 23. (consulta: 12 de octubre del 2016) (http://web.a.ebscohost.com/ehost/pdfviewer/pdfviewer?sid=9f6927ff-02294bc0-a9d1-97e179e56909\%40sessionmgr4009\&vid=46\&hid=4214)

MEJÍA, Christopher; AGUDELO, Isabel y SOTO, Osman (2016) Planeación por escenarios: un caso de estudio de una empresa de consultoría logística en Colombia, pp. 96-107. En: revista Estudios Gerenciales, vol. 32. Enero - Marzo 2016 (consulta: 22 de junio del 2016) (http://www.sciencedirect.com.ezproxy.upc.edu.pe:2048/science/article/pii/S01235923160000 
MINISTERIO DE EDUCACIÓN (MINEDU) (2018) (http://www.minedu.gob.pe/files/2261_201203050942.pdf) Sitio web oficial del MINEDU; contiene información sobre la institución y enlaces de interés (consulta: 25 de Abril del 2018)

MISIEGO, Belinda y SOLS, Alberto (2017) Lessons learned in the tailoring of life cycle models and systems engineering processes to sociocultural diversity, pp. 1-10. En: Proceedings of the American Society for Engineering Management 2017 International Annual Conference (consulta: 18 de abril del (https://search.proquest.com/abiglobal/docview/2010278688/fulltextPDF/4D4914EE37EC420 9PQ/5? accountid=43860)

MYERSON, Paul (2012a) Lean Supply Chain and Logistics Management. Historical Perspective: From Lean Manufacturing to Lean Enterprise . . . the Need for Speed, Chapter (McGraw-Hill Professional, 2012), AccessEngineering (consulta: 12 de junio 2016) (https://accessengineeringlibrary.com/browse/lean-supply-chain-and-logisticsmanagement/c9780071766265ch02)

MYERSON, Paul (2012b) Lean Supply Chain and Logistics Management. Lean Global Supply Chain and Logistics: The Long and Winding Road, Chapter (McGraw-Hill Professional, 2012), AccessEngineering (consulta: 12 de junio del 2016) (https://accessengineeringlibrary.com/browse/lean-supply-chain-and-logisticsmanagement/c9780071766265ch09)

MYERSON, Paul (2012c) Lean Supply Chain and Logistics Management. Basic Lean Tools: You Can't Build a House without a Solid Foundation, Chapter (McGraw-Hill Professional, 2012), AccessEngineering. (consulta: 16 de junio del 2016) (https://accessengineeringlibrary.com/browse/lean-supply-chain-and-logisticsmanagement/c9780071766265ch05)

MYERSON, Paul (2015) How Do You Know If your Supply Chain is LEAN Enough? pp. 3234. En: Material Handling \& Logistics. (consulta: 16 de abril del 2016) (http://web.a.ebscohost.com/bsi/pdfviewer/pdfviewer?vid=11\&sid=c8915b4a-d227-473fb0df-46426a472460\%40sessionmgr4005\&hid=4104)

OLSZEWSKI, David y MCHANN (2010) The industrial engineer as organizational leader: An assessment of contemporary industrial engineering skills, pp.1-6. En: IIE Annual Conference.Proceedings (consulta: 27 de marzo del 2018) (https://search.proquest.com/abitrade/docview/733014297/fulltextPDF/1272C8BD0A464EF3 $\mathrm{PQ} / 8$ ? accountid=43860)

PACHECO, Diego (2015) TOC, lean and six sigma: The missing link to increase productivity? pp. 513-520. En African Journal of Business Management, vol. 9 (consulta: 20 de noviembre del 2016) (http://academicjournals.org/journal/AJBM/article-full-text-pdf/4EFB8C353788) 
PAREDES, Andrés (2017) Aplicación de la herramienta Value Stream Mapping a una empresa embaladora de productos de vidrios pp. 262-274. En: Revista Entramado vol.13. (consulta: 13 de enero del 2018) (http://web.a.ebscohost.com/ehost/pdfviewer/pdfviewer?vid=21\&sid=f2342f59-1ed1-4b189631-de4b294e2989\%40sessionmgr4007)

PEÑA, Diego (2016) Aplicación de técnicas de balanceo de línea para equilibrar las cargas de trabajo en el área de almacenaje de una bodega de almacenamiento pp. 239 - 247. En: Revista Scientia et Technica, vol. 21 (consulta: 10 de enero del 2018) (http://web.a.ebscohost.com/ehost/pdfviewer/pdfviewer?vid=12\&sid=9561828e-b141-4ab5abb6-3f34dc04e93d\%40sessionmgr4007)

PROFESSIONAL SAFETY (2015) Exploring Kaizen Events pp. 20. En: Professional Safety, vol. 60. Octubre del 2015 (consulta: 24 de agosto del 2016) (http://web.a.ebscohost.com/ehost/pdfviewer/pdfviewer?vid=6\&sid=f92944ed-8fe8-42a2b73f-e59726327e0d\%40sessionmgr4008\&hid=4214)

PUERTAS, Rosa; MARTÍ Luisa y GARCÍA, Leandro (2014) Índice de desempeño logístico: Exportaciones europeas, pp. 77-99. En: Revista de Economía Mundial, vol. 38. (consulta: 22 de agosto del 2016) (http://web.b.ebscohost.com/ehost/pdfviewer/pdfviewer?sid=366242e4-ba1b4f54-a7db-7849fdd496a7\%40sessionmgr105\&vid=10\&hid=118)

RONCANCIO, Mitzy y OTROS (2017) Utilización de curvas de aprendizaje e intervalos de confianza en un estudio de tiempos para el cálculo de tiempos estándar, pp. 18-27. En: INGE CUC, vol. 13 (consulta: 02 de Abril del 2018) (http://web.a.ebscohost.com/ehost/pdfviewer/pdfviewer?vid=24\&sid=ae5d54be-6d7c-467a976c-c21cc56399f5\%40sessionmgr4006)

RUIZ, Jesús y OTROS (2017) Optimización de tiempos de proceso en desestibadora y en llenadora, pp. 291-298. En: Ra Ximhai, vol. 13 (consulta 02 de abril 2018) (http://web.a.ebscohost.com/ehost/pdfviewer/pdfviewer?vid=22\&sid=ae5d54be-6d7c-467a976c-c21cc56399f5\%40sessionmgr4006)

SACRISTÁN, Macarena; GARRIDO, Pedro y GARCÍA, Antonio (2012) La implantación de lean production en los proveedores del sector aeronáutico: ¿dependencia o compromiso?, pp. 32-47. En: Universia Business Review vol. 36. (consulta: 11 de octubre del 2016) (http://web.b.ebscohost.com/ehost/pdfviewer/pdfviewer?sid=4843a0e0-8efc-4e31-866b5216a6051a5e\%40sessionmgr105\&vid=25\&hid=102)

SHAKED, David y STAMPF, Nicolas (2015) Appreciative \& Strengths-based Lean Thinking: Positive Engagement with Business Improvement and Efficiency, pp. 4-8. En: Academic Journal AI Practitioner, vol. 17. Noviembre 2015 (consulta: 15 de mayo del 2016) (http://web.b.ebscohost.com/bsi/pdfviewer/pdfviewer?vid=12\&sid=4a2e4959-dd6f-48a2b477-a520aff05e03\%40sessionmgr120\&hid=102) 
SHARARAH, Mohamed (2013) A value stream map in motion. Simulation makes static tool dynamic, increasing its usefulness, pp. 46-50. En: Industrial Engineer (IE) (consulta: 13 de junio del 2016) (http://web.b.ebscohost.com/ehost/pdfviewer/pdfviewer?sid=53738c70-9b33-43119ed1-3295068ca402\%40sessionmgr106\&vid=13\&hid=102)

SIMAMORA, Manaek; AIMAN, Syahrul y SUBIYANTO, Bambang (2016) How Supply Chain Management Enhances SMEs' Competitiveness: A Case Study, pp. 33-47. En: IUP Journal of Supply Chain Management, vol. 13. Junio 2016 (consulta: 22 de Agosto del 2016) (http://web.b.ebscohost.com/ehost/pdfviewer/pdfviewer?sid=c46eb3a2-f92b-4fdc-9bc2d7114155ff21\%40sessionmgr105\&vid=14\&hid=102)

THE SAFETY \& HEALTH PRACTITIONER (2015) Kenyan firm wins IOSH railway group international safety award, pp. 17. En: The Safety \& Health Practitioner, Octubre (consulta: 22 Marzo del 2017) (https://search.proquest.com/abitrade/docview/1727756858/fulltextPDF/729D19E4960C4DF5 $\mathrm{PQ} / 1$ ? accountid=43860)

TODOROVA, Daniela y DUGGER, John (2015) Lean Manufacturing Tools In Job Shop, Batch Shop and Assembly Line Manufacturing Settings, pp. 1-19. En: Journal Of Technology, Management \& Applied Engineering, vol. 31. (consulta: 04 de octubre del 2015) (http://web.a.ebscohost.com/ehost/pdfviewer/pdfviewer?sid=9f6927ff-0229-4bc0-a9d1 97e179e56909\%40sessionmgr4009\&vid=39\&hid=4214)

ZAPATA, Julían y MORENO, Ricardo (2011) Lean Logistics ¿moda o necesidad? pp. 117-120 En: Mercatec, vol.49. Enero - Junio 2011 (consulta 07 de abril 2016) (http://www.esumer.edu.co/institucional/publicaciones-institucionales/item/331-revistamercatec)

ZAKARIA, Zamzulaila (2015) A cultural approach of embedding KPIs into organizational practices pp. 932-946. En: International Journal of productivity and Performance Management, vol. $64 . \quad$ (consulta $25 \quad$ de $\quad$ Marzo 2 2018) (https://search.proquest.com/abiglobal/docview/1712468426/fulltextPDF/245A4BE78171400 $0 \mathrm{PQ} / 4$ ?accountid=43860) 


\section{ANEXOS}

\section{Anexo 1. Importaciones 2015 - Partida Arancelaria 4901999000}

\begin{tabular}{|c|c|c|c|}
\hline IMPORTADOR & Total FOB \$ & Participación & Acumulado \\
\hline SPECIAL BOOK SERVICES S.A. & $10,436,575.73$ & $16.310 \%$ & $16.310 \%$ \\
\hline UNIDAD EJECUTORA 120 PROGRAMA NACIONAL D & $4,809,306.49$ & $7.516 \%$ & $23.827 \%$ \\
\hline DISTRIBUIDORA EUROPEA DE EDICIONES S.A.C & $3,897,537.16$ & $6.091 \%$ & $29.918 \%$ \\
\hline LIBRERIAS CRISOL S.A.C. & $3,578,318.77$ & $5.592 \%$ & $35.510 \%$ \\
\hline FUNDACION DEL LIBRO UNIVERSITARIO-LIBUN & $2,996,015.26$ & $4.682 \%$ & $40.192 \%$ \\
\hline EDITORIAL ANGLO DEL PERU SA & $2,240,938.93$ & $3.502 \%$ & $43.694 \%$ \\
\hline ASOCIACION SERVICIO EDUCACIONAL HOGAR Y & $2,136,938.75$ & $3.340 \%$ & $47.034 \%$ \\
\hline PRODUCCIONES CANTABRIA S.A.C. & 2,021,223.31 & $3.159 \%$ & $50.193 \%$ \\
\hline DISTRIBUIDORA BOLIVARIANA S A & $1,834,844.73$ & $2.868 \%$ & $53.060 \%$ \\
\hline NUEVAS TECNICAS EDUCATIVAS S.A.C.-NUTESA & $1,571,949.10$ & $2.457 \%$ & $55.517 \%$ \\
\hline SOCIEDAD BIBLICA PERUANA ASOC CULTURAL & $1,567,672.00$ & $2.450 \%$ & $57.967 \%$ \\
\hline IBERO A \& G S.A.C. & $1,510,806.36$ & $2.361 \%$ & $60.328 \%$ \\
\hline MACMILLAN PUBLISHERS S.A. & $1,255,522.08$ & $1.962 \%$ & $62.290 \%$ \\
\hline LENGUAJE Y COMERCIO SRLTDA. & $913,233.76$ & $1.427 \%$ & $63.717 \%$ \\
\hline EDITORIAL OCEANO PERUANA S.A. & $902,765.75$ & $1.411 \%$ & $65.128 \%$ \\
\hline SAN CRISTOBAL LIBROS S.A.C. & $862,220.54$ & $1.347 \%$ & $66.476 \%$ \\
\hline PRESCRIPTION DATA DEL PERU S.A.C. & $751,113.00$ & $1.174 \%$ & $67.650 \%$ \\
\hline COMMUNITAS S.A.C. & $751,087.84$ & $1.174 \%$ & $68.824 \%$ \\
\hline LIBRERIA PERUANO BRITANICA S.R.LTDA. & $749,366.16$ & $1.171 \%$ & $69.995 \%$ \\
\hline ASOCIACION PERUANA DE LA IGLESIA DE JESU & $714,799.48$ & $1.117 \%$ & $71.112 \%$ \\
\hline EDITORIAL PANAMERICANA PERU S.A.C. & $695,426.49$ & $1.087 \%$ & $72.199 \%$ \\
\hline EDITORIAL VICENS VIVES PERU SOCIEDAD ANO & $641,127.59$ & $1.002 \%$ & $73.201 \%$ \\
\hline DISTRIBUIDORA INCA S.A.C. & $620,650.66$ & $0.970 \%$ & $74.170 \%$ \\
\hline PRENSMART S.A.C. & $596,890.33$ & $0.933 \%$ & $75.103 \%$ \\
\hline EDITORIAL PLANETA PERU S.A. & $595,084.59$ & $0.930 \%$ & $76.033 \%$ \\
\hline V \& D DISTRIBUIDORES SOCIEDAD ANONIMA CE & $579,302.57$ & $0.905 \%$ & $76.939 \%$ \\
\hline EXPRESSO BIBLIOGRAFICO PERU S.A.C. & $564,281.95$ & $0.882 \%$ & $77.821 \%$ \\
\hline SANTILLANA SA & $535,176.67$ & $0.836 \%$ & $78.657 \%$ \\
\hline PENGUIN RANDOM HOUSE GRUPO EDITORIAL S.A & $528,667.36$ & $0.826 \%$ & $79.483 \%$ \\
\hline DISTRIBUIDORA DE LIBROS HERALDOS NEGROS & $520,340.53$ & $0.813 \%$ & $80.296 \%$ \\
\hline EUROMATEX S.A.C. & $515,502.26$ & $0.806 \%$ & $81.102 \%$ \\
\hline VIDOTI SERVICIOS EDUCATIVOS SOCIEDAD ANO & $416,748.68$ & $0.651 \%$ & $81.753 \%$ \\
\hline G Y M S.A. & $395,786.02$ & $0.619 \%$ & $82.372 \%$ \\
\hline SOCIEDAD DE SAN PABLO & $385,167.78$ & $0.602 \%$ & $82.974 \%$ \\
\hline LIBRERIA KAIROS S.A.C. & $379,674.78$ & $0.593 \%$ & $83.567 \%$ \\
\hline AMOLCA S.A.C. & $370,399.97$ & $0.579 \%$ & $84.146 \%$ \\
\hline DISTRIBUCIONES MEDITERRANEO S.A.C. & $356,584.51$ & $0.557 \%$ & $84.703 \%$ \\
\hline PUNTO Y COMA EDITORES S.A.C & $348,358.41$ & $0.544 \%$ & $85.248 \%$ \\
\hline DISTRIBUIDORA MADOX BOOKS S.R.L. & $339,233.36$ & $0.530 \%$ & $85.778 \%$ \\
\hline GRUPO EDITORIAL CULTURAL PERU SOCIEDAD A & $316,251.63$ & $0.494 \%$ & $86.272 \%$ \\
\hline DESARROLLO CRISTIANO DEL PERU & $303,591.41$ & $0.474 \%$ & $86.747 \%$ \\
\hline CORPORATIVO V Y T S.R.L. & $269,364.20$ & $0.421 \%$ & $87.168 \%$ \\
\hline ASOCIACION HIJAS DE SAN PABLO & $255,940.15$ & $0.400 \%$ & $87.568 \%$ \\
\hline GRUPO EDITORIAL NORMA S.A.C. & $250,190.96$ & $0.391 \%$ & $87.959 \%$ \\
\hline MUNDO DE INGLES S.A.C. & $249,000.00$ & $0.389 \%$ & $88.348 \%$ \\
\hline LIBRERIA EL INCA S.A.C & $232,777.45$ & $0.364 \%$ & $88.711 \%$ \\
\hline LA FAMILIA DISTRIBUIDORA DE LIBROS SA & $223,490.35$ & $0.349 \%$ & $89.061 \%$ \\
\hline
\end{tabular}

Fuente: SUNAT (Elaboración propia) 


\begin{tabular}{|c|c|c|c|}
\hline EDICIONES SEMBRANDO S.A.C - EDICSEM & $194,839.06$ & $0.304 \%$ & $89.365 \%$ \\
\hline WORLD BOOKS E.I.R.L. & $177,435.00$ & $0.277 \%$ & $89.643 \%$ \\
\hline CENTRO NEOCATECUMENAL ARQUIDIOCESANO & $157,724.91$ & $0.246 \%$ & $89.889 \%$ \\
\hline LIGA BIBLICA DEL PERU & $156,303.09$ & $0.244 \%$ & $90.133 \%$ \\
\hline IGLESIA ADVENTISTA DEL SEPTIMO DIA & $151,144.49$ & $0.236 \%$ & $90.369 \%$ \\
\hline THE GIDEONS INTERNATIONAL IN PERU & $147,573.51$ & $0.231 \%$ & $90.600 \%$ \\
\hline MEDICINE BOOK S.A.C. & $145,380.14$ & $0.227 \%$ & $90.827 \%$ \\
\hline IMPORTADORA DISTRIBUIDORA LIBRERIA VIDA & $132,530.06$ & $0.207 \%$ & $91.034 \%$ \\
\hline BRITT PERU S.A.C. & $131,603.66$ & $0.206 \%$ & $91.240 \%$ \\
\hline CULTURAL EDUCACIONAL WINDSOR DEL PERU S. & $130,973.07$ & $0.205 \%$ & $91.445 \%$ \\
\hline FONDO DE CULTURA ECONOMICA DEL PERU S.A. & $127,141.17$ & $0.199 \%$ & $91.644 \%$ \\
\hline LITERATURA MEDICA E.I.R.L. & $124,480.98$ & $0.195 \%$ & $91.838 \%$ \\
\hline DAVAU S.A.C & $120,074.11$ & $0.188 \%$ & $92.026 \%$ \\
\hline ASOCIACION DE LITERATURA CRISTIANA DEL V & $115,136.43$ & $0.180 \%$ & $92.206 \%$ \\
\hline INSTITUTO EDUCACIONAL FRANKLIN DELANO RO & $113,523.02$ & $0.177 \%$ & $92.383 \%$ \\
\hline EUROSUR S.A.C. & $105,578.44$ & $0.165 \%$ & $92.548 \%$ \\
\hline ASOCIACION EDUCACIONAL WILLIAMSON DEL PE & $103,704.66$ & $0.162 \%$ & $92.710 \%$ \\
\hline TEXT BOOK S.A. & $102,014.49$ & $0.159 \%$ & $92.870 \%$ \\
\hline UNIVERSIDAD PERUANA DE CIENCIAS APLICADA & $91,990.70$ & $0.144 \%$ & $93.013 \%$ \\
\hline COLEGIO MARKHAM & $91,096.08$ & $0.142 \%$ & $93.156 \%$ \\
\hline PONTIFICIA UNIVERSIDAD CATOLICA DEL PERU & $88,558.13$ & $0.138 \%$ & $93.294 \%$ \\
\hline N.L.C. EDITORES DEL PERU S.A. & $88,376.70$ & $0.138 \%$ & $93.432 \%$ \\
\hline COLEGIO ANTONIO RAIMONDI & $86,088.81$ & $0.135 \%$ & $93.567 \%$ \\
\hline ORGAN PARA EL DESARR CULT DEL PERU SRL & $84,394.63$ & $0.132 \%$ & $93.699 \%$ \\
\hline EDICIONES SM SOCIEDAD ANONIMA CERRADA & $80,482.94$ & $0.126 \%$ & $93.824 \%$ \\
\hline CTO PERU S.A.C. & $80,320.48$ & $0.126 \%$ & $93.950 \%$ \\
\hline COLEGIO SAN JORGE DE MIRAFLORES S.C.R.L & $76,410.66$ & $0.119 \%$ & $94.069 \%$ \\
\hline PEARSON EDUCACION DE PERU S.A. & $73,904.93$ & $0.115 \%$ & $94.185 \%$ \\
\hline ASOCIACION EDUCATIVA DAVY & $72,687.75$ & $0.114 \%$ & $94.298 \%$ \\
\hline GREEN BUSINESS EDITORES S.A.C. & $66,809.79$ & $0.104 \%$ & $94.403 \%$ \\
\hline S E RECURSOS EDUCATIVOS SOCIEDAD ANONIM & $66,690.27$ & $0.104 \%$ & $94.507 \%$ \\
\hline LIBRERIA DEL VIRREY S.A.C & $66,127.16$ & $0.103 \%$ & $94.610 \%$ \\
\hline LIBRERIAS LA CASTELLANA S.A.C. & $65,487.85$ & $0.102 \%$ & $94.713 \%$ \\
\hline YEPEZ SERRANO CAROLINA CECILIA & $64,948.23$ & $0.102 \%$ & $94.814 \%$ \\
\hline ASOCIACION BAUTISTA CALVARIO & $64,195.00$ & $0.100 \%$ & $94.915 \%$ \\
\hline ZETA BOOKSTORE S.R.L. & $63,269.96$ & $0.099 \%$ & $95.013 \%$ \\
\hline RENA WARE DEL PERU S A & $62,568.62$ & $0.098 \%$ & $95.111 \%$ \\
\hline ASOCIACION COLEGIO PESTALOZZI & $62,185.57$ & $0.097 \%$ & $95.208 \%$ \\
\hline ALMACENES ANDINOS SOCIEDAD ANONIMA CERRA & $61,934.43$ & $0.097 \%$ & $95.305 \%$ \\
\hline E-TRADING \& SUPPLY SOCIEDAD ANONIMA CERR & $61,452.55$ & $0.096 \%$ & $95.401 \%$ \\
\hline EDITORIAL SEPTIEMBRE S.A.C. & $59,289.50$ & $0.093 \%$ & $95.494 \%$ \\
\hline FUXION BIOTECH S.A.C. & $58,001.61$ & $0.091 \%$ & $95.585 \%$ \\
\hline SICOBEN PERU SAC & $56,700.72$ & $0.089 \%$ & $95.673 \%$ \\
\hline TECNICAS AMERICANAS DE ESTUDIO PARA PERU & $56,320.00$ & $0.088 \%$ & $95.761 \%$ \\
\hline GENERAL BUSINESS COMPANY S.A.C. & $55,142.50$ & $0.086 \%$ & $95.847 \%$ \\
\hline CANET EDUCACION SOCIEDAD ANONIMA CERRADA & $53,339.42$ & $0.083 \%$ & $95.931 \%$ \\
\hline IMPORTACIONES RIGUSE S.A.C. & $52,068.63$ & $0.081 \%$ & $96.012 \%$ \\
\hline SAN SILVESTRE SCHOOL ASOCIACION CIVIL & $51,957.27$ & $0.081 \%$ & $96.093 \%$ \\
\hline DISTRIBUIDORA NAVARRETE S A & $51,600.00$ & $0.081 \%$ & $96.174 \%$ \\
\hline UNIVERSIDAD SAN IGNACIO DE LOYOLA S.A & $48,251.67$ & $0.075 \%$ & $96.249 \%$ \\
\hline INST.PERUANO DE PSICOLOGIA Y EDUCACION & $44,438.04$ & $0.069 \%$ & $96.319 \%$ \\
\hline EDICIONES ZETA S.R.L. & $42,856.37$ & $0.067 \%$ & $96.386 \%$ \\
\hline COLEGIO FRANCO PERUANO & $41,690.56$ & $0.065 \%$ & $96.451 \%$ \\
\hline GRUPO EDITOR EL QUIJOTE S.A.C. & $41,600.31$ & $0.065 \%$ & $96.516 \%$ \\
\hline
\end{tabular}

Fuente: SUNAT (Elaboración propia) 


\begin{tabular}{|c|c|c|c|}
\hline EMBAJADA DEL JAPON & $41,221.08$ & $0.064 \%$ & $96.580 \%$ \\
\hline ECB EDICIONES S.A.C. & $41,057.70$ & $0.064 \%$ & $96.645 \%$ \\
\hline EDICIONES LIBRO AMIGO E.I.R.L. & $40,954.99$ & $0.064 \%$ & $96.709 \%$ \\
\hline DISTRIBUIDORA XTREMO S.R.L. & $39,111.08$ & $0.061 \%$ & $96.770 \%$ \\
\hline SER Y EDUCAR S.A.C. & $37,065.70$ & $0.058 \%$ & $96.828 \%$ \\
\hline IMPORTACIONES Y EXPORTACIONES ATACHAHUA & $36,436.00$ & $0.057 \%$ & $96.885 \%$ \\
\hline EDICIONES EL LECTOR S.R.L. & $35,642.85$ & $0.056 \%$ & $96.940 \%$ \\
\hline MISION CRISTIANA VIDA NUEVA & $35,544.00$ & $0.056 \%$ & $96.996 \%$ \\
\hline ASOCIACION MINISTERIO RBC & $34,953.86$ & $0.055 \%$ & $97.050 \%$ \\
\hline EDICIONES BARCELONA SA & $34,913.79$ & $0.055 \%$ & $97.105 \%$ \\
\hline CORPORACION PRIMI GUTIERREZ E.I.R.L. & $34,063.82$ & $0.053 \%$ & $97.158 \%$ \\
\hline EQUO S.A. & $33,317.82$ & $0.052 \%$ & $97.210 \%$ \\
\hline GHELLER DOIG ROBERTO AUGUSTO & $32,856.01$ & $0.051 \%$ & $97.262 \%$ \\
\hline BERLITZ CENTERS DEL PERU S.A.C. & $31,321.38$ & $0.049 \%$ & $97.311 \%$ \\
\hline PLUSPETROL PERU CORPORATION S.A. & $31,231.40$ & $0.049 \%$ & $97.359 \%$ \\
\hline FE GOLD S.A.C. & $28,906.40$ & $0.045 \%$ & $97.405 \%$ \\
\hline CORPORACION BIBLIOGRAFICAS DEL PERU S.A. & $28,420.20$ & $0.044 \%$ & $97.449 \%$ \\
\hline ORIENTANDO S.A.C. & $27,846.65$ & $0.044 \%$ & $97.493 \%$ \\
\hline DISTRIBUIDORA E IMPORTADORA CELI S.R.L. & $26,474.93$ & $0.041 \%$ & $97.534 \%$ \\
\hline OPERACIONES ARCOS DORADOS DE PERU SA & $26,089.69$ & $0.041 \%$ & $97.575 \%$ \\
\hline CRISTOFARO S.A.C. & $25,861.81$ & $0.040 \%$ & $97.615 \%$ \\
\hline L TGEBTER BENJAMIN MICHAEL MATTHIAS & $25,786.44$ & $0.040 \%$ & $97.655 \%$ \\
\hline A.C.E. SCHOOL OF TOMORROW PERU & $25,510.16$ & $0.040 \%$ & $97.695 \%$ \\
\hline DORICH \& WATKIN S.A.C & $25,412.88$ & $0.040 \%$ & $97.735 \%$ \\
\hline NOPO AGUILAR HUGO ROLANDO & $25,075.00$ & $0.039 \%$ & $97.774 \%$ \\
\hline CAMBRIDGE COLLEGE LIMA SRL & $24,971.87$ & $0.039 \%$ & $97.813 \%$ \\
\hline IGLESIA BAUTISTA VIDA NUEVA MONTERRICO C & $24,552.11$ & $0.038 \%$ & $97.852 \%$ \\
\hline A B REPRESENTACIONES GENERALES S R LTDA & $24,483.80$ & $0.038 \%$ & $97.890 \%$ \\
\hline UNIVERSIDAD DEL PACIFICO & $24,230.00$ & $0.038 \%$ & $97.928 \%$ \\
\hline COMITE INTERNACIONAL DE LA CRUZ ROJA (Cl & $23,846.10$ & $0.037 \%$ & $97.965 \%$ \\
\hline TORRES RUBIO CARLOS HUMBERTO & $23,144.86$ & $0.036 \%$ & $98.001 \%$ \\
\hline FERREYROS SOCIEDAD ANËNIMA & $23,010.58$ & $0.036 \%$ & $98.037 \%$ \\
\hline IMPORTACIONES \& EXPORTACIONES MELANIE S. & $22,035.00$ & $0.034 \%$ & $98.072 \%$ \\
\hline ASOCIACION DE PRODUCTORES DE PALTA HASS & $21,056.00$ & $0.033 \%$ & $98.104 \%$ \\
\hline PORRAS DE URIBE FELICIA EDELMIRA & $20,911.66$ & $0.033 \%$ & $98.137 \%$ \\
\hline ALCANCE MUNDIAL PERU & $19,267.05$ & $0.030 \%$ & $98.167 \%$ \\
\hline THE BHAKTIVEDANTA BOOK TRUST ANDINO EMPR & $19,210.00$ & $0.030 \%$ & $98.197 \%$ \\
\hline INTERNATIONAL STUDY GROUP S.A.C. & $19,113.60$ & $0.030 \%$ & $98.227 \%$ \\
\hline VISUAL EDICIONES S.A.C. & $19,042.90$ & $0.030 \%$ & $98.257 \%$ \\
\hline ESKE CORPORATION S.A.C. & $18,834.16$ & $0.029 \%$ & $98.286 \%$ \\
\hline LIBRERIA CIENTIF.Y TECNOL.UNIV. S.A.C. & $18,808.80$ & $0.029 \%$ & $98.316 \%$ \\
\hline CENCOSUD RETAIL PERU S.A. & $17,729.52$ & $0.028 \%$ & $98.343 \%$ \\
\hline DISTRIBUIDORA FONO LIBROS E.I.R.L. & $17,498.16$ & $0.027 \%$ & $98.371 \%$ \\
\hline BEREKET S.A.C. & $17,289.04$ & $0.027 \%$ & $98.398 \%$ \\
\hline INVERSIONES CIENTIFICAS \& TECNOLOGICA S. & $17,203.55$ & $0.027 \%$ & $98.425 \%$ \\
\hline GRIJLE IMPORT S.A. & $17,161.00$ & $0.027 \%$ & $98.451 \%$ \\
\hline DSM MARINE LIPIDS PERU S.A.C. & $16,758.49$ & $0.026 \%$ & $98.478 \%$ \\
\hline URBIZAGASTEGUI SIPION CRISTOBAL HERNAN & $16,593.12$ & $0.026 \%$ & $98.504 \%$ \\
\hline CASA DEL SABER SOCIEDAD ANONIMA CERRADA & $16,209.75$ & $0.025 \%$ & $98.529 \%$ \\
\hline MAGIC ENGLISH LEARNING EDITORES E.I.R.L. & $16,000.00$ & $0.025 \%$ & $98.554 \%$ \\
\hline RIPANO PERU S.A.C. & $15,975.50$ & $0.025 \%$ & $98.579 \%$ \\
\hline PRODUCTOS MEDICOS S.A.C. & $15,773.33$ & $0.025 \%$ & $98.604 \%$ \\
\hline SOCIEDAD MINERA CERRO VERDE S.A.A. & & $0.024 \%$ & $98.628 \%$ \\
\hline AVANSIL S.A.C. & $15,611.40$ & $0.024 \%$ & $98.652 \%$ \\
\hline
\end{tabular}

Fuente: SUNAT (Elaboración propia) 


\begin{tabular}{|c|c|c|c|}
\hline TOLEDO CHIRITO JESSICA MARIA & $15,479.11$ & $0.024 \%$ & $98.677 \%$ \\
\hline COMPAĐIA DE JESUS PROVINCIA DEL PERU & $15,399.22$ & $0.024 \%$ & $98.701 \%$ \\
\hline BRITISH AMERICAN HOSPITAL S.A. & $15,388.05$ & $0.024 \%$ & $98.725 \%$ \\
\hline PAREDES, ZALDIVAR, BURGA \& ASOCIADOS S. & $14,949.52$ & $0.023 \%$ & $98.748 \%$ \\
\hline LIBRERIA CIENTIFICA DEL PERU E.I.R.L. & $14,098.50$ & $0.022 \%$ & $98.770 \%$ \\
\hline ONEBODY & $13,890.00$ & $0.022 \%$ & $98.792 \%$ \\
\hline INVERSIONES NACIONALES DE TURISMO S.A. & $13,800.00$ & $0.022 \%$ & $98.813 \%$ \\
\hline INTERCAMBIO CULTURAL SINO-PERUANO S.A.C. & $13,633.90$ & $0.021 \%$ & $98.835 \%$ \\
\hline HOSPIRA PER $\Gamma$ S.R.L. & $13,248.84$ & $0.021 \%$ & $98.855 \%$ \\
\hline REPRESENTACIONES CULTURALES MARDI Y CARD & $13,091.50$ & $0.020 \%$ & $98.876 \%$ \\
\hline EDITORIAL CARAL S.A.C. & $12,883.20$ & $0.020 \%$ & $98.896 \%$ \\
\hline A W FABER CASTELL PERUANA S A & $12,310.32$ & $0.019 \%$ & $98.915 \%$ \\
\hline COMUNIDAD CRISTIANA DEL ESPIRITU SANTO & $12,270.00$ & $0.019 \%$ & $98.934 \%$ \\
\hline MEDIOS Y ASESORAMIENTO EDUCATIVO SOCIEDA & $12,125.05$ & $0.019 \%$ & $98.953 \%$ \\
\hline ROTARY CLUB SAN ISIDRO ESTE & $12,055.00$ & $0.019 \%$ & $98.972 \%$ \\
\hline MASTER OF THE SKY S.R.L. & $11,973.70$ & $0.019 \%$ & $98.991 \%$ \\
\hline INVERSIONES EDUCATIVAS S.A.C. & $11,908.20$ & $0.019 \%$ & $99.010 \%$ \\
\hline LENOVO (ASIA PACIFIC) LIMITED SUCURSAL D & $11,701.74$ & $0.018 \%$ & $99.028 \%$ \\
\hline ENGINZONE S.A.C. & $11,529.20$ & $0.018 \%$ & $99.046 \%$ \\
\hline TRANS AMERICAN AIR LINES S.A. & $11,128.01$ & $0.017 \%$ & $99.063 \%$ \\
\hline CENTRO EDUCATIVO PRIVADO HIRAM BINGHAM & $11,093.06$ & $0.017 \%$ & $99.081 \%$ \\
\hline CAMPOS ARMAS JORGE LUIS JUNIOR & $10,790.16$ & $0.017 \%$ & $99.097 \%$ \\
\hline ASOC.LIBRERIA EDITORIAL SALESIANA & $9,978.04$ & $0.016 \%$ & $99.113 \%$ \\
\hline TECSUP N 1 & $9,489.86$ & $0.015 \%$ & $99.128 \%$ \\
\hline UNIVERSIDAD DE LIMA & $9,238.02$ & $0.014 \%$ & $99.142 \%$ \\
\hline ASOCIACION LOS ANDES DE CAJAMARCA & $9,212.28$ & $0.014 \%$ & $99.157 \%$ \\
\hline GRUPO LECTUM S.A.C & $9,204.93$ & $0.014 \%$ & $99.171 \%$ \\
\hline LAS PALMERAS MANAGEMENT TRUST \& CONSULTI & $8,919.75$ & $0.014 \%$ & $99.185 \%$ \\
\hline PITS LOGISTICA INTEGRAL S.A.C. & $8,563.29$ & $0.013 \%$ & $99.198 \%$ \\
\hline SIGLO XXI DISTRIBUIDORES SOCIEDAD ANONIM & $8,427.57$ & $0.013 \%$ & $99.212 \%$ \\
\hline GRUPO EDITORIAL EUROHISPANO S.A.C. & $8,410.02$ & $0.013 \%$ & $99.225 \%$ \\
\hline ASOCIACION EDUCACIONAL ANTONIO RAIMONDI & $8,407.54$ & $0.013 \%$ & $99.238 \%$ \\
\hline INDUMOTORA DEL PERU S.A. & $8,372.00$ & $0.013 \%$ & $99.251 \%$ \\
\hline CORPORACION JRC Y CIA S.A.C. & $7,826.17$ & $0.012 \%$ & $99.263 \%$ \\
\hline UNIVERSIDAD ALAS PERUANAS S.A. & $7,802.91$ & $0.012 \%$ & $99.275 \%$ \\
\hline MEDIFARMA S A & $7,759.65$ & $0.012 \%$ & $99.288 \%$ \\
\hline INVERSIONES ZHANG - LINARES S.A.C. - INV & $7,742.48$ & $0.012 \%$ & $99.300 \%$ \\
\hline UNIVERSIDAD PERUANA CAYETANO HEREDIA & $7,681.68$ & $0.012 \%$ & $99.312 \%$ \\
\hline COOP SERV EDUC AUGUSTO WEBERBAUER LTDA. & $7,639.45$ & $0.012 \%$ & $99.324 \%$ \\
\hline PRORICHARD S.R.L. & $7,560.00$ & $0.012 \%$ & $99.335 \%$ \\
\hline ASOCIACION CIVIL RELIGIOSA DIOSPI SUYANA & $7,308.00$ & $0.011 \%$ & $99.347 \%$ \\
\hline BIBLIO MEDICA S.R.LTDA. & $7,118.02$ & $0.011 \%$ & $99.358 \%$ \\
\hline UGARTE VASQUEZ ELSA ROSARIO & $6,982.81$ & $0.011 \%$ & $99.369 \%$ \\
\hline VETPHARMA PERU E.I.R.L. & $6,580.97$ & $0.010 \%$ & $99.379 \%$ \\
\hline CONSORCIO EMPRESARIAL AGNAV S.A. & $6,579.70$ & $0.010 \%$ & $99.389 \%$ \\
\hline EQUIPEX GYM SAC & $6,441.47$ & $0.010 \%$ & $99.399 \%$ \\
\hline MISION CARISMATICA INTERNACIONAL -MCI & $6,400.00$ & $0.010 \%$ & $99.409 \%$ \\
\hline ASOCIACION ACADEMIA DE CULTURA JAPONESA & $6,376.51$ & $0.010 \%$ & $99.419 \%$ \\
\hline LEADERSHIP MANAGEMENT PERU S.A.C. & $6,314.61$ & $0.010 \%$ & $99.429 \%$ \\
\hline SOUTHERN PERU COPPER CORPORATION SUCURSA & $6,014.92$ & $0.009 \%$ & $99.439 \%$ \\
\hline EDITORIAL SUPER GRAFICA E I R L & $6,000.01$ & $0.009 \%$ & $99.448 \%$ \\
\hline DELL PERU S.A.C & $5,908.80$ & $0.009 \%$ & $99.457 \%$ \\
\hline CENTRO CULTURAL DE INVESTIGACION Y PUBLI & $5,562.50$ & $0.009 \%$ & $99.466 \%$ \\
\hline AGRIBRANDS PURINA PERU S.A. & $5,501.04$ & $0.009 \%$ & $99.475 \%$ \\
\hline
\end{tabular}

Fuente: SUNAT (Elaboración propia) 


\begin{tabular}{|c|c|c|c|}
\hline MINERA LAS BAMBAS S.A. & $5,486.40$ & $0.009 \%$ & $99.483 \%$ \\
\hline COLGATE-PALMOLIVE PERU S A & $5,263.40$ & $0.008 \%$ & $99.491 \%$ \\
\hline ROBERT BOSCH S.A.C. & $5,191.36$ & $0.008 \%$ & $99.500 \%$ \\
\hline PORTAFOLIO PARA EL DESARROLLO INTEGRALS & $5,162.66$ & $0.008 \%$ & $99.508 \%$ \\
\hline LOS LIBROS MAS PEQUE $\pm O S$ DEL MUNDO EIRL & $5,112.49$ & $0.008 \%$ & $99.516 \%$ \\
\hline MICHIGAN EDITORES S.A.C. & $5,112.00$ & $0.008 \%$ & $99.524 \%$ \\
\hline ASOCIACION PERUANA DE LA SOKA GAKKAI INT & $5,024.17$ & $0.008 \%$ & $99.531 \%$ \\
\hline ASTRAZENECA PERU S.A. & $4,697.34$ & $0.007 \%$ & $99.539 \%$ \\
\hline CIA MINERA PODEROSA S A & $4,576.00$ & $0.007 \%$ & $99.546 \%$ \\
\hline POLO ALCANTARA OSCAR ELMER & $4,434.21$ & $0.007 \%$ & $99.553 \%$ \\
\hline FUNDACION UNIVERSITARIA IBEROAMERICANA & $4,378.88$ & $0.007 \%$ & $99.560 \%$ \\
\hline DHI PERU S.A.C. & $4,342.30$ & $0.007 \%$ & $99.566 \%$ \\
\hline MERCK PERUANA S A & $4,337.82$ & $0.007 \%$ & $99.573 \%$ \\
\hline EMPRESA DE TURISMO ANDINO S.R.L. & $4,306.31$ & $0.007 \%$ & $99.580 \%$ \\
\hline EMB. ESTADOS UNIDOS-INL-ASUNTOS ANTINARC & $4,299.47$ & $0.007 \%$ & $99.587 \%$ \\
\hline ESCUELA PERUANA DE AVIACION CIVIL S.A. & $4,292.24$ & $0.007 \%$ & $99.593 \%$ \\
\hline CAMBRIDGE UNIVERSITY PRESS (HOLDINGS) LI & $4,271.05$ & $0.007 \%$ & $99.600 \%$ \\
\hline ETEK INTERNATIONAL CORPORATION SUCURSAL & $4,200.00$ & $0.007 \%$ & $99.607 \%$ \\
\hline LOSTAUNAU JAUREGUI JEAN GABRIEL & $4,160.48$ & $0.007 \%$ & $99.613 \%$ \\
\hline MPC COMPANY S.A.C. & $4,078.16$ & $0.006 \%$ & $99.620 \%$ \\
\hline MERCK SHARP \& DOHME PERU S.R.L. & $3,896.00$ & $0.006 \%$ & $99.626 \%$ \\
\hline ELECTRO FERRO CENTRO S.A.C. - EFC SAC & $3,887.46$ & $0.006 \%$ & $99.632 \%$ \\
\hline GUTIERREZ AGUILAR GINGER PATRICIA & $3,869.50$ & $0.006 \%$ & $99.638 \%$ \\
\hline AEROPUERTOS DEL PERU S.A. & $3,807.75$ & $0.006 \%$ & $99.644 \%$ \\
\hline STUDIO A S.A.C & $3,743.29$ & $0.006 \%$ & $99.650 \%$ \\
\hline CAUDA S.A.C & $3,640.61$ & $0.006 \%$ & $99.655 \%$ \\
\hline EDITORA ESCOLANI E.I.R.L. & $3,575.14$ & $0.006 \%$ & $99.661 \%$ \\
\hline ORGANIZACION PANAMERICANA DE LA SALUD & $3,544.30$ & $0.006 \%$ & $99.666 \%$ \\
\hline METALURGICA PERUANA S A & $3,534.01$ & $0.006 \%$ & $99.672 \%$ \\
\hline CORONEL ROJAS LEYDI ELIANA & $3,518.99$ & $0.005 \%$ & $99.677 \%$ \\
\hline CORPORACION MUSICAL S.A. & $3,320.37$ & $0.005 \%$ & $99.683 \%$ \\
\hline EMBAJADA DE LA REPUBLICA DE CUBA & $3,315.50$ & $0.005 \%$ & $99.688 \%$ \\
\hline TETRA PAK S.A. & $3,314.99$ & $0.005 \%$ & $99.693 \%$ \\
\hline SAGA FALABELLA S A & $3,272.34$ & $0.005 \%$ & $99.698 \%$ \\
\hline EXTERRAN PERU SOCIEDAD COMERCIAL DE RESP & $3,239.47$ & $0.005 \%$ & $99.703 \%$ \\
\hline CHOLITA EDICIONES E.I.R.L. & $3,230.75$ & $0.005 \%$ & $99.708 \%$ \\
\hline PETREX SA & $3,201.79$ & $0.005 \%$ & $99.713 \%$ \\
\hline BEBE \& MAS S.A.C. & $3,174.52$ & $0.005 \%$ & $99.718 \%$ \\
\hline IBM DEL PERU S A C & $3,062.02$ & $0.005 \%$ & $99.723 \%$ \\
\hline WHIRLPOOL PERU S.R.L. & $3,051.25$ & $0.005 \%$ & $99.728 \%$ \\
\hline MAMIS PAN E.I.R.L. & $3,050.83$ & $0.005 \%$ & $99.732 \%$ \\
\hline INDUSTRIA GRAFICA CIMAGRAF S.A.C. & $2,982.52$ & $0.005 \%$ & $99.737 \%$ \\
\hline EDITORIAL C S.A.C. & $2,932.17$ & $0.005 \%$ & $99.742 \%$ \\
\hline SERVICIOS INDUSTRIALES DE LA MARINA S.A. & $2,860.01$ & $0.004 \%$ & $99.746 \%$ \\
\hline MODULAR MINING SYSTEMS SOCIEDAD COMERCIA & $2,823.88$ & $0.004 \%$ & $99.751 \%$ \\
\hline OCEAN MASTER PERU SOCIEDAD ANONIMA CERRA & $2,795.57$ & $0.004 \%$ & $99.755 \%$ \\
\hline CONCRETOS SUPERMIX SOCIEDAD ANONIMA - CO & $2,759.93$ & $0.004 \%$ & $99.759 \%$ \\
\hline GAS NATURAL FENOSA PERU S.A. & $2,668.20$ & $0.004 \%$ & $99.763 \%$ \\
\hline RESCUE S.A.C. & $2,574.00$ & $0.004 \%$ & $99.767 \%$ \\
\hline ASOCIACION EDUCATIVA CASUARINAS & $2,538.00$ & $0.004 \%$ & $99.771 \%$ \\
\hline MINISTERIO DE CULTURA & $2,535.47$ & $0.004 \%$ & $99.775 \%$ \\
\hline HY CITE PERU S.R.L. & $2,498.51$ & $0.004 \%$ & $99.779 \%$ \\
\hline MAGIC BUSINESS S.A.C & $2,487.85$ & $0.004 \%$ & $99.783 \%$ \\
\hline OSCANOA ORDOĐEZ LUIS ALBERTO & $2,420.13$ & $0.004 \%$ & $99.787 \%$ \\
\hline
\end{tabular}

Fuente: SUNAT (Elaboración propia) 


\begin{tabular}{|c|c|c|c|}
\hline ROCA S.A.C. & $2,358.71$ & $0.004 \%$ & $99.791 \%$ \\
\hline CENTRO EDUCATIVO PARTICULAR SANTA URSULA & $2,335.30$ & $0.004 \%$ & $99.794 \%$ \\
\hline ASOC. CULTURAL EDUC. CRISTIANO PIONERO & $2,296.80$ & $0.004 \%$ & $99.798 \%$ \\
\hline CONSORCIO IMPERIO PERU SOCIEDAD ANONIMA & $2,249.10$ & $0.004 \%$ & $99.801 \%$ \\
\hline INDECOPI & $2,235.00$ & $0.003 \%$ & $99.805 \%$ \\
\hline ASOCIACIËN CIVIL CENTRO CULTURALE ITALIA & $2,229.43$ & $0.003 \%$ & $99.808 \%$ \\
\hline SIFUENTES CHOTA DIANA CAROLINA & $2,222.00$ & $0.003 \%$ & $99.812 \%$ \\
\hline ASOCIACION CIVIL RADIO INTEGRIDAD LIMA & $2,220.00$ & $0.003 \%$ & $99.815 \%$ \\
\hline IT ERA PERU SAC & $2,216.60$ & $0.003 \%$ & $99.819 \%$ \\
\hline FLORES GALLARDO DE UGAZ YVONN MERLE & $2,216.04$ & $0.003 \%$ & $99.822 \%$ \\
\hline PETROLEOS DEL PERU PETROPERU SA & $2,205.00$ & $0.003 \%$ & $99.826 \%$ \\
\hline SAAVEDRA GARCIA ZABALETA ARNALDO & $2,158.98$ & $0.003 \%$ & $99.829 \%$ \\
\hline DISPOLAB FARMACEUTICA PERU S.A. & $2,070.00$ & $0.003 \%$ & $99.832 \%$ \\
\hline JCDECAUX AEROPUERTO DE LIMA S.A.C. & $2,066.15$ & $0.003 \%$ & $99.836 \%$ \\
\hline PERFUMERIAS UNIDAS S.A. & $2,038.15$ & $0.003 \%$ & $99.839 \%$ \\
\hline MINISTERIO DE JUSTICIA Y DERECHOS HUMANO & $2,010.00$ & $0.003 \%$ & $99.842 \%$ \\
\hline YURA S.A. & $1,998.56$ & $0.003 \%$ & $99.845 \%$ \\
\hline SAVIA EDITORIAL S.R.L. & $1,990.00$ & $0.003 \%$ & $99.848 \%$ \\
\hline INVERSIONES REEH S.A.C. & $1,988.98$ & $0.003 \%$ & $99.851 \%$ \\
\hline PRICEWATERHOUSECOOPERS S.CIVIL DE R.L. & $1,987.22$ & $0.003 \%$ & $99.854 \%$ \\
\hline MC AUTOS DEL PERU S.A. & $1,933.68$ & $0.003 \%$ & $99.857 \%$ \\
\hline SAXON SERVICES DEL PERU S.A. & $1,922.25$ & $0.003 \%$ & $99.860 \%$ \\
\hline MOTORED SOCIEDAD ANONIMA - MOTORED S.A. & $1,920.14$ & $0.003 \%$ & $99.863 \%$ \\
\hline INSTITUTO LA FAMILIA Y EL DINERO & $1,863.00$ & $0.003 \%$ & $99.866 \%$ \\
\hline MON VERTICAL S.A.C. & $1,810.99$ & $0.003 \%$ & $99.869 \%$ \\
\hline NATIONAL OILWELL VARCO PERU S.R.L. & $1,636.63$ & $0.003 \%$ & $99.872 \%$ \\
\hline EDITORIAL CONSTELACIONES S.A.C. & $1,630.32$ & $0.003 \%$ & $99.874 \%$ \\
\hline DECORLUX S.A.C. & $1,618.49$ & $0.003 \%$ & $99.877 \%$ \\
\hline MINISTERIO CRISTIANO A CADA HOGAR PERU-E & $1,533.40$ & $0.002 \%$ & $99.879 \%$ \\
\hline MISION CRISTIANA CAMINO DE VIDA & $1,517.36$ & $0.002 \%$ & $99.881 \%$ \\
\hline MEDINET S.A.C. & $1,510.00$ & $0.002 \%$ & $99.884 \%$ \\
\hline IPESA S.A.C. & $1,505.66$ & $0.002 \%$ & $99.886 \%$ \\
\hline GLAXOSMITHKLINE PERU S.A. & $1,502.80$ & $0.002 \%$ & $99.889 \%$ \\
\hline ATLAS COPCO PERUANA S A & $1,470.00$ & $0.002 \%$ & $99.891 \%$ \\
\hline COMERCIAL ISABEL SOCIEDAD ANONIMA CERRAD & $1,440.00$ & $0.002 \%$ & $99.893 \%$ \\
\hline TELLO VALVERDE LILIANA & $1,436.00$ & $0.002 \%$ & $99.895 \%$ \\
\hline SIEMENS SAC & $1,431.70$ & $0.002 \%$ & $99.898 \%$ \\
\hline INTERVET S A & $1,416.10$ & $0.002 \%$ & $99.900 \%$ \\
\hline OSTER DEL PERU S.A.C. & $1,370.00$ & $0.002 \%$ & $99.902 \%$ \\
\hline NATURE'S SUNSHINE PRODUCTS DEL PERU S.A & $1,363.90$ & $0.002 \%$ & $99.904 \%$ \\
\hline UNIVERSIDAD DE PIURA & $1,300.00$ & $0.002 \%$ & $99.906 \%$ \\
\hline VOLVO PERU SA & $1,293.48$ & $0.002 \%$ & $99.908 \%$ \\
\hline TEXTIL EL AMAZONAS S.A. & $1,279.59$ & $0.002 \%$ & $99.910 \%$ \\
\hline ASOCIACION TECSUP N $\| 2$ & $1,266.32$ & $0.002 \%$ & $99.912 \%$ \\
\hline IMPORT EXPORT NIELS SOCIEDAD ANONIMA CER & $1,221.94$ & $0.002 \%$ & $99.914 \%$ \\
\hline DIVEIMPORT S.A. & $1,221.77$ & $0.002 \%$ & $99.916 \%$ \\
\hline SANDERSON S.A. (PERU) & $1,200.00$ & $0.002 \%$ & $99.918 \%$ \\
\hline JASREKAPA S.R.L. & $1,132.53$ & $0.002 \%$ & $99.920 \%$ \\
\hline CIENTIFICA ANDINA S.A.C. & $1,109.76$ & $0.002 \%$ & $99.921 \%$ \\
\hline MAQUINARIAS S.A. & $1,089.03$ & $0.002 \%$ & $99.923 \%$ \\
\hline COVIDIEN PERU S.A. & $1,075.46$ & $0.002 \%$ & $99.925 \%$ \\
\hline IMEX TRADE PERU SOCIEDAD ANONIMA C & $1,045.77$ & $0.002 \%$ & $99.926 \%$ \\
\hline TECNOLOGIA INDUSTRIAL Y NACIONAL S.A. & 996.72 & $0.002 \%$ & $99.928 \%$ \\
\hline UNIVERSIDAD CATOLICA DE SANTA MARIA & 986.00 & $0.002 \%$ & $99.929 \%$ \\
\hline
\end{tabular}

Fuente: SUNAT (Elaboración propia) 


\begin{tabular}{|c|c|c|c|}
\hline ELECTRO MEDICAL EQUIPEMENT S.A.C. & 981.23 & $0.002 \%$ & $99.931 \%$ \\
\hline DIOCESIS DE LURIN & 961.54 & $0.002 \%$ & $99.932 \%$ \\
\hline PRELATURA DE SICUANI & 939.85 & $0.001 \%$ & $99.934 \%$ \\
\hline MEJIA SANDOVAL ANDREA LILIANA & 890.00 & $0.001 \%$ & $99.935 \%$ \\
\hline TERREMARK PERU S.A.C & 878.00 & $0.001 \%$ & $99.937 \%$ \\
\hline H.W.KESSEL S.A.C. & 872.50 & $0.001 \%$ & $99.938 \%$ \\
\hline IGLESIA ALIANZA CRISTIANA Y MISIONERA DE & 800.00 & $0.001 \%$ & $99.939 \%$ \\
\hline CRUSARDI S.A.C. & 767.37 & $0.001 \%$ & $99.940 \%$ \\
\hline C\&P INDUSTRIAL AND MINING SUPPLIES E.I.R & 752.01 & $0.001 \%$ & $99.942 \%$ \\
\hline COMPAD=A DE PRODUCTOS MECANICOS S.A.C & 750.00 & $0.001 \%$ & $99.943 \%$ \\
\hline PERU EXPLORING S.A.C. & 739.46 & $0.001 \%$ & $99.944 \%$ \\
\hline UB HAPIQAY S.A.C. & 736.57 & $0.001 \%$ & $99.945 \%$ \\
\hline EDUTEC LABIMPORT SOCIEDAD ANONIMA CERRAD & 720.63 & $0.001 \%$ & $99.946 \%$ \\
\hline UNIVERSIDAD CATOLICA SAN PABLO & 700.00 & $0.001 \%$ & $99.947 \%$ \\
\hline ZURITA VERA MARLIS MABEL & 700.00 & $0.001 \%$ & $99.948 \%$ \\
\hline A \& A REPRESENTACIONES Y SERVICIOS S.R.L & 673.20 & $0.001 \%$ & $99.949 \%$ \\
\hline SANDI TELLO RICARDO JOEL & 650.00 & $0.001 \%$ & $99.951 \%$ \\
\hline COLUMBIA HELICOPTERS PERU S.A.C. & 649.19 & $0.001 \%$ & $99.952 \%$ \\
\hline PERU LNG S.R.L. & 641.74 & $0.001 \%$ & $99.953 \%$ \\
\hline MARTOS JUGO CECILIA MARINA & 632.76 & $0.001 \%$ & $99.954 \%$ \\
\hline UBILLUZ RAMOS JUAN JOSE & 607.52 & $0.001 \%$ & $99.954 \%$ \\
\hline TOPSA RETAIL S.A.C. & 595.52 & $0.001 \%$ & $99.955 \%$ \\
\hline OUALI ALAOUI MOULAY MAMOUN & 586.43 & $0.001 \%$ & $99.956 \%$ \\
\hline M.A.D. IMPORTS S.A.C. & 579.60 & $0.001 \%$ & $99.957 \%$ \\
\hline PLAGIO S.A.C. & 564.17 & $0.001 \%$ & $99.958 \%$ \\
\hline BERTLING LOGISTICS (PERU) S.A.C. & 556.04 & $0.001 \%$ & $99.959 \%$ \\
\hline RIMAC STF S.A. & 552.45 & $0.001 \%$ & $99.960 \%$ \\
\hline UNIVERSIDAD RICARDO PALMA & 540.17 & $0.001 \%$ & $99.961 \%$ \\
\hline ASOCIACION PERU YANTALO FOUNDATION & 540.00 & $0.001 \%$ & $99.962 \%$ \\
\hline CORPORACION PETROLERA S.A.C. & 511.00 & $0.001 \%$ & $99.962 \%$ \\
\hline TECNIFLOW S.A.C. & 503.85 & $0.001 \%$ & $99.963 \%$ \\
\hline INDUSTRIA TEXTIL PIURA S.A. & 479.30 & $0.001 \%$ & $99.964 \%$ \\
\hline DACHSER PERU S.A.C. & 476.29 & $0.001 \%$ & $99.965 \%$ \\
\hline MAGUSA LOGISTICS E.I.R.L & 467.00 & $0.001 \%$ & $99.965 \%$ \\
\hline DRAEGER PERU S.A.C. & 466.16 & $0.001 \%$ & $99.966 \%$ \\
\hline SPIRAX SARCO PERU S.A.C. & 463.58 & $0.001 \%$ & $99.967 \%$ \\
\hline ASOCIACION PERUANA DE INGENIEROS DE CORR & 450.30 & $0.001 \%$ & $99.967 \%$ \\
\hline VIZCARRA ALOSILLA ELIAS FABRIZIO & 448.00 & $0.001 \%$ & $99.968 \%$ \\
\hline PAPELERA DE LOS ANDES S.A. & 411.15 & $0.001 \%$ & $99.969 \%$ \\
\hline HELICOPTER TRANSPORT SERVICES DEL PERU S & 410.00 & $0.001 \%$ & $99.969 \%$ \\
\hline DISTRIBUIDORES Y CONSULTORES TECNICOS E. & 407.42 & $0.001 \%$ & $99.970 \%$ \\
\hline GESTORA EMPRESARIAL SOCIEDAD ANONIMA CER & 378.76 & $0.001 \%$ & $99.971 \%$ \\
\hline TRUPAL S.A. & 376.37 & $0.001 \%$ & $99.971 \%$ \\
\hline RHONA PERU S.A.C. & 373.97 & $0.001 \%$ & $99.972 \%$ \\
\hline LIBAR PERU E.I.R.L. & 354.61 & $0.001 \%$ & $99.972 \%$ \\
\hline UNIMAQ S.A. & 354.03 & $0.001 \%$ & $99.973 \%$ \\
\hline REBECCA SHOP S.A.C. & 317.12 & $0.000 \%$ & $99.973 \%$ \\
\hline TDP CORP S.A. & 311.40 & $0.000 \%$ & $99.974 \%$ \\
\hline HARTMETALL SOCIEDAD ANONIMA CERRADA - HA & 306.28 & $0.000 \%$ & $99.974 \%$ \\
\hline THE LIVING OCEANS & 302.66 & $0.000 \%$ & $99.975 \%$ \\
\hline JALIN IMPORT \& EXPORT S.A.C. & 302.25 & $0.000 \%$ & $99.975 \%$ \\
\hline HELICOPTEROS DEL SUR S.A. & 299.00 & $0.000 \%$ & $99.976 \%$ \\
\hline KOMATSU-MITSUI MAQUINARIAS PERU S.A. & 298.24 & $0.000 \%$ & $99.976 \%$ \\
\hline DIAZ AGUILAR ALBERTO GONZALO & 280.00 & $0.000 \%$ & $99.977 \%$ \\
\hline
\end{tabular}

Fuente: SUNAT (Elaboración propia) 


\begin{tabular}{|c|c|c|c|}
\hline SILMED S.A.C. & 280.00 & $0.000 \%$ & $99.977 \%$ \\
\hline ENSYS S.A.C. & 278.56 & $0.000 \%$ & $99.978 \%$ \\
\hline AVIBIOL S.A.C. & 269.94 & $0.000 \%$ & $99.978 \%$ \\
\hline GRUPO SAINCA S.A.C. & 261.00 & $0.000 \%$ & $99.978 \%$ \\
\hline INARM E.I.R.L & 250.00 & $0.000 \%$ & $99.979 \%$ \\
\hline RAMIREZ RIVERA VERONICA JEANETTE & 248.00 & $0.000 \%$ & $99.979 \%$ \\
\hline DISTRIBUIDORA TECNICA Y REPRESENTACIONES & 247.25 & $0.000 \%$ & $99.980 \%$ \\
\hline TRICIA STORE S.A.C. & 246.84 & $0.000 \%$ & $99.980 \%$ \\
\hline PERU KOKUSAI SOCIEDAD ANONIMA CERRADA & 246.75 & $0.000 \%$ & $99.980 \%$ \\
\hline GRUPO DELTRON S.A. & 242.99 & $0.000 \%$ & $99.981 \%$ \\
\hline REFINERIA LA PAMPILLA S.A.A & 233.47 & $0.000 \%$ & $99.981 \%$ \\
\hline ALITECNO S.A.C. & 217.60 & $0.000 \%$ & $99.981 \%$ \\
\hline CODIMAX SERVICIOS GENERALES SOCIEDAD ANO & 214.02 & $0.000 \%$ & $99.982 \%$ \\
\hline COOPERATIVA DE SERVICIOS EDUC. LA UNION & 210.24 & $0.000 \%$ & $99.982 \%$ \\
\hline OSSO S.A.C. & 208.40 & $0.000 \%$ & $99.982 \%$ \\
\hline PANDUIT PERU S.A.C. & 207.15 & $0.000 \%$ & $99.983 \%$ \\
\hline EATHISA PERU S.A. & 207.12 & $0.000 \%$ & $99.983 \%$ \\
\hline LG ELECTRONICS PERU S.A. & 203.00 & $0.000 \%$ & $99.983 \%$ \\
\hline CLASSICA !ES MEJOR! S.R.L. & 201.50 & $0.000 \%$ & $99.984 \%$ \\
\hline CONSORCIO MINERO HORIZONTE S.A. & 200.10 & $0.000 \%$ & $99.984 \%$ \\
\hline AUTO PERIQUITO SRL & 200.00 & $0.000 \%$ & $99.984 \%$ \\
\hline COLEGIO NUESTRA SENORA DEL PILAR & 198.55 & $0.000 \%$ & $99.985 \%$ \\
\hline BLOOMBERG L.P. (SUCURSAL PERU) & 196.50 & $0.000 \%$ & $99.985 \%$ \\
\hline TRUJILLO ESPINOZA FELISA & 188.00 & $0.000 \%$ & $99.985 \%$ \\
\hline OPTIMAL TECH S.A.C. & 182.82 & $0.000 \%$ & $99.986 \%$ \\
\hline TEJIDOS SAN JACINTO S.A. & 182.37 & $0.000 \%$ & $99.986 \%$ \\
\hline FESTO S.R.L. & 177.33 & $0.000 \%$ & $99.986 \%$ \\
\hline DISTRIBUIDORA CUMMINS PERU S.A.C & 172.03 & $0.000 \%$ & $99.986 \%$ \\
\hline MM AUTOMATION \& POWER SYSTEMS SOLUTIONS & 171.78 & $0.000 \%$ & $99.987 \%$ \\
\hline PRIME TRADERS S.A.C. & 164.34 & $0.000 \%$ & $99.987 \%$ \\
\hline PASTIFICIO CLASSICO SOCIEDAD ANONIMA CER & 157.05 & $0.000 \%$ & $99.987 \%$ \\
\hline OUTOTEC ( PERU ) S.A.C. & 155.44 & $0.000 \%$ & $99.987 \%$ \\
\hline IMPORT EXPORT OPTICAL AB \& CA S.A.C. & 150.06 & $0.000 \%$ & $99.988 \%$ \\
\hline ENERGOTEC SAC & 143.53 & $0.000 \%$ & $99.988 \%$ \\
\hline AGROINDUSTRIAS DEL PACIFICO S.A. & 141.99 & $0.000 \%$ & $99.988 \%$ \\
\hline OSTOLAZA DE FITZGERALD LUZ AURORA & 140.00 & $0.000 \%$ & $99.988 \%$ \\
\hline MUSICAL TRADING S.A. & 135.00 & $0.000 \%$ & $99.989 \%$ \\
\hline GRUPO BARE S.A.C. & 133.98 & $0.000 \%$ & $99.989 \%$ \\
\hline REPRESENTACIONES YAGO S.A.C. & 130.09 & $0.000 \%$ & $99.989 \%$ \\
\hline RM \& L LOGISTICS SAC & 130.00 & $0.000 \%$ & $99.989 \%$ \\
\hline SERPAC AGENCIAS S.A.C. & 130.00 & $0.000 \%$ & $99.989 \%$ \\
\hline MARCO PERUANA S A & 128.87 & $0.000 \%$ & $99.990 \%$ \\
\hline TRITON TRADING SOCIEDAD ANONIMA & 127.87 & $0.000 \%$ & $99.990 \%$ \\
\hline COMITE DE OPERACION ECONOMICA DEL SIST E & 126.81 & $0.000 \%$ & $99.990 \%$ \\
\hline CIMEC INGENIEROS S A & 123.64 & $0.000 \%$ & $99.990 \%$ \\
\hline WILHELMI MONGE SRL & 122.22 & $0.000 \%$ & $99.990 \%$ \\
\hline ABB S.A. & 116.63 & $0.000 \%$ & $99.991 \%$ \\
\hline HONDA SELVA DEL PERU S.A. & 115.45 & $0.000 \%$ & $99.991 \%$ \\
\hline AUDICION SOCIEDAD ANONIMA CERRADA & 114.80 & $0.000 \%$ & $99.991 \%$ \\
\hline PANDURO ASOCIACION DE EXPORTACION S.A. & 111.98 & $0.000 \%$ & $99.991 \%$ \\
\hline AUTOMOTORES GILDEMEISTER-PERU S.A. & 110.27 & $0.000 \%$ & $99.991 \%$ \\
\hline INSERCOMGAS S.A.C. & 110.00 & $0.000 \%$ & $99.991 \%$ \\
\hline EMC DEL PERU S A & 109.00 & $0.000 \%$ & $99.992 \%$ \\
\hline AQUASPORT S.A.C. & 107.82 & $0.000 \%$ & $99.992 \%$ \\
\hline
\end{tabular}

Fuente: SUNAT (Elaboración propia) 


\begin{tabular}{|c|c|c|c|}
\hline BENITES DAVILA LIZARDO ARTURO & 106.33 & $0.000 \%$ & $99.992 \%$ \\
\hline 11 Y 6 ENTRETENIMIENTO SOCIEDAD ANONIMA & 105.61 & $0.000 \%$ & $99.992 \%$ \\
\hline IBEROTEX SOCIEDAD ANONIMA CERRADA & 101.06 & $0.000 \%$ & $99.992 \%$ \\
\hline TALMA SERVICIOS AEROPORTUARIOS S.A & 100.93 & $0.000 \%$ & $99.992 \%$ \\
\hline CERVECERIA SAN JUAN S.A. & 100.70 & $0.000 \%$ & $99.993 \%$ \\
\hline JINAN BUSINESS E.I.R.L. & 100.17 & $0.000 \%$ & $99.993 \%$ \\
\hline CENTRO AUDIOLOGICO EIRL & 98.41 & $0.000 \%$ & $99.993 \%$ \\
\hline SHIN HWA E.I.R.L. & 97.46 & $0.000 \%$ & $99.993 \%$ \\
\hline BIOTECNIA DAYMSA DE PERU S.A.C. & 94.04 & $0.000 \%$ & $99.993 \%$ \\
\hline ECOCOPTER PERU S.A. & 92.00 & $0.000 \%$ & $99.993 \%$ \\
\hline HEWLETT - PACKARD PERU S.R.L. & 90.27 & $0.000 \%$ & $99.993 \%$ \\
\hline DFJ INGENIERIA Y SUMINISTROS S.A.C. & 86.79 & $0.000 \%$ & $99.994 \%$ \\
\hline TECNOLOGIA AUDITIVA AMERICANA S A & 86.61 & $0.000 \%$ & $99.994 \%$ \\
\hline CKI INTERNACIONAL S.A.C. & 86.50 & $0.000 \%$ & $99.994 \%$ \\
\hline UNIËN DE CERVECER=AS PERUANAS BACKUS Y J & 86.09 & $0.000 \%$ & $99.994 \%$ \\
\hline IMPORTACIONES Y SERVICIOS GERMANIA S.A. & 82.62 & $0.000 \%$ & $99.994 \%$ \\
\hline CASA WELSCH SA & 80.96 & $0.000 \%$ & $99.994 \%$ \\
\hline WURTH PERU S.A.C. & 80.73 & $0.000 \%$ & $99.994 \%$ \\
\hline DSICA S.A.C. & 79.82 & $0.000 \%$ & $99.994 \%$ \\
\hline STICHTING DE WAAL FOUNDATION & 76.28 & $0.000 \%$ & $99.995 \%$ \\
\hline PLASTICOS BARRERA PERU S.A.C. & 75.46 & $0.000 \%$ & $99.995 \%$ \\
\hline QUIMICA SUIZA S A & 74.05 & $0.000 \%$ & $99.995 \%$ \\
\hline PERI - PERUANA SAC & 72.28 & $0.000 \%$ & $99.995 \%$ \\
\hline FERRIER S.A. & 70.43 & $0.000 \%$ & $99.995 \%$ \\
\hline REPRESENTACIONES DIF S.A.C. - REDIF S.A. & 70.20 & $0.000 \%$ & $99.995 \%$ \\
\hline UNIVERSIDAD PRIVADA DEL NORTE SAC & 69.97 & $0.000 \%$ & $99.995 \%$ \\
\hline AUSTRAL PERU S.A. & 67.85 & $0.000 \%$ & $99.995 \%$ \\
\hline COSMOS AGENCIA MARITIMA SAC & 67.31 & $0.000 \%$ & $99.995 \%$ \\
\hline CORPORACION CIENTIFICA S.R.L. & 66.39 & $0.000 \%$ & $99.996 \%$ \\
\hline SKS PERU SAC & 64.70 & $0.000 \%$ & $99.996 \%$ \\
\hline COMPONENTES INDUSTRIALES DEL PERU S.A.C. & 64.14 & $0.000 \%$ & $99.996 \%$ \\
\hline JGK TRADING E.I.R.L. & 63.53 & $0.000 \%$ & $99.996 \%$ \\
\hline LINEA PLASTICA PERU S.A. & 62.36 & $0.000 \%$ & $99.996 \%$ \\
\hline IMPO STORES S.A.C. & 61.73 & $0.000 \%$ & $99.996 \%$ \\
\hline MIDSUTECH S.A.C. & 60.45 & $0.000 \%$ & $99.996 \%$ \\
\hline DISTRIBUIDORA CONTINENTAL 6 S A & 60.00 & $0.000 \%$ & $99.996 \%$ \\
\hline PRADO DIAZ MAIRA LORENA & 59.49 & $0.000 \%$ & $99.996 \%$ \\
\hline KORMOTOR S.A.C. & 56.68 & $0.000 \%$ & $99.996 \%$ \\
\hline PERUVIAN ART \& HOBBY SUPPLIERS S.A.C. & 53.46 & $0.000 \%$ & $99.997 \%$ \\
\hline COMPASS GROUP S.A.F.I. S.A. & 51.50 & $0.000 \%$ & $99.997 \%$ \\
\hline XIMENG S.A.C. & 51.13 & $0.000 \%$ & $99.997 \%$ \\
\hline GRAFIMUNDO ETIQUETAS PAPELES Y AUTOADHES & 51.02 & $0.000 \%$ & $99.997 \%$ \\
\hline PIERINELLI SOCIEDAD ANONIMA CERRADA & 50.08 & $0.000 \%$ & $99.997 \%$ \\
\hline INDURA PERU S.A. & 50.07 & $0.000 \%$ & $99.997 \%$ \\
\hline RUBENS E.I.R.L. & 50.04 & $0.000 \%$ & $99.997 \%$ \\
\hline DROKASA LICORES S.A. & 45.06 & $0.000 \%$ & $99.997 \%$ \\
\hline MOVISUN E.I.R.L. & 45.00 & $0.000 \%$ & $99.997 \%$ \\
\hline INVERSIONES VETERINARIAS S.A. & 44.03 & $0.000 \%$ & $99.997 \%$ \\
\hline BRIMALI INDUSTRIAL S.A.C. & 44.00 & $0.000 \%$ & $99.997 \%$ \\
\hline COMERCIAL RAMOS LIMA S.A. & 42.50 & $0.000 \%$ & $99.997 \%$ \\
\hline CAMARA DE COMERCIO E INDUST PERU ALEMANA & 42.27 & $0.000 \%$ & $99.997 \%$ \\
\hline GRUPO TECNOLOGIES S.A. & 42.02 & $0.000 \%$ & $99.997 \%$ \\
\hline INVERSION Y NEGOCIOS A.MONSALVE S.A.C. - & 40.04 & $0.000 \%$ & $99.998 \%$ \\
\hline MINISTERIO INTERNACIONAL YIREH & 40.00 & $0.000 \%$ & $99.998 \%$ \\
\hline
\end{tabular}

Fuente: SUNAT (Elaboración propia) 


\begin{tabular}{|c|c|c|c|}
\hline VENTYMONT SAC & 40.00 & $0.000 \%$ & $99.998 \%$ \\
\hline BLUNT DISTRIBUTION S.A.C. & 39.00 & $0.000 \%$ & $99.998 \%$ \\
\hline SCHARFF LOGISTICA INTEGRADA S.A. & 38.13 & $0.000 \%$ & $99.998 \%$ \\
\hline LAN PERU S.A. & 35.93 & $0.000 \%$ & $99.998 \%$ \\
\hline MACROFARMA SOCIEDAD ANONIMA CERRADA & 35.40 & $0.000 \%$ & $99.998 \%$ \\
\hline EUROPEAN TRADING DEL PER $\Gamma$ S.A.C. & 34.34 & $0.000 \%$ & $99.998 \%$ \\
\hline CYMED MEDICAL SAC & 34.00 & $0.000 \%$ & $99.998 \%$ \\
\hline MARTIN ENGINEERING PERU S.R.L & 33.31 & $0.000 \%$ & $99.998 \%$ \\
\hline UNIVERSIDAD NACIONAL DE SAN AGUSTIN & 32.22 & $0.000 \%$ & $99.998 \%$ \\
\hline METALPREN S A & 32.18 & $0.000 \%$ & $99.998 \%$ \\
\hline HONDA DEL PERU S.A & 31.36 & $0.000 \%$ & $99.998 \%$ \\
\hline GRAINGER PERU S.R.L. & 31.35 & $0.000 \%$ & $99.998 \%$ \\
\hline LA LLAVE S.A. & 30.60 & $0.000 \%$ & $99.998 \%$ \\
\hline CONTRERAS NAVARRETE HAHNS CRISTOPHER & 30.58 & $0.000 \%$ & $99.998 \%$ \\
\hline KE GRUPO S.A.C. & 30.48 & $0.000 \%$ & $99.998 \%$ \\
\hline EESAPERU S.A.C. & 30.24 & $0.000 \%$ & $99.998 \%$ \\
\hline DEUTSCHE PHARMA S.A.C. & 30.00 & $0.000 \%$ & $99.999 \%$ \\
\hline GC IMPORTADORES S.A.C. & 29.21 & $0.000 \%$ & $99.999 \%$ \\
\hline GESTION Y SISTEMAS DE CALIDAD ELECTRICA & 28.47 & $0.000 \%$ & $99.999 \%$ \\
\hline H. STERN PERU SOCIEDAD ANONIMA & 28.06 & $0.000 \%$ & $99.999 \%$ \\
\hline MARKET MUNDI PERU S.A.C. & 25.50 & $0.000 \%$ & $99.999 \%$ \\
\hline EQUIPOS Y MEDICINAS S.A.C. & 25.17 & $0.000 \%$ & $99.999 \%$ \\
\hline PETROVICH STEVEN CHAD & 24.44 & $0.000 \%$ & $99.999 \%$ \\
\hline INCHCAPE MOTORS PERU SA & 24.37 & $0.000 \%$ & $99.999 \%$ \\
\hline CIA ERICSSON S.A. & 23.14 & $0.000 \%$ & $99.999 \%$ \\
\hline PATHROSREP S.A.C. & 23.08 & $0.000 \%$ & $99.999 \%$ \\
\hline GE HEALTHCARE DEL PERU S.A.C. & 22.00 & $0.000 \%$ & $99.999 \%$ \\
\hline LUZ DEL SUR S.A.A. & 21.98 & $0.000 \%$ & $99.999 \%$ \\
\hline IPM INGENIEROS SOLUCIONES INTEGRALES SOC & 21.30 & $0.000 \%$ & $99.999 \%$ \\
\hline ERGOMATIC S.A.C & 20.35 & $0.000 \%$ & $99.999 \%$ \\
\hline IMPORTVET JEHOVA JIREH E.I.R.L. & 20.18 & $0.000 \%$ & $99.999 \%$ \\
\hline MANUFACTURAS ELECTRICAS S A & 20.12 & $0.000 \%$ & $99.999 \%$ \\
\hline FIREMED SOCIEDAD ANONIMA CERRADA & 20.11 & $0.000 \%$ & $99.999 \%$ \\
\hline LA GRANJA VILLA Y SU MUNDO MAGICO S.A. & 20.00 & $0.000 \%$ & $99.999 \%$ \\
\hline METAX INDUSTRIA Y COMERCIO S.A.C. & 20.00 & $0.000 \%$ & $99.999 \%$ \\
\hline MINAS \& LABORATORIOS INTERNACIONAL S.R.L & 19.25 & $0.000 \%$ & $99.999 \%$ \\
\hline CRUBHER S.R.L. & 18.98 & $0.000 \%$ & $99.999 \%$ \\
\hline TOYOTA DEL PERU S A & 18.06 & $0.000 \%$ & $99.999 \%$ \\
\hline CARDIO PERFUSION E.I.R.LTDA & 16.97 & $0.000 \%$ & $99.999 \%$ \\
\hline PERU PIMA SA. & 16.35 & $0.000 \%$ & $99.999 \%$ \\
\hline CHENG JIN DEL PERU S.A.C. & 15.00 & $0.000 \%$ & $99.999 \%$ \\
\hline RELIPER PERU S.A.C. & 13.80 & $0.000 \%$ & $99.999 \%$ \\
\hline PISCOYA SILVA BENJAMIN LUIS & 12.95 & $0.000 \%$ & $99.999 \%$ \\
\hline INTERVOZ DEL PERU S.R.L. & 12.82 & $0.000 \%$ & $99.999 \%$ \\
\hline GALAXY REPRESENTACIONES S R LTDA & 12.50 & $0.000 \%$ & $99.999 \%$ \\
\hline TECNOMED S A & 12.33 & $0.000 \%$ & $99.999 \%$ \\
\hline EMPRESA ALGODONERA S A & 12.32 & $0.000 \%$ & $99.999 \%$ \\
\hline SEGO SEGURIDAD OPTIMA S A & 10.65 & $0.000 \%$ & $99.999 \%$ \\
\hline FILASUR S.A. & 10.40 & $0.000 \%$ & $99.999 \%$ \\
\hline ATB RIVA CALZONI PERU S.A.C. & 10.00 & $0.000 \%$ & $99.999 \%$ \\
\hline G \& S CHOICE S.A.C. & 10.00 & $0.000 \%$ & $100.000 \%$ \\
\hline IFLUTECH S.A.C. & 10.00 & $0.000 \%$ & $100.000 \%$ \\
\hline PREMIUM BRANDS S.A.C & 10.00 & $0.000 \%$ & $100.000 \%$ \\
\hline TALI HAMIDEH BITAR GONZALO ANDRES & 10.00 & $0.000 \%$ & $100.000 \%$ \\
\hline
\end{tabular}

Fuente: SUNAT (Elaboración propia) 


\begin{tabular}{|c|c|c|c|}
\hline TERMOINOX S.A.C. & 10.00 & $0.000 \%$ & $100.000 \%$ \\
\hline GENERAL ELECTRIC INTERNATIONAL PERU & 9.70 & $0.000 \%$ & $100.000 \%$ \\
\hline TEXTIL SAN RAMON S A & 9.25 & $0.000 \%$ & $100.000 \%$ \\
\hline INTCOMEX PERU S.A.C & 9.02 & $0.000 \%$ & $100.000 \%$ \\
\hline VITRALES PERU S.A.C & 8.99 & $0.000 \%$ & $100.000 \%$ \\
\hline REACTIVOS PARA ANALISIS S.A.C. & 8.31 & $0.000 \%$ & $100.000 \%$ \\
\hline ARQUITECTURA TRANSPARENTE S.A. & 8.01 & $0.000 \%$ & $100.000 \%$ \\
\hline ARTEAGA HUAMAN ALAN DENIS & 8.00 & $0.000 \%$ & $100.000 \%$ \\
\hline KGS BUSINESS GROUP S.A.C. & 8.00 & $0.000 \%$ & $100.000 \%$ \\
\hline MOTOREX S A & 8.00 & $0.000 \%$ & $100.000 \%$ \\
\hline SEW EURODRIVE DEL PERU S.A.C. & 7.86 & $0.000 \%$ & $100.000 \%$ \\
\hline ZTE CORPORATION -PERU & 7.80 & $0.000 \%$ & $100.000 \%$ \\
\hline V.I. NEGOCIOS SAC & 7.65 & $0.000 \%$ & $100.000 \%$ \\
\hline JAR INTERNACIONAL TRADING COMPANY S.A.C. & 7.20 & $0.000 \%$ & $100.000 \%$ \\
\hline INVERSIONES INTERAMERICANAS S A & 6.53 & $0.000 \%$ & $100.000 \%$ \\
\hline METREON S.A.C. & 6.35 & $0.000 \%$ & $100.000 \%$ \\
\hline INVERSIONES CYS S.A. & 6.05 & $0.000 \%$ & $100.000 \%$ \\
\hline GAMMA SOLUCIONES S.A.C. & 6.00 & $0.000 \%$ & $100.000 \%$ \\
\hline MAVEGSA DRYWALL S.A.C. & 6.00 & $0.000 \%$ & $100.000 \%$ \\
\hline PERUCHEF.COM S.A.C. & 5.93 & $0.000 \%$ & $100.000 \%$ \\
\hline PEVISO INGENIEROS S.A.C. & 5.68 & $0.000 \%$ & $100.000 \%$ \\
\hline EFCO DEL PERU LTD, SUCURSAL & 5.61 & $0.000 \%$ & $100.000 \%$ \\
\hline GRAFICA BIBLOS SA & 5.60 & $0.000 \%$ & $100.000 \%$ \\
\hline A JAIME ROJAS REPRESENTACIONES GRLES S A & 5.47 & $0.000 \%$ & $100.000 \%$ \\
\hline CREDITEX S.A.A. & 5.35 & $0.000 \%$ & $100.000 \%$ \\
\hline ENTELIN PERU SAC & 5.23 & $0.000 \%$ & $100.000 \%$ \\
\hline MAQUICENTRO PARTES S.A. & 5.20 & $0.000 \%$ & $100.000 \%$ \\
\hline ANDINA DESARROLLO DE COMERCIO SAC & 5.00 & $0.000 \%$ & $100.000 \%$ \\
\hline FARMINDUSTRIA S.A. & 5.00 & $0.000 \%$ & $100.000 \%$ \\
\hline PROTECCION Y SERVICIOS DE MANTENIMIENTO & 5.00 & $0.000 \%$ & $100.000 \%$ \\
\hline SEGELECTRICA S.A.C. & 5.00 & $0.000 \%$ & $100.000 \%$ \\
\hline MOTOS STILOS S.A.C. & 4.60 & $0.000 \%$ & $100.000 \%$ \\
\hline MAQUINARIA NACIONAL S.A. PERU & 4.57 & $0.000 \%$ & $100.000 \%$ \\
\hline COMERCIANTES IMPORTADORES SA EN LIQUIDAC & 4.52 & $0.000 \%$ & $100.000 \%$ \\
\hline DISTRIBUIDORA DE RELOJES Y ACCESORIOS S. & 4.25 & $0.000 \%$ & $100.000 \%$ \\
\hline IDEAS TEXTILES S.A.C. & 4.04 & $0.000 \%$ & $100.000 \%$ \\
\hline COMPUDISKETT S R L & 4.00 & $0.000 \%$ & $100.000 \%$ \\
\hline KE YOU S.A.C. & 4.00 & $0.000 \%$ & $100.000 \%$ \\
\hline PLUSPETROL NORTE S.A. & 3.43 & $0.000 \%$ & $100.000 \%$ \\
\hline PEDRO CAMAIORA S.A. & 3.39 & $0.000 \%$ & $100.000 \%$ \\
\hline IMPULSO INFORMATICO S.A. & 2.80 & $0.000 \%$ & $100.000 \%$ \\
\hline AQUAJET STORE S.A.C. & 2.50 & $0.000 \%$ & $100.000 \%$ \\
\hline PEL PERU S.R.L. & 2.49 & $0.000 \%$ & $100.000 \%$ \\
\hline CIA.DE EXP.Y NEGOCIOS GNRLES.S.A.(COEXA) & 2.43 & $0.000 \%$ & $100.000 \%$ \\
\hline AKROS SEGURIDAD INTEGRAL S.A.C. & 2.24 & $0.000 \%$ & $100.000 \%$ \\
\hline AMERICAN SUPPLY SOCIEDAD COMERCIAL DE RE & 2.07 & $0.000 \%$ & $100.000 \%$ \\
\hline J.C.METALES INDUSTRIALES S.A.C. & 2.00 & $0.000 \%$ & $100.000 \%$ \\
\hline FRENOS Y AUTOPARTES MASTER S.A. & 1.87 & $0.000 \%$ & $100.000 \%$ \\
\hline MULTIVAC CHILE SUCURSAL DEL PERU & 1.80 & $0.000 \%$ & $100.000 \%$ \\
\hline LIMA ART OFFICE E.I.R.L. & 1.75 & $0.000 \%$ & $100.000 \%$ \\
\hline SOKMAQ SOCIEDAD ANONIMA CERRADA & 1.52 & $0.000 \%$ & $100.000 \%$ \\
\hline DAZA COMPANY S.A.C. & 1.50 & $0.000 \%$ & $100.000 \%$ \\
\hline POWER FLOW SYSTEMS S.A.C. & 1.31 & $0.000 \%$ & $100.000 \%$ \\
\hline OLEOHIDRAULICS SERVICES S.A.C. & 1.12 & $0.000 \%$ & $100.000 \%$ \\
\hline
\end{tabular}

Fuente: SUNAT (Elaboración propia) 


\begin{tabular}{|l|l|l|l|} 
SAMSON CONTROLS S.A. & 1.09 & $0.000 \%$ & $100.000 \%$ \\
\hline BANCO FINANCIERO DEL PERU & 1.06 & $0.000 \%$ & $100.000 \%$ \\
\hline IMPORTACIONES Y REPRESENTACIONES ELECTRO & 1.04 & $0.000 \%$ & $100.000 \%$ \\
\hline OPP FILM S.A. & 1.03 & $0.000 \%$ & $100.000 \%$ \\
\hline RICHER COMPANY S.A.C. - RICHER S.A.C. & 1.00 & $0.000 \%$ & $100.000 \%$ \\
\hline TECNOIL S.A.C. & 1.00 & $0.000 \%$ & $100.000 \%$ \\
\hline ASOCIACION VIDA PERU & 0.93 & $0.000 \%$ & $100.000 \%$ \\
\hline BIENES DE HUMBERTO VASQUEZ SA & 0.89 & $0.000 \%$ & $100.000 \%$ \\
\hline PHONIX WORLD S.A.C & 0.78 & $0.000 \%$ & $100.000 \%$ \\
\hline EMPRESA SIDERURGICA DEL PERU S.A.A. & 0.75 & $0.000 \%$ & $100.000 \%$ \\
\hline MACHEN PERU S.A.C. & 0.73 & $0.000 \%$ & $100.000 \%$ \\
\hline INTRIAL S.A.C. & 0.71 & $0.000 \%$ & $100.000 \%$ \\
\hline TOSHIBA GLOBAL COMMERCE SOLUTIONS (PER $\Gamma)$ & 0.39 & $0.000 \%$ & $100.000 \%$ \\
\hline PROSEMEDIC SOCIEDAD ANONIMA CERRADA & 0.20 & $0.000 \%$ & $100.000 \%$ \\
\hline JANTEX S.A.C. & 0.12 & $0.000 \%$ & $100.000 \%$ \\
\hline ALGODONERA PERUANA S.A.C & 0.08 & $0.000 \%$ & $100.000 \%$ \\
\hline SSK INGENIERIA Y CONSTRUCCION S.A.C. & 0.07 & $0.000 \%$ & $100.000 \%$ \\
\hline ARIS INDUSTRIAL S.A. & 0.02 & $0.000 \%$ & $100.000 \%$ \\
\hline
\end{tabular}

Fuente: SUNAT (Elaboración propia) 


\section{Anexo 2. Ideas - Causas - Problemas que afectan la productividad}

\begin{tabular}{|c|c|}
\hline cod & Causas de improductividad en la empresa SBS \\
\hline P01 & Libros dañados físicamente \\
\hline P02 & Pedidos atrasados \\
\hline P03 & Atraso de unidades de transporte \\
\hline P04 & Atraso de importaciones \\
\hline P05 & Libros faltantes en la importación \\
\hline P06 & Despachos con libros faltantes \\
\hline P07 & Anulación de pedidos / adopciones \\
\hline P08 & Deserción de clientes \\
\hline P09 & Sobrecarga de trabajo para almacén \\
\hline P10 & Falta de información de las operaciones a tiempo real \\
\hline P11 & Falta de orden y limpieza \\
\hline $\mathrm{P} 12$ & Falta de un mapeo de ubicaciones y/o anaqueles \\
\hline P13 & El mismo título se encuentran guardado en distintos anaqueles \\
\hline P14 & Falta de ventilación en el centro de labores \\
\hline P15 & Movimientos y transportes innecesarios \\
\hline P16 & Servicios de damas alejado del almacén \\
\hline P17 & Servicios alejados de las oficinas \\
\hline P18 & No se encuentran las herramientas e insumos cuando urgen \\
\hline P19 & Cajas llenas de libros muy pesadas \\
\hline P20 & Herramientas para el transporte de pedidos dentro del CD no son las adecuadas \\
\hline P21 & Piso del CD con desniveles \\
\hline $\mathrm{P} 22$ & Procesos y procedimientos no estandarizados / ni documentados \\
\hline P23 & Falta de conocimiento de procesos y procedimientos \\
\hline P24 & Duplicidad de operaciones \\
\hline P25 & No se trabaja sobre mediciones de resultados y productividad \\
\hline P26 & Presencia de polvo en los libros \\
\hline P27 & Exposición de los libros al aire libre, al sol, humedad, etc. \\
\hline P28 & Inventario obsoleto / no vigente para su uso \\
\hline P29 & Deficiente distribución de pedidos \\
\hline P30 & Inventario dañado por manipulación \\
\hline P31 & Falta establecer y comunicar el método de pronóstico de demanda \\
\hline P32 & Diferencias totales entre lo pronosticado y las ventas efectivas \\
\hline P33 & Falta de control y seguimiento del stock \\
\hline P34 & Stock del sistema no sincerado con lo real \\
\hline P35 & Distribución de las importaciones es tediosa y toma largo tiempo \\
\hline P36 & Falta de trazabilidad hacia el proveedor y hacia el cliente \\
\hline P37 & El sistema no permite integrar la información a tiempo real \\
\hline P38 & La impresión de las NDS no genera valor y registra tiempos excesivos desde su aprobación \\
\hline P39 & El área comercial ingresa en varias oportunidades la misma solicitud \\
\hline
\end{tabular}

Elaboración propia 


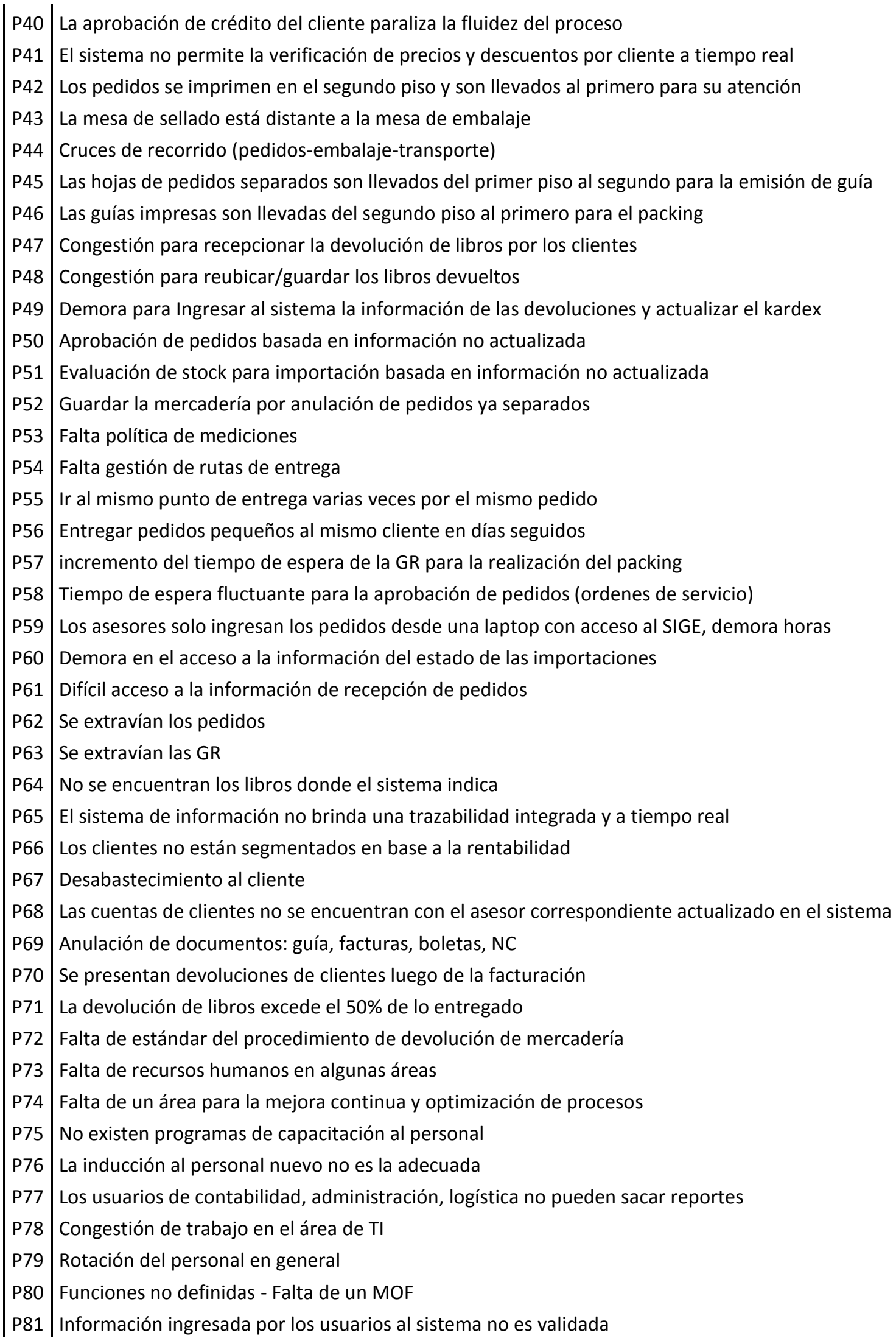


P82 Falta de espacio para recepción de importaciones

P83 El área de inventario de importación está alejada al área de recepción

P84 Mercadería con constante rotación ubicada en anaqueles de difícil acceso

P85 Elevados niveles de stock

Elaboración propia 


\section{Anexo 3. Matriz Relacional: Análisis de las causas de improductividad}

\begin{tabular}{|c|c|c|c|c|c|c|c|c|c|c|c|c|c|c|c|c|c|c|c|c|c|c|c|c|c|c|c|c|c|c|c|c|c|c|c|c|c|c|c|c|c|c|c|c|c|c|c|c|}
\hline \multirow{2}{*}{\begin{tabular}{|l|l|} 
Cod \\
P01 L \\
\end{tabular}} & \multirow{2}{*}{\multicolumn{2}{|c|}{\begin{tabular}{|l|l|}
\multicolumn{1}{|c|}{ Causas de improductividad en la empresa SBS } & P0 \\
Libros dañados fisicamente &
\end{tabular}}} & \multirow{2}{*}{\multicolumn{7}{|c|}{ 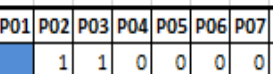 }} & \multirow{2}{*}{\multicolumn{4}{|c|}{ 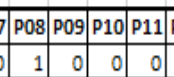 }} & \multirow{2}{*}{\multicolumn{2}{|c|}{\begin{tabular}{|r|r|} 
P12 & P13 \\
0 & 0 \\
\end{tabular}}} & \multirow{2}{*}{\multicolumn{2}{|c|}{\begin{tabular}{r|r|} 
P14 & P15 \\
0 & 1 \\
\end{tabular}}} & \multirow{2}{*}{\multicolumn{2}{|c|}{ 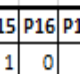 }} & & & & & & & & & & & & & & & & & & & & 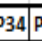 & & 6. & 37 & 38 & 39 & P4 & p4 & 41 & \\
\hline & & & & & & & & & & & & & & & & & & & & 0 & & 이 & 0 & 0 & 0 & 0 & 0 & & 0 & 0 & 0 & 1 & 0 & 0 & 0 & & & & 1 & 0 & 0 & 0 & & & & & & \\
\hline $\mathrm{PO} 2$ & Pedidos atrasados & 0 & & & 0 & 0 & & & & & & 0 & & 0 & 0 & & & & & 0 & 0 & 0 & 0 & & & & & & & 0 & 0 & & 0 & & & & & 0 & 0 & 0 & 0 & 0 & 0 & & & & & \\
\hline 03 & Atraso de unidades de & & & & 0 & & & & & & & & & & & & & & & & 0 & & & & & & & & & 0 & & & 0 & & & & & & 0 & 0 & 0 & 0 & $\underline{0}$ & & & & & \\
\hline $\mathrm{PO4}$ & Atraso de importaci & & 1 & & & 0 & & & & & & & & & & & & & & & & & & & & & & & & & & & & & & & & & & 1 & 0 & & & & & & & \\
\hline POS & Libros fa & & 1 & & 1 & & & & & & & & & & & & & & & & 0 & & & 0 & & & & & & 0 & & & 1 & & & & & 0 & & 0 & 0 & 0 & $\underline{0}$ & & & & 0 & \\
\hline P06 & Despact & & 1 & & 0 & 0 & & & 1 & & & 0 & & 0 & 0 & & & & & & 0 & 0 & & 0 & & & & & & 0 & 0 & & 0 & & & & & 0 & 0 & 0 & 0 & 0 & 0 & 1 & 1 & 0 & 0 & \\
\hline P07 & Anulaci & & 0 & & 0 & & 0 & & & 0 & & & & 0 & 0 & & & & & & 0 & 0 & 0 & 0 & & c & 0 & 0 & & 0 & & & 0 & & & & & 0 & & 0 & 0 & 0 & 0 & & & & 0 & \\
\hline POB & Deserc & 0 & 0 & & 0 & 0 & 0 & & 0 & & 0 & 0 & & 0 & 0 & & & 0 & 0 & 0 & 0 & 0 & 0 & 0 & 0 & & 0 & 0 & 0 & 0 & 0 & 0 & 0 & 0 & & & & 0 & 0 & 0 & 0 & of & 0 & & & & & 0 \\
\hline POS & Sobre & & 1 & & 0 & 0 & & & 1 & 1 & & 0 & & 0 & 0 & 0 & c & 0 & 0 & of & 0 & of & 의 & 0 & 0 & c & 0 & 1 & 0 & 0 & 0 & 0 & 0 & 1 & 0 & & & 0 & 0 & 의 & 0 & 의 & 0 & & & 0 & 0 & $\begin{array}{ll}0 & 0 \\
\end{array}$ \\
\hline P10 & Falta de informaciór & 0 & 1 & & 1 & 0 & & & 1 & & 1 & & 0 & 0 & 0 & 0 & 1 & & 0 & 0 & 0 & 0 & 0 & 0 & 0 & c & 0 & 1 & 1 & 0 & 0 & 0 & 1 & 0 & $\underline{0}$ & 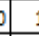 & & 1 & 1 & 1 & 1 & 0 & 0 & 1 & 1 & 1 & 1 & \begin{tabular}{l|l}
0 & 0 \\
\end{tabular} \\
\hline P11 & Falta de orden y limpieza & 1 & 1 & $=$ & 0 & 0 & 1 & 1 & 0 & 0 & 1 & 0 & & 0 & 1 & 0 & 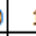 & 1 & 0 & 0 & 1 & 0 & 0 & 0 & 0 & 0 & 0 & 1 & 0 & 1 & 1 & 1 & 0 & 1 & & & & 0 & 0 & 0 & 0 & 0 & 0 & 0 & 0 & 0 & 0 & \begin{tabular}{l|l}
0 & 0 \\
\end{tabular} \\
\hline P12 & Falta de un mapeo de ubica & 0 & 1 & te & 0 & 0 & 1 & 1 & 0 & 0 & 1 & 0 & 1 & & 1 & 0 & 1 & 1 & 0 & 0 & 0 & of & of & 0 & 0 & c & 0 & & of & 의 & 0 & 의 & 0 & 1 & 0 & & & 0 & 0 & 의 & 0 & 0 & 0 & 0 & 0 & 0 & 0 & \begin{tabular}{l|l}
0 & 0 \\
\end{tabular} \\
\hline P13 & El mismo tit & 1 & 1 & 1 & 0 & 0 & 1 & 1 & 0 & 0 & 1 & 0 & 0 & 0 & & 0 & ) & & 0 & 0 & of & 0 & of & 0 & 0 & c & 0 & & 0 & 1 & 1 & 1 & 0 & 1 & 0 & & 0 & 0 & 0 & 0 & 0 & 0 & 0 & 0 & 0 & & 0 & \begin{tabular}{l|l}
0 & 0 \\
\end{tabular} \\
\hline P14 & Falta & 0 & 1 & 0 & 0 & 0 & 0 & & 0 & 0 & 0 & 0 & 0 & 0 & 0 & & 1 & & 0 & 0 & 0 & 0 & 0 & 0 & 0 & c & 0 & & 0 & 1 & 1 & 1 & 0 & 0 & 0 & & & & 0 & 0 & 0 & 0 & 0 & & 0 & & & \begin{tabular}{l|l}
0 & 0 \\
\end{tabular} \\
\hline P15 & Movir & 1 & 1 & 1 & 0 & 0 & 1 & 1 & 0 & 0 & 1 & 0 & 1 & 0 & 0 & 0 & & & 0 & 0 & 1 & 0 & 0 & 0 & 0 & 0 & 0 & & 0 & 0 & 0 & 0 & 0 & 1 & 0 & & & & 0 & 0 & 0 & 0 & 0 & & & & & \\
\hline P16 & Servici & 0 & 0 & 0 & 0 & 0 & 0 & 0 & 0 & 0 & 0 & 0 & 0 & 0 & 0 & 0 & ] & & & 0 & 0 & 0 & 0 & 0 & 0 & & & & 0 & 0 & 0 & 0 & 0 & 0 & & & & & 0 & 0 & 0 & 0 & 0 & & & 0 & & \\
\hline P17 & Servici & 0 & 0 & 0 & 0 & 0 & 0 & 0 & 0 & 0 & 0 & 0 & 1 & 0 & 0 & & & & & & 0 & 0 & 0 & 0 & & & & & & 0 & 0 & & 0 & & & & & & 0 & 0 & 0 & 0 & 0 & & & & & \\
\hline P18 & No se en & 0 & 1 & 1 & 0 & 0 & & & & 0 & 1 & 0 & 0 & 0 & 0 & & & & 0 & 0 & & 0 & 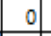 & 0 & & & & & & 0 & 0 & & 0 & & & & & & & 0 & 0 & 0 & & & & & 0 & \\
\hline P19 & Cajas & 1 & 0 & 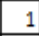 & 0 & 0 & & & & 0 & 0 & 0 & 0 & 0 & 0 & & & & & 0 & 0 & & & 0 & & & & & & 0 & 0 & & 0 & & & & & & 0 & 0 & 0 & 0 & & & & & 0 & \\
\hline P20 & Herramientas para el transp & 1 & 1 & 1 & 0 & 0 & & & 0 & 0 & 1 & 0 & c & 0 & 0 & & ces & 0 & & 0 & 0 & 1 & & 0 & 0 & c & 0 & 1 & & 0 & 0 & & 0 & & & & & 0 & 0 & 0 & 0 & 0 & 0 & 0 & 0 & 0 & 0 & \begin{tabular}{l|l}
0 & 0 \\
\end{tabular} \\
\hline P21 & Piso del CD con de & 0 & 1 & 1 & 0 & 0 & 0 & 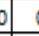 & 0 & 0 & 0 & 0 & 0 & 0 & 0 & & 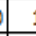 & & 0 & 0 & 0 & 0 & 1 & & 0 & $\mathrm{c}$ & 0 & 0 & & 0 & 0 & & 0 & & & & & 0 & 0 & 0 & 0 & 0 & $\underline{0}$ & 0 & & & 0 & \begin{tabular}{l|l}
0 & 0 \\
\end{tabular} \\
\hline 222 & Procesos y procedir & 0 & 1 & $=$ & 1 & 0 & 0 & 0 & 0 & 0 & 1 & 1 & 0 & 1 & 1 & & & & 0 & 0 & 1 & 1 & 0 & 0 & & 1 & 1 & 1 & 0 & 0 & 0 & 의 & 1 & & & & & 1 & 1 & 1 & 1 & 1 & $\underline{0}$ & & & & 1 & \begin{tabular}{l|l}
0 & 0 \\
\end{tabular} \\
\hline 223 & Falta dec & 0 & 1 & 1 & 1 & 0 & 1 & & & 0 & 1 & 0 & 0 & 의 & 1 & & & & 0 & 의 & 1 & 1 & 의 & 0 & 인 & & & 1 & 의 & 0 & 0 & 의 & 1 & 1 & & & & 1 & 1 & 1 & 1 & 0 & 1 & & 1 & & & $\begin{array}{ll}0 & 0 \\
\end{array}$ \\
\hline 224 & Duplicidad de operaciones & 0 & 1 & 1 & 0 & 0 & 0 & 0 & 0 & 0 & 1 & 0 & 0 & 의 & 0 & 0 & 1 & & 0 & 의 & 의 & 0 & 의 & 0 & 0 & c & 0 & & 의 & 0 & 0 & 의 & 1 & 1 & 0 & & & 0 & 0 & 0 & 0 & 0 & $\underline{0}$ & 0 & 0 & 1 & 1 & $\begin{array}{lll}0 & 0 \\
\end{array}$ \\
\hline P25 & No se trabaja sobre medici & 0 & 1 & 1 & 0 & 0 & 0 & 0 & & 1 & 1 & 0 & 0 & 0 & 0 & 0 & & & 0 & 0 & 0 & 0 & 0 & 0 & 0 & c & & of & & 0 & 0 & 0 & 1 & 0 & & & & & 0 & 의 & 0 & 0 & 1 & 0 & 0 & 0 & 0 & $\begin{array}{ll}0 & 0 \\
\end{array}$ \\
\hline P26 & Presencia de polvo & 1 & 1 & 1 & 0 & 0 & 1 & 1 & 1 & 0 & 1 & 0 & 0 & 의 & 0 & 0 & 1 & & 0 & 0 & 0 & 0 & 0 & 0 & 0 & c & & & 의 & & 0 & 1 & 1 & 1 & 0 & & & & 0 & 0 & 0 & 0 & 0 & 0 & 0 & 0 & 0 & \begin{tabular}{l|l}
0 & 0 \\
\end{tabular} \\
\hline P27 & Exposici & 1 & 1 & 1 & 0 & 0 & & 1 & 0 & 0 & 1 & 0 & 0 & 0 & 0 & 0 & t) & & 0 & of & 0 & 0 & of & 0 & 0 & c & 0 & & of & 1 & & 1 & 0 & 0 & 0 & & & & 0 & 0 & 0 & 0 & 0 & 0 & 0 & 0 & 0 & \begin{tabular}{l|l}
0 & 0 \\
\end{tabular} \\
\hline P28 & Inventario obsoleto /r & 0 & 1 & 1 & 0 & 0 & & 1 & 0 & 0 & 1 & 1 & 0 & 0 & 0 & 0 & & & 0 & 0 & 0 & 0 & 0 & 0 & 0 & c & 0 & & 0 & 0 & 0 & & 1 & 0 & 0 & & & & 1 & 0 & 0 & 0 & 0 & & 0 & 0 & & $\begin{array}{lll}0 & 0 \\
\end{array}$ \\
\hline P29 & Deficiente distribución de pedidos & 0 & 1 & 1 & 0 & 0 & & 1 & & 1 & 1 & 0 & 0 & 0 & 0 & 0 & & & 0 & 0 & 0 & of & 0 & 0 & 0 & 0 & 0 & & 0 & 0 & 0 & 0 & & 1 & 0 & & & & 0 & 0 & 0 & 0 & & 0 & 0 & & & $\begin{array}{ll}0 & 0 \\
\end{array}$ \\
\hline P30 & Inventar & 1 & 1 & 1 & 0 & 0 & 1 & 1 & 0 & 0 & 1 & 0 & 0 & 0 & 1 & 1 & & & 0 & 0 & 0 & 0 & 0 & 0 & 0 & 0 & 0 & & 0 & 0 & 0 & 1 & 1 & & 0 & & & & 0 & 0 & 0 & 0 & 0 & & 0 & 0 & & \begin{tabular}{l|l}
0 & 0 \\
\end{tabular} \\
\hline P31 & Falta establecer y comunicar el métod & 0 & 0 & 0 & 1 & 1 & 1 & 1 & & 1 & 1 & 0 & 0 & 0 & 0 & 0 & & & 0 & 0 & 0 & 0 & 0 & 0 & 0 & & 1 & & 0 & 0 & 0 & 1 & & 0 & & & & & 0 & 0 & 0 & 0 & $\underline{0}$ & & 0 & 0 & & \\
\hline P32 & Diferencias totale & 0 & 0 & 0 & 1 & 0 & 1 & 1 & 1 & 1 & 1 & 1 & 0 & 0 & 0 & 0 & ) & & 0 & 0 & 0 & 0 & of & 0 & 0 & c & & & 1 & 0 & 0 & 1 & 1 & & $\underline{0}$ & & & & 0 & 의 & 0 & 0 & & & 0 & 0 & & $\begin{array}{lll}0 & 0 \\
\end{array}$ \\
\hline P33 & Faltade & 1 & 1 & 1 & 0 & 0 & 1 & 1 & 1 & 1 & 1 & 0 & 0 & 1 & 1 & 0 & e & & 0 & 0 & 1 & 0 & 의 & 의 & 0 & c & & & of & 0 & 1 & 17 & 1 & & & & & & 1 & 0 & 0 & 0 & & 0 & 0 & 0 & & $\begin{array}{ll}0 & 0 \\
\end{array}$ \\
\hline & Stock del sistema no sincerado con lo real & 00 & 1 & & 1 & 0 & & 1 & & 1 & 1 & & & 0 & & & & & & & 0 & 0 & & & & & 0 . & & 0 & 0 & & & & & & & & 1 & & & 0 & 0 & & 0 & 0 故 & 0 & & \\
\hline
\end{tabular}

Elaboración propia. Parte 1 de 4 


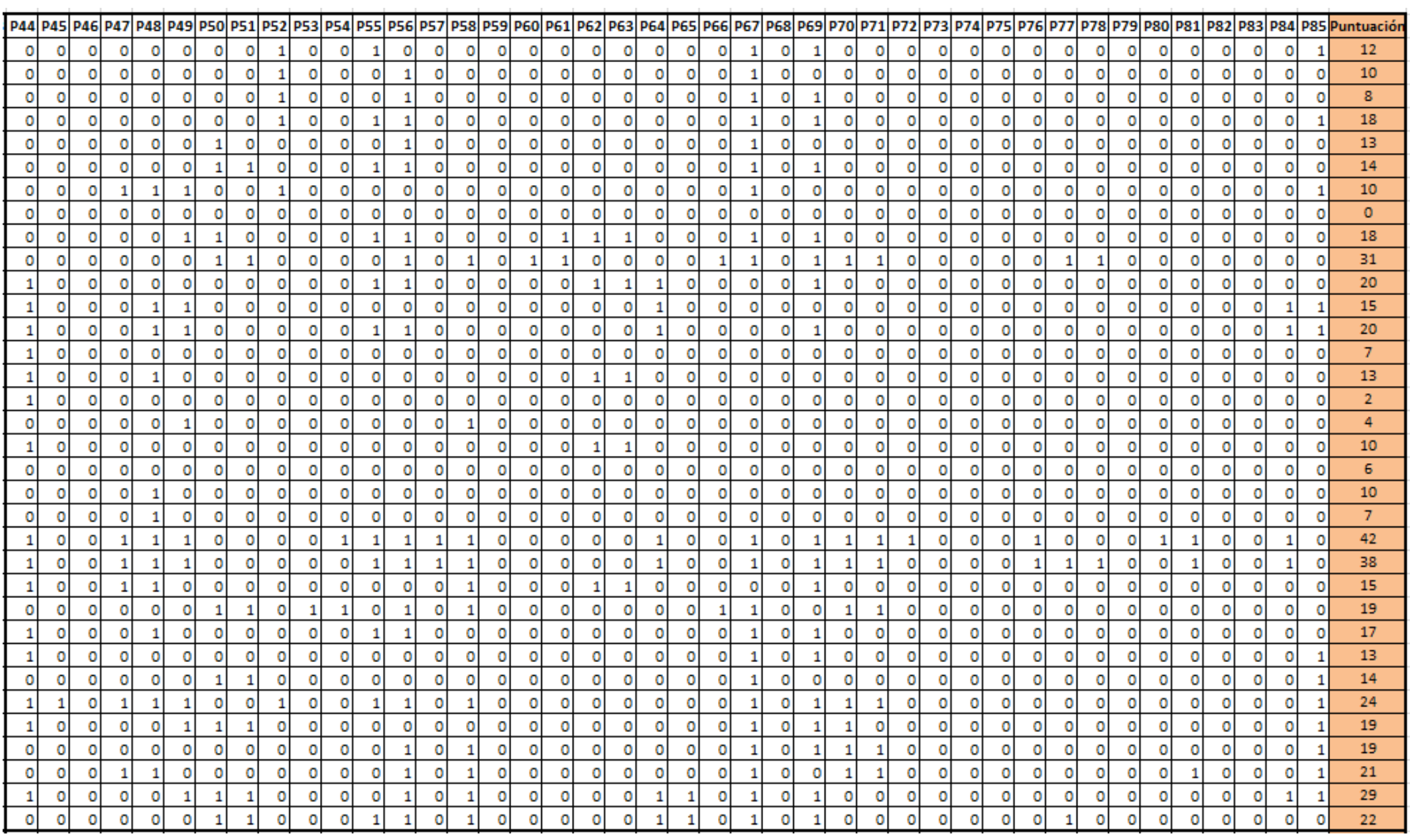

Elaboración propia. Parte 2 de 4

pág. 309 
P52 2 Guardar la mercadería por anulación de pedidos ya separados P53 3 Falta politica de mediciones

P54 Falta gestión de rutas de entrega

(1)

P5y Ir al mismo punto de entrega varias veces por el mismo pedido

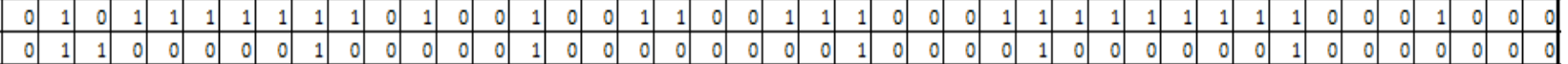

\begin{tabular}{lllllllllllllllllllllllllllllllllllllllllllllllllllllll} 
& \\
\hline
\end{tabular}

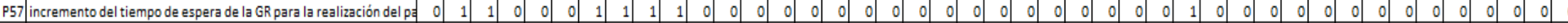

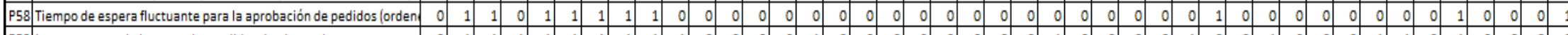

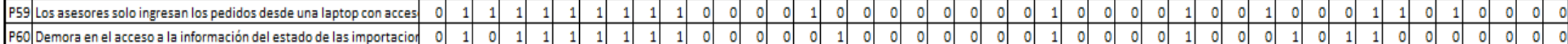
$\begin{array}{llllllllllllllllllllllllllllllllllllllllllllllll} & 0 & 0 & 0 & 1 & 0 & 1 & 0 & 0 & 0 & 1 & 0 & 0 & 0 & 0 & 0 & 0 & 0 & 0 & 0 & 0 & 0 & 0 & 0 & 0 & 0 & 0 & 0 & 0 & 1 & 0 & 0 & 0 & 0 & 0 & 0 & 1 & 0 & 0 & 0 & 0 & 0 & 0 & 0 \\ \end{array}$ 052 se extravin P62 Se extravían los pedidos

P63 Se extravían las GR

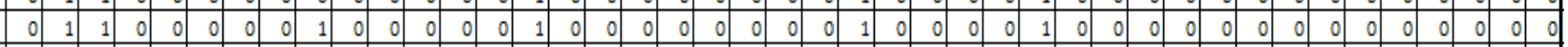

P65 El sistema de información no brinda una träabilidadinterrada

P66 Los clientes no están segmentados en base a la rentabilidad

P67 Desabastecimiento al cliente \begin{tabular}{llllllllllllllllllllllllllllllllllllllllllllll}
0 & 1 & 1 & 1 & 0 & 1 & 0 & 0 & 1 & 1 & 0 & 0 & 0 & 0 & 1 & 0 & 0 & 0 & 0 & 0 & 0 & 0 & 0 & 1 & 0 & 0 & 0 & 1 & 1 & 0 & 0 & 0 & 1 & 0 & 0 & 0 & 0 & 0 & 0 & 0 & 0 & 0 & 0 \\
\hline
\end{tabular}

P68 Las cuentas de clientes no se encuentran con el asesor correspon

P69 Anulación de documentos: guía, facturas, boletas, NC

P70 Se presentan devoluciones de clientes luego de la facturación

P71 La devolución de libros excede el $50 \%$ de lo entregado

P72 Falta de estandar del procediemiento de devolución de mercaderi

P73 Falta de recursos humanos en algunas áreas

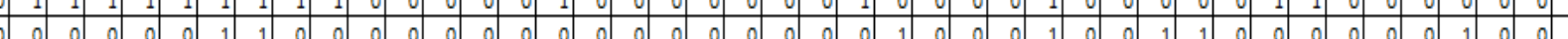
\begin{tabular}{lllllllllllllllllllllllllllllllllllllllllllll} 
& 0 & 0 & 0 & 0 & 0 & 1 & 1 & 0 & 0 & 0 & 0 & 0 & 0 & 0 & 0 & 0 & 0 & 0 & 0 & 0 & 0 & 0 & 0 & 0 & 0 & 0 & 0 & 0 & 0 & 0 & 0 & 0 & 0 & 0 & 0 & 0 & 0 & 0 & 0 & 0 & 0 & 0 \\
\hline
\end{tabular}

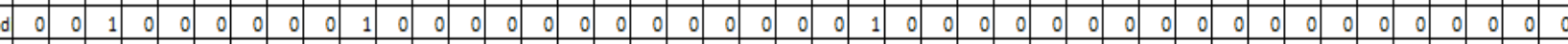
\begin{tabular}{llllllllllllllllllllllllllllllllllllllllllll}
0 & 0 & 0 & 0 & 0 & 0 & 0 & 0 & 1 & 0 & 0 & 0 & 0 & 0 & 1 & 0 & 0 & 0 & 0 & 0 & 0 & 0 & 0 & 1 & 0 & 0 & 0 & 0 & 0 & 1 & 0 & 0 & 0 & 0 & 0 & 0 & 0 & 0 & 0 & 0 & 0 & 0 & 0 \\
\hline
\end{tabular} \begin{tabular}{llllllllllllllllllllllllllllllllllllllllllllllll}
1 & 0 & 0 & 0 & 0 & 0 & 0 & 0 & 1 & 0 & 0 & 0 & 0 & 0 & 0 & 0 & 0 & 0 & 0 & 0 & 0 & 0 & 0 & 1 & 0 & 0 & 0 & 1 & 0 & 1 & 0 & 1 & 1 & 0 & 0 & 0 & 0 & 0 & 0 & 0 & 0 & 0 & 0 \\
\hline
\end{tabular} \begin{tabular}{lllllllllllllllllllllllllllllllllllllllllll}
1 & 0 & 0 & 0 & 0 & 0 & 0 & 0 & 1 & 0 & 0 & 0 & 0 & 0 & 0 & 0 & 0 & 0 & 0 & 0 & 0 & 0 & 0 & 1 & 0 & 0 & 0 & 1 & 0 & 1 & 0 & 1 & 1 & 0 & 0 & 0 & 0 & 0 & 0 & 0 & 0 & 0 & 0 \\
\hline
\end{tabular} \begin{tabular}{lllllllllllllllllllllllllllllllllllllllllllllllllllll}
\hline & 0 & 0 & 0 & 0 & 0 & 0 & 0 & 0 & 0 & 0 & 0 & 0 & 0 & 0 & 1 & 0 & 0 & 0 & 0 & 0 & 0 & 1 & 1 & 1 & 1 & 0 & 0 & 0 & 0 & 1 & 0 & 0 & 0 & 0 & 0 & 0 & 0 & 0 & 0 & 0 & 0 & 0 & 0 \\
0 & 1 & 1 & 0 & 0 & 1 & 0 & 0 & 1 & 0 & 0 & 0 & 0 & 0 & 1 & 0 & 0 & 0 & 0 & 0 & 0 & 0 & 0 & 1 & 0 & 0 & 1 & 0 & 1 & 1 & 0 & 0 & 1 & 1 & 1 & 0 & 0 & 0 & 0 & 0 & 0 & 0 & 0 \\
\hline
\end{tabular}

P74 Falta de un área para la mejora continua y optimización de proceso

P75 No existen programas de capacitación al personal \begin{tabular}{lllllllllllllllllllllllllllllllllllllllllll} 
& 1 & 1 & 1 & 1 & 1 & 1 & 1 & 1 & 1 & 1 & 0 & 0 & 0 & 1 & 0 & 0 & 0 & 0 & 0 & 0 & 1 & 1 & 1 & 1 & 0 & 0 & 0 & 1 & 1 & 1 & 1 & 1 & 1 & 1 & 1 & 0 & 0 & 0 & 0 & 0 & 0 & 0 \\
\hline
\end{tabular}

P76 La inducción al personal nuevo no es la adecuada \begin{tabular}{lllllllllllllllllllllllllllllllllllllllllllllllll}
0 & 1 & 0 & 0 & 0 & 1 & 0 & 0 & 1 & 0 & 0 & 0 & 1 & 0 & 1 & 0 & 0 & 0 & 1 & 0 & 0 & 0 & 1 & 1 & 0 & 0 & 0 & 0 & 1 & 1 & 1 & 0 & 1 & 0 & 1 & 0 & 0 & 0 & 0 & 0 & 0 & 0 & 0 \\
\hline
\end{tabular} \begin{tabular}{llllllllllllllllllllllllllllllllllllllllllll}
0 & 1 & 1 & 0 & 0 & 1 & 0 & 0 & 1 & 0 & 1 & 0 & 1 & 0 & 1 & 0 & 0 & 1 & 1 & 0 & 0 & 0 & 1 & 1 & 0 & 0 & 0 & 0 & 1 & 0 & 1 & 0 & 0 & 0 & 1 & 0 & 0 & 0 & 0 & 0 & 0 & 0 & 0 \\
\hline
\end{tabular}

977 Los usuarios de contabilidad, administración, logistica no pueden P78 Congestión de trabajo en el área de Tl

\begin{tabular}{llllllllllllllllllllllllllllllllllllllllllllll}
0 & 0 & 0 & 0 & 0 & 0 & 0 & 0 & 0 & 0 & 0 & 0 & 0 & 0 & 0 & 0 & 0 & 0 & 0 & 0 & 0 & 0 & 0 & 0 & 0 & 0 & 0 & 0 & 0 & 0 & 0 & 0 & 0 & 0 & 0 & 0 & 0 & 0 & 0 & 0 & 0 & 0 & 0 \\
\hline
\end{tabular}

\begin{tabular}{llllllllllllllllllllllllllllllllllllllllllllll}
0 & 1 & 0 & 0 & 0 & 1 & 0 & 0 & 1 & 1 & 1 & 0 & 1 & 0 & 1 & 0 & 0 & 1 & 1 & 0 & 0 & 0 & 1 & 1 & 0 & 0 & 0 & 0 & 1 & 1 & 0 & 0 & 0 & 1 & 1 & 0 & 0 & 0 & 1 & 0 & 0 & 0 & 0 \\
\hline
\end{tabular} \begin{tabular}{lllllllllllllllllllllllllllllllllllllllllll}
0 & 1 & 1 & 1 & 0 & 1 & 1 & 0 & 1 & 0 & 1 & 0 & 0 & 0 & 1 & 0 & 0 & 0 & 0 & 1 & 0 & 0 & 1 & 1 & 1 & 0 & 0 & 0 & 1 & 0 & 0 & 0 & 1 & 1 & 1 & 0 & 0 & 0 & 0 & 0 & 0 & 0 & 0 \\
\hline
\end{tabular}

880 Funciones no definidas - Falta de un MOF

P81 Información ingresada por los usuarios al sistema no es validada P82 Falta de espacio para recepción de importaciones

\begin{tabular}{llllllllllllllllllllllllllllllllllllllllllll}
0 & 0 & 0 & 0 & 1 & 0 & 1 & 1 & 1 & 1 & 0 & 0 & 0 & 0 & 1 & 0 & 0 & 0 & 0 & 0 & 0 & 0 & 0 & 1 & 0 & 0 & 0 & 1 & 1 & 0 & 0 & 1 & 1 & 1 & 1 & 0 & 0 & 0 & 0 & 0 & 0 & 0 & 0 \\
\hline
\end{tabular}

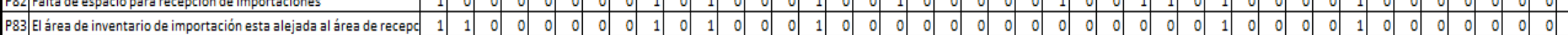

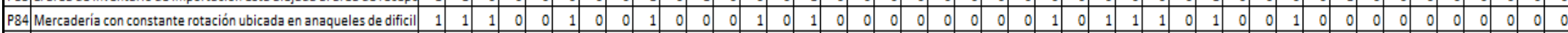
P85 Elevados niveles de stock 


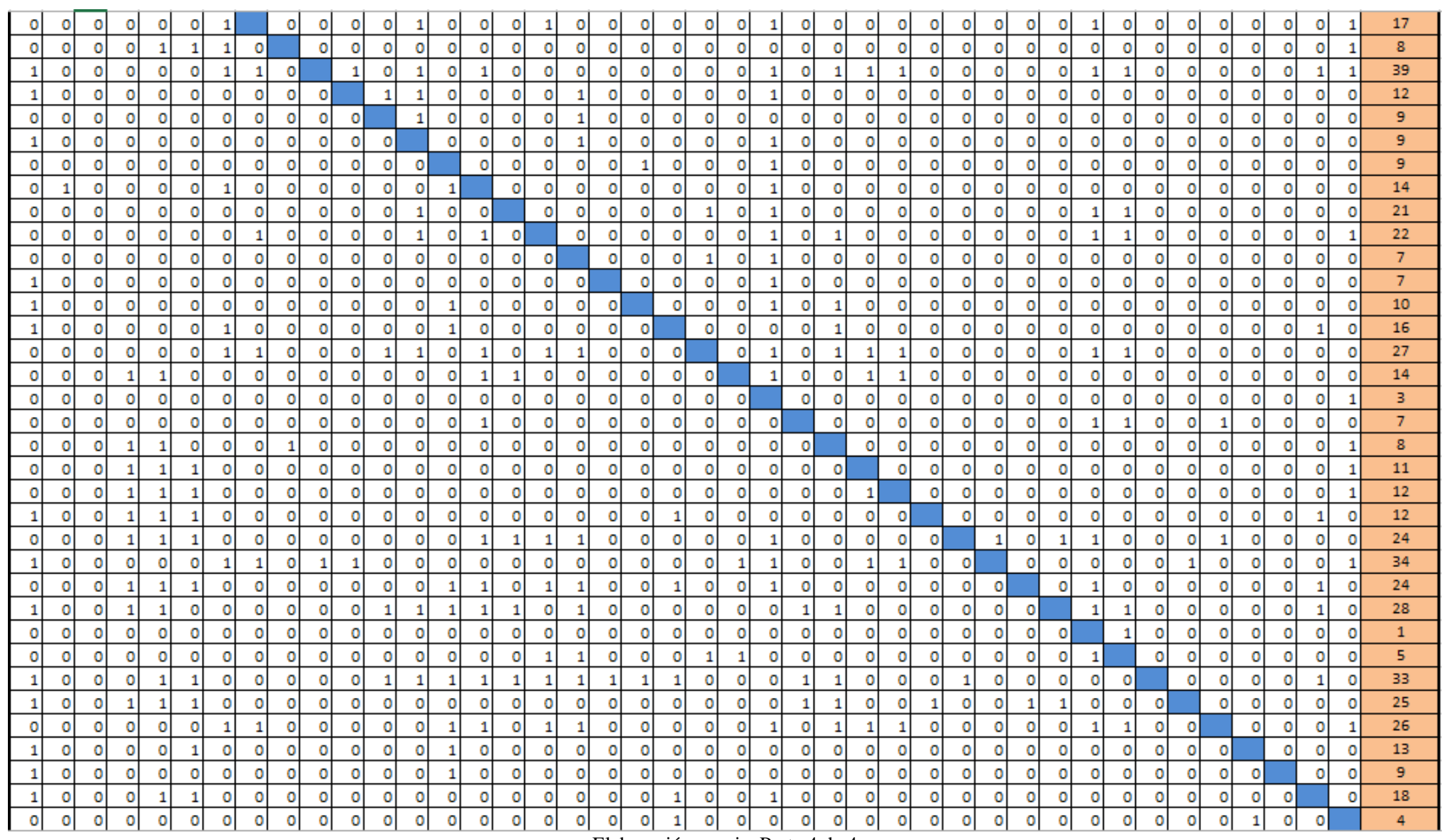
Elaboración propia. Parte 4 de 4 


\section{Anexo 4. Frecuencia acumulada para la elaboración del análisis Pareto}

\begin{tabular}{|c|c|c|c|c|}
\hline Causas de improductividad en la empresa SBS / OPERACIONES & \begin{tabular}{|c|} 
Causa de \\
Improductividad \\
\end{tabular} & Impacto & $\%$ & $\%$ acumulado \\
\hline Demora para Ingresar al sistema la información de las devoluciones y actualizar el kard & P49 & 24 & $9.06 \%$ & $9.06 \%$ \\
\hline Falta de orden y limpieza & P11 & 20 & $7.55 \%$ & $16.60 \%$ \\
\hline El mismo título se encuentran guardado en distintos anaqueles & P13 & 20 & $7.55 \%$ & $24.15 \%$ \\
\hline Inventario dañado por manipulación & P30 & 19 & $7.17 \%$ & $31.32 \%$ \\
\hline Presencia de polvo en los libros & P26 & 17 & $6.42 \%$ & $37.74 \%$ \\
\hline El área comercial ingresa en varias oportunidades la misma solicitud & P39 & 16 & $6.04 \%$ & $43.77 \%$ \\
\hline No se encuentran los libros donde el sistema indica & P64 & 16 & $6.04 \%$ & $49.81 \%$ \\
\hline Despachos con libros faltantes & P06 & 14 & $5.28 \%$ & $55.09 \%$ \\
\hline La mesa de sellado está distante a la mesa de embalaje & P43 & 14 & $5.28 \%$ & $60.38 \%$ \\
\hline Libros faltantes en la importación & P05 & 13 & $4.91 \%$ & $65.28 \%$ \\
\hline Exposición de los libros al aire libre, al sol, humedad, etc & P27 & 13 & $4.91 \%$ & $70.19 \%$ \\
\hline Libros dañados físicamente & P01 & 12 & $4.53 \%$ & $74.72 \%$ \\
\hline Pedidos atrasados & P02 & 10 & $3.77 \%$ & $78.49 \%$ \\
\hline No se encuentran las herramientas e insumos cuando urgen & P18 & 10 & $3.77 \%$ & $82.26 \%$ \\
\hline Se extravian las GR & P63 & 10 & $3.77 \%$ & $86.04 \%$ \\
\hline Atraso de unidades de transporte & $\mathrm{P} 03$ & 8 & $3.02 \%$ & $89.06 \%$ \\
\hline Anulación de documentos: guía, facturas, boletas, NC & P69 & 8 & $3.02 \%$ & $92.08 \%$ \\
\hline Se extravían los pedidos & P62 & 7 & $2.64 \%$ & $94.72 \%$ \\
\hline Las cuentas de clientes no se encuentran con el asesor correspondiente actualizado en & P68 & 7 & $2.64 \%$ & $97.36 \%$ \\
\hline Cajas Ilenas de libros muy pesadas & P19 & 6 & $2.26 \%$ & $99.62 \%$ \\
\hline Los usuarios de contabilidad, administración, logística no pueden sacar reportes & P77 & 1 & $0.38 \%$ & $100.00 \%$ \\
\hline
\end{tabular}

Elaboración propia

\begin{tabular}{|c|c|c|c|c|}
\hline Causas de improductividad en la empresa SBS / GESTIÓN & \begin{tabular}{|c|} 
Causa de \\
Improductividad \\
\end{tabular} & Impacto & $\%$ & $\%$ acumulado \\
\hline Falta política de mediciones & P53 & 39 & $13.54 \%$ & $13.54 \%$ \\
\hline Rotación del personal en general & P79 & 33 & $11.46 \%$ & $25.00 \%$ \\
\hline Falta de control y seguimiento del stock & P33 & 29 & $10.07 \%$ & $35.07 \%$ \\
\hline La inducción al personal nuevo no es la adecuada & P76 & 28 & $9.72 \%$ & $44.79 \%$ \\
\hline Falta de recursos humanos en algunas áreas & P73 & 24 & $8.33 \%$ & $53.13 \%$ \\
\hline No existen programas de capacitación al personal & P75 & 24 & $8.33 \%$ & $61.46 \%$ \\
\hline No se trabaja sobre mediciones de resultados y productividad & P25 & 19 & $6.60 \%$ & $68.06 \%$ \\
\hline Los clientes no están segmentados en base a la rentabilidad & P66 & 14 & $4.86 \%$ & $72.92 \%$ \\
\hline Falta de espacio para recepción de importaciones & P82 & 13 & $4.51 \%$ & $77.43 \%$ \\
\hline Falta gestión de rutas de entrega & P54 & 12 & $4.17 \%$ & $81.60 \%$ \\
\hline Anulación de pedidos / adopciones & P07 & 10 & $3.47 \%$ & $85.07 \%$ \\
\hline Herramientas para el transporte de pedidos dentro del CD no son las adecuadas & P20 & 10 & $3.47 \%$ & $88.54 \%$ \\
\hline El área de inventario de importación esta alejada al área de recepción & P83 & 9 & $3.13 \%$ & $91.67 \%$ \\
\hline Falta de ventilación en el centro de labores & P14 & 7 & $2.43 \%$ & $94.10 \%$ \\
\hline Piso del CD con desniveles & P21 & 7 & $2.43 \%$ & $96.53 \%$ \\
\hline Servicios alejados de las oficinas & P17 & 4 & $1.39 \%$ & $97.92 \%$ \\
\hline Elevados niveles de stock & P85 & 4 & $1.39 \%$ & $99.31 \%$ \\
\hline Servicios de damas alejado del almacén & P16 & 2 & $0.69 \%$ & $100.00 \%$ \\
\hline Deserción de clientes & P08 & 0 & $0.00 \%$ & $100.00 \%$ \\
\hline
\end{tabular}

Elaboración propia. 


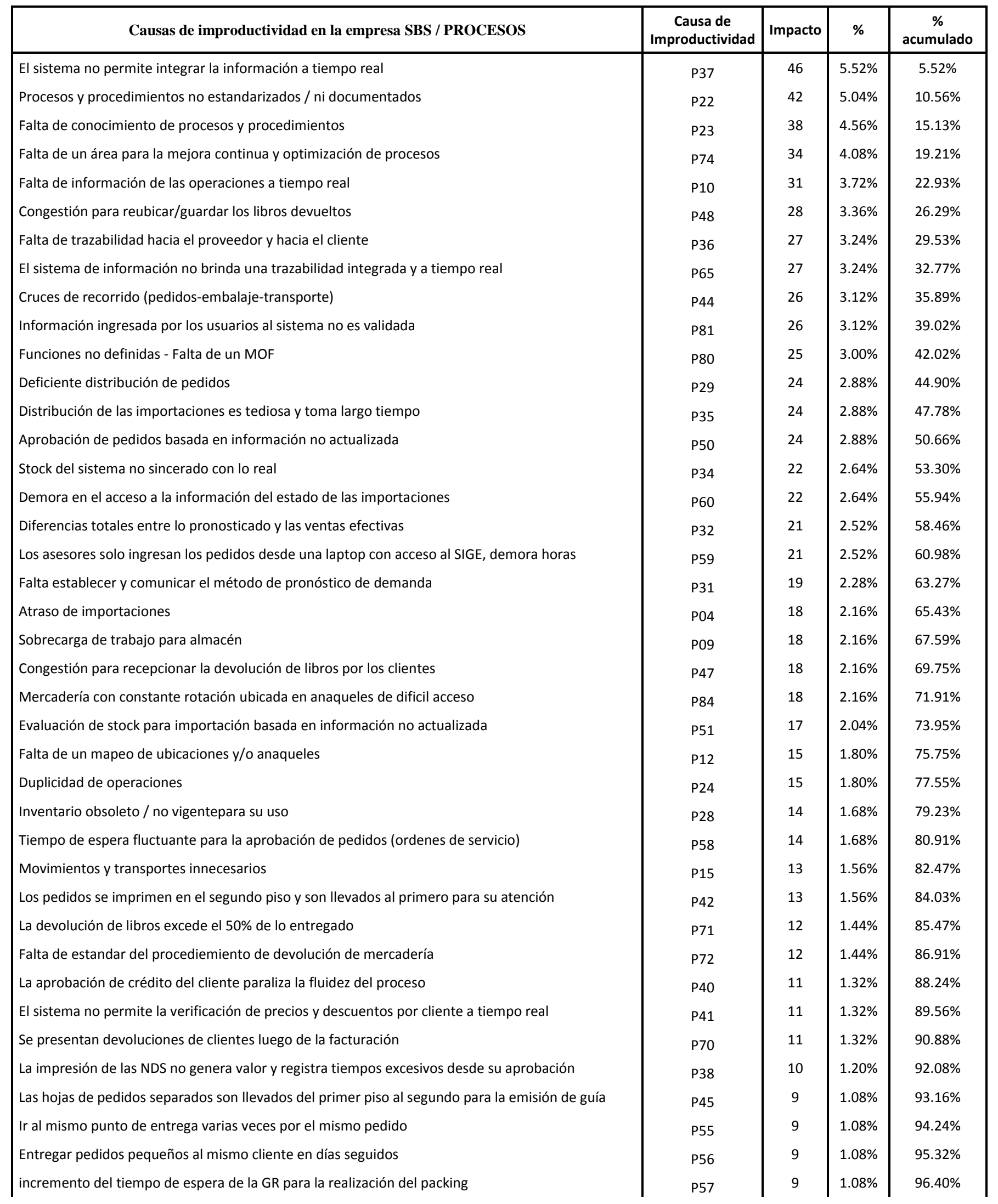

Elaboración propia 
Guardar la mercadería por anulación de pedidos ya separados

Las guías impresas son llevadas del segundo piso al primero para el packing

Difícil acceso a la información de recepción de pedidos

Congestión de trabajo en el área de TI

Desabastecimiento al cliente

\begin{tabular}{l|l|l|l} 
P52 & 8 & $0.96 \%$ & $97.36 \%$ \\
P46 & 7 & $0.84 \%$ & $98.20 \%$ \\
P61 & 7 & $0.84 \%$ & $99.04 \%$ \\
P78 & 5 & $0.60 \%$ & $99.64 \%$ \\
P67 & 3 & $0.36 \%$ & $100.00 \%$
\end{tabular}

Elaboración propia. 
Anexo 5. Elaboración ABC de almacén // frecuencia de pedidos solicitados

\begin{tabular}{|c|c|c|c|c|}
\hline ISBN & TITULO & $\begin{array}{l}\text { CANTIDA } \\
\text { D }\end{array}$ & $\begin{array}{l}\text { REGISTRO } \\
\mathrm{S}\end{array}$ & CLASIFICACION \\
\hline 9780194337335 & $\begin{array}{l}\text { DICCIONARIO OXFORD POCKET DICCIONARIO PARA } \\
\text { ESTUDIANTES LATINOAMERICANOS DE INGLES C/CD }\end{array}$ & 8,193 & 282 & A \\
\hline 9780521688284 & KID’S BOX (BE) 6 PUPIL'S BOOK & 2,144 & 207 & A \\
\hline 9781447900610 & OUR DISCOVERY ISLAND (AE) 1 SB W/CD-ROM * & 3,913 & 183 & A \\
\hline 9788575831243 & HUB PLE - BEM-VINDO! 8ED. LA - NAO & 7,259 & 180 & A \\
\hline 9781447900627 & OUR DISCOVERY ISLAND (AE) 2 SB W/CD-ROM * & 3,664 & 178 & $\mathrm{~A}$ \\
\hline 9781107617575 & KID’S BOX (BE) 2ED. 1 PUPIL’S BOOK & 2,797 & 177 & A \\
\hline 9780132455572 & TOP NOTCH 2ED. FUNDAMENTALS SB W/ACTIVEBOOK & 17,821 & 165 & A \\
\hline 9780132985543 & BIG ENGLISH (AE) 1 SB & 3,751 & 164 & A \\
\hline 9781447900634 & OUR DISCOVERY ISLAND (AE) 3 SB W/CD-ROM * & 3,396 & 161 & A \\
\hline 9781107689404 & $\begin{array}{l}\text { KID'S BOX (BE) 2ED. } 1 \text { ACTIVITY BOOK W/ONLINE } \\
\text { RESOURCES }\end{array}$ & 2,450 & 161 & A \\
\hline 9781447900672 & OUR DISCOVERY ISLAND (AE) 1 WB W/AUDIO CD & 3,438 & 160 & A \\
\hline 9780132469913 & TOP NOTCH 2ED. FUNDAMENTALS WB & 17,711 & 159 & $\mathrm{~A}$ \\
\hline 9781447900641 & OUR DISCOVERY ISLAND (AE) 4 SB W/CD-ROM & 3,076 & 158 & A \\
\hline 9781107656857 & KID’S BOX (BE) 2ED. 4 PUPIL’S BOOK & 2,561 & 155 & $\mathrm{~A}$ \\
\hline 9781447900689 & OUR DISCOVERY ISLAND (AE) 2 WB W/AUDIO CD * & 3,376 & 153 & A \\
\hline 9780133044898 & BIG ENGLISH (AE) 1 WB W/AUDIO CD & 3,703 & 149 & A \\
\hline 9781107644977 & KID’S BOX (BE) 2ED. 2 PUPIL'S BOOK & 2,936 & 146 & A \\
\hline 9780132470414 & TOP NOTCH 2ED. 1 WB & 11,432 & 145 & A \\
\hline 9781447900658 & OUR DISCOVERY ISLAND (AE) 5 SB W/CD-ROM * & 2,985 & 145 & $\mathrm{~A}$ \\
\hline 9780521131988 & KID’S BOX (BE) 6 ACTIVITY BOOK W/CD-ROM & 1,757 & 145 & A \\
\hline 9780132861861 & BIG ENGLISH (AE) 3 SB & 3,314 & 144 & $\mathrm{~A}$ \\
\hline 9780138140830 & TOP NOTCH 2ED. 1 SB W/ACTIVEBOOK & 11,537 & 142 & A \\
\hline 9780132985567 & BIG ENGLISH (AE) 2 SB & 3,403 & 141 & A \\
\hline 9780133044966 & BIG ENGLISH (AE) 2 WB W/AUDIO CD & 3,341 & 139 & A \\
\hline 9780133045031 & BIG ENGLISH (AE) 3 WB W/AUDIO CD & 3,293 & 136 & $\mathrm{~A}$ \\
\hline 9781447900696 & OUR DISCOVERY ISLAND (AE) 3 WB W/AUDIO CD * & 2,922 & 136 & A \\
\hline 9781447900702 & OUR DISCOVERY ISLAND (AE) 4 WB W/AUDIO CD $*$ & 2,611 & 135 & $\mathrm{~A}$ \\
\hline 9786124149047 & DICCIONARIO ESCOLAR PEARSON & 3,121 & 133 & $\mathrm{~A}$ \\
\hline 9781107654501 & KID’S BOX (BE) 2ED. 3 PUPIL’S BOOK & 2,621 & 133 & A \\
\hline 9781447900665 & OUR DISCOVERY ISLAND (AE) 6 SB W/CD-ROM & 2,352 & 131 & A \\
\hline
\end{tabular}

Elaboración propia.

pág. 315 


\begin{tabular}{|c|c|c|c|c|}
\hline 9781107661462 & $\begin{array}{l}\text { KID'S BOX (BE) 2ED. } 4 \text { ACTIVITY BOOK W/ONLINE } \\
\text { RESOURCES }\end{array}$ & 2,012 & 129 & A \\
\hline 9780194407120 & $\begin{array}{l}\text { SMART CHOICE 2ED. STARTER A MULTI-PACK SB/WB } \\
\text { W/ONLINE PRACTICE }\end{array}$ & 5,029 & 127 & A \\
\hline 9781107671614 & $\begin{array}{l}\text { KID'S BOX (BE) 2ED. } 2 \text { ACTIVITY BOOK W/ONLINE } \\
\text { RESOURCES }\end{array}$ & 2,495 & 126 & A \\
\hline 9781447937968 & $\begin{array}{l}\text { SPEAKOUT ACPB ELEM. SB PACK A1-A2 (WB AUDIO CD } \\
\text { AND ACTIVEBOOK \& DVD) }\end{array}$ & 33,250 & 125 & A \\
\hline 9781447900719 & OUR DISCOVERY ISLAND (AE) $5 \mathrm{WB}$ W/AUDIO CD $*$ & 2,618 & 123 & A \\
\hline 9781107476387 & $\begin{array}{l}\text { CAMBRIDGE ENGLISH OBJECTIVE FIRST 4ED. B2 SB } \\
\text { W/ANSWERS AND CD-ROM \& AUDIO CD }\end{array}$ & 7,922 & 118 & A \\
\hline 9788575832172 & HUB PLE - BEM-VINDO! 5ED. CE -OL & 4,084 & 114 & A \\
\hline 9781107628915 & KID’S BOX (BE) 2ED. 5 PUPIL’S BOOK & 1,908 & 113 & A \\
\hline 9781447938002 & $\begin{array}{l}\text { SPEAKOUT ACPB PRE-INTER. SB PACK A2-B1 (WB AUDIO } \\
\text { CD AND ACTIVEBOOK \& DVD) }\end{array}$ & 18,870 & 109 & A \\
\hline 9781447938026 & $\begin{array}{l}\text { SPEAKOUT ACPB UPPER-INTER. SB PACK B1-B2 (WB } \\
\text { AUDIO CD AND ACTIVEBOOK \& DVD) }\end{array}$ & 9,858 & 108 & A \\
\hline 9781107644007 & $\begin{array}{l}\text { KID'S BOX (BE) 2ED. } 3 \text { ACTIVITY BOOK W/ONLINE } \\
\text { RESOURCES }\end{array}$ & 2,225 & 108 & A \\
\hline 9781447900726 & OUR DISCOVERY ISLAND (AE) $6 \mathrm{WB}$ W/AUDIO CD $*$ & 1,978 & 108 & A \\
\hline 9781107699113 & $\begin{array}{l}\text { KID'S BOX (BE) 2ED. } 5 \text { ACTIVITY BOOK W/ONLINE } \\
\text { RESOURCES }\end{array}$ & 1,622 & 104 & A \\
\hline 9781447937982 & $\begin{array}{l}\text { SPEAKOUT ACPB INTER. SB PACK B1-B1+ (WB AUDIO CD } \\
\text { AND ACTIVEBOOK \& DVD) }\end{array}$ & 13,874 & 103 & A \\
\hline 9780132470483 & $\begin{array}{l}\text { TOP NOTCH 2ED. } 2 \text { SB } \\
\text { MYENGLISHLAB }\end{array}$ & 6,138 & 102 & A \\
\hline 9789871486342 & CONTABILIDAD FINANCIERA & 1,693 & 100 & A \\
\hline 9780133045086 & BIG ENGLISH (AE) 4 SB W/MYENGLISHLAB & 1,976 & 99 & A \\
\hline 9780194407205 & $\begin{array}{l}\text { SMART CHOICE 2ED. STARTER B MULTI-PACK SB/WB } \\
\text { W/ONLINE PRACTICE }\end{array}$ & 3,125 & 98 & A \\
\hline 9786073211864 & $\begin{array}{l}\text { ADMINISTRACION DE LAS OPERACIONES PRODUCTIVAS } \\
*\end{array}$ & 1,221 & 98 & A \\
\hline 9781408267219 & $\begin{array}{l}\text { NEW TOTAL ENGLISH STARTER SB W/ACTIVE BOOK } \\
\text { PACK }\end{array}$ & 2,062 & 97 & A \\
\hline 9780194407137 & $\begin{array}{l}\text { SMART CHOICE 2ED. 1A SB \& WB SPLIT W/ONLINE } \\
\text { PRACTICE }\end{array}$ & 2,244 & 96 & A \\
\hline 9781408267400 & $\begin{array}{l}\text { NEW TOTAL ENGLISH STARTER WB WO/KEY AND AUDIO } \\
\text { CD PACK * }\end{array}$ & 2,016 & 96 & A \\
\hline 9780521688239 & KID'S BOX (BE) 5 PUPIL'S BOOK & 1,355 & 96 & A \\
\hline 9780132470278 & 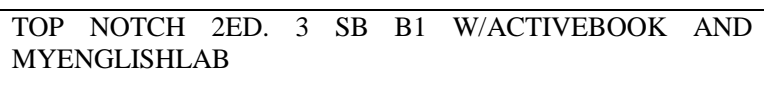 & 5,234 & 95 & A \\
\hline 9780194307574 & ENGLISH FOR LIFE BEGIN. SB W/MULTI-ROM & 19,697 & 94 & A \\
\hline 9780194307536 & ENGLISH FOR LIFE BEGIN. WB WO/KEY & 19,697 & 94 & A \\
\hline 9780132679862 & SUMMIT 2ED. 1 SB W/ACTIVEBOOK \& MYENGLISHLAB & 4,143 & 92 & A \\
\hline
\end{tabular}

Elaboración propia. 


\begin{tabular}{|c|c|c|c|c|}
\hline 9789972648076 & $\begin{array}{lcccc}\text { COCINA } & \text { PERUANA: } 100 & \text { MARAVILLAS } & \text { DE } & \text { LA } \\
\text { GASTRONOMIA DEL PERU } & & & \end{array}$ & 1,185 & 92 & A \\
\hline 9780133045239 & BIG ENGLISH (AE) 6 SB W/MYENGLISHLAB & 1,571 & 91 & A \\
\hline 9780194776158 & AMERICAN ENGLISH FILE 2ED. 1 SB W/ITUTOR * & 6,063 & 90 & A \\
\hline 9780521688079 & KID’S BOX (BE) 2 PUPIL'S BOOK & 680 & 90 & A \\
\hline 9786124149122 & $\begin{array}{l}\text { PLANEAMIENTO ESTRATEGICO RAZONADO: ASPECTOS } \\
\text { CONCEPTUALES Y APLICADOS }\end{array}$ & 1,364 & 89 & A \\
\hline 9780194046558 & PLAYTIME B & 917 & 89 & A \\
\hline 9786073209496 & SISTEMAS DE INFORMACION GERENCIAL 12 ED. & 1,541 & 85 & A \\
\hline 9780194799027 & $\begin{array}{l}\text { OXFORD ADVANCED LEARNER'S DICTIONARY } \\
\text { W/CD-ROM. }\end{array}$ & 833 & 84 & $\mathrm{~A}$ \\
\hline 9786076184226 & CUENTOS DE LOS HERMANOS GRIMM & 529 & 84 & A \\
\hline 9780194598705 & $\begin{array}{l}\text { ENGLISH FILE 3ED. ELEM. WB WO/KEY AND CD-ROM \& } \\
\text { ICHECKER } *\end{array}$ & 5,835 & 83 & $\mathrm{~A}$ \\
\hline 9780133045178 & BIG ENGLISH (AE) 5 SB W/MYENGLISHLAB & 1,779 & 83 & A \\
\hline 9780521688185 & KID’S BOX (BE) 4 PUPIL'S BOOK & 721 & 82 & $\mathrm{~A}$ \\
\hline 9780194774185 & AMERICAN ENGLISH FILE 1 WB W/CD-ROM & 19,027 & 80 & $\mathrm{~A}$ \\
\hline 9780521183260 & ENGLISH IN MIND 2ED. 1A SB + WB W/DVD-ROM * & 649 & 80 & A \\
\hline 9780136038856 & POCKETS 2ED. 3 SB W/ CD-ROM & 1,513 & 79 & A \\
\hline 9786073210249 & $\begin{array}{l}\text { HORNGREN - CONTABILIDAD DE COSTOS: UN ENFOQUE } \\
\text { GERENCIAL 14ED. }\end{array}$ & 1,340 & 79 & $\mathrm{~A}$ \\
\hline 9786073218863 & $\begin{array}{l}\text { EL PROCESO ESTRATEGICO. UN ENFOQUE DE GERENCIA } \\
\text { 2ED. }\end{array}$ & 1,038 & 77 & A \\
\hline 9786076184233 & CUENTOS INFANTILES & 501 & 77 & A \\
\hline 9780521712194 & INTERACTIVE 3 SB WITH WEB ZONE ACCESS & 658 & 76 & A \\
\hline 9780136038986 & POCKETS 2ED. 1 SB & 1,556 & 75 & A \\
\hline 9780521131940 & KID’S BOX (BE) 4 ACTIVITY BOOK W/CD-ROM & 716 & 75 & A \\
\hline 9780132679992 & 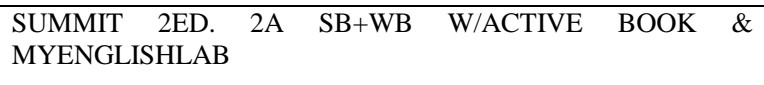 & 2,796 & 74 & A \\
\hline 9780194407212 & $\begin{array}{l}\text { SMART CHOICE 2ED. 1B SB \& WB SPLIT W/ONLINE } \\
\text { PRACTICE }\end{array}$ & 1,751 & 74 & A \\
\hline 9780136038788 & POCKETS 2ED. 2 SB W/CD-ROM & 1,389 & 74 & A \\
\hline 9780521131964 & KID’S BOX (BE) 5 ACTIVITY BOOK W/CD-ROM & 1,205 & 72 & $\mathrm{~A}$ \\
\hline 9780194626187 & LET'S GO 4ED. 1 SB W/AUDIO CD & 1,165 & 72 & A \\
\hline 9780521688017 & KID'S BOX (BE) 1 PUPIL'S BOOK & 754 & 72 & A \\
\hline 9786076180853 & $\begin{array}{l}\text { FROZEN: UNA AVENTURA CONGELADA - UN CORAZON } \\
\text { CONGELADO }\end{array}$ & 241 & 72 & A \\
\hline 9781408232347 & $\begin{array}{lccc}\text { LONGMAN } & \text { DICCIONARIO } & \text { POCKET } & \text { INGLES- } \\
\text { ESPAÑOL/ESPAÑOL-INGLES 2ED. C/CD-ROM } & \end{array}$ & 1,758 & 71 & $\bar{A}$ \\
\hline 9780194103190 & EVERYBODY UP 1 SB W/AUDIO CD & 1,546 & 70 & A \\
\hline
\end{tabular}

Elaboración propia.

pág. 317 


\begin{tabular}{|c|c|c|c|c|}
\hline 9780194626200 & LET'S GO 4ED. 3 SB W/AUDIO CD & 1,058 & 70 & A \\
\hline 9780521688130 & KID’S BOX (BE) 3 PUPIL'S BOOK & 836 & 70 & A \\
\hline 9780132680011 & $\begin{array}{lllllll}\text { SUMMIT } & \text { 2ED. } & \text { 2B } & \text { SB+WB } & \text { W/ACTIVE } & \text { BOOK } & \& \\
\text { MYENGLISHLAB } & & & & & \end{array}$ & 2,460 & 69 & $\mathrm{~A}$ \\
\hline 9780133437447 & BIG FUN 3 SB W/CD-ROM & 1,425 & 68 & A \\
\hline 9786071507617 & INGENIERIA ECONOMICA 7ED. & 1,235 & 68 & A \\
\hline 9780132985581 & BIG ENGLISH (AE) 5 SB & 1,160 & 68 & A \\
\hline 9786073221337 & $\begin{array}{l}\text { ADMINISTRACION DE LA CADENA DE SUMINISTRO: } \\
\text { ESTRATEGIA PLANEACION Y OPERACION 5ED. * }\end{array}$ & 978 & 68 & A \\
\hline 9780132470520 & TOP NOTCH 2ED. 2 WB & 6,338 & 67 & A \\
\hline 9780132455589 & TOP NOTCH 2ED. 2 SB W/ACTIVEBOOK & 6,306 & 67 & $\mathrm{~A}$ \\
\hline 9780133437430 & BIG FUN 2 SB W/CD-ROM & 3,147 & 67 & A \\
\hline 9781408267165 & NEW TOTAL ENGLISH ELEM. SB W/ACTIVE BOOK PACK & 2,422 & 67 & A \\
\hline 9780194034050 & TEEN2TEEN 2 PACK PLUS (SB+WB) & 921 & 67 & A \\
\hline 9780194046534 & PLAYTIME STARTER & 587 & 67 & A \\
\hline 9780194579803 & $\begin{array}{l}\text { OXFORD PRACTICE GRAMMAR INTERMEDIATE W/TESTS } \\
\text { \& CD-ROM }\end{array}$ & 405 & 67 & A \\
\hline 9781133939337 & OUR WORLD (AE) 1 SB W/CD-ROM & 2,304 & 66 & A \\
\hline 9780194407144 & $\begin{array}{l}\text { SMART CHOICE 2ED. 2A SB \& WB SPLIT W/ONLINE } \\
\text { PRACTICE }\end{array}$ & 1,293 & 66 & $\bar{A}$ \\
\hline 9786124149139 & $\begin{array}{llllll}\text { ESTADISTICA } & \text { PARA } & \text { LA } & \text { ADMINISTRACION } & \text { Y } & \text { LOS } \\
\text { NEGOCIOS 2ED. } & & & & \end{array}$ & 991 & 66 & A \\
\hline 9781133939382 & OUR WORLD (AE) 3 SB W/CD-ROM & 1,932 & 65 & A \\
\hline 9780194626194 & LET'S GO 4ED. 2 SB W/AUDIO CD & 1,150 & 65 & A \\
\hline 9780521183277 & ENGLISH IN MIND 2ED. 1B SB + WB W/DVD-ROM * & 781 & 65 & A \\
\hline 9780194046541 & PLAYTIME A & 751 & 65 & A \\
\hline 9780132795418 & MY LITTLE ISLAND (AE) 3 SB W/ACTIVE TEACH & 1,210 & 64 & A \\
\hline 9780133045185 & BIG ENGLISH (AE) 5 WB W/AUDIO CD & 1,096 & 64 & A \\
\hline 9780521746489 & COMPLETE PET SB WITHOUT ANSWERS W/CD-ROM & 969 & 64 & A \\
\hline 9780521131926 & KID'S BOX (BE) 2 ACTIVITY BOOK W/CD-ROM * & 651 & 64 & A \\
\hline 9781405876926 & PR 1: PELE 2ED. * & 7,720 & 63 & $\mathrm{~A}$ \\
\hline 9780132546690 & IN SYNC 1B SB + LANGUAGE BUILDER W/CD-ROM & 1,314 & 63 & $\mathrm{~A}$ \\
\hline 9781107659865 & KID'S BOX (BE) 2ED. STARTER CLASS BOOK W/CD-ROM & 999 & 63 & A \\
\hline 9780194626217 & LET'S GO 4ED. 4 SB W/AUDIO CD & 961 & 63 & A \\
\hline 9786073201445 & 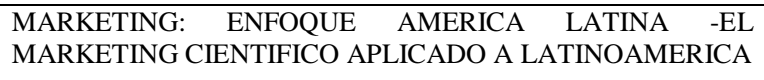 & 887 & 63 & A \\
\hline 9780194462938 & $\begin{array}{l}\text { GOT IT! PLUS STARTER: SB+WB W/CD-ROM \& ONLINE } \\
\text { SKILLS PRACTICE }\end{array}$ & 432 & 63 & A \\
\hline 9781405842877 & PR 2: THE LAST OF THE MOHICANS 2ED. & 6,102 & 62 & A \\
\hline
\end{tabular}

Elaboración propia. 


\begin{tabular}{|c|c|c|c|c|}
\hline 9780133445220 & BIG FUN 2 WB W/AUDIO CD & 3,109 & 62 & A \\
\hline 9781408267349 & NEW TOTAL ENGLISH ELEM. WB WO/KEY AND AUDIO CD & 2,199 & 62 & A \\
\hline 9780194103374 & EVERYBODY UP 2 SB W/AUDIO CD & 1,342 & 62 & A \\
\hline 9780194103916 & EVERYBODY UP 5 SB W/AUDIO CD & 1,330 & 62 & A \\
\hline 9780194103220 & EVERYBODY UP $1 \mathrm{WB}$ & 1,163 & 62 & $\bar{A}$ \\
\hline 9780132547840 & IN SYNC 1 LANGUAGE BUILDER & 824 & 62 & A \\
\hline 9781456223960 & METODOLOGIA DE LA INVESTIGACION 6ED. & 688 & 62 & A \\
\hline 9780194579780 & OXFORD PRACTICE GRAMMAR BASIC W/KEY \& CD-ROM & 502 & 62 & A \\
\hline 9780142414934 & PAPER TOWNS & 282 & 62 & A \\
\hline 9786074046779 & LA HISTORIA DEL MUNDO & 210 & 62 & A \\
\hline 9781405842778 & PR 1: THE ADVENTURES OF TOM SAWYER 2ED. & 7,887 & 61 & A \\
\hline 9780194776141 & $\begin{array}{l}\text { AMERICAN ENGLISH FILE 2ED. STARTER SB WITH } \\
\text { ITUTOR * }\end{array}$ & 4,754 & 61 & A \\
\hline 9780132985574 & BIG ENGLISH (AE) 4 SB & 1,365 & 61 & A \\
\hline 9780132547871 & IN SYNC 1A SB + LANGUAGE BUILDER W/CD-ROM & 1,206 & 61 & A \\
\hline 9786073219808 & COMPORTAMIENTO ORGANIZACIONAL 15ED. & 994 & 61 & A \\
\hline 9780194626224 & LET'S GO 4ED. 5 SB W/AUDIO CD & 902 & 61 & $\bar{A}$ \\
\hline 9780194034067 & TEEN2TEEN 3 PACK PLUS (SB+WB) & 895 & 61 & A \\
\hline 9780521131933 & KID’S BOX (BE) 3 ACTIVITY BOOK W/CD-ROM & 782 & 61 & $\bar{A}$ \\
\hline 9780521712200 & INTERACTIVE 3 WB WITH DOWNLOADABLE AUDIO & 551 & 61 & A \\
\hline 9786076184363 & $\begin{array}{l}\text { MI PEQUEÑA BIBLIOTECA: DISNEY } \\
\text { FROZEN: } \\
\text { AVENTURA CONGELADA }\end{array}$ & 766 & 60 & A \\
\hline 9780132470759 & TOP NOTCH 2ED. 3 WB & 4,103 & 59 & A \\
\hline 9780194107372 & EVERYBODY UP 4 SB W/AUDIO CD & 1,118 & 59 & A \\
\hline 9780136038535 & POCKETS 2ED. 2 WB W/AUDIO CD & 1,175 & 59 & A \\
\hline 9786074425239 & $\begin{array}{l}\text { LIDERAZGO Y ATRIBUTOS GERENCIALES: UNA VISION } \\
\text { GLOBAL Y ESTRATEGICA }\end{array}$ & 1,050 & 59 & A \\
\hline 9780132795364 & MY LITTLE ISLAND (AE) 2 SB W/ACTIVE TEACH & 1,040 & 59 & A \\
\hline 9780194407229 & $\begin{array}{l}\text { SMART CHOICE 2ED. 2B SB \& WB SPLIT W/ONLINE } \\
\text { PRACTICE * }\end{array}$ & 1,015 & 59 & A \\
\hline 9780521712095 & INTERACTIVE 1 WB WITH DOWNLOADABLE AUDIO $*$ & 695 & 59 & A \\
\hline 9786074041972 & 50 HISTORIAS DE HADAS & 314 & 59 & A \\
\hline 9780194307581 & ENGLISH FOR LIFE ELEM. SB W/MULTI-ROM & 4,773 & 58 & A \\
\hline 9780194307543 & ENGLISH FOR LIFE ELEM. WB WO/KEY & 4,773 & 58 & A \\
\hline 9780133045093 & BIG ENGLISH (AE) 4 WB W/AUDIO CD & 1,308 & 58 & A \\
\hline 9786074429664 & 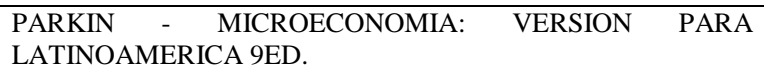 & 1,117 & 58 & A \\
\hline 9780132940542 & BIG FUN 1 SB W/CD-ROM & 828 & 58 & A \\
\hline
\end{tabular}

Elaboración propia. 


\begin{tabular}{|c|c|c|c|c|}
\hline 9780194643207 & LET'S GO 4ED. 1 WB & 808 & 58 & $\bar{A}$ \\
\hline 9780194776394 & AMERICAN ENGLISH FILE 2ED. 1 WB AND ICHECKER * & 3,157 & 57 & A \\
\hline 9780521144216 & $\begin{array}{l}\text { TOUCHSTONE PREMIUM } 1 \text { SB W/CD, CD-ROM, ONLINE } \\
\text { COURSE AND INTERACTIVE WB } *\end{array}$ & 2,667 & 57 & $\mathrm{~A}$ \\
\hline 9780194774505 & AMERICAN ENGLISH FILE 3 WB W/CD-ROM & 2,405 & 57 & A \\
\hline 9780136039068 & POCKETS 2ED. 1 WB W/AUDIO CD & 1,216 & 57 & A \\
\hline 9780194103558 & EVERYBODY UP 3 SB W/AUDIO CD & 1,205 & 57 & A \\
\hline 9780133445275 & BIG FUN 3 WB W/AUDIO CD & 1,139 & 57 & A \\
\hline 9780194034043 & TEEN2TEEN 1 PACK PLUS (SB+WB) & 929 & 57 & A \\
\hline 9780194104098 & EVERYBODY UP 6 SB W/AUDIO CD & 866 & 57 & A \\
\hline 9786074429480 & $\begin{array}{llll}\text { FUNDAMENTOS DE ADMINISTRACION } & \text { FINANCIERA } \\
\text { 13ED. } & & & \end{array}$ & 721 & 57 & $\mathrm{~A}$ \\
\hline 9780194407151 & $\begin{array}{l}\text { SMART CHOICE 2ED. 3A SB \& WB SPLIT W/ONLINE } \\
\text { PRACTICE }\end{array}$ & 707 & 57 & A \\
\hline 9780521183291 & ENGLISH IN MIND 2ED. 2A SB + WB W/DVD-ROM * & 705 & 57 & A \\
\hline 9780194104128 & EVERYBODY UP 6 WB & 589 & 57 & A \\
\hline 9786074047561 & $\begin{array}{l}\text { ARCON DE CUENTOS: SUPER HERO SQUAD LO MEJOR DE } \\
\text { LO MEJOR }\end{array}$ & 194 & 57 & $\overline{\mathrm{A}}$ \\
\hline 9780194774345 & AMERICAN ENGLISH FILE 2 WB W/CD-ROM & 7,645 & 56 & A \\
\hline 9786075220086 & ¡COMUNICATE! 12ED. & 983 & 56 & A \\
\hline 9780194643221 & LET'S GO 4ED. 3 WB & 783 & 56 & A \\
\hline 9780194643214 & LET'S GO 4ED. 2 WB & 778 & 56 & A \\
\hline 9780521221689 & SUPER MINDS 3 SB W/DVD-ROM & 621 & 56 & A \\
\hline 9780133348057 & $\begin{array}{l}\text { LONGMAN PREPARATION COURSE FOR TOEFL IBT W/CD- } \\
\text { ROM \& TEST W/O AK 2ED. }\end{array}$ & 427 & 56 & $\bar{A}$ \\
\hline 9786074045697 & MI LIBRO DE HISTORIAS MAGNETICAS: SPIDERMAN * & 120 & 56 & A \\
\hline 9780194775212 & $\begin{array}{l}\text { AMERICAN ENGLISH } \\
\text { PRACTICE } *\end{array}$ & 16,864 & 55 & A \\
\hline 9781107422049 & FACE2FACE 2ED. ELEMENTARY SB W/DVD-ROM & 6,344 & 55 & A \\
\hline 9781405881562 & PR 2: APOLLO 13 2ED. * & 5,275 & 55 & A \\
\hline 9780132469876 & TOP NOTCH 2ED. 3 SB W/ACTIVEBOOK & 4,087 & 55 & A \\
\hline 9781408267202 & $\begin{array}{l}\text { NEW TOTAL ENGLISH PRE-INTER. SB W/ACTIVE BOOK } \\
\text { PACK } *\end{array}$ & 1,271 & 55 & A \\
\hline 9780136039297 & POCKETS 2ED. 3 WB W/AUDIO CD & 1,197 & 55 & A \\
\hline 9780132546676 & IN SYNC 2A SB + LANGUAGE BUILDER W/CD-ROM & 979 & 55 & A \\
\hline 9780194034074 & TEEN2TEEN 4 PACK PLUS (SB+WB) & 908 & 55 & A \\
\hline 9780521221696 & SUPER MINDS 3 WB & 614 & 55 & A \\
\hline 9780521185370 & ENGLISH IN MIND 2ED. STARTER SB W/DVD & 593 & 55 & A \\
\hline 9780521222181 & SUPER MINDS 4 SB W/DVD-ROM & 539 & 55 & $\mathrm{~A}$ \\
\hline
\end{tabular}

Elaboración propia.

pág. 320 


\begin{tabular}{|c|c|c|c|c|}
\hline 9780521170246 & ENGLISH IN MIND 2ED. STARTER WB & 507 & 55 & A \\
\hline 9786073215268 & $\begin{array}{l}\text { BIOLOGIA LA VIDA EN LA TIERRA CON FISIOLOGIA 9ED. } \\
(\mathrm{K}-12)\end{array}$ & 382 & 55 & A \\
\hline 9781447928812 & CHOICES ELEMENTARY SB W/MYENGLISHLAB & 269 & 55 & A \\
\hline 9780194774215 & AMERICAN ENGLISH FILE 1A SB+WB W/MULTI-ROM & 1,386 & 54 & A \\
\hline 9786074814989 & $\begin{array}{l}\text { ANDERSON - METODOS CUANTITATIVOS PARA LOS } \\
\text { NEGOCIOS } 11 \mathrm{ED} \text {. }\end{array}$ & 1,055 & 54 & A \\
\hline 9780521179072 & ENGLISH IN MIND 2ED. 1 SB W/DVD-ROM * & 964 & 54 & A \\
\hline 9780521131902 & KID’S BOX (BE) 1 ACTIVITY BOOK W/CD-ROM & 695 & 54 & A \\
\hline 9780521148573 & SUPER MINDS $1 \mathrm{WB}$ & 691 & 54 & A \\
\hline 9780521712125 & INTERACTIVE 2 SB WITH WEB ZONE ACCESS & 615 & 54 & A \\
\hline 9780194046701 & PLAYTIME B WB & 594 & 54 & A \\
\hline 9780141357027 & THE LONG HAUL (DIARY OF A WIMPY KID BOOK 9) & 416 & 54 & A \\
\hline 9786074049671 & MI LIBRO DE HISTORIAS MAGNETICAS - BATMAN & 112 & 54 & A \\
\hline 9781133939351 & OUR WORLD (AE) 2 SB W/CD-ROM & 2,106 & 53 & A \\
\hline 9781133942405 & OUR WORLD (AE) 4 SB W/CD-ROM & 891 & 53 & A \\
\hline 9780132314770 & MY LITTLE ISLAND (AE) 1 SB W/ACTIVE TEACH & 833 & 53 & A \\
\hline 9780132442909 & POSTCARDS 2ED. 1B SPLIT SB W/CD-ROM AND AUDIO CD & 735 & 53 & A \\
\hline 9780521148559 & SUPER MINDS 1 SB W/DVD-ROM & 698 & 53 & A \\
\hline 9786074049701 & 50 HISTORIAS DE PRINCESAS & 295 & 53 & A \\
\hline 9789707187450 & EXPLORADOR 3D: EL SISTEMA SOLAR & 143 & 53 & A \\
\hline 9780194517881 & $\begin{array}{l}\text { ENGLISH FILE 3ED. ELEM. SB W/ITUTOR AND ONLINE } \\
\text { SKILLS * }\end{array}$ & 2,926 & 52 & A \\
\hline 9780194462037 & GOT IT! STARTER SB+WB W/CD-ROM & 1,081 & 52 & A \\
\hline 9781133945123 & OUR WORLD (AE) $1 \mathrm{WB}$ W/AUDIO CD & 1,067 & 52 & A \\
\hline 9780521712088 & INTERACTIVE 1 SB WITH WEB ZONE ACCESS & 655 & 52 & A \\
\hline 9780194596176 & OXFORD PHONICS WORLD 1 SB W/MULTI-ROM & 638 & 52 & A \\
\hline 9780132547697 & IN SYNC 1 SB W/MULTI-ROM & 847 & 51 & A \\
\hline 9780133437546 & BIG FUN 1 WB W/AUDIO CD & 635 & 51 & A \\
\hline 9780131109971 & ENGLISH ADVENTURE (AE) 1 SB W/CD & 1,035 & 50 & A \\
\hline 9780132985598 & BIG ENGLISH (AE) $6 \mathrm{SB}$ & 896 & 50 & A \\
\hline 9780133045246 & BIG ENGLISH (AE) 6 WB W/AUDIO CD & 870 & 50 & A \\
\hline 9780194643238 & LET'S GO 4ED. 4 WB & 734 & 50 & A \\
\hline 9780521712156 & INTERACTIVE 2 WB WITH DOWNLOADABLE AUDIO & 651 & 50 & A \\
\hline 9780521279789 & ENGLISH IN MIND 2ED. 3A COMBO W/DVD-ROM & 454 & 50 & A \\
\hline 9786076180495 & $\begin{array}{l}\text { MI PEQUEÑA BIBLIOTECA: LA SIRENITA (INCLUYE } 3 \\
\text { LIBROS) } *\end{array}$ & 126 & 50 & A \\
\hline
\end{tabular}

Elaboración propia.

pág. 321 
Anexo 6. Manual 5’S Distribuidora SBS

\begin{tabular}{|c|c|c|c|}
\hline \multirow{2}{*}{ SBS $\mid$ internacional } & \multirow{2}{*}{\multicolumn{2}{|c|}{ ESTRATEGIA 5'S - ALMACÉN CENTRAL }} & $\begin{array}{l}\text { Código: } \\
\text { GG - SCM - } 01 \\
\end{array}$ \\
\hline & & & Página: 1 de 4 \\
\hline \multirow{2}{*}{ MANUAL 5} & Elabodado por: Comité 5's & Fecha de Publicación: 18.06.16 & Aprobado por: \\
\hline & Revisado y modificado: & Fecha de Efectividad: 18.06.16 & \\
\hline
\end{tabular}

\section{1.- OBJETIVO GENERAL:}

Establecer los Objetivos, criterios y lineamientos para la implementación, aplicación, mantenimiento y mejora del método de las 5'S dentro del Almacén Central de Librería SBS.

\section{2.- ALCANCE}

Se ha definido como ámbito de aplicación el Almacén Central de SBS por el flujo de mercadería (entrada - salida) del proceso de acondicionamiento de la mercadería, recepción y almacenamiento, Picking, Packing y Transporte.

\section{3.- DEFINICIONES}

El presente manual de las 5'S es la guía de aplicación de la propuesta de las Metodología ${ }^{5}$ 'S, que significa en japonés Seiri, Seiton, Seiso, Seiketsu y Shitsuke; que tiene como base el compromiso de los colaboradores con respecto al orden, la limpieza y disciplina en el lugar de trabajo, estableciendo estándares y controles que buscan la mejora continua.

- Seiri : Clasificación mantener solo lo necesario.

- Seiton: Organización, mantener todo en orden.

- Seiso: Mantener todo limpio

- Seiketsu; Establecer estándares de aplicación.

- Shitsuke; Disciplina, crear cultura para el sostenimiento de las 5's

- Comité 5'S: Colaboradores asignados y responsables de la implementación, coordinación y seguimiento de las actividades relacionadas a las 5'S.

\section{4.- RESPONSABILIDADES}

Es responsabilidad de la Gerente General la aprobación del Manual 5’S así como destinar los recursos necesarios para su implementación. 


\begin{tabular}{|c|c|c|c|}
\hline \multirow{2}{*}{ SBS librería } & \multirow{2}{*}{\multicolumn{2}{|c|}{ ESTRATEGIA 5'S - ALMACÉN CENTRAL }} & $\begin{array}{l}\text { Código: } \\
\text { GG - SCM - } 01\end{array}$ \\
\hline & & & Página: 2 de 4 \\
\hline \multirow{2}{*}{ MANUAL 5'S } & Elabodado por: Comité 5'S & Fecha de Publicación: 18.06 .16 & \multirow[t]{2}{*}{ Aprobado por: } \\
\hline & Revisado y modificado: & Fecha de Efectividad: 18.06.16 & \\
\hline
\end{tabular}

Es responsabilidad de los colaboradores del Almacén central aplicar la metodología 5'S en su área de trabajo.

Es responsabilidad del Comité 5'S la implementación y el seguimiento del cumplimiento de la metodología en el Almacén de la empresa, así como, disponer acciones de control y correctivas en caso hubieran.

\section{5.-DOCUMENTACIÓN RELACIONADA}

- Aplicación del Seiri.

- Aplicación de Seiton,

- Tarjeta Roja de identificación

- Informe de actividades de 5'S,

- Informe de avances obtenidos 5'S

- Lista de objetos enviados al almacén Seiri

\section{6.- ORGANIGRAMA 5'S}

A continuación el Organigrama del Comité 5'S. El principio de organización del Comité 5'S está basado en el trabajo colectivo y responsabilidad individual.

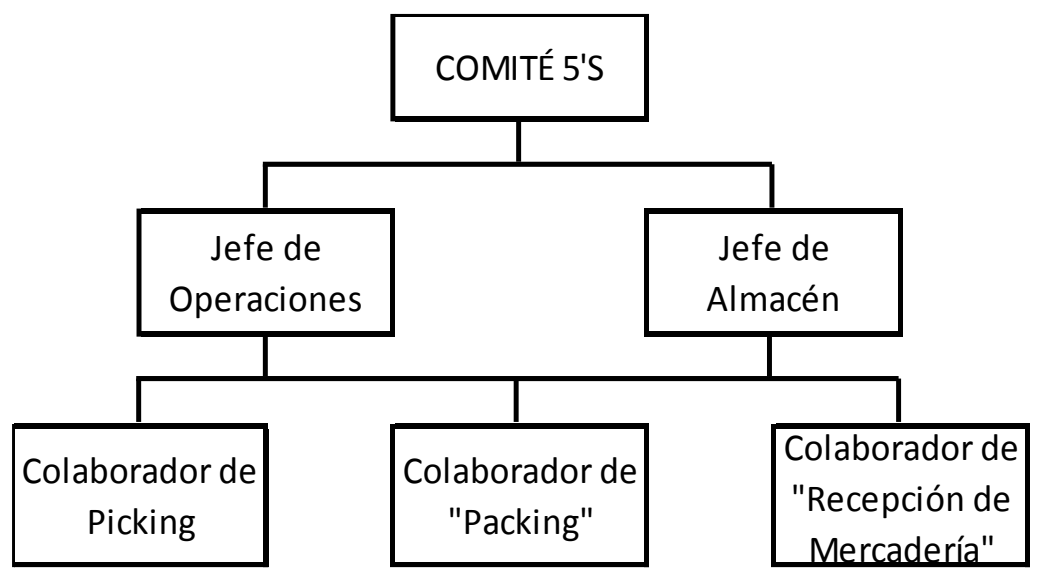




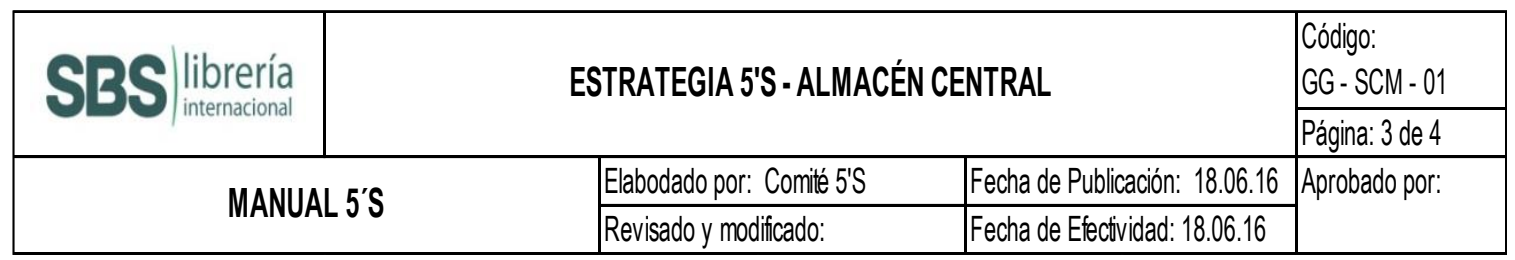

\section{7.- PROGRAMA 5'S}

\subsection{PLANEAR}

El Comité 5'S es el encargado de elaborar el Plan de Implementación y Mantenimiento del Programa 5'S, asimismo, mantener una participación activa y verificar el cumplimiento de la acciones que conducen a la mejora. El Comité 5'S es el responsable de garantizar la disponibilidad de los documentos e informes para el cumplimiento del plan.

\subsection{HACER}

Fomentar la práctica del trabajo en equipo, velar por el cumplimiento de la programación establecida en el plan de trabajo.

Verificar y hacer seguimiento que todo el personal de Almacén Central de Special Book Services se involucre activamente en el cumplimiento de las acciones de mejora.

Programar, convocar y asistir a todas las reuniones programadas por el comité 5'S, así como dejar en actas los acuerdos, avances y evidencias de la misma.

Reportar los avances y levantar las observaciones de las actividades que se desarrollan, mediante la elaboración de informes periódicos en los formatos pre establecidos.

\subsection{VERIFICAR}

Verificar in situ que las acciones programadas se estén ejecutando en forma adecuada y en tiempo oportuno siempre respetando la metodología 5'S.

La Gerencia General y el Comité 5'S son los responsables de las Auditorias que evalúan el cumplimiento del programa 5'S.

La Gerencia General y el Comité 5'S son los responsables de la ejecución y cumplimiento del plan de Auditoria. 


\begin{tabular}{|c|c|c|c|}
\hline \multirow{2}{*}{ SBS $\mid$ interracional } & \multirow{2}{*}{\multicolumn{2}{|c|}{ ESTRATEGIA 5'S - ALMACÉN CENTRAL }} & $\begin{array}{l}\text { Código: } \\
\text { GG - SCM - } 01 \\
\end{array}$ \\
\hline & & & Página: 4 de 4 \\
\hline \multirow{2}{*}{ MANUAL 5'S } & Elabodado por: Comité 5'S & Fecha de Publicación: 18.06.16 & \multirow[t]{2}{*}{ Aprobado por: } \\
\hline & Revisado y modificado: & Fecha de Efectividad: 18.06.16 & \\
\hline
\end{tabular}

\subsection{ACTUAR}

El Comité 5'S elaborará los informes de avances y resultados de la implementación del plan de trabajo, el cual debe incluir necesariamente evidencias objetivas, como fotografías o diagramas que expliquen y justifiquen la mejora.

Con los informes de avances y resultados de la implementación, el Comité 5'S efectuara los análisis respectivos que permita la evaluación de la nueva situación y de ser el caso, tomar medidas correctivas o de fortalecimiento. Así, será una retroalimentación de la implementación que busca la mejora permanente y continua. 
Anexo 7. Cronograma de planificación de metodología 5'S

\begin{tabular}{|c|c|c|c|c|c|c|c|c|c|c|c|c|c|c|c|}
\hline \multirow{3}{*}{ ACTIVIDAD } & \multirow{3}{*}{ RESPONSABLE } & \multirow{3}{*}{ ACTIVIDADES } & \multicolumn{13}{|c|}{2016} \\
\hline & & & \multirow{2}{*}{\begin{tabular}{|c|} 
MES \\
SEMANA
\end{tabular}} & \multicolumn{4}{|c|}{ JUN } & \multicolumn{4}{|c|}{ JULIO } & \multicolumn{4}{|c|}{ AGO } \\
\hline & & & & 1 & 2 & 3 & 4 & 3 & 4 & 5 & 6 & 7 & 8 & 9 & 10 \\
\hline \multirow{3}{*}{$\begin{array}{l}\text { Organización } \\
\text { del comité }\end{array}$} & Gerente General & Conformación del Comité 5'S & & & & & & & & & & & & & \\
\hline & Jefe de Proyecto & Determinarlas directices y Objetivos & & & & & & & & & & & & & \\
\hline & Jefe de Proceso & Velar por el cumplimiento del Proyecto & & & & & & & & & & & & & \\
\hline \multirow{3}{*}{$\begin{array}{l}\text { Lanzamiento } \\
\text { Oficial }\end{array}$} & Jefe de Proyecto & Organizar con GEP las campañas de intriga & le las 5 'S & & & & & & & & & & & & \\
\hline & Gerente General & Lanzamiento Oficial & & & & & & & & & & & & & \\
\hline & & & & & & & & & & & & & & & \\
\hline \multirow{3}{*}{$\begin{array}{l}\text { Capacitación } \\
\text { Interna }\end{array}$} & Jefe de Proyecto & Capacitación al grupo guía & & & & & & & & & & & & & \\
\hline & \begin{tabular}{|l|} 
Jefe de Proyecto \\
\end{tabular} & Elaboración del Material para la capacitaci & & & & & & & & & & & & & \\
\hline & Jefe de Proceso & Capacitación del Personal & & & & & & & & & & & & & \\
\hline \multirow{3}{*}{$\begin{array}{l}\text { Inicio de } \\
\text { Clasificar }\end{array}$} & Jefe de Proyecto & Separarlo necesario de lo innecesario & & & & & & & & & & & & & \\
\hline & Jefe de Proceso & Buscar destino a lo no necesario & & & & & & & & & & & & & \\
\hline & & & & & & & & & & & & & & & \\
\hline \multirow{3}{*}{$\begin{array}{l}\text { Inicio de } \\
\text { Ordenar }\end{array}$} & & Organizar espacios & & & & & & & & & & & & & \\
\hline & Jefe de Proyecto & Ubicar e identificar las herramientas según & su uso & & & & & & & & & & & & \\
\hline & Jefe de Proceso & Delimitar, áreas, estantes & & & & & & & & & & & & & \\
\hline \multirow{3}{*}{$\begin{array}{l}\text { Inicio de } \\
\text { Limpiar }\end{array}$} & & Asgnación de limpieza poráreas & & & & & & & & & & & & & \\
\hline & Jefe de Proyecto & Establecer roles de limpieza y frecuencia & & & & & & & & & & & & & \\
\hline & Jefe de Proceso & Concientizar para manener todo limpio & & & & & & & & & & & & & \\
\hline \multirow{3}{*}{$\begin{array}{l}\text { Inicio de } \\
\text { estándarizar }\end{array}$} & & Preservar orden y limpieza & & & & & & & & & & & & & \\
\hline & Jefe de Proyecto & Definir estándares & & & & & & & & & & & & & \\
\hline & Jefe de Proceso & Informar avances y retroalimentación al pe & sonal & & & & & & & & & & & & \\
\hline \multirow{3}{*}{$\begin{array}{l}\text { Inicio de } \\
\text { Disciplina }\end{array}$} & & & & & & & & & & & & & & & \\
\hline & Jefe de Proyecto & Implementación de procedimientos y forma & & & & & & & & & & & & & \\
\hline & Jefe de Proceso & Curso de trabajo en equipo & & & & & & & & & & & & & \\
\hline
\end{tabular}

Elaboración propia. 


\section{Anexo 8. Informativo de aplicación del Seiri}

\begin{tabular}{|c|c|c|c|}
\hline \multirow{2}{*}{ SBS librería } & \multirow{2}{*}{\multicolumn{2}{|c|}{ ESTRATEGIA 5'S - ALMACÉN CENTRAL }} & \begin{tabular}{|l} 
Código: \\
GG - SCM - 01
\end{tabular} \\
\hline & & & Página: 1 de 2 \\
\hline \multirow{2}{*}{ APLICACIÓN SEIRI } & Elabodado por: Comité 5'S & Fecha de Publicación: & \multirow[t]{2}{*}{ Aprobado por: } \\
\hline & \begin{tabular}{|l|} 
Revisado y modificado: \\
\end{tabular} & Fecha de Efectividad: & \\
\hline
\end{tabular}

Todo el personal debe:

- Identificar los objetos necesarios

- Clasificar los objetos innecesarios, según la tabla siguiente:

\begin{tabular}{|l|l|l|c|}
\hline \multicolumn{4}{|c|}{ ETAPA SEIRI : TABLA PARA EL CRITERIO DE DECISIONES } \\
\hline \multicolumn{1}{|c|}{ CRITERIO } & \multicolumn{1}{|c|}{ DEFINICIÓN } & ACCIÓN A TOMAR & TARJETA \\
\hline MAL ESTADO & $\begin{array}{l}\text { Son objetos que ya no se utilizan y } \\
\text { no se pueden reparar }\end{array}$ & Resechar \\
\hline FUERA DE USO & $\begin{array}{l}\text { Objetos fuera de uso, pueden } \\
\text { estar en buen estado. }\end{array}$ & Almacen SEIRI & Roja \\
\hline PELIGROSO & $\begin{array}{l}\text { Liquidos inflamables, polvo } \\
\text { químico, gas. }\end{array}$ & $\begin{array}{l}\text { Procedimiento de } \\
\text { Manual Seguridad }\end{array}$ & Roja \\
\hline $\begin{array}{l}\text { OBJETOS AJENOS AL } \\
\text { ÁREA }\end{array}$ & $\begin{array}{l}\text { Objetos en buen estado pero no } \\
\text { son del área en que se encuentran }\end{array}$ & $\begin{array}{l}\text { Trasladar al área que } \\
\text { pertenece }\end{array}$ & Roja \\
\hline ARTICULO DE OFICINA & $\begin{array}{l}\text { Lapiceros, borradores, hojas, } \\
\text { engrapador, etc. }\end{array}$ & $\begin{array}{l}\text { Trasladar al lugar que } \\
\text { pertenece }\end{array}$ & Roja \\
\hline
\end{tabular}

El coordinador del área debe tener presente:

Asignar el área en la cual se almacenarán temporalmente los objetos calificados como innecesarios, esto hasta su posterior traslado

- Verificar que todos los objetos estén debidamente clasificados

- Codificar los objetos obsoletos con AS - 1S - 01

- Codificar los objetos vencidos con AS - 1S - 01

- Codificar los objetos en mal estado con AS - 1S - 01

- Codificar los objetos peligrosos con AS - $1 \mathrm{~S}-01$

- Codificar los objetos ajenos al área con AS - 1S - 01 


\begin{tabular}{|c|c|c|c|}
\hline SBS librería & \multirow{2}{*}{\multicolumn{2}{|c|}{ ESTRATEGIA 5'S - ALMACÉN CENTRAL }} & $\begin{array}{l}\text { Código: } \\
\text { GG - SCM - } 01\end{array}$ \\
\hline & & & Página: 2 de 2 \\
\hline \multirow{2}{*}{ APLICACIÓN SEIRI } & Elabodado por: Comité 5'S & Fecha de Publicación: & \multirow[t]{2}{*}{ Aprobado por: } \\
\hline & Revisado y modificado: & Fecha de Efectividad: & \\
\hline
\end{tabular}

- Elaborar la Lista de Objetos enviados al almacén Seiri AS - 1S - 01

- Designar fecha para traslado de objetos innecesarios y trasladarlos

- Elaborar Informe de Actividades 5'S, IA - 1S - 02

El comité 5'S,

- Revisar Informe de Actividades 5'S, IA - 1S - 02

- Preparar Informe de Avances Obtenidos IO - 1S - 03

- Elaborar informe final al Gerente General 
Anexo 9. Lista de objetos enviados al almacén SEIRI

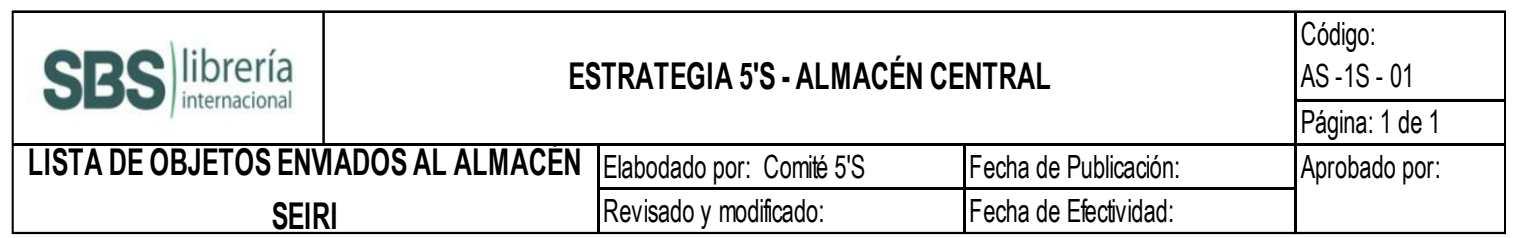

Área:

Coordinador de área:.

Fecha:

\begin{tabular}{|l|l|l|}
\hline CANTIDAD & OBJETO & \\
\hline & & \\
\hline & & \\
\hline & & \\
\hline & & \\
\hline & & \\
\hline & & \\
\hline & & \\
\hline & & \\
\hline & & \\
\hline & & \\
\hline & & \\
\hline & & \\
\hline & & \\
\hline & & \\
\hline
\end{tabular}


Anexo 10. Informe de actividades 5'S

\begin{tabular}{|c|c|c|c|}
\hline \multirow{2}{*}{ SBS librería } & \multirow{2}{*}{\multicolumn{2}{|c|}{ ESTRATEGIA 5'S - ALMACÉN CENTRAL }} & $\begin{array}{l}\text { Woalgo: } \\
\text { |A-1S-02 }\end{array}$ \\
\hline & & & Página: 1 de 1 \\
\hline \multirow{2}{*}{ STIMDADES 5 'S } & Elabodado por: Comité 5'S & Fecha de Publicación: & \multirow[t]{2}{*}{ Aprobado por: } \\
\hline & Revisado y modificado: & Fecha de Efectividad: & \\
\hline
\end{tabular}

Coordinador de área

Comité 5'S

Fecha de entrega:

Área:

S - Aplicada:

Descripción:

\section{Actividades realizadas:}

\section{Observaciones:}


Anexo 11. Informe de avances obtenidos

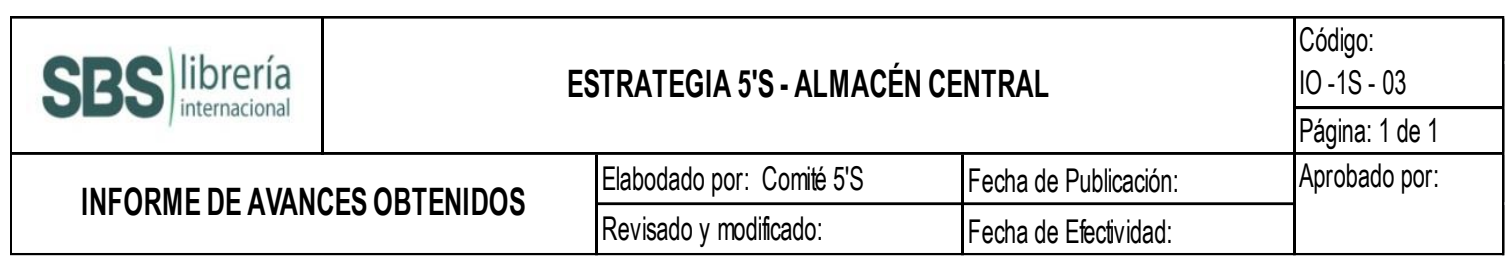

Fecha de entrega:

\section{Actividad:}

\section{1.- Avance por área.}

\section{3.- Recomendaciones}

\section{Comite 5'S}

Gerente General 
Anexo 12. Instructivo de aplicación del Seiton

\begin{tabular}{|c|c|c|c|}
\hline \multirow{2}{*}{ SBS $\mid$ internacional } & \multirow{2}{*}{\multicolumn{2}{|c|}{ ESTRATEGIA 5'S - ALMACÉN CENTRAL }} & $\begin{array}{l}\text { Código: } \\
\text { AS - 2S - } 04\end{array}$ \\
\hline & & & Página: 1 de 2 \\
\hline \multirow{2}{*}{ APLICACIÓN DEL SEITON } & Elabodado por: Comité 5'S & Fecha de Publicación: & \multirow[t]{2}{*}{ Aprobado por } \\
\hline & Revisado y modificado: & Fecha de Efectividad: & \\
\hline
\end{tabular}

\section{Pasos a seguir para la aplicación del Seiton:}

Todas las áreas de trabajo deben estar debidamente identificadas y rotuladas:

Todo el personal debe:

- Verificar que se haya realizado el paso Seiri

- Ordenar los objetos necesarios según:

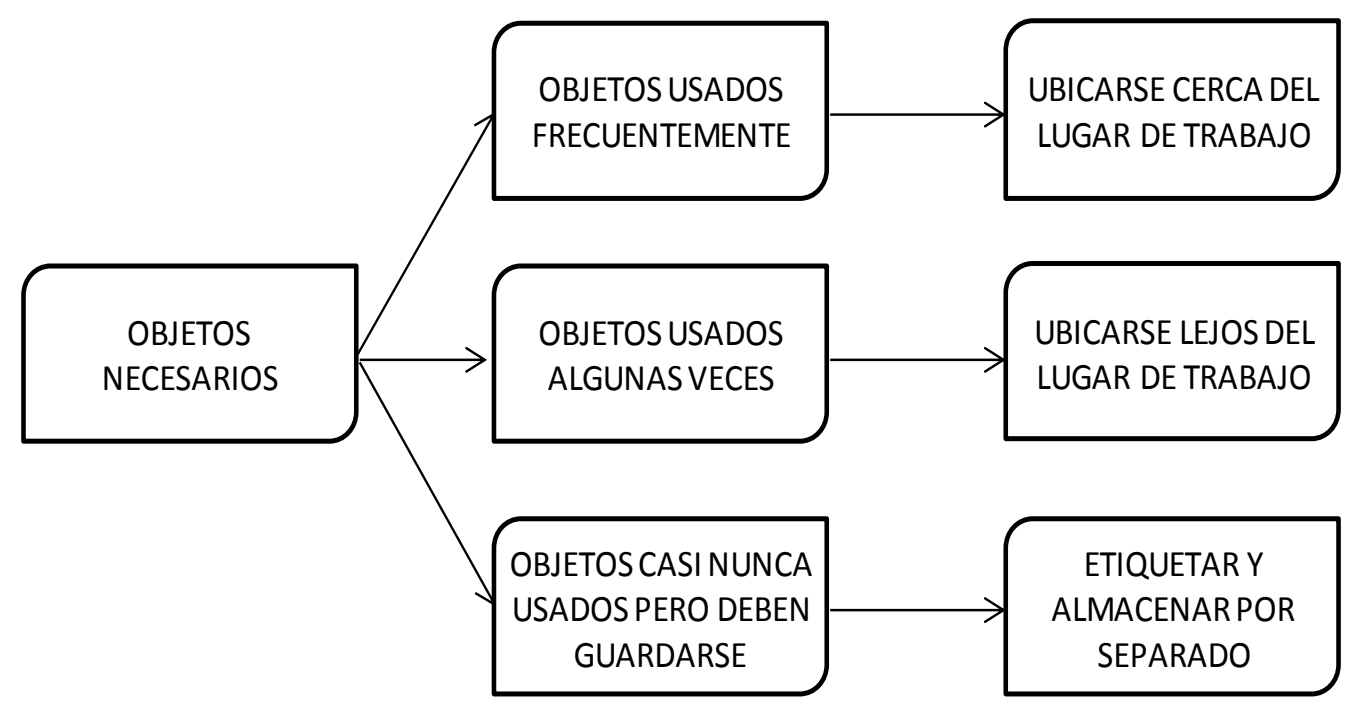

- Asignar ubicaciones específicas a cada objeto

- Definir criterios para ordenar los objetos, por áreas, por color, por orden alfabético, orden numérico; para facilitar la ubicación rápida por cualquier persona.

- Seleccionar, enlistar y rotular los objetos o lugares según aplique

- Asegurar los medios para que cada cosa regrese a su lugar una vez haya sido utilizado 


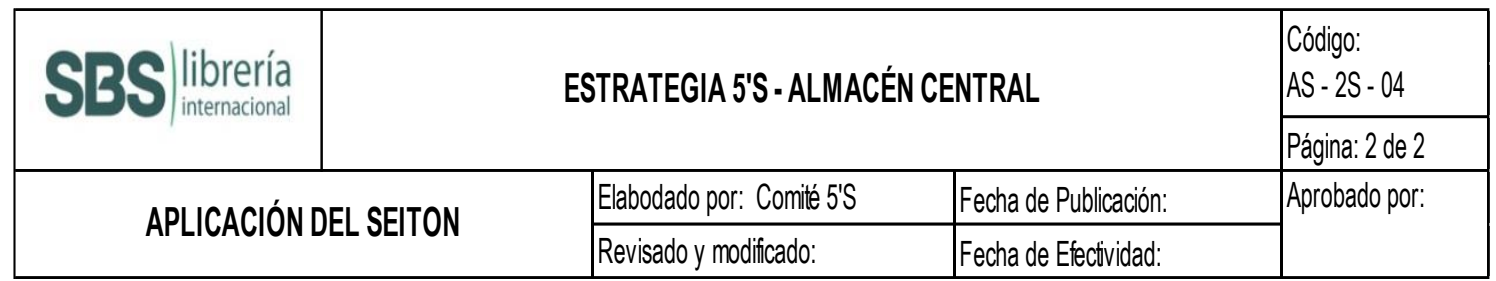

El coordinador de área:

- Supervisas y velar por el cumplimiento de la segunda S, Seiton

- Elaborar y entregar el informe de actividades TR - GG- 12

El comité 5'S

- Revisar Informe de actividades 5'S, TR GG 12

- Preparar Informe de avances Obtenidos TR GG 11

- Elaborar informe final al Gerente General 
Anexo 13. Agenda Día de la Gran Limpieza

\begin{tabular}{|c|c|c|}
\hline SBS librería & \multicolumn{2}{|l|}{ DIA DE LA GRAN LIMPIEZA } \\
\hline \multirow{3}{*}{ AGEN } & \multicolumn{2}{|c|}{ COMITÉ 5'S Y GEP } \\
\hline & FECHA: & PERSONAS \\
\hline & ACIIVIDAD & ASIGNADAS \\
\hline Perimetros & $\begin{array}{l}\text { Áreas verdes, aceras, paredes exteriores, } \\
\text { accesos, ventanas, luminarias }\end{array}$ & Coord. Almacén \\
\hline $\begin{array}{l}\text { Señalización } \\
\text { general }\end{array}$ & $\begin{array}{l}\text { Áreas de parqueo, rutas de acceso, zonas de } \\
\text { seguridad, vías de circulación en almacén y áreas } \\
\text { de trabajo }\end{array}$ & Coord. Almacén \\
\hline $\begin{array}{l}\text { Almacén - } \\
\text { Recepcion } \\
\text { Mercadería }\end{array}$ & $\begin{array}{l}\text { Pisos, mesas de trabajo, estantes, racks } \\
\text { inferiores }\end{array}$ & $\begin{array}{l}\text { Coord. } \\
\text { Devoluciones }\end{array}$ \\
\hline Almacén - Picking & Pisos, paredes, estantes, racks de 06 niveles & Coord. Picking \\
\hline Almacén - Packing & $\begin{array}{l}\text { Pisos, mesas de trabajo, estantes, racks } \\
\text { inferiores }\end{array}$ & Coord. Packing \\
\hline $\begin{array}{l}\text { Almacén - } \\
\text { Retractilado }\end{array}$ & $\begin{array}{l}\text { Pisos, paredes, puntos de luz, maquinaria, luces, } \\
\text { secadoras }\end{array}$ & $\begin{array}{c}\text { Coord. } \\
\text { Retractilado }\end{array}$ \\
\hline $\begin{array}{l}\text { Almacén - } \\
\text { Transporte }\end{array}$ & Pisos, paredes, poleas, porton de metal & Coord. Transporte \\
\hline $\begin{array}{l}\text { Almacén } \\
\text { Entreplanta }\end{array}$ & Pisos, paredes, estantes, escritorios, & Lider almacén 1 \\
\hline $\begin{array}{l}\text { Almacén Zona } \\
\text { descarga }\end{array}$ & Pisos, paredes, luminarias & Lider almacén 2 \\
\hline $\begin{array}{l}\text { Almacén - Área } \\
\text { Consignación }\end{array}$ & Pisos, paredes, luminarias & $\begin{array}{c}\text { Personal } \\
\text { administrativo } \\
\end{array}$ \\
\hline Servicios Higiénicos & $\begin{array}{l}\text { Limpieza total, limpieza de techos, pisos y } \\
\text { luminarias, desinfección, acondicionamiento, } \\
\text { contenedores papel y jabon }\end{array}$ & $\begin{array}{c}\text { Personal } \\
\text { mantenimiento }\end{array}$ \\
\hline $\begin{array}{l}\text { Almacén } \\
\text { Administrativo }\end{array}$ & $\begin{array}{l}\text { Pisos, paredes, luminarias, ventana, escritorios, } \\
\text { estantes, archivadores, equipos }\end{array}$ & $\begin{array}{l}\text { Asistente } \\
\text { Almacén }\end{array}$ \\
\hline $\begin{array}{l}\text { Almacén Zona de } \\
\text { cafeteria }\end{array}$ & $\begin{array}{l}\text { Pisos, paredes, luminarias, equipos, utencilios, } \\
\text { mesas, sillas. }\end{array}$ & Asistente GEP \\
\hline
\end{tabular}


Anexo 14. Formulario del Plan de Actividades de Mejora

\begin{tabular}{|c|c|}
\hline SBS librería & FORMULARIO DEL PLAN DE ACTIVDADES DE MEJORA \\
\hline \multicolumn{2}{|l|}{ Área } \\
\hline \multicolumn{2}{|l|}{ Grupo } \\
\hline \multicolumn{2}{|l|}{ Lider } \\
\hline \multicolumn{2}{|l|}{ Miembros } \\
\hline \multicolumn{2}{|l|}{ Fecha } \\
\hline \multicolumn{2}{|l|}{ Asunto } \\
\hline \multicolumn{2}{|l|}{$\begin{array}{l}\text { Situación } \\
\text { actual }\end{array}$} \\
\hline \multicolumn{2}{|l|}{ Meta } \\
\hline \multicolumn{2}{|l|}{ Periodo } \\
\hline Comentarios & \\
\hline
\end{tabular}


Anexo 15. Minuta de reunión 5'S

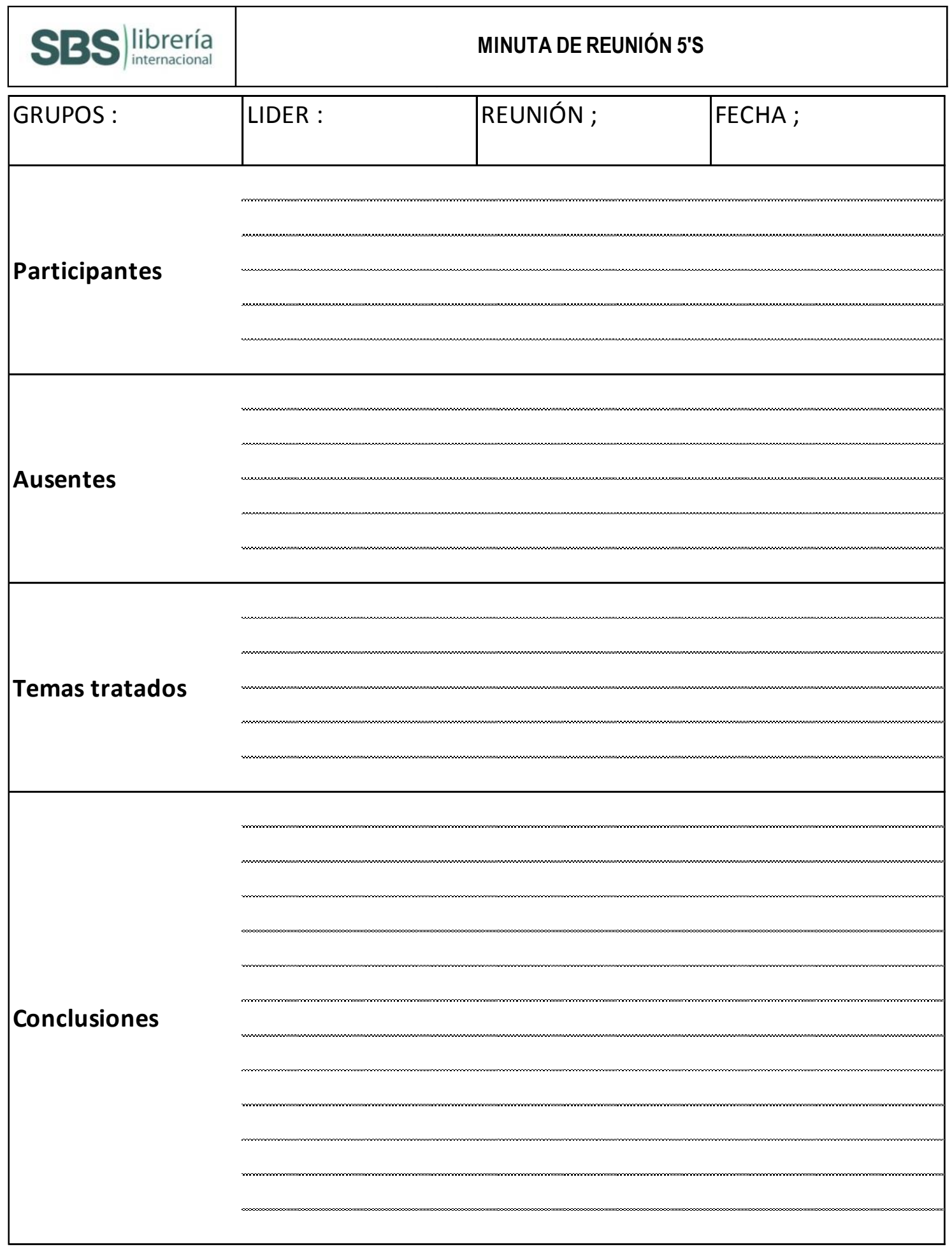




\section{Anexo 16. Autoevaluación}

\begin{tabular}{|l|l|l|}
\hline SBS librería & \multicolumn{3}{|l|}{ CUESTIONARIO DE AUDITORIA } \\
\hline LIDER: & GRUPO: & FECHA: \\
\hline
\end{tabular}

\begin{tabular}{|c|c|c|c|c|}
\hline CATEGORIA & $|\mathbf{N} 0|$ & DPEG INT AS & 19 & 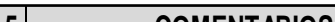 \\
\hline \multirow{5}{*}{ SELECCIONAR } & $\theta_{1}$ & & & \\
\hline & & ¿Existen objetos innecesario en su puesto de trabajo? & & \\
\hline & 2 & ¿Existen equipos y herramientas innecesarias en su puesto de trabajo? & & \\
\hline & 3 & ¿Los corredores y áreas de trabajo están limpios, libres y señalizados? & & \\
\hline & & $\begin{array}{l}\text { PUNTAJE TOTAL SELECCIONAR } \\
\end{array}$ & & \\
\hline \multirow{6}{*}{ ORDENAR } & 1 & ¿Están marcadas visualmente las herramientas? & & \\
\hline & 2 & ¿Están en su sitio las herramientas, materiales y equipos? & & \\
\hline & 3 & ¿Los lugares de los artículos fallados son fáciles de reconocer? & & \\
\hline & 4 & ¿El fací reconocer el lugar de cada objeto? & & \\
\hline & 5 & ¿Se vuelve a colocar en su lugar las cosas luego de usarla? & & \\
\hline & & PUNTAJE TOTAL ORDENAR & & \\
\hline \multirow{5}{*}{ LIMPIAR } & 1 & $\begin{array}{l}\text { ¿Las áreas de trabajo están limpias y cuenta con elementos apropiados } \\
\text { para limpiarlos? }\end{array}$ & & \\
\hline & 2 & ¿Las mesas de trabajo, pisos, paredes, pasillos se encuentran limpios? & & \\
\hline & 3 & ¿Localiza facilmente los materiales de limpieza? & & \\
\hline & 4 & ¿Son visibles los horarios de limpieza? & & \\
\hline & & PUNTAJE DE LIMPIAR & & \\
\hline \multirow{5}{*}{ ESTANDARIZAR } & 1 & $\begin{array}{l}\text { ¿Los colaboradores disponen de toda información necesaria como } \\
\text { normas, procedimientos, tiempos para el desempeño en el puesto de } \\
\text { trabajo? }\end{array}$ & & \\
\hline & 2 & ¿Se aplicas las 3 primeras "S"? & & \\
\hline & 3 & ¿Se respetan las normas y procedimientos? & & \\
\hline & 4 & ¿Están asignadas las presponsabilidades de limpieza? & & \\
\hline & & PUNTAJE DE ESTANDARIZAR & & \\
\hline \multirow{6}{*}{ AUTODISCIPLINA } & 1 & ¿Los trabajadores respetan los procedimientos y medidas de seguridad? & & \\
\hline & 2 & ¿son observadas las reglas de seguridad y limpieza? & & \\
\hline & 3 & ¿Se verifica el cumplimiento de la labor de limpieza? & & \\
\hline & 4 & ¿Los desperdicios están bien localizado y ordenados? & & \\
\hline & & PUNTAJE DE AUTODISCIPLINA & & \\
\hline & & PUNTAJE TOTAL & & \\
\hline
\end{tabular}




\section{Anexo 17. Matriz de calificación 5'S Almacén SBS - Clasificar}

\begin{tabular}{|l|l|}
\hline S & Mibrería \\
internacional & MATRIZ DE CALIFICACIÓN - CLASIFICAR \\
\hline
\end{tabular}

\begin{tabular}{|c|c|c|c|c|c|}
\hline \multicolumn{6}{|c|}{ MATRIZ DE CALIFICACION 5'S ALMACEN SBS - CLASIFICAR } \\
\hline CLASIFICAR & 1 & 2 & 3 & 4 & 5 \\
\hline $\begin{array}{l}\text { Objetos } \\
\text { innecesarios y } \\
\text { basura en el piso }\end{array}$ & $\begin{array}{l}\text { Objetos innecesarios, } \\
\text { basura en el piso, } \\
\text { perjudicando la } \\
\text { circulación con riesgo de } \\
\text { provocar accidentes }\end{array}$ & $\begin{array}{l}\text { Objetos innecesarios en } \\
\text { el piso perjudicando la } \\
\text { circulacion }\end{array}$ & $\begin{array}{l}\text { Objetos innecesarios en } \\
\text { el piso sin perjudicar la } \\
\text { circulación }\end{array}$ & $\begin{array}{l}\text { Objetos innecesarios } \\
\text { en el piso con } \\
\text { indicación para } \\
\text { moverlos }\end{array}$ & $\begin{array}{l}\text { Pisos totalmente } \\
\text { libres y demarcados }\end{array}$ \\
\hline $\begin{array}{l}\text { Equipos, } \\
\text { herramientas y } \\
\text { materiales } \\
\text { innecearios }\end{array}$ & $\begin{array}{l}\text { Existen herramientas, } \\
\text { materiales y equipos } \\
\text { innecesarios mezclados } \\
\text { con los necesarios }\end{array}$ & $\begin{array}{l}\text { Existen herramientas, } \\
\text { materiales y equipos } \\
\text { innecesarios separados } \\
\text { de los necesarios. No se } \\
\text { descarta lo innecesario }\end{array}$ & $\begin{array}{l}\text { Herramientas, } \\
\text { materiales y equipos } \\
\text { innecesarios separados } \\
\text { de los necesarios. Los } \\
\text { necesarios no están } \\
\text { acondicionados }\end{array}$ & $\begin{array}{l}\text { Existen herramientas, } \\
\text { materiales y equipos } \\
\text { necesarios pero no } \\
\text { están todos } \\
\text { acondicionados }\end{array}$ & $\begin{array}{l}\text { Existen herramientas, } \\
\text { materiales y equipos } \\
\text { necesarios, todos en } \\
\text { condiciones de uso }\end{array}$ \\
\hline $\begin{array}{l}\text { Objetos } \\
\text { innecesarios en } \\
\text { mesas de trabajo }\end{array}$ & $\begin{array}{l}\text { Lo necesarios esta } \\
\text { totalmente mezclado } \\
\text { con lo innecesario }\end{array}$ & $\begin{array}{l}\text { Lo neccesario está } \\
\text { separado de lo } \\
\text { innecesario. No se } \\
\text { descarta lo necesario }\end{array}$ & $\begin{array}{l}\text { Lo necesario está } \\
\text { separado de lo } \\
\text { innecesario. Lo } \\
\text { necesario no esta } \\
\text { acondicionado }\end{array}$ & $\begin{array}{l}\text { Está lo necesario, pero } \\
\text { sin acondicionar }\end{array}$ & $\begin{array}{l}\text { Solo esta lo } \\
\text { necesario, en buenas } \\
\text { condiciones de uso }\end{array}$ \\
\hline $\begin{array}{l}\text { Bolsas, cajas, } \\
\text { poleas, cables, } \\
\text { objetos en áreas } \\
\text { de circulación }\end{array}$ & $\begin{array}{l}\text { No hay lugar para } \\
\text { circular, existen objetos } \\
\text { de todo tipo } \\
\text { desparramados }\end{array}$ & $\begin{array}{l}\text { Existen objetos } \\
\text { desparramados que } \\
\text { dificultan la circulación }\end{array}$ & $\begin{array}{l}\text { Objetos apilados que } \\
\text { dificultan la circulación }\end{array}$ & $\begin{array}{l}\text { Objetos apilados que } \\
\text { no perjudican la libre } \\
\text { circulación }\end{array}$ & $\begin{array}{l}\text { Libre y limpio } \\
\text { totalmente }\end{array}$ \\
\hline
\end{tabular}


Anexo 18. Matriz de calificación 5'S Almacén SBS - Ordenar \begin{tabular}{|l|l|l|l|l|l|l|l|l|l|}
\hline internacional & MATRIZ DE CALIFICACIÓN - ORDENAR
\end{tabular}

\begin{tabular}{|c|c|c|c|c|c|}
\hline \multicolumn{6}{|c|}{ MATRIZ DE CALIFICACION 5'S ALMACÉN SBS - ORDENAR } \\
\hline ORDENAR & 1 & 2 & 3 & 4 & 5 \\
\hline $\begin{array}{l}\text { Ubicación y/o } \\
\text { devolución de } \\
\text { herramientas, } \\
\text { materiales y } \\
\text { equipos }\end{array}$ & $\begin{array}{l}\text { Dificiles de localizar, sin } \\
\text { identificación, ni lugar } \\
\text { definido para guardar. }\end{array}$ & $\begin{array}{l}\text { Dificiles de localizar, sin } \\
\text { identificación, ni lugar } \\
\text { definido para guardar. }\end{array}$ & $\begin{array}{l}\text { Fáciles de localizar, sin } \\
\text { identificación, con lugar } \\
\text { definido para guardar. } \\
\text { Luego de su uso no se } \\
\text { retornan } \\
\text { adecuadamente. }\end{array}$ & $\begin{array}{l}\text { Fáciles de localizar, } \\
\text { con identificación, } \\
\text { lugar definido para } \\
\text { guardar. Luego de su } \\
\text { uso no se retornan } \\
\text { adecuadamente. }\end{array}$ & $\begin{array}{l}\text { Fáciles de localizar, } \\
\text { con identificación, } \\
\text { lugar definido para } \\
\text { guardar. Luego de su } \\
\text { uso se retornan } \\
\text { adecuadamente }\end{array}$ \\
\hline $\begin{array}{l}\text { Armarios, } \\
\text { estantes, equipos } \\
\text { están } \\
\text { identificados }\end{array}$ & $\begin{array}{l}\text { Totalmente } \\
\text { desordenados. Ningún } \\
\text { tipo de identificación } \\
\text { del lugar donde guardar } \\
\text { y lo que se guarda. }\end{array}$ & $\begin{array}{l}\text { Parcialmente } \\
\text { desordenados. Ningún } \\
\text { tipo de identificación } \\
\text { del lugar donde guardar } \\
\text { y lo que se guarda. }\end{array}$ & $\begin{array}{l}\text { Ordenados. No poseen } \\
\text { ningún tipo de } \\
\text { identificación del lugar } \\
\text { donde guardar y lo que } \\
\text { se guarda. }\end{array}$ & $\begin{array}{l}\text { Ordenados. Poseen } \\
\text { parcialmente } \\
\text { identificación del } \\
\text { lugar donde guardary } \\
\text { lo que seguarda. }\end{array}$ & $\begin{array}{l}\text { Ordenados. Todo } \\
\text { posee identificación } \\
\text { del lugar donde } \\
\text { guardar y lo que se } \\
\text { guarda }\end{array}$ \\
\hline $\begin{array}{l}\text { Herramientas y } \\
\text { materiales están } \\
\text { en su lugar }\end{array}$ & $\begin{array}{l}\text { No hay nada } \\
\text { identificado, ni el lugar } \\
\text { ni las herramientas. }\end{array}$ & $\begin{array}{l}\text { Hay una identificación } \\
\text { elemental del lugar, no } \\
\text { de las herramientas. }\end{array}$ & $\begin{array}{l}\text { Los lugares y } \\
\text { herramientas están } \\
\text { parcialmente } \\
\text { identificadas }\end{array}$ & $\begin{array}{l}\text { Los lugares están } \\
\text { identificados, las } \\
\text { herramientas } \\
\text { parcialmente }\end{array}$ & \begin{tabular}{|l} 
Todo está \\
identificado, sean \\
lugares o \\
herramientas. \\
\end{tabular} \\
\hline $\begin{array}{l}\text { Objetos sobre y } \\
\text { debajo de } \\
\text { armarios, } \\
\text { estantes y } \\
\text { equipos }\end{array}$ & $\begin{array}{l}\text { Estos lugares se utilizan } \\
\text { para guardar objetos en } \\
\text { forma rutinaria }\end{array}$ & $\begin{array}{l}\text { Estos lugares se utilizan } \\
\text { para guardar objetos en } \\
\text { forma rutinaria en } \\
\text { armarios y estantes, no } \\
\text { debajo de equipos }\end{array}$ & $\begin{array}{l}\text { Solo se utiliza arriba de } \\
\text { los estantes y armarios } \\
\text { como lugar para guardar } \\
\text { objetos en forma } \\
\text { rutinaria. }\end{array}$ & $\begin{array}{l}\text { Solo se utiliza arriba } \\
\text { de los estantes y } \\
\text { armarios como lugar } \\
\text { para guardar objetos } \\
\text { en forma esporádica } \\
\text { debajo no. }\end{array}$ & $\begin{array}{l}\text { No se utiliza ni arriba } \\
\text { ni debajo como lugar } \\
\text { para guardar objetos }\end{array}$ \\
\hline
\end{tabular}


Anexo 19. Matriz de calificación 5'S Almacén SBS - Limpiar

\begin{tabular}{|l|l|}
\hline SBS & librería \\
internacional & MATRIZ DE CALIFICACIÓN - LIMPIAR \\
\hline
\end{tabular}

\begin{tabular}{|c|c|c|c|c|c|}
\hline \multicolumn{6}{|c|}{ MATRIZ DE CALIFICACION 5'S - LIMPIAR } \\
\hline LIMPIAR & 1 & 2 & 3 & 4 & 5 \\
\hline Pisos & $\begin{array}{l}\text { Permanentemente con } \\
\text { polvo, papeles, trapos y } \\
\text { restos de basura }\end{array}$ & Con polvo & $\begin{array}{l}\text { Con polvo, se ensucian } \\
\text { rápidamente. }\end{array}$ & $\begin{array}{l}\text { Limpios al final de la } \\
\text { jornada }\end{array}$ & $\begin{array}{l}\text { Limpios } \\
\text { permanentemente }\end{array}$ \\
\hline $\begin{array}{l}\text { Techos, paredes y } \\
\text { ventanas }\end{array}$ & $\begin{array}{l}\text { Deteriorados } \\
\text { totalmente, con } \\
\text { humedad, manchas o } \\
\text { sucias. Ventanas con } \\
\text { vidrios rotos y sucios. }\end{array}$ & $\begin{array}{l}\text { Techos y paredes } \\
\text { limpias y pintadas, con } \\
\text { polvillo y telas de } \\
\text { arañas. Ventanas y } \\
\text { vidrios sucios. }\end{array}$ & $\begin{array}{l}\text { Techos y ventanas } \\
\text { deteriorados, vidrios con } \\
\text { algo de polvo. }\end{array}$ & $\begin{array}{l}\text { Techos, paredes } \\
\text { limpias y pintadas, } \\
\text { ventanas con vidrios } \\
\text { empolvados. }\end{array}$ & $\begin{array}{l}\text { Techos y paredes } \\
\text { limpios y pintados. } \\
\text { Ventanas con vidrios } \\
\text { limpios }\end{array}$ \\
\hline $\begin{array}{l}\text { Armarios, } \\
\text { estantes, } \\
\text { herramientas y } \\
\text { muebles }\end{array}$ & $\begin{array}{l}\text { Deteriorados con oxido, } \\
\text { sin pintura, sucios, no se } \\
\text { limpian. }\end{array}$ & $\begin{array}{l}\text { Deteriorados, con } \\
\text { oxido, sin pintura, poca } \\
\text { limpieza. Algunas } \\
\text { herramientas en buenas } \\
\text { condiciones de uso } \\
(10 \%)\end{array}$ & $\begin{array}{l}\text { Pintadas, limpieza } \\
\text { semanal. Herramientas } \\
\text { en buenas condiciones } \\
\text { de uso }(50 \%)\end{array}$ & $\begin{array}{l}\text { Pintados, se limpian al } \\
\text { final de la jornada. } \\
\text { Herramientas en un } \\
90 \% \text { en buenas } \\
\text { condiciones de uso }\end{array}$ & $\mid \begin{array}{l}\text { Pintadas, limpieza } \\
\text { diaria al final de } \\
\text { jornada, } \\
\text { herramientas en } \\
100 \% \text { en buenas } \\
\text { condiciones de uso }\end{array}$ \\
\hline $\begin{array}{l}\text { Máquinas y } \\
\text { equipos }\end{array}$ & $\begin{array}{l}\text { Sucias, con oxido y } \\
\text { aceite. Limpieza } \\
\text { exporádica. }\end{array}$ & $\begin{array}{l}\text { Sucias, con aceite, sin } \\
\text { oxido. Se limpian una } \\
\text { vez al mes. }\end{array}$ & $\begin{array}{l}\text { Limpios el 50\%, el resto } \\
\text { con aceite. Existen } \\
\text { rutinas de limpieza }\end{array}$ & $\begin{array}{l}\text { Limpios en 90\%, el } \\
\text { resto con algo de } \\
\text { aceite. Rutina de } \\
\text { limpieza se cumple al } \\
80 \%\end{array}$ & $\begin{array}{l}\text { Todo esta limpio. } \\
\text { Rutina de limpieza se } \\
\text { cumple totalmente. }\end{array}$ \\
\hline
\end{tabular}




\section{Anexo 20. Matriz de 5'S calificación Almacén SBS - Estandarizar}

\begin{tabular}{|l|l|}
\hline SB librería $_{\text {internacional }}$ & MATRIZ DE CALIFICACIÓN - ESTANDARIZAR \\
\hline
\end{tabular}

\begin{tabular}{|c|c|c|c|c|c|}
\hline \multicolumn{6}{|c|}{ MATRIZ DE CALIFICACION 5'S - ESTANDARIZAR } \\
\hline ESTANDARIZAR & 1 & 2 & 3 & 4 & 5 \\
\hline $\begin{array}{l}\text { Aplicación de las } 3 \\
\text { primeras "S" }\end{array}$ & $\begin{array}{l}\text { Puntaje de las } 3 \\
\text { primeras "S" es igual } 0 \\
\text { menor que } 24\end{array}$ & \begin{tabular}{|l|} 
El puntaje de las 3 \\
primeras "S" es igual o \\
mayor que 24 e igual o \\
menor que 33
\end{tabular} & \begin{tabular}{|l} 
El puntaje de las 3 \\
primeras "S" es igual 0 \\
mayor que 33 e igual 0 \\
menor que 42
\end{tabular} & \begin{tabular}{|l|} 
El puntaje de las 3 \\
primeras "S" es igual o \\
mayor que 42 e igual o \\
menor que 51 \\
\end{tabular} & $\begin{array}{l}\text { El puntaj de las } 3 \\
\text { primeras "S" es igual } \\
\text { o mayo que } 51\end{array}$ \\
\hline Medio ambiente & $\begin{array}{l}\text { Ruidoso, incomodo y } \\
\text { muy oscuro. El lugar } \\
\text { resulta pesado. Frio en } \\
\text { invierno, cal uroso en } \\
\text { verano. }\end{array}$ & $\begin{array}{l}\text { Sin ruidos, incomoda y } \\
\text { oscura. El lugar resulta } \\
\text { pesado. Frio en invierno } \\
\text { y caluroso en verano. }\end{array}$ & $\begin{array}{l}\text { Sin ruidos, incomoda, } \\
\text { poca iluminación. Lugar } \\
\text { no resulta pesado. Frio } \\
\text { en invierno, caluroso en } \\
\text { verano }\end{array}$ & \begin{tabular}{|l|} 
Sin ruidos, cómoda e \\
iluminado. Lugar \\
agradable. \\
Temperaturas \\
tolerables en invierno \\
y verano.
\end{tabular} & $\begin{array}{l}\text { Sin ruidos, cómoda, } \\
\text { iluminada. } \\
\text { Confortable. } \\
\text { Temperaturas } \\
\text { agradables todo el } \\
\text { año }\end{array}$ \\
\hline Mejora Continua & $\begin{array}{l}\text { Entre inspección e } \\
\text { inspección, no se } \\
\text { realizan mejoras. }\end{array}$ & $\begin{array}{l}\text { Entre inspección e } \\
\text { inspección se realizo (1) } \\
\text { una mejora. }\end{array}$ & $\begin{array}{l}\text { Entre inspección e } \\
\text { inspección se realizo } \\
\text { tres (3) mejoras. }\end{array}$ & $\begin{array}{l}\text { Entre inspección e } \\
\text { inspección realizó } 5 \\
\text { mejoras }\end{array}$ & $\begin{array}{l}\text { Entre inspección e } \\
\text { inspección realizó } 10 \\
\text { mejoras }\end{array}$ \\
\hline Control visual & No se conoce & $\begin{array}{l}\text { Se conoce pero no se } \\
\text { hace }\end{array}$ & $\begin{array}{l}\text { Se conoce pero se aplica } \\
\text { parcialmente, menos del } \\
50 \% \text {. }\end{array}$ & Se aplica mas del 80\% & Se utiliza totalmente \\
\hline
\end{tabular}


Anexo 21. Matriz de calificación 5'S Almacén SBS - Autodisciplina

\begin{tabular}{|c|c|c|c|c|c|}
\hline \multicolumn{6}{|c|}{ MATRIZ DE CALIFICACIÓN - AUTODISCIPLINA } \\
\hline \multicolumn{6}{|c|}{ MATRIZ DE CALIFICACION 5'S - AUTODISCIPLINA } \\
\hline AUTODISCIPLINA & 1 & 2 & 3 & 4 & 5 \\
\hline $\begin{array}{l}\text { Aplicación de las } 4 \\
\text { primeras "S" }\end{array}$ & $\begin{array}{l}\text { El puntaje de las } 4 \\
\text { primeras "S" es igual } 0 \\
\text { menor que } 32\end{array}$ & $\begin{array}{l}\text { El puntaje de las } 4 \\
\text { primeras "S" es igual } 0 \\
\text { mayor que } 32 \text { e igual } 0 \\
\text { menor que } 44\end{array}$ & $\begin{array}{l}\text { El puntaje de las } 4 \\
\text { primeras "S" es igual } 0 \\
\text { mayor que } 44 \text { es igual } 0 \\
\text { menor que } 56\end{array}$ & $\begin{array}{l}\text { El puntaje de las } 4 \\
\text { primeras "S" es igual } 0 \\
\text { mayor que } 56 \text { es igual } \\
\text { o menor que } 68 \\
\end{array}$ & $\begin{array}{l}\text { El puntaje de las } 4 \\
\text { primeras "S" es igual } \\
\text { o mayor a } 68\end{array}$ \\
\hline $\begin{array}{l}\text { Normas de la } \\
\text { empresa y del } \\
\text { grupo }\end{array}$ & No se conocen & $\begin{array}{l}\text { Se conocen pero no se } \\
\text { usan }\end{array}$ & $\begin{array}{l}\text { Se cumplen } \\
\text { ocasionalmente }\end{array}$ & $\begin{array}{l}\text { Se cumple con un } \\
\text { fuerte seguimiento }\end{array}$ & $\begin{array}{l}\text { Se cumplen } \\
\text { permanentemente }\end{array}$ \\
\hline $\begin{array}{l}\text { Uniformes de } \\
\text { trabajo }\end{array}$ & $\begin{array}{l}\text { No se tiene uniforme } \\
\text { completo. Sin fajas, sin } \\
\text { botas de seguridad. Sin } \\
\text { identificación. }\end{array}$ & $\begin{array}{l}\text { Se tiene, pero no } \\
\text { completo. Sucias, } \\
\text { desgastadas. No se usan } \\
\text { las identificaciones. }\end{array}$ & $\begin{array}{l}\text { Se tiene pero está sucia. } \\
\text { Las personas tienen su } \\
\text { identificación pero no se } \\
\text { usan }\end{array}$ & $\begin{array}{l}\text { Se usa limpio y casi } \\
\text { completo. Las } \\
\text { personas tienen su } \\
\text { identificación pero no } \\
\text { se usan. }\end{array}$ & $\begin{array}{l}\text { Esta completo y } \\
\text { limpio. Las personas } \\
\text { usan su } \\
\text { identificación. }\end{array}$ \\
\hline $\begin{array}{l}\text { Cumplimiento de } \\
\text { acciones } \\
\text { programadas }\end{array}$ & No se conocen & $\begin{array}{l}\text { Se cumple menos del } \\
50 \% \text { y bajo extricto } \\
\text { seguimiento. Actitud } \\
\text { reactiva. }\end{array}$ & $\begin{array}{l}\text { Se cumple entre el } 50 \% \text { y } \\
90 \% \text {, bajo seguimiento. } \\
\text { Actitud proactiva baja. }\end{array}$ & $\begin{array}{l}\text { Se cumple entre el } \\
90 \% \text { y } 100 \% \text {, sin } \\
\text { seguimiento. Actitud } \\
\text { proactiva. }\end{array}$ & $\begin{array}{l}\text { Se cumple el } 100 \% \text { sin } \\
\text { seguimiento. Actitud } \\
\text { proactiva. }\end{array}$ \\
\hline
\end{tabular}


Anexo 22. Planilla 1: Planificación de acciones 5'S

\begin{tabular}{|l|l|}
\hline SBS & librería \\
internacional & PLANILLA No1 - PLANIFICACIÓN DE ACCIONES "5S" \\
\hline
\end{tabular}

\begin{tabular}{|c|c|c|c|c|c|c|}
\hline Problema a resolver & Acción Correctiva & 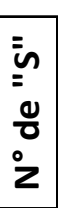 & Responsable & $\begin{array}{l}\frac{8}{\pi} \\
\frac{\pi}{0} \\
\frac{0}{0} \\
\frac{0}{2}\end{array}$ & \begin{tabular}{|c|}
$\begin{array}{c}\text { Inicio } \\
\text { acción }\end{array}$ \\
Prevista \\
Real
\end{tabular} & \begin{tabular}{|c|}
$\begin{array}{c}\text { Fin } \\
\text { acción }\end{array}$ \\
Prevista \\
Real \\
\end{tabular} \\
\hline & & & & & & \\
\hline & & & & & & \\
\hline & & & & & & \\
\hline & & & & & & \\
\hline & & & & & & \\
\hline & & & & & & \\
\hline & & & & & & \\
\hline & & & & & & \\
\hline & & & & & & \\
\hline & & & & & & \\
\hline
\end{tabular}


Anexo 23. Planilla 2: Comienzo y fin de acción

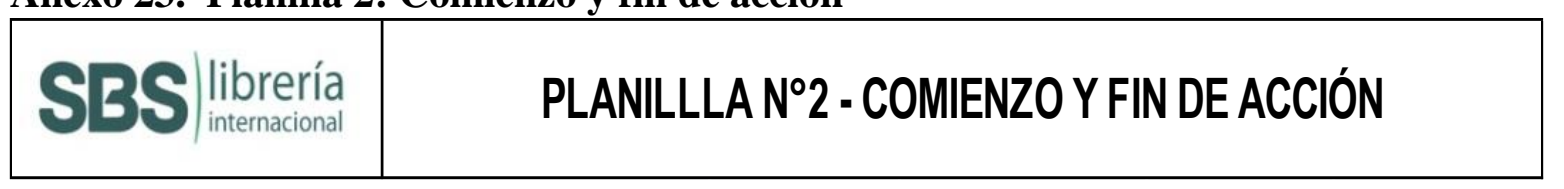

\begin{tabular}{|l|l|}
\hline \hline Acción: & Nro. de S: \\
\hline Grupo: & Responsable: \\
\hline Colaboradores: & Lider: \\
\hline Fotografía antes de comenzar la acción: Fecha: ..................... \\
\hline \\
\\
\hline Fotografía después de finalizar la acción: Fecha: ...................... \\
\hline
\end{tabular}

pág. 344 